\title{
Management of Primary Headaches in Pregnancy
}




\section{Comparative Effectiveness Review}

Number 234

\section{Management of Primary Headaches in Pregnancy}

\section{Prepared for:}

Agency for Healthcare Research and Quality

U.S. Department of Health and Human Services

5600 Fishers Lane

Rockville, MD 20857

www.ahrq.gov

Contract No. 290-2015-00002-I

Prepared by:

Brown Evidence-based Practice Center

Providence, RI

Investigators:

Ian J. Saldanha, M.B.B.S., M.P.H., Ph.D.

Julie L. Roth, M.D.

Kenneth K. Chen, M.D.

Andrew R. Zullo, Pharm.D., Ph.D.

Gaelen P. Adam, M.L.I.S., M.P.H.

Kristin J. Konnyu, Ph.D.

Wangnan Cao, Ph.D.

Monika Reddy Bhuma, B.D.S., M.P.H.

Hannah J. Kimmel, M.P.H.

Shivani Mehta, B.A.

Melissa R. Riester, Pharm.D.

Mark N. Sorial, Pharm.D.

Ethan M. Balk, M.D., M.P.H.

AHRQ Publication No. 20(21)-EHC026

November 2020 
This report is based on research conducted by the Brown Evidence-based Practice Center (EPC) under contract to the Agency for Healthcare Research and Quality (AHRQ), Rockville, MD (Contract No. 290-2015-00002-I). The findings and conclusions in this document are those of the authors, who are responsible for its contents; the findings and conclusions do not necessarily represent the views of AHRQ. Therefore, no statement in this report should be construed as an official position of AHRQ or of the U.S. Department of Health and Human Services.

\section{None of the investigators have any affiliations or financial involvement that conflicts with the material presented in this report.}

The information in this report is intended to help healthcare decision makers-patients and clinicians, health system leaders, and policymakers, among others-make well-informed decisions and thereby improve the quality of healthcare services. This report is not intended to be a substitute for the application of clinical judgment. Anyone who makes decisions concerning the provision of clinical care should consider this report in the same way as any medical reference and in conjunction with all other pertinent information, i.e., in the context of available resources and circumstances presented by individual patients.

This report is made available to the public under the terms of a licensing agreement between the author and the Agency for Healthcare Research and Quality. This report may be used and reprinted without permission except those copyrighted materials that are clearly noted in the report. Further reproduction of those copyrighted materials is prohibited without the express permission of copyright holders.

AHRQ or U.S. Department of Health and Human Services endorsement of any derivative products that may be developed from this report, such as clinical practice guidelines, other quality enhancement tools, or reimbursement or coverage policies, may not be stated or implied.

AHRQ appreciates appropriate acknowledgment and citation of its work. Suggested language for acknowledgment: This work was based on an evidence report, Management of Primary Headaches in Pregnancy, by the Evidence-based Practice Center Program at the Agency for Healthcare Research and Quality (AHRQ).

Suggested citation: Saldanha IJ, Roth JL, Chen KK, Zullo AR, Adam GP, Konnyu KJ, Cao W, Bhuma MR, Kimmel HJ, Mehta S, Riester MR, Sorial MN, Balk EM. Management of Primary Headaches in Pregnancy. Comparative Effectiveness Review No. 234. (Prepared by the Brown Evidence-based Practice Center under Contract No. 290-2015-00002-I.) AHRQ Publication No. 20(21)-EHC026. Rockville, MD: Agency for Healthcare Research and Quality; November 2020. DOI: https://doi.org/10.23970/AHRQEPCCER234. Posted final reports are located on the Effective Health Care Program search page. 


\section{Preface}

The Agency for Healthcare Research and Quality (AHRQ), through its Evidence-based Practice Centers (EPCs), sponsors the development of systematic reviews to assist public- and private-sector organizations in their efforts to improve the quality of healthcare in the United States. These reviews provide comprehensive, science-based information on common, costly medical conditions, and new healthcare technologies and strategies.

Systematic reviews are the building blocks underlying evidence-based practice; they focus attention on the strength and limits of evidence from research studies about the effectiveness and safety of a clinical intervention. In the context of developing recommendations for practice, systematic reviews can help clarify whether assertions about the value of the intervention are based on strong evidence from clinical studies. For more information about AHRQ EPC systematic reviews, see www.effectivehealthcare.ahrq.gov/about/epc/evidence-synthesis.

AHRQ expects that these systematic reviews will be helpful to health plans, providers, purchasers, government programs, and the healthcare system as a whole. Transparency and stakeholder input are essential to the Effective Health Care Program. Please visit the website (www.effectivehealthcare.ahrq.gov) to see draft research questions and reports or to join an email list to learn about new program products and opportunities for input.

If you have comments on this systematic review, they may be sent by mail to the Task Order Officers named below at: Agency for Healthcare Research and Quality, 5600 Fishers Lane, Rockville, MD 20857, or by email to epc@ahrq.hhs.gov.

Gopal Khanna, M.B.A.

Director

Agency for Healthcare Research and Quality

Stephanie Chang, M.D., M.P.H.

Director

Evidence-based Practice Center Program

Center for Evidence and Practice

Improvement

Agency for Healthcare Research and Quality
Arlene S. Bierman, M.D., M.S.

Director

Center for Evidence and Practice Improvement

Agency for Healthcare Research and Quality

Jill Huppert, M.D., M.P.H.

Task Order Officer

Center for Evidence and Practice

Improvement

Agency for Healthcare Research and Quality

Suchitra Iyer, Ph.D.

Task Order Officer

Center for Evidence and Practice

Improvement

Agency for Healthcare Research and Quality 


\section{Acknowledgments}

The authors gratefully acknowledge the following individuals for their contributions to this project: Associate Editor Marian McDonagh, Ph.D., from the Pacific Northwest Evidence-based Practice Center, Portland, OR; Task Order Officers Jill Huppert, M.D., M.P.H., and Suchitra Iyer, Ph.D., from AHRQ; and EPC Program Director Stephanie Chang, M.D., M.P.H., from AHRQ.

\section{Key Informants}

In designing the study questions, the EPC consulted several Key Informants who represent the end-users of research. The EPC sought the Key Informant input on the priority areas for research and synthesis. Key Informants are not involved in the analysis of the evidence or the writing of the report. Therefore, in the end, study questions, design, methodological approaches, and/or conclusions do not necessarily represent the views of individual Key Informants.

Key Informants must disclose any financial conflicts of interest greater than $\$ 5,000$ and any other relevant business or professional conflicts of interest. Because of their role as end-users, individuals with potential conflicts may be retained. The TOO and the EPC work to balance, manage, or mitigate any conflicts of interest.

The list of Key Informants who provided input to this report follows:

Matthew Collins, M.D., M.B.A.

Executive Vice President and Chief Medical Officer

Blue Cross \& Blue Shield of Rhode Island Providence, RI

Elisabeth Howard, Ph.D., C.N.M., FACNM $\dagger$

Department of Obstetrics \& Gynecology Brown University

Providence, RI

Elizabeth Loder, M.D., M.P.H. ${ }^{\dagger}$

Department of Neurology

Harvard University Brigham and Women's Hospital

Boston, MA

Patient Key Informant (Name Withheld for Privacy Purposes)

Providence, RI
Leyla Sahin, M.D. ${ }^{\dagger *}$

Office of New Drugs, Division of Pediatric and Maternal Health

Food and Drug Administration

Silver Spring, MD

Jonathan Schaffir, M.D. $^{\dagger *}$

Department of Obstetrics \& Gynecology

The Ohio State University Wexner Medical

Center

Columbus, $\mathrm{OH}$

Amaal J. Starling, M.D. ${ }^{\dagger}$

Department of Neurology

The Mayo Clinic

Scottsdale, AZ

Edwina Yeung, Ph.D.

Epidemiology Branch

Eunice Kennedy Shriver National Institute of Child Health and Human Development Bethesda, MD 
${ }^{*}$ Provided input on Draft Report

${ }^{\dagger}$ Also a Technical Expert Panel member

\section{Technical Expert Panel}

In designing the study questions and methodology at the outset of this report, the EPC consulted several technical and content experts. Broad expertise and perspectives were sought. Divergent and conflicted opinions are common and perceived as healthy scientific discourse that results in a thoughtful, relevant systematic review. Therefore, in the end, study questions, design, methodologic approaches, and/or conclusions do not necessarily represent the views of individual technical and content experts.

Technical Experts must disclose any financial conflicts of interest greater than $\$ 5,000$ and any other relevant business or professional conflicts of interest. Because of their unique clinical or content expertise, individuals with potential conflicts may be retained. The TOO and the EPC work to balance, manage, or mitigate any potential conflicts of interest identified.

The list of Technical Experts who provided input to this report follows:

Michael P. Carson, M.D.

Consultant Internist

Monmouth Family Medical Group and

Hackensack Meridian Health

Sea Girt, NJ

Wanda K. Nicholson, M.D., M.P.H., M.B.A.

Department of Obstetrics \& Gynecology

University of North Carolina

Chapel Hill, NC

*Provided input on Draft Report
Brandi Ring, M.D., FACOG, FAWM*

Consultant Obstetrician \& Gynecologist

Mile High Obstetrics/Gynecology

Denver, CO

Catherine S. Stika, M.D.

Department of Obstetrics \& Gynecology

Northwestern University

Chicago, IL

\section{Peer Reviewers}

Prior to publication of the final evidence report, EPCs sought input from independent Peer Reviewers without financial conflicts of interest. However, the conclusions and synthesis of the scientific literature presented in this report do not necessarily represent the views of individual reviewers.

Peer Reviewers must disclose any financial conflicts of interest greater than $\$ 5,000$ and any other relevant business or professional conflicts of interest. Because of their unique clinical or content expertise, individuals with potential nonfinancial conflicts may be retained. The TOO and the EPC work to balance, manage, or mitigate any potential nonfinancial conflicts of interest identified. 
The list of Peer Reviewers follows:

Kimberly D. Gregory, M.D., M.P.H.

Matthew S. Robbins, M.D.

Department of Obstetrics \& Gynecology

Department of Neurology

Cedars Sinai Medical Center

Los Angeles, CA

Weill Cornell Medicine

New York, NY

Robert G. Kaniecki, M.D.

Department of Neurology

University of Pittsburgh Medical Center

Pittsburgh, PA 


\section{Management of Primary Headaches in Pregnancy}

\section{Structured Abstract}

Objectives. This systematic review (SR) evaluates the literature on pharmacologic and nonpharmacologic interventions to prevent or treat attacks of primary headaches (migraine, tension headache, cluster headache, and other trigeminal autonomic cephalgias) in women who are pregnant (or attempting to become pregnant), postpartum, or breastfeeding.

Data sources. We searched Medline ${ }^{\circledR}$, Embase ${ }^{\circledR}$, Cochrane CENTRAL, CINAHL ${ }^{\circledR}$, and ClinicalTrials.gov to identify primary studies (comparative studies and single-group studies) in women who are pregnant (or attempting to become pregnant), postpartum, or breastfeeding with primary headache (direct evidence). We searched Medline, the Cochrane Database of Systematic Reviews, and Epistemonikos for existing SRs of harms of interventions in pregnant women regardless of indication (indirect evidence).

Review methods. We extracted study data into the Systematic Review Data Repository. We assessed the risk of bias and evaluated the strength of evidence (SoE) using standard methods. The PROSPERO protocol registration number is CRD42020158310.

Results. Our searches for direct and indirect evidence yielded 8,549 citations and 2,788 citations, respectively. Sixteen primary studies comprising 14,185 patients in total and 26 SRs met criteria. Risk of bias was high for most primary studies. We found no evidence addressing effectiveness of any intervention for prevention of primary headaches. We found one single-group study (of topiramate) and 11 SRs reporting potential harms of various interventions used for primary headache prevention during pregnancy. Antiepileptics (except lamotrigine), venlafaxine, tricyclic antidepressants, benzodiazepines, beta blockers, prednisolone, and oral magnesium may be associated with increased risk of fetal/child adverse effects, but calcium channel blockers and antihistamines may have low risk of adverse effects (indirect evidence; low to moderate SoE). For treatment of acute attacks of primary headache, we found three randomized controlled trials (RCTs), eight nonrandomized comparative studies (NRCSs), and four single-group studies. Combination metoclopramide and diphenhydramine may be more effective than codeine in reducing severity of migraine or tension headache; adverse effect profiles were similar (1 RCT; low SoE). Triptans used for migraine during pregnancy were not associated with spontaneous abortions or congenital anomalies (8 NRCSs; low SoE). Acetaminophen, prednisolone, indomethacin, ondansetron, antipsychotics, and intravenous magnesium may be associated with increased risk of fetal/child adverse effects, but low-dose aspirin (either during pregnancy or postpartum) may not be associated with increased risk (indirect evidence; low to moderate SoE). There is insufficient evidence to make conclusions about the benefits or harms of nonpharmacologic treatments used during pregnancy, including acupuncture (1 RCT); biofeedback, relaxation therapy, and physical therapy (1 RCT and 2 single-group studies); nerve blocks (1 single-group study); and transcranial magnetic stimulation (1 single-group study).

Conclusions. Evidence regarding the benefits and harms of all interventions in women who are pregnant (or attempting to become pregnant), postpartum, or breastfeeding is insufficient, or at 
best of low strength of evidence. Future research is needed to identify the most effective and safe interventions for preventing or treating primary headaches in these populations of women. 


\section{Contents}

Evidence Summary ............................................................................................................................. ES-1

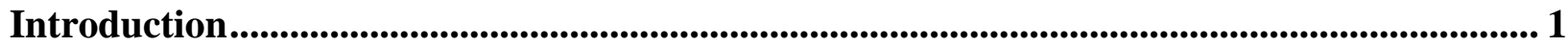

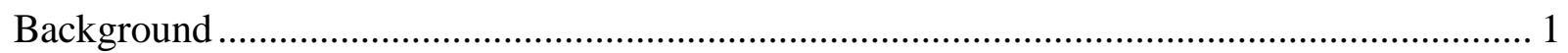

Purpose and Scope of the Systematic Review ………….................................................. 2

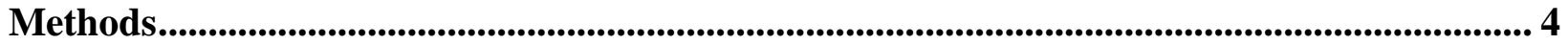





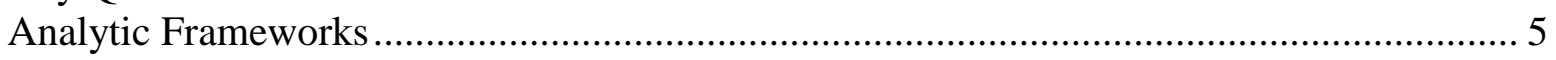

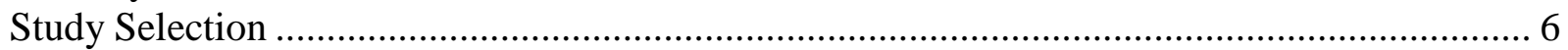

Direct Evidence (Primary Studies) ………………............................................................. 6

Indirect Evidence (Systematic Reviews of Harms, Regardless of Indication) ………….......... 7

Supplemental Evidence (Case Reports) ……………….................................................... 7

Data Extraction and Risk of Bias Assessment ........................................................................ 7

Direct Evidence (Primary Studies) ……………………........................................................... 7

Indirect Evidence (Systematic Reviews of Harms, Regardless of Indication) ........................ 8

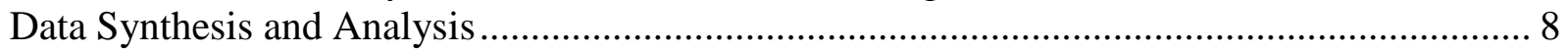

Grading the Strength of the Body of Evidence..................................................................... 8

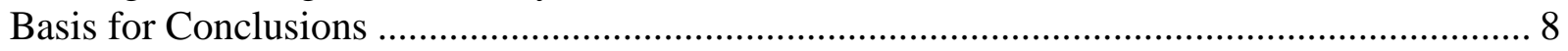

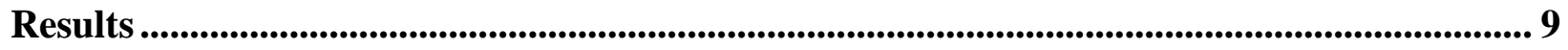

Description of Included Evidence...................................................................................... 9

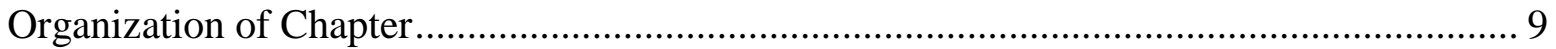

Literature Search Results ............................................................................................ 9

Direct Evidence (Primary Studies) and Indirect Evidence (Systematic Reviews of Harms,

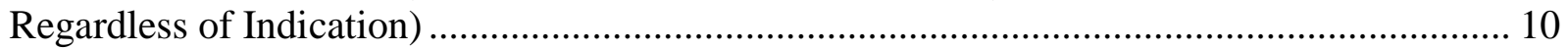

Key Question 1: Prevention of Primary Headache .............................................................. 10

Key Question 1: Pharmacologic Interventions To Prevent Attacks of Primary Headache .. 12

Key Question 1: Nonpharmacologic Interventions To Prevent Attacks of Primary Headache

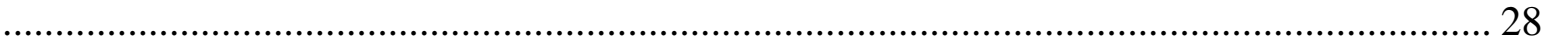

Key Question 2: Treatment of Primary Headache ............................................................... 28

Key Question 2: Pharmacologic Interventions To Treat Attacks of Primary Headache ...... 29

Key Question 2: Nonpharmacologic Interventions To Treat Attacks of Primary Headache 61

Supplemental Evidence (Case Reports) ......................................................................................6 69

Case Reports Specific to Key Question 1 (Prevention of Primary Headache) ....................... 69

Case Reports Specific to Key Question 2 (Treatment of Primary Headache)....................... 69

Case Reports Addressing Both Key Question 1 (Prevention of Primary Headache) and Key

Question 2 (Treatment of Primary Headache) .......................................................................... 70

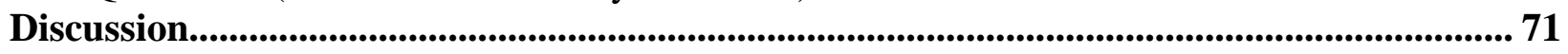

Findings in Relation to the Decisional Dilemmas ................................................................. 71

Caveats to Indirect Evidence (Systematic Reviews of Harms, Regardless of Indication) ........ 82

Supplemental Evidence (Case Reports) ................................................................................... 83

Strengths and Limitations ...................................................................................................... 83

Strengths and Limitations of the Evidence Base ................................................................... 83

Strengths and Limitations of the Systematic Review Process .................................................. 85



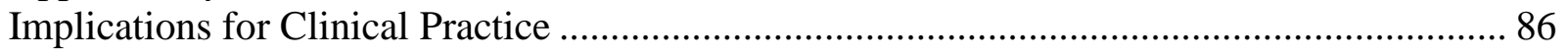




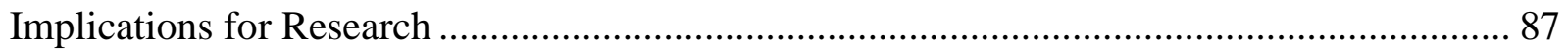



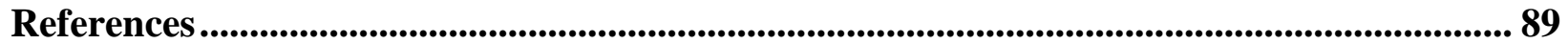

Tables

Table A. High-level summary of benefits and harms of interventions................................. ES-4

Table 1. Antiepileptics: Summary of direct evidence regarding use to prevent primary headaches

Table 2. Antiepileptics: Evidence profile for direct evidence regarding use to prevent primary headaches 14

Table 3. Antiepileptics: Summary of indirect evidence of fetal/child harms, statistically significant findings.

Table 4. Antiepileptics: Evidence profile for indirect evidence regarding harms of use during pregnancy.... 15

Table 5. SNRIs: Summary of indirect evidence of fetal/child harms, statistically significant

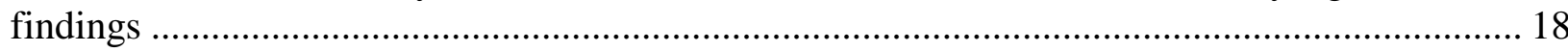

Table 6. SNRIs: Evidence profile for indirect evidence regarding harms of use during pregnancy

Table 7. Tricyclic antidepressants: Summary of indirect evidence of fetal/child harms, statistically significant findings 19 Table 8. Tricyclic antidepressants: Evidence profile for indirect evidence regarding harms of use

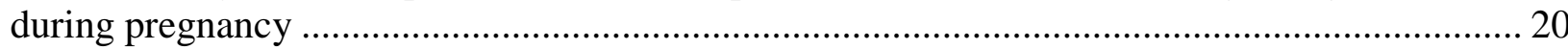
Table 9. Benzodiazepines: Summary of indirect evidence of fetal/child harms, statistically

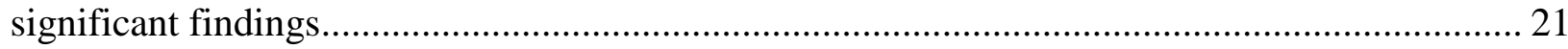
Table 10. Benzodiazepines: Evidence profile for indirect evidence regarding harms of use during pregnancy.... 21

Table 11. Beta blockers: Summary of indirect evidence of fetal/child harms, statistically

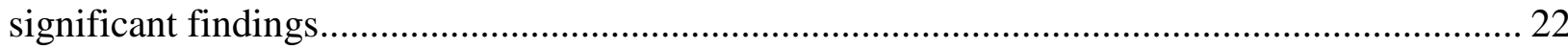
Table 12. Beta blockers: Evidence profile for indirect evidence regarding harms of use during

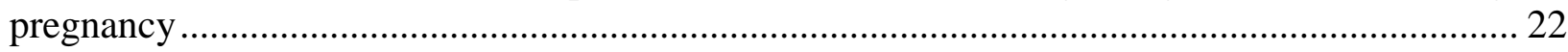
Table 13. Calcium channel blockers: Evidence profile for indirect evidence regarding harms of


Table 14. Corticosteroids: Summary of indirect evidence of fetal/child harms, statistically

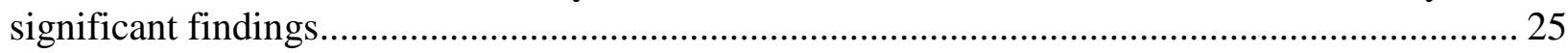
Table 15. Corticosteroids: Evidence profile for direct evidence regarding use to prevent primary headaches 25 Table 16. Antihistamines: Evidence profile for direct evidence regarding use to prevent primary headaches ..... 26

Table 17. Oral magnesium: Summary of indirect evidence of maternal harms, statistically

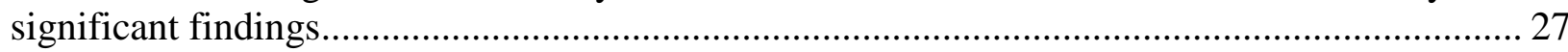
Table 18. Oral magnesium: Summary of indirect evidence of fetal/child harms, statistically

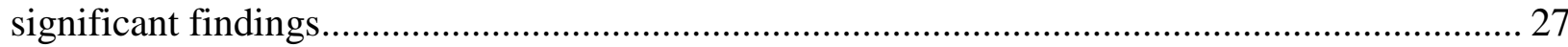
Table 19. Oral magnesium: Evidence profile for indirect evidence regarding harms of use during

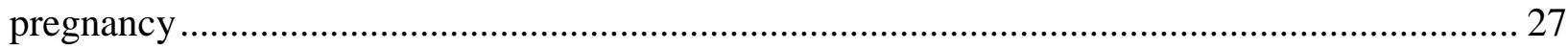
Table 20. Triptans: Summary of direct evidence regarding fetal/child harms ......................... 42 Table 21. Triptans, ergot products, NSAIDs (naproxen), and antihistamines (pizotifen): Evidence profile for direct evidence regarding use to treat primary headaches 45 
Table 22. Triptans: Evidence profile for existing systematic review regarding harms 48 Table 23. NSAIDs (indomethacin and low-dose aspirin): Summary of indirect evidence of fetal/child harms, statistically significant findings

Table 24. NSAIDs (indomethacin and low-dose aspirin): Evidence profile for indirect evidence regarding harms of use during pregnancy.....

Table 25. Combination metoclopramide and diphenhydramine versus codeine: Summary of direct evidence regarding use to treat primary headaches

Table 26. Combination metoclopramide and diphenhydramine versus codeine: Evidence profile

for direct evidence regarding use to prevent primary headaches.

Table 27. Antiemetics (5HT3 antagonists): Summary of indirect evidence of fetal/child harms, statistically significant findings 55

Table 28. Antiemetics (5HT3 antagonists): Evidence profile for indirect evidence regarding harms of use during pregnancy....

Table 29. Antipsychotics: Summary of indirect evidence of fetal/child harms, statistically significant findings

Table 30. Antipsychotics: Evidence profile for indirect evidence regarding harms of use during pregnancy....

Table 31. Analgesics/antipyretics (acetaminophen): Summary of indirect evidence of fetal/child

harms, statistically significant findings. 58

Table 32. Analgesics/antipyretics (acetaminophen): Evidence profile for indirect evidence of fetal/child harms, statistically significant findings 59

Table 33. Intravenous magnesium: Summary of indirect evidence of maternal harms, statistically significant findings. 60 Table 34. Intravenous magnesium: Evidence profile for indirect evidence regarding harms of use during pregnancy 60

Table 35. Nonpharmacologic interventions: Summary of direct evidence regarding use to treat primary headaches

Table 36. Nonpharmacologic interventions: Evidence profile for direct evidence regarding use to

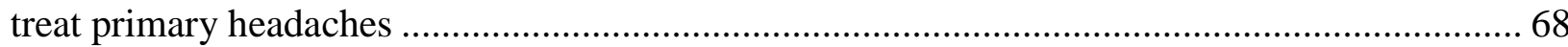

Table 37. Map of direct and indirect evidence identified in this systematic review .................. 71

Table 38. Summary of direct and indirect evidence identified in this systematic review ............ 73

\section{Figures}

Figure 1. Analytic framework for KQ 1: Interventions to prevent attacks of primary headache during pregnancy, postpartum, and breastfeeding ......................................................... 5 Figure 2. Analytic framework for KQ 2: Interventions to treat attacks of primary headache during pregnancy, postpartum, and breastfeeding.

\section{Appendixes}

Appendix A. Methods

Appendix B. Results 


\section{Evidence Summary}

\section{Main Points}

- Prevention of primary headache in women who are pregnant (or attempting to become pregnant), postpartum, or breastfeeding with a history of primary headache

o Pharmacologic and nonpharmacologic interventions

- There is no evidence regarding the effectiveness of any pharmacologic or nonpharmacologic intervention in women who are pregnant (or attempting to become pregnant), postpartum, or breastfeeding.

- A single primary study provided insufficient (direct) evidence to make conclusions about the harms of topiramate when used for preventing primary headache during pregnancy, but use during pregnancy outside the primary headache context (indirect evidence) suggests increased risk of fetal/child adverse effects. Indirect evidence also suggests that other antiepileptics, such as carbamazepine, gabapentin, and valproate may have similar adverse effect profiles, but lamotrigine may have a low risk of adverse effects.

- Venlafaxine, tricyclic antidepressants (any), benzodiazepines (any), beta blockers (any), prednisolone, and oral magnesium use during pregnancy may have increased risk of fetal/child adverse effects, but calcium channel blockers (any, but nifedipine in particular) and antihistamines (any) may have a low risk of adverse effects (indirect evidence).

- Treatment of patients with acute attacks of primary headache in women who are pregnant (or attempting to become pregnant), postpartum, or breastfeeding

o Pharmacologic interventions

- Use of triptans for migraine during pregnancy may not be more harmful than their use before pregnancy (both direct and systematic review evidence). Compared with nonuse (either during or before pregnancy), triptan use may not be associated with spontaneous abortions or congenital anomalies, but may be associated with worse child emotionality and activity outcomes at 3 years of age.

- A single primary study found that compared with oral codeine, combination metoclopramide and diphenhydramine may be more effective to reduce migraine or tension headache severity during pregnancy, and may not be associated with greater serious or nonserious maternal harms; fetal/child harms were not reported. Indirect evidence found that antihistamines (any) during pregnancy (used for indications other than primary headache) may have a low risk of adverse effects.

- Systematic reviews of harms (regardless of indication) report that acetaminophen, prednisolone, indomethacin, ondansetron, antipsychotics (any), and intravenous magnesium use during pregnancy may be associated with fetal/child adverse effects, but low-dose aspirin use may not be associated with increased risk of adverse effects.

o Nonpharmacologic interventions

- There is insufficient direct evidence to make conclusions about the benefits or harms of acupuncture, thermal biofeedback, relaxation therapy, physical therapy, peripheral nerve blocks, and transcranial magnetic stimulation when used for treatment of primary headache during pregnancy.

- No indirect evidence regarding harms of nonpharmacologic interventions in pregnancy was identified. 


\section{Background and Purpose}

Primary headaches (i.e., conditions in which the headache itself is the disorder) are common in pregnancy and comprise four types: migraine, tension headache, cluster headache, and other trigeminal autonomic cephalgias (TACs). Although tension headaches are more common, migraine is by far the most common primary headache to present to clinical practice. Primary headache and its treatments can have significant consequences for the mother and fetus or infant. Given the heightened sensitivity about the potential impact of drugs on the fetus or infant, there is a tension between treatment decisions that might be best for the mother and those best for the fetus/infant. The uncertainty about the comparative effectiveness and harms of various treatment options underscores the importance of identifying effective interventions to treat primary headaches during pregnancy.

This systematic review (SR) aims to inform healthcare providers, policymakers, and the American College of Obstetricians and Gynecologists (ACOG) as developers of clinical guidance about currently available evidence on interventions for preventing or treating acute attacks of primary headaches in women who are pregnant (or attempting to become pregnant), postpartum, or breastfeeding. The SR addresses both pharmacologic and nonpharmacologic interventions for migraine, tension headache, cluster headache, and other TACs.

\section{Methods}

We used methods consistent with those outlined in the Agency for Healthcare Research and Quality’s Evidence-based Practice Center Methods Guidance (https://effectivehealthcare.ahrq.gov/products/cer-methods-guide/overview). Our searches covered published and unpublished primary studies (direct evidence) and case reports (supplemental evidence) in women who are pregnant (or attempting to become pregnant), postpartum, or breastfeeding from database inception to June 5, 2020. For additional information on harms, we also searched for relevant SRs of interventions in women in the same phase, regardless of the indication for which the intervention was used (indirect evidence), from database inception to June 5, 2020.

\section{Results}

We found 16 primary studies (14,185 patients), representing direct evidence (3 randomized controlled trials, 8 nonrandomized comparative studies [i.e., observational studies that compared 2 or more interventions], and 5 single-group studies [i.e., studies without a comparison group]), and 26 SRs of interventions for any indication during pregnancy, representing indirect evidence. We also identified 19 case reports, representing supplemental evidence. Most primary studies enrolled patients with migraine and some with migraine and/or tension headache.

Table A provides a high-level summary of findings, summarized below.

Prevention-antiepileptics: There was insufficient direct evidence to make conclusions about harms of topiramate when used for migraine (one single-group study). However, we identified indirect evidence (i.e., systematic reviews regardless of indication) that carbamazepine, gabapentin, topiramate, and valproate use during pregnancy had increased fetal/child adverse effects (all moderate strength of evidence [SoE], except for gabapentin, which had low SoE). Lamotrigine may have a lower risk of adverse effects: no increased risk of spontaneous abortion, stillbirth, preterm birth, or congenital anomalies (moderate SoE), although increased risk of autism/dyspraxia but not other neurodevelopmental adverse effects (moderate SoE).

Prevention-other pharmacologic interventions: We identified no direct evidence. We identified indirect evidence (i.e., systematic reviews regardless of indication) that the following, 
when used during pregnancy, were associated with fetal/child adverse effects: venlafaxine (a serotonin and norepinephrine reuptake inhibitor; moderate SoE), tricyclic antidepressants (moderate SoE), benzodiazepines (low SoE), beta blockers (moderate SoE), prednisolone (low SoE), and oral magnesium (low SoE). But, calcium channel blockers (any, but nifedipine in particular) (low to moderate SoE for specific adverse effects) and antihistamines (moderate SoE) had low risks of maternal or fetal/child adverse effects.

Prevention—nonpharmacologic interventions: We found no direct or indirect evidence.

Treatment-triptans, ergot products, nonsteroidal anti-inflammatory drugs (NSAIDs: naproxen), and antihistamines (pizotifen): Eight observational NRCSs addressed adverse effects of triptans, ergot products, naproxen, and pizotifen, but none reported on treatment effectiveness. Among the studies that adjusted for underlying differences between study groups, child neurodevelopmental, behavioral, and social outcomes did not differ between use of any triptan during pregnancy and use only before pregnancy, except for worse emotionality and activity outcomes at 3 years of age with triptan use during pregnancy (low SoE). Triptan use during pregnancy was not associated with spontaneous abortion, elective or induced abortion, or major or minor congenital anomalies, compared with nonuse (low SoE). An existing SR found that triptan use was not associated with spontaneous abortion (moderate SoE), preterm birth (low SoE), or major congenital anomalies (moderate SoE). We also identified indirect evidence (not focused on primary headaches) regarding NSAIDs: indomethacin may be associated with neonatal periventricular leukomalacia, intraventricular hemorrhage, and necrotizing enterocolitis (low SoE), but low-dose aspirin was not associated with maternal (moderate SoE) or fetal/child adverse effects (low SoE).

Treatment-antiemetics (dopamine receptor antagonists), antihistamines, and opioids: One RCT found that, compared with codeine, combination metoclopramide and diphenhydramine reduced migraine or tension headache severity and was more likely to resolve headache (low SoE). No serious maternal adverse effects occurred (low SoE). We also identified indirect evidence (i.e., systematic reviews regardless of indication) that antihistamines were not associated with serious fetal/child adverse effects (moderate SoE).

Treatment-other pharmacologic interventions: We did not find any direct evidence. We identified indirect evidence (i.e., systematic reviews regardless of indication) that use of the following interventions during pregnancy may be associated with fetal/child adverse effects: acetaminophen (low SoE), prednisolone (low SoE), ondansetron (a 5HT3 antagonist antiemetic) (moderate SoE), antipsychotics (low to moderate SoE), and intravenous magnesium (low SoE).

Treatment-nonpharmacologic interventions: There was insufficient direct evidence to make conclusions about thermal biofeedback (one RCT and two single-group studies), acupuncture (one RCT), relaxation therapy (one RCT and two single-group studies), physical therapy (one RCT and one single-group study), peripheral nerve blocks (one single-group study), and transcranial magnetic stimulation (one single-group study). We found no indirect evidence.

\section{Limitations}

Evidence for intervention benefits and harms was often sparse or absent. Entire classes, such as tricyclic antidepressants, beta blockers, and calcium channel blockers, were not identified in any primary study of pregnant patients with primary headache. Similarly, no primary study addressed entire classes of nonpharmacologic agents, such as hydration and chemodenervation (see full report for full lists). Most studies focused on patients with migraine. We deemed individual studies to have high or moderate risk of bias, most commonly due to lack of adjustment for confounders; lack of blinding of participants, personnel, and outcome assessors; and/or incomplete outcome data. 


\section{Implications and Conclusions}

Evidence regarding the benefits and harms of interventions in women who are pregnant or breastfeeding is insufficient or of at best low strength of evidence. The paucity of evidence emphasizes the need for further primary research to identify effective and safe pharmacologic and nonpharmacologic interventions for primary headaches during pregnancy. Future studies should either randomize patients or adequately account for important confounders and evaluate important maternal outcomes, such as headache-related symptoms, quality of life, functional outcomes, and important fetal/child adverse outcomes; we found negligible data for these outcomes.

Table A. High-level summary of benefits and harms of interventions

\begin{tabular}{|c|c|c|c|c|c|c|c|c|}
\hline KQ & $\begin{array}{l}\text { Intervention } \\
\text { Type }\end{array}$ & Intervention Class & Intervention & Comparator & Condition & $\begin{array}{l}\text { Maternal } \\
\text { Benefits }\end{array}$ & $\begin{array}{l}\text { Maternal } \\
\text { AEs }\end{array}$ & $\begin{array}{l}\text { Fetall } \\
\text { Child } \\
\text { AEs }\end{array}$ \\
\hline \multirow[t]{17}{*}{1} & \multirow[t]{16}{*}{ Pharm } & \multirow[t]{7}{*}{ Antiepileptics } & \multirow[t]{2}{*}{ Topiramate } & None & Migraine & - & - & ?? (I) \\
\hline & & & & Nonuse & Various & - & - & $\uparrow(++)$ \\
\hline & & & Carbamazepine & Nonuse & Various & - & - & $\uparrow(++)$ \\
\hline & & & Gabapentin & Nonuse & Various & - & - & $\uparrow(+)$ \\
\hline & & & Lamotrigine & Nonuse & Various & - & - & $\uparrow(++)$ \\
\hline & & & Valproate & Nonuse & Various & - & - & $\uparrow(++)$ \\
\hline & & & Gabapentin & Nonuse & Various & - & - & $\uparrow(+)$ \\
\hline & & SNRIS & Venlafaxine & Nonuse & Various & - & - & $\uparrow(++)$ \\
\hline & & $\begin{array}{l}\text { Tricyclic } \\
\text { antidepressants }\end{array}$ & Any & Nonuse & Various & - & - & $\uparrow(++)$ \\
\hline & & Benzodiazepines & Any & Nonuse & Various & - & - & $\uparrow(+)$ \\
\hline & & Beta blockers & Any & Nonuse & Various & - & $\sim(+)$ & $\uparrow(++)$ \\
\hline & & \multirow[t]{2}{*}{$\begin{array}{l}\text { Calcium channel } \\
\text { blockers }\end{array}$} & Any & Nonuse & Various & - & $\sim(+)$ & $\sim(++)$ \\
\hline & & & Nifedipine & Nonuse & Various & - & - & $\sim(++)$ \\
\hline & & Corticosteroids & Prednisolone & Nonuse & Various & - & - & $\uparrow(+)$ \\
\hline & & Antihistamines & Any & Nonuse & Various & - & - & $\sim(++)$ \\
\hline & & Oral magnesium & Oral magnesium & Nonuse & Various & - & $\sim(+)$ & $\uparrow(+)$ \\
\hline & Nonpharm & - & - & - & - & - & - & - \\
\hline \multirow[t]{11}{*}{2} & \multirow[t]{11}{*}{ Pharm } & \multirow{9}{*}{$\begin{array}{l}\text { Triptans, Ergot } \\
\text { products, and } \\
\text { NSAIDs }\end{array}$} & \multirow{2}{*}{$\begin{array}{l}\text { Sumatriptan } \\
\text { Sumatriptan }\end{array}$} & \multirow{2}{*}{$\begin{array}{l}\text { Naratriptan } \\
\text { Sumatriptan + } \\
\text { naratriptan } \\
\end{array}$} & Migraine & - & - & ?? (I) \\
\hline & & & & & Migraine & - & - & ?? (I) \\
\hline & & & Naratriptan & $\begin{array}{l}\text { Sumatriptan + } \\
\text { naratriptan }\end{array}$ & Migraine & - & - & ?? (I) \\
\hline & & & Any triptan & $\begin{array}{l}\text { Any ergot } \\
\text { product }\end{array}$ & Migraine & - & - & ?? (I) \\
\hline & & & Any triptan & Pizotifen & Migraine & - & - & ?? (I) \\
\hline & & & Any ergot product & Pizotifen & Migraine & - & - & ?? (I) \\
\hline & & & $\begin{array}{l}\text { Any triptan during } \\
\text { pregnancy }\end{array}$ & $\begin{array}{l}\text { Any triptan } \\
\text { before } \\
\text { pregnancy only }\end{array}$ & Migraine & - & ?? (I) & $\uparrow(+)$ \\
\hline & & & $\begin{array}{l}\text { Sumatriptan during } \\
\text { pregnancy }\end{array}$ & $\begin{array}{l}\text { Sumatriptan } \\
\text { before } \\
\text { pregnancy only }\end{array}$ & Migraine & - & ?? (I) & ?? (I) \\
\hline & & & $\begin{array}{l}\text { Any triptan during } \\
\text { pregnancy }\end{array}$ & No triptan & Migraine & - & ?? (I) & $\uparrow(+)$ \\
\hline & & $\begin{array}{l}\text { Antiemetics } \\
\text { (Dopamine } \\
\text { antagonists), } \\
\text { Antihistamines, } \\
\text { Opioid-like } \\
\text { analgesics } \\
\end{array}$ & $\begin{array}{l}\text { Metoclopramide + } \\
\text { Diphenhydramine }\end{array}$ & Codeine & $\begin{array}{l}\text { Migraine } \\
\text { or tension } \\
\text { HA }\end{array}$ & $\begin{array}{l}\text { Maternal } \\
\text { benefit } \\
(+)\end{array}$ & $\sim(+)$ & - \\
\hline & & NSAIDS & Any & Nonuse & Various & - & $\sim(++)$ & - \\
\hline
\end{tabular}




\begin{tabular}{|c|c|c|c|c|c|c|c|c|}
\hline KQ & $\begin{array}{l}\text { Intervention } \\
\text { Type }\end{array}$ & Intervention Class & Intervention & Comparator & Condition & $\begin{array}{l}\text { Maternal } \\
\text { Benefits }\end{array}$ & $\begin{array}{l}\text { Maternal } \\
\text { AEs }\end{array}$ & $\begin{array}{l}\text { Fetall } \\
\text { Child } \\
\text { AEs }\end{array}$ \\
\hline & & & Indomethacin & Nonuse & Various & - & - & $\uparrow(+)$ \\
\hline & & & Low-dose aspirin & Nonuse & Various & - & $\sim(++)$ & $\sim(+)$ \\
\hline & & $\begin{array}{l}\text { Antiemetics (5HT3 } \\
\text { antagonists }\end{array}$ & Ondansetron & Nonuse & Various & - & - & $\uparrow(++)$ \\
\hline & & Antipsychotics & Any & Nonuse & Various & - & - & $\uparrow(++)$ \\
\hline & & Corticosteroids & Prednisolone & Nonuse & Various & - & - & $\uparrow(++)$ \\
\hline & & $\begin{array}{l}\text { Analgesics/ } \\
\text { Antipyretics }\end{array}$ & Acetaminophen & Nonuse & Various & - & - & $\uparrow(+)$ \\
\hline & & IV magnesium & IV magnesium & Nonuse & Various & - & $\uparrow(+)$ & - \\
\hline & & Antihistamines & Any & Nonuse & Various & - & - & $\sim(++)$ \\
\hline & Nonpharm & Complementary, & Acupuncture & Routine care & Migraine & ?? (I) & - & $? ?(\mathrm{I})$ \\
\hline & & $\begin{array}{l}\text { behavioral, and } \\
\text { physical therapy }\end{array}$ & $\begin{array}{l}\text { Thermal } \\
\text { biofeedback, } \\
\text { relaxation, physical } \\
\text { therapy }\end{array}$ & $\begin{array}{l}\text { Thermal } \\
\text { biofeedback }\end{array}$ & $\begin{array}{l}\text { Migraine } \\
\text { or tension } \\
\text { HA }\end{array}$ & ?? (I) & - & - \\
\hline & & & $\begin{array}{l}\text { Thermal } \\
\text { biofeedback and } \\
\text { relaxation therapy }\end{array}$ & None & Migraine & ?? (I) & - & - \\
\hline & & Procedures & $\begin{array}{l}\text { Peripheral nerve } \\
\text { blocks }\end{array}$ & None & Migraine & ?? (I) & ?? (I) & - \\
\hline & & $\begin{array}{l}\text { Noninvasive } \\
\text { neuromodulation } \\
\text { devices }\end{array}$ & $\begin{array}{l}\text { Transcranial } \\
\text { magnetic } \\
\text { stimulation }\end{array}$ & None & Migraine & ?? (I) & - & - \\
\hline
\end{tabular}

For interventions with evidence of an increased risk of any fetal/child AE and evidence of no increased risk or unknown risk of other fetal/child AEs, this table includes only the indicator for increased risk. Table 38 in the full report includes further details.

Abbreviations: $\mathrm{AE}=$ adverse effect, $\mathrm{HA}=$ headache, $\mathrm{IV}=$ intravenous, $\mathrm{KQ}=$ Key Question, Nonpharm = nonpharmacologic, NSAID = nonsteroidal anti-inflammatory drug, Pharm = pharmacologic, SNRI = serotonin and norepinephrine reuptake inhibitor.

$\uparrow=$ Increase in adverse effects, $\sim=$ No increase in adverse effects, ? ? = Direction unknown, $-=$ No evidence, $\mathrm{I}=$ Insufficient strength of evidence, $+=$ Low strength of evidence, ++ = Moderate strength of evidence, $+++=$ High strength of evidence (none in Table). 


\section{Introduction}

\section{Background}

Headache, one of the most common symptoms in the general population, is also common during pregnancy. Primary headaches are conditions where the headache itself is the disorder. In contrast, secondary headaches are caused by an underlying disorder, such as stroke, venous thromboembolism, ${ }^{1,2}$ and pituitary tumors. ${ }^{3,4}$ Management of secondary headache in pregnancy generally targets the underlying disorder, and, thus, is not the focus of this systematic review (SR).

Primary headaches that occur in pregnant women are classified into four types: migraine, tension headache, cluster headache, and other trigeminal autonomic cephalgias (TACs). ${ }^{5}$ At the end of Appendix A, we have provided a glossary of terms and abbreviations used in this report. The lifetime prevalence of migraine disorder among pregnant women is approximately 30 percent. $^{6,7}$ While tension headaches are most common in pregnant women in the population, migraine is by far the most common primary headache for which pregnant women seek care, accounting for about 90 percent of visits for primary headaches. ${ }^{2}$ Tension headache is a less common reason for seeking care, and cluster headache and other TACs are rare. ${ }^{8}$ Primary headaches can be pre-existing (i.e., they began before pregnancy) or can occur for the first time during pregnancy, postpartum, or while breastfeeding. The stress of pregnancy and imminent infant care may exacerbate the frequency and/or severity of primary headaches.

Both pre-existing and pregnancy-onset primary headaches can have significant consequences for the mother, the fetus/child, and mother-child bonding. ${ }^{8}$ In addition to the symptoms themselves, primary headaches can lead to social consequences, including reduced productivity, loss of employment, financial detriment, and impacted family life, and clinical consequences, including depression, spontaneous abortion, preterm birth, and low birth weight. ${ }^{9}$

Although outside of pregnancy migraine frequency and severity often vary with a woman's menstrual cycle, during pregnancy the course of migraine frequency and intensity can be more variable. In some cases, hormonal fluctuations can precipitate attacks of migraine and can make them more severe, ${ }^{10,11}$ while in others, elevated estrogen and endogenous opioid levels can improve migraine symptoms and/or reduce their frequency. ${ }^{12-14}$

Management approaches for primary headaches may harm the fetus and breastfed newborn. From a diagnostic standpoint, radiation and/or contrast agents (primarily neuroimaging) may harm

the fetuses of pregnant women. ${ }^{15-17}$ From a treatment standpoint, decisions during pregnancy, postpartum, and breastfeeding need to be made after consideration of both potential benefits and harms, which poses major decisional dilemmas. Regarding treatment for acute attacks of migraine, many of the commonly-prescribed drugs with the highest level of evidence in the general population can be harmful during pregnancy. For example, nonsteroidal antiinflammatory drugs (NSAIDs) have been shown to be associated with a higher risk of spontaneous abortion (when used early in pregnancy) and of developmental malformations in the fetus, such as premature closure of the ductus arteriosus and oligohydramnios (when used in the third trimester). ${ }^{18}$ Similarly, sodium valproate, a commonly-used antiepileptic drug for prevention of migraine attacks, is contraindicated in pregnancy due to its teratogenicity and adverse neurocognitive outcomes in the offspring. ${ }^{19,20}$

Other therapies used outside of pregnancy, such as complementary and alternative therapies and biologic drugs (e.g., monoclonal antibodies), have unclear and/or mixed safety profiles during pregnancy and lactation. Therapies that are commonly used in patients with migraine during pregnancy include pharmacologic therapies, such as acetaminophen, antihistamines, caffeine, and magnesium. The first-line agents used for prophylaxis (i.e., migraine prevention) are beta blockers, 
such as metoprolol; low-dose tricyclic antidepressants, such as amitriptyline; and oral magnesium supplements. ${ }^{21}$ Metoclopramide, alone or in combination with other therapies, is frequently used for treatment of acute attacks, particularly in inpatient and emergency settings. ${ }^{22-24}$ While other pharmacologic agents, such as low-dose aspirin and intravenous magnesium, that were used in the past are now less frequently prescribed. Other nonpharmacologic interventions for treatment and prophylaxis include hydration, physical therapy, and acupuncture. Pericranial nerve blocks, including occipital nerve blocks, are also increasingly used for treatment and prophylaxis against headaches in pregnancy. ${ }^{25}$

Management of the other types of primary headache also presents decisional dilemmas. While patients with tension headache respond best to NSAIDs, they can be treated with acetaminophen, although often with only moderate success. Because cluster headache and other TACs are rare and inadequately studied during pregnancy, little is known about ideal treatments and prophylactic strategies for them. While some subtypes of TACs, such as paroxysmal hemicrania, hemicrania continua, and primary stabbing headache, respond to indomethacin (an NSAID), this drug is contraindicated in the latter phases of pregnancy. Little is known about nonpharmacologic treatments for primary headaches during pregnancy.

Unique aspects of the pregnancy and postpartum phases present challenges for managing primary headaches. Given the heightened sensitivity about the impact of pharmacotherapy on the developing fetus or breastfed infant, there is a tension between treatment decisions that might be best for the mother's health and those that might be best for the fetus/infant. Regardless of treatment, migraine during pregnancy has been shown to be associated with various adverse maternal outcomes, such as preeclampsia, hypertension, pulmonary embolism, stroke, myocardial infarction, unplanned cesarean section, and adverse neonatal outcomes, including preterm birth, low birth weight, and respiratory distress. ${ }^{9}$ Sound risk-benefit assessments that optimize the health of both mother and fetus/child require clinical expertise and careful shared decision making between providers and patients.

The stresses on women during pregnancy and the ethical challenges in designing studies in this population have been obstacles to conducting studies to identify the most effective and safest therapies for these women and their offspring. Uncertainty about the comparative effectiveness and harms among various treatment options has meant that specific clinical practice guidelines for management of primary headaches during pregnancy do not exist. Existing guidelines on perinatal care from organizations, such as the American Academy of Pediatrics (AAP) and the American College of Obstetricians and Gynecologists (ACOG), do not discuss primary headaches. ${ }^{26}$ Existing guidelines on the management of headache from the American Headache Society (AHS) do not discuss pregnancy. ${ }^{27-29}$ To address the gap related to the overlap of primary headaches and pregnancy, ACOG nominated this SR.

\section{Purpose and Scope of the Systematic Review}

This SR assesses the prevention and acute treatment of primary headaches during pregnancy, postpartum, and breastfeeding. Specifically, the SR assesses: (1) the (comparative) benefits and harms of pharmacologic and nonpharmacologic interventions to prevent attacks of primary headache in women who have a history of primary headache and are pregnant (or attempting to become pregnant, i.e., in the preconception phase), postpartum, or breastfeeding; and (2) the (comparative) benefits and harms of pharmacologic and nonpharmacologic interventions to treat acute attacks of primary headache in women who are pregnant (or attempting to become pregnant), postpartum, or breastfeeding. The intended audience for this SR includes guideline developers, clinicians, and other providers of care for women with primary headaches and are pregnant, postpartum, and 
breastfeeding. ACOG nominated the topic of this SR. The findings of this SR are intended to be used in development of ACOG clinical guidance. 


\section{Methods}

\section{Review Approach}

The Evidence-based Practice Center conducted this systematic review (SR) based on the Agency for Healthcare Research and Quality (AHRQ) Methods Guide for Effectiveness and Comparative Effectiveness Reviews (available at https://effectivehealthcare.ahrq.gov/products/cer-methodsguide/overview). This SR is reported in accordance with the Preferred Items for Reporting in Systematic Reviews and Meta-Analyses (PRISMA), ${ }^{30}$ A Measurement Tool to Assess Systematic Reviews (AMSTAR 2), ${ }^{31}$ and any relevant extension statements.

The topic of this report and preliminary Key Questions (KQs) arose through a process involving the public and AHRQ (https:/effectivehealthcare.ahrq.gov/about/epc/nomination/). Initially, a panel of Key Informants gave input on the KQs, including the outcomes, to be examined. AHRQ then posted these KQs and solicited public comment through its Effective Health Care (EHC) Program website (March 22, 2019, for 3 weeks) and on the Federal Register (November 22, 2019, for 1 month). AHRQ did not receive any comments. A Technical Expert Panel provided high-level content and methodological expertise throughout development of the SR protocol. The final protocol was posted on the EHC website at https://effectivehealthcare.ahrq.gov/products/headachespregnancy/protocol on November 12, 2019. We registered the protocol for this systematic review in PROSPERO (registration number CRD42020158310).

\section{Key Questions}

\section{KQ 1:}

What are the (comparative) benefits and harms of interventions to prevent attacks of primary headache in women who have a history of primary headache and are pregnant (or attempting to become pregnant), postpartum, or breastfeeding?

KQ 1a. Do the (comparative) benefits and harms vary by phase (i.e., preconception, first trimester of pregnancy, second trimester of pregnancy, third trimester of pregnancy, postpartum, breastfeeding)?

KQ 1b. Do the (comparative) benefits and harms vary by type of primary headache (i.e., migraine, tension headache, cluster headache, and other trigeminal autonomic cephalgias)?

\section{KQ 2:}

What are the (comparative) benefits and harms of interventions to treat acute attacks of primary headache in women who are pregnant (or attempting to become pregnant), postpartum, or breastfeeding?

KQ 2a. Do the (comparative) benefits and harms vary by phase (i.e., preconception, first trimester of pregnancy, second trimester of pregnancy, third trimester of pregnancy, postpartum, breastfeeding)?

KQ 2b. Do the (comparative) benefits and harms vary by type of primary headache (i.e., migraine, tension headache, cluster headache, and other trigeminal autonomic cephalgias)?

\section{Contextual Question:}

What is the available evidence concerning levels in maternal serum/blood, fetal/child serum/blood, breast milk, amniotic fluid, meconium, cord blood, or child urine of drugs used 
to prevent or treat attacks of primary headache in women who are pregnant (or attempting to become pregnant), postpartum, or breastfeeding?

\section{Analytic Frameworks}

Figures 1 and 2 provide the analytic frameworks for KQs 1 and 2, respectively.

Figure 1. Analytic framework for KQ 1: Interventions to prevent attacks of primary headache during pregnancy, postpartum, and breastfeeding

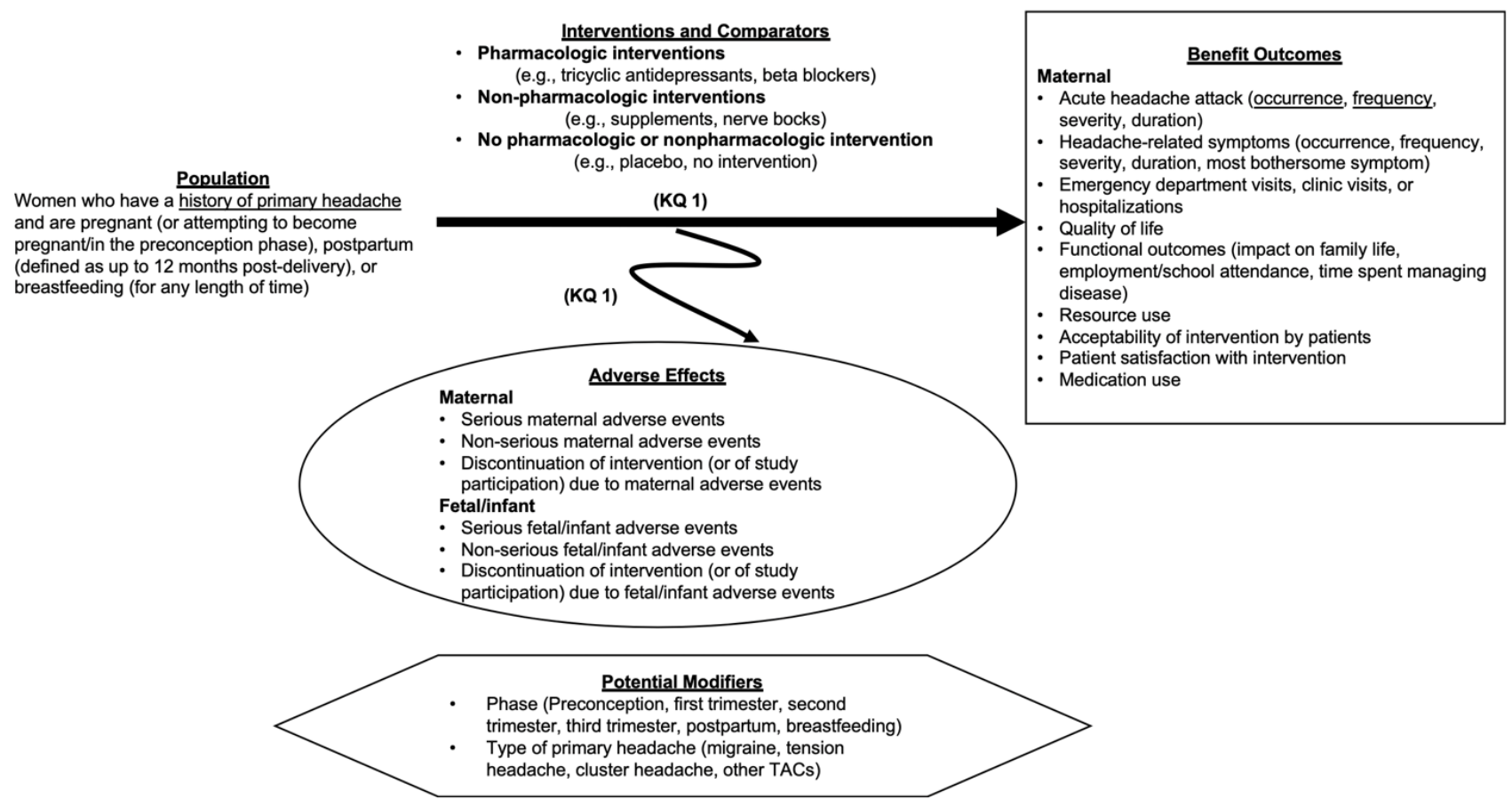

Abbreviations: $\mathrm{KQ}=$ Key Question, TAC = trigeminal autonomic cephalgia.

Underlined text in regular font refers to aspects that are distinct to KQ 1. 
Figure 2. Analytic framework for KQ 2: Interventions to treat attacks of primary headache during pregnancy, postpartum, and breastfeeding



Abbreviations: KQ = Key Question, NSAID = nonsteroidal anti-inflammatory drug, TAC = trigeminal autonomic cephalgia.

Underlined text in regular font refers to aspects that are distinct to KQ 2.

\section{Study Selection}

Appendix A provides full details on all search strategies, inclusion and exclusion criteria, and screening processes (for all types of evidence described above).

\section{Direct Evidence (Primary Studies)}

We searched for published primary studies for both KQs in Medline ${ }^{\circledR}$ (via PubMed ${ }^{\circledR}$ ), Embase ${ }^{\circledR}$, the Cochrane Central Register of Clinical Trials, and CINAHL ${ }^{\circledR}$, and for unpublished studies in ClinicalTrials.gov. Searches were current as of June 5, 2020.

For KQ 1 (prevention), the population of interest was women who were pregnant (or attempting to become pregnant), postpartum, or breastfeeding and had a history of, but were not currently undergoing, an attack of primary headache (migraine, tension headache, cluster headache, or other trigeminal autonomic cephalgias [TACs]) in any setting. We were interested in various pharmacologic and nonpharmacologic interventions used to prevent primary headaches (irrespective of their approval status by the U.S. Food and Drug Administration or their availability in the U.S.), and their association with various effectiveness outcomes (for the mother, such as headache onset and functional outcomes) and harms (for the mother, such as cardiovascular adverse effects, and for the fetus/child, such as spontaneous abortion, congenital anomalies, and neurodevelopmental adverse effects) at any time. Randomized controlled trials (RCTs), nonrandomized comparative studies (NRCSs: prospective or retrospective cohort studies comparing two or more interventions), single-group studies (prospective or retrospective, without a comparison group), case control studies, and cross-sectional studies or surveys were eligible. Our criteria for KQ 2 (treatment) differed from 
KQ 1 in that eligible patients were undergoing an ongoing attack of primary headache. Thus, the interventions and outcomes differed somewhat between the KQs.

\section{Indirect Evidence (Systematic Reviews of Harms, Regardless of Indication)}

For additional information about harms from the primary studies for both KQs, we searched for published SRs that have reported adverse effects to mother or child of interventions used in women who are pregnant, postpartum, or breastfeeding, regardless of the indication for which the intervention was used. To identify SRs, we searched Medline, the Cochrane Database of Systematic Reviews, and Epistemonikos through June 5, 2020. We did not enforce a date restriction when screening for eligible SRs, but we required that, at a minimum, SRs should have fulfilled each of the following four criteria:

1. Specified eligibility criteria for primary studies;

2. Conducted a comprehensive search (defined as searched at least two electronic databases and searched for unpublished studies through at least one source);

3. Assessed risk of bias in included studies using any instrument; and

4. Used appropriate methods for meta-analysis, if conducted.

\section{Supplemental Evidence (Case Reports)}

We included case reports as supplemental evidence only. From these, we simply report what occurred to individual patients in terms of headache progression and adverse effects (neither of which can be ascribed to individual interventions in case reports). We did not use case reports to inform conclusions in this SR. Instead, we separately summarized the supplemental evidence (briefly at the end of the Results section and in more detail in the Appendix B).

\section{Data Extraction and Risk of Bias Assessment}

For all types of evidence (primary studies, SRs, and case reports), one researcher extracted and entered data, which were confirmed by a second, independent researcher. We assessed risk of bias of the primary studies (but not case reports) and quality of the SRs using currently recommended study design-specific tools.

\section{Direct Evidence (Primary Studies)}

For RCTs, we used the Cochrane Risk of Bias Tool. ${ }^{32}$ For NRCSs (whether prospective or retrospective cohort studies) and case-control studies, we used specific items of the Risk of Bias in Nonrandomized Studies of Interventions (ROBINS-I) tool ${ }^{33}$ that pertain to confounding and selection bias, and items from the Cochrane Risk of Bias tool that relate to blinding, incomplete outcome data, selective outcome reporting, and other issues that could be related to bias. For singlegroup studies (i.e., noncomparative interventional studies, also known as single-arm studies), we used items from the Cochrane Risk of Bias tool that relate to participant loss to followup, selective outcome reporting, and other issues that could be related to bias. For all study designs, we also used items from the National Heart, Lung, and Blood Institute (NHLBI) tool focusing on the adequacy of descriptions of study eligibility criteria, interventions, and outcomes. ${ }^{34}$ 


\section{Indirect Evidence (Systematic Reviews of Harms, Regardless of Indication)}

We assessed the quality of the SRs using specific items from the A Measurement Tool to Assess Systematic Reviews, version 2 (AMSTAR 2). ${ }^{31}$

\section{Data Synthesis and Analysis}

In consultation with a panel of invited Key Informants and members of a Technical Expert Panel, we identified relevant outcomes and prioritized some outcomes for strength of evidence (SoE) assessment. Where appropriate, we calculated between-arm effect sizes based on reported withinarm data. Because of the overall paucity of evidence identified, our approach to synthesis was qualitative. The evidence base did not allow for meta-analysis.

Where applicable, we compared data reported in the direct evidence (i.e., primary studies) with data reported in the indirect evidence (i.e., SRs).

\section{Grading the Strength of the Body of Evidence}

We graded the SoE in both the direct evidence and the indirect evidence as per the AHRQ Methods Guide. ${ }^{35,}{ }^{36}$ The SoE for each conclusion is based on a qualitative combination of the summary risk of bias across all relevant studies, the consistency of the studies, the precision of the available estimates, and the directness of the evidence. When only one study addressed a given comparison, it was not possible to evaluate consistency. When only single-group studies addressed a given comparison, estimates were rated as indirect because of the lack of direct comparisons of interest. Although there was some variability in the definitions of various outcomes, such as pain severity, we deemed these to be sufficiently minor so as not to affect directness.

We graded SoE for acute headache attacks, headache-related symptoms, emergency department or clinic visits, hospitalizations, quality of life, serious maternal adverse effects or discontinuation of intervention (or of study participation) due to maternal adverse effects, and serious fetal/child adverse effects or discontinuation of intervention (or of study participation) due to fetal/child adverse effects. As noted, we did not use case reports to make conclusions, and, thus, we did not consider the case reports in the SoE assessments.

\section{Basis for Conclusions}

For each class of interventions for each KQ, we have based our conclusions regarding benefits and harms on: (1) the direct evidence-primary studies (not case reports) conducted in patients who were pregnant (or attempting to become pregnant), postpartum, or breastfeeding with primary headache; and (2) the indirect evidence- existing SRs of studies conducted in patients who were pregnant (or attempting to become pregnant), postpartum, or breastfeeding regardless of indication. In the one instance where we found a SR in this population of patients with primary headache (on triptan use), we have denoted that evidence as "SR Evidence" because it focused on our population of interest. 


\section{Results}

\section{Description of Included Evidence}

\section{Organization of Chapter}

We have organized the Results Chapter by type of evidence (direct, indirect, and supplemental), as follows:

- Direct Evidence (Primary Studies) and Indirect Evidence (Systematic Reviews [SRs] of Harms, Regardless of Indication): We describe the direct evidence and the indirect evidence because we use both these types of evidence to inform our conclusions. We have organized this first section, by Key Question (KQ) (first prevention [KQ 1], then treatment [KQ 2]). For each KQ, we provide Key Points. Subsections within KQs are organized by type of intervention (i.e., pharmacologic and nonpharmacologic, and within types, guided by the research identified, by groupings of intervention classes and comparisons). Each subsection includes the following components (in order):

o A description of the direct evidence

o A description of the indirect evidence

o Results for maternal benefit and maternal and fetal/child harm outcomes

o Where applicable, a comparison of how the harms reported in the direct evidence compare with those reported in the indirect evidence

o A summary table of results from the direct evidence

0 An evidence profile (with strength of evidence [SoE]) of the direct evidence

o A summary table of statistically significant adverse effects (harms) from the indirect evidence

o An evidence profile (with SoE) of the indirect evidence.

Detailed findings from the direct evidence (i.e., primary studies), including tables for study designs and arms, risk of bias, and all outcomes are in Appendix B. We call attention to specific Appendix Table numbers in the relevant subsections. Detailed findings from the indirect evidence (i.e., SRs regardless of indication), including tables for SR design and arms, SR quality, and all reported adverse effects (either statistically significant or otherwise) are also in Appendix B.

- Supplemental Evidence (Case Reports): We provide a brief summary of the findings from the supplemental evidence (case reports). This summary is organized by KQ, and within each KQ, by type of outcomes (benefit outcomes versus harms). Details about the individual case reports and detailed tables are in Appendix B.

\section{Literature Search Results}

We conducted two separate literature searches - one for the primary studies and case reports, and the other for SRs. The electronic literature search for primary studies and case reports, combined with a handsearch of existing SRs, yielded 8,549 citations. The search for SRs yielded 2,788 citations.

In total, 16 primary studies (direct evidence), 26 SRs (indirect evidence), and 19 case reports (supplemental evidence) met criteria.

The 16 included primary studies, published between 1990 and 2018, comprised three randomized controlled trials (RCTs) (reported in five articles ${ }^{37-41}$ ), eight nonrandomized comparative studies 
(NRCSs) (observational cohort studies, reported in 16 articles ${ }^{42-57}$ ), and five single-group studies (reported in six articles ${ }^{25,38,58-61}$ ). Of note, one article reported both an RCT and a single-group study (Marcus 1995). ${ }^{38}$ The 16 primary studies included a total of 14,185 patients, all of whom were pregnant. No studies examined women who were attempting to become pregnant or who were postpartum or breastfeeding. The 16 included studies comprised three RCTs with 138 patients (ranging from 25 to 70 patients each), eight NRCSs with 13,907 patients (ranging from 123 to 5,900 patients each), and five single-group studies with 121 patients (ranging from 3 to 240 patients each). Table B-1 summarizes the design and arm details of all 16 primary studies. Tables B-2, B-3, B-4, and B-5 summarize the risk of bias assessment of all 16 primary studies.

The 26 included SRs, published between 2000 and 2020, assessed harms of pharmacologic interventions used during pregnancy (Table B-25), regardless of indication. ${ }^{62-90}$ These included eight SRs that assessed nonsteroidal anti-inflammatory drugs (NSAIDs), ${ }^{64,66,67,70,73-75,81}$ two that assessed antiepileptics, ${ }^{87-89}$ two that assessed beta blockers, ${ }^{62,} 90$ two that assessed calcium channel blockers, ${ }^{62}$, 65 two that assessed antiemetics (5HT3 antagonists), ${ }^{76,85}$ two that assessed antipsychotics, ${ }^{68,86}$ two that assessed antihistamines, ${ }^{72,77}$ and one each that assessed serotonin and norepinephrine reuptake inhibitors (SNRIs), ${ }^{82,} 83$ tricyclic antidepressants, ${ }^{82,} 83$ benzodiazepines, ${ }^{69,} 71$ corticosteroids, ${ }^{84}$ oral magnesium, ${ }^{78}$ triptans, ${ }^{79}$ analgesics/antipyretics, ${ }^{80}$ and intravenous magnesium. ${ }^{63}$ Only one of the 26 SRs, which addressed triptans, ${ }^{79}$ was focused on studies of pregnant women with primary headache (migraine); the remaining 25 SRs included studies of pregnant women with various conditions. Twelve of the 26 SRs reported maternal adverse effects, and 23 reported fetal/child adverse effects.

Table B-25 summarizes the characteristics and arm details of all 26 SRs. Table B-26 summarizes the quality assessment of all 26 SRs (assessed using AMSTAR 2). Tables providing the adverse effects with statistically significant effect sizes, suggesting evidence of drug harms, are included within the descriptions of each intervention class in this report. Tables B-27 and B-28 provide the complete lists of maternal and fetal/child adverse effects, respectively, that were reported in the 26 SRs.

Details of the 19 included case reports ${ }^{91-109}$ are provided in Tables B-29 and B-30.

Further details about the literature searches; included primary studies, SRs, and case reports; and excluded primary studies, SRs, and case reports (with reasons for their exclusion) are in Appendix B.

\section{Direct Evidence (Primary Studies) and Indirect Evidence (Systematic Reviews of Harms, Regardless of Indication)}

\section{Key Question 1: Prevention of Primary Headache}

\section{Key Points}

- No direct or indirect evidence evaluated the beneficial effects of interventions to prevent primary headache in women who are pregnant (or attempting to become pregnant), postpartum, or breastfeeding.

- There is insufficient direct evidence (studies of pregnant women with primary headaches) to make conclusions about the harms of topiramate during pregnancy (but see indirect evidence below).

- Indirect evidence (SRs of use during pregnancy regardless of indication) found that:

0 The following pharmacologic interventions have increased risks of maternal or fetal/child adverse effects: 
- Antiepileptics:

$\diamond$ Topiramate: Increased risk of fetal death or spontaneous abortion (combined), fetal growth restriction, cleft lip/palate, and other major congenital anomalies (moderate SoE)

$\diamond$ Carbamazepine: Increased risk of major and minor congenital anomalies (moderate SoE)

$\diamond$ Gabapentin: Increased risk of congenital cardiovascular anomalies, hypospadias, and psychomotor developmental delay (low SoE)

$\diamond \quad$ Lamotrigine: Increased risk of autism/dyspraxia, but not other adverse effects (moderate SoE)

$\diamond$ Valproate: Increased risk of fetal death or spontaneous abortion, major congenital malformations, cleft lip/palate, developmental delays, and autism/dyspraxia (moderate SoE)

- Venlafaxine: Increased risk of preterm birth (moderate SoE)

- Tricyclic antidepressants (any): Increased risk of small for gestational age, major congenital anomalies, cardiovascular anomalies, neonatal convlusions, and neonatal respiratory distress, but not low birth weight (moderate SoE)

- Benzodiazepines (any): Increased risk of oral cleft and other major congenital anomalies (low SoE)

- Beta blockers (any): Increased risk of cardiovascular anomalies, cleft lip/palate, and neural tube defects, but no increased risk of preterm birth (moderate SoE)

- Prednisolone: Increased risk of oral clefts, but not other major congenital anomalies (low SoE)

- Oral magnesium: Increased risk of neonatal death, but not low birth weight (low SoE). No increased risk of maternal adverse effects (low SoE).

o The following pharmacologic interventions have no increased risk of maternal or fetal/child AEs:

- Calcium channel blockers (any): No increased risk of maternal (low SoE) or fetal/child adverse effects (low to moderate SoE)

- Calcium channel blockers (nifedipine): No increased risk of fetal/child adverse effects (low to moderate SoE)

- Antihistamines (any): No increased risk of spontaneous abortion, stillbirth, preterm birth, low birth weight, or major congenital anomalies (moderate SoE)

- No direct or indirect evidence evaluated nonpharmacologic interventions to prevent primary headaches in women who are pregnant (or attempting to become pregnant), postpartum, or breastfeeding.

Only one of the 16 primary studies included in this SR (direct evidence) addressed prevention of primary headaches. This study, a single-group study, addressed a pharmacologic intervention topiramate (an antiepileptic). ${ }^{59}$ No primary studies addressed nonpharmacologic interventions for prevention.

Eleven existing SRs (indirect evidence) addressed interventions relevant to KQ 1. These included: antiepileptics, serotonin and norepinephrine reuptake inhibitors (SNRIs), tricyclic antidepressants, benzodiazepines, beta blockers, calcium channel blockers, corticosteroids, antihistamines, and oral magnesium. No SRs addressed nonpharmacologic interventions used for prevention. 


\section{Key Question 1: Pharmacologic Interventions To Prevent Attacks of Primary Headache}

\section{Antiepileptics}

\section{Description of Direct Evidence for Antiepileptics}

One retrospective single-group study reported the harms of an antiepileptic drug (topiramate) in pregnant patients with primary headache (Tables 1 and 2 and Tables B-1, B-5, B-6, and B-31). ${ }^{59}$ The study did not report the drug's effect in preventing migraine.

Castilla-Puentes 2014 studied 81 pregnant women with a history of migraine in the U.S., U.K., Canada, Australia, and 36 other countries. ${ }^{59}$ The patients received topiramate, but its dose, duration, route, and frequency were not reported. Patient age, race, trimester, gestational age, and parity were also not reported. We assessed the study at overall low risk of bias.

\section{Description of Indirect Evidence for Antiepileptics}

Two high-quality SRs (Veroniki 2017 [reported in two articles] ${ }^{87,88}$ and Weston $2016^{89}$ ) assessed harms associated with antiepileptic use during pregnancy (regardless of indication) (Tables 3 and 4 and Tables B-26, B-27, B-28, and B-37).

Each of the SRs assessed five antiepileptics: valproate, topiramate, gabapentin, carbamazepine, and lamotrigine. Veroniki 2017 conducted a network meta-analysis, but Weston 2016 did not. Veroniki 2017 was thus able incorporate more studies (96 studies) than Weston 2016 (50 studies). We therefore summarize harms reported in Veroniki 2017 and supplement additional harms that were reported only in Weston 2016.

\section{Maternal Benefit Outcomes of Antiepileptics}

No primary study or SR reported on maternal benefit outcomes of antiepileptics.

\section{Maternal Adverse Effects of Antiepileptics}

No primary study or SR reported on maternal adverse effects of antiepileptics.

\section{Fetal/Child Adverse Effects of Antiepileptics}

In Castilla-Puentes 2014 (direct evidence), among the 81 pregnant women treated with topiramate to prevent migraines, 23 women (28.4\%) lost their fetuses due to spontaneous abortion and another 10 women (12.3\%) underwent elective or induced abortion (Table 1).

Castilla-Puentes 2014 also reported that, among the 81 infants exposed to topiramate during pregnancy (being used to prevent migraines), 10 infants (12.3\%) had congenital anomalies. Two infants (2.5\%) had cleft palate. The following anomalies were found in one infant $(1.2 \%)$ each: hydrocephalus, meningomyelocele, spina bifida, an unspecified cardiovascular congenital anomaly, syndactyly, polydactyly, gastrointestinal obstruction, and pyloric stenosis (Table 1).

\section{Fetal/Child Adverse Effects Reported in Indirect Evidence}

Topiramate: Topiramate use was associated with fetal death or spontaneous abortion (odds ratio [OR] 23.6, 95\% confidence interval [CI] 1.2 to 549.6), fetal growth restriction (OR 2.64, 95\% CI 1.41 to 4.63), major congenital anomalies (OR 1.90, 95\% CI 1.17 to 2.97), and cleft lip/palate (OR 6.12, 95\% CI 1.89 to 19.05) (Table 3). Topiramate use was associated with hypospadias (OR 3.52, 95\% CI 0.77 to 15.72), cognitive developmental delay (OR 3.14, 95\% CI 0.45 to 16.53), and 
psychomotor developmental delay (OR 3.89, 95\% CI 0.41 to 24.27), but these were not statistically significant. However, topiramate use was not associated with congenital skeletal or limb defects.

Carbamazepine: Carbamazepine use was associated with major congenital anomalies (OR 1.37, 95\% CI 1.10 to 1.71) and minor congenital anomalies (OR 10.8, 95\% CI 1.4 to 373.9) (Table 3). Carbamazepine was also associated with cognitive developmental delay (OR 2.07, 95\% CI 0.82 to 5.48), autism/dyspraxia (OR 5.76, 95\% CI 0.76 to 73.43), language delay (OR 4.32, 95\% CI 0.81 to 26.93), and attention deficit hyperactivity disorder (OR 2.32, 95\% CI 0.70 to 7.86 ), but none of the ORs for these individual adverse effects were statistically significant.

Gabapentin: Gabapentin was associated with congenital cardiovascular anomalies (OR 5.98, 95\% CI 1.34 to 19.73), hypospadias (OR 16.5, 95\% CI 2.5 to 121.7), and psychomotor developmental delay (OR 9.03, 95\% CI 1.00 to 62.78) (Table 3). Gabapentin was associated with cleft lip/palate (OR 5.14, 95\% CI 0.16 to 38.06), club foot (OR 5.55, 95\% CI 0.01 to 165.5), and inguinal hernia (OR 10.86, 95\% CI 0.02 to 282.60), but these were not statistically significant.

Lamotrigine: There was no association between lamotrigine use and in utero (e.g., fetal death or spontaneous abortion [combined], fetal growth restriction), perinatal (e.g., preterm birth), or neonatal (e.g., congenital anomalies, inguinal hernia) adverse effects. Lamotrigine use was, however, associated with autism/dyspraxia (OR 8.88, 95\% CI 1.28 to 112.0) (Table 3). Lamotrigine use was associated with language delay, but this was not statistically significant (OR 4.36, 95\% CI 0.68 to 25.41).

Valproate: Valproate use was associated with increased fetal/child harms. These included fetal death or spontaneous abortion (combined) (OR 1.83, 95\% CI 1.04 to 3.45), congenital anomalies (ORs exceeding 3.0), neural tube defects (RR 5.30, 95\% CI 1.05 to 26.70), hypospadias (OR 2.58, 95\% CI 1.24 to 5.76), cleft lip/palate (OR 3.26, 95\% CI 1.38 to 7.57), club foot (OR 3.26, 95\% CIC 1.38 to 7.57 ), and minor anomalies (OR 17.8, 95\% CI 1.6 to 633.3). Valproate was also associated with cognitive developmental delay, autism/dyspraxia, psychomotor developmental delay, and language delay (all ORs exceeding 4) (Table 3). 
Table 1. Antiepileptics: Summary of direct evidence regarding use to prevent primary headaches

\begin{tabular}{|l|l|l|l|l|}
\hline Outcome* & Outcome Definition & Study, Year, Design, PMID & Intervention & n/N (\%) \\
\hline $\begin{array}{l}\text { AEs - Spontaneous } \\
\text { abortion or elective } \\
\text { or induced abortion }\end{array}$ & Spontaneous abortion & $\begin{array}{l}\text { Castilla-Puentes, 2014, } \\
\text { Single-group study, } \\
24598456\end{array}$ & Topiramate & $23 / 81(28.4)$ \\
\cline { 1 - 2 } $\begin{array}{l}\text { AEs - Elective or } \\
\text { induced abortion }\end{array}$ & Elective or induced abortion & & \\
\cline { 1 - 2 } $\begin{array}{l}\text { AEs - Fetal/child } \\
\text { serious congenital } \\
\text { anomalies }\end{array}$ & Any & $\begin{array}{l}\text { Various neurological, cardiovascular, } \\
\text { malformations, gastrointestinal anomalies }\end{array}$ & & $10 / 81(12.3)$ \\
\cline { 5 - 6 }
\end{tabular}

Abbreviations: $\mathrm{AE}=$ adverse effect, $\mathrm{CS}$ = cesarean section, $\mathrm{PMID}=$ PubMed identifier.

* No studies reported acute headache attack outcomes (occurrence, frequency, severity, duration), headache-related symptom outcomes (occurrence, frequency, severity, duration), emergency department or clinic visits, hospitalizations, quality of life, functional outcomes (impact on family life, work/school attendance, time spent managing disease), resource use, acceptability of intervention by patients, patient satisfaction with intervention, medication use, serious maternal AEs (any serious AE, cardiovascular), nonserious maternal AEs (any nonserious, nonobstetrical, preterm labor/CS, reduced breast milk, medication withdrawal symptoms),

discontinuation due to maternal AEs, serious fetal/child AEs (any serious AE, stillbirth or fetal death, neonatal or infant death, preterm birth, low birth weight, perinatal complications, neurodevelopmental/behavioral/social), nonserious fetal/child AEs (any nonserious $\mathrm{AE}$, breastfeeding delay/cessation/etc., poor infant attachment/bonding, medication withdrawal symptoms), or discontinuation due to fetal/child AEs.

Table 2. Antiepileptics: Evidence profile for direct evidence regarding use to prevent primary headaches

\begin{tabular}{|l|l|l|l|l|l|l|l|l|l|}
\hline Topic & Comparison & Outcome & $\begin{array}{l}\text { N Studies } \\
(\text { Subjects) }\end{array}$ & RoB & Consistency & Precision & Directness & SoE & Conclusion \\
\hline Benefits & - & - & 0 & - & - & - & - & None & None \\
\hline Harms & $\begin{array}{l}\text { Topiramate } \\
\text { (no } \\
\text { comparison) }\end{array}$ & $\begin{array}{l}\text { Spontaneous } \\
\text { abortion or } \\
\text { elective or } \\
\text { induced } \\
\text { abortion }\end{array}$ & $1(81)$ & Low & N/A & Imprecise & Indirect & Insufficient & $\begin{array}{l}\text { No } \\
\text { conclusion } \\
\text { made }\end{array}$ \\
\cline { 2 - 8 } & $\begin{array}{l}\text { Fetal/child } \\
\text { serious } \\
\text { congenital } \\
\text { anomalies }\end{array}$ & $1(81)$ & Low & N/A & Imprecise & Indirect & Insufficient & $\begin{array}{l}\text { No } \\
\text { conclusion } \\
\text { made }\end{array}$ \\
\hline
\end{tabular}

Abbreviations: N/A = not applicable, RoB = risk of bias, SoE = strength of evidence.

Consistency was deemed N/A when it could not be assessed because only one study was one found.

Table B-31 provides the complete version of this Evidence Profile, including displaying outcomes for which no studies were identified. 
Table 3. Antiepileptics: Summary of indirect evidence of fetal/child harms, statistically significant findings

\begin{tabular}{|c|c|c|c|c|c|c|}
\hline $\begin{array}{l}\text { SR, Year } \\
\text { Published, } \\
\text { PMI D }\end{array}$ & Drug Class & Drug Name & $\begin{array}{l}\text { Timing of } \\
\text { Occurrence of } \\
\text { Adverse Effect }\end{array}$ & Adverse Effect & $\begin{array}{l}\mathbf{N} \\
\text { Studies }\end{array}$ & Effect Size $(95 \% \mathrm{Cl})$ \\
\hline \multirow{20}{*}{$\begin{array}{l}\text { Veroniki, 2017, } \\
28472982\end{array}$} & \multirow{4}{*}{$\begin{array}{l}\text { Antiepileptics: Multiple } \\
\text { mechanisms }\end{array}$} & \multirow[t]{4}{*}{ Topiramate } & \multirow[t]{2}{*}{ In utero } & Fetal death or spontaneous abortion (combined) & 96 & OR $23.6(1.2,549.6)$ \\
\hline & & & & Fetal growth restriction & 96 & OR $2.64(1.41,4.63)$ \\
\hline & & & \multirow[t]{2}{*}{ Neonatal } & Congenital anomalies, Major & 96 & OR $1.90(1.17,2.97)$ \\
\hline & & & & Congenital anomalies, Cleft lip/palate & 96 & OR $6.12(1.89,19.1)$ \\
\hline & \multirow{2}{*}{$\begin{array}{l}\text { Antiepileptic: Sodium } \\
\text { channel modulators }\end{array}$} & \multirow[t]{2}{*}{ Carbamazepine } & \multirow[t]{2}{*}{ Neonatal } & Congenital anomalies, Major & 96 & OR $1.37(1.10,1.71)$ \\
\hline & & & & Congenital anomalies, Minor & 96 & OR $10.8(1.4,373.9)$ \\
\hline & \multirow{3}{*}{$\begin{array}{l}\text { Antiepileptics: Calcium } \\
\text { channel modulators }\end{array}$} & \multirow[t]{3}{*}{ Gabapentin } & \multirow[t]{2}{*}{ Neonatal } & Congenital anomalies, Cardiovascular & 96 & OR $5.98(1.34,19.7)$ \\
\hline & & & & Congenital anomalies, Hypospadias & 96 & OR $16.5(2.5,121.7)$ \\
\hline & & & Child & Psychomotor developmental delay & 96 & OR $9.03(1.00,62.78)$ \\
\hline & $\begin{array}{l}\text { Antiepileptic: Sodium } \\
\text { channel modulator }\end{array}$ & Lamotrigine & Child & Autism/dyspraxia & 96 & OR $8.88(1.28,112.0)$ \\
\hline & \multirow{10}{*}{$\begin{array}{l}\text { Antiepileptics: Multiple } \\
\text { mechanisms }\end{array}$} & \multirow[t]{10}{*}{ Valproate } & In utero & Fetal death or spontaneous abortion (combined) & 96 & OR $1.83(1.04,3.45)$ \\
\hline & & & \multirow[t]{5}{*}{ Neonatal } & Congenital anomalies, Major & 96 & OR $3.04(1.23,7.07)$ \\
\hline & & & & Congenital anomalies, Hypospadias & 96 & OR $2.58(1.24,5.76)$ \\
\hline & & & & Congenital anomalies, Cleft lip/palate & 96 & OR $3.26(1.38,7.57)$ \\
\hline & & & & Congenital anomalies, Club foot & 96 & OR $3.26(1.43,8.25)$ \\
\hline & & & & Congenital anomalies, Minor & 96 & OR $17.8(1.6,633.3)$ \\
\hline & & & \multirow[t]{4}{*}{ Child } & Cognitive developmental delay & 96 & OR $7.40(3.00,18.46)$ \\
\hline & & & & Autism/dyspraxia & 96 & OR $17.29(2.40,217.6)$ \\
\hline & & & & Psychomotor developmental delay & 96 & OR $4.16(2.04,8.75)$ \\
\hline & & & & Language delay & 96 & OR $7.95(1.50,49.1)$ \\
\hline \multirow{2}{*}{$\begin{array}{l}\text { Weston, 2016, } \\
27819746\end{array}$} & \multirow{2}{*}{$\begin{array}{l}\text { Antiepileptics: Multiple } \\
\text { mechanisms }\end{array}$} & \multirow[t]{2}{*}{ Valproate } & \multirow[t]{2}{*}{ Neonatal } & Congenital anomalies, Neural tube defects & 6 & RR $5.30(1.05,26.7)$ \\
\hline & & & & Congenital anomalies, Orofacial clefts & 6 & RD $0.03(0.01,0.05)$ \\
\hline
\end{tabular}

Abbreviations: $\mathrm{CI}$ = confidence interval, $\mathrm{OR}=$ odds ratio, $\mathrm{PMID}=$ PubMed identifier, $\mathrm{RD}=$ risk difference, $\mathrm{RR}=$ relative risk, $\mathrm{SR}=$ systematic review. 
Table 4. Antiepileptics: Evidence profile for indirect evidence regarding harms of use during pregnancy

\begin{tabular}{|c|c|c|c|c|c|c|c|c|c|}
\hline Drug & $\begin{array}{l}\text { Outcome } \\
\text { Category }\end{array}$ & Outcome & $\begin{array}{l}\text { N SRs (N } \\
\text { Studies) }\end{array}$ & $\begin{array}{l}\text { RoB in I ncluded } \\
\text { Studies }\end{array}$ & Consistency & Precision & Directness & SoE & Conclusions \\
\hline \multirow[t]{6}{*}{ Topiramate } & \multirow[t]{6}{*}{$\begin{array}{l}\text { AEs - Fetal/ } \\
\text { Child }\end{array}$} & Any & $1(96)$ & Low to moderate & Consistent & Precise & Indirect & Moderate & $\begin{array}{l}\text { Increased fetal growth } \\
\text { restriction }\end{array}$ \\
\hline & & $\begin{array}{l}\text { Spontaneous abortion or } \\
\text { elective or induced abortion }\end{array}$ & $1(96)$ & Low to moderate & Consistent & Precise & Indirect & Moderate & $\begin{array}{l}\text { Increased spontaneous } \\
\text { abortion }\end{array}$ \\
\hline & & Stillbirth or fetal death & 1 (96) & Low to moderate & Consistent & Precise & Indirect & Moderate & Increased fetal death \\
\hline & & Preterm birth & $1(96)$ & Low to moderate & Consistent & Precise & Indirect & Moderate & No increased risk \\
\hline & & Congenital anomalies & $1(96)$ & Low to moderate & Consistent & Precise & Indirect & Moderate & $\begin{array}{l}\text { Increased major } \\
\text { anomalies and cleft } \\
\text { lip/palate }\end{array}$ \\
\hline & & $\begin{array}{l}\text { Neurodevelopmental/ } \\
\text { behavioral/social }\end{array}$ & 1 (96) & Low to moderate & Consistent & Imprecise & Indirect & Low & $\begin{array}{l}\text { No increased risk of } \\
\text { cognitive or } \\
\text { developmental delays }\end{array}$ \\
\hline \multirow[t]{5}{*}{$\begin{array}{l}\text { Carba- } \\
\text { mazepine }\end{array}$} & \multirow[t]{5}{*}{$\begin{array}{l}\text { AEs - Fetal/ } \\
\text { Child }\end{array}$} & $\begin{array}{l}\text { Spontaneous abortion or } \\
\text { elective or induced abortion }\end{array}$ & $1(96)$ & Low to moderate & Consistent & Precise & Indirect & Low & No increased risk \\
\hline & & Stillbirth or fetal death & $1(96)$ & Low to moderate & Consistent & Precise & Indirect & Low & No increased risk \\
\hline & & Preterm birth & $1(96)$ & Low to moderate & Consistent & Precise & Indirect & Low & No increased risk \\
\hline & & Congenital anomalies & 1 (96) & Low to moderate & Consistent & Precise & Indirect & Moderate & $\begin{array}{l}\text { Increased major and } \\
\text { minor anomalies }\end{array}$ \\
\hline & & $\begin{array}{l}\text { Neurodevelopmental/ } \\
\text { behavioral/social }\end{array}$ & $1(96)$ & Low to moderate & Consistent & Precise & Indirect & Low & No increased risk \\
\hline \multirow[t]{4}{*}{ Gabapentin } & \multirow[t]{4}{*}{$\begin{array}{l}\text { AEs - Fetal/ } \\
\text { Child }\end{array}$} & Any & $1(96)$ & Low to moderate & Consistent & Imprecise & Indirect & Low & $\begin{array}{l}\text { No increased risk of fetal } \\
\text { growth restriction }\end{array}$ \\
\hline & & Preterm birth & $1(96)$ & Low to moderate & Consistent & Precise & Indirect & Low & No increased risk \\
\hline & & Congenital anomalies & 1 (96) & Low to moderate & Inconsistent & Imprecise & Indirect & Low & $\begin{array}{l}\text { Increased cardiovascular } \\
\text { anomalies and } \\
\text { hypospadias, but not cleft } \\
\text { lip/palate or club foot }\end{array}$ \\
\hline & & $\begin{array}{l}\text { Neurodevelopmental/ } \\
\text { behavioral/social }\end{array}$ & $1(96)$ & Low to moderate & Inconsistent & Precise & Indirect & Low & $\begin{array}{l}\text { Increased psychomotor } \\
\text { developmental delay, but } \\
\text { not cognitive } \\
\text { developmental delays }\end{array}$ \\
\hline \multirow[t]{5}{*}{ Lamotrigine } & \multirow{5}{*}{$\begin{array}{l}\text { AEs - Fetal/ } \\
\text { Child }\end{array}$} & Any & $1(96)$ & Low to moderate & Consistent & Precise & Indirect & Moderate & No increased risk \\
\hline & & $\begin{array}{l}\text { Spontaneous abortion or } \\
\text { elective or induced abortion }\end{array}$ & $1(96)$ & Low to moderate & Consistent & Precise & Indirect & Moderate & No increased risk \\
\hline & & Stillbirth or fetal death & $1(96)$ & Low to moderate & Consistent & Precise & Indirect & Moderate & No increased risk \\
\hline & & Preterm birth & $1(96)$ & Low to moderate & Consistent & Precise & Indirect & Moderate & No increased risk \\
\hline & & Congenital anomalies & $1(96)$ & Low to moderate & Consistent & Precise & Indirect & Moderate & No increased risk \\
\hline
\end{tabular}




\begin{tabular}{|c|c|c|c|c|c|c|c|c|c|}
\hline Drug & $\begin{array}{l}\text { Outcome } \\
\text { Category }\end{array}$ & Outcome & $\begin{array}{l}\text { N SRs (N } \\
\text { Studies) }\end{array}$ & $\begin{array}{l}\text { RoB in I ncluded } \\
\text { Studies }\end{array}$ & Consistency & Precision & Directness & SoE & Conclusions \\
\hline & & $\begin{array}{l}\text { Neurodevelopmental/ } \\
\text { behavioral/social }\end{array}$ & $1(96)$ & Low to moderate & Consistent & Precise & Indirect & Moderate & $\begin{array}{l}\text { Increased } \\
\text { autism/dyspraxia, but no } \\
\text { increased risk of cognitive } \\
\text { or psychomotor } \\
\text { developmental delays, } \\
\text { language delay, for } \\
\text { attention deficit } \\
\text { hyperactivity disorder }\end{array}$ \\
\hline \multirow[t]{5}{*}{ Valproate } & \multirow[t]{5}{*}{$\begin{array}{l}\text { AEs - Fetal/ } \\
\text { Child }\end{array}$} & $\begin{array}{l}\text { Spontaneous abortion or } \\
\text { elective or induced abortion }\end{array}$ & $1(96)$ & Low to moderate & Consistent & Precise & Indirect & Moderate & $\begin{array}{l}\text { Increased spontaneous } \\
\text { abortion }\end{array}$ \\
\hline & & Stillbirth or fetal death & $1(96)$ & Low to moderate & Consistent & Precise & Indirect & Moderate & Increased fetal death \\
\hline & & Preterm birth & $1(96)$ & Low to moderate & Consistent & Precise & Indirect & Moderate & No increased risk \\
\hline & & Congenital anomalies & $2(96)$ & Low to moderate & Consistent & Precise & Indirect & Moderate & $\begin{array}{l}\text { Increased major } \\
\text { anomalies, hypospadias, } \\
\text { cleft lip/palate, club foot, } \\
\text { neural tube defects }\end{array}$ \\
\hline & & $\begin{array}{l}\text { Neurodevelopmental/ } \\
\text { behavioral/social }\end{array}$ & $1(96)$ & Low to moderate & Consistent & Precise & Indirect & Moderate & $\begin{array}{l}\text { Increased cognitive delay } \\
\text { autism/dyspraxia, } \\
\text { psychomotor } \\
\text { developmental delay, } \\
\text { language delay }\end{array}$ \\
\hline
\end{tabular}

Abbreviations: $\mathrm{AE}$ = adverse effect, $\mathrm{RoB}$ = risk of bias, SoE = strength of evidence, $\mathrm{SR}$ = systematic review.

When a range is provided for $\mathrm{N}$ studies, it implies that different numbers of studies reported data for the different individual measures of a given outcome.

Table B-37 provides the complete version of this Evidence Profile, including displaying outcomes for which no evidence was identified. 


\section{Serotonin and Norepinephrine Reuptake Inhibitors}

\section{Description of Direct Evidence for SNRIs}

We did not find any primary studies on use of SNRIs for preventing attacks of primary headache in women who were pregnant (or attempting to become pregnant), postpartum, or breastfeeding.

\section{Description of Indirect Evidence for SNRIs}

One high-quality SR (McDonagh 2014) assessed harms associated with venlafaxine use during late pregnancy (regardless of indication) (Tables 5 and 6 and Tables B-26, B-27, B-28, and B-37). ${ }^{82,83}$

\section{Maternal Benefit Outcomes of SNRIs}

No primary study or SR reported on maternal benefit outcomes of SNRIs.

\section{Maternal Adverse Effects of SNRIs}

No primary study or SR reported on maternal adverse effects of SNRIs.

\section{Fetal/Child Adverse Effects of SNRIs}

No primary study (direct evidence) reported on fetal/child adverse effects of SNRIs.

The McDonagh 2014 SR (indirect evidence) found that venlafaxine use in pregnant women (for any indication) was associated with preterm birth (OR 1.79, 95\% CI 1.46 to 2.19) and neonatal withdrawal symptoms (OR 3.1, 95\% CI 1.3 to 7.1) (Table 5).

Table 5. SNRIs: Summary of indirect evidence of fetal/child harms, statistically significant findings

\begin{tabular}{|l|l|l|l|l|l|l|}
\hline $\begin{array}{l}\text { SR, Year } \\
\text { Published, } \\
\text { PMI D }\end{array}$ & Drug Class & $\begin{array}{l}\text { Drug } \\
\text { Name(s) }\end{array}$ & $\begin{array}{l}\text { Timing of } \\
\text { Occurrence of } \\
\text { Adverse Effect }\end{array}$ & Adverse Effect & $\begin{array}{l}\text { N } \\
\text { Studies }\end{array}$ & $\begin{array}{l}\text { Effect Size (95\% } \\
\text { CI ) }\end{array}$ \\
\hline $\begin{array}{l}\text { McDonagh, 2014, } \\
25004304\end{array}$ & SNRIs & Venlafaxine & Perinatal & Preterm birth & 2 & OR 1.79(1.46, 2.19) \\
\cline { 3 - 7 } & & Neonatal & Neonatal withdrawal symptoms & 1 & OR 3.1 (1.3, 7.1) \\
\hline
\end{tabular}

Abbreviations: $\mathrm{CI}$ = confidence interval, $\mathrm{OR}$ = odds ratio, PMID = PubMed identifier, SNRI = serotonin and norepinephrine reuptake inhibitor, $\mathrm{SR}=$ systematic review.

Table 6. SNRIs: Evidence profile for indirect evidence regarding harms of use during pregnancy

\begin{tabular}{|c|c|c|c|c|c|c|c|c|c|}
\hline Drug & $\begin{array}{l}\text { Outcome } \\
\text { Category }\end{array}$ & Outcome & $\begin{array}{l}\text { N SRs } \\
\text { (N } \\
\text { Studies) }\end{array}$ & $\begin{array}{l}\text { RoB in } \\
\text { Included } \\
\text { Studies }\end{array}$ & Consistency & Precision & Directness & SoE & Conclusions \\
\hline Venlafaxine & $\begin{array}{l}\text { AEs - } \\
\text { Fetal/Child }\end{array}$ & $\begin{array}{l}\text { Preterm } \\
\text { birth }\end{array}$ & $1(2)$ & Moderate & Consistent & Precise & Indirect & Moderate & $\begin{array}{l}\text { Increased } \\
\text { preterm birth }\end{array}$ \\
\hline
\end{tabular}

Abbreviations: $\mathrm{AE}=$ adverse effect, $\mathrm{RoB}$ = risk of bias, $\mathrm{SoE}=$ strength of evidence, $\mathrm{SNRI}=$ serotonin and norepinephrine reuptake inhibitor, $\mathrm{SR}=$ systematic review.

Table B-37 provides the complete version of this Evidence Profile, including displaying outcomes for which no evidence was identified. 


\section{Tricyclic Antidepressants}

\section{Description of Direct Evidence for Tricyclic Antidepressants}

We did not find any primary studies on use of tricyclic antidepressants for preventing attacks of primary headache in women who were pregnant (or attempting to become pregnant), postpartum, or breastfeeding.

\section{Description of Indirect Evidence for Tricyclic Antidepressants}

One high-quality SR (McDonagh 2014) assessed harms associated with (any) tricyclic antidepressant use during pregnancy (regardless of indication) (Tables 7 and 8 and Tables B-26, B-27, B-28, and B-37). ${ }^{82,83}$

\section{Maternal Benefit Outcomes of Tricyclic Antidepressants}

No primary study or SR reported on maternal benefit outcomes of tricyclic antidepressants.

\section{Maternal Adverse Effects of Tricyclic Antidepressants}

No primary study or SR reported on maternal adverse effects of tricyclic antidepressants.

\section{Fetal/Child Adverse Effects of Tricyclic Antidepressants}

No primary study (direct evidence) reported on fetal/child adverse effects of tricyclic antidepressants.

The McDonagh 2014 SR (indirect evidence) found that (any) tricyclic antidepressant use in pregnant women (for any indication) was associated with neonatal convulsions (OR 7.82, 95\% CI 2.81 to 21.8), neonatal respiratory distress (OR 2.11, 95\% CI 1.57 to 2.83), major congenital anomalies (OR 1.31, 95\% CI 1.04 to 1.65), and cardiovascular anomalies (OR 1.58, 95\% CI 1.10 to 2.19) (Table 7). There was no increased risk of low birth weight, however. Tricyclic antidepressant use was also associated with the child being unable to sit without support at 6 months (relative risk [RR] 2.9, 95\% CI 0.89 to 9.51), but this was not statistically significant.

Table 7. Tricyclic antidepressants: Summary of indirect evidence of fetal/child harms, statistically significant findings

\begin{tabular}{|c|c|c|c|c|c|c|}
\hline $\begin{array}{l}\text { SR, Year } \\
\text { Published, } \\
\text { PMI D }\end{array}$ & Drug Class & Drug & $\begin{array}{l}\text { Timing of } \\
\text { Occurrence } \\
\text { of Adverse } \\
\text { Effect }\end{array}$ & Adverse Effect & $\begin{array}{l}\mathbf{N} \\
\text { Studies }\end{array}$ & $\begin{array}{l}\text { Effect Size (95\% } \\
\text { CI) }\end{array}$ \\
\hline \multirow{4}{*}{$\begin{array}{l}\text { McDonagh, 2014, } \\
25004304\end{array}$} & \multirow{4}{*}{$\begin{array}{l}\text { Tricyclic } \\
\text { antidepressants }\end{array}$} & \multirow[t]{4}{*}{ Any } & \multirow[t]{4}{*}{ Neonatal } & Neonatal convulsions & 2 & OR $7.82(2.81,21.8)$ \\
\hline & & & & Neonatal respiratory distress & 2 & OR $2.11(1.57,2.83)$ \\
\hline & & & & Congenital anomalies, Major & 2 & OR $1.31(1.04,1.65)$ \\
\hline & & & & Congenital anomalies, Cardiovascular & 2 & OR $1.58(1.10,2.29)$ \\
\hline
\end{tabular}

Abbreviations: $\mathrm{CI}=$ confidence interval, $\mathrm{OR}=$ odds ratio, $\mathrm{PMID}=$ PubMed identifier, $\mathrm{SR}=$ systematic review. 
Table 8. Tricyclic antidepressants: Evidence profile for indirect evidence regarding harms of use during pregnancy

\begin{tabular}{|c|c|c|c|c|c|c|c|c|c|}
\hline Drug & $\begin{array}{l}\text { Outcome } \\
\text { Category }\end{array}$ & Outcome & $\begin{array}{l}\text { N SRS } \\
\text { (N } \\
\text { Studies) }\end{array}$ & $\begin{array}{l}\text { RoB in } \\
\text { I ncluded } \\
\text { Studies }\end{array}$ & Consistency & Precision & Directness & SoE & Conclusions \\
\hline \multirow[t]{4}{*}{$\begin{array}{l}\text { Tricyclic } \\
\text { anti- } \\
\text { depressants, } \\
\text { any }\end{array}$} & \multirow[t]{4}{*}{$\begin{array}{l}\text { AEs - } \\
\text { Fetal/Child }\end{array}$} & $\begin{array}{l}\text { Low birth } \\
\text { weight }\end{array}$ & $1(2)$ & Moderate & Consistent & Precise & Indirect & Moderate & $\begin{array}{l}\text { No increased } \\
\text { risk of small } \\
\text { for gestationa } \\
\text { age }\end{array}$ \\
\hline & & $\begin{array}{l}\text { Congenital } \\
\text { anomalies }\end{array}$ & $1(2)$ & Moderate & Consistent & Precise & Indirect & Moderate & $\begin{array}{l}\text { Increased } \\
\text { major and } \\
\text { cardiovascular } \\
\text { anomalies }\end{array}$ \\
\hline & & $\begin{array}{l}\text { Perinatal } \\
\text { complications }\end{array}$ & $1(2)$ & Moderate & Consistent & Precise & Indirect & Moderate & $\begin{array}{l}\text { Increased } \\
\text { neonatal } \\
\text { convulsions } \\
\text { and } \\
\text { respiratory } \\
\text { distress }\end{array}$ \\
\hline & & $\begin{array}{l}\text { Neuro- } \\
\text { developmental/ } \\
\text { behavioral/ } \\
\text { social }\end{array}$ & $1(1)$ & Moderate & $\mathrm{N} / \mathrm{A}$ & Imprecise & Indirect & Insufficient & None \\
\hline
\end{tabular}

Abbreviations: $\mathrm{AE}=$ adverse effect, N/A = not applicable, RoB = risk of bias, SoE = strength of evidence, $\mathrm{SR}=$ systematic review.

Table B-37 provides the complete version of this Evidence Profile, including displaying outcomes for which no evidence was identified.

\section{Benzodiazepines}

\section{Description of Direct Evidence for Benzodiazepines}

We did not find any primary studies on use of benzodiazepines for preventing attacks of primary headache in women who were pregnant (or attempting to become pregnant), postpartum, or breastfeeding .

\section{Description of Indirect Evidence for Benzodiazepines}

One high-quality SR (Enato 2011), reported in two articles, assessed harms associated with (any) benzodiazepine use during the first trimester (regardless of indication) (Tables 9 and 10 and Tables B-26, B-27, B-28, and B-37). ${ }^{69,71}$

\section{Maternal Benefit Outcomes of Benzodiazepines}

No primary study or SR reported on maternal benefit outcomes of benzodiazepines.

\section{Maternal Adverse Effects of Benzodiazepines}

No primary study or SR reported on maternal adverse effects of benzodiazepines.

\section{Fetal/Child Adverse Effects of Benzodiazepines}

No primary study (direct evidence) reported on fetal/child adverse effects of benzodiazepines.

The Enato 2011 SR (indirect evidence) reported that, in case-control studies included in the SR, benzodiazepine use during the first trimester was associated with major congenital anomalies (OR 3.01, 95\% CI 1.32 to 6.84) and oral clefts, specifically (OR 1.79, 95\% CI 1.13 to 2.82) (Table 9). However, cohort studies included in the SR did not show such associations. 
Benzodiazepine use was not associated with cardiovascular anomalies (assessed in case-control studies only).

Table 9. Benzodiazepines: Summary of indirect evidence of fetal/child harms, statistically significant findings

\begin{tabular}{|c|c|c|c|c|c|c|}
\hline $\begin{array}{l}\text { SR, Year } \\
\text { Published, } \\
\text { PMI D }\end{array}$ & Drug Class & Drug & $\begin{array}{l}\text { Timing of } \\
\text { Occurrence } \\
\text { of Adverse } \\
\text { Effect }\end{array}$ & Adverse Effect & $\begin{array}{l}\mathbf{N} \\
\text { Studies }\end{array}$ & Effect Size (95\% CI) \\
\hline \multirow[t]{2}{*}{$\begin{array}{l}\text { Enato, 2011, } \\
21272436\end{array}$} & \multirow[t]{2}{*}{ Benzodiazepines } & \multirow[t]{2}{*}{$\begin{array}{l}\text { Any (First } \\
\text { trimester) }\end{array}$} & \multirow[t]{2}{*}{ Neonatal } & $\begin{array}{l}\text { Congenital anomalies, } \\
\text { Major }\end{array}$ & 9 & CC studies: OR $3.01(1.32,6.84)$ \\
\hline & & & & $\begin{array}{l}\text { Congenital anomalies, } \\
\text { Oral cleft }\end{array}$ & 6 & CC studies: OR $1.79(1.13,2.82)$ \\
\hline
\end{tabular}

Abbreviations: CC = case-control, CI = confidence interval, OR = odds ratio, PMID = PubMed identifier, SR = systematic review.

Table 10. Benzodiazepines: Evidence profile for indirect evidence regarding harms of use during pregnancy

\begin{tabular}{|c|c|c|c|c|c|c|c|c|c|}
\hline Drug & $\begin{array}{l}\text { Outcome } \\
\text { Category }\end{array}$ & Outcome & $\begin{array}{l}\text { N SRs } \\
\text { (N } \\
\text { Studies) } \\
\end{array}$ & $\begin{array}{l}\text { RoB in } \\
\text { I ncluded } \\
\text { Studies } \\
\end{array}$ & Consistency & Precision & Directness & SoE & Conclusions \\
\hline $\begin{array}{l}\text { Benzo- } \\
\text { diazepines, } \\
\text { any }\end{array}$ & $\begin{array}{l}\text { AEs - } \\
\text { Fetal/Child }\end{array}$ & $\begin{array}{l}\text { Congenital } \\
\text { anomalies }\end{array}$ & $1(6-9)$ & Moderate & Consistent & Precise & Indirect & Low & $\begin{array}{l}\text { Increased } \\
\text { major } \\
\text { congenital } \\
\text { anomalies and } \\
\text { oral cleft }\end{array}$ \\
\hline
\end{tabular}

Abbreviations: $\mathrm{AE}=$ adverse effect, RoB = risk of bias, SoE = strength of evidence, $\mathrm{SR}=$ systematic review.

Table B-37 provides the complete version of this Evidence Profile, including displaying outcomes for which no evidence was identified.

\section{Beta Blockers}

\section{Description of Direct Evidence for Beta Blockers}

We did not find any primary studies on use of beta blockers for preventing attacks of primary headache in women who were pregnant (or attempting to become pregnant), postpartum, or breastfeeding.

\section{Description of Indirect Evidence for Beta Blockers}

Two high-quality SRs (Yakoob $2013^{90}$ and Abalos 2018 ${ }^{62}$ ) assessed harms associated with (any) beta blocker use during pregnancy (regardless of indication) (Tables 11 and 12 and Tables B-26, B-27, B-28, and B-37).

\section{Maternal Benefit Outcomes of Beta Blockers}

No primary study or SR reported on maternal benefit outcomes of beta blockers.

\section{Maternal Adverse Effects of Beta Blockers}

No primary study (direct evidence) reported on maternal adverse effects of beta blockers.

The Abalos 2018 SR (indirect evidence) reported that beta blocker use was associated with placental abruption, but this was not statistically significant (RR 5.11, 95\% CI 0.25 to 104.96). Beta blocker use was not associated with other adverse effects antepartum (e.g., hospitalization) or during delivery (e.g., induction of labor, cesarean section). 


\section{Fetal/Child Adverse Effects of Beta Blockers}

No primary study (direct evidence) reported on fetal/child adverse effects of beta blockers.

Both SRs (indirect evidence) reported on fetal/child adverse effects. The Yakoob 2013 SR reported that beta blocker use was associated with cardiovascular anomalies (OR 2.01, 95\% CI 1.18 to 3.42), cleft lip or palate (OR 3.11, 95\% CI 1.79 to 5.43), and neural tube defects (OR 3.56, 95\% CI 1.19 to 10.67) (Table 11). Beta blocker use was also associated with severe hypospadias, but this was not statistically significant (RR 2.27, 95\% CI 0.69 to 7.46).

The Abalos 2018 SR reported on a different set of fetal/child adverse effects and found no increased association of beta blocker use with in utero, perinatal, and neonatal adverse effects. However, beta blocker use was associated with neonatal pulmonary edema (RR 5.23, 95\% CI 0.25 to 107.39) and neonatal bradycardia (RR 2.20, 95\% CI 0.68 to 7.16), but these were not statistically significant.

Table 11. Beta blockers: Summary of indirect evidence of fetal/child harms, statistically significant findings

\begin{tabular}{|c|c|c|c|c|c|c|}
\hline $\begin{array}{l}\text { SR, Year } \\
\text { Published, } \\
\text { PMI D }\end{array}$ & Drug Class & Drug & $\begin{array}{l}\text { Timing of } \\
\text { Occurrence of } \\
\text { Adverse Effect }\end{array}$ & Adverse Effect & $\begin{array}{l}\mathbf{N} \\
\text { Studies }\end{array}$ & $\begin{array}{l}\text { Effect Size }(95 \% \\
\mathrm{Cl})\end{array}$ \\
\hline \multirow{3}{*}{$\begin{array}{l}\text { Yakoob } 2013 \\
23753416\end{array}$} & \multirow{3}{*}{$\begin{array}{l}\text { Beta } \\
\text { blockers }\end{array}$} & \multirow[t]{3}{*}{ Any } & \multirow[t]{3}{*}{ Neonatal } & Cardiovascular anomalies, Any & 4 & OR $2.01(1.18,3.42)$ \\
\hline & & & & $\begin{array}{l}\text { Congenital anomalies, Cleft lip or } \\
\text { palate }\end{array}$ & 4 & OR $3.11(1.79,5.43)$ \\
\hline & & & & $\begin{array}{l}\text { Congenital anomalies, Neural tube } \\
\text { defects }\end{array}$ & 3 & OR $3.56(1.19,10.67)$ \\
\hline
\end{tabular}

Abbreviations: $\mathrm{CI}=$ confidence interval, $\mathrm{OR}=$ odds ratio, $\mathrm{PMID}=$ PubMed identifier, $\mathrm{SR}=$ systematic review.

Table 12. Beta blockers: Evidence profile for indirect evidence regarding harms of use during pregnancy

\begin{tabular}{|l|l|l|l|l|l|l|l|l|l|}
\hline Drug & $\begin{array}{l}\text { Outcome } \\
\text { Category }\end{array}$ & Outcome & $\begin{array}{l}\text { N SRs } \\
\text { (N } \\
\text { Studies) }\end{array}$ & $\begin{array}{l}\text { RoB in } \\
\text { Included } \\
\text { Studies }\end{array}$ & Consistency & Precision & Directness & SoE & Conclusions \\
\hline $\begin{array}{l}\text { Beta } \\
\text { blockers, } \\
\text { any }\end{array}$ & $\begin{array}{l}\text { AEs - } \\
\text { Maternal }\end{array}$ & $\begin{array}{l}\text { Discontinuation } \\
\text { due to AEs }\end{array}$ & $1(9)$ & Moderate & Consistent & Precise & Indirect & Low & $\begin{array}{l}\text { No increased } \\
\text { risk }\end{array}$ \\
\cline { 3 - 9 } & $\begin{array}{l}\text { AEs - } \\
\text { Fetal/Child }\end{array}$ & $\begin{array}{l}\text { Perinatal } \\
\text { complications }\end{array}$ & $1(1)$ & Moderate & N/A & Precise & Indirect & Insufficient & None \\
\cline { 3 - 9 } & Preterm birth & $1(4)$ & Moderate & Consistent & Precise & Indirect & Moderate & $\begin{array}{l}\text { No increased } \\
\text { risk }\end{array}$ \\
\cline { 3 - 8 } & $\begin{array}{l}\text { Congenital } \\
\text { anomalies }\end{array}$ & $1(1-5)$ & $\begin{array}{l}\text { Low to } \\
\text { moderate }\end{array}$ & Consistent & Precise & Indirect & Moderate & $\begin{array}{l}\text { Increased } \\
\text { cardiovascular } \\
\text { anomalies, } \\
\text { cleft } \\
\text { lip/palate, and } \\
\text { neural tube } \\
\text { defects }\end{array}$ \\
\hline
\end{tabular}

Abbreviations: $\mathrm{AE}=$ adverse effect, $\mathrm{N} / \mathrm{A}=$ not applicable, $\mathrm{RoB}=$ risk of bias, $\mathrm{SoE}=$ strength of evidence, $\mathrm{SR}=$ systematic review.

Table B-37 provides the complete version of this Evidence Profile, including displaying outcomes for which no evidence was identified.

\section{Calcium Channel Blockers}

\section{Description of Direct Evidence for Calcium Channel Blockers}

We did not find any primary studies on use of calcium channel blockers for preventing attacks of primary headache in women who were pregnant (or attempting to become pregnant), postpartum, or breastfeeding. 


\section{Description of Indirect Evidence for Calcium Channel Blockers}

Two high-quality SRs assessed harms associated with calcium channel blocker use during pregnancy (regardless of indication): one SR (Abalos 2018 ${ }^{62}$ ) examined any calcium channel blocker use and the other SR (Bellos 2020a $a^{65}$ ) examined nifedipine use, specifically (Table 13 and Tables B-26, B-27, B-28, and B-37).

\section{Maternal Benefit Outcomes of Calcium Channel Blockers}

No primary study or SR reported on maternal benefit outcomes of calcium channel blockers.

\section{Maternal Adverse Effects of Calcium Channel Blockers}

No primary study (direct evidence) reported on maternal adverse effects of calcium channel blockers.

The Abalos 2018 SR (indirect evidence) reported that (any) calcium channel blocker use was not associated with placental abruption or cesarean section. The Bellos 2020a SR (indirect evidence) reported that nifedipine use, specifically, was also not associated with placental abruption or cesarean section.

\section{Fetal/Child Adverse Effects of Calcium Channel Blockers}

No primary study (direct evidence) reported on fetal/child adverse effects of calcium channel blockers.

The Abalos 2018 SR (indirect evidence) reported that calcium channel blocker use was not associated with total fetal or neonatal death (including spontaneous abortion), preterm birth, small for gestational age, or neonatal outcomes, such as hypoglycemia, jaundice, or respiratory distress syndrome.

The Bellos 2020a SR (indirect evidence) reported that nifedipine use, specifically, was not associated with gestational age at delivery, preterm birth, small for gestational age, or perinatal death. 
Table 13. Calcium channel blockers: Evidence profile for indirect evidence regarding harms of use during pregnancy

\begin{tabular}{|c|c|c|c|c|c|c|c|c|c|}
\hline Drug & $\begin{array}{l}\text { Outcome } \\
\text { Category }\end{array}$ & Outcome & $\begin{array}{l}\text { N SRs } \\
\text { (N } \\
\text { Studies) }\end{array}$ & $\begin{array}{l}\text { RoB in } \\
\text { I ncluded } \\
\text { Studies }\end{array}$ & Consistency & Precision & Directness & SoE & Conclusions \\
\hline \multirow{6}{*}{$\begin{array}{l}\text { Calcium } \\
\text { channel } \\
\text { blockers, } \\
\text { any }\end{array}$} & $\begin{array}{l}\text { AEs - } \\
\text { Maternal }\end{array}$ & $\begin{array}{l}\text { Discontinuation } \\
\text { due to } A E s\end{array}$ & $1(2)$ & Moderate & Consistent & Imprecise & Indirect & Low & $\begin{array}{l}\text { No increased } \\
\text { risk }\end{array}$ \\
\hline & \multirow[t]{5}{*}{$\begin{array}{l}\text { AEs - } \\
\text { Fetal/Child }\end{array}$} & $\begin{array}{l}\text { Perinatal } \\
\text { complications }\end{array}$ & $1(1-3)$ & $\begin{array}{l}\text { Low to } \\
\text { moderate }\end{array}$ & Consistent & Precise & Indirect & Moderate & $\begin{array}{l}\text { No increased } \\
\text { risk of NICU } \\
\text { admission, } \\
\text { neonatal } \\
\text { respiratory } \\
\text { distress } \\
\text { syndrome }\end{array}$ \\
\hline & & $\begin{array}{l}\text { Spontaneous } \\
\text { abortion or } \\
\text { elective or } \\
\text { induced } \\
\text { abortion }\end{array}$ & $1(5)$ & Moderate & Consistent & Imprecise & Indirect & Low & $\begin{array}{l}\text { No increased } \\
\text { risk }\end{array}$ \\
\hline & & $\begin{array}{l}\text { Stillbirth or fetal } \\
\text { death }\end{array}$ & $1(5)$ & Moderate & Consistent & Imprecise & Indirect & Low & $\begin{array}{l}\text { No increased } \\
\text { risk }\end{array}$ \\
\hline & & $\begin{array}{l}\text { Neonatal or } \\
\text { infant death }\end{array}$ & $1(5)$ & Moderate & Consistent & Imprecise & Indirect & Low & $\begin{array}{l}\text { No increased } \\
\text { risk }\end{array}$ \\
\hline & & Preterm birth & $1(4)$ & Moderate & Consistent & Precise & Indirect & Low & $\begin{array}{l}\text { No increased } \\
\text { risk }\end{array}$ \\
\hline \multirow{2}{*}{$\begin{array}{l}\text { Calcium } \\
\text { channel } \\
\text { blockers, } \\
\text { nifedipine }\end{array}$} & \multirow[t]{2}{*}{$\begin{array}{l}\text { AEs - } \\
\text { Fetal/Child }\end{array}$} & $\begin{array}{l}\text { Neonatal or } \\
\text { infant death }\end{array}$ & $1(2)$ & Moderate & Consistent & Precise & Indirect & Moderate & $\begin{array}{l}\text { No increased } \\
\text { risk }\end{array}$ \\
\hline & & Preterm birth & $1(2)$ & Moderate & Consistent & Imprecise & Indirect & Low & $\begin{array}{l}\text { No increased } \\
\text { risk }\end{array}$ \\
\hline
\end{tabular}

Abbreviations: $\mathrm{AE}=$ adverse effect, $\mathrm{NICU}=$ neonatal intensive care unit, RoB $=$ risk of bias, $\mathrm{SoE}=$ strength of evidence, $\mathrm{SR}=$ systematic review.

Table B-37 provides the complete version of this Evidence Profile, including displaying outcomes for which no evidence was identified.

\section{Corticosteroids}

\section{Description of Direct Evidence for Corticosteroids}

We did not find any primary studies on use of corticosteroids for preventing attacks of primary headache in women who were pregnant (or attempting to become pregnant), postpartum, or breastfeeding.

\section{Description of Indirect Evidence for Corticosteroids}

One high-quality SR (Park-Wyllie 2000) assessed harms associated with use of corticosteroids, specifically prednisolone, during pregnancy (regardless of indication) (Tables 14 and 15 and Tables B-26, B-27, B-28, and B-37). ${ }^{84}$

\section{Maternal Benefit Outcomes of Corticosteroids}

No primary study or SR reported on maternal benefit outcomes of corticosteroids.

\section{Maternal Adverse Effects of Corticosteroids}

No primary study or SR reported on maternal adverse effects of corticosteroids.

\section{Fetal/Child Adverse Effects of Corticosteroids}

No primary study (direct evidence) reported on fetal/child adverse effects of corticosteroids. 
The Park-Wyllie 2000 SR (indirect evidence) reported that prednisolone use was associated with increased likelihood of oral clefts (OR 3.35, 95\% CI 1.97 to 5.69), but not other major congenital anomalies (Table 14).

Table 14. Corticosteroids: Summary of indirect evidence of fetal/child harms, statistically significant findings

\begin{tabular}{|l|l|l|l|l|l|l|}
\hline $\begin{array}{l}\text { SR, Year } \\
\text { Published, } \\
\text { PMI D }\end{array}$ & Drug Class & Drug & $\begin{array}{l}\text { Timing of } \\
\text { Occurrence } \\
\text { of Adverse } \\
\text { Effect }\end{array}$ & Adverse Effect & N Studies & Effect Size (95\% CI ) \\
\hline $\begin{array}{l}\text { Park-Wyllie, } \\
2000,11091360\end{array}$ & Corticosteroids & Prednisolone & Neonatal & $\begin{array}{l}\text { Congenital anomalies, } \\
\text { Oral clefts }\end{array}$ & 4 & OR 3.35 (1.97, 5.69) \\
\hline
\end{tabular}

Abbreviations: $\mathrm{CI}$ = confidence interval, $\mathrm{OR}$ = odds ratio, PMID = PubMed identifier, SR = systematic review.

Table 15. Corticosteroids: Evidence profile for direct evidence regarding use to prevent primary headaches

\begin{tabular}{|c|c|c|c|c|c|c|c|c|c|}
\hline Drug & $\begin{array}{l}\text { Outcome } \\
\text { Category }\end{array}$ & Outcome & $\begin{array}{l}\text { N SRs } \\
\text { (N } \\
\text { Studies) }\end{array}$ & $\begin{array}{l}\text { RoB in } \\
\text { Included } \\
\text { Studies } \\
\end{array}$ & Consistency & Precision & Directness & SoE & Conclusions \\
\hline Prednisolone & $\begin{array}{l}\text { AEs - } \\
\text { Fetal/Child }\end{array}$ & $\begin{array}{l}\text { Congenital } \\
\text { anomalies }\end{array}$ & $1(4-6)$ & Unclear & Inconsistent & Precise & Indirect & Low & $\begin{array}{l}\text { Increased oral } \\
\text { clefts, but no } \\
\text { increased risk } \\
\text { of other major } \\
\text { anomalies }\end{array}$ \\
\hline
\end{tabular}

Abbreviations: $\mathrm{AE}=$ adverse effect, $\mathrm{RoB}=$ risk of bias, $\mathrm{SoE}=$ strength of evidence, $\mathrm{SR}=$ systematic review.

Table B-37 provides the complete version of this Evidence Profile, including displaying outcomes for which no evidence was identified.

\section{Antihistamines}

\section{Description of Direct Evidence for Antihistamines}

We did not find any primary studies on use of antihistamines for preventing attacks of primary headache in women who were pregnant (or attempting to become pregnant), postpartum, or breastfeeding.

\section{Description of Indirect Evidence for Antihistamines}

Two high-quality SRs (Etwel $2017^{72}$ and Li 2019 ${ }^{77}$ ) assessed harms associated with (any) antihistamine use during pregnancy (regardless of indication) (Table 16 and Tables B-26, B-27, B-28, and B-37).

\section{Maternal Benefit Outcomes of Antihistamines}

No primary study or SR reported on maternal benefit outcomes of antihistamines.

\section{Maternal Adverse Effects of Antihistamines}

No primary study or SR reported on maternal adverse effects of antihistamines.

\section{Fetal/Child Adverse Effects of Antihistamines}

No primary study (direct evidence) reported on fetal/child adverse effects of antihistamines.

The Etwel 2017 SR (indirect evidence) reported that antihistamine use was not associated with spontaneous abortion, stillbirth, preterm birth, low birth weight, or major congenital anomalies. 
The Li 2019 SR (indirect evidence) reported that antihistamine use was not associated with congenital anomalies (overall) or hypospadias (in particular).

Table 16. Antihistamines: Evidence profile for direct evidence regarding use to prevent primary headaches

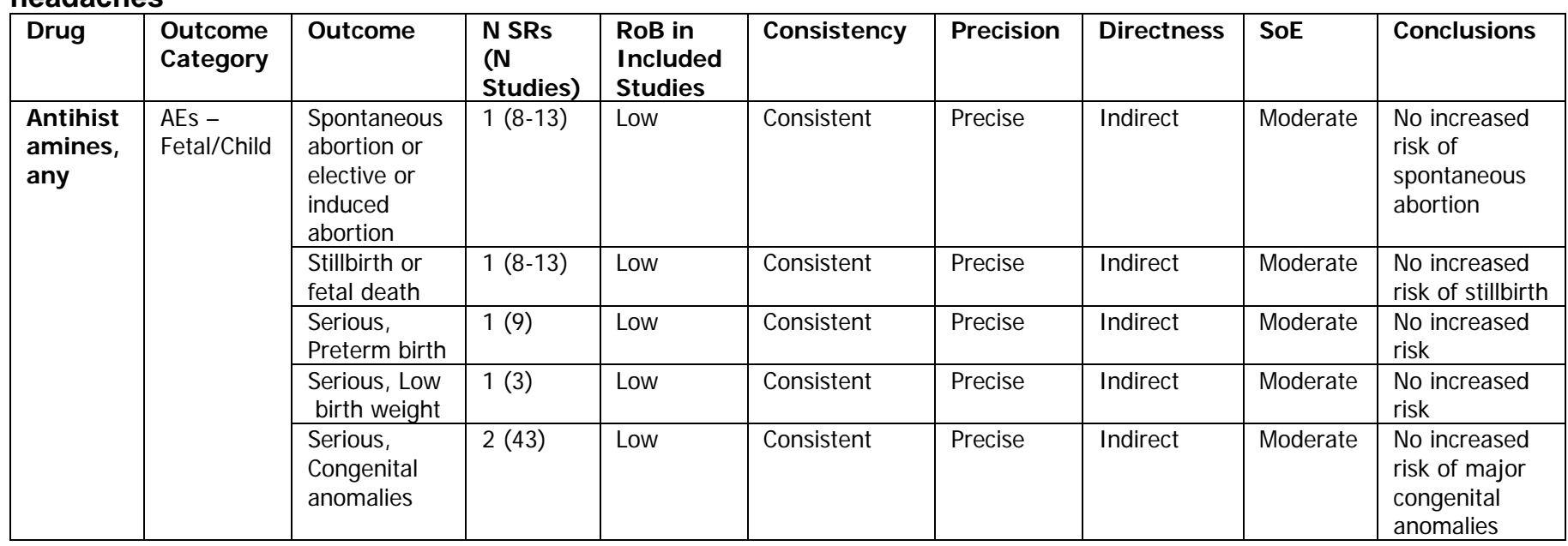

Abbreviations: $\mathrm{AE}=$ adverse effect, $\mathrm{RoB}$ = risk of bias, $\mathrm{SoE}=$ strength of evidence, $\mathrm{SR}=$ systematic review.

Table B-37 provides the complete version of this Evidence Profile, including displaying outcomes for which no evidence was identified.

\section{Oral Magnesium}

\section{Description of Direct Evidence for Oral Magnesium}

We did not find primary studies on oral magnesium for preventing attacks of primary headache in women who were pregnant (or attempting to become pregnant), postpartum, or breastfeeding.

\section{Description of Indirect Evidence for Oral Magnesium}

One high-quality SR (Makredes 2014) assessed harms associated with oral magnesium sulphate use during pregnancy (regardless of indication) (Tables 17, 18, and 19 and Tables B-26, B-27, B-28, and B-37). ${ }^{78}$

\section{Maternal Benefit Outcomes}

No primary study or SR reported on maternal benefit outcomes of oral magnesium.

\section{Maternal Adverse Effects of Oral Magnesium}

No primary study or SR reported on maternal adverse effects of oral magnesium.

The Makredes 2014 SR (indirect evidence) reported that patients who used oral magnesium during pregnancy experienced a marginally higher systolic blood pressure (1 mm of Hg) than those who did not (Table 17). Oral magnesium use was not associated with other maternal adverse effects, such as gastrointestinal symptoms, hospitalizations, antepartum hemorrhage, or increased length of labor. 


\section{Fetal/Child Adverse Effects of Oral Magnesium}

No primary study or SR reported on fetal/child adverse effects of oral magnesium.

The Makredes 2014 SR (indirect evidence) reported that oral magnesium use was associated with neonatal death (RR 2.21, 95\% CI 1.02 to 4.75), but not spontaneous abortion, stillbirth, low birth weight, or neonatal intensive care unit admissions (Table 18).

Table 17. Oral magnesium: Summary of indirect evidence of maternal harms, statistically significant findings

\begin{tabular}{|l|l|l|l|l|l|l|}
\hline $\begin{array}{l}\text { SR, Year } \\
\text { Published, } \\
\text { PMI D }\end{array}$ & $\begin{array}{l}\text { Intervention } \\
\text { Class }\end{array}$ & $\begin{array}{l}\text { Intervention } \\
\text { Name }\end{array}$ & $\begin{array}{l}\text { Timing of } \\
\text { Occurrence of } \\
\text { Adverse Effect }\end{array}$ & $\begin{array}{l}\text { Adverse } \\
\text { Effect }\end{array}$ & $\begin{array}{l}\text { N } \\
\text { Studies }\end{array}$ & Effect Size (95\% CI) \\
\hline $\begin{array}{l}\text { Makredes, 2014, } \\
24696187\end{array}$ & $\begin{array}{l}\text { Oral } \\
\text { magnesium }\end{array}$ & $\begin{array}{l}\text { Oral magnesium } \\
\text { sulphate }\end{array}$ & NR & $\begin{array}{l}\text { Systolic blood } \\
\text { pressure }\end{array}$ & 3 & MD 1 mm Hg (0.03, 1.97) \\
\hline
\end{tabular}

Abbreviations: $\mathrm{CI}=$ confidence interval, $\mathrm{MD}=$ mean difference, $\mathrm{NR}=$ not reported, $\mathrm{PMID}=$ PubMed identifier, $\mathrm{SR}=$ systematic review.

Table 18. Oral magnesium: Summary of indirect evidence of fetal/child harms, statistically significant findings

\begin{tabular}{|l|l|l|l|l|l|l|}
\hline $\begin{array}{l}\text { SR, Year } \\
\text { Published, } \\
\text { PMI D }\end{array}$ & $\begin{array}{l}\text { Intervention } \\
\text { Class }\end{array}$ & Intervention Name & $\begin{array}{l}\text { Timing of } \\
\text { Occurrence } \\
\text { of Adverse } \\
\text { Effect }\end{array}$ & $\begin{array}{l}\text { Adverse } \\
\text { Effect }\end{array}$ & $\begin{array}{l}\text { N } \\
\text { Studies }\end{array}$ & $\begin{array}{l}\text { Effect Size (95\% } \\
\text { CI ) }\end{array}$ \\
\hline $\begin{array}{l}\text { Makredes, 2014, } \\
24696187\end{array}$ & $\begin{array}{l}\text { Oral } \\
\text { magnesium }\end{array}$ & $\begin{array}{l}\text { Oral magnesium } \\
\text { sulphate }\end{array}$ & Neonatal & $\begin{array}{l}\text { Neonatal } \\
\text { death }\end{array}$ & 4 & RR 2.21 (1.02, 4.75) \\
\hline
\end{tabular}

Abbreviations: $\mathrm{CI}$ = confidence interval, PMID = PubMed identifier, RR = relative risk, SR = systematic review.

Table 19. Oral magnesium: Evidence profile for indirect evidence regarding harms of use during pregnancy

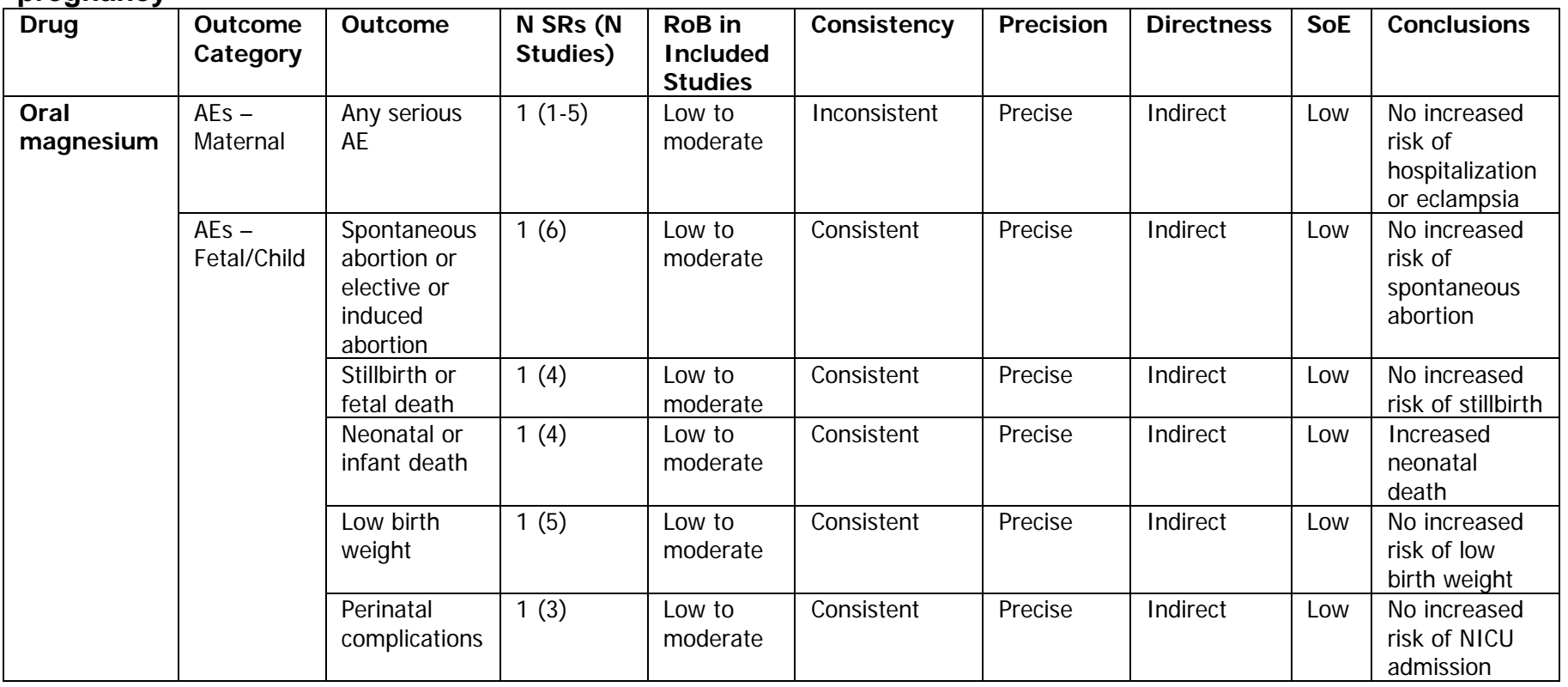

Abbreviations: $\mathrm{AE}=$ adverse effect, $\mathrm{NICU}=$ neonatal intensive care unit, RoB $=$ risk of bias, $\mathrm{SoE}=$ strength of evidence, $\mathrm{SR}=$ systematic review.

Table B-37 provides the complete version of this Evidence Profile, including displaying outcomes for which no evidence was identified. 


\section{Other Pharmacologic Interventions for KQ 1}

We did not find direct evidence (i.e., primary studies) or indirect evidence (i.e., SRs regardless of indication) on the use of the following pharmacologic interventions for preventing primary headaches in women who are pregnant (or attempting to be pregnant), postpartum, or breastfeeding: tetracyclic antidepressants, mood-stabilizing agents, other antihypertensive medications, N-methyl-D-aspartate (NMDA) receptor antagonists, and calcitonin gene-related peptide (CGRP) inhibitors.

\section{Key Question 1: Nonpharmacologic Interventions To Prevent Attacks of Primary Headache}

We did not find direct evidence (i.e., primary studies) or indirect evidence (i.e., SRs regardless of indication) addressing the use of nonpharmacologic interventions for preventing attacks of primary headaches in women who are pregnant (or attempting to become pregnant), postpartum, or breastfeeding. These included complementary therapy, behavioral therapy, physical therapy, procedures, noninvasive neuromodulation devices, chemodenervation, hydration, and supplements.

\section{Key Question 2: Treatment of Primary Headache}

\section{Key Points}

- Pharmacologic interventions

o No direct or indirect evidence evaluated the beneficial effects or harms of pharmacologic interventions in women attempting to become pregnant or in women who were postpartum or breastfeeding.

o Direct evidence (studies of pregnant women with primary headache) about pharmacologic interventions found that:

- Triptan use for migraine during pregnancy, when compared with triptan nonuse or use only before pregnancy, may have a lower risk of adverse effects, except for increased child emotionality and hyperactivity at 3 years of age (low SoE).

- Combination metoclopramide and diphenhydramine may be more effective (low SoE) and not more harmful (low SoE) than codeine for treatment of migraine or tension headache during pregnancy.

- Nonpharmacologic interventions

o No direct or indirect evidence evaluated the beneficial effects or harms of nonpharmacologic interventions in women attempting to become pregnant or in women who were postpartum or breastfeeding.

o There is insufficient direct evidence to make conclusions about the benefit or harms of acupuncture, thermal biofeedback, relaxation therapy, physical therapy, peripheral nerve blocks, or transcranial magnetic stimulation when used for treatment of primary headache during pregnancy.

o No indirect evidence evaluated nonpharmacologic interventions for treatment of primary headache during pregnancy.

Fifteen of the 16 primary studies included in this SR (direct evidence) addressed KQ 2. These included nine primary studies addressing the following pharmacologic interventions: triptans, 
ergot products, NSAIDs, antiemetics (dopamine receptor antagonists), antihistamines, and opioid analgesics, and six primary studies addressing the following nonpharmacologic interventions: complementary therapies, behavioral therapy, physical therapy, procedures, and noninvasive neuromodulation devices.

Eighteen existing SRs (indirect evidence) addressed the following pharmacologic interventions relevant to KQ 2: triptans, NSAIDs, antihistamines, antiemetics (5HT3 antagonists), antipsychotics, corticosteroids, analgesics/antipyretics, and intravenous magnesium. No SRs addressed nonpharmacologic interventions for KQ 2.

\section{Key Question 2: Pharmacologic Interventions To Treat Attacks of Primary Headache}

Fifteen of the 16 included primary studies (i.e., direct evidence) addressed KQ 2. These included nine studies of pharmacologic treatments (eight observational NRCSs of triptans, ergot products, and NSAIDs ${ }^{42-57}$ and one RCT of antiemetics [dopamine receptor antagonists], antihistamines, and opioid-containing analgesics, ${ }^{37,39,40}$ ) and six studies of nonpharmacologic treatments (two RCTs ${ }^{38,41}$ and two single-group studies ${ }^{38,60,61}$ of complementary, behavioral, and physical therapies, one single-group study ${ }^{25}$ of nerve blocks, and one single-group study of noninvasive neuromodulation devices ${ }^{58}$ ), all in women who were pregnant.

\section{Triptans, Ergot Products, NSAIDs (Naproxen), and Antihistamines (Pizotifen)}

\section{Description of Direct Evidence for Triptans, Ergot Products, NSAIDs (Naproxen), and Antihistamines (Pizotifen)}

Eight primary studies (direct evidence), all observational NRCSs (described in 16 articles ${ }^{42-}$

${ }^{57}$ ), reported the harms of triptans, ergot products, NSAIDs (naproxen), and antihistamines (pizotifen) in pregnant patients with primary headaches (all with migraine). These included three prospective cohort studies $^{42,44,48,52,54}$ and five retrospective cohort studies. ${ }^{43,45-47,49-51,53,55-57}$ The eight studies enrolled a total of 13,907 patients (Tables 20 and 21 and Tables B-1, B-3, B-4, B-10 to B-16, and B-32).

Ephross 2014, reported in three articles, studied 689 pregnant patients with migraine in 18 countries. ${ }^{42,44,48}$ Patient data were obtained from the Sumatriptan, Naratriptan, and Treximet Pregnancy Registry. This study was funded by industry. The study compared three arms: subcutaneous sumatriptan (626 patients), oral naratriptan (57 patients), and a subcutaneous combination of sumatriptan and naproxen (6 patients). No information about treatment doses, frequencies, or durations, or patient age, race, trimester/gestational age, gravidity, or parity was reported. We assessed the study at overall high risk of bias because of serious risk of confounding bias and high risks of performance and detection biases due to lack of blinding of patients, study personnel, and outcome assessors. Furthermore, the treatments were not clearly described.

O’Quinn 1999 studied 168 pregnant patients with migraine in the U.S. ${ }^{52}$ This study was funded by industry. The study compared subcutaneous sumatriptan use during the first trimester of pregnancy (76 patients) with its use before pregnancy only (92 patients). No information about treatment doses, frequencies, or durations, or patient age, race, gestational age, gravidity, or parity was reported. We assessed the study at overall high risk of bias because of serious risk 
of confounding bias and high risk of performance bias due to lack of blinding of patients and study personnel. We rated the risk of detection bias as unclear. Furthermore, the participant eligibility criteria, treatments, and outcomes were not clearly described.

Shuhaiber 1998 studied 192 pregnant patients with migraine in the U.S. and Canada. ${ }^{54}$ The funding source for this study was not reported. The study compared sumatriptan use (96 patients) with no triptan use (96 patients) during the first trimester of pregnancy. No information about treatment doses, frequencies, or durations was reported. Patient ages were similar in the triptan (mean 32.3 years) and no triptan arms (mean 31.7 years). No information about patient race, gestational age, gravidity, or parity was reported. We assessed the study at overall high risk of bias because of serious risk of confounding bias and high risks of performance and detection biases due to lack of blinding of patients, study personnel, and outcome assessors. We rated the risk of detection bias as unclear. Furthermore, the treatments were not clearly described.

Nezvalova-Henriksen 2013 studied 2,560 pregnant patients with migraine in Norway. ${ }^{50}$ Patient data were obtained from the Norwegian Prescription Database and their birth outcomes were linked to the Medical Birth Registry of Norway. The funding source for this study was not reported. The study compared the use of any triptan use during pregnancy (1,465 patients) with use only before pregnancy (1,095 patients). No information about treatment doses, frequencies, or durations, or patient age, race, trimester/gestational age, gravidity, or parity was reported. We assessed the study at overall high risk of bias because of moderate risk of confounding bias and high risks of performance and detection biases due to lack of blinding of patients, study personnel, and outcome assessors. Furthermore, the treatments were not clearly described.

Nezvalova-Henriksen 2010, reported in five articles, studied 5,900 pregnant patients with migraine in Norway. ${ }^{45,49,51,56,57}$ Patient data were obtained from the Norwegian Mother and Child Cohort Study and, like Nezvalova-Henriksen 2013, patient birth outcomes were linked to the Medical Birth Registry of Norway. Nezvalova-Henriksen 2010 was funded by nonindustry sources. The study compared three arms: any triptan use during pregnancy (1,045 patients), any triptan use only before pregnancy (805 patients), and no triptan use either during or before pregnancy (4,050 patients). No information about treatment doses, frequencies, or durations, or patient age, race, trimester/gestational age, gravidity, or parity was reported. We assessed the study at overall high risk of bias because of moderate risk of confounding bias; high risks of performance and detection biases due to lack of blinding of patients, study personnel, and outcome assessors; and high risk of attrition bias due to incomplete outcome data. Furthermore, the treatments were not clearly described.

Kallen 2011, reported in two articles, studied 3,368 pregnant patients with migraine in Sweden. ${ }^{46,47}$ Patient data and birth outcomes were obtained from the Swedish Medical Birth Register. Kallen 2011 was funded by a nonindustry source. The study compared three arms: any triptan use during pregnancy (2,777 patients), any ergot product use during pregnancy (527 patients), and pizotifen use during pregnancy (64 patients). No information about treatment doses, frequencies, or durations, or patient age, race, trimester/gestational age, gravidity, or parity was reported. We assessed the study at overall high risk of bias because of serious risk of confounding bias and high risks of performance and detection biases due to lack of blinding of patients, study personnel, and outcome assessors. Furthermore, the treatments were not clearly described.

Olesen 2000 studied 123 pregnant patients with migraine in Denmark. ${ }^{53}$ Patient data and birth outcomes were obtained from the Pharmaco-epidemiological Prescription Database of North Jutland County, Denmark. Olesen 2000 was funded by nonindustry sources. The study 
compared sumatriptan use during pregnancy (34 patients) with sumatriptan or ergotamine use only before pregnancy (89 patients). No information about treatment doses, frequencies, or durations was reported. Patient ages were similar in the sumatriptan during pregnancy (mean 29.6 years) and the sumatriptan or ergotamine before pregnancy arms (mean 28.4 years). No information about patient race, trimester/gestational age, gravidity, or parity was reported. We assessed the study at overall moderate risk of bias because of high risks of performance and detection biases due to lack of blinding of patients, study personnel, and outcome assessors. Furthermore, the treatments were not clearly described.

Spielmann 2018, reported in two articles, studied 907 pregnant patients with migraine in Germany. ${ }^{43,} 55$ Patient data and birth outcomes were obtained from the German Embryotox System. The funding source for this study was not reported. The study compared triptan use during pregnancy (432 patients) with no use during pregnancy (475 patients). No information about treatment doses, frequencies, or durations was reported. Patient ages were similar in the triptan (median 33 years) and no triptan arms (median 32 years). No information about patient race, trimester/gestational age, gravidity, or parity was reported. We assessed the study at overall high risk of bias because of high risks of performance and detection biases due to lack of blinding of patients, study personnel, and outcome assessors, and high risk of attrition bias due to incomplete outcome data. Furthermore, the treatments were not clearly described.

We have organized the rest of this section on triptans, ergot products, and NSAIDs by timing of use of the drugs. First, we discuss studies that compared the use of drugs (or drug classes) with each other during pregnancy. Next, we discuss studies that compared the use of drugs (or drug classes) during pregnancy versus the same drugs (or drug classes) only before pregnancy. Finally, we discuss studies that compared the use of drugs (or drug classes) during pregnancy versus nonuse of the same drug (or drug classes) either during or before pregnancy. None of the studies described in this section reported on maternal benefit outcomes.

\section{Description of SR Evidence for Triptans}

One high-quality SR (Marchenko 2015) assessed harms associated with (any) triptan use during pregnancy (Table 22 and Tables B-26, B-27, B-28, and B-37). ${ }^{79}$

\section{Description of Indirect Evidence for Antihistamines}

Two high-quality SRs (Etwel $2017^{72}$ and Li 2019 ${ }^{77}$ ) assessed harms associated with (any) antihistamine use during pregnancy (regardless of indication) (Table 16 and Tables B-26, B-27, B-28, and B-37).

\section{Sumatriptan Versus Naratriptan During Pregnancy}

\section{Description of Direct Evidence for Sumatriptan Versus Naratriptan During Pregnancy}

One observational NRCS (Ephross 2014), reported in three articles, addressed this comparison in pregnant patients with migraine. ${ }^{42,44,48}$ Although this study reported subgroup analyses by trimester of drug use, most patients (585/689 patients; $84.9 \%$ ) were in the first trimester (Tables B-11 and B-13). No statistical analyses for subgroup differences were reported. Only fetal/child adverse effects were reported.

\section{Description of SR Evidence for Sumatriptan Versus Naratriptan During Pregnancy No SR reported on this comparison.}


Maternal Benefit Outcomes of Sumatriptan Versus Naratriptan During Pregnancy

No primary study or SR reported on maternal benefit outcomes for this comparison.

Maternal Adverse Effects of Sumatriptan Versus Naratriptan During Pregnancy

No primary study or SR reported on maternal adverse effects for this comparison.

Fetal/Child Adverse Effects of Sumatriptan Versus Naratriptan During Pregnancy

Ephross 2014 (direct evidence) reported that spontaneous abortion occurred in 34 of 626

patients receiving sumatriptan (5.4\%) and 5 of 57 patients receiving naratriptan (8.8\%) (Table B11). No adjusted effect sizes were reported.

Ephross 2014 also reported that elective or induced abortion occurred in patients 16 of 626 receiving sumatriptan (2.6\%) and 1 of 57 patients receiving naratriptan (1.8\%) (Table B-11). No adjusted effect sizes were reported.

Ephross 2014 also reported that stillbirth or fetal death occurred in patients 5 of 626 receiving sumatriptan $(0.8 \%)$ and none of the 57 patients receiving naratriptan (Table B-11). No adjusted effect sizes were reported.

Ephross 2014 also reported that major congenital anomalies occurred in patients 19 of 626 patients receiving sumatriptan (3.0\%) and 1 of 57 patients receiving naratriptan (1.8\%) (Table B13). No adjusted effect sizes were reported.

\section{Sumatriptan Versus Combination Sumatriptan and Naproxen During Pregnancy}

\section{Direct Evidence for Sumatriptan Versus Combination Sumatriptan and Naproxen During Pregnancy}

One observational NRCS (Ephross 2014), reported in three articles, addressed this comparison in pregnant patients with migraine, although only 6 patients received the combination treatment (Tables B-11 and B-13). ${ }^{42,44,48}$ Although this study reported subgroup analyses by trimester of drug use, most patients (585/689 patients; $84.9 \%$ ) were in the first trimester. No statistical analyses for subgroup differences were reported. The study reported fetal/child adverse effects only.

Description of SR Evidence for Sumatriptan Versus Combination Sumatriptan and Naproxen During Pregnancy

No SR reported on this comparison.

Maternal Benefit Outcomes of Sumatriptan Versus Combination Sumatriptan and Naproxen During Pregnancy

No primary study or SR reported on maternal benefit outcomes for this comparison.

Maternal Adverse Effects of Sumatriptan Versus Combination Sumatriptan and Naproxen During Pregnancy

No primary study or SR reported on maternal adverse effects for this comparison. 
Fetal/Child Adverse Effects of Sumatriptan Versus Combination Sumatriptan and Naproxen During Pregnancy

Ephross 2014 (direct evidence) reported that spontaneous abortion occurred in 34 of 626 patients receiving sumatriptan (5.4\%) and 1 of 6 patients receiving the sumatriptan and naproxen combination (16.7\%) (Table B-11). No adjusted effect sizes were reported.

Ephross 2014 also reported that elective or induced abortion occurred in 16 of 626 patients receiving sumatriptan (2.6\%) and none of the 6 patients receiving the sumatriptan and naproxen combination (Table B-11). No adjusted effect sizes were reported.

Ephross 2014 also reported that stillbirth or fetal death occurred in 5 of 626 patients receiving sumatriptan $(0.8 \%)$ and none of the 6 patients receiving the sumatriptan and naproxen combination (Table B-11). No adjusted effect sizes were reported.

Ephross 2014 also reported that major congenital anomalies occurred in 19 of 626 patients receiving sumatriptan (3.0\%) and none of the 6 patients receiving the sumatriptan and naproxen combination (Table B-13). No adjusted effect sizes were reported.

\section{Naratriptan Versus Combination Sumatriptan and Naproxen During Pregnancy}

\section{Direct Evidence for Naratriptan Versus Combination Sumatriptan and Naproxen During Pregnancy}

One observational NRCS (Ephross 2014), reported in three articles, addressed this comparison in pregnant patients in pregnant patients with migraine, although only 6 patients received the combination treatment (Tables B-11 and B-13). ${ }^{42,44,48}$ Although this study reported subgroup analyses by trimester of drug use, most patients (585/689 patients; $84.9 \%$ ) were in the first trimester. No statistical analyses for subgroup differences were reported. The study reported fetal/child adverse effects only.

Description of SR Evidence for Naratriptan Versus Combination Sumatriptan and Naproxen During Pregnancy

No SR reported on this comparison.

Maternal Benefit Outcomes of Naratriptan Versus Combination Sumatriptan and Naproxen During Pregnancy

No primary study or SR reported on maternal benefit outcomes for this comparison.

Maternal Adverse Effects of Naratriptan Versus Combination Sumatriptan and Naproxen During Pregnancy:

No primary study or SR reported on maternal adverse effects for this comparison.

\section{Fetal/Child Adverse Effects of Naratriptan Versus Combination Sumatriptan and Naproxen During Pregnancy}

Ephross 2014 (direct evidence) reported that spontaneous abortion occurred in 5 of 57 patients receiving naratriptan (8.8\%) and one of $6(16.7 \%)$ of patients receiving the sumatriptan and naproxen combination (Table B-11). No adjusted effect sizes were reported.

Ephross 2014 also reported that elective or induced abortion occurred in 1 of 57 patients receiving naratriptan (1.8\%) and none of the 6 patients receiving the sumatriptan and naproxen combination (Table B-11). No adjusted effect sizes were reported. 
Ephross 2014 also reported that stillbirth or fetal death did not occur in the patients receiving either naratriptan or the sumatriptan and naproxen combination (Table B-11).

Ephross 2014 also reported that major congenital anomalies occurred in 1 of 57 patients receiving naratriptan (1.8\%) and none of the 6 patients receiving the sumatriptan and naproxen combination (Table B-13). No adjusted effect sizes were reported.

\section{Any Triptan Versus Any Ergot Product During Pregnancy}

\section{Description of Direct Evidence for Any Triptan Versus Any Ergot Product During Pregnancy}

One observational NRCS (Kallen 2011), reported in two articles, addressed this comparison in 3,368 pregnant patients with migraine (Tables B-11 to B-13). ${ }^{46,47}$ This study report subgroup results for specific triptans (sumatriptan, naratriptan, zolmitriptan, rizatriptan, almotriptan, and eletriptan) and specific ergot products (dihydroergotamine and ergotamine combinations), but did not report statistical analyses for differences between subgroups. The study reported fetal/child adverse effects only.

\section{Description of SR Evidence for Any Triptan Versus Any Ergot Product During Pregnancy \\ No SR reported on this comparison.}

\section{Maternal Benefit Outcomes of Any Triptan Versus Any Ergot Product During Pregnancy}

No primary study or SR reported on maternal benefit outcomes for this comparison.

\section{Maternal Adverse Effects of Any Triptan Versus Any Ergot Product During Pregnancy}

No primary study or SR reported on maternal adverse effects for this comparison.

\section{Fetal/Child Adverse Effects of Any Triptan Versus Any Ergot Product During Pregnancy}

Kallen 2011 (direct evidence) reported that perinatal death occurred in 5 of 658 patients receiving sumatriptan $(0.75 \%)$ (Table B-11). Data for the other triptan subgroups or for the any ergot product arm were not reported.

Kallen 2011 also reported that preterm birth (<37 weeks) occurred in 34 of 658 patients receiving sumatriptan (5.1\%) (Table B-12). Data for the other triptan subgroups or for the any ergot product arm were not reported.

Kallen 2011 also reported that low birth weight $(<\mathbf{2 5 0 0}$ g) occurred in 34 of 658 patients receiving sumatriptan (5.1\%) (Table B-12). Data for the other triptan subgroups or for the any ergot product arm were not reported.

Kallen 2011 also reported that congenital anomalies occurred in 127 of 2,777 patients receiving any triptan (4.57\%) and 21 of 527 patients receiving any ergot product (3.98\%) (Table B-13). No adjusted effect sizes were reported.

Kallen 2011 also reported that major congenital anomalies occurred in 92 of 2,777 patients receiving any triptan (3.31\%) and 17 of 527 patients receiving any ergot product (3.23\%) (Table B-13). No adjusted effect sizes were reported. 
Kallen 2011 also reported that congenital cardiovascular anomalies occurred in 29 of 2,777 patients receiving any triptan (1.04\%) and 7 of 527 patients receiving any ergot product (1.33\%) (Table B-13). No adjusted effect sizes were reported.

Kallen 2011 also reported that ventricular septum defect and/or atrial septum defect occurred in 12 of 2,777 patients receiving any triptan (0.61\%) and 6 of 527 patients receiving any ergot product (1.14\%) (Table B-13). No adjusted effect sizes were reported.

\section{Any Triptan Versus Pizotifen During Pregnancy}

\section{Description of Direct Evidence for Any Triptan Versus Pizotifen During Pregnancy}

One observational NRCS (Kallen 2011), reported in two articles, addressed this comparison in 3,368 pregnant patients with migraine (Tables B-11 to B-13). ${ }^{46,47}$ This study reported subgroup results for specific triptans (sumatriptan, naratriptan, zolmitriptan, rizatriptan, almotriptan, and eletriptan), but not statistical analyses for differences between subgroups. The study reported fetal/child adverse effects only.

\section{Description of SR Evidence for Any Triptan Versus Pizotifen During Pregnancy}

No SR reported on this comparison.

\section{Maternal Benefit Outcomes of Any Triptan Versus Pizotifen During Pregnancy}

No primary study or SR reported on maternal benefit outcomes for this comparison.

\section{Maternal Adverse Effects of Any Triptan Versus Pizotifen During Pregnancy}

No primary study or SR reported on maternal adverse effects for this comparison.

\section{Fetal/Child Adverse Effects of Any Triptan Versus Pizotifen During Pregnancy}

Kallen 2011 (direct evidence) reported that perinatal death of newborns occurred in 5 of 658 patients receiving sumatriptan (0.75\%) (Table B-11). Data for the other triptan subgroups or for the pizotifen arm were not reported.

Kallen 2011 also reported that preterm birth (<37 weeks) occurred in 34 of 658 patients receiving sumatriptan (5.1\%) (Table B-12). Data for the other triptan subgroups or for the pizotifen arm were not reported.

Kallen 2011 also reported that low birth weight ( $<2500$ g) occurred in 34 of 658 patients receiving sumatriptan (5.1\%) (Table B-12). Data for the other triptan subgroups or for the pizotifen arm were not reported.

Kallen 2011 also reported that congenital anomalies occurred in 127 of 2,777 (4.57\%) percent of patients receiving any triptan and 3 of 64 patients receiving pizotifen (4.69\%) (Table B-13). No adjusted effect sizes were reported.

\section{Any Ergot Product Versus Pizotifen During Pregnancy}

\section{Description of Direct Evidence for Any Ergot Product Versus Pizotifen During Pregnancy}

One observational NRCS (Kallen 2011), reported in two articles, addressed this comparison in 3,368 pregnant patients with migraine (Table B-13). ${ }^{46,47}$ This study reported subgroup results for specific triptans (sumatriptan, naratriptan, zolmitriptan, rizatriptan, almotriptan, and 
eletriptan), but not statistical analyses for differences between subgroups. The study reported fetal/child adverse effects only.

\section{Description of SR Evidence for Any Ergot Product Versus Pizotifen During} Pregnancy

No SR reported on this comparison.

\section{Maternal Benefit Outcomes of Any Ergot Product Versus Pizotifen During} Pregnancy

No primary study or SR reported on maternal benefit outcomes for this comparison.

\section{Maternal Adverse Effects of Any Ergot Product Versus Pizotifen During Pregnancy}

No primary study or SR reported on maternal adverse effects for this comparison.

\section{Fetal/Child Adverse Effects of Any Ergot Product Versus Pizotifen During Pregnancy}

Kallen 2011 (direct evidence) reported that congenital anomalies occurred in 21 of 527 patients receiving any ergot product (3.98\%) and 3 of 64 patients receiving pizotifen (4.69\%) (Table B-13). ${ }^{46,47}$ No adjusted effect sizes were reported.

\section{Any Triptan During Pregnancy Versus Any Triptan Before Pregnancy Only}

\section{Description of Direct Evidence for Any Triptan During Pregnancy Versus Any} Triptan Before Pregnancy Only

Two observational NRCSs (Nezvalova-Henriksen $2013^{50}$ and Nezvalova-Henriksen 2010 [reported in five articles] ${ }^{45,49,51,56,57}$ ) addressed this comparison in a total of 8,460 pregnant patients with migraine (Tables 20 and 21 and Tables B-10 to B-15). Although these studies reported subgroup analyses by specific triptan and/or trimester of use, no statistical analyses for subgroup differences were reported. Both studies reported maternal as well as fetal/child adverse effects.

\section{Description of SR Evidence for Any Triptan During Pregnancy Versus Any Triptan Before Pregnancy Only}

No SR reported on this comparison.

\section{Maternal Benefit Outcomes of Any Triptan During Pregnancy Versus Any Triptan} Before Pregnancy Only

No primary study or SR reported on maternal benefit outcomes for this comparison.

\section{Maternal Adverse Effects of Any Triptan During Pregnancy Versus Any Triptan Before Pregnancy Only}

Both Nezvalova-Henriksen 2013 and Nezvalova-Henriksen 2010 (direct evidence) reported on the outcome of postpartum hemorrhage $(>\mathbf{5 0 0} \mathbf{~ m L}$ ) (Table B-10). Nezvalova-Henriksen 2013 reported that the rates of postpartum hemorrhage were similar comparing women who used triptans during pregnancy with those who only used them before pregnancy (248 of 1,465 patients [16.9\%] and 195 of 1,095 patients [17.8\%], respectively). Nezvalova-Henriksen 2010, 
however, reported that the rates were 255 of 1,045 patients (24.4\%) and 63 of 805 patients (7.8\%), respectively. In this study, women using triptans in the first trimester appeared to have higher rates of postpartum hemorrhage than those using it in the second and/or third trimester. In Nezvalova-Henriksen 2013, the rates of postpartum hemorrhage were similar across the triptans and across the subgroups, with somewhat higher rates in the zolmitriptan subgroups. No adjusted effect sizes were reported in either study for this outcome, either overall or within the subgroups.

\section{Fetal/Child Adverse Effects of Any Triptan During Pregnancy Versus Any Triptan Before Pregnancy Only}

Nezvalova-Henriksen 2010 (direct evidence) reported on stillbirths and perinatal deaths separately. ${ }^{45,49,51,56,57}$ The rate of stillbirth was 2 of 805 patients in the triptans before pregnancy only arm (0.2\%) and not reported for the triptans during pregnancy arm (Table B-11). The rates of perinatal death were 6 of 1,045 patients (0.6\%) and 3 of 805 patients $(0.4 \%)$ in the triptans during pregnancy and triptans before pregnancy only arms, respectively (Table B-11). No adjusted effect sizes were reported.

Nezvalova-Henriksen 2010 also reported on the outcome of infant death by 1 year of age. The rate of infant death was 5 of 1,045 patients in the triptans during pregnancy arm (0.5\%). No infant deaths were reported in the triptans before pregnancy only arm (Table B-11). ${ }^{45,49,51,56,57}$

Both Nezvalova-Henriksen 2013 and Nezvalova-Henriksen 2010 (direct evidence) reported on the outcome of preterm birth ( $<37$ weeks) (Table B-12). No patterns were observed in either study, except that preterm birth rates were somewhat higher rates in the zolmitriptan subgroups than the other subgroups in the Nezvalova-Henriksen 2013 study. No adjusted effect sizes were reported for this outcome.

Both Nezvalova-Henriksen 2013 and Nezvalova-Henriksen 2010 reported on the outcome of low birth weight (Table B-12). No patterns were observed in either study; rates of low birth weight were approximately 6 percent in both studies. No adjusted effect sizes were reported. Nezvalova-Henriksen 2013 also reported on the outcome of low birth weight for gestational age. The rates of low birth weight for gestational age were 132 of 1,465 patients $(9.0 \%)$ and 91 of 1,095 patients (8.3\%) in the triptans during pregnancy and triptans before pregnancy only arms, respectively. No adjusted effect sizes were reported for this outcome.

Nezvalova-Henriksen 2010 reported on the outcome of Apgar score being less than 7 at both 1 minute and at 5 minutes after birth. A larger proportion of newborns born to patients who used triptans during versus only before pregnancy had Apgar scores less than 7 at 1 minute (8.4\% vs. 2.2\%) and at 5 minutes (2.1\% vs. 0.5\%), but no adjusted effect sizes were reported for this outcome (Table B-12).

Nezvalova-Henriksen 2013 reported on neonatal intensive care unit admission rates for each of the triptans, by trimester of use only. No patterns were observed, and no adjusted effect sizes were reported for this outcome (Table B-12).

Both Nezvalova-Henriksen 2013 and Nezvalova-Henriksen 2010 reported on congenital anomalies. Nezvalova-Henriksen 2013 reported that the rates of any congenital anomalies were similar between triptan during pregnancy and triptan before pregnancy only arms (85 of 1,465 patients [5.7\%] and 67 of 1,095 patients [6.1\%]), but Nezvalova-Henriksen 2010 reported higher rates in the during pregnancy arm (Table B-13). No adjusted effect sizes were reported for this outcome.

Both Nezvalova-Henriksen 2013 and Nezvalova-Henriksen 2010 reported on major congenital anomalies. Nezvalova-Henriksen 2013 reported that the rates of major congenital anomalies were similar between triptan during pregnancy and triptans before pregnancy only 
arms (51 of 1,465 patients [3.5\%] and 50 of 1,095 patients [4.6\%]), but Nezvalova-Henriksen 2010 reported higher rates in the during pregnancy arm (75 of 1,045 patients [7.2\%]) (Table B13). No adjusted effect sizes were reported for this outcome.

Nezvalova-Henriksen 2010 reported on neurodevelopmental outcomes at 1.5 years and 3 years of age, as measured by the Ages and Stages Questionnaire (ASQ). Compared with children whose mothers used triptans only before pregnancy, those whose mothers used triptans during pregnancy had similar gross motor development (adjusted RR for being above a Z-score of 1.5 on the ASQ: $0.86,95 \%$ CI 0.23 to 3.19) and fine motor development (adjusted RR 0.85 , $95 \%$ CI 0.52 to 1.37 ) at 3 years of age (Table B-14).

Nezvalova-Henriksen 2010 reported on various behavioral and social outcomes at 1.5 years, 3 years, and 5 years of age. These included externalizing problems, internalizing problems, and emotionality (measured using the Child Behavior Check List [CBCL]); activity, shyness, and sociability (measured using the Emotionality, Activity, and Shyness Temperament [EAST] Questionnaire), and communication (measured using the ASQ). At 3 years of age, compared with children of triptan users only before pregnancy, children of triptan users during pregnancy were more likely to have emotionality problems (adjusted RR 2.18, 95\% CI 1.03 to 4.53) and activity problems (adjusted RR 1.70, 95\% CI 1.02 to 2.80) (Table 20 and Table B15).

\section{Sumatriptan During Pregnancy Versus Sumatriptan Before Pregnancy Only}

\section{Description of Direct Evidence for Sumatriptan During Pregnancy Versus Sumatriptan Before Pregnancy Only}

Two observational NRCSs (O’Quinn 1999 and Olesen 2000) addressed this comparison in a total of 291 pregnant patients with migraine (Tables B-10 to B-12). ${ }^{52,53}$ O’Quinn 1999 reported maternal adverse effects, while both studies reported fetal/child adverse effects.

\section{Description of SR Evidence for Sumatriptan During Pregnancy Versus Sumatriptan Before Pregnancy Only \\ No SR reported on this comparison.}

\section{Maternal Benefit Outcomes of Sumatriptan During Pregnancy Versus Sumatriptan Before Pregnancy Only}

No primary study or SR reported on maternal benefit outcomes for this comparison.

\section{Maternal Adverse Effects of Sumatriptan During Pregnancy Versus Sumatriptan Before Pregnancy Only \\ O’Quinn 1999 (direct evidence) reported abnormal pregnancy outcomes occurred in 9 of 76 sumatriptan users during pregnancy (12\%) and 19 of 92 sumatriptan users only before pregnancy (21\%) (Table B-10). The authors did not, however, define abnormal pregnancy outcomes or report an adjusted effect size.}

\section{Fetal/Child Adverse Effects of Sumatriptan During Pregnancy Versus Sumatriptan Before Pregnancy Only \\ O’Quinn 1999 (direct evidence) reported that the rates of spontaneous abortions were 8 of 76 sumatriptan users during pregnancy (10.5\%) and 11 of 92 sumatriptan users only before pregnancy (12\%) (Table B-11). No adjusted effect sizes were reported.}


Olesen 2000 (direct evidence) reported higher rates of preterm births ( $<37$ weeks) in infants of sumatriptan users during pregnancy (5 of 34 patients; 14.7\%) than infants of users before pregnancy only (3 of 89 patients; 3.4\%) (adjusted OR 6.3, 95\% CI 1.2 to 32.0) (Table 20 and Table B-12).

Olesen 2000 also reported similar rates of low birth weight $(<2,500$ g) in infants of sumatriptan users during pregnancy (1 of 34 patients; 3.4\%) than infants of users only before pregnancy (5 of 89 patients; 5.8\%) (adjusted OR 0.9, 95\% CI 0.1 to 11.8) (Table 20 and Table B12).

\section{Any Triptan During Pregnancy Versus No Triptan During or Before Pregnancy}

\section{Description of Direct Evidence for Any Triptan During Pregnancy Versus No Triptan During or Before Pregnancy}

Three observational NRCSs (Shuhaiber 1997, Nezvalova-Henriksen 2010, and Spielmann 2018) addressed this comparison in a total of 6,999 pregnant patients with migraine (Tables B-10 to B-16). ${ }^{43,45,49,51,54-57}$ Although Nezvalova-Henriksen 2010 reported subgroup analyses by trimester of triptan use, no statistical analyses for subgroup differences were reported. One study reported maternal adverse effects, while all three studies reported fetal/child adverse effects.

\section{Description of SR Evidence for Any Triptan During Pregnancy Versus No Triptan During or Before Pregnancy \\ One high-quality SR (Marchenko 2015) assessed harms associated with (any) triptan use during pregnancy (Table 22 and Tables B-26, B-27, B-28, and B-37). ${ }^{79}$}

\section{Maternal Benefit Outcomes of Any Triptan During Pregnancy Versus No Triptan During or Before Pregnancy}

No primary study or SR reported on maternal benefit outcomes for this comparison.

\section{Maternal Adverse Effects of Any Triptan During Pregnancy Versus No Triptan During or Before Pregnancy}

Nezvalova-Henriksen 2010 (direct evidence) reported on the outcome of postpartum hemorrhage $(>\mathbf{5 0 0} \mathbf{~ m L})$. The rate of postpartum hemorrhage was 255 of 1,045 triptan users (24.4\%) and not reported for nonusers (Table B-10). Women using triptans in the first trimester appeared to have higher rates of postpartum hemorrhage than those using it in the second or third trimester, but statistical analyses of subgroup differences were not reported.

The SR did not report maternal adverse effects.

\section{Fetal/Child Adverse Effects of Any Triptan During Pregnancy Versus No Triptan During or Before Pregnancy}

Two studies (Shuhaiber 1998 and Spielmann 2018) (direct evidence) reported on spontaneous abortions. Spielmann 2018 reported that rates of spontaneous abortions were similar between triptan users and nonusers (adjusted hazard ratio [HR] 1.41, 95\% CI 0.9 to 2.2) (Table 20 and Table B-11). Shuhaiber 1998 also reported similar rates in the two arms, but did not report an adjusted effect size.

Two studies (Shuhaiber 1998 and Spielmann 2018) (direct evidence) reported on elective or induced abortions that were likely to be related to drug use. Spielmann 2018 reported that rates 
of elective or induced abortions were similar between triptan users and nonusers (adjusted HR 1.58, 95\% CI 0.8 to 3.0) (Table 20 and Table B-11). Shuhaiber 1998 also reported similar rates in the two arms, but did not report an adjusted effect size.

Two studies (Nezvalova-Henriksen 2010 and Spielmann 2018) (direct evidence) reported on the outcome of stillbirth. Spielmann 2018 reported that the rates of stillbirth were 0.2 percent in each arm. No adjusted effect sizes were reported (Table B-11). Nezvalova-Henriksen 2010 also reported on this outcome, but there were no stillbirths in either the triptan user or nonuser arms. Nezvalova-Henriksen 2010 (direct evidence) also reported on the outcome of perinatal death. The rate of perinatal death was 6 of 1,045 triptan users (0.6\%) and not reported for nonusers.

Nezvalova-Henriksen 2010 (direct evidence) reported on the outcome of infant death by 1 year of age. The rate of infant death was 5 of 1,045 triptan users (0.5\%). Infant deaths were not reported in the nonuser arm (Table B-11).

Nezvalova-Henriksen 2010 (direct evidence) reported on the outcome of preterm birth (<37 weeks). The rate of preterm birth was 86 of 1,045 triptan users (8.2\%) (Table B-12). Preterm births were not reported for the nonuser arm.

Nezvalova-Henriksen 2010 (direct evidence) reported on the outcome of low birth weight. The rate of low birth weight was 65 of 1,045 triptan users (6.2\%) (Table B-12). Birth weights were not reported for the nonuser arm.

Nezvalova-Henriksen 2010 (direct evidence) reported on the outcome of Apgar score being less than 7 at both 1 minute and at 5 minutes after birth. The proportion of newborns born to patients who used triptans had Apgar scores of 8.4 percent vs. 2.2 percent at 1 minute and 5 minutes, respectively (Table B-12). Apgar scores were not reported for the nonuser arm.

Two studies (Nezvalova-Henriksen 2010 and Spielmann 2018) (direct evidence) reported congenital anomalies. Nezvalova-Henriksen 2010 reported a 7.2\% rate of any anomalies in infants in the triptan user arm, but no data were reported for the nonuser arm. Spielmann reported similar rates of any congenital anomalies between triptan users and nonusers (adjusted OR 1.00, 95\% CI 0.51 to 2.10). (Table 20 and Table B-13).

All three studies (Shuhaiber 1999, Nezvalova-Henriksen 2010, and Spielmann 2018) (direct evidence) reported data on major congenital anomalies. Spielmann 2018 reported similar rates of major congenital anomalies between infants of users and nonusers (adjusted OR 1.01, 95\% CI 0.3 to 3.3) (Table 20 and Table B-13). The other two studies also reported similar rates of major congenital anomalies in the two arms (Table 9).

Spielmann 2018 (direct evidence) reported similar rates of (unnamed) genetic birth defects between infants of triptan users and nonusers (adjusted OR 1.10, 95\% CI 0.2 to 6.6) (Table 20 and Table B-13).

Two studies (Shuhaiber 1999 and Spielmann 2018) (direct evidence) reported on minor congenital anomalies. Spielmann 2018 reported similar rates of minor congenital anomalies (e.g., congenital finger hypoplasia, club foot) between infants of triptan users and nonusers (adjusted OR 1.48, 95\% CI 0.5 to 4.4) (Table 20 and Table B-13). Shuhaiber 1999 also reported similar rates of minor congenital anomalies (e.g., brown marks, red marks) in the two arms, but a between-group effect size was not reported.

Nezvalova-Henriksen 2010 (direct evidence) reported on neurodevelopmental outcomes at 1.5 years and 3 years of age, as measured by the ASQ. Compared with children of nonusers, children of triptan users during pregnancy had similar gross motor development (adjusted RR for being above a Z-score of 1.5 on the ASQ: $0.58,95 \%$ CI 0.17 to 2.03) and fine motor 
development (adjusted RR 0.85, 95\% CI 0.56 to 1.29) at 3 years of age (Table 20 and Tables B14).

Nezvalova-Henriksen 2010 (direct evidence) reported on various behavioral and social outcomes at 1.5 years, 3 years, and 5 years of age. These outcomes included externalizing problems, internalizing problems, and emotionality (measured using the CBCL); activity, shyness, and sociability (measured using the Emotionality, Activity, and Shyness Temperament [EAST] Questionnaire), and communication (measured using the ASQ). Triptan use, compared with nonuse, was not associated with differences in most of these outcomes, except for emotionality and activity. At 3 years of age, compared with children of triptan nonusers, children of triptan users during pregnancy were more likely to have emotionality problems (adjusted RR 2.51, 95\% CI 1.27 to 4.90) and activity problems (hyperactivity) (adjusted RR 1.57, 95\% CI 1.04 to 2.36) (Table 20 and Tables B-15 and B-16) At 5 years of age, there were no differences between groups in these outcomes.

\section{Fetal/Child Adverse Effects Reported in SR Evidence for Triptans}

The Marchenko 2015 SR reported that (any) triptan use was not associated with spontaneous abortion, preterm birth, or major congenital anomalies.

The findings in the Marchenko 2015 SR are consistent with the findings in the three primary studies that we identified for the same comparison of triptan use versus nonuse (Shuhaiber 1997, Nezvalova-Henriksen 2010, and Spielmann 2018). In these three primary studies, triptan use was not associated with an increased likelihood of spontaneous abortion, elective or induced abortion, or major or minor congenital anomalies.

\section{Fetal/Child Adverse Effects Reported in Indirect Evidence for Antihistamines}

The Etwel 2017 and Li 2019 SRs (indirect evidence) reported that (any) antihistamine use was not associated with spontaneous abortion, stillbirth, preterm birth, low birth weight, or major congenital anomalies.

The findings in the Etwel 2017 and Li 2019 SRs are consistent with the findings in the primary study that we identified for the use of pizotifen (a specific antihistamine) (Kallen 2011). 


\begin{tabular}{|c|c|c|c|c|c|}
\hline Outcome* $^{*}$ & $\begin{array}{l}\text { Outcome } \\
\text { Definition }\end{array}$ & $\begin{array}{l}\text { Study, Year, Design, } \\
\text { PMID }\end{array}$ & Arm & $\begin{array}{l}\mathrm{n} / \mathrm{N}(\%) \text { or } \\
\text { Mean (SD) }\end{array}$ & Adj Effect Size (95\% Cl) \\
\hline \multirow[t]{4}{*}{ Fetal/child death } & \multirow{2}{*}{$\begin{array}{l}\text { Spontaneous } \\
\text { abortion }\end{array}$} & \multirow{4}{*}{$\begin{array}{l}\text { Spielmann, 2018, NRCS, } \\
28758416\end{array}$} & Triptans: Any (during pregnancy) & $50 / 432(11.6)$ & \multirow[t]{2}{*}{ Adj HR $1.41(0.2,2.2)$} \\
\hline & & & No triptans during or before pregnancy & $37 / 475(7.8)$ & \\
\hline & \multirow{2}{*}{$\begin{array}{l}\text { Elective or induced } \\
\text { abortion }\end{array}$} & & Triptans: Any (during pregnancy) & $23 / 432(5.3)$ & \multirow[t]{2}{*}{ Adj HR $1.58(0.8,3.0)$} \\
\hline & & & No triptans during or before pregnancy & $17 / 475$ (3.6) & \\
\hline \multirow[t]{2}{*}{ Preterm birth } & \multirow[t]{2}{*}{$<37 \mathrm{w}$} & \multirow[t]{4}{*}{$\begin{array}{l}\text { Olesen, 2000. NRCS, } \\
10759898\end{array}$} & $\begin{array}{l}\text { Triptans: Sumatriptan (during } \\
\text { pregnancy) }\end{array}$ & $5 / 34(14.7)$ & \multirow[t]{2}{*}{ Adj OR $6.3(1.2,32.0)$} \\
\hline & & & $\begin{array}{l}\text { No sumatriptan during or before } \\
\text { pregnancy }\end{array}$ & $3 / 89(3.4)$ & \\
\hline \multirow[t]{2}{*}{ Low birth weight } & \multirow[t]{2}{*}{$<2500 \mathrm{~g}$} & & $\begin{array}{l}\text { Triptans: Sumatriptan (during } \\
\text { pregnancy) }\end{array}$ & $1 / 34(3.4)$ & \multirow[t]{2}{*}{ Adj OR $0.9(0.1,11.8)$} \\
\hline & & & $\begin{array}{l}\text { No sumatriptan during or before } \\
\text { pregnancy }\end{array}$ & $5 / 89(5.8)$ & \\
\hline \multirow{8}{*}{$\begin{array}{l}\text { Congenital } \\
\text { anomalies }\end{array}$} & \multirow[t]{2}{*}{ Any } & \multirow{8}{*}{$\begin{array}{l}\text { Spielmann, 2018, NRCS, } \\
28758416\end{array}$} & Triptans: Any (during pregnancy) & $25 / 372(6.7)$ & \multirow[t]{2}{*}{ Adj OR $1.00(0.51,2.10)$} \\
\hline & & & No triptans during or before pregnancy & $28 / 431(6.5)$ & \\
\hline & \multirow[t]{2}{*}{ Major } & & Triptans: Any (during pregnancy) & 9/367 (2.5) & \multirow[t]{2}{*}{ Adj OR $1.01(0.3,3.3)$} \\
\hline & & & No triptans during or before pregnancy & $12 / 429(2.8)$ & \\
\hline & \multirow{2}{*}{$\begin{array}{l}\text { Genetic birth } \\
\text { defects }\end{array}$} & & Triptans: Any (during pregnancy) & $5 / 369(1.4)$ & \multirow[t]{2}{*}{ Adj OR $1.10(0.2,6.6)$} \\
\hline & & & No triptans during or before pregnancy & $4 / 429(0.9)$ & \\
\hline & \multirow[t]{2}{*}{ Minor } & & Triptans: Any (during pregnancy) & $11 / 364(3.0)$ & \multirow[t]{2}{*}{ Adj OR $1.48(0.5,4.4)$} \\
\hline & & & No triptans during or before pregnancy & $12 / 427(2.8)$ & \\
\hline \multirow[t]{6}{*}{$\begin{array}{l}\text { Neurodevelopmental } \\
\text { AEs }\end{array}$} & \multirow[t]{3}{*}{$\begin{array}{l}\text { Gross motor } \\
\text { development at } 3 \mathrm{y}\end{array}$} & \multirow[t]{6}{*}{$\begin{array}{l}\text { Nezvalova-Henriksen } \\
\text { 2010, NRCS, } 20132339\end{array}$} & Triptans: Any (during pregnancy) & $6 / 495(1.2)$ & \multirow[t]{3}{*}{$\begin{array}{l}\text { Vs. Triptans before pregnancy only } \\
\text { RR } 0.86(0.23,3.19) \\
\text { Vs. No Triptans } \\
\text { RR } 0.58(0.17,2.03)\end{array}$} \\
\hline & & & Triptans: Any (before pregnancy only) & $30 / 1002(3.0)$ & \\
\hline & & & No triptans during or before pregnancy & $122 / 4050(3.0)$ & \\
\hline & \multirow[t]{3}{*}{$\begin{array}{l}\text { Fine motor } \\
\text { development at } 3 y\end{array}$} & & Triptans: Any (during pregnancy) & $47 / 495(9.5)$ & \multirow[t]{3}{*}{$\begin{array}{l}\text { Vs. Triptans before pregnancy only } \\
\text { Adj RR } 0.85(0.52,1.37) \\
\text { Vs. No Triptans } \\
\text { Adj RR } 0.85(0.56,1.29)\end{array}$} \\
\hline & & & Triptans: Any (before pregnancy only) & $94 / 1002(9.4)$ & \\
\hline & & & No triptans during or before pregnancy & $373 / 4050(9.2)$ & \\
\hline
\end{tabular}




\begin{tabular}{|c|c|c|c|c|c|}
\hline Outcome* $^{*}$ & $\begin{array}{l}\text { Outcome } \\
\text { Definition }\end{array}$ & $\begin{array}{l}\text { Study, Year, Design, } \\
\text { PMID }\end{array}$ & Arm & $\begin{array}{l}\mathrm{n} / \mathrm{N}(\%) \text { or } \\
\text { Mean (SD) }\end{array}$ & Adj Effect Size (95\% Cl) \\
\hline \multirow{22}{*}{$\begin{array}{l}\text { Social and } \\
\text { behavioral AEs }\end{array}$} & \multirow{2}{*}{$\begin{array}{l}\text { Externalizing } \\
\text { problems at } 3 y\end{array}$} & \multirow{22}{*}{$\begin{array}{l}\text { Nezvalova-Henriksen } \\
\text { 2010, NRCS, } 20132339\end{array}$} & Triptans: Any (during pregnancy) & $101 / 1085(9.3)$ & \multirow[t]{2}{*}{ Adj RR $0.99(0.77,1.27)$} \\
\hline & & & $\begin{array}{l}\text { No triptans (during or before } \\
\text { pregnancy) }\end{array}$ & 297/3354 (8.9) & \\
\hline & \multirow{2}{*}{$\begin{array}{l}\text { Externalizing } \\
\text { problems at } 5 \text { y }\end{array}$} & & Triptans: Any (during pregnancy) & $25 / 340(7.4)$ & \multirow[t]{2}{*}{ Adj RR $0.68(0.44,1.05)$} \\
\hline & & & $\begin{array}{l}\text { No triptans (during or before } \\
\text { pregnancy) }\end{array}$ & 15/1457 (10.6) & \\
\hline & \multirow[t]{3}{*}{$\begin{array}{l}\text { Internalizing } \\
\text { problems at } 3 \text { y }\end{array}$} & & Triptans: Any (during pregnancy) & $47 / 495$ (9.5) & \multirow[t]{3}{*}{$\begin{array}{l}\text { Vs. Triptans before pregnancy only } \\
\text { Adj RR } 0.69(0.41,1.14) \\
\text { Vs. No Triptans } \\
\text { Adj RR } 1.02(0.66,1.57)\end{array}$} \\
\hline & & & Triptans: Any (before pregnancy only) & $\begin{array}{l}108 / 1002 \\
(10.8)\end{array}$ & \\
\hline & & & $\begin{array}{l}\text { No triptans (during or before } \\
\text { pregnancy) }\end{array}$ & $\begin{array}{l}425 / 4050 \\
(10.5)\end{array}$ & \\
\hline & \multirow[t]{3}{*}{$\begin{array}{l}\text { Emotionality at } 3 y \\
\text { on the } C B C L\end{array}$} & & Triptans: Any (during pregnancy) & $31 / 495(6.3)$ & \multirow[t]{3}{*}{$\begin{array}{l}\text { Vs. Triptans before pregnancy only } \\
\text { Adj RR } 2.18(1.03,4.53) \\
\text { Vs. No Triptans } \\
\text { Adj RR } 2.51(1.27,4.90)\end{array}$} \\
\hline & & & Triptans: Any (before pregnancy only) & $47 / 1002(4.7)$ & \\
\hline & & & $\begin{array}{l}\text { No triptans (during or before } \\
\text { pregnancy) }\end{array}$ & $158 / 4050(3.9)$ & \\
\hline & \multirow[t]{2}{*}{ Emotionality at $5 \mathrm{y}$} & & Triptans: Any (during pregnancy) & $49.7(9.9)$ & \multirow[t]{2}{*}{ Adj NMD -1.02 (-2.3, 0.29) } \\
\hline & & & $\begin{array}{l}\text { No triptans (during or before } \\
\text { pregnancy) }\end{array}$ & $50.5(10.0)$ & \\
\hline & \multirow[t]{3}{*}{$\begin{array}{l}\text { Activity at } 3 \mathrm{y} \text { on } \\
\text { the EAST } \\
\text { Questionnaire }\end{array}$} & & Triptans: Any (during pregnancy) & $41 / 495(8.3)$ & \multirow[t]{2}{*}{$\begin{array}{l}\text { Vs. Triptans before pregnancy only } \\
\text { Adj RR } 1.70(1.02,2.80) \\
\text { Vs. No Triptans } \\
\text { Adj RR } 1.57(1.04,2.36)\end{array}$} \\
\hline & & & Triptans: Any (before pregnancy only) & $47 / 1002(4.7)$ & \\
\hline & & & $\begin{array}{l}\text { No triptans (during or before } \\
\text { pregnancy) }\end{array}$ & $215 / 4050(5.3)$ & \\
\hline & \multirow[t]{2}{*}{ Activity at $5 \mathrm{y}$} & & Triptans: Any (during pregnancy) & $49.3(10.2)$ & \multirow[t]{2}{*}{ Adj NMD $-0.06(-1.35,1.23)$} \\
\hline & & & $\begin{array}{l}\text { No triptans (during or before } \\
\text { pregnancy) }\end{array}$ & $50.1(10.2)$ & \\
\hline & \multirow[t]{3}{*}{ Shyness at 3 y } & & Triptans: Any (during pregnancy) & $61 / 495(12.3)$ & \multirow[t]{3}{*}{$\begin{array}{l}\text { Vs. Triptans before pregnancy only } \\
\text { Adj RR } 0.92(0.52,1.63) \\
\text { Vs. No Triptans } \\
\text { RR } 1.30(0.81,2.08)\end{array}$} \\
\hline & & & Triptans: Any (before pregnancy only) & $96 / 1002(9.6)$ & \\
\hline & & & $\begin{array}{l}\text { No triptans (during or before } \\
\text { pregnancy) }\end{array}$ & $312 / 4050(7.7)$ & \\
\hline & \multirow[t]{2}{*}{ Shyness at 5 y } & & Triptans: Any (during pregnancy) & $50.1(10.0)$ & \multirow[t]{2}{*}{ Adj NMD -0.71 $(-0.28,0.65)$} \\
\hline & & & $\begin{array}{l}\text { No triptans (during or before } \\
\text { pregnancy) }\end{array}$ & $50.5(10.1)$ & \\
\hline
\end{tabular}




\begin{tabular}{|c|c|c|c|c|c|}
\hline Outcome* $^{*}$ & $\begin{array}{l}\text { Outcome } \\
\text { Definition }\end{array}$ & $\begin{array}{l}\text { Study, Year, Design, } \\
\text { PMID }\end{array}$ & Arm & $\begin{array}{l}\mathrm{n} / \mathrm{N}(\%) \text { or } \\
\text { Mean (SD) }\end{array}$ & Adj Effect Size (95\% Cl) \\
\hline \multirow[t]{8}{*}{$\begin{array}{l}\text { Social and } \\
\text { behavioral AEs } \\
\text { (continued) }\end{array}$} & \multirow[t]{3}{*}{ Sociability at $3 \mathrm{y}$} & \multirow[t]{3}{*}{$\begin{array}{l}\text { Nezvalova-Henriksen } \\
\text { 2010, NRCS, } 20132339\end{array}$} & Triptans: Any (during pregnancy) & $31 / 495(6.3)$ & \multirow[t]{3}{*}{$\begin{array}{l}\text { Vs. Triptans before pregnancy only } \\
\text { Adj RR } 0.70(0.40,1.38) \\
\text { Vs. No Triptans } \\
\text { Adj RR } 1.13(0.70,1.82)\end{array}$} \\
\hline & & & Triptans: Any (before pregnancy only) & $64 / 1002(6.4)$ & \\
\hline & & & $\begin{array}{l}\text { No triptans (during or before } \\
\text { pregnancy) }\end{array}$ & $247 / 4050(6.1)$ & \\
\hline & \multirow[t]{2}{*}{ Sociability at $5 \mathrm{y}$} & & Triptans: Any (during pregnancy) & $51.0(10.4)$ & \multirow[t]{2}{*}{ Adj NMD $1.66(-0.30,3.02)$} \\
\hline & & & $\begin{array}{l}\text { No triptans (during or before } \\
\text { pregnancy) }\end{array}$ & $49.6(10.5)$ & \\
\hline & \multirow[t]{3}{*}{$\begin{array}{l}\text { Communication at } \\
3 \mathrm{y}\end{array}$} & & Triptans: Any (during pregnancy) & $23 / 495(4.6)$ & \multirow[t]{3}{*}{$\begin{array}{l}\text { Vs. Triptans before pregnancy only } \\
\text { Adj RR } 1.22(0.56,2.68) \\
\text { Vs. No Triptans } \\
\text { Adj RR } 0.97(0.48,1.95)\end{array}$} \\
\hline & & & Triptans: Any (before pregnancy only) & $45 / 1002(4.5)$ & \\
\hline & & & $\begin{array}{l}\text { No triptans (during or before } \\
\text { pregnancy) }\end{array}$ & $211 / 4050(5.2)$ & \\
\hline
\end{tabular}

Abbreviations: Adj = adjusted, AE = adverse effect, CBCL = Child Behavior Checklist, CI = confidence interval, EAST = Emotionality, Activity, and Shyness Temperament, HR $=$ hazard ratio, $\min =$ minutes, $\mathrm{NMD}=$ net mean difference, $\mathrm{NRCS}=$ nonrandomized comparative study, $\mathrm{OR}=$ odds ratio, $\mathrm{PMID}=\mathrm{PubMed}$ identifier, RR $=$ relative risk, $\mathrm{y}=$ years, $\mathrm{SD}=$ standard deviation.

This table provides only data pertaining to outcomes with reported adjusted effect sizes. For full data, please refer to individual evidence tables. (Tables B-10 to B-16).

* No studies reported acute headache attack outcomes (severity, duration, resolution, recurrence), headache-related symptom outcomes (severity, duration, resolution, recurrence), emergency department or clinic visits, hospitalizations, quality of life, functional outcomes (impact on family life, work/school attendance, time spent managing disease), resource use, acceptability of intervention by patients, patient satisfaction with intervention, medication use, serious maternal AEs (any serious, cardiovascular), nonserious maternal AEs (any nonserious, nonobstetrical, preterm labor/CS, reduced breast milk, medication withdrawal symptoms), discontinuation due to maternal AEs, serious fetal/child AEs (any serious AE, perinatal complications), nonserious fetal/child AEs (any nonserious AE, breastfeeding delay/cessation/etc., poor infant attachment/bonding, medication withdrawal symptoms), or discontinuation due to fetal/child AEs. 
Table 21. Triptans, ergot products, NSAIDs (naproxen), and antihistamines (pizotifen): Evidence profile for direct evidence regarding use to treat primary headaches

\begin{tabular}{|c|c|c|c|c|c|c|c|c|c|c|}
\hline Topic & Comparison & $\begin{array}{l}\text { Outcome } \\
\text { Category }\end{array}$ & Outcome & $\begin{array}{l}\text { N Studies } \\
\text { (Subjects) }\end{array}$ & RoB & Consistency & Precision & Directness & SoE & Conclusions \\
\hline Benefits & - & - & - & 0 & - & - & - & - & None & None \\
\hline \multirow[t]{18}{*}{ Harms } & \multirow[t]{3}{*}{$\begin{array}{l}\text { Sumatriptan vs. } \\
\text { naratriptan (during } \\
\text { pregnancy) }\end{array}$} & \multirow[t]{3}{*}{$\begin{array}{l}\text { AEs - } \\
\text { Fetal/Child }\end{array}$} & $\begin{array}{l}\text { Spontaneous abortion or } \\
\text { elective or induced } \\
\text { abortion }\end{array}$ & 1 (689) & High & $\mathrm{N} / \mathrm{A}$ & $\mathrm{N} / \mathrm{A}$ & Direct & Insufficient & No conclusion made \\
\hline & & & Stillbirth or fetal death & $1(689)$ & High & $\mathrm{N} / \mathrm{A}$ & $\mathrm{N} / \mathrm{A}$ & Direct & Insufficient & No conclusion made \\
\hline & & & Congenital anomalies & 1 (689) & High & $\mathrm{N} / \mathrm{A}$ & $\mathrm{N} / \mathrm{A}$ & Direct & Insufficient & No conclusion made \\
\hline & \multirow{3}{*}{$\begin{array}{l}\text { Sumatriptan vs. } \\
\text { sumatriptan and } \\
\text { naproxen } \\
\text { combination } \\
\text { (during pregnancy) }\end{array}$} & \multirow[t]{3}{*}{$\begin{array}{l}\text { AEs - } \\
\text { Fetal/Child }\end{array}$} & $\begin{array}{l}\text { Spontaneous abortion or } \\
\text { elective or induced } \\
\text { abortion }\end{array}$ & $1(689)$ & High & $\mathrm{N} / \mathrm{A}$ & N/A & Direct & Insufficient & No conclusion made \\
\hline & & & Stillbirth or fetal death & $1(689)$ & High & $\mathrm{N} / \mathrm{A}$ & $\mathrm{N} / \mathrm{A}$ & Direct & Insufficient & No conclusion made \\
\hline & & & Congenital anomalies & $1(689)$ & High & $\mathrm{N} / \mathrm{A}$ & $\mathrm{N} / \mathrm{A}$ & Direct & Insufficient & No conclusion made \\
\hline & \multirow{3}{*}{$\begin{array}{l}\text { Naratriptan vs. } \\
\text { sumatriptan and } \\
\text { naproxen } \\
\text { combination } \\
\text { (during pregnancy) }\end{array}$} & \multirow[t]{3}{*}{$\begin{array}{l}\text { AEs - } \\
\text { Fetal/Child }\end{array}$} & $\begin{array}{l}\text { Spontaneous abortion or } \\
\text { elective or induced } \\
\text { abortion }\end{array}$ & $1(689)$ & High & $\mathrm{N} / \mathrm{A}$ & $\mathrm{N} / \mathrm{A}$ & Direct & Insufficient & No conclusion made \\
\hline & & & Stillbirth or fetal death & $1(689)$ & High & $\mathrm{N} / \mathrm{A}$ & $\mathrm{N} / \mathrm{A}$ & Direct & Insufficient & No conclusion made \\
\hline & & & Congenital anomalies & $1(689)$ & High & $\mathrm{N} / \mathrm{A}$ & $\mathrm{N} / \mathrm{A}$ & Direct & Insufficient & No conclusion made \\
\hline & \multirow{4}{*}{$\begin{array}{l}\text { Any triptan vs. any } \\
\text { ergot product } \\
\text { (during pregnancy) }\end{array}$} & \multirow{4}{*}{$\begin{array}{l}\text { AEs - } \\
\text { Fetal/Child }\end{array}$} & Stillbirth or fetal death & $1(3368)$ & High & $\mathrm{N} / \mathrm{A}$ & $\mathrm{N} / \mathrm{A}$ & Direct & Insufficient & No conclusion made \\
\hline & & & Preterm birth & $1(3368)$ & High & $\mathrm{N} / \mathrm{A}$ & $\mathrm{N} / \mathrm{A}$ & Direct & Insufficient & No conclusion made \\
\hline & & & Low birth weight & $1(3368)$ & High & $\mathrm{N} / \mathrm{A}$ & $\mathrm{N} / \mathrm{A}$ & Direct & Insufficient & No conclusion made \\
\hline & & & Congenital anomalies & $1(3368)$ & High & $\mathrm{N} / \mathrm{A}$ & $\mathrm{N} / \mathrm{A}$ & Direct & Insufficient & No conclusion made \\
\hline & \multirow{4}{*}{$\begin{array}{l}\text { Any triptan vs. } \\
\text { pizotifen (during } \\
\text { pregnancy) }\end{array}$} & \multirow{4}{*}{$\begin{array}{l}\text { AEs - } \\
\text { Fetal/Child }\end{array}$} & Stillbirth or fetal death & $1(3368)$ & High & $\mathrm{N} / \mathrm{A}$ & $\mathrm{N} / \mathrm{A}$ & Direct & Insufficient & No conclusion made \\
\hline & & & Preterm birth & $1(3368)$ & High & $\mathrm{N} / \mathrm{A}$ & $\mathrm{N} / \mathrm{A}$ & Direct & Insufficient & No conclusion made \\
\hline & & & Low birth weight & $1(3368)$ & High & $\mathrm{N} / \mathrm{A}$ & $\mathrm{N} / \mathrm{A}$ & Direct & Insufficient & No conclusion made \\
\hline & & & Congenital anomalies & $1(3368)$ & High & $\mathrm{N} / \mathrm{A}$ & $\mathrm{N} / \mathrm{A}$ & Direct & Insufficient & No conclusion made \\
\hline & $\begin{array}{l}\text { Any ergot product } \\
\text { vs. pizotifen } \\
\text { (during pregnancy) }\end{array}$ & $\begin{array}{l}\text { AEs - } \\
\text { Fetal/Child }\end{array}$ & Congenital anomalies & $1(5900)$ & High & $\mathrm{N} / \mathrm{A}$ & $\mathrm{N} / \mathrm{A}$ & Direct & Insufficient & No conclusion made \\
\hline
\end{tabular}




\begin{tabular}{|c|c|c|c|c|c|c|c|c|c|c|}
\hline Topic & Comparison & $\begin{array}{l}\text { Outcome } \\
\text { Category }\end{array}$ & Outcome & $\begin{array}{l}\text { N Studies } \\
\text { (Subjects) }\end{array}$ & RoB & Consistency & Precision & Directness & SoE & Conclusions \\
\hline \multirow[t]{12}{*}{$\begin{array}{l}\text { Harms } \\
\text { (continued) }\end{array}$} & \multirow{8}{*}{$\begin{array}{l}\text { Any triptan (during } \\
\text { pregnancy) vs. any } \\
\text { triptan (before } \\
\text { pregnancy) }\end{array}$} & $\begin{array}{l}\text { AEs - } \\
\text { Maternal }\end{array}$ & Serious AEs & $2(8460)$ & High & $\mathrm{N} / \mathrm{A}$ & $\mathrm{N} / \mathrm{A}$ & Direct & Insufficient & No conclusion made \\
\hline & & \multirow{7}{*}{$\begin{array}{l}\text { AEs - } \\
\text { Fetal/Child }\end{array}$} & Stillbirth or fetal death & $1(5900)$ & High & $\mathrm{N} / \mathrm{A}$ & $\mathrm{N} / \mathrm{A}$ & Direct & Insufficient & No conclusion made \\
\hline & & & Neonatal or infant death & $1(5900)$ & High & $\mathrm{N} / \mathrm{A}$ & N/A & Direct & Insufficient & No conclusion made \\
\hline & & & Preterm birth & $2(8460)$ & High & $\mathrm{N} / \mathrm{A}$ & $\mathrm{N} / \mathrm{A}$ & Direct & Insufficient & No conclusion made \\
\hline & & & Low birth weight & $2(8460)$ & High & $\mathrm{N} / \mathrm{A}$ & $\mathrm{N} / \mathrm{A}$ & Direct & Insufficient & No conclusion made \\
\hline & & & Congenital anomalies & $2(8460)$ & High & $\mathrm{N} / \mathrm{A}$ & $\mathrm{N} / \mathrm{A}$ & Direct & Insufficient & No conclusion made \\
\hline & & & Perinatal complications & $2(8460)$ & High & $\mathrm{N} / \mathrm{A}$ & $\mathrm{N} / \mathrm{A}$ & Direct & Insufficient & No conclusion made \\
\hline & & & $\begin{array}{l}\text { Neurodevelopmental/ } \\
\text { behavioral/social AEs }\end{array}$ & $1(5900)$ & High & $\mathrm{N} / \mathrm{A}$ & Imprecise & Direct & Low & $\begin{array}{l}\text { Similar gross motor } \\
\text { and fine motor } \\
\text { development, but } \\
\text { worse emotionality } \\
\text { and activity } \\
\text { outcomes } \\
\text { (hyperactivity) at } 3 \\
\text { years of age for use } \\
\text { during pregnancy } \\
\text { versus before } \\
\text { pregnancy. }\end{array}$ \\
\hline & \multirow{4}{*}{$\begin{array}{l}\text { Sumatriptan } \\
\text { (during pregnancy) } \\
\text { vs. sumatriptan } \\
\text { (before pregnancy) }\end{array}$} & $\begin{array}{l}\text { AEs - } \\
\text { Maternal }\end{array}$ & Serious Maternal AEs & 1 (168) & High & $\mathrm{N} / \mathrm{A}$ & $\mathrm{N} / \mathrm{A}$ & Direct & Insufficient & No conclusion made \\
\hline & & \multirow{3}{*}{$\begin{array}{l}\text { AEs - } \\
\text { Fetal/Child }\end{array}$} & Spontaneous abortion & 1 (168) & High & $\mathrm{N} / \mathrm{A}$ & $\mathrm{N} / \mathrm{A}$ & Direct & Insufficient & No conclusion made \\
\hline & & & Preterm birth & $1(123)$ & $\begin{array}{l}\text { Mode } \\
\text { rate }\end{array}$ & $\mathrm{N} / \mathrm{A}$ & Imprecise & Direct & Insufficient & No conclusion made \\
\hline & & & Low birth weight & $1(123)$ & $\begin{array}{l}\text { Mode } \\
\text { rate }\end{array}$ & $\mathrm{N} / \mathrm{A}$ & Imprecise & Direct & Insufficient & No conclusion made \\
\hline
\end{tabular}




\begin{tabular}{|c|c|c|c|c|c|c|c|c|c|c|}
\hline Topic & Comparison & $\begin{array}{l}\text { Outcome } \\
\text { Category }\end{array}$ & Outcome & $\begin{array}{l}\text { N Studies } \\
\text { (Subjects) }\end{array}$ & RoB & Consistency & Precision & Directness & SoE & Conclusions \\
\hline \multirow[t]{9}{*}{$\begin{array}{l}\text { Harms } \\
\text { (continued) }\end{array}$} & \multirow{9}{*}{$\begin{array}{l}\text { Any triptan (during } \\
\text { pregnancy) vs. no } \\
\text { triptans (during or } \\
\text { before pregnancy) }\end{array}$} & $\begin{array}{l}\text { AEs - } \\
\text { Maternal }\end{array}$ & Serious Maternal AEs & $1(5900)$ & High & $\mathrm{N} / \mathrm{A}$ & $\mathrm{N} / \mathrm{A}$ & Indirect & Insufficient & No conclusion made \\
\hline & & \multirow[t]{8}{*}{$\begin{array}{l}\text { AEs - } \\
\text { Fetal/Child }\end{array}$} & $\begin{array}{l}\text { Spontaneous abortion or } \\
\text { elective or induced } \\
\text { abortion }\end{array}$ & 2 (1099) & High & $\mathrm{N} / \mathrm{A}$ & $\mathrm{N} / \mathrm{A}$ & Direct & Low & $\begin{array}{l}\text { No difference for } \\
\text { spontaneous or } \\
\text { elective abortion }\end{array}$ \\
\hline & & & Stillbirth or fetal death & $2(6807)$ & High & $\mathrm{N} / \mathrm{A}$ & $\mathrm{N} / \mathrm{A}$ & Direct & Insufficient & $\begin{array}{l}\text { No adjusted } \\
\text { between-arm } \\
\text { estimates available }\end{array}$ \\
\hline & & & Neonatal or infant death & $1(5900)$ & High & $\mathrm{N} / \mathrm{A}$ & $\mathrm{N} / \mathrm{A}$ & Direct & Insufficient & $\begin{array}{l}\text { No adjusted } \\
\text { between-arm } \\
\text { estimates available }\end{array}$ \\
\hline & & & Preterm birth & $1(5900)$ & High & $\mathrm{N} / \mathrm{A}$ & $\mathrm{N} / \mathrm{A}$ & Indirect & Insufficient & No conclusion made \\
\hline & & & Low birth weight & $1(5900)$ & High & $\mathrm{N} / \mathrm{A}$ & $\mathrm{N} / \mathrm{A}$ & Indirect & Insufficient & No conclusion made \\
\hline & & & Congenital anomalies & $3(6999)$ & High & $\mathrm{N} / \mathrm{A}$ & Imprecise & Direct & Low & $\begin{array}{l}\text { No difference for } \\
\text { any, major, minor, } \\
\text { and genetic birth } \\
\text { defects. } \\
\text { spontaneous or } \\
\text { elective abortion. }\end{array}$ \\
\hline & & & Perinatal complications & $1(5900)$ & High & $\mathrm{N} / \mathrm{A}$ & $\mathrm{N} / \mathrm{A}$ & Indirect & Insufficient & No conclusion made \\
\hline & & & $\begin{array}{l}\text { Neurodevelopmental/ } \\
\text { behavioral/social AEs }\end{array}$ & $1(5900)$ & High & $\mathrm{N} / \mathrm{A}$ & $\mathrm{N} / \mathrm{A}$ & Direct & Low & $\begin{array}{l}\text { Similar gross motor } \\
\text { and fine motor } \\
\text { development, but } \\
\text { worse emotionality } \\
\text { and activity } \\
\text { (hyperactivity) for } \\
\text { use during } \\
\text { pregnancy versus } \\
\text { nonuse (during or } \\
\text { before pregnancy). }\end{array}$ \\
\hline
\end{tabular}

Abbreviations: AE = adverse effect, N/A = not applicable, NS = not statistically significant, RoB = risk of bias, SoE = strength of evidence.

Consistency was deemed "N/A" when it could not be assessed because only one study was found. Consistency was also deemed "N/A" in some instances where more than one study was found because at least one of the studies did not report adjusted between-arm effect sizes, precluding an assessment of consistency.

Table B-32 provides the complete version of this Evidence Profile, including displaying outcomes for which no studies were identified. 
Table 22. Triptans: Evidence profile for existing systematic review regarding harms

\begin{tabular}{|c|c|c|c|c|c|c|c|c|c|}
\hline Drug & $\begin{array}{l}\text { Outcome } \\
\text { Category }\end{array}$ & Outcome & $\begin{array}{l}\text { N SRs } \\
\text { (N } \\
\text { Studies) }\end{array}$ & $\begin{array}{l}\text { RoB in } \\
\text { I ncluded } \\
\text { Studies }\end{array}$ & Consistency & Precision & Directness & SoE & Conclusion \\
\hline \multirow[t]{3}{*}{$\begin{array}{l}\text { Triptans, } \\
\text { any }\end{array}$} & \multirow[t]{3}{*}{$\begin{array}{l}\text { AEs - } \\
\text { Fetal/Child }\end{array}$} & $\begin{array}{l}\text { Spontaneous } \\
\text { abortion or } \\
\text { elective or } \\
\text { induced } \\
\text { abortion }\end{array}$ & $1(2)$ & Unclear & Consistent & Precise & Direct & Moderate & $\begin{array}{l}\text { No increased } \\
\text { risk of } \\
\text { spontaneous } \\
\text { abortion }\end{array}$ \\
\hline & & Preterm birth & $1(3)$ & Unclear & Inconsistent & Imprecise & Direct & Low & $\begin{array}{l}\text { No increased } \\
\text { risk }\end{array}$ \\
\hline & & $\begin{array}{l}\text { Congenital } \\
\text { anomalies }\end{array}$ & $1(3)$ & Unclear & Consistent & Precise & Direct & Moderate & $\begin{array}{l}\text { No increased } \\
\text { risk of major } \\
\text { anomalies }\end{array}$ \\
\hline
\end{tabular}

Abbreviations: $\mathrm{AE}=$ adverse effect, $\mathrm{RoB}=$ risk of bias, $\mathrm{SoE}=$ strength of evidence, $\mathrm{SR}=$ systematic review .

Table B-37 provides the complete version of this Evidence Profile, including displaying outcomes for which no evidence was identified.

\section{NSAIDs (Any, Indomethacin, and Low-Dose Aspirin)}

\section{Description of Direct Evidence for NSAIDs (Any, Indomethacin, and Low- Dose Aspirin)}

We did not find any primary studies on use of "any" NSAID or of indomethacin or low-dose aspirin for treating attacks of primary headache in women who were pregnant (or attempting to become pregnant), postpartum, or breastfeeding.

\section{Description of Indirect Evidence for NSAIDs (Any, Indomethacin, and Low- Dose Aspirin)}

Eight SRs (six of high quality $66,70,73-75,81$ and two of moderate quality ${ }^{64,67}$ ) assessed harms associated with use of any NSAID (one medium-quality SR), indomethacin (one high-quality SR), and low-dose aspirin (five high-quality SRs and one moderate-quality SR) (regardless of indication) (Tables 23 and 24 and Tables B-26, B-27, B-28, and B-37). One of these SRs (Bellos $2020 b^{64}$ ) examined NSAID use in the postpartum period; the rest examined NSAID use during pregnancy.

\section{Maternal Benefit Outcomes of NSAIDs (Any, Indomethacin, and Low-Dose} Aspirin)

No primary study or SR reported on maternal benefit outcomes of "any" NSAID or of indomethacin or low-dose aspirin.

\section{Maternal Adverse Effects of NSAIDs (Any, Indomethacin, and Low-Dose Aspirin)}

No primary study (direct evidence) reported on maternal adverse effects of "any" NSAID or of indomethacin or low-dose aspirin.

The Bellos 2020b SR (indirect evidence) reported that use of "any" NSAID in the postpartum period was not associated with postpartum hypertension.

No SR (indirect evidence) reported on maternal adverse effects of indomethacin.

Five SRs (Henderson 2014, Coomarasamy 2003, Duley 2007, Hamulyak 2020, and Maze 2019) (indirect evidence) reported that low-dose aspirin use during pregnancy was not associated 
with adverse effects antepartum (e.g., placental abruption or other antepartum bleeding), during delivery (e.g., cesarean section), or postpartum (e.g., postpartum hemorrhage).

\section{Fetal/Child Adverse Effects of NSAIDs (Any, Indomethacin, and Low-Dose Aspirin)}

No primary study (direct evidence) reported on fetal/child adverse effects of indomethacin or low-dose aspirin.

The Bellos 2020b SR (indirect evidence) did not report on fetal/child adverse effects of "any" NSAID.

The Hammers 2015 SR (indirect evidence) reported that indomethacin use during pregnancy was associated with neonatal complications, such as periventricular leukomalacia (RR 1.59, 95\% CI 1.17 to 2.17), Grade III-IV intraventricular hemorrhage (RR 1.29, 95\% CI 1.06 to 1.56), and necrotizing enterocolitis (RR 1.36, 95\% CI 1.08 to 1.71) (Table 23). Indomethacin use was not associated with neonatal mortality, sepsis, or patent ductus arteriosus.

Five SRs (indirect evidence) reported that low-dose aspirin use during pregnancy was not associated with adverse effects in utero (e.g., spontaneous abortion, fetal growth restriction), perinatal (e.g., low birth weight, small for gestational age), or during infant/child growth (e.g., gross motor function, fine motor problems, behavioral problems). The Duley 2007 SR (indirect evidence) reported that low-dose aspirin use during pregnancy was associated with hearing problems in the child, but this was not statistically significant (RR 2.54, 95\% CI 0.10 to 62.10).

Table 23. NSAIDs (indomethacin and low-dose aspirin): Summary of indirect evidence of fetal/child harms, statistically significant findings

\begin{tabular}{|l|l|l|l|l|l|l|}
\hline $\begin{array}{l}\text { SR, Year } \\
\text { Published, } \\
\text { PMI D }\end{array}$ & $\begin{array}{l}\text { Intervention } \\
\text { Class }\end{array}$ & $\begin{array}{l}\text { Intervention } \\
\text { Name }\end{array}$ & $\begin{array}{l}\text { Timing of } \\
\text { Occurrence } \\
\text { of Adverse } \\
\text { Effect }\end{array}$ & Adverse Effect & $\begin{array}{l}\text { N } \\
\text { Studies }\end{array}$ & $\begin{array}{l}\text { Effect Size (95\% } \\
\text { CI ) }\end{array}$ \\
\hline $\begin{array}{l}\text { Hammers, 2015, } \\
25448524\end{array}$ & NSAIDS & Indomethacin & Neonatal & $\begin{array}{l}\text { Periventricular } \\
\text { leukomalacia }\end{array}$ & 9 & RR 1.59 (1.17, 2.17) \\
\cline { 4 - 7 } & & & $\begin{array}{l}\text { Intraventricular } \\
\text { hemorrhage: Grade III-IV }\end{array}$ & 16 & RR 1.29 (1.06, 1.56) \\
\cline { 4 - 7 } & & & Necrotizing enterocolitis & 18 & RR 1.36 (1.08, 1.71) \\
\hline
\end{tabular}

Abbreviations: $\mathrm{CI}$ = confidence interval, IV = intravenous, NSAID = nonsteroidal antiinflammatory drug, PMID = PubMed identifier, $\mathrm{RR}=$ relative risk, $\mathrm{SR}=$ systematic review .

Low-dose aspirin was not found to be statistically significantly associated with fetal/child harms, and is thus omitted from this table. 
Table 24. NSAIDs (indomethacin and low-dose aspirin): Evidence profile for indirect evidence regarding harms of use during pregnancy

\begin{tabular}{|c|c|c|c|c|c|c|c|c|c|}
\hline Drug & $\begin{array}{l}\text { Outcome } \\
\text { Category }\end{array}$ & Outcome & $\begin{array}{l}\text { N SRs } \\
\text { (N } \\
\text { Studies) }\end{array}$ & $\begin{array}{l}\text { RoB in } \\
\text { I ncluded } \\
\text { Studies }\end{array}$ & Consistency & Precision & Directness & SoE & Conclusions \\
\hline Any & $\begin{array}{l}\text { AEs - } \\
\text { Maternal }\end{array}$ & Cardiovascular & $1(4)$ & Moderate & Consistent & Precise & Indirect & Moderate & $\begin{array}{l}\text { No increased } \\
\text { risk of } \\
\text { postpartum } \\
\text { hypertension }\end{array}$ \\
\hline \multirow[t]{3}{*}{$\begin{array}{l}\text { Indomet } \\
\text { hacin }\end{array}$} & \multirow[t]{3}{*}{$\begin{array}{l}\text { AEs - } \\
\text { Fetal/Child }\end{array}$} & $\begin{array}{l}\text { Neonatal or } \\
\text { infant death }\end{array}$ & $1(15)$ & Unclear & Consistent & Precise & Indirect & Low & $\begin{array}{l}\text { No increased } \\
\text { risk of neonatal } \\
\text { death }\end{array}$ \\
\hline & & $\begin{array}{l}\text { Congenital } \\
\text { anomalies }\end{array}$ & $1(17)$ & Unclear & Consistent & Precise & Indirect & Low & $\begin{array}{l}\text { No increased } \\
\text { risk of patent } \\
\text { ductus } \\
\text { arteriosus }\end{array}$ \\
\hline & & $\begin{array}{l}\text { Perinatal } \\
\text { complications }\end{array}$ & $1(9-18)$ & Unclear & Consistent & Precise & Indirect & Low & $\begin{array}{l}\text { Increased risk } \\
\text { of } \\
\text { periventricular } \\
\text { leukomalacia, } \\
\text { Grade III-IV } \\
\text { intraventricular } \\
\text { hemorrhage, } \\
\text { and necrotizing } \\
\text { enterocolitis }\end{array}$ \\
\hline \multirow[t]{8}{*}{$\begin{array}{l}\text { Low- } \\
\text { dose } \\
\text { aspirin }\end{array}$} & $\begin{array}{l}\text { AEs - } \\
\text { Maternal }\end{array}$ & $\begin{array}{l}\text { Any serious } \\
A E\end{array}$ & $1(3)$ & Low & Consistent & Precise & Indirect & Moderate & $\begin{array}{l}\text { No increased } \\
\text { risk of } \\
\text { hospitalization }\end{array}$ \\
\hline & \multirow[t]{7}{*}{$\begin{array}{l}\text { AEs - } \\
\text { Fetal/Child }\end{array}$} & $\begin{array}{l}\text { Spontaneous } \\
\text { abortion or } \\
\text { elective or } \\
\text { induced } \\
\text { abortion }\end{array}$ & $3(3-28)$ & $\begin{array}{l}\text { Low to } \\
\text { moderate }\end{array}$ & Consistent & Precise & Indirect & Low & $\begin{array}{l}\text { No increased } \\
\text { risk of } \\
\text { spontaneous } \\
\text { abortion }\end{array}$ \\
\hline & & $\begin{array}{l}\text { Stillbirth or } \\
\text { fetal death }\end{array}$ & $3(3-28)$ & $\begin{array}{l}\text { Low to } \\
\text { moderate }\end{array}$ & Consistent & Precise & Indirect & Low & $\begin{array}{l}\text { No increased } \\
\text { risk of stillbirth, } \\
\text { perinatal } \\
\text { mortality }\end{array}$ \\
\hline & & $\begin{array}{l}\text { Neonatal or } \\
\text { infant death }\end{array}$ & $3(3-28)$ & $\begin{array}{l}\text { Low to } \\
\text { moderate }\end{array}$ & Consistent & Precise & Indirect & Low & $\begin{array}{l}\text { No increased } \\
\text { risk of infant } \\
\text { death }\end{array}$ \\
\hline & & Preterm birth & $4(9)$ & $\begin{array}{l}\text { Low to } \\
\text { moderate }\end{array}$ & Consistent & Precise & Indirect & Low & $\begin{array}{l}\text { No increased } \\
\text { risk }\end{array}$ \\
\hline & & $\begin{array}{l}\text { Low birth } \\
\text { weight }\end{array}$ & $2(8)$ & $\begin{array}{l}\text { Low to } \\
\text { moderate }\end{array}$ & Inconsistent & Precise & Indirect & Low & $\begin{array}{l}\text { No increased } \\
\text { risk }\end{array}$ \\
\hline & & $\begin{array}{l}\text { Perinatal } \\
\text { complications }\end{array}$ & $1(8-15)$ & $\begin{array}{l}\text { Low to } \\
\text { moderate }\end{array}$ & Inconsistent & Precise & Indirect & Low & $\begin{array}{l}\text { No increased } \\
\text { risk of NICU } \\
\text { admission, } \\
\text { intraventricular } \\
\text { hemorrhage, } \\
\text { other neonatal } \\
\text { bleed }\end{array}$ \\
\hline & & $\begin{array}{l}\text { Neurodevelop } \\
\text { mental/ } \\
\text { behavioral/ } \\
\text { social }\end{array}$ & $1(1)$ & Low & $\mathrm{N} / \mathrm{A}$ & Imprecise & Indirect & Low & $\begin{array}{l}\text { No increased } \\
\text { risk of gross } \\
\text { motor, fine } \\
\text { motor, } \\
\text { language, } \\
\text { hearing, } \\
\text { speech, etc. }\end{array}$ \\
\hline
\end{tabular}

Abbreviations: AE = adverse effect, NICU = neonatal intensive care unit, NSAID = nonsteroidal antiinflammatory drug, RoB = risk of bias, $\mathrm{SoE}=$ strength of evidence, $\mathrm{SR}=$ systematic review .

Table B-37 provides the complete version of this Evidence Profile, including displaying outcomes for which no evidence was identified. 


\section{Antiemetics (Metoclopramide), Antihistamines (Diphenhydramine), and Opioid Analgesics (Codeine)}

\section{Description of Direct Evidence for Metoclopramide, Diphenhydramine, and Codeine}

One RCT, described in three articles, ${ }^{37,39,40}$ reported on the effects and harms of metoclopramide, diphenhydramine, and codeine in pregnant patients with primary headaches (Tables 25 and 26 and Tables B-1, B-2, B-7 to 9, and B-33).

Childress 2018, reported in three articles, studied 70 pregnant women with either migraine or tension headache in the U.S. ${ }^{37,39,40}$ The study did not report how many patients had migraine and how many had tension headache. Other eligibility criteria included being in the second or third trimester, normotensive, and headaches not relieved by acetaminophen. Patients were randomized to a combination of metoclopramide (a dopamine receptor antagonist antiemetic) 10 $\mathrm{mg}$ and diphenhydramine (an antihistamine) $25 \mathrm{mg}$ intravenously, as a single dose, or to codeine (an opioid-containing analgesic) $30 \mathrm{mg}$ orally, as a single dose. Patients in either arm could receive a second dose of the same intervention, if the pain was not relieved. Patients were relatively young (median age 23 years) and majority black (76\%). The median gravidity was 3 and parity 1 . The median gestational ages were 31.9 weeks in the combination arm and 28.4 weeks in the codeine arm. We assessed the study at overall high risk of bias due to lack of blinding of patients, study personnel, and outcome assessors, and due to selective outcome reporting.

\section{Description of Indirect Evidence for Diphenhydramine}

Two high-quality SRs (Etwel $2017^{72}$ and Li 201977) assessed fetal/child harms associated with (any) antihistamine use during pregnancy (regardless of indication) (Table 16 and Tables B26, B-27, B-28, and B-37). The SRs did not report maternal benefit outcomes or maternal adverse effects.

\section{Maternal Benefit Outcomes of Metoclopramide, Diphenhydramine, and Codeine}

Childress 2018 (direct evidence) reported on the effect of treatment on severity of acute headache attacks over 24 hours using a visual analog scale (VAS) from 0 to 10 (maximum pain). Patients in the combination metoclopramide and diphenhydramine treatment arm experienced greater reductions in pain than did patients in the codeine arm, as measured by the net mean difference (NMD), i.e., the between-arm difference in the within-arm changes (difference-in-difference). The NMDs were statistically significant at 30 minutes $(-3.0,95 \% \mathrm{CI}$ -4.2 to -1.8$)$, at 1 hour $(-2.1,95 \% \mathrm{CI}-3.3$ to -0.9$)$, and at 12 hours $(-1.6,95 \% \mathrm{CI}-2.9$ to -0.3 ), but not at 6 hours or 24 hours. At 24 hours, all patients in both arms experienced at least a 2-point reduction in pain on the VAS (Table 25).

Childress 2018 also reported that patients in the combination treatment arm were more likely than patients in the codeine arm to experience relief from headache with one dose (OR 1.37, 95\% CI 1.07 to 1.75) and to experience complete resolution of headache at 24 hours (OR 5.42, 95\% CI 1.86 to 15.76) (Table 25). Combination treatment also provided relief from headache 42.2 minutes sooner (95\% CI 20.7 to 63.7) than codeine treatment.

Childress 2018 also found lower recurrence of headache by 24 hours in patients in the combination treatment arm (13 of 34 patients; 38.2\%) than the codeine arm (19 of 32 patients; 
59.4\%), but the between-arm comparison was not statistically significant (OR 0.42, 95\% CI 0.16 to 1.14) (Table 25).

Childress 2018 also found lower use of nonstudy medications by 24 hours in patients in the combination treatment arm (7 of 34 patients; 20.6\%) than the codeine arm (12 of 32 patients; $37.5 \%$ ), but the between-arm comparison was not statistically significant (OR $0.43,95 \%$ CI 0.14 to 1.29 ) (Table 25).

\section{Maternal Adverse Effects of Metoclopramide, Diphenhydramine, and Codeine}

Childress 2018 (direct evidence) reported that no serious maternal adverse effects occurred within 24 hours in either arm (Table 25). Reported nonserious adverse effects included fatigue, dizziness, agitation, nausea, and intravenous site pain (Table 25). Within 24 hours, 44.1 percent of the 34 women in the combination drug arm and 31.3 percent of the 32 women in the opioid arms had nonserious adverse effects. The between-arm comparison was not statistically significant (OR 1.74, 95\% CI 0.63 to 4.76).

The Etwel 2017 and Li 2019 SRs (indirect evidence) reported that (any) antihistamine use was not associated with spontaneous abortion, stillbirth, preterm birth, low birth weight, or major congenital anomalies. 
Table 25. Combination metoclopramide and diphenhydramine versus codeine: Summary of direct evidence regarding use to treat primary headaches

\begin{tabular}{|c|c|c|c|c|c|}
\hline Outcome* $^{*}$ & Definition & $\begin{array}{l}\text { Study, Year, } \\
\text { Design, PMID }\end{array}$ & Arm & $\begin{array}{l}\mathrm{n} / \mathrm{N}(\%) \text { or Mean } \\
\text { (SD) }\end{array}$ & Effect Size $(95 \% \mathrm{Cl})$ \\
\hline \multirow{12}{*}{$\begin{array}{l}\text { Severity of acute } \\
\text { headache } \\
\text { attacks }\end{array}$} & \multirow{2}{*}{$\begin{array}{l}\text { Pain score on VAS (0-10), } 30 \\
\text { min }\end{array}$} & \multirow{24}{*}{$\begin{array}{l}\text { Childress, 2018, } \\
\text { RCT, } 29723901\end{array}$} & Comb metoclopramide \& diphenhydramine & $3.0(2.8)$ & \multirow[t]{2}{*}{ NMD - $3.0(-4.2,-1.8) \dagger$} \\
\hline & & & Codeine & $5.8(2.3)$ & \\
\hline & \multirow[t]{2}{*}{ Pain score on VAS (0-10), $1 \mathrm{hr}$} & & Comb metoclopramide \& diphenhydramine & $2.2(2.3)$ & \multirow[t]{2}{*}{ NMD - $2.1(-3.3,-0.9) \dagger$} \\
\hline & & & Codeine & $4.1(3.0)$ & \\
\hline & \multirow[t]{2}{*}{ Pain score on VAS (0-10), $6 \mathrm{hr}$} & & Comb metoclopramide \& diphenhydramine & $1.8(\mathrm{NR})$ & \multirow[t]{2}{*}{ NMD -0.9 $(-2.2,0.4) \dagger$} \\
\hline & & & Codeine & $2.5(\mathrm{NR})$ & \\
\hline & \multirow[t]{2}{*}{ Pain score on VAS (0-10), $12 \mathrm{hr}$} & & Comb metoclopramide \& diphenhydramine & $1.3(2.5)$ & \multirow[t]{2}{*}{ NMD - $1.6(-2.9,-0.3)$} \\
\hline & & & Codeine & $2.7(3.0)$ & \\
\hline & \multirow[t]{2}{*}{ Pain score on VAS (0-10), $24 \mathrm{hr}$} & & Comb metoclopramide \& diphenhydramine & $2.1(\mathrm{NR})$ & \multirow[t]{2}{*}{ NMD -1.0 (-2.3, 0.3) † } \\
\hline & & & Codeine & 2.9 (NR) & \\
\hline & \multirow{2}{*}{$\begin{array}{l}\text { Reduction }>=2 \text { on VAS }(0-10) \text {, } \\
24 \mathrm{hr}\end{array}$} & & Comb metoclopramide \& diphenhydramine & $34 / 34(100)$ & \multirow[t]{2}{*}{ No nonevents } \\
\hline & & & Codeine & $32 / 32(100)$ & \\
\hline \multirow{6}{*}{$\begin{array}{l}\text { Resolution of } \\
\text { acute headache } \\
\text { attack }\end{array}$} & \multirow[t]{2}{*}{ Relief with 1 dose } & & Comb metoclopramide \& diphenhydramine & $32 / 34(94.1)$ & \multirow[t]{2}{*}{ OR $1.37(1.07,1.75)$} \\
\hline & & & Codeine & $22 / 32(68.8)$ & \\
\hline & \multirow[t]{2}{*}{ Time to relief } & & Comb metoclopramide \& diphenhydramine & $20.2 \min (13.4)$ & \multirow[t]{2}{*}{$\mathrm{MD}-42.2 \min (-63.7,-20.7)$} \\
\hline & & & Codeine & $62.4 \min (62.2)$ & \\
\hline & \multirow[t]{2}{*}{ Complete resolution at $24 \mathrm{hr}$} & & Comb metoclopramide \& diphenhydramine & $26 / 34(76.5)$ & \multirow[t]{2}{*}{ OR $5.42(1.86,15.76)$} \\
\hline & & & Codeine & $12 / 32(37.5)$ & \\
\hline $\begin{array}{l}\text { Recurrence of } \\
\text { acute headache } \\
\text { attacks }\end{array}$ & $\begin{array}{l}\text { Recurrence of headache at } 24 \\
\mathrm{hr}\end{array}$ & & Codeine & $19 / 32(59.4)$ & OR $0.42(0.16,1.14)$ \\
\hline \multirow[t]{2}{*}{ Medication use } & \multirow[t]{2}{*}{ Use of nonstudy medication } & & Comb metoclopramide \& diphenhydramine & $7 / 34(20.6)$ & \multirow[t]{2}{*}{ OR $0.43(0.14,1.29)$} \\
\hline & & & Codeine & $12 / 32(37.5)$ & \\
\hline \multirow{2}{*}{$\begin{array}{l}\text { AEs - Maternal } \\
\text { - Serious, Any }\end{array}$} & \multirow[t]{2}{*}{ Any serious $\mathrm{AE}$} & & Comb metoclopramide \& diphenhydramine & $0 / 34(0.0)$ & \multirow[t]{2}{*}{ No events } \\
\hline & & & Codeine & $0 / 34(0.0)$ & \\
\hline $\begin{array}{l}\text { AEs - Maternal } \\
\text { - Nonserious, } \\
\text { Any }\end{array}$ & Any nonserious maternal $\mathrm{AE}$ & & $\begin{array}{l}\text { Comb metoclopramide \& diphenhydramine } \\
\text { Codeine }\end{array}$ & $\begin{array}{l}15 / 34(44.1) \\
10 / 32(31.3)\end{array}$ & OR $1.74(0.63,4.76)$ \\
\hline
\end{tabular}

Abbreviations: $\mathrm{AE}=$ adverse effect, $\mathrm{CI}=$ confidence interval, $\mathrm{Comb}=$ combination, $\mathrm{hr}=$ hours, $\mathrm{MD}=$ mean difference, min $=$ minutes, $\mathrm{NMD}=$ net mean difference, $\mathrm{NR}=$ not reported, OR = odds ratio, PMID = PubMed identifier, RCT = randomized controlled trial, $\mathrm{SD}=$ standard deviation, VAS = visual analog scale.

* No studies reported acute headache attack outcomes (duration), headache-related symptom outcomes (severity, duration, resolution, recurrence), emergency department or clinic visits, hospitalizations, quality of life, functional outcomes (impact on family life, work/school attendance, time spent managing disease), resource use, acceptability of intervention by patients, patient satisfaction with intervention, serious maternal AEs (cardiovascular), nonserious maternal AEs (nonobstetrical, preterm labor/CS, reduced breast milk, medication withdrawal symptoms), discontinuation due to maternal AEs, serious fetal/child AEs (any serious AE, spontaneous abortion or elective or induced abortion, stillbirth or fetal death, neonatal or infant death, preterm birth, low birth weight, congenital anomalies, perinatal complications, neurodevelopmental/behavioral/social), nonserious fetal/child AEs (any nonserious AE, breastfeeding delay/cessation/etc., poor infant attachment/bonding, medication withdrawal symptoms), or discontinuation due to fetal/child AEs.

† Calculated by us based on reported arm-specific data. 
Table 26. Combination metoclopramide and diphenhydramine versus codeine: Evidence profile for direct evidence regarding use to

\begin{tabular}{|c|c|c|c|c|c|c|c|c|c|c|}
\hline Topic & Comparison & $\begin{array}{l}\text { Outcome } \\
\text { Category }\end{array}$ & Outcome & $\begin{array}{l}\text { N Studies } \\
\text { (Subjects) }\end{array}$ & RoB & Consistency & Precision & Directness & SoE & Conclusion \\
\hline \multirow[t]{3}{*}{ Benefits } & \multirow{3}{*}{$\begin{array}{l}\text { Combination of } \\
\text { metoclopramide and } \\
\text { diphenhydramine vs. } \\
\text { codeine }\end{array}$} & \multirow[t]{3}{*}{$\begin{array}{l}\text { Acute headache } \\
\text { attacks }\end{array}$} & $\begin{array}{l}\text { Severity of acute } \\
\text { headache attacks }\end{array}$ & $1(70)$ & High & $\mathrm{N} / \mathrm{A}$ & Imprecise & Direct & Low & $\begin{array}{l}\text { Severity reduced more } \\
\text { in combination arm }\end{array}$ \\
\hline & & & $\begin{array}{l}\text { Resolution of } \\
\text { acute headache } \\
\text { attacks }\end{array}$ & $1(70)$ & High & $\mathrm{N} / \mathrm{A}$ & Imprecise & Direct & Low & $\begin{array}{l}\text { More and quicker } \\
\text { resolution in } \\
\text { combination arm }\end{array}$ \\
\hline & & & $\begin{array}{l}\text { Recurrence of } \\
\text { acute headache } \\
\text { attacks }\end{array}$ & $1(70)$ & High & $\mathrm{N} / \mathrm{A}$ & Imprecise & Direct & Low & $\begin{array}{l}\text { Recurrence lower in } \\
\text { combination arm, but } \\
\text { NS }\end{array}$ \\
\hline Harms & $\begin{array}{l}\text { Combination of } \\
\text { metoclopramide and } \\
\text { diphenhydramine vs. } \\
\text { codeine }\end{array}$ & AEs - Maternal & Any serious $\mathrm{AE}$ & $1(70)$ & High & N/A & Imprecise & Direct & Low & No events in either arm \\
\hline
\end{tabular}

Abbreviations: $\mathrm{AE}=$ adverse effect, N/A = not applicable, NS = not statistically significant, RoB = risk of bias, SoE = strength of evidence.

Consistency was deemed "N/A" when it could not be assessed because only one study was one found.

Table B-33 provides the complete version of this Evidence Profile, including displaying outcomes for which no studies were identified. 


\section{Antiemetics (5HT3 Antagonists)}

\section{Description of Direct Evidence for Antiemetics (5HT3 Antagonists)}

We did not find any primary studies on use of antiemetics (5HT3 antagonists) for treating attacks of primary headache in women who were pregnant (or attempting to become pregnant), postpartum, or breastfeeding.

\section{Description of Indirect Evidence for Antiemetics (5HT3 Antagonists)}

Two high-quality SRs (Kaplan $2019^{76}$ and Picot 2020 ${ }^{85}$ ) assessed harms associated with use of antiemetics (5HT3 antagonists), specifically ondansetron, during pregnancy (regardless of indication) (Tables 27 and 28 and Tables B-26, B-27, B-28, and B-37).

The search for Kaplan 2019 was conducted in 2016, while that for Picot 2020 was run in 2019. Picot 2020 was thus able to include more relevant studies than Kaplan 2019 (12 versus 9). We therefore summarize harms reported in Picot 2020.

\section{Maternal Benefit Outcomes of Antiemetics (5HT3 Antagonists)}

No primary study or SR reported on maternal benefit outcomes of antiemetics (5HT3 antagonists).

\section{Maternal Adverse Effects of Antiemetics (5HT3 Antagonists)}

No primary study or SR reported on maternal adverse effects of antiemetics (5HT3 antagonists).

\section{Fetal/Child Adverse Effects of Antiemetics (5HT3 Antagonists)}

No primary study (direct evidence) reported on fetal/child adverse effects of antiemetics (5HT3 antagonists).

The Picot 2020 SR (indirect evidence) reported that use of ondansetron was associated with various congenital anomalies, such as ventricular septum defect, hypoplastic left heart, orofacial clefts, diaphragmatic hernia, and respiratory system anomalies.

Table 27. Antiemetics (5HT3 antagonists): Summary of indirect evidence of fetal/child harms, statistically significant findings

\begin{tabular}{|c|c|c|c|c|c|c|}
\hline $\begin{array}{l}\text { SR, Year } \\
\text { Published, } \\
\text { PMI D }\end{array}$ & $\begin{array}{l}\text { Intervention } \\
\text { Class }\end{array}$ & $\begin{array}{l}\text { Intervention } \\
\text { Name }\end{array}$ & $\begin{array}{l}\text { Timing of } \\
\text { Occurrence } \\
\text { of Adverse } \\
\text { Effect }\end{array}$ & Adverse Effect & $\begin{array}{l}\mathbf{N} \\
\text { Studies }\end{array}$ & $\begin{array}{l}\text { Effect Size }(95 \% \\
\text { CI ) }\end{array}$ \\
\hline \multirow[t]{5}{*}{$\begin{array}{l}\text { Picot, 2020, } \\
32420702\end{array}$} & \multirow[t]{5}{*}{$\begin{array}{l}\text { Antiemetics: } 5 \mathrm{HT} 3 \\
\text { Antagonists }\end{array}$} & \multirow[t]{5}{*}{ Ondansetron } & \multirow[t]{5}{*}{ Neonatal } & $\begin{array}{l}\text { Congenital anomalies, } \\
\text { Ventricular septum defect }\end{array}$ & 6 & OR $1.11(1.00,1.23)$ \\
\hline & & & & $\begin{array}{l}\text { Congenital anomalies, } \\
\text { Hypoplastic left heart }\end{array}$ & 3 & OR $1.49(1.03,2.17)$ \\
\hline & & & & $\begin{array}{l}\text { Congenital anomalies, } \\
\text { Orofacial clefts (any) }\end{array}$ & 4 & OR $1.22(1.00,1.49)$ \\
\hline & & & & $\begin{array}{l}\text { Congenital anomalies, } \\
\text { Diaphragmatic hernia }\end{array}$ & 3 & OR $1.71(1.18,2.49)$ \\
\hline & & & & $\begin{array}{l}\text { Congenital anomalies, } \\
\text { Respiratory system anomalies }\end{array}$ & 2 & OR $1.13(1.01,1.27)$ \\
\hline
\end{tabular}

Abbreviations: $\mathrm{CI}$ = confidence interval, $\mathrm{OR}$ = odds ratio, $\mathrm{PMID}=$ PubMed identifier, $\mathrm{SR}$ = systematic review. 
Table 28. Antiemetics (5HT3 antagonists): Evidence profile for indirect evidence regarding harms of use during pregnancy

\begin{tabular}{|l|l|l|l|l|l|l|l|l|l|}
\hline Drug & $\begin{array}{l}\text { Outcome } \\
\text { Category }\end{array}$ & Outcome & $\begin{array}{l}\text { N SRs } \\
\text { (N } \\
\text { Studies) }\end{array}$ & $\begin{array}{l}\text { RoB in } \\
\text { Included } \\
\text { Studies }\end{array}$ & Consistency & Precision & Directness & SoE & Conclusions \\
\hline Ondansetron & $\begin{array}{l}\text { AEs - } \\
\text { Fetal/Child }\end{array}$ & $\begin{array}{l}\text { Congenital } \\
\text { anomalies }\end{array}$ & 2 (16) & Moderate & Consistent & Precise & Indirect & $\begin{array}{l}\text { Mode } \\
\text { rate }\end{array}$ & $\begin{array}{l}\text { Increased risk } \\
\text { of } \\
\text { cardiovascular } \\
\text { anomalies, } \\
\text { orofacial } \\
\text { clefts, } \\
\text { diaphragmatic } \\
\text { hernia, and } \\
\text { respiratory } \\
\text { system } \\
\text { anomalies }\end{array}$ \\
\hline
\end{tabular}

Abbreviations: $\mathrm{AE}=$ adverse effect, $\mathrm{RoB}=$ risk of bias, $\mathrm{SoE}=$ strength of evidence, $\mathrm{SR}=$ systematic review.

Table B-37 provides the complete version of this Evidence Profile, including displaying outcomes for which no evidence was identified.

\section{Antipsychotics}

\section{Description of Direct Evidence for Antipsychotics}

We did not find any primary studies on use of antipsychotics for treating attacks of primary headache in women who were pregnant (or attempting to become pregnant), postpartum, or breastfeeding.

\section{Description of Indirect Evidence for Antipsychotics}

Two SRs (one of high quality [Coughlin 2015] ${ }^{68}$ and one of moderate quality [Terrana $2015]^{86}$ ) assessed harms associated with (any) antipsychotic use during pregnancy (regardless of indication) (Tables 29 and 30 and Tables B-26, B-27, B-28, and B-37).

\section{Maternal Benefit Outcomes of Antipsychotics}

No primary study or SR reported on maternal benefit outcomes of antipsychotics.

\section{Maternal Adverse Effects of Antipsychotics}

No primary study or SR reported on maternal adverse effects of antipsychotics.

\section{Fetal/Child Adverse Effects of Antipsychotics}

No primary study (direct evidence) reported on fetal/child adverse effects of antipsychotics.

Both SRs (indirect evidence) reported that antipsychotic use was associated with increased likelihood of preterm birth (<37 weeks) (ORs approximately 1.9) and major congenital anomalies (ORs approximately 2.1). Coughlin 2015 also reported that antipsychotic use was associated somewhat lower birth weight (mean difference [MD] -58 g, CI -103 to -12) and increased likelihood of infants being small for gestational age (OR 2.44, 95\% CI 1.22 to 4.86). Terrana 2015 also reported an association for small for gestational age, but this was not statistically significant (OR 1.58, 95\% CI 0.91 to 2.74). Finally, Coughlin 2015 also reported an increased likelihood of congenital cardiovascular anomalies (OR 2.09, 95\% CI 1.50 to 2.91) (Table 29). 
Table 29. Antipsychotics: Summary of indirect evidence of fetal/child harms, statistically significant findings

\begin{tabular}{|c|c|c|c|c|c|c|}
\hline $\begin{array}{l}\text { SR, Year } \\
\text { Published, } \\
\text { PMI D } \\
\end{array}$ & $\begin{array}{l}\text { Intervention } \\
\text { Class }\end{array}$ & $\begin{array}{l}\text { Intervention } \\
\text { Name }\end{array}$ & $\begin{array}{l}\text { Timing of } \\
\text { Occurrence of } \\
\text { Adverse Effect } \\
\end{array}$ & Adverse Effect & $\begin{array}{l}\mathbf{N} \\
\text { Studies }\end{array}$ & $\begin{array}{l}\text { Effect Size (95\% } \\
\text { CI ) }\end{array}$ \\
\hline \multirow{4}{*}{$\begin{array}{l}\text { Coughlin, 2015, } \\
25932852\end{array}$} & \multirow[t]{4}{*}{ Antipsychotics } & \multirow[t]{4}{*}{ Any } & \multirow[t]{2}{*}{ Perinatal } & Preterm birth (<37 weeks) & 7 & OR $1.86(1.45,2.39)$ \\
\hline & & & & Small for gestational age & 4 & OR $2.44(1.22,4.86)$ \\
\hline & & & \multirow[t]{2}{*}{ Neonatal } & Congenital anomalies, Major & 7 & OR $2.12(1.25,3.57)$ \\
\hline & & & & $\begin{array}{l}\text { Congenital anomalies, } \\
\text { Cardiovascular }\end{array}$ & 4 & OR $2.09(1.50,2.91)$ \\
\hline
\end{tabular}

Abbreviations: $\mathrm{CI}=$ confidence interval, $\mathrm{IV}=$ intravenous, $\mathrm{MD}=$ mean difference, $\mathrm{OR}$ = odds ratio, PMID = PubMed identifier, $\mathrm{SR}=$ systematic review.

Table 30. Antipsychotics: Evidence profile for indirect evidence regarding harms of use during pregnancy

\begin{tabular}{|c|c|c|c|c|c|c|c|c|c|}
\hline Drug & $\begin{array}{l}\text { Outcome } \\
\text { Category }\end{array}$ & Outcome & $\begin{array}{l}\text { N SRs } \\
\text { (N } \\
\text { Studies) }\end{array}$ & $\begin{array}{l}\text { RoB in } \\
\text { Included } \\
\text { Studies }\end{array}$ & Consistency & Precision & Directness & SoE & Conclusions \\
\hline \multirow[t]{5}{*}{$\begin{array}{l}\text { Antipsychotics, } \\
\text { any }\end{array}$} & \multirow[t]{5}{*}{$\begin{array}{l}\text { AEs - } \\
\text { Fetal/Child }\end{array}$} & $\begin{array}{l}\text { Spontaneous } \\
\text { abortion or } \\
\text { elective or } \\
\text { induced } \\
\text { abortion }\end{array}$ & $2(7)$ & Moderate & Inconsistent & Precise & Indirect & Low & $\begin{array}{l}\text { No increased } \\
\text { risk of } \\
\text { spontaneous } \\
\text { abortion }\end{array}$ \\
\hline & & $\begin{array}{l}\text { Stillbirth or } \\
\text { fetal }\end{array}$ & $2(7)$ & Moderate & Inconsistent & Precise & Indirect & Low & $\begin{array}{l}\text { No increased } \\
\text { risk of stillbirth }\end{array}$ \\
\hline & & Preterm birth & $2(7)$ & Moderate & Consistent & Precise & Indirect & $\begin{array}{l}\text { Moder } \\
\text { ate }\end{array}$ & $\begin{array}{l}\text { Increased } \\
\text { preterm birth }\end{array}$ \\
\hline & & $\begin{array}{l}\text { Low birth } \\
\text { weight }\end{array}$ & $2(3)$ & Moderate & Consistent & Precise & Indirect & $\begin{array}{l}\text { Moder } \\
\text { ate }\end{array}$ & $\begin{array}{l}\text { Increased risk } \\
\text { of low birth } \\
\text { weight, small } \\
\text { for gestational } \\
\text { age }\end{array}$ \\
\hline & & $\begin{array}{l}\text { Congenital } \\
\text { anomalies }\end{array}$ & $2(4-7)$ & Moderate & Inconsistent & Precise & Indirect & Low & $\begin{array}{l}\text { Increased } \\
\text { major and } \\
\text { cardiovascular } \\
\text { anomalies }\end{array}$ \\
\hline
\end{tabular}

Abbreviations: $\mathrm{AE}=$ adverse effect, $\mathrm{RoB}=$ risk of bias, $\mathrm{SoE}=$ strength of evidence, $\mathrm{SR}=$ systematic review.

Table B-37 provides the complete version of this Evidence Profile, including displaying outcomes for which no evidence was identified.

\section{Corticosteroids}

\section{Description of Direct Evidence for Corticosteroids}

We did not find any primary studies on use of corticosteroids for preventing attacks of primary headache in women who were pregnant (or attempting to become pregnant), postpartum, or breastfeeding.

\section{Description of Indirect Evidence for Corticosteroids}

One high-quality SR (Park-Wyllie 2000) assessed harms associated with use of corticosteroids, specifically prednisolone, during pregnancy (regardless of indication) (Tables 14 and 15 and Tables B-26, B-27, B-28, and B-37). ${ }^{84}$

\section{Maternal Benefit Outcomes of Corticosteroids}

No primary study or SR reported on maternal benefit outcomes of corticosteroids. 


\section{Maternal Adverse Effects of Corticosteroids}

No primary study or SR reported on maternal adverse effects of corticosteroids.

\section{Fetal/Child Adverse Effects of Corticosteroids}

No primary study (direct evidence) reported on fetal/child adverse effects of corticosteroids.

The Park-Wyllie 2000 SR (indirect evidence) reported that prednisolone use was associated with increased likelihood of oral clefts (OR 3.35, 95\% CI 1.97 to 5.69), but not other major congenital anomalies (Table 14).

\section{Analgesics/Antipyretics}

\section{Description of Direct Evidence for Analgesics/Antipyretics}

We did not find any primary studies on use of analgesics/antipyretics for treating attacks of primary headache in women who were pregnant (or attempting to become pregnant), postpartum, or breastfeeding.

\section{Description of Indirect Evidence for Analgesics/Antipyretics}

One moderate-quality SR (Masarwa 2018) assessed harms associated with analgesic/antipyretic, specifically acetaminophen, use during pregnancy (regardless of indication) (Tables 31 and 32 and Tables B-26, B-27, B-28, and B-37). ${ }^{80}$

\section{Maternal Benefit Outcomes of Analgesics/Antipyretics}

No primary study or SR reported on maternal benefit outcomes of analgesics/antipyretics.

\section{Maternal Adverse Effects of Analgesics/Antipyretics}

No primary study or SR reported on maternal adverse effects of analgesics/antipyretics.

\section{Fetal/Child Adverse Effects of Analgesics/Antipyretics}

No primary study (direct evidence) reported on fetal/child adverse effects of corticosteroids.

The Masarwa 2018 SR (indirect evidence) reported that acetaminophen use was associated with attention deficit hyperactivity disorder (RR 1.34, 95\% CI 1.21 to 1.47), hyperactivity symptoms (RR 1.24, 95\% CI 1.04 to 1.43), autism spectrum disorder (RR 1.19, 95\% CI 1.14 to 1.25 ), and conduct disorder (RR 1.23, 95\% CI 1.04 to 1.42) (Table 31). No other harms were reported in this SR.

Table 31. Analgesics/antipyretics (acetaminophen): Summary of indirect evidence of fetal/child harms, statistically significant findings

\begin{tabular}{|c|c|c|c|c|c|c|}
\hline $\begin{array}{l}\text { SR, Year } \\
\text { Published, } \\
\text { PMI D }\end{array}$ & $\begin{array}{l}\text { Intervention } \\
\text { Class }\end{array}$ & $\begin{array}{l}\text { Intervention } \\
\text { Name }\end{array}$ & $\begin{array}{l}\text { Timing of } \\
\text { Occurrence of } \\
\text { Adverse Effect }\end{array}$ & Adverse Effect & $\begin{array}{l}\text { N } \\
\text { Studie } \\
\text { S }\end{array}$ & $\begin{array}{l}\text { Effect Size (95\% } \\
\mathrm{CI})\end{array}$ \\
\hline \multirow[t]{4}{*}{$\begin{array}{l}\text { Masarwa, 2018, } \\
29688261\end{array}$} & \multirow[t]{4}{*}{$\begin{array}{l}\text { Analgesic/ } \\
\text { Antipyretic }\end{array}$} & \multirow[t]{4}{*}{ Acetaminophen } & \multirow[t]{4}{*}{ Child } & $\begin{array}{l}\text { Attention deficit } \\
\text { hyperactivity disorder }\end{array}$ & 6 & RR $1.34(1.21,1.47)$ \\
\hline & & & & Hyperactivity symptoms & 4 & RR $1.24(1.04,1.43)$ \\
\hline & & & & Autism spectrum disorder & 5 & RR $1.19(1.14,1.25)$ \\
\hline & & & & Conduct disorder & 4 & RR $1.23(1.04,1.42)$ \\
\hline
\end{tabular}

Abbreviations: $\mathrm{CI}$ = confidence interval, PMID = PubMed identifier, RR = relative risk, SR = systematic review. 
Table 32. Analgesics/antipyretics (acetaminophen): Evidence profile for indirect evidence of fetal/child harms, statistically significant findings

\begin{tabular}{|c|c|c|c|c|c|c|c|c|c|}
\hline Drug & $\begin{array}{l}\text { Outcome } \\
\text { Category }\end{array}$ & Outcome & $\begin{array}{l}\text { N SRs } \\
\text { (N } \\
\text { Studies) }\end{array}$ & $\begin{array}{l}\text { RoB in } \\
\text { Included } \\
\text { Studies }\end{array}$ & Consistency & Precision & Directness & SoE & Conclusions \\
\hline Acetaminophen & $\begin{array}{l}\text { AEs - } \\
\text { Fetal/Child }\end{array}$ & $\begin{array}{l}\text { Neuro- } \\
\text { developmental/ } \\
\text { behavioral/ } \\
\text { social }\end{array}$ & $1(4-6)$ & Moderate & Inconsistent & Precise & Indirect & Low & $\begin{array}{l}\text { Increased } \\
\text { attention deficit } \\
\text { hyperactivity } \\
\text { disorder, } \\
\text { hyperactivity } \\
\text { symptoms, } \\
\text { autism } \\
\text { spectrum } \\
\text { disorder, and } \\
\text { conduct } \\
\text { disorder }\end{array}$ \\
\hline
\end{tabular}

Abbreviations: $\mathrm{AE}$ = adverse effect, $\mathrm{RoB}$ = risk of bias, SoE = strength of evidence, $\mathrm{SR}$ = systematic review.

Table B-37 provides the complete version of this Evidence Profile, including displaying outcomes for which no evidence was identified.

\section{Intravenous Magnesium}

\section{Description of Direct Evidence for Intravenous Magnesium}

We did not find any primary studies on use of intravenous magnesium for treating attacks of primary headache in women who were pregnant (or attempting to become pregnant), postpartum, or breastfeeding.

\section{Description of Indirect Evidence for Intravenous Magnesium}

One high-quality SR (Bain 2014) assessed harms associated with intravenous magnesium sulphate use during pregnancy (regardless of indication) (Tables 33 and 34 and Tables B-26, B27, B-28, and B-37). ${ }^{63}$

\section{Maternal Benefit Outcomes of Intravenous Magnesium}

No primary study or SR reported on maternal benefit outcomes of intravenous magnesium.

\section{Maternal Adverse Effects of Intravenous Magnesium}

The Bain 2014 SR (indirect evidence) reported that, compared with patients who had not been prescribed intravenous magnesium, those who had were more likely to experience an adverse effect (RR 4.62, 95\% CI 2.42 to 8.83) and to discontinue the intervention due to adverse effects (RR 2.77, 95\% CI 2.32 to 3.30). Adverse effects with notable effect sizes included flushing and/or warmth (RR 6.94, 95\% CI 4.19 to 11.49), muscle weakness (RR 15.81, 95\% CI 7.36 to 33.96), and sweating (RR 6.37, 95\% CI 1.96 to 20.65) (Table 33). Intravenous magnesium use was not associated with increased incidence of cesarean section or postpartum hemorrhage.

\section{Fetal/Child Adverse Effects of Intravenous Magnesium}

No primary study or SR reported on fetal/child adverse effects of intravenous magnesium. 
Table 33. Intravenous magnesium: Summary of indirect evidence of maternal harms, statistically significant findings

\begin{tabular}{|c|c|c|c|c|c|c|}
\hline $\begin{array}{l}\text { SR, Year } \\
\text { Published, } \\
\text { PMI D }\end{array}$ & $\begin{array}{l}\text { Intervention } \\
\text { Class }\end{array}$ & $\begin{array}{l}\text { Intervention } \\
\text { Name }\end{array}$ & $\begin{array}{l}\text { Timing of } \\
\text { Occurrence of } \\
\text { Adverse Effect }\end{array}$ & Adverse Effect & $\begin{array}{l}\mathbf{N} \\
\text { Studies }\end{array}$ & $\begin{array}{l}\text { Effect Size }(95 \% \\
\text { CI ) }\end{array}$ \\
\hline \multirow{15}{*}{$\begin{array}{l}\text { Bain, 2013, } \\
24139447\end{array}$} & \multirow{15}{*}{$\begin{array}{l}\text { Intravenous } \\
\text { magnesium }\end{array}$} & \multirow{15}{*}{$\begin{array}{l}\text { Intravenous } \\
\text { magnesium } \\
\text { sulphate }\end{array}$} & \multirow{15}{*}{ NR } & Any adverse effect & 4 & RR $4.62(2.42,8.83)$ \\
\hline & & & & $\begin{array}{l}\text { Discontinuation due to } \\
\text { adverse effects }\end{array}$ & 5 & RR $2.77(2.32,3.30)$ \\
\hline & & & & $\begin{array}{l}\text { Respiratory depression/ } \\
\text { other respiratory problems }\end{array}$ & 5 & RR $1.41(1.07,1.86)$ \\
\hline & & & & Hypotension & 3 & RR $1.52(1.10,2.11)$ \\
\hline & & & & Tachycardia & 1 & RR $1.53(1.03,2.29)$ \\
\hline & & & & Flushing and/or warmth & 5 & RR $6.94(4.19,11.49)$ \\
\hline & & & & Nausea and/or vomiting & 4 & RR $5.50(2.29,13.22)$ \\
\hline & & & & Muscle weakness & 3 & RR $15.81(7.36,34.0)$ \\
\hline & & & & Drowsiness or confusion & 3 & RR $2.46(1.83,3.29)$ \\
\hline & & & & Headache & 2 & RR $2.21(1.27,3.86)$ \\
\hline & & & & Thirst or mouth dryness & 2 & RR $2.38(1.59,3.56)$ \\
\hline & & & & Dizziness & 2 & RR $2.62(1.63,4.21)$ \\
\hline & & & & Sweating & 2 & RR $6.37(1.96,20.65)$ \\
\hline & & & & Itching and/or tingling & 1 & RR $14.5(2.0,113.4)$ \\
\hline & & & & Blurred vision & 1 & RR $2.34(1.32,4.14)$ \\
\hline
\end{tabular}

Abbreviations: $\mathrm{CI}=$ confidence interval, $\mathrm{NR}=$ not reported, PMID $=$ PubMed identifier, $\mathrm{RR}=$ relative risk, $\mathrm{SR}=$ systematic review.

Table 34. Intravenous magnesium: Evidence profile for indirect evidence regarding harms of use during pregnancy

\begin{tabular}{|c|c|c|c|c|c|c|c|c|c|}
\hline Drug & $\begin{array}{l}\text { Outcome } \\
\text { Category }\end{array}$ & Outcome & $\begin{array}{l}\text { N SRs } \\
\text { (N } \\
\text { Studies) }\end{array}$ & $\begin{array}{l}\text { RoB in } \\
\text { I ncluded } \\
\text { Studies }\end{array}$ & Consistency & Precision & Directness & SoE & Conclusions \\
\hline \multirow[t]{3}{*}{$\begin{array}{l}\text { IV } \\
\text { magnesium }\end{array}$} & \multirow[t]{3}{*}{$\begin{array}{l}\text { AEs - } \\
\text { Maternal }\end{array}$} & $\begin{array}{l}\text { Any serious } \\
A E\end{array}$ & $1(4-5)$ & Unclear & Unclear & Precise & Indirect & Low & $\begin{array}{l}\text { Increased } \\
\text { respiratory } \\
\text { depression/other } \\
\text { respiratory } \\
\text { problems, but no } \\
\text { increased risk of } \\
\text { increased } \\
\text { respiratory arrest } \\
\text { or death }\end{array}$ \\
\hline & & Cardiovascular & $1(4-5)$ & Unclear & Unclear & Imprecise & Indirect & Low & $\begin{array}{l}\text { Increased } \\
\text { hypotension, } \\
\text { tachycardia, but } \\
\text { no increased risk } \\
\text { of increased } \\
\text { cardiac arrest or } \\
\text { death }\end{array}$ \\
\hline & & $\begin{array}{l}\text { Discontinuatio } \\
\mathrm{n} \text { due to } \mathrm{AEs}\end{array}$ & $1(5)$ & Unclear & Unclear & Precise & Indirect & Low & $\begin{array}{l}\text { Increased } \\
\text { discontinuation } \\
\text { due to } A E s\end{array}$ \\
\hline
\end{tabular}

Abbreviations: AE = adverse effect, IV = intravenous, RoB = risk of bias, SoE = strength of evidence, SR = systematic review.

Table B-37 provides the complete version of this Evidence Profile, including displaying outcomes for which no evidence was identified.

\section{Other Pharmacologic Interventions for KQ 2}

We did not find any direct evidence (i.e., primary studies) or indirect evidence (i.e., SRs regardless of indication) for the following pharmacologic interventions for treating attacks of primary headaches in women who are pregnant (or attempting to become pregnant), postpartum, or breastfeeding: central nervous system stimulants, muscle relaxants, butalbital-containing 
analgesics, sympathomimetic amines, topical anesthetics, somatostatin analogs, and over-thecounter analgesics.

\section{Key Question 2: Nonpharmacologic Interventions To Treat Attacks of Primary Headache}

\section{Complementary, Behavioral, and Physical Therapies}

\section{Description of Direct Evidence for Complementary, Behavioral, and Physical Therapies}

We found four studies (two RCTs ${ }^{38,41}$ and two single-group studies ${ }^{38,60,61}$ ) that reported on the benefits and harms of complementary, behavioral, and physical therapies in a total of 92 pregnant patients with primary headaches (Tables 35 and 36 and Table B-34).

Silva 2012 was an RCT of 43 pregnant women experiencing attacks of tension headaches in Brazil. ${ }^{41}$ Eligibility criteria included being 15 to 30 weeks of gestation and experiencing tension headache of at least 4 on a VAS of 0 to 10 (maximum pain). Patients were randomized to either complementary therapy (acupuncture through 15 needles of $40 \mathrm{~mm}$ length and $0.2 \mathrm{~mm}$ diameter for 25 min, once a week for 8 weeks; 20 patients) or conventional treatment (routine care; 23 patients). The arms were similar in terms of age (mean 27.3 and 25.3 years in the acupuncture and routine care arms, respectively), gestational age (mean 19.8 and 19.4 years, respectively), gravidity (mean 2 each), and parity (mean 1 each). Race distributions were not reported. We assessed the study at overall high risk of bias because the random sequence generation process was not reported, and patients, study personnel, and outcome assessors were not blinded.

The second study described in Marcus 1995, hereafter called Marcus (Study 2) 1995, was an RCT of 25 pregnant women experiencing attacks of either migraine (nine patients), tension headache (seven patients), or coexisting migraine and tension headache (nine patients) in the U.S. ${ }^{38}$ Other eligibility criteria included being in the second or third trimester and experiencing at least one headache attack a week or at least five headache attacks a month. Patients were randomized to either of two arms: (1) a combination of complementary therapy (thermal biofeedback), behavioral therapy (relaxation therapy), and physical therapy; and (2) complementary therapy (thermal biofeedback) only. In both arms, sessions lasted for 1 hour and occurred four times over the course of 2 months. The arms were similar in terms of age (mean 28.6 and 29.2 years in the combination and complementary only arms, respectively) and gestational age (mean 17.6 and 19.8 years, respectively). Race, trimester, gravidity, and parity distributions were not reported. We assessed the study at overall high risk of bias because the random sequence generation and allocation concealment processes were not reported; patients, study personnel, and outcome assessors (for subjective outcomes) were not blinded; and there was incomplete outcome data.

The first study described in Marcus $1995^{38}$ (and in another article ${ }^{61}$ ), hereafter called Marcus (Study 1) 1995, was a prospective single-group study of 19 pregnant women in the U.S.

Participating women were experiencing attacks of either migraine (15 patients), tension headache (three patients), or coexisting migraine and tension headache (one patient). The patients received the same intervention as arm 1 in Marcus (Study 1) 1995 (i.e., a combination of complementary therapy [thermal biofeedback], behavioral therapy [relaxation therapy], and physical therapy); sessions lasted for 1 hour and occurred four times over the course of 2 months. The mean patient 
and gestational ages were 31.7 years and 17.7 weeks, respectively. Race, trimester, gravidity, and parity distributions were not reported. We assessed the study at overall low risk of bias.

Hickling 1990 was a prospective single-group study of five pregnant women with migraine in their first or second trimester in the U.S. ${ }^{60}$ The patients received a combination of complementary therapy (thermal biofeedback) and behavioral therapy (muscle relaxation); sessions occurred 4 to 12 times. The mean patient age and parity were 34 years and 1 , respectively. One patient (20\%) was in her first trimester and four patients were in their second trimester. Race, gestational age, and gravidity distributions were not reported. We assessed the study at overall low risk of bias.

We have organized the rest of this section on complementary, behavioral, and physical therapies (direct evidence) by type of complementary therapy. First, we discuss the study that compared use versus nonuse of acupuncture. Next, we discuss the two studies that addressed the combination of thermal biofeedback, relaxation therapy, and physical therapy. Finally, we discuss the study that addressed the combination of thermal biofeedback and relaxation therapy.

\section{Description of Indirect Evidence for Complementary, Behavioral, and Physical Therapies}

We did not identify any SRs of complementary, behavioral, and physical therapies in pregnancy (indirect evidence).

\section{Acupuncture Use Versus Nonuse}

\section{Description of Direct Evidence for Acupuncture Use Versus Nonuse}

One RCT (Silva 2012) compared acupuncture use versus nonuse in 43 pregnant patients with migraine (Tables B-17 to B-19). ${ }^{41}$ Silva 2012 reported maternal benefit outcomes as well fetal/child adverse effects.

\section{Description of Indirect Evidence for Acupuncture Use Versus Nonuse}

We did not identify any SR (indirect evidence).

\section{Maternal Benefit Outcomes of Acupuncture Use Versus Nonuse}

Silva 2012 (direct evidence) reported the effect of acupuncture on severity of acute headache attacks using a VAS from 0 to 10 (maximum pain). Compared with patients receiving routine care, patients receiving acupuncture experienced a greater reduction in severity of pain (MD 2.2, 95\% CI 0.3 to 4.7) and were more likely to experience a reduction of average pain intensity by 25 percent or more (OR 4.36, 95\% CI 1.11 to 17.13) (Table 35).

Silva 2012 also reported that, compared with patients receiving routine care, patients receiving acupuncture had a greater reduction in number of acetaminophen doses used (MD $5.4,95 \%$ CI 1.3 to 9.5 ) and were more likely to reduce their acetaminophen by 50 percent or more (OR 6.61, 95\% CI 1.74 to 25.1) (Table 35).

\section{Maternal Adverse Acupuncture Use Versus Nonuse}

No primary study or SR reported on maternal adverse effects of acupuncture use.

\section{Fetal/Child Adverse Effects of Acupuncture Use Versus Nonuse}

Silva 2012 (direct evidence) reported that birth weight was similar in infants of patients treated and not treated with acupuncture (MD 98 g, 95\% CI -141 to 336) (Table 35). 
Silva 2012 also reported that Apgar scores were similar in infants of patients treated and not treated with acupuncture, both at 1 minute (MD 0, 95\% CI -0.5 to 0.5) and 5 minutes after birth (MD 0, 95\% CI -0.1 to 0.1) (Table 35).

\section{Combination Thermal Biofeedback, Relaxation Therapy, and Physical Therapy}

\section{Description of Direct Evidence for Combination Thermal Biofeedback, Relaxation Therapy, and Physical Therapy}

Two studies, one RCT (Marcus [Study 2] 1995 ${ }^{38}$ ) and one single-group study (Marcus [Study 1] $1995^{38,61}$ ) addressed the use of a combination of thermal biofeedback, relaxation therapy, and physical therapy in a total of 44 patients with migraine and/or tension headache (Table 7). Both studies reported on maternal benefit outcomes, but neither study reported maternal or fetal/child adverse effects.

\section{Description of Indirect Evidence for Combination Thermal Biofeedback, Relaxation Therapy, and Physical Therapy \\ We did not identify any SR (indirect evidence).}

\section{Maternal Benefit Outcomes of Combination of Thermal Biofeedback, Relaxation Therapy, and Physical Therapy}

Both studies (direct evidence) reported on severity of headache using the VAS (0 to 10) and the Headache Index. ${ }^{38,61}$ Marcus [Study 2] 1995 (the RCT) reported that at the 2-month timepoint, compared with patients only receiving thermal biofeedback, patients receiving the combination treatment experienced a greater reduction in their worst headache score in the past 2 weeks (NMD -3.4, 95\% CI -5.61 to -1.19) and in the number of days in the past 2 weeks with a headache of at least 1 on the VAS (NMD -5.60, 95\% CI -8.74 to -2.46). However, the arms were similar in terms of reductions in their average headache score over the past weeks (using the Headache Index) (NMD -0.86, 95\% CI -1.95 to 0.23). Marcus [Study 1] 1995 (the single-group study) also reported reductions in these three measures of pain at 2 months, and that 79 percent of patients had significant improvements in pain score (Table 35).

Marcus [Study 2] 1995 (direct evidence), the RCT, reported that the likelihood of using any medication for headache at 2 months was similar between patients receiving the combination treatment and those only receiving thermal biofeedback (OR 0.50, 95\% CI 0.09 to 2.73) (Table 35).

\section{Maternal Adverse Effects of Combination of Thermal Biofeedback, Relaxation Therapy, and Physical Therapy}

No primary study or SR reported on maternal adverse effects.

\section{Fetal/Child Adverse Effects of Combination of Thermal Biofeedback, Relaxation Therapy, and Physical Therapy \\ No primary study or SR reported on fetal/child adverse effects.}




\section{Combination Thermal Biofeedback and Relaxation Therapy}

\section{Description of Direct Evidence for Combination Thermal Biofeedback and Relaxation Therapy}

One study (Hickling 1990), a single-group study, reported on the use of a combination of thermal biofeedback and relaxation therapy in five pregnant patients with migraine (Tables B-20 to B-22). ${ }^{60}$ The study only reported maternal benefit outcomes.

\section{Description of Indirect Evidence for Combination Thermal Biofeedback and Relaxation Therapy \\ We did not identify any SR (indirect evidence).}

\section{Description of Direct Evidence for Maternal Benefit Outcomes of Combination Thermal Biofeedback and Relaxation Therapy}

Hickling 1990 (direct evidence) reported on the severity of headache using an atypical VAS of 0 to 5 (maximum pain). The mean average pain score of patients' worst headache reduced from 2.9 before the intervention to 0.5 and 0.3 after the intervention and after delivery, respectively. The mean worst headache score reduced from 3.9 before the intervention to 0.6 and 0.9 after the intervention and after delivery, respectively (Table 35).

Hickling 1990 reported that the mean duration of headache reduced from 20.6 hours before the intervention to 1.2 hours and 4.8 hours after the intervention and after delivery, respectively (Table 35).

Hickling 1990 reported that the mean number of headache-free days per week increased from 2.8 before the intervention to 7, both after the intervention and after delivery (Table 35).

\section{Maternal Adverse Effects of Combination Thermal Biofeedback and Relaxation Therapy}

No primary study or SR reported on maternal adverse effects.

\section{Fetal/Child Adverse Effects of Combination Thermal Biofeedback and Relaxation Therapy}

No primary study or SR reported on fetal/child adverse effects.

\section{Procedures}

\section{Description of Direct Evidence for Procedures}

We found only one study, a retrospective single-group study, that reported the effects and harms of nerve blocks in 13 pregnant patients with migraine in the U.S. (Tables 35 and 36 and Tables B-20, B-21, B-22, and B-35). ${ }^{25}$ Govindappagari 2014 studied patients who had previously tried other forms of treatment that failed. Patients received greater occipital, auriculotemporal, supraorbital, and supratrochlear nerve injections with local anesthetics (1-2\% lidocaine or 0.5\% bupivacaine). The mean age of patients was 28 years, but their race and gravidity were not reported. The mean gestational age of the patients was 23.5 weeks. Most women (61.5\%) were nulliparous. We assessed the study at overall low risk of bias.

\section{Description of Indirect Evidence for Procedures}

We did not identify any SR (indirect evidence). 


\section{Maternal Benefit Outcomes of Procedures}

Govindappagari 2014 (direct evidence) reported on the effect of peripheral nerve blocks on severity of acute headache attacks using a VAS from 0 to 10 (maximum pain). Compared with baseline, the severity of pain was significantly lower both immediately after the procedure (mean change -4.0, standard deviation [SD] 2.6) and at 24 hours (mean change -4.0, SD 4.4) (Table 35).

\section{Maternal Adverse Effects of Procedures}

Govindappagari 2014 (direct evidence) reported that none of the 13 patients who received nerve blocks experienced serious adverse effects immediately post-procedure (Table 35).

One of the 13 patients who received nerve blocks (7.7\%) experienced a vasovagal syncopal episode with nausea immediately post-procedure (Table 35).

\section{Fetal/Child Adverse Effects of Procedures}

Govindappagari 2014 (direct evidence) reported that infants of two of the 13 patients (15.3\%) were born preterm (Table 35).

\section{Noninvasive Neuromodulation Devices}

\section{Description of Direct Evidence for Noninvasive Neuromodulation Devices}

We found only one study, a prospective single-group study, that reported the effects and harms of transcranial magnetic stimulation in three pregnant patients with migraine in the U.K. (Tables 35 and 36 and Tables B-23, B-24, and B-36). ${ }^{58}$ Bhola 2015 studied patients who had previously tried other forms of treatment that failed. Patients received up to two pulses of transcranial (over the back of the head) magnetic stimulation of $0.9 \mathrm{~T}$. Pulses were separated by at least 15 minutes. Patients could receive up to 16 single pulses or eight double pulses per day, on as many migraine days as needed. The mean age of patients was 30.3 years, and all were in their second trimester, but mean gestational age was not reported. Patient race, gravidity, and parity status were also not reported. We assessed the study at overall moderate risk of bias.

\section{Description of Indirect Evidence for Noninvasive Neuromodulation Devices}

We did not identify any SR (indirect evidence).

\section{Maternal Benefit Outcomes of Noninvasive Neuromodulation Devices}

Bhola 2015 (direct evidence) reported that all three patients who received transcranial magnetic stimulation experienced resolution of their acute migraine (Table 35).

All three patients who received transcranial magnetic stimulation experienced resolution of their acute migraine-related symptoms (Table 35).

\section{Maternal Adverse Effects of Noninvasive Neuromodulation Devices}

Bhola 2015 (direct evidence) reported that none of the three patients who received transcranial magnetic stimulation experienced adverse effects (Table 35).

\section{Fetal/Child Adverse Effects of Noninvasive Neuromodulation Devices}

No primary study or SR reported on fetal/child adverse effects. 
Table 35. Nonpharmacologic interventions: Summary of direct evidence regarding use to treat primary headaches

\begin{tabular}{|c|c|c|c|c|c|c|}
\hline Outcome* $^{*}$ & Outcome Measurement & Time-Point & Study, Year, Design, PMID & Intervention(s) & $\begin{array}{l}\text { n/N (\%) or } \\
\text { Mean (SD) }\end{array}$ & $\begin{array}{l}\text { Effect Size (95\% Cl) or } \\
\text { Effect Size (SD) }\end{array}$ \\
\hline \multirow{25}{*}{$\begin{array}{l}\text { Severity of acute } \\
\text { headache attacks }\end{array}$} & \multirow{2}{*}{$\begin{array}{l}\text { Reduction in pain on a VAS (0- } \\
\text { 10) }\end{array}$} & \multirow[t]{2}{*}{$8 \mathrm{wk}$} & \multirow[t]{4}{*}{ Silva, 2012, RCT, no PMID } & Acupuncture & $3.9(3.4)$ & \multirow[t]{2}{*}{ MD $2.2(0.3,4.7)$} \\
\hline & & & & Routine care & $1.7(4.4)$ & \\
\hline & \multirow{2}{*}{$\begin{array}{l}25 \% \text { reduction in pain on a } \\
\text { VAS (0 to } 10)\end{array}$} & \multirow[t]{2}{*}{$8 \mathrm{wk}$} & & Acupuncture & $16 / 20(80.0)$ & \multirow[t]{2}{*}{ OR $4.36(1.11,17.13)$} \\
\hline & & & & Routine care & $11 / 23(47.8)$ & \\
\hline & \multirow[t]{2}{*}{$\begin{array}{l}\text { Worst pain score on a VAS (0- } \\
10) \text { in past } 2 \mathrm{wk}\end{array}$} & \multirow[t]{2}{*}{$2 \mathrm{mo}$} & \multirow[t]{2}{*}{$\begin{array}{l}\text { Marcus [Study 2] 1995, RCT, } \\
8600478\end{array}$} & $\begin{array}{l}\text { Combination thermal biofeedback, } \\
\text { relaxation therapy, \& physical } \\
\text { therapy }\end{array}$ & $2.3(3.1)$ & \multirow[t]{2}{*}{ NMD -3.4 (-5.61, -1.19) } \\
\hline & & & & Thermal biofeedback & $5.7(3.3)$ & \\
\hline & \multirow[t]{2}{*}{$\begin{array}{l}\text { Worst pain score on a VAS }(0- \\
10) \text { in past } 2 \mathrm{wk}\end{array}$} & Baseline & \multirow[t]{2}{*}{$\begin{array}{l}\text { Marcus [Study 1] 1995, } \\
\text { Single-group study, } 8600478\end{array}$} & \multirow[t]{2}{*}{$\begin{array}{l}\text { Combination thermal biofeedback, } \\
\text { relaxation therapy, \& physical } \\
\text { therapy }\end{array}$} & $7.7(2.0)$ & \multirow[t]{2}{*}{ NR } \\
\hline & & $2 \mathrm{mo}$ & & & $4.2(3.8)$ & \\
\hline & \multirow[t]{2}{*}{$\begin{array}{l}\text { Number of days in past } 2 \text { wk } \\
\text { with headache }>1 \text { on a VAS } \\
(0-10)\end{array}$} & \multirow[t]{2}{*}{$2 \mathrm{mo}$} & \multirow[t]{2}{*}{$\begin{array}{l}\text { Marcus [Study 2] 1995, RCT, } \\
8600478\end{array}$} & $\begin{array}{l}\text { Combination thermal biofeedback, } \\
\text { relaxation therapy, \& physical } \\
\text { therapy }\end{array}$ & $2.9(4.3)$ & \multirow[t]{2}{*}{$\begin{array}{l}\text { NMD -5.60 (-8.74, - } \\
2.46)\end{array}$} \\
\hline & & & & Thermal biofeedback & 7.7 (NR) & \\
\hline & \multirow[t]{2}{*}{$\begin{array}{l}\text { Number of days in past } 2 \text { wk } \\
\text { with headache }>1 \text { on a VAS } \\
(0-10)\end{array}$} & Baseline & \multirow[t]{2}{*}{$\begin{array}{l}\text { Marcus [Study 1] 1995, } \\
8600478\end{array}$} & \multirow[t]{2}{*}{$\begin{array}{l}\text { Combination thermal biofeedback, } \\
\text { relaxation therapy, \& physical } \\
\text { therapy }\end{array}$} & $8.0(3.5)$ & \multirow[t]{2}{*}{ NR } \\
\hline & & $2 \mathrm{mo}$ & & & $2.9(4.0)$ & \\
\hline & \multirow[t]{2}{*}{$\begin{array}{l}\text { Headache score average over } 2 \\
\text { wk on Headache Index }\end{array}$} & $2 \mathrm{mo}$ & \multirow[t]{2}{*}{$\begin{array}{l}\text { Marcus [Study 2] 1995, RCT, } \\
8600478\end{array}$} & $\begin{array}{l}\text { Combination thermal biofeedback, } \\
\text { relaxation therapy, \& physical } \\
\text { therapy }\end{array}$ & $0.44(0.70)$ & \multirow[t]{2}{*}{ NMD -0.86 (-1.95, 0.23) } \\
\hline & & & & Thermal biofeedback & $1.8(2.0)$ & \\
\hline & \multirow[t]{2}{*}{$\begin{array}{l}\text { Headache score average over } 2 \\
\text { wk on Headache Index }\end{array}$} & Baseline & \multirow[t]{2}{*}{$\begin{array}{l}\text { Marcus [Study 1] 1995, } \\
\text { Single-group study, } 8600478\end{array}$} & \multirow[t]{2}{*}{$\begin{array}{l}\text { Combination thermal biofeedback, } \\
\text { relaxation therapy, \& physical } \\
\text { therapy }\end{array}$} & $1.7(1.3)$ & \multirow[t]{2}{*}{ NR } \\
\hline & & $2 \mathrm{mo}$ & & & $0.45(0.77)$ & \\
\hline & \multirow[t]{3}{*}{$\begin{array}{l}\text { Average of worst headache on } \\
\text { a VAS (0-5) }\end{array}$} & Baseline & \multirow[t]{6}{*}{$\begin{array}{l}\text { Hickling, 1990, Single-group } \\
\text { study, } 2401622\end{array}$} & $\begin{array}{l}\text { Combination thermal biofeedback } \\
\text { \& relaxation therapy }\end{array}$ & $2.9(0.6)$ & NR \\
\hline & & After int & & & $0.5(1.1)$ & \\
\hline & & After delivery & & & $0.3(0.7)$ & \\
\hline & Worst headache on a VAS (0- & Baseline & & & $3.9(1.0)$ & NR \\
\hline & & After int & & & $0.6(1.3)$ & \\
\hline & & After delivery & & & $0.9(1.3)$ & \\
\hline & Pain, VAS (0-10) pre-procedure & Pre-procedure & $\begin{array}{l}\text { Govindappagari, 2014, } \\
\text { Single-group study, } \\
25415168\end{array}$ & Peripheral nerve blocks & $8.4(1.8)$ & - \\
\hline & & Post-procedure & & & $4.5(3.8)$ & MD -4.0 (2.6) \\
\hline & & $24 \mathrm{hr}$ & & & $4.5(4.5)$ & MD -4.0 (4.4) \\
\hline
\end{tabular}




\begin{tabular}{|c|c|c|c|c|c|c|}
\hline Outcome $^{*}$ & Outcome Measurement & Time-Point & Study, Year, Design, PMID & Intervention(s) & $\begin{array}{l}\mathrm{n} / \mathrm{N}(\%) \text { or } \\
\text { Mean (SD) }\end{array}$ & $\begin{array}{l}\text { Effect Size (95\% Cl) o } \\
\text { Effect Size (SD) }\end{array}$ \\
\hline \multirow[t]{3}{*}{$\begin{array}{l}\text { Duration of acute } \\
\text { headache attacks }\end{array}$} & \multirow[t]{3}{*}{ Duration in $\mathrm{hr}$} & Baseline & \multirow[t]{3}{*}{$\begin{array}{l}\text { Hickling, 1990, Single-group } \\
\text { study, } 2401622\end{array}$} & \multirow{3}{*}{$\begin{array}{l}\text { Combination thermal biofeedback } \\
\& \text { relaxation therapy }\end{array}$} & $20.6 \mathrm{hr}(16.0)$ & \multirow[t]{3}{*}{ NR } \\
\hline & & After int & & & $1.2 \mathrm{hr}(2.7)$ & \\
\hline & & After delivery & & & $4.8 \mathrm{hr}(10.7)$ & \\
\hline \multirow{4}{*}{$\begin{array}{l}\text { Resolution of } \\
\text { acute headache }\end{array}$} & \multirow{3}{*}{$\begin{array}{l}\text { Number of headache-free days } \\
\text { per week }\end{array}$} & Baseline & \multirow{3}{*}{$\begin{array}{l}\text { Hickling, 1990, Single-group } \\
\text { study, } 2401622\end{array}$} & \multirow{3}{*}{$\begin{array}{l}\text { Combination thermal biofeedback } \\
\& \text { relaxation therapy }\end{array}$} & $2.8 \mathrm{~d} / \mathrm{wk}(2.6)$ & \multirow[t]{3}{*}{ NR } \\
\hline & & After int & & & $7 \mathrm{~d} / \mathrm{wk}(0)$ & \\
\hline & & After delivery & & & $7 \mathrm{~d} / \mathrm{wk}(0)$ & \\
\hline & NR & NR & \multirow{2}{*}{$\begin{array}{l}\text { Bhola, 2015, Single-group } \\
\text { study, 26055242 } \\
\text { Bhola, 2015, Single-group } \\
\text { study, } 26055242\end{array}$} & Transcranial magnetic stimulation & $3 / 3(100)$ & - \\
\hline $\begin{array}{l}\text { Resolution of } \\
\text { headache-related } \\
\text { symptoms }\end{array}$ & NR & NR & & Transcranial magnetic stimulation & $3 / 3(100)$ & - \\
\hline \multirow[t]{6}{*}{ Medication use } & \multirow{2}{*}{$\begin{array}{l}\text { Reduction in number of } \\
\text { acetaminophen doses }\end{array}$} & \multirow[t]{2}{*}{8 wk } & \multirow[t]{2}{*}{ Silva, 2012, RCT, no PMID } & Acupuncture & $6.0(9.0)$ & \multirow[t]{2}{*}{ MD $5.4(1.3,9.5)$} \\
\hline & & & & Routine care & $0.6(3.3)$ & \\
\hline & \multirow{2}{*}{$\begin{array}{l}50 \% \text { reduction in number of } \\
\text { acetaminophen doses }\end{array}$} & \multirow[t]{2}{*}{$8 \mathrm{wk}$} & \multirow[t]{2}{*}{ Silva, 2012, RCT, no PMID } & Acupuncture & $14 / 20(70.0)$ & \multirow{2}{*}{ OR $6.61(\mathrm{Cl} 1.74,25.1)$} \\
\hline & & & & Routine care & $6 / 23(26.1)$ & \\
\hline & \multirow[t]{2}{*}{$\begin{array}{l}\text { Use of any medication for } \\
\text { headache }\end{array}$} & \multirow[t]{2}{*}{$2 \mathrm{mo}$} & \multirow[t]{2}{*}{$\begin{array}{l}\text { Marcus [Study 2] 1995, RCT, } \\
8600478\end{array}$} & $\begin{array}{l}\text { Combination of thermal } \\
\text { biofeedback, relaxation therapy, } \\
\text { and physical therapy }\end{array}$ & $4 / 11(36.4)$ & \multirow[t]{2}{*}{ OR $0.50(0.09,2.73)$} \\
\hline & & & & Thermal biofeedback & $10 / 14(71.4)$ & \\
\hline $\begin{array}{l}\text { AEs - Maternal - } \\
\text { Serious, Any }\end{array}$ & Any serious $\mathrm{AE}$ & Post-procedure & \multirow[t]{2}{*}{$\begin{array}{l}\text { Govindappagari, 2014, } \\
\text { Single-group study, } \\
25415168\end{array}$} & \multirow[t]{2}{*}{ Peripheral nerve blocks } & $0 / 13(0.0)$ & - \\
\hline $\begin{array}{l}\text { AEs - Maternal - } \\
\text { Nonserious, Any }\end{array}$ & $\begin{array}{l}\text { Vasovagal near syncopal } \\
\text { episode with nausea }\end{array}$ & Post-procedure & & & $1 / 13(7.7)$ & - \\
\hline $\begin{array}{l}\text { AEs - Maternal - } \\
\text { Any }\end{array}$ & NR & $\mathrm{NR}$ & $\begin{array}{l}\text { Bhola, 2015, Single-group } \\
\text { study, } 26055242\end{array}$ & Transcranial magnetic stimulation & $0 / 13(0.0)$ & - \\
\hline Preterm birth & Birth at $<37$ wk gestation & At birth & $\begin{array}{l}\text { Govindappagari, 2014, } \\
\text { Single-group study, } \\
25415168\end{array}$ & Peripheral nerve blocks & $2 / 13(15.3)$ & - \\
\hline \multirow[t]{2}{*}{ Low birth weight } & \multirow[t]{2}{*}{ Birth weight } & \multirow[t]{2}{*}{ At birth } & \multirow[t]{6}{*}{ Silva, 2012, RCT, no PMID } & Acupuncture & $3244 \mathrm{~g}(336)$ & \multirow[t]{2}{*}{ MD $98 \mathrm{~g}(-141,336)$} \\
\hline & & & & Routine care & $3146 \mathrm{~g}(424)$ & \\
\hline \multirow{4}{*}{$\begin{array}{l}\text { Perinatal } \\
\text { complications }\end{array}$} & \multirow[t]{4}{*}{ Apgar score } & At 1 min after birth & & Acupuncture & $9(0)$ & MD $0(-0.5,0.5)$ \\
\hline & & & & Routine care & $9(1)$ & \\
\hline & & At 5 min after birth & & Acupuncture & $10(0)$ & MD 0 (-0.1, 0.1) \\
\hline & & & & Routine care & $10(0)$ & \\
\hline
\end{tabular}

Abbreviations: $\mathrm{AE}=$ adverse effect, $\mathrm{CI}=$ confidence interval, $\mathrm{d}=$ days, $\mathrm{hr}=$ hours, int $=$ intervention, $\mathrm{MD}=$ mean difference, min $=$ minutes, mo $=$ months, NMD = net mean difference, $\mathrm{NR}=$ not reported, $\mathrm{OR}=$ odds ratio, $\mathrm{PMID}=$ PubMed identifier, $\mathrm{RCT}=$ randomized controlled trial, $\mathrm{SD}=$ standard deviation, $\mathrm{VAS}=$ visual analog scale, wk $=$ weeks. 
* No studies reported acute headache outcomes (recurrence), headache-related symptom(severity, duration, resolution, recurrence), emergency department or clinic visits, hospitalizations, quality of life, functional outcomes (family life, work/school attendance, time spent managing disease), resource use, acceptability of int by patients, patient satisfaction with int, serious maternal AEs (any AE, cardiovascular), nonserious maternal AEs (any nonserious AE, nonobstetrical, preterm labor/CS, reduced breast milk, medication withdrawal symptoms), discontinuation due to maternal AEs, serious fetal/child AEs (any serious AE, death, preterm birth, congenital anomalies,

neurodevelopmental/behavioral/social), nonserious fetal/child AEs (any nonserious AE, breastfeeding delay/cessation/etc., poor infant attachment/bonding, medication withdrawal symptoms), or discontinuation due to fetal/child AEs.

\begin{tabular}{|c|c|c|c|c|c|c|c|c|c|c|}
\hline Topic & Comparison & $\begin{array}{l}\text { Outcome } \\
\text { Category }\end{array}$ & Outcome & $\begin{array}{l}\text { N Studies } \\
\text { (Subjects) }\end{array}$ & RoB & Consistency & Precision & Directness & SoE & Conclusions \\
\hline \multirow[t]{8}{*}{ Benefits } & $\begin{array}{l}\text { Acupuncture vs. } \\
\text { routine care }\end{array}$ & $\begin{array}{l}\text { Acute headache } \\
\text { attack }\end{array}$ & $\begin{array}{l}\text { Severity of acute } \\
\text { headache attacks }\end{array}$ & $1(43)$ & High & $\mathrm{N} / \mathrm{A}$ & Imprecise & Direct & Insufficient & No conclusion made \\
\hline & $\begin{array}{l}\text { Combination thermal } \\
\text { biofeedback, } \\
\text { relaxation therapy, } \\
\text { and physical therapy } \\
\text { vs. thermal } \\
\text { biofeedback }\end{array}$ & $\begin{array}{l}\text { Acute headache } \\
\text { attack }\end{array}$ & $\begin{array}{l}\text { Severity of acute } \\
\text { headache attacks }\end{array}$ & $2(44)$ & High & $\mathrm{N} / \mathrm{A}$ & Imprecise & Direct & Insufficient & No conclusion made \\
\hline & \multirow{3}{*}{$\begin{array}{l}\text { Combination of } \\
\text { thermal biofeedback } \\
\text { and relaxation } \\
\text { therapy (no } \\
\text { comparison) }\end{array}$} & \multirow[t]{3}{*}{$\begin{array}{l}\text { Acute headache } \\
\text { attack }\end{array}$} & $\begin{array}{l}\text { Severity of acute } \\
\text { headache attacks }\end{array}$ & $1(5)$ & Low & $\mathrm{N} / \mathrm{A}$ & Imprecise & Indirect & Insufficient & No conclusion made \\
\hline & & & $\begin{array}{l}\text { Duration of acute } \\
\text { headache attacks }\end{array}$ & 1 (5) & Low & $\mathrm{N} / \mathrm{A}$ & Imprecise & Indirect & Insufficient & No conclusion made \\
\hline & & & $\begin{array}{l}\text { Resolution of acute } \\
\text { headache attack }\end{array}$ & $1(5)$ & Low & $\mathrm{N} / \mathrm{A}$ & Imprecise & Indirect & Insufficient & No conclusion made \\
\hline & $\begin{array}{l}\text { Peripheral nerve } \\
\text { blocks (no } \\
\text { comparison) }\end{array}$ & $\begin{array}{l}\text { Acute headache } \\
\text { attack }\end{array}$ & $\begin{array}{l}\text { Severity of acute } \\
\text { headache attacks }\end{array}$ & $1(13)$ & Low & $\mathrm{N} / \mathrm{A}$ & Imprecise & Indirect & Insufficient & No conclusion made \\
\hline & \multirow{2}{*}{$\begin{array}{l}\text { Transcranial magnetic } \\
\text { stimulation (No } \\
\text { comparison) }\end{array}$} & $\begin{array}{l}\text { Acute headache } \\
\text { attack }\end{array}$ & $\begin{array}{l}\text { Acute headache attacks } \\
\text { - Resolution }\end{array}$ & 1 (3) & Moderate & $\mathrm{N} / \mathrm{A}$ & $\mathrm{N} / \mathrm{A}$ & Indirect & Insufficient & No conclusion made \\
\hline & & $\begin{array}{l}\text { Headache- } \\
\text { related } \\
\text { symptoms }\end{array}$ & $\begin{array}{l}\text { Headache-related } \\
\text { symptoms - Resolution }\end{array}$ & $1(3)$ & Moderate & $\mathrm{N} / \mathrm{A}$ & $\mathrm{N} / \mathrm{A}$ & Indirect & Insufficient & No conclusion made \\
\hline \multirow[t]{5}{*}{ Harms } & \multirow{2}{*}{$\begin{array}{l}\text { Acupuncture vs. } \\
\text { routine care }\end{array}$} & \multirow[t]{2}{*}{ AEs - Fetal/Child } & Low birth weight & $1(43)$ & High & $\mathrm{N} / \mathrm{A}$ & Imprecise & Direct & Insufficient & No conclusion made \\
\hline & & & Perinatal complications & $1(43)$ & High & $\mathrm{N} / \mathrm{A}$ & Imprecise & Direct & Insufficient & No conclusion made \\
\hline & \multirow{2}{*}{$\begin{array}{l}\text { Peripheral nerve } \\
\text { blocks (no } \\
\text { comparison) }\end{array}$} & AEs - Maternal & Any serious AEs & $1(13)$ & Low & $\mathrm{N} / \mathrm{A}$ & Imprecise & Indirect & Insufficient & No conclusion made \\
\hline & & AEs - Fetal/Child & Preterm birth & $1(13)$ & Low & $\mathrm{N} / \mathrm{A}$ & Imprecise & Indirect & Insufficient & No conclusion made \\
\hline & $\begin{array}{l}\text { Transcranial magnetic } \\
\text { stimulation (No } \\
\text { comparison) }\end{array}$ & AEs - Maternal & Any serious $A E s$ & $1(3)$ & Moderate & $\mathrm{N} / \mathrm{A}$ & $\mathrm{N} / \mathrm{A}$ & Indirect & Insufficient & No conclusion made \\
\hline
\end{tabular}

Abbreviations: AE = adverse effect, N/A = not applicable, RoB = risk of bias, SoE = strength of evidence.

Consistency was deemed "N/A" when it could not be assessed because only one study was one found. Consistency was also deemed "N/A" when two studies were found because one of the studies was a single-group study for which no between-arm effect size was feasible, precluding an assessment of consistency.

Tables B-34 and B-35 provide the complete versions of this Evidence Profile, including displaying outcomes for which no studies were identified 


\section{Other Nonpharmacologic Interventions for KQ 2}

We did not find any direct evidence (i.e., primary studies) or indirect evidence (i.e., SRs regardless of indication) specifically for hydration and supplements for treating attacks of primary headaches in women who are pregnant (or attempting to become pregnant), postpartum, or breastfeeding.

\section{Supplemental Evidence (Case Reports)}

We identified 19 case reports, ${ }^{91-109}$ of which five reported on interventions relevant to KQ 1 only, seven reported on interventions relevant to KQ 2 only, and seven reported on interventions relevant to both KQs. Overall, thirteen case reports reported on benefit outcomes intervention effects and six on adverse effects.

The text in Appendix B and Tables B-29 and B-30 provide detailed descriptions of the case reports. Here we provide a simple summary of what occurred to individual patients in terms of headache progression and adverse effects.

Because case reports do not provide evidence of whether the benefit or harms reported can be ascribed to individual interventions, and generally represent cherry-picked "interesting" examples, this evidence is not considered in our conclusions about effects, harms, or strength of evidence.

\section{Case Reports Specific to Key Question 1 (Prevention of Primary Headache)}

\section{Summary of Benefit Outcomes}

Four case reports described benefits of preventive interventions for primary headaches.

- Migraines were prevented in one woman who received complementary therapy (chiropractic therapy, massage therapy), hydration and advice to avoid triggering foods and sleep with an orthopedic pillow, and in one woman who received onabotulinumtoxinA.

- Cluster headache was prevented in one woman who received methylprednisolone.

- Other trigeminal autonomic cephalgia (TAC) headache was prevented in one woman who received nerve blocks and methylprednisolone.

\section{Summary of Harms}

- One case report described harms of an intervention used for prevention of primary headaches. The patient, who had migraine and received valproate, had an induced abortion of a fetus that was detected as having a cardiac defect.

\section{Case Reports Specific to Key Question 2 (Treatment of Primary Headache)}

\section{Summary of Benefit Outcomes}

Five case reports described benefits of interventions used for treatment of primary headaches.

- Migraines were treated in one woman who received a butalbital, acetaminophen, and caffeine combination, a second woman who received sumatriptan, a third woman who received 
acetaminophen and ibuprofen, and a fourth woman who received intravenous prochlorperazine and magnesium.

- In one woman, an unspecified primary postpartum headache was treated using intravenous saline and ketorolac.

\section{Summary of Harms}

Two case reports described harms of interventions used for treatment of primary headaches.

- One woman with migraine treated with acetaminophen, ergotamine, caffeine, and mecloxamine during the first trimester lost her newborn 13 hours after birth due to cardiopulmonary arrest, and another woman with migraine treated with acetaminophen and codeine during her second trimester had an infant born with neonatal abstinence syndrome, which resolved without requiring pharmacologic therapy.

\section{Case Reports Addressing Both Key Question 1 (Prevention of Primary Headache) and Key Question 2 (Treatment of Primary Headache)}

\section{Summary of Benefit Outcomes}

Four case reports described benefits of interventions used for both prevention and treatment of primary headaches.

- Migraines were prevented and/or treated in one woman who received sphenopalantine ganglion block, another woman who received oral magnesium supplements, and a third woman who received labetalol.

- In one woman, cluster headache was prevented using occipital nerve stimulation device and treated using sumatriptan.

\section{Summary of Harms}

Three case reports described harms of interventions used for both prevention and treatment of primary headaches.

- One woman with migraine who received candesartan, pramipexole, and amitriptyline (as prevention) and zolmitriptan and metoclopramide (as treatment) had a baby with renal tubular dysgenesis, hypoplasia of the skull and the lungs, and hyaline membranes of the lungs; a second woman who received acetaminophen, codeine, propranolol, ergotamine, and caffeine had a baby with severe malformations and paraplegia; and a third woman receiving bisoprolol, naproxen, sumatriptan, and acetaminophen had an infant with various birth defects. 


\section{Discussion}

\section{Findings in Relation to the Decisional Dilemmas}

We identified a sparse body of evidence addressing the many interventions of interest in this systematic review (SR). This included 16 primary studies providing direct evidence of benefits and harms in pregnant women with primary headache, and 26 existing SRs that provided indirect evidence of harms in pregnant women regardless of indication. Table 37 maps out the investigated interventions for both Key Questions (KQs), by type of evidence (direct and indirect) and specific study design (for direct evidence). Table 38 provides a summary of the identified direct and indirect evidence addressing pharmacologic and nonpharmacologic interventions for prevention (KQ 1) or treatment of primary headaches (KQ 2).

Table 37. Map of direct and indirect evidence identified in this systematic review

\begin{tabular}{|c|c|c|c|c|c|c|c|}
\hline $\begin{array}{l}\text { Topic } \\
\text { (KQ) }\end{array}$ & Type & Class & I ntervention(s) & $\begin{array}{l}\text { Direct } \\
\text { Evidence: } \\
\text { RCTs } \\
\mathrm{N}_{\mathrm{s}}\left(\mathrm{N}_{\mathrm{P}}\right)\end{array}$ & $\begin{array}{l}\text { Direct } \\
\text { Evidence: } \\
\text { NRCSs } \\
\mathbf{N}_{\mathrm{S}}\left(\mathbf{N}_{\mathrm{P}}\right) \\
\end{array}$ & $\begin{array}{l}\text { Direct } \\
\text { Evidence: } \\
\text { Single- } \\
\text { group } \\
\text { studies } \\
\mathrm{N}_{\mathrm{s}}\left(\mathrm{N}_{\mathrm{p}}\right) \\
\end{array}$ & $\begin{array}{l}\text { Indirect } \\
\text { Evidence: } \\
\text { SRs } \\
\mathbf{N}_{\mathrm{SR}}\left(\mathbf{N}_{\mathrm{s}}{ }^{*}\right)\end{array}$ \\
\hline \multirow[t]{22}{*}{$\begin{array}{l}\text { Prevention } \\
\text { (KQ 1) }\end{array}$} & \multirow[t]{14}{*}{ Pharm } & Antiepileptics & $\begin{array}{l}\text { Topiramate, } \\
\text { Carbamazepine, } \\
\text { Gabapentin, } \\
\text { Lamotrigine, } \\
\text { Valproate }\end{array}$ & - & - & $1(81)$ & $2(146)$ \\
\hline & & SNRIS & Venlafaxine & - & - & - & $1(2)$ \\
\hline & & Tricyclic antidepressants & Any & - & - & - & $1(2)$ \\
\hline & & Tetracyclic antidepressants & - & - & - & - & - \\
\hline & & Mood-stabilizing agents & - & - & - & - & - \\
\hline & & Benzodiazepines & Any & - & - & - & $1(26)$ \\
\hline & & Beta blockers & Any & - & - & - & $2(76)$ \\
\hline & & Calcium channel blockers & Any, Nifedipine & - & - & - & $2(85)$ \\
\hline & & $\begin{array}{l}\text { Other antihypertensive } \\
\text { medications }\end{array}$ & - & - & - & - & - \\
\hline & & Corticosteroids & Prednisolone & - & - & - & $1(10)^{\dagger}$ \\
\hline & & Antihistamines & Any & - & - & - & $2(63)^{\dagger}$ \\
\hline & & Oral magnesium & Magnesium & - & - & - & $1(10)$ \\
\hline & & NMDA receptor antagonists & - & - & - & - & - \\
\hline & & CGRP inhibitors & - & - & - & - & - \\
\hline & \multirow{8}{*}{$\begin{array}{l}\text { Non- } \\
\text { pharm }\end{array}$} & Complementary therapy & - & - & - & - & - \\
\hline & & Behavioral therapy & - & - & - & - & - \\
\hline & & Physical therapy & - & - & - & - & - \\
\hline & & Procedures & - & - & - & - & - \\
\hline & & $\begin{array}{l}\text { Noninvasive neuromodulation } \\
\text { devices }\end{array}$ & - & - & - & - & - \\
\hline & & Chemodenervation & - & - & - & - & - \\
\hline & & Hydration & - & - & - & - & - \\
\hline & & Supplements & - & - & - & - & \\
\hline
\end{tabular}




\begin{tabular}{|c|c|c|c|c|c|c|c|}
\hline $\begin{array}{l}\text { Topic } \\
\text { (KQ) }\end{array}$ & Type & Class & Intervention(s) & $\begin{array}{l}\text { Direct } \\
\text { Evidence: } \\
\text { RCTs } \\
\text { Ns (NP) }\end{array}$ & $\begin{array}{l}\text { Direct } \\
\text { Evidence: } \\
\text { NRCSs } \\
\text { Ns (Np) }\end{array}$ & $\begin{array}{l}\text { Direct } \\
\text { Evidence: } \\
\text { Single- } \\
\text { group } \\
\text { studies } \\
\mathrm{N}_{\mathrm{s}}\left(\mathrm{N}_{\mathrm{P}}\right) \\
\end{array}$ & $\begin{array}{l}\text { Indirect } \\
\text { Evidence: } \\
\text { SRs } \\
\mathrm{N}_{\mathrm{SR}}\left(\mathrm{Ns}^{*}\right)\end{array}$ \\
\hline \multirow[t]{26}{*}{$\begin{array}{l}\text { Treatment } \\
\text { (KQ 2) }\end{array}$} & \multirow[t]{19}{*}{ Pharm } & Triptans & $\begin{array}{l}\text { Any, Sumatriptan, } \\
\text { Naratriptan }\end{array}$ & - & $8(13,907)$ & - & $1(6)$ \\
\hline & & Ergot products & Any & - & $1(3,368)$ & - & - \\
\hline & & NSAI Ds & Naproxen & - & $1(689)$ & - & - \\
\hline & & NSAI Ds & $\begin{array}{l}\text { Any, } \\
\text { Indomethacin, } \\
\text { Low-dose aspirin }\end{array}$ & - & - & - & $8(174)$ \\
\hline & & $\begin{array}{l}\text { Antiemetics: Dopamine } \\
\text { receptor antagonists }\end{array}$ & Metoclopramide & $1(70)$ & - & - & - \\
\hline & & Antihistamines & Any & $1(70)$ & $1(3,368)$ & - & $2(63)^{\dagger}$ \\
\hline & & $\begin{array}{l}\text { Opioid containing } \\
\text { analgesics }\end{array}$ & Codeine & $1(70)$ & - & - & - \\
\hline & & $\begin{array}{l}\text { Antiemetics: } 5 \mathrm{HT} 3 \\
\text { antagonists }\end{array}$ & Ondansetron & - & - & - & $2(20)$ \\
\hline & & Antipsychotics & Any & - & - & - & $2(22)$ \\
\hline & & Corticosteroids & Prednisolone & - & - & - & $1(10)^{\dagger}$ \\
\hline & & Analgesics/ antipyretics & Acetaminophen & - & - & - & $1(7)$ \\
\hline & & Intravenous magnesium & $\begin{array}{l}\text { Intravenous } \\
\text { Magnesium }\end{array}$ & - & - & - & $1(143)$ \\
\hline & & $\begin{array}{l}\text { Central nervous system } \\
\text { stimulants }\end{array}$ & - & - & - & - & - \\
\hline & & Muscle relaxants & - & - & - & - & - \\
\hline & & $\begin{array}{l}\text { Butalbital-containing } \\
\text { analgesics }\end{array}$ & - & - & - & - & - \\
\hline & & Sympathomimetic amines & - & - & - & - & - \\
\hline & & Topical anesthetics & - & - & - & - & - \\
\hline & & Somatostatin analogs & - & - & - & - & - \\
\hline & & $\begin{array}{l}\text { Other over-the-counter } \\
\text { analgesics }\end{array}$ & - & - & - & - & - \\
\hline & \multirow[t]{7}{*}{$\begin{array}{l}\text { Nonph } \\
\text { arm }\end{array}$} & Complementary therapy & $\begin{array}{l}\text { Thermal } \\
\text { biofeedback }\end{array}$ & $2(68)$ & - & $2(24)$ & - \\
\hline & & Behavioral therapy & $\begin{array}{l}\text { Relaxation } \\
\text { therapy }\end{array}$ & $1(25)$ & - & $2(24)$ & - \\
\hline & & Physical therapy & Physical therapy & $1(25)$ & - & $1(19)$ & - \\
\hline & & Procedures & $\begin{array}{l}\text { Peripheral nerve } \\
\text { blocks }\end{array}$ & - & - & $1(13)$ & - \\
\hline & & $\begin{array}{l}\text { Noninvasive } \\
\text { neuromodulation devices }\end{array}$ & $\begin{array}{l}\text { Transcranial } \\
\text { magnetic } \\
\text { stimulation }\end{array}$ & - & - & $1(3)$ & - \\
\hline & & Hydration & - & - & - & - & - \\
\hline & & Supplements & - & - & - & - & - \\
\hline
\end{tabular}

Abbreviations: CGRP = calcitonin gene-related peptide, KQ = Key Question, $\mathrm{N}_{\mathrm{CR}}=$ number of case reports, NMDA = N-methylD-aspartate, Nonpharm = nonpharmacologic, $\mathrm{N}_{\mathrm{P}}=$ number of participants, $\mathrm{NRCS}=$ nonrandomized comparative study, $\mathrm{N}_{\mathrm{S}}=$ number of studies, NSAID = nonsteroidal antiinflammatory drug, NsR = number of systematic reviews, Pharm = pharmacologic, $\mathrm{RCT}$ = randomized controlled trial, SNRI = serotonin and norepinephrine reuptake inhibitor, SR = systematic review.

Intervention classes in bold font are those for which we identified at least one primary study (direct evidence) or SR (indirect evidence).

Direct evidence = primary studies in women who are pregnant (or attempting to become pregnant), postpartum, or breastfeeding with primary headache. Indirect evidence = systematic reviews in women who are pregnant (or attempting to become pregnant), postpartum, or breastfeeding regardless of indication.

* Does not account for overlap of studies across existing SRs.

† SRs addressing interventions that can be used for either prevention or treatment of primary headache are counted in both categories. 
Table 38. Summary of direct and indirect evidence identified in this systematic review

\begin{tabular}{|c|c|c|c|c|c|c|c|c|c|c|}
\hline KQ & $\begin{array}{l}\text { Interventi } \\
\text { on Type }\end{array}$ & Intervention Class & $\begin{array}{l}\text { Intervention } \\
\text { Name }\end{array}$ & Comparator & $\begin{array}{l}\text { Type of } \\
\text { Evidence }\end{array}$ & Condition & $\begin{array}{l}\text { Maternal } \\
\text { Benefits }\end{array}$ & $\begin{array}{l}\text { Maternal } \\
\text { Harms }\end{array}$ & \multicolumn{2}{|c|}{ Fetal/ Child Harms } \\
\hline \multirow[t]{28}{*}{1} & \multirow{27}{*}{ Pharm } & \multirow{11}{*}{ Antiepileptics } & \multirow{3}{*}{ Topiramate } & & Direct & Migraine & - & - & ?? & Spontaneous or elective/induced abortion, congenital anomalies (I) \\
\hline & & & & \multirow[t]{2}{*}{ Nonuse } & \multirow[t]{2}{*}{ Indirect } & \multirow[t]{2}{*}{ Various } & \multirow[t]{2}{*}{-} & \multirow[t]{2}{*}{-} & $\uparrow$ & $\begin{array}{l}\text { Spontaneous or elective/induced abortion, stillbirth/fetal death, } \\
\text { preterm birth, congenital anomalies }(++)\end{array}$ \\
\hline & & & & & & & & & $\sim$ & Neurodevelopmental AEs (+) \\
\hline & & & \multirow[t]{2}{*}{ Carbamazepine } & \multirow[t]{2}{*}{ Nonuse } & \multirow[t]{2}{*}{ Indirect } & \multirow[t]{2}{*}{ Various } & \multirow[t]{2}{*}{ - } & \multirow[t]{2}{*}{-} & $\uparrow$ & Congenital anomalies $(++)$ \\
\hline & & & & & & & & & $\sim$ & $\begin{array}{l}\text { Spontaneous or elective/induced abortion, preterm birth, , } \\
\text { neurodevelopmental AEs }(+)\end{array}$ \\
\hline & & & \multirow[t]{2}{*}{ Gabapentin } & \multirow[t]{2}{*}{ Nonuse } & \multirow[t]{2}{*}{ Indirect } & \multirow[t]{2}{*}{ Various } & \multirow[t]{2}{*}{-} & \multirow[t]{2}{*}{-} & $\uparrow$ & Congenital anomalies, neurodevelopmental AEs (+) \\
\hline & & & & & & & & & $\sim$ & Fetal growth restriction, preterm birth $(+)$ \\
\hline & & & \multirow[t]{2}{*}{ Lamotrigine } & \multirow[t]{2}{*}{ Nonuse } & \multirow[t]{2}{*}{ Indirect } & \multirow[t]{2}{*}{ Various } & \multirow[t]{2}{*}{-} & \multirow[t]{2}{*}{-} & $\uparrow$ & Neurodevelopmental AEs (++) \\
\hline & & & & & & & & & $\sim$ & $\begin{array}{l}\text { Spontaneous or elective/induced abortion, stillbirth/fetal death, } \\
\text { preterm birth, congenital anomalies }(++)\end{array}$ \\
\hline & & & \multirow[t]{2}{*}{ Valproate } & Nonuse & Indirect & Various & - & - & $\uparrow$ & $\begin{array}{l}\text { Spontaneous or elective/induced abortion, stillbirth/fetal death, } \\
\text { congenital anomalies, neurodevelopmental AEs }(++)\end{array}$ \\
\hline & & & & & & & & & $\sim$ & Preterm birth $(++)$ \\
\hline & & SNRIS & Venlafaxine & Nonuse & Indirect & Various & - & - & $\uparrow$ & Preterm birth $(++)$ \\
\hline & & Tricyclic antidepressants & Any & Nonuse & Indirect & Various & - & - & $\uparrow$ & Congenital anomalies and perinatal complications (++) \\
\hline & & & & & & & & & $\sim$ & Low birth weight $(++)$ \\
\hline & & & & & & & & & $? ?$ & Neurodevelopmental AEs (I) \\
\hline & & Benzodiazepines & Any & Nonuse & Indirect & Various & - & - & $\uparrow$ & Congenital anomalies $(+)$ \\
\hline & & Beta blockers & Any & Nonuse & Indirect & Various & - & $\sim$ Discontinuation & $\uparrow$ & Congenital anomalies $(++)$ \\
\hline & & & & & & & & due to $\mathrm{AES}(+)$ & $\tilde{\sim}$ & Preterm birth $(++)$ \\
\hline & & & & & & & & & $? ?$ & Perinatal complications (I) \\
\hline & & $\begin{array}{l}\text { Calcium channel } \\
\text { blockers }\end{array}$ & Any & Nonuse & Indirect & Various & - & $\begin{array}{l}\sim \text { Discontinuation } \\
\text { due to AEs }(+)\end{array}$ & $\sim$ & Perinatal complications (++) \\
\hline & & & & & & & & & $\sim$ & $\begin{array}{l}\text { Spontaneous/elective/induced abortion, stillbirth/fetal death, } \\
\text { neonatal/infant death, or preterm birth }(+)\end{array}$ \\
\hline & & & Nifedipine & Nonuse & Indirect & Various & - & - & $\sim$ & Neonatal/infant death $(++)$ \\
\hline & & & & & & & & & $\sim$ & Preterm birth (+) \\
\hline & & Corticosteroids & Prednisolone & Nonuse & Indirect & Various & - & - & $\uparrow$ & Congenital anomalies (+) \\
\hline & & Antihistamines & Any & Nonuse & Indirect & Various & - & - & $\sim$ & $\begin{array}{l}\text { Spontaneous or elective/induced abortion, stillbirth/fetal death, } \\
\text { preterm birth, low birth weight, congenital anomalies }(++)\end{array}$ \\
\hline & & Oral magnesium & Oral magnesium & Nonuse & Indirect & Various & - & $\sim$ Discontinuation & $\uparrow$ & Neonatal/infant death $(+)$ \\
\hline & & & & & & & & due to $A E s(+)$ & $\sim$ & $\begin{array}{l}\text { Spontaneous or elective/induced abortion, stillbirth/fetal death, low } \\
\text { birth weight, perinatal complications }(+)\end{array}$ \\
\hline & Nonpharm & - & - & - & - & - & - & - & & $\mathrm{N} / \mathrm{E}$ \\
\hline
\end{tabular}




\begin{tabular}{|c|c|c|c|c|c|c|c|c|c|c|}
\hline KQ & $\begin{array}{l}\text { Interventi } \\
\text { on Type }\end{array}$ & Intervention Class & $\begin{array}{l}\text { Intervention } \\
\text { Name }\end{array}$ & Comparator & $\begin{array}{l}\text { Type of } \\
\text { Evidence }\end{array}$ & Condition & $\begin{array}{l}\text { Maternal } \\
\text { Benefits }\end{array}$ & $\begin{array}{l}\text { Maternal } \\
\text { Harms }\end{array}$ & \multicolumn{2}{|c|}{ Fetal/ Child Harms } \\
\hline \multirow[t]{26}{*}{2} & \multirow[t]{26}{*}{ Pharm } & \multirow[t]{13}{*}{$\begin{array}{l}\text { Triptans, Ergot } \\
\text { products, and NSAIDs }\end{array}$} & Sumatriptan & Naratriptan & Direct & Migraine & & - & $? ?$ & $\begin{array}{l}\text { Spontaneous or elective/induced abortion, stillbirth/fetal death, } \\
\text { congenital anomalies (I) }\end{array}$ \\
\hline & & & Sumatriptan & $\begin{array}{l}\text { Sumatriptan + } \\
\text { Naproxen }\end{array}$ & Direct & Migraine & - & - & $? ?$ & $\begin{array}{l}\text { Spontaneous or elective/induced abortion, stillbirth/fetal death, } \\
\text { congenital anomalies (I) }\end{array}$ \\
\hline & & & Naratriptan & $\begin{array}{l}\text { Sumatriptan + } \\
\text { Naproxen }\end{array}$ & Direct & Migraine & - & - & $? ?$ & $\begin{array}{l}\text { Spontaneous or elective/induced abortion, stillbirth/fetal death, } \\
\text { congenital anomalies (I) }\end{array}$ \\
\hline & & & Any triptan & Any ergot product & Direct & Migraine & - & - & $? ?$ & $\begin{array}{l}\text { Stillbirth/fetal death, preterm birth, low birth weight, congenital } \\
\text { anomalies (I) }\end{array}$ \\
\hline & & & Any triptan & Pizotifen & Direct & Migraine & - & - & $? ?$ & $\begin{array}{l}\text { Stillbirth/fetal death, preterm birth, low birth weight, congenital } \\
\text { anomalies (I) }\end{array}$ \\
\hline & & & Any ergot product & Pizotifen & Direct & Migraine & - & - & $? ?$ & Congenital anomalies (I) \\
\hline & & & \multirow{2}{*}{$\begin{array}{l}\text { Any triptan during } \\
\text { pregnancy }\end{array}$} & \multirow{2}{*}{$\begin{array}{l}\text { Any triptan before } \\
\text { pregnancy only }\end{array}$} & \multirow[t]{2}{*}{ Direct } & \multirow[t]{2}{*}{ Migraine } & \multirow[t]{2}{*}{-} & \multirow[t]{2}{*}{ ?? Serious AEs (I) } & $\uparrow$ & Behavioral and social AEs (+) \\
\hline & & & & & & & & & $? ?$ & $\begin{array}{l}\text { Spontaneous or elective/induced abortion, preterm birth, low birth } \\
\text { weight (I) }\end{array}$ \\
\hline & & & $\begin{array}{l}\text { Sumatriptan during } \\
\text { pregnancy }\end{array}$ & $\begin{array}{l}\text { Sumatriptan before } \\
\text { pregnancy only }\end{array}$ & Direct & Migraine & - & ?? Serious AEs (I) & $? ?$ & $\begin{array}{l}\text { Stillbirth/fetal death, neonatal/infant death, preterm birth, low birth } \\
\text { weight, congenital anomalies, perinatal complications (I) }\end{array}$ \\
\hline & & & \multirow{4}{*}{$\begin{array}{l}\text { Any triptan during } \\
\text { pregnancy }\end{array}$} & \multirow{4}{*}{$\begin{array}{l}\text { No triptan use during } \\
\text { or before pregnancy }\end{array}$} & \multirow[t]{2}{*}{ Direct } & \multirow[t]{2}{*}{ Migraine } & \multirow[t]{2}{*}{-} & \multirow[t]{2}{*}{ ?? Serious AEs (I) } & $\uparrow$ & Behavioral and social AEs (+) \\
\hline & & & & & & & & & $\sim ?$ & $\begin{array}{l}\text { Spontaneous or elective/induced abortion, congenital anomalies (+) } \\
\text { Preterm birth, low birth weight, perinatal complications (I) }\end{array}$ \\
\hline & & & & & \multirow[t]{2}{*}{$\begin{array}{l}\text { Existing } \\
\mathrm{SR}\end{array}$} & \multirow[t]{2}{*}{ Migraine } & \multirow[t]{2}{*}{-} & \multirow[t]{2}{*}{ - } & $\sim$ & $\begin{array}{l}\text { Spontaneous or elective/induced abortion, congenital anomalies } \\
(++)\end{array}$ \\
\hline & & & & & & & & & $\sim$ & Preterm birth $(+)$ \\
\hline & & $\begin{array}{l}\text { Antiemetics (Dopamine } \\
\text { antagonists), } \\
\text { Antihistamines, Opioid- } \\
\text { like analgesics }\end{array}$ & $\begin{array}{l}\text { Metoclopramide + } \\
\text { Diphenhydramine }\end{array}$ & Codeine & Direct & $\begin{array}{l}\text { Migraine or } \\
\text { tension HA }\end{array}$ & $\begin{array}{l}\text { Effective in } \\
\text { improving } \\
\text { severity, } \\
\text { resolution, } \\
\text { and } \\
\text { recurrence of } \\
\text { acute HA (+) }\end{array}$ & $\sim$ Serious AEs $(+)$ & & 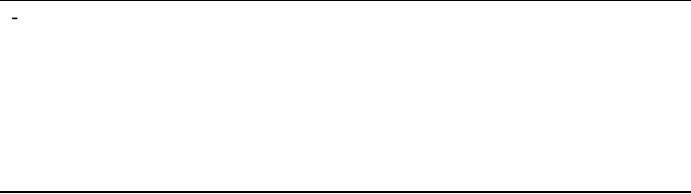 \\
\hline & & \multirow[t]{4}{*}{ NSAIDS } & Any & Nonuse & Indirect & Various & - & $\begin{array}{l}\text { Cardiovascular } \\
\text { AEs }(++)\end{array}$ & & - \\
\hline & & & \multirow[t]{2}{*}{ Indomethacin } & \multirow[t]{2}{*}{ Nonuse } & \multirow[t]{2}{*}{ Indirect } & \multirow[t]{2}{*}{ Various } & \multirow[t]{2}{*}{-} & \multirow[t]{2}{*}{-} & $\uparrow$ & Perinatal complications (+) \\
\hline & & & & & & & & & $\sim$ & Neonatal/infant death, congenital anomalies (+) \\
\hline & & & Low-dose aspirin & Nonuse & Indirect & Various & - & $\begin{array}{l}\sim \text { Serious AEs } \\
(++)\end{array}$ & $\sim$ & $\begin{array}{l}\text { Spontaneous or elective/induced abortion, stillbirth/fetal death, } \\
\text { neonatal/infant death, preterm birth, low birth weight, perinatal } \\
\text { complications, or neurodevelopmental AEs ( }+ \text { ) }\end{array}$ \\
\hline & & $\begin{array}{l}\text { Antiemetics (5HT3 } \\
\text { antagonists }\end{array}$ & Ondansetron & Nonuse & Indirect & Various & - & - & $\uparrow \uparrow$ & Congenital anomalies $(++)$ \\
\hline & & \multirow{3}{*}{ Antipsychotics } & \multirow[t]{3}{*}{ Any } & \multirow[t]{3}{*}{ Nonuse } & Indirect & Various & - & - & $\uparrow$ & Preterm birth, low birth weight $(++)$ \\
\hline & & & & & & & & & $\uparrow$ & Congenital anomalies $(+)$ \\
\hline & & & & & & & & & $\sim$ & Spontaneous or elective/induced abortion, stillbirth/fetal death $(+)$ \\
\hline & & Corticosteroids & Prednisolone & Nonuse & Indirect & Various & - & - & $\uparrow$ & Congenital anomalies $(++)$ \\
\hline & & Analgesics/Antipyretics & Acetaminophen & Nonuse & Indirect & Various & - & - & $\uparrow$ & Neurodevelopmental, behavioral, and social AEs (+) \\
\hline & & Intravenous magnesium & $\begin{array}{l}\text { Intravenous } \\
\text { magnesium }\end{array}$ & Nonuse & Indirect & Various & - & $\uparrow$ Serious AEs (+) & & \\
\hline & & Antihistamines & Any & Nonuse & Indirect & Various & - & - & $\sim$ & $\begin{array}{l}\text { Spontaneous or elective/induced abortion, stillbirth/fetal death, } \\
\text { preterm birth, low birth weight, congenital anomalies }(++)\end{array}$ \\
\hline
\end{tabular}




\begin{tabular}{|c|c|c|c|c|c|c|c|c|c|c|}
\hline $\mathbf{K Q}$ & $\begin{array}{l}\text { Interventi } \\
\text { on Type }\end{array}$ & Intervention Class & $\begin{array}{l}\text { Intervention } \\
\text { Name }\end{array}$ & Comparator & $\begin{array}{l}\text { Type of } \\
\text { Evidence }\end{array}$ & Condition & $\begin{array}{l}\text { Maternal } \\
\text { Benefits }\end{array}$ & $\begin{array}{l}\text { Maternal } \\
\text { Harms }\end{array}$ & \multicolumn{2}{|c|}{ Fetal/Child Harms } \\
\hline & \multirow[t]{5}{*}{ Nonpharm } & Complementary therapy & Acupuncture & Routine care & Direct & Migraine & $\begin{array}{l}\text { ?? Severity } \\
\text { of acute } \\
\text { attack (I) }\end{array}$ & & $? ?$ & Low birth weight and perinatal complications (I) \\
\hline & & $\begin{array}{l}\text { Complementary } \\
\text { therapy, Behavioral } \\
\text { therapy, and Physical } \\
\text { therapy }\end{array}$ & $\begin{array}{l}\text { Thermal } \\
\text { biofeedback, } \\
\text { Relaxation therapy, } \\
\text { and Physical } \\
\text { therapy }\end{array}$ & Thermal biofeedback & Direct & $\begin{array}{l}\text { Migraine } \\
\text { and/or } \\
\text { tension HA }\end{array}$ & $\begin{array}{l}\text { ?? Severity } \\
\text { of acute } \\
\text { attack (I) }\end{array}$ & - & & - \\
\hline & & $\begin{array}{l}\text { Complementary therapy } \\
\text { and Behavioral therapy, }\end{array}$ & $\begin{array}{l}\text { Thermal } \\
\text { biofeedback and } \\
\text { Relaxation therapy }\end{array}$ & - & Direct & Migraine & $\begin{array}{l}\text { ?? Severity, } \\
\text { duration, and } \\
\text { resolution of } \\
\text { acute attacks } \\
\text { (I) }\end{array}$ & - & & - \\
\hline & & Procedures & $\begin{array}{l}\text { Peripheral nerve } \\
\text { blocks }\end{array}$ & - & Direct & Migraine & $\begin{array}{l}\text { ?? Severity } \\
\text { of acute } \\
\text { attack }\end{array}$ & ?? Serious AEs & $? ?$ & Preterm birth (I) \\
\hline & & $\begin{array}{l}\text { Noninvasive } \\
\text { neuromodulation } \\
\text { devices }\end{array}$ & $\begin{array}{l}\text { Transcranial } \\
\text { magnetic } \\
\text { stimulation }\end{array}$ & - & Direct & Migraine & $\begin{array}{l}\text { ?? Resolution } \\
\text { of acute } \\
\text { attack and } \\
\text { HA-related } \\
\text { symptoms (I) }\end{array}$ & - & $? ?$ & Serious AEs (I) \\
\hline
\end{tabular}

Abbreviations: $\mathrm{AE}=$ adverse effect, $\mathrm{HA}=$ headache, $\mathrm{KQ}=$ Key Question, N/E = no evidence, Nonpharm = nonpharmacologic, NSAID = nonsteroidal antiinflammatory drug, Pharm = pharmacologic, SNRI = serotonin and norepinephrine reuptake inhibitor, $\mathrm{SR}=$ systematic review

Clarifications: $\uparrow=$ Increase, $~=$ No increase, ?? = Direction unknown, I = Insufficient strength of evidence, $+=$ Low strength of evidence, $++=$ Moderate strength of evidence, $+++=$ High strength of evidence (none in Table), Direct $=$ evidence from primary studies in pregnant women with primary headache, Indirect $=$ evidence from SRs in pregnant women regardless of indication. We did not search for SRs of benefits for any intervention class or intervention. 
For prevention of acute attacks of primary headache in patients who are pregnant (or attempting to become pregnant), postpartum, or breastfeeding with a history of primary headache (KQ 1), we found no direct evidence for effectiveness of pharmacologic interventions. While we found insufficient direct evidence regarding the harms of topiramate, indirect evidence suggested that topiramate and other antiepileptics (carbamazepine, gabapentin, and valproate) used during pregnancy may be associated with increased risk of fetal/infant adverse effects. However, one antiepileptic (lamotrigine) may not be associated with increased risk of serious adverse effects, except for neurodevelopmental adverse effects, for which there may be increased risk. Indirect evidence also suggested that venlafaxine, tricyclic antidepressants, benzodiazepines, beta blockers, prednisolone, and oral magnesium used during pregnancy may be associated with increased risk of fetal/infant adverse effects, but calcium channel blockers and antihistamines may not be. We found no direct or indirect evidence for the effectiveness or harms of nonpharmacologic interventions when used for prevention.

For treatment of acute attacks of primary headache in patients who are pregnant (or attempting to become pregnant), postpartum, or breastfeeding (KQ 2), we found direct evidence that, when used during pregnancy, combination metoclopramide and diphenhydramine may be more effective than codeine in reducing migraine or tension headache severity, and may have a lower risk of maternal adverse effects; but, fetal/infant adverse effects were not reported. While we did not find any evidence for effectiveness of triptans, direct and existing SR evidence suggested that triptan use for migraine may have a low risk of adverse effects, except for increased child emotionality and hyperactivity at 3 years of age. SRs of harms of medications regardless of indication suggested that indomethacin, ondansetron, antipsychotics, prednisolone, acetaminophen, and intravenous magnesium, when used during pregnancy, may be associated with increased risk of fetal/infant adverse effects, but low-dose aspirin and antihistamines may not be. Regarding nonpharmacologic treatments for primary headache, we found insufficient direct evidence (and no indirect evidence) to make conclusions about the benefits or harms of acupuncture, thermal biofeedback, relaxation therapy, physical therapy, peripheral nerve blocks, or transcranial magnetic stimulation when used during pregnancy.

\section{Caveats to Indirect Evidence (Systematic Reviews of Harms, Regardless of Indication)}

We suggest caution in interpretation of the findings from the indirect evidence (existing SRs of harms of interventions in pregnancy regardless of indication) for various reasons.

First, although obvious, it is worth repeating that the evidence examined in these SRs is not exclusively based on patients with primary headache. It is possible that the harms of interventions may be different in pregnant patients with primary headaches (and their offspring) than pregnant patients with other conditions (and their offspring).

Second, findings regarding classes of drugs (e.g., tricyclic antidepressants, beta blockers those denoted by “any”) apply to classes as wholes, rather than to individual drugs (or doses) within a class, which may have greater (or lesser) risks of adverse effects than other drugs (or doses) in the same class. A concern in this context is that pharmacodynamic profiles and associated degrees of cross-placental and/or breast milk transmission can be variable across drugs within a class and across doses of a drug.

Third, the SRs included variable numbers of studies, and frequently only a subset of the studies (often one or two) included in a given SR contributed data to estimates of specific harms for specific interventions. 
Fourth, it is possible, even likely, that some relevant studies of harms in pregnancy were not included in the SRs we identified. Some potential reasons for this include that the SRs may have had narrow eligibility criteria, included studies may have underreported harms, and newer studies may have been published after the searches for the SRs were run. Another reason might be that the existence of established harms for decades, such as harms of indomethacin on premature closure of the ductus arteriosus when used after 32 weeks of gestation, may have contributed to the lack of quality SRs. Updating these SRs was beyond the scope of the current SR.

Fifth, because we required included SRs to have fulfilled minimum quality criteria, we likely excluded some insufficient-quality SRs of harms.

Sixth, although we required SRs to fulfill minimum quality criteria, even well-conducted SRs cannot overcome methodological limitations of studies that they include. For example, the one SR on harms of acetaminophen conducted a meta-analysis of observational studies on the association between acetaminophen use during pregnancy and neurodevelopmental adverse effects in the child. The positive association that remained despite adjustment for potential confounders provides a potential signal, but the moderate risk of bias of the included studies contributed to our assessment of an overall low strength of evidence for this association.

Notwithstanding these caveats, the indirect evidence from the SRs we identified contributes supplemental information that can be particularly valuable in making conclusions about drugs for which we did not find primary evidence (as we have done above in the section-Findings in Relation to the Decisional Dilemmas). For drugs for which we identified both direct and indirect evidence (i.e., topiramate, antihistamines, and triptans), the harms were generally consistent in both types of evidence.

\section{Supplemental Evidence (Case Reports)}

We identified 19 case reports and summarized them as supplemental evidence, but have not used them to make conclusions because of three major limitations.

First, due to the combination of the lack of a comparison group, the singular sample size, and the nonexperimental setting (i.e., they were not $\mathrm{N}$-of-1 trials), it is highly inappropriate (and even impossible) to make inferences about treatment effectiveness or harms from a case report.

Second, most case reports that we identified involved the use of multiple interventions, often in combination, as attempts to prevent and/or treat primary headache. Teasing apart which intervention (or combination of interventions) was associated with which outcomes in this setting is unfeasible and, more so, inappropriate.

Third, case reports are subject to publication bias and a lack of generalizability in that the cases that are reported, almost by definition, are the select ones that the authors found to be interesting in terms of beneficial effects and/or harms of a given treatment(s). For descriptive information of the individual cases, we refer the reader to the section-Supplemental Evidence (Case Reports)—and to Appendix B.

\section{Strengths and Limitations}

\section{Strengths and Limitations of the Evidence Base}

The limitations of the evidence we identified vastly outnumber its strengths. A major limitation is that, for most interventions, direct evidence about the effectiveness and/or harms in 
patients who are pregnant (or attempting to become pregnant), postpartum, or breastfeeding is sparse or absent. We did not identify any primary studies for entire classes of pharmacologic agents: analgesics/antipyretics, tricyclic antidepressants, beta blockers, calcium channel blockers, other antihypertensive medications, serotonin and norepinephrine reuptake inhibitors (SNRIs), benzodiazepines, central nervous system stimulants, muscle relaxants, N-methyl-D-aspartate (NMDA) receptor antagonists, calcitonin gene-related peptide (CGRP) inhibitors, moodstabilizing agents, tetracyclic antidepressants, corticosteroids, butalbital-containing analgesics, sympathomimetic amines, topical anesthetics, antipsychotics, somatostatin analogs, and intravenous magnesium. Similarly, no primary studies addressed entire classes of nonpharmacologic agents: supplements, chemodenervation, and hydration therapy. However, as discussed above, some of these interventions were described in the indirect evidence.

Where evidence was identified, all studies included women exposed to the interventions (or comparators) during pregnancy; we did not find evidence in women attempting to become pregnant or when postpartum or breastfeeding (except for some studies of triptans [direct evidence] that compared treatments during versus before pregnancy and one SR [indirect evidence] that examined nonsteroidal anti-inflammatory drug (NSAID) use in the postpartum period). In terms of type of primary headache, most primary studies focused on migraine and some focused on tension headache, but none focused on cluster headache or other trigeminal autonomic cephalgias (TACs).

A related limitation of the sparse evidence base is that the studies we identified did not report data for many of our outcomes of interest. Unreported or rarely reported maternal outcomes include headache-related symptoms (nausea/vomiting, photosensitivity, dizziness), quality of life, functional outcomes (impact on family life, impact on employment/school attendance, time spent managing disease), resource use, acceptability of intervention, satisfaction with intervention, and certain adverse effects (stroke, myocardial infarction, reduced breast milk production, and maternal symptoms related to withdrawal of medication). Unreported or rarely reported fetal/child adverse effects include breastfeeding outcomes (delayed initiation, cessation, reduced frequency, reduced volume), poor infant attachment/bonding, and neonatal signs related to withdrawal of medication. Relatedly, few studies reported on the long-term effects and harms of the interventions for mother or child.

Three limitations with the evidence base pertain specifically to the included nonrandomized comparative studies (NRCSs). First, few of the NRCSs reported adjusted between-arm effect sizes. In the absence of the individual patient data, we were unable to calculate adjusted effect sizes. While feasible in some instances (i.e., when arm-specific data were reported), we did not consider it appropriate to calculate unadjusted effect sizes because the populations of women in the treatment arms were generally dissimilar on one or more important confounders. The primary headache disorders result in the use of interventions (for prevention or treatment). While interventions can cause harms that were investigated in this SR, the underlying disorders themselves can cause some of the harms, irrespective of exposure to interventions. This issue can contribute to confounding. Moreover, nonrandomized studies are prone to unmeasured confounding, which can only be accounted for satisfactorily by well-conducted randomized controlled trials (RCTs). Second, triptans, which were the most studied classes of pharmacologic interventions, were discussed by the included studies only in the context of their harms.

Currently, their use in clinical practice appears to be based on their effectiveness in nonpregnant populations; the findings of the current SR suggest the absence of evidence of their effectiveness in pregnant women. Third, none of the NRCSs reported information about the doses, durations, 
and routes of administration. This is likely because most of the NRCSs were registry-based studies that might not have had access to such information, but the absence of such information can weaken conclusions.

We assessed most of the primary studies at an overall high risk of bias. The main reasons were because of a high risk of serious confounding; because participants, care providers, and/or outcome assessors were not blinded; and because of incomplete outcome data. Furthermore, the participant eligibility criteria, interventions, and outcomes were often inadequately described.

Finally, the included SRs of harms of pharmacologic interventions (indirect evidence) reported limited information regarding the doses, timings, durations, and routes of administration during pregnancy. Consequently, the estimates of harms obtained from these SRs were restricted to use versus nonuse of specific drugs or drug classes. We were unable to make conclusions regarding relative harms of various doses, timings, durations, and routes of administration.

\section{Strengths and Limitations of the Systematic Review Process}

We followed contemporary standards for SRs, including multiple stakeholder engagement in KQ development and refinement and careful adherence to recommended methods for literature searching, screening, data extraction, risk of bias assessment, data (narrative) synthesis, and strength of evidence (SoE) assessment. In anticipation of a sparse evidence base, we were very inclusive in our eligibility criteria, especially in terms of study designs, including RCTs, NRCSs, and single-group studies of interventions for primary headaches in pregnancy (as direct evidence); SRs of harms of interventions in pregnancy regardless of indication (as indirect evidence); and case reports (as supplemental evidence).

For all interventions examined in this SR, the paucity of the evidence precluded us from being able to be conduct meta-analyses (either pairwise or network) or make definitive conclusions about treatment effectiveness or harms of the various interventions.

Despite our comprehensive search and approach to using indirect evidence to find harms from SRs regardless of indication, some well-accepted harms of treatment were not addressed. For example, we did not find a SR that fulfilled our minimum quality criteria and provided evidence for the association between indomethacin and increased risk of premature closure of the ductus arteriosus (despite indomethacin being an effective treatment to close a patent ductus arteriosus in neonates ${ }^{110}$ ). Searching for primary studies of harms (or benefits) of medications regardless of indication during pregnancy was beyond the scope of this review.

\section{Applicability}

In addition to the sparseness of the evidence discussed above, a few factors may limit the applicability of our findings. As discussed, the limited information about doses, durations, and frequencies of the interventions reported in the NRCSs (especially triptans) constrains our ability to make definitive conclusions about individual triptans.

The population in the studies included in this SR were varied in terms of the trimester and gestational age, which limits our ability to apply our findings specifically to different trimesters of pregnancy.

Most primary studies in this SR were conducted in the U.S., Canada, or Europe. Various contextual factors may impact the effectiveness of treatments. It is unclear to what extent the findings of this SR might apply outside of these high-income settings. 


\section{Implications for Clinical Practice}

Although we used both direct and indirect evidence to inform our conclusions in this SR, we emphasize that the direct evidence is sparse. There is surprisingly little directly useful evidence for guiding clinical practice for women with primary headache who are pregnant (or attempting to become pregnant), postpartum, or breastfeeding. This paucity of information also applies to medications more recently approved for migraine by the Food and Drug Administration, such as CGRP inhibitors, noninvasive neuromodulation devices, and botulinum toxin, and some that are available over the counter, such as acetaminophen. Our a priori approach to examining harms of relevant medications in this review was restricted to harms reported in (1) primary studies of women with primary headache who were pregnant (or attempting to become pregnant), postpartum, or breastfeeding, and (2) existing SRs that met minimal quality criteria in this population of women regardless of indication. Thus, as discussed above, some harms, such as the risks of NSAIDs when used after 32 weeks of gestation, may not have been found in our search of these two sources of evidence.

Given the paucity of information regarding estimates of the effectiveness of various interventions to prevent or treat primary headaches, decision makers will need to rely on the evidence from the general population. This is especially true for interventions for prevention of primary headaches and for treatments of primary headaches other than migraine, for which we found limited studies among pregnant, postpartum, or breastfeeding women. Ideally, high SoE information from studies of pregnant women with migraine (or other types of primary headache) would inform this decision, but there is generally sparse information for this population. Thus, decision makers are left to extrapolate from studies of pregnant women with mostly other conditions regarding the safety of the interventions, especially regarding potential harms to the fetus or infant. However, the risks involved in using the same drugs for treatment of other conditions (e.g., seizures, psychosis, depression) may not translate well to the risks for women with primary headaches because the underlying risks of fetal/child adverse effects may differ. Treatment doses and durations often differ by indication. Concomitant drug use (and thus drugdrug interactions) are likely to differ. Psychosocial behaviors, such as smoking, substance use, and caffeine intake, may also differ. Nevertheless, clinicians, patients, and policymakers are left with the options of making treatment decisions based on: (1) extrapolating information about harms from studies where these drugs were used for other indications (not included as direct evidence in this SR, but summarized as indirect evidence through examination of published SRs); and/or (2) depending on what is known about the levels of the various drugs in maternal serum/blood or that are transmitted to the fetus through amniotic fluid and/or cord blood, or to the infant through breast milk.

We did not consider levels of various drugs in maternal serum/blood or in other fluids transmitted to the fetus/infant as relevant outcomes in our SR. However, especially given the absence of studies examining interventions for primary headache in breastfeeding women, we recognize that decision makers may be interested in drug levels in various fluids. We found that the most complete resource with data about levels of the various drugs is the Drugs and Lactation Database (LactMed ${ }^{\circledR}$, available at https://toxnet.nlm.nih.gov/newtoxnet/lactmed.htm). Because the data in LactMed are readily available and are being continually updated, we refer the interested reader there for current information on specific drugs of interest. LactMed contains extensive information about the levels of drugs that are of interest to the current SR. This information is reported in LactMed for specific drugs, often at the level of individual studies and/or specific body fluids. Data are often reported for individual (deidentified) women at 
various time-points. While LactMed is frequently used by clinicians and sometimes incorporated into discussions with patients about potential risks, it should be noted that for many drugs, the association between levels of drug exposure in body fluids and harms, either short- or long-term, is not well established. In other words, drug levels are, at best, intermediate outcomes and may not correlate well with harms to the offspring.

We encourage clinicians to inform patients about the limitations of existing research on interventions for preventing or treating primary headaches during pregnancy, postpartum, or breastfeeding phases. Given the limitations of the evidence, the patient's values and preferences and the clinician's expertise and experience are even more important. A related important aspect that should be considered is the severity of the primary headache, which could shift the balance between benefits and harms of a given intervention, or comparative benefits and harms between a set of interventions, under consideration.

\section{Implications for Research}

The sparseness of the direct evidence addressing the interventions addressed in this comprehensive SR is striking. It does not imply, however, that interventions are not beneficial or harmful. Because interventions may affect pregnant women (and their offspring) differently than non-pregnant individuals, there is an important and urgent research need for direct evidence in pregnancy, postpartum, or breastfeeding phases.

Research is needed both for pharmacologic and nonpharmacologic interventions. Triptans, the most studied classes of pharmacologic interventions, were discussed by the included studies only in the context of their harms. Currently, their use in clinical practice appears to be based on their effectiveness in nonpregnant populations; the findings of the current SR suggests the absence of evidence in pregnant women. We found low strength of evidence that combination metoclopramide and diphenhydramine was more effective and no more harmful than codeine when used for treating migraine or tension headache. In an era of heightened concern about opioid use, the evidence suggests that it is possible that this combination is a viable alternative to codeine for pregnant women experiencing migraine or tension headache.

For some interventions, although we concluded that studies provided insufficient evidence to make conclusions, these studies found a signal of potential effectiveness and/or safety that should be explored in future research. These include topiramate for prevention of primary headache, and acupuncture, thermal biofeedback, behavioral therapy, physical therapy, peripheral nerve blocks, and transcranial magnetic stimulation for treatment.

Because of the absence of studies addressing prevention or treatment of cluster headache and other TACs in pregnant women, researchers should also design studies that, either entirely or in part, enroll these patients. When enrolled as part of a larger study, subgroup-specific data for these types of primary headache, should be reported.

It is important that future studies either randomize patients (after considering the ethical issues in this population) to minimize selection bias, or report between-arm estimates of treatment effect that adequately account for important confounders, such as age and severity of headache attack (or of history of headaches). Studies should also, where feasible, conduct blinding of participants, care providers, and outcome assessors to minimize the likelihood of performance and detection biases. Given the concern regarding exposing the fetus to potentially harmful pharmacologic interventions, we recognize that RCTs will likely continue to be infrequent. As an alternative to randomization, when observational studies, such as those using patient registries, are conducted, they should be adequately designed and analyzed to compare 
treatments. Such analyses should appropriately account for differences between comparison groups of patients that are inherently different. Ideally, propensity score analyses (or similar rigorous techniques) should be used to adequately adjust for these differences. A propensity score analysis, for example, estimates the likelihood that each patient had one or the other intervention (conditional on their measured characteristics) and controls for this likelihood. These analyses generally require relatively large numbers of patients for whom there are granular data about risk factors for outcomes. Additionally, while registry data will likely continue to be important in identifying harms, researchers should report more details about disease severity as well as intervention doses, durations, and frequencies.

When reporting studies, it is also important that authors adhere to relevant reporting guidelines so that adequate details about the population, interventions (and comparators), and outcomes are clearly described.

Future studies should also evaluate other important maternal outcomes, such as headacherelated symptoms (e.g., photosensitivity), quality of life, functional outcomes (e.g., impact on employment/school attendance), and patient satisfaction with intervention; adverse effects on breastfeeding, such as decreased milk supply; and some important fetal/child adverse outcomes. None of the studies included in this SR addressed these outcomes.

\section{Conclusions}

We were able to make few specific conclusions in this SR, most of which were based on low strength of evidence. Future research should identify the most effective and safe interventions for preventing or treating primary headaches in this population. 


\section{References}

1. Pearce CF, Hansen WF. Headache and neurological disease in pregnancy. Clinical obstetrics and gynecology. 2012 Sep;55(3):810-28. doi: 10.1097/GRF.0b013e31825d7b68. PMID: 22828113.

2. Robbins MS, Farmakidis C, Dayal AK, et al. Acute headache diagnosis in pregnant women: a hospital-based study. Neurology. 2015 Sep 22;85(12):1024-30. doi: 10.1212/wnl.0000000000001954. PMID: 26291282.

3. Karaca Z, Tanriverdi F, Unluhizarci K, et al. Pregnancy and pituitary disorders. European journal of endocrinology. 2010 Mar;162(3):453-75. doi: 10.1530/eje-090923. PMID: 19934270.

4. Molitch ME. Prolactinomas and pregnancy. Clinical endocrinology. 2010 Aug;73(2):147-8. doi: 10.1111/j.13652265.2010.03823.x. PMID: 20550542.

5. Headache Classification Committee of the International Headache Society (IHS) The International Classification of Headache Disorders, 3rd edition. Cephalalgia : an international journal of headache. 2018 Jan;38(1):1-211. doi: 10.1177/0333102417738202. PMID: 29368949.

6. Frederick IO, Qiu C, Enquobahrie DA, et al. Lifetime prevalence and correlates of migraine among women in a pacific northwest pregnancy cohort study. Headache. 2014 Apr;54(4):675-85. doi: 10.1111/head.12206. PMID: 23992560.

7. Gelaye B, Do N, Avila S, et al. Childhood Abuse, Intimate Partner Violence and Risk of Migraine Among Pregnant Women: An Epidemiologic Study. Headache. 2016 Jun;56(6):976-86. doi: 10.1111/head.12855. PMID: 27242154.

8. Negro A, Delaruelle Z, Ivanova TA, et al. Headache and pregnancy: a systematic review. The journal of headache and pain. 2017 Oct 19;18(1):106. doi: 10.1186/s10194-017-0816-0. PMID: 29052046.
9. Skajaa N, Szepligeti SK, Xue F, et al. Pregnancy, Birth, Neonatal, and Postnatal Neurological Outcomes After Pregnancy With Migraine. Headache. 2019 Jun;59(6):869-79. doi: 10.1111/head.13536. PMID: 31069791.

10. Sacco S, Ricci S, Degan D, et al. Migraine in women: the role of hormones and their impact on vascular diseases. The journal of headache and pain. 2012 Apr;13(3):177-89. doi: 10.1007/s10194-012-0424-y. PMID: 22367631.

11. Petrovski BE, Vetvik KG, Lundqvist C, et al. Characteristics of menstrual versus nonmenstrual migraine during pregnancy: a longitudinal population-based study. The journal of headache and pain. $2018 \mathrm{Apr}$ 2;19(1):27. doi: 10.1186/s10194-018-08533. PMID: 29611008.

12. Allais G, Chiarle G, Sinigaglia S, et al. Migraine during pregnancy and in the puerperium. Neurological sciences : official journal of the Italian Neurological Society and of the Italian Society of Clinical Neurophysiology. 2019 Mar 18. doi: 10.1007/s10072-01903792-9. PMID: 30880362.

13. Robbins MS. Headache in Pregnancy. Continuum (Minneap Minn). 2018 Aug;24(4, Headache):1092-107. doi: 10.1212/con.0000000000000642. PMID: 30074551.

14. Silberstein SD. Migraine and pregnancy. Neurologic clinics. 1997 Feb;15(1):209-31. doi: 10.1016/s0733-8619(05)70305-4. PMID: 9058407.

15. Brass SD, Copen WA. Neurological disorders in pregnancy from a neuroimaging perspective. Seminars in neurology. 2007 Nov;27(5):411-24. doi: 10.1055/s-2007991123. PMID: 17940920.

16. Chansakul T, Young GS. Neuroimaging in Pregnant Women. Seminars in neurology. 2017 Dec;37(6):712-23. doi: 10.1055/s0037-1608939. PMID: 29270945.

17. Klein JP, Hsu L. Neuroimaging during pregnancy. Seminars in neurology. 2011 Sep;31(4):361-73. doi: 10.1055/s-00311293535. PMID: 22113508. 
18. Antonucci R, Zaffanello M, Puxeddu E, et al. Use of non-steroidal anti-inflammatory drugs in pregnancy: impact on the fetus and newborn. Curr Drug Metab. 2012 May 1;13(4):474-90. PMID: 22299823.

19. U.S. Food and Drug Administration. FDA Drug Safety Communication: Valproate Antiseizure Products Contraindicated for Migraine Prevention in Pregnant Women due to Decreased IQ Scores in Exposed Children. https://www.fda.gov/drugs/drugsafety/ucm3 50684.htm. Accessed on March 23, 2019.

20. Andrade C. Valproate in Pregnancy: Recent Research and Regulatory Responses. The Journal of clinical psychiatry. 2018 May/Jun;79(3). doi: 10.4088/JCP.18f12351. PMID: 29873961.

21. Burch R. Headache in Pregnancy and the Puerperium. Neurologic clinics. 2019 Feb;37(1):31-51. doi: 10.1016/j.ncl.2018.09.004. PMID: 30470274.

22. Becker WJ. Acute Migraine Treatment in Adults. Headache. 2015 Jun;55(6):778-93. doi: 10.1111/head.12550. PMID: 25877672.

23. Hamilton KT, Robbins MS. Migraine Treatment in Pregnant Women Presenting to Acute Care: A Retrospective Observational Study. Headache. 2019 Feb;59(2):173-9. doi: 10.1111/head.13434. PMID: 30403400.

24. Worthington I, Pringsheim T, Gawel MJ, et al. Canadian Headache Society Guideline: acute drug therapy for migraine headache. Can J Neurol Sci. 2013 Sep;40(5 Suppl 3):S1-s80. PMID: 23968886.

25. Govindappagari S, Grossman TB, Dayal AK, et al. Peripheral nerve blocks in the treatment of migraine in pregnancy. Obstetrics and gynecology. 2014 Dec;124(6):1169-74. doi: 10.1097/aog.0000000000000555. PMID: 25415168.

26. American Academy of Pediatrics, American College of Obstetricians and Gynecologists. Guidelines for Perinatal Care. 8th ed.
27. Robbins MS, Starling AJ, Pringsheim TM, et al. Treatment of Cluster Headache: The American Headache Society EvidenceBased Guidelines. Headache. 2016 Jul;56(7):1093-106. doi: 10.1111/head.12866. PMID: 27432623.

28. Orr SL, Friedman BW, Christie S, et al. Management of Adults With Acute Migraine in the Emergency Department: The American Headache Society Evidence Assessment of Parenteral Pharmacotherapies. Headache. 2016 Jun;56(6):911-40. doi: 10.1111/head.12835. PMID: 27300483.

29. Marmura MJ, Silberstein SD, Schwedt TJ. The acute treatment of migraine in adults: the american headache society evidence assessment of migraine pharmacotherapies. Headache. 2015 Jan;55(1):3-20. doi: 10.1111/head.12499. PMID: 25600718.

30. Moher D, Liberati A, Tetzlaff J, et al. Preferred reporting items for systematic reviews and meta-analyses: the PRISMA statement. Journal of clinical epidemiology. 2009 Oct;62(10):1006-12. doi: 10.1016/j.jclinepi.2009.06.005. PMID: 19631508.

31. Shea BJ, Reeves BC, Wells G, et al. AMSTAR 2: a critical appraisal tool for systematic reviews that include randomised or nonrandomised studies of healthcare interventions, or both. BMJ (Clinical research ed). 2017 Sep 21;358:j4008. doi: 10.1136/bmj.j4008. PMID: 28935701.

32. Higgins JP, Altman DG, Gotzsche PC, et al. The Cochrane Collaboration's tool for assessing risk of bias in randomised trials. BMJ (Clinical research ed). 2011 Oct 18;343:d5928. doi: 10.1136/bmj.d5928. PMID: 22008217.

33. Sterne JA, Hernan MA, Reeves BC, et al. ROBINS-I: a tool for assessing risk of bias in non-randomised studies of interventions. BMJ (Clinical research ed). 2016 Oct 12;355:i4919. doi: 10.1136/bmj.i4919. PMID: 27733354.

34. National Heart, Lung, and Blood Institute. Study Quality Assessment Tools.; 2019. https://www.nhlbi.nih.gov/healthtopics/study-quality-assessment-tools. Accessed on January 23, 2020. 
35. Berkman ND, Lohr KN, Ansari M, et al. AHRQ Methods for Effective Health Care

Grading the Strength of a Body of Evidence When Assessing Health Care Interventions for the Effective Health Care Program of the Agency for Healthcare Research and Quality: An Update. Methods Guide for Effectiveness and Comparative Effectiveness Reviews. Rockville (MD): Agency for Healthcare Research and Quality (US); 2008.

36. Berkman ND, Lohr KN, Ansari MT, et al. Grading the strength of a body of evidence when assessing health care interventions: an EPC update. Journal of clinical epidemiology. 2015 Nov;68(11):1312-24. doi: 10.1016/j.jclinepi.2014.11.023. PMID: 25721570 .

37. Childress KMS, Dothager C, Gavard JA, et al. Metoclopramide and Diphenhydramine: A Randomized Controlled Trial of a Treatment for Headache in Pregnancy when Acetaminophen Alone Is Ineffective (MAD Headache Study). Am J Perinatol. 2018 Nov;35(13):1281-6. doi: 10.1055/s-00381646952. PMID: 29723901.

38. Marcus DA, Scharff L, Turk DC. Nonpharmacological management of headaches during pregnancy. Psychosom Med. 1995 Nov-Dec;57(6):527-35. doi: 10.1097/00006842-199511000-00004. PMID: 8600478.

39. Nct. A Cost Effective Treatment for Headache in Pregnancy When Acetaminophen Alone is Ineffective. https:/clinicaltrialsgov/show/NCT02295280 . 2014. PMID: CN-01550349.

40. Scolari Childress KM, Lebovitz SJ, Mostello DJ. Metoclopramide and diphenhydramine costeffective therapy for headache in an obstetric triage unit. Obstetrics and gynecology. 2015;125:1S-2S. doi: 10.1097/01.AOG.0000463522.05160.e6. PMID: CN-01173373.

41. Silva JBGd, Nakamura MU, Cordeiro JA, et al. Acupuncture for tension-type headache in pregnancy: A prospective, randomized, controlled study. European Journal of Integrative Medicine. 2012 2012/12/01/;4(4):e366-e70. doi: https://doi.org/10.1016/j.eujim.2012.04.002.
42. Cunnington M, Ephross S, Churchill P. The safety of sumatriptan and naratriptan in pregnancy: what have we learned? Headache. 2009 Nov-Dec;49(10):1414-22. doi: 10.1111/j.1526-4610.2009.01529.x. PMID: 19804390.

43. Drks. Fetotoxical risk analysis of maternal triptan therapy during pregnancy in the context of migraine disorder.

Http://wwwwhoint/trialsearch/trial2aspx? Trialid=drks00007660. 2019. PMID: CN01550349.

44. Ephross SA, Sinclair SM. Final results from the 16-year sumatriptan, naratriptan, and treximet pregnancy registry. Headache. 2014 Jul-Aug;54(7):1158-72. doi: 10.1111/head.12375. PMID: 24805878.

45. Harris GE, Wood M, Ystrom E, et al. Prenatal triptan exposure and neurodevelopmental outcomes in 5-year-old children: Follow-up from the Norwegian Mother and Child Cohort Study. Paediatr Perinat Epidemiol. 2018 May;32(3):247-55. doi: 10.1111/ppe.12461. PMID: 29569251.

46. Kallen B, Lygner PE. Delivery outcome in women who used drugs for migraine during pregnancy with special reference to sumatriptan. Headache. 2001 Apr;41(4):351-6. doi: 10.1046/j.15264610.2001.111006351.x. PMID: 11318881.

47. Kallen B, Nilsson E, Otterblad Olausson P. Delivery outcome after maternal use of drugs for migraine: a register study in Sweden. Drug Saf. 2011 Aug 1;34(8):691703. doi: 10.2165/11590370-00000000000000. PMID: 21751829.

48. Nct. Sumatriptan and Naratriptan Pregnancy Registry. https://ClinicalTrialsgov/show/NCT0105960 4. 2014. PMID: NCT01059604.

49. Nezvalova-Henriksen K, Spigset O, Nordeng H. Triptan exposure during pregnancy and the risk of major congenital malformations and adverse pregnancy outcomes: results from the Norwegian Mother and Child Cohort Study. Headache. 2010 Apr;50(4):563-75. doi: 10.1111/j.1526-4610.2010.01619.x. PMID: 20132339. 
50. Nezvalova-Henriksen K, Spigset O, Nordeng H. Triptan safety during pregnancy: a Norwegian population registry study. Eur J Epidemiol. 2013 Sep;28(9):759-69. doi: 10.1007/s10654-013-9831-X. PMID: 23884894.

51. Nezvalova-Henriksen K, Spigset O, Nordeng HM. Errata in "Triptan exposure during pregnancy and the risk of major congenital malformations and adverse pregnancy outcomes: results from the norwegian mother and child cohort study". Headache. 2012 Sep;52(8):1319-20. doi: 10.1111/j.1526-4610.2012.02207.x. PMID: 22946832.

52. O'Quinn S, Ephross SA, Williams V, et al. Pregnancy and perinatal outcomes in migraineurs using sumatriptan: a prospective study. Arch Gynecol Obstet. 1999 Nov;263(1-2):7-12. doi: 10.1007/s004040050252. PMID: 10728620.

53. Olesen C, Steffensen FH, Sorensen HT, et al. Pregnancy outcome following prescription for sumatriptan. Headache. 2000 Jan;40(1):20-4. doi: 10.1046/j.15264610.2000.00003.x. PMID: 10759898.

54. Shuhaiber S, Pastuszak A, Schick B, et al. Pregnancy outcome following first trimester exposure to sumatriptan. Neurology. 1998 Aug;51(2):581-3. doi: 10.1212/wnl.51.2.581. PMID: 9710039.

55. Spielmann K, Kayser A, Beck E, et al. Pregnancy outcome after anti-migraine triptan use: A prospective observational cohort study. Cephalalgia : an international journal of headache. 2018 May;38(6):1081-92. doi: 10.1177/0333102417724152. PMID: 28758416.

56. Wood ME, Frazier JA, Nordeng HM, et al. Longitudinal changes in neurodevelopmental outcomes between 18 and 36 months in children with prenatal triptan exposure: findings from the Norwegian Mother and Child Cohort Study. BMJ Open. 2016 Sep 13;6(9):e011971. doi: 10.1136/bmjopen-2016-011971. PMID: 27625061.
57. Wood ME, Lapane K, Frazier JA, et al. Prenatal Triptan Exposure and Internalising and Externalising Behaviour Problems in 3Year-Old Children: Results from the Norwegian Mother and Child Cohort Study. Paediatr Perinat Epidemiol. 2016 Mar;30(2):190-200. doi: 10.1111/ppe.12253. PMID: 26525300.

58. Bhola R, Kinsella E, Giffin N, et al. Single-pulse transcranial magnetic stimulation (sTMS) for the acute treatment of migraine: evaluation of outcome data for the UK post market pilot program. The journal of headache and pain. 2015;16:535. doi: 10.1186/s10194-015-0535-3. PMID: 26055242.

59. Castilla-Puentes R, Ford L, Manera L, et al. Topiramate monotherapy use in women with and without epilepsy: pregnancy and neonatal outcomes. Epilepsy Res. 2014 May;108(4):717-24. doi: 10.1016/j.eplepsyres.2014.01.021. PMID: 24598456.

60. Hickling EJ, Silverman DJ, Loos W. A nonpharmacological treatment of vascular headache during pregnancy. Headache. 1990 Jun;30(7):407-10. doi: 10.1111/j.15264610.1990.hed3007407.x. PMID: 2401622.

61. Scharff L, Marcus DA, Turk DC. Maintenance of effects in the nonmedical treatment of headaches during pregnancy. Headache. 1996 May;36(5):285-90. doi: 10.1046/j.1526-4610.1996.3605285.x. PMID: 8682668.

62. Abalos E, Duley L, Steyn DW, et al. Antihypertensive drug therapy for mild to moderate hypertension during pregnancy. Cochrane Database Syst Rev. 2018 Oct 1;10:Cd002252. doi: 10.1002/14651858.CD002252.pub4. PMID: 30277556.

63. Bain ES, Middleton PF, Crowther CA. Maternal adverse effects of different antenatal magnesium sulphate regimens for improving maternal and infant outcomes: a systematic review. BMC Pregnancy Childbirth. 2013 Oct 21;13:195. doi: 10.1186/1471-2393-13195. PMID: 24139447. 
64. Bellos I, Pergialiotis V, Antsaklis A, et al. Safety of non-steroidal anti-inflammatory drugs in the postpartum period among women with hypertensive disorders of pregnancy: a meta-analysis. Ultrasound Obstet Gynecol. 2020 Feb 18. doi: 10.1002/uog.21997. PMID: 32068930.

65. Bellos I, Pergialiotis V, Papapanagiotou A, et al. Comparative efficacy and safety of oral antihypertensive agents in pregnant women with chronic hypertension: a network metaanalysis. American journal of obstetrics and gynecology. 2020 Mar 19. doi: 10.1016/j.ajog.2020.03.016. PMID: 32199925.

66. Chaemsaithong P, Cuenca-Gomez D, Plana MN, et al. Does low-dose aspirin initiated before 11 weeks' gestation reduce the rate of preeclampsia? American journal of obstetrics and gynecology. 2019 Sep 5. doi: 10.1016/j.ajog.2019.08.047. PMID: 31494125 .

67. Coomarasamy A, Honest H, Papaioannou S, et al. Aspirin for prevention of preeclampsia in women with historical risk factors: a systematic review. Obstetrics and gynecology. 2003 Jun;101(6):1319-32. doi: 10.1016/s0029-7844(03)00169-8. PMID: 12798543.

68. Coughlin CG, Blackwell KA, Bartley C, et al. Obstetric and neonatal outcomes after antipsychotic medication exposure in pregnancy. Obstetrics and gynecology. 2015 May;125(5):1224-35. doi: 10.1097/aog.0000000000000759. PMID: 25932852.

69. Dolovich LR, Addis A, Vaillancourt JM, et al. Benzodiazepine use in pregnancy and major malformations or oral cleft: meta-analysis of cohort and case-control studies. BMJ (Clinical research ed). 1998 Sep 26;317(7162):839-43. doi: 10.1136/bmj.317.7162.839. PMID: 9748174.

70. Duley L, Henderson-Smart DJ, Meher S, et al. Antiplatelet agents for preventing preeclampsia and its complications. Cochrane Database Syst Rev. 2007 Apr 18(2):Cd004659. doi: 10.1002/14651858.CD004659.pub2. PMID: 17443552.
71. Enato E, Moretti M, Koren G. The fetal safety of benzodiazepines: an updated meta-analysis. J Obstet Gynaecol Can. 2011 Jan;33(1):468. doi: 10.1016/s1701-2163(16)34772-7. PMID: 21272436.

72. Etwel F, Faught LH, Rieder MJ, et al. The Risk of Adverse Pregnancy Outcome After First Trimester Exposure to H1 Antihistamines: A Systematic Review and Meta-Analysis. Drug Saf. 2017 Feb;40(2):121-32. doi: 10.1007/s40264-016-0479-9. PMID: 27878468.

73. Hammers AL, Sanchez-Ramos L, Kaunitz AM. Antenatal exposure to indomethacin increases the risk of severe intraventricular hemorrhage, necrotizing enterocolitis, and periventricular leukomalacia: a systematic review with metaanalysis. American journal of obstetrics and gynecology. 2015 Apr;212(4):505.e1-13. doi: 10.1016/j.ajog.2014.10.1091. PMID: 25448524.

74. Hamulyák EN, Scheres LJ, Marijnen MC, et al. Aspirin or heparin or both for improving pregnancy outcomes in women with persistent antiphospholipid antibodies and recurrent pregnancy loss. Cochrane Database Syst Rev. 2020 May 2;5(5):Cd012852. doi: 10.1002/14651858.CD012852.pub2. PMID: 32358837.

75. Henderson JT, Whitlock EP, O'Connor E, et al. Low-dose aspirin for prevention of morbidity and mortality from preeclampsia: a systematic evidence review for the U.S. Preventive Services Task Force. Annals of internal medicine. 2014 May 20;160(10):695-703. doi: 10.7326/m132844. PMID: 24711050.

76. Kaplan YC, Richardson JL, Keskin-Arslan E, et al. Use of ondansetron during pregnancy and the risk of major congenital malformations: A systematic review and meta-analysis. Reprod Toxicol. 2019 Jun;86:1-13. doi: 10.1016/j.reprotox.2019.03.001. PMID: 30849498.

77. Li CM, Zhernakova A, Engstrand L, et al. Systematic review with meta-analysis: the risks of proton pump inhibitors during pregnancy. Aliment Pharmacol Ther. 2020 Feb;51(4):410-20. doi: 10.1111/apt.15610. PMID: 31909512. 
78. Makrides M, Crosby DD, Bain E, et al. Magnesium supplementation in pregnancy. Cochrane Database Syst Rev. 2014 Apr 3(4):Cd000937. doi: 10.1002/14651858.CD000937.pub2. PMID: 24696187.

79. Marchenko A, Etwel F, Olutunfese O, et al. Pregnancy outcome following prenatal exposure to triptan medications: a metaanalysis. Headache. 2015 Apr;55(4):490501. doi: 10.1111/head.12500. PMID: 25644494.

80. Masarwa R, Levine H, Gorelik E, et al. Prenatal Exposure to Acetaminophen and Risk for Attention Deficit Hyperactivity Disorder and Autistic Spectrum Disorder: A Systematic Review, Meta-Analysis, and MetaRegression Analysis of Cohort Studies. Am J Epidemiol. 2018 Aug 1;187(8):1817-27. doi: 10.1093/aje/kwy086. PMID: 29688261.

81. Maze D, Kazi S, Gupta V, et al. Association of Treatments for Myeloproliferative Neoplasms During Pregnancy With Birth Rates and Maternal Outcomes: A Systematic Review and Meta-analysis. JAMA Netw Open. 2019 Oct 2;2(10):e1912666. doi: 10.1001/jamanetworkopen.2019.12666. PMID: 31584685.

82. McDonagh M, Matthews A, Phillipi C, et al. Antidepressant Treatment of Depression During Pregnancy and the Postpartum Period. Evid Rep Technol Assess (Full Rep). 2014 Jul(216):1-308. doi: 10.23970/ahrqepcerta216. PMID: 30313002.

83. McDonagh MS, Matthews A, Phillipi C, et al. Depression drug treatment outcomes in pregnancy and the postpartum period: a systematic review and meta-analysis. Obstetrics and gynecology. 2014

Sep;124(3):526-34. doi: 10.1097/aog.0000000000000410. PMID: 25004304.

84. Park-Wyllie L, Mazzotta P, Pastuszak A, et al. Birth defects after maternal exposure to corticosteroids: prospective cohort study and meta-analysis of epidemiological studies. Teratology. 2000 Dec;62(6):385-92. doi: 10.1002/1096-9926(200012)62:6<385::Aidtera5>3.0.Co;2-z. PMID: 11091360.
85. Picot C, Berard A, Grenet G, et al. Risk of malformation after ondansetron in pregnancy: An updated systematic review and meta-analysis. Birth Defects Res. 2020 May 18. doi: 10.1002/bdr2.1705. PMID: 32420702.

86. Terrana N, Koren G, Pivovarov J, et al. Pregnancy Outcomes Following In Utero Exposure to Second-Generation Antipsychotics: A Systematic Review and Meta-Analysis. J Clin Psychopharmacol. 2015 Oct;35(5):559-65. doi: 10.1097/jcp.0000000000000391. PMID: 26274044.

87. Veroniki AA, Cogo E, Rios P, et al. Comparative safety of anti-epileptic drugs during pregnancy: a systematic review and network meta-analysis of congenital malformations and prenatal outcomes. BMC Med. 2017 May 5;15(1):95. doi: 10.1186/s12916-0170845-1. PMID: 28472982.

88. Veroniki AA, Rios P, Cogo E, et al. Comparative safety of antiepileptic drugs for neurological development in children exposed during pregnancy and breast feeding: a systematic review and network meta-analysis. BMJ Open. 2017 Jul 20;7(7):e017248. doi: 10.1136/bmjopen-2017-017248. PMID: 28729328.

89. Weston J, Bromley R, Jackson CF, et al. Monotherapy treatment of epilepsy in pregnancy: congenital malformation outcomes in the child. Cochrane Database Syst Rev. 2016 Nov 7;11:Cd010224. doi: 10.1002/14651858.CD010224.pub2. PMID: 27819746.

90. Yakoob MY, Bateman BT, Ho E, et al. The risk of congenital malformations associated with exposure to beta-blockers early in pregnancy: a meta-analysis. Hypertension. 2013 Aug;62(2):375-81. doi: 10.1161/hypertensionaha.111.00833. PMID: 23753416.

91. Alcantara J, Cossette M. Intractable migraine headaches during pregnancy under chiropractic care. Complement Ther Clin Pract. 2009 Nov;15(4):192-7. doi: 10.1016/j.ctcp.2009.03.005. PMID: 19880080. 
92. Asioli GM, Merli E, Favoni V, et al. Greater Occipital Nerve Infiltration During Pregnancy in Cluster Headache: A Case Report. Headache. 2019 Jun;59(6):930-2. doi: 10.1111/head.13553. PMID: 31106401.

93. de Coo IF, Wilbrink LA, Haan J. Effective occipital nerve stimulation during pregnancy in a cluster headache patient. Cephalalgia : an international journal of headache. 2016 Jan;36(1):98-9. doi: 10.1177/0333102415580111. PMID: 25834272.

94. Demirel G, Oguz SS, Erdeve O, et al. Unilateral renal agenesis and urethral atresia associated with ergotamine intake during pregnancy. Ren Fail. 2012;34(5):643-4. doi: 10.3109/0886022x.2012.668156. PMID: 22417229.

95. Dey R, Khan S, Akhouri V, et al. Labetalol for prophylactic treatment of intractable migraine during pregnancy. Headache. 2002 Jul-Aug;42(7):642-5. doi: 10.1046/j.15264610.2002.02152.x. PMID: 12482217.

96. Evans RW, Diamond ML. Is sumatriptan use safe during pregnancy? Headache. 2000 NovDec;40(10):856-7. doi: 10.1046/j.15264610.2000.00156.x. PMID: 11135034.

97. Evans RW, Loder EW. Migraine with aura during pregnancy. Headache. 2003 Jan;43(1):80-4. doi: 10.1046/j.1526-4610.2003.03017.x. PMID: 12864766.

98. Evans RW, Wilson MC. Postpartum headaches. Headache. 2001 Jul-Aug;41(7):731-2. doi: 10.1046/j.1526-4610.2001.041007731.x. PMID: 11554965.

99. Haaland K. Angiotensin II receptor antagonists against migraine in pregnancy: fatal outcome. The journal of headache and pain. 2010 Apr;11(2):167-9. doi: 10.1007/s10194009-0182-7. PMID: 20063032.

100. Hughes HE, Goldstein DA. Birth defects following maternal exposure to ergotamine, beta blockers, and caffeine. J Med Genet. 1988 Jun;25(6):396-9. doi: 10.1136/jmg.25.6.396. PMID: 3398007.

101. Kajantie E, Somer M. Bilateral cleft lip and palate, hypertelorism and hypoplastic toes. Clin Dysmorphol. 2004 Jul;13(3):195-6. doi: 10.1097/01.mcd.0000133499.91871.52. PMID: 15194960.
102. Levin D, Cohen S, Mellender S, et al. Sphenopalatine Ganglion Block Successfully Treats Migraines in a Type 1 Arnold Chiari Malformation Pregnant Patient: A Case Report. A A Pract. 2018 Jul 15;11(2):32-4. doi: 10.1213/xaa.0000000000000722. PMID: 29634560.

103. Nair V, Soraisham AS, Akierman A. Neonatal withdrawal syndrome due to maternal codeine use. Paediatr Child Health. 2012 May;17(5):e40-1. doi: 10.1093/pch/17.5.e40. PMID: 23633904.

104. Papadopoulos G. A case of migraine headache successfully treated with low-dose magnesium phosphate in a pregnant woman. Australian Journal of Herbal Medicine. 2017;29(4):136.

105. Richardson KJ. Postpartum Headache. Adv Emerg Nurs J. 2017 Oct/Dec;39(4):258-65. doi: 10.1097/tme.0000000000000162. PMID: 29095177.

106. Robinson AY, Grogan PM. OnabotulinumtoxinA successfully used as migraine prophylaxis during pregnancy: a case report. Mil Med. 2014 Jun;179(6):e703-4. doi: 10.7205/milmed-d13-00477. PMID: 24902141.

107. Rozen TD. Aborting a prolonged migrainous aura with intravenous prochlorperazine and magnesium sulfate. Headache. 2003 Sep;43(8):901-3. PMID: 12940813.

108. ten Berg K, van Oppen AC, Nikkels PG, et al. Complex cardiac defect with hypoplastic right ventricle in a fetus with valproate exposure. Prenat Diagn. 2005 Feb;25(2):156-8. doi: 10.1002/pd.1098. PMID: 15712340.

109. Yalin OO, Uluduz D, Ozge A. Peripheral nerve blocks for the treatment of short-lasting unilateral neuralgiform headache with conjunctival injection and tearing (SUNCT) during pregnancy. Agri. 2018 Jan;30(1):2830. doi: 10.5505/agri.2016.25991. PMID: 29450873.

110. Cooke L, Steer P, Woodgate P. Indomethacin for asymptomatic patent ductus arteriosus in preterm infants. Cochrane Database Syst Rev. 2003(2):Cd003745. doi: 10.1002/14651858.Cd003745. PMID: 12804488. 


\title{
Appendix A. Methods
}

\section{Details of Study Selection}

\section{Search Strategy (Details)}

\section{Search Strategy for Primary Studies}

We searched for published primary studies for both Key Questions (KQs) in Medline (via PubMed), the Cochrane Central Register of Clinical Trials, Embase, and the Cumulative Index to Nursing and Allied Health Literature (CINAHL). Duplicate citations were removed prior to screening. Searches did not have any date or language restrictions. Search strategies included filters to remove nonhuman studies. The searches included medical subject headings (MeSH) or Emtree terms, along with free-text words, related to pregnancy, postpartum, breastfeeding, headache, migraine, tension headache, cluster headache, and other trigeminal autonomic cephalgias (TACs). The searches were independently peer reviewed. The exact search terms used for identifying primary studies in each database are listed below. To identify additional eligible studies, we also reviewed the reference lists of relevant existing systematic reviews (SRs). Searches for primary studies will be updated upon submission of this draft report for public review.

\author{
Medline (via PubMed) \\ Last run June 5, 2020 \\ (“Breast Feeding”[Mesh] \\ OR “Fertilization”[Mesh] \\ OR “Gestational age”[Mesh] \\ OR “Lactation”[Mesh] \\ OR “Maternal Behavior”[Mesh] \\ OR “Maternal exposure”[Mesh] \\ OR “Maternal-Fetal Exchange”[Mesh] \\ OR "Perinatal Care”[Mesh] \\ OR “Pregnancy”[Mesh] \\ OR “pregnancy complications”[Mesh] \\ OR “pregnancy trimesters”[Mesh] \\ OR breastfeeding \\ OR "fetal growth" \\ OR "gestational age" \\ OR postpartum \\ OR pregnancy \\ OR pregnant \\ OR trimester \\ OR lactation \\ OR polycystic ovary syndrome \\ OR IVF \\ OR "In Vitro Fertilization” \\ OR insemination
}


OR “Polycystic Ovary Syndrome”[Mesh]

OR “Fertilization in Vitro”[Mesh])

AND

(Migraine

OR "Migraine Disorders"[Mesh]

OR "Tension-Type Headache"[Mesh]

OR "Cluster Headache"[Mesh]

OR headache

OR “Headache Disorders, Primary”[Mesh]

OR ((tension OR cluster) AND headache))

\section{Cochrane CENTRAL}

Last run June 5, 2020

((breastfeeding

OR "fetal growth"

OR "gestational age"

OR postpartum

OR pregnancy

OR pregnant

OR trimester

OR lactation

OR polycystic ovary syndrome

OR IVF

OR “In Vitro Fertilization”

OR insemination)

AND

(Migraine

OR headache))

NOT ("post-dural" or "post dural" or postdural) and puncture))

\section{CINAHL}

Last run June 5, 2020

((breastfeeding

OR "fetal growth"

OR "gestational age"

OR postpartum

OR pregnancy

OR pregnant

OR trimester

OR lactation 
OR polycystic ovary syndrome

OR IVF

OR "In Vitro Fertilization"

OR insemination)

AND

(Migraine

OR headache))

NOT ("post-dural" or "post dural" or postdural) and puncture))

\section{EMBASE}

Last run June 5, 2020

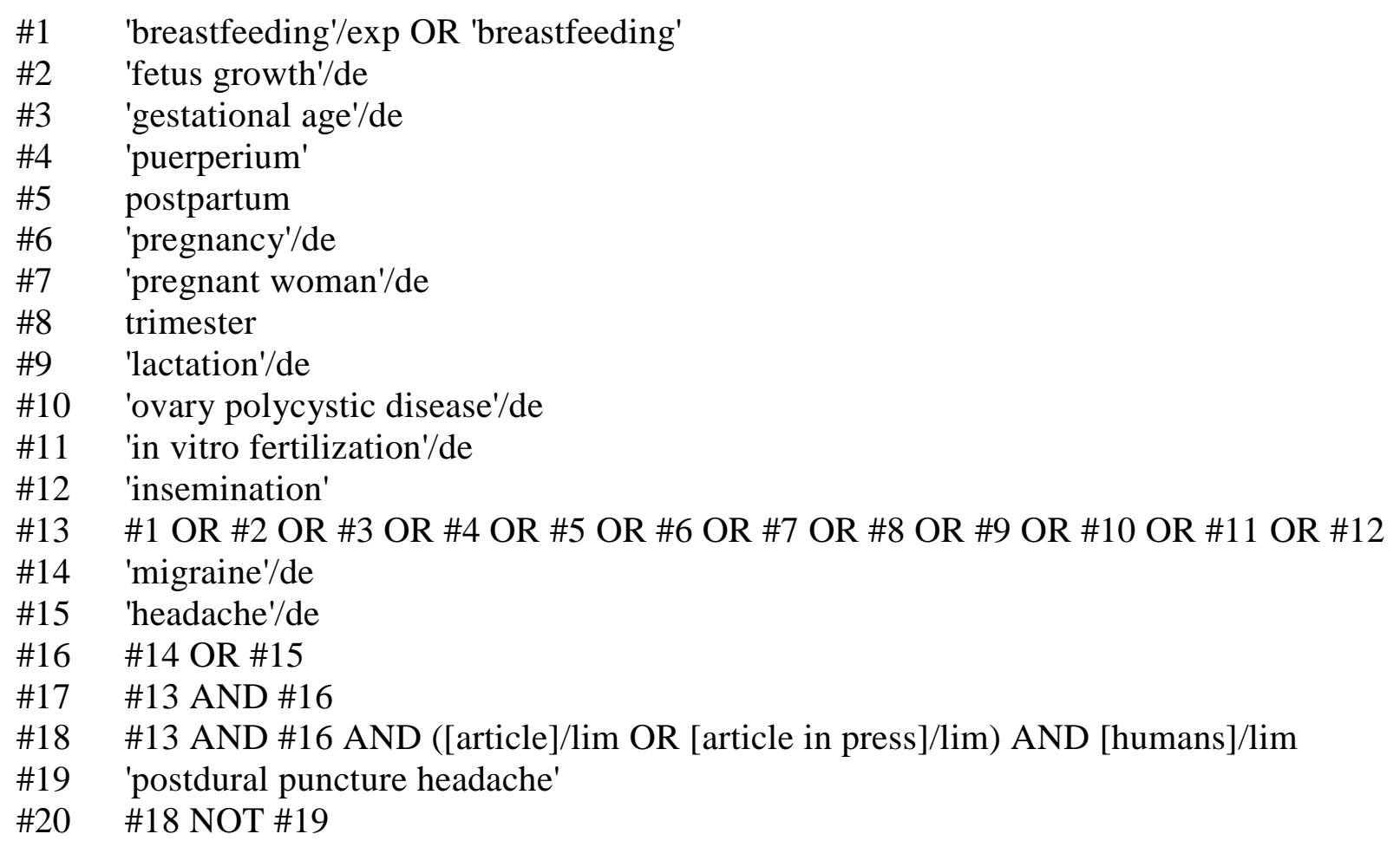

We also searched the ClinicalTrials.gov registry for unpublished study protocols, unpublished study results, and ongoing studies using the following exact terms.

\section{CLINICALTRIALS.GOV}

Last run June 5, 2020

(headache

OR migraine) [in condition field]

AND 
(breastfeeding

OR “fetal growth"

OR "gestational age"

OR postpartum

OR pregnancy

OR pregnant

OR trimester

OR lactation

OR polycystic ovary syndrome

OR IVF

OR “In Vitro Fertilization”

OR insemination) [in other terms field]

We also asked all members of the Technical Expert Panel (TEP) to review our list of included studies and suggest any additional studies that might be relevant, which we checked against our list of citations and, where applicable, added to our list. Non-English language articles were screened by readers of the relevant languages or after translation via Google Translate (https://translate.google.com/), where possible. Additional articles suggested to us in any language from any source, during peer and public review, will be screened applying identical eligibility criteria.

\title{
Search Strategy for SRs
}

To supplement information about adverse effects from the primary studies for both KQs, we searched for published SRs that have reported adverse effects of interventions, regardless of the indication for which the intervention was used, i.e., we did not restrict to primary headache (or even headache). We searched for SRs in Medline (via PubMed), the Cochrane Database of Systematic Reviews, and Epistemonikos. Duplicate citations were removed prior to screening. Searches did not have any date or language restrictions. The searches included MeSH and freetext words related to pregnancy, postpartum, breastfeeding, and each of the interventions and classes of interventions of interest (for both KQs). The exact search terms used for identifying SRs in each database are listed below. Searches for SRs will be updated upon submission of this draft report for public review.

\author{
Medline (via PubMed) \\ Last run June 5, 2020 \\ (“Breast Feeding”[Mesh] \\ OR “Fertilization”[Mesh] \\ OR “Gestational age”[Mesh] \\ OR “Lactation”[Mesh] \\ OR “Maternal Behavior”[Mesh] \\ OR “Maternal exposure”[Mesh] \\ OR “Maternal-Fetal Exchange”[Mesh] \\ OR "Perinatal Care”[Mesh] \\ OR “Pregnancy”[Mesh]
}


OR “pregnancy complications”[Mesh]

OR “pregnancy trimesters”[Mesh]

OR breastfeeding

OR "fetal growth"

OR "gestational age"

OR postpartum

OR pregnancy

OR pregnant

OR trimester

OR lactation)

AND

(“Antidepressive agents, Tricyclic”[Mesh]

OR “Adrenergic beta-Antagonists”[Mesh]

OR “Calcium Channel Blockers”[Mesh]

OR “Anticonvulsants”[Mesh]

OR “Serotonin Uptake Inhibitors”[Mesh]

OR "Benzodiazepines”[Mesh]

OR “Anti-Inflammatory Agents, Non-Steroidal”[Mesh]

OR “Neuromuscular Blocking Agents”[Mesh]

OR “Histamine Antagonists”[Mesh]

OR “Central Nervous System Stimulants”[Mesh]

OR “Tryptamines”[Mesh]

OR "narcotics”[Mesh]

OR “Analgesics, Opioid”[Mesh]

OR “Antimanic Agents”[Mesh]

OR “Antipsychotic Agents”[Mesh]

OR “Antiemetics”[Mesh]

OR “Anesthetics, Local”[Mesh]

OR “Analgesics”[Mesh]

OR "Tricyclic antidepressants"

OR amitriptyline

OR nortriptyline

OR imipramine

OR "Beta blockers"

OR metoprolol

OR propranolol

OR nadolol

OR atenolol

OR timolol

OR nebivolol

OR "Calcium channel blockers"

OR verapamil

OR nimodipine

OR nifedipine 
OR nicardipine

OR lisinopril

OR candesartan

OR Antiepileptic*

OR “divalproex sodium”

OR "valproic acid"

OR "sodium valproate”

OR topiramate

OR carbamazepine

OR lamotrigine

OR gabapentin

OR ((Serotonin OR norepinephrine) AND “reuptake inhibitor”)

OR venlafaxine

OR duloxetine

OR benzodiazepines

OR clonazepam

OR (NMDA AND receptor AND (inhibitor OR antagonist))

OR memantine

OR (CGRP AND (inhibitor OR antagonist))

OR erenumab

OR fremanezumab

OR galcanezumab

OR riboflavin

OR “coenzyme Q10”

OR melatonin

OR feverfew

OR "herbal supplement”

OR feverfew

OR butterbur

OR frankincense

OR cannabidiol

OR cyproheptadine

OR acetaminophen

OR paracetamol

OR (Nonsteroidal AND (antiinflammatory OR anti-inflammatory))

OR NSAID

OR Excedrin

OR ibuprofen

OR naproxen

OR aspirin

OR celecoxib

OR ketorolac

OR indomethacin

OR ketoprofen

OR diclofenac

OR "mefenamic acid” 
OR Midrin

OR isometheptene

OR dichloralphenazone

OR Antiemetics

OR metoclopramide

OR Antihistamines

OR meclizine

OR dimenhydrinate

OR diphenhydramine

OR promethazine

OR prochlorperazine

OR ((“Central Nervous System” OR “CNS”) AND “Stimulant”)

OR caffeine

OR "muscle relaxant"

OR baclofen

OR cyclobenzaprine

OR tizanidine

OR metaxolone

OR carisoprodol

OR "neuromuscular block"

OR OnabotulinumtoxinA

OR botox

OR AbobotulinumtoxinA

OR dysport

OR magnesium

OR corticosteroids

OR methylprednisolone

OR triamcinolone

OR prednisolone

OR prednisone

OR triptans

OR sumatriptan

OR frovatriptan

OR naratriptan

OR rizatriptan

OR almotriptan

OR eletriptan

OR zolmitriptan

OR narcotics

OR opioids

OR codeine

OR nalbuphine

OR butorphanol

OR hydrocodone

OR oxycodone

OR morphine 
OR meperidine

OR tramadol

OR Fioricet

OR Fiorinal

OR butalbital

OR dihydroergotamine

OR ergotamine

OR (“5HT3” AND (“inhibitor” OR “antagonist”))

OR ondansetron

OR "Sympathomimetic Amine”

OR isometheptene

OR "topical anesthetics"

OR lidocaine

OR bupivacaine

OR Antipsychotics

OR chlorpromazine

OR droperidol

OR olanzapine

OR antimanic

OR lithium

OR “Tetracyclic antidepressant”

OR mirtazapine

OR “Somatostatin analog”

OR octreotide)

AND

("drug-related side effects and adverse reactions"[MESH]

OR “abnormalities, drug-induced”[MESH]

OR birth defect

OR congenital abnormality

OR ((adverse or undesirable or harm or harms or harmful or toxic or injurious or serious or fatal)

AND (effect* or reaction* or event* or outcome* or incident*)))

OR Pharmacokinetic* OR pharmacodynamic* OR "Pharmacokinetics"[Mesh]

OR "Breast milk"

OR “Milk, Human”[Mesh]

OR "human milk"

OR "Fetal blood”[Mesh]

OR "fetal blood"

OR "cord blood"

OR "amniotic fluid"

OR “Amniotic Fluid”[Mesh])

AND 
(systematic[sb] OR meta-analysis[pt] OR meta-analysis as topic[mh] OR meta-analysis[mh] OR meta analy* OR metanaly* OR metaanaly* OR met analy* OR (systematic AND (review* OR overview*)) OR "Review Literature as Topic"[Mesh] OR cochrane[tiab] OR embase[tiab] OR (psychlit[tiab] or psyclit[tiab]) OR (psychinfo[tiab] or psycinfo[tiab]) OR (cinahl[tiab] or cinhal[tiab] OR “cumulative index to nursing and allied health”) OR science citation index[tiab] OR ibids[tiab] OR “international bibliographic information on dietary supplements” OR cancerlit[tiab] OR reference list*[tiab] OR bibliograph*[tiab] OR hand-search*[tiab] OR relevant journals[tiab] OR manual search*[tiab] OR ((selection OR inclusion OR exclusion) AND criteria[tiab]) OR data extraction[tiab] OR relevant journals OR "Systematic Review" [Publication Type])

Epistemonikos and Cochrane (same strategy for both databases)

Last run June 5, 2020

(breastfeeding

OR "fetal growth"

OR "gestational age”

OR postpartum

OR pregnancy

OR pregnant

OR trimester

OR lactation)

AND

("Tricyclic antidepressants"

OR amitriptyline

OR nortriptyline

OR imipramine

OR "Beta blockers"

OR metoprolol

OR propranolol

OR nadolol

OR atenolol

OR timolol

OR nebivolol

OR “Calcium channel blockers”

OR verapamil

OR nimodipine

OR nifedipine

OR nicardipine

OR lisinopril

OR candesartan

OR Antiepileptic*

OR “divalproex sodium” 
OR "valproic acid"

OR "sodium valproate”

OR topiramate

OR carbamazepine

OR lamotrigine

OR gabapentin

OR ((Serotonin OR norepinephrine) AND “reuptake inhibitor”)

OR venlafaxine

OR duloxetine

OR benzodiazepines

OR clonazepam

OR (NMDA AND receptor AND (inhibitor OR antagonist))

OR memantine

OR (CGRP AND (inhibitor OR antagonist))

OR erenumab

OR fremanezumab

OR galcanezumab

OR riboflavin

OR “coenzyme Q10”

OR melatonin

OR feverfew

OR "herbal supplement"

OR feverfew

OR butterbur

OR frankincense

OR cannabidiol

OR cyproheptadine

OR acetaminophen

OR paracetamol

OR (Nonsteroidal AND (antiinflammatory OR anti-inflammatory))

OR NSAID

OR Excedrin

OR ibuprofen

OR naproxen

OR aspirin

OR celecoxib

OR ketorolac

OR indomethacin

OR ketoprofen

OR diclofenac

OR “mefenamic acid”

OR Midrin

OR isometheptene

OR dichloralphenazone

OR Antiemetics

OR metoclopramide 
OR Antihistamines

OR meclizine

OR dimenhydrinate

OR diphenhydramine

OR promethazine

OR prochlorperazine

OR ((“Central Nervous System” OR “CNS”) AND “Stimulant”)

OR caffeine

OR “muscle relaxant"

OR baclofen

OR cyclobenzaprine

OR tizanidine

OR metaxolone

OR carisoprodol

OR "neuromuscular block"

OR OnabotulinumtoxinA

OR botox

OR AbobotulinumtoxinA

OR dysport

OR magnesium

OR corticosteroids

OR methylprednisolone

OR triamcinolone

OR prednisolone

OR prednisone

OR triptans

OR sumatriptan

OR frovatriptan

OR naratriptan

OR rizatriptan

OR almotriptan

OR eletriptan

OR zolmitriptan

OR narcotics

OR opioids

OR codeine

OR nalbuphine

OR butorphanol

OR hydrocodone

OR oxycodone

OR morphine

OR meperidine

OR tramadol

OR Fioricet

OR Fiorinal

OR butalbital 
OR dihydroergotamine

OR ergotamine

OR (“5HT3” AND (“inhibitor” OR “antagonist”))

OR ondansetron

OR “Sympathomimetic Amine"

OR isometheptene

OR "topical anesthetics"

OR lidocaine

OR bupivacaine

OR Antipsychotics

OR chlorpromazine

OR droperidol

OR olanzapine

OR antimanic

OR lithium

OR “Tetracyclic antidepressant”

OR mirtazapine

OR "Somatostatin analog”

OR octreotide)

AND

(birth defect

OR congenital abnormality

OR ((adverse or undesirable or harm or harms or harmful or toxic or injurious or serious or fatal)

AND (effect* or reaction* or event* or outcome* or incident*))

OR Pharmacokinetic*

OR pharmacodynamic*

OR "Breast milk"

OR "human milk"

OR "fetal blood”

OR "cord blood"

OR “amniotic fluid”)

\section{Inclusion and Exclusion Criteria (Details)}

\section{Inclusion and Exclusion Criteria for KQ 1 (Prevention of Primary Headache)}

\section{Population(s)}

- Women who are pregnant (or attempting to become pregnant/in the preconception phase), postpartum (defined as up to 12 months postdelivery), or breastfeeding (for any length of time) with history of primary headache

o Migraine, tension headache, cluster headache or other trigeminal autonomic cephalgia (TACs) 
o Women attempting to become pregnant include those actively planning pregnancy, by any method, who may wish to use only treatments found to be safe and effective during pregnancy.

- Exclude: Women with history of secondary headache of any origin

\section{Interventions}

- Pharmacologic interventions

o Tricyclic antidepressants (e.g., amitriptyline, nortriptyline, imipramine)

o Serotonin and norepinephrine reuptake inhibitors (SNRIs) (e.g., venlafaxine, duloxetine)

o Beta blockers (e.g., metoprolol, propranolol, nadolol, atenolol, timolol, nebivolol)

o Calcium channel blockers (e.g., verapamil, nimodipine, nifedipine, nicardipine)

o Other antihypertensive medications (e.g., lisinopril, candesartan, clonidine)

o Antiepileptic drugs (e.g., divalproex sodium, sodium valproate, valproic acid, topiramate, gabapentin, carbamazepine, lamotrigine)

o Benzodiazepines (e.g., clonazepam)

o N-methyl-D-aspartate (NMDA) receptor antagonists (e.g., memantine)

o Calcitonin gene-related peptide (CGRP) inhibitors (e.g., erenumab, fremanezumab, galcanezumab)

o Antihistamines (e.g., cyproheptadine)

o Mood-stabilizing agents (e.g., lithium)

o Tetracyclic antidepressants (e.g., mirtazapine)

o Corticosteroids (e.g., methylprednisolone, triamcinolone acetonide, combinations of local anesthetics and corticosteroids)

o Oral magnesium

o Other pharmacologic interventions used to prevent primary headaches (whether or not available or approved in the United States)

- Nonpharmacologic interventions

o Supplements (e.g., riboflavin, coenzyme Q10, melatonin, feverfew, butterbur, frankincense)

o Procedures (e.g., occipital nerve blocks, sphenopalatine ganglion blocks, trigger point injections)

o Chemodenervation (e.g., onabotulinumtoxin A, abobotulinumtoxin A)

o Physical therapy

o Hydration

o Noninvasive neuromodulation devices (e.g., transcutaneous electrical nerve stimulation, transcranial magnetic stimulation, transcutaneous vagal stimulation, remote electrical neurostimulation)

o Behavioral therapy (e.g., cognitive behavioral therapy, diet therapy, sleep therapy, exercise therapy, support group therapy)

o Complementary therapies (e.g., biofeedback, acupuncture, mindfulness-based stress reduction)

o Other nonpharmacologic interventions used to prevent primary headaches

\section{Comparators}

- Pharmacologic interventions

o Other class 
o Other drug within class

o Same drug(s), different route, treatment duration, initiation time, or other aspect

o As comparator to nonpharmacologic intervention

- Nonpharmacologic interventions

o Other nonpharmacologic intervention class

o Other nonpharmacologic intervention, within class

o As comparator to pharmacologic intervention

- No pharmacologic or nonpharmacologic interventions

o Placebo

o No intervention

\section{Outcomes}

(* denotes important outcomes that were considered when developing Strength of Evidence tables):

- Acute headache attacks*

o Occurrence of acute headache attacks

o Frequency of acute headache attacks

o Severity of acute headache attacks

o Duration of acute headache attacks

- Headache-related symptoms (e.g., nausea/vomiting, photosensitivity, dizziness)*

o Occurrence of headache-related symptoms

o Frequency of headache-related symptoms

o Severity of headache-related symptoms

o Duration of headache-related symptoms

o Most bothersome symptom

- Emergency department visits, clinic visits, or hospitalizations*

- Quality of life*

- Functional outcomes

o Impact on family life

o Employment/school attendance

0 Time spent managing disease

- Resource use

- Acceptability of intervention by patients

- Patient satisfaction with intervention

- Medication use

- Adverse effects

o Maternal

- Serious maternal adverse effects*

o "Serious" adverse effects (including those that are composite outcomes), as defined by study authors

o Cardiovascular outcomes, such as stroke, myocardial infarction

- Nonserious maternal adverse effects

o Nonobstetrical (e.g., maternal weight gain, tachycardia, hypertension, gastrointestinal)

o Preterm labor, cesarean section

o Reduced breast milk production 
o Symptoms related to withdrawal of medication

- Discontinuation of intervention (or of study participation) due to maternal adverse effects*

o Fetal/Child

- Serious fetal/child adverse effects*

o "Serious" adverse effects (including those that are composite outcomes), as defined by study authors

o Spontaneous abortion or elective or induced abortion ( $<20$ weeks)

o Stillbirth or fetal death ( $\geq 20$ weeks)

o Neonatal or infant death

o Preterm birth

o Low birth weight for gestational age

o Congenital anomalies

o Perinatal complications, e.g., low APGAR score, respiratory distress, admission to neonatal intensive care unit (NICU)

o Neurodevelopmental, behavioral, or social - gross motor development, fine motor development, social, emotional, or cognitive delay or disability

- Nonserious fetal/child adverse effects

o Breastfeeding - delayed initiation, cessation, reduced frequency, reduced volume of breast milk

o Poor infant attachment/bonding

o Symptoms related to withdrawal of medication

- Discontinuation of intervention (or of study participation) due to fetal/child adverse effects*

\section{Potential Modifiers}

- Phase

o Preconception

o First trimester

o Second trimester

o Third trimester

o Postpartum

o Breastfeeding

- Type of primary headache

o Migraine

o Tension headache

o Cluster headache

o Other TACs

Timing

- Any

Setting

- Any

Design

- Direct Evidence 
o Randomized controlled trials (RCTs)

o Nonrandomized comparative studies (NRCSs)

o Single-group studies

o N-of-1 trials

o Case-control studies

o Cross-sectional studies/surveys

o Prospective or retrospective (all applicable study types)

- Indirect Evidence

o For adverse effects, we searched for existing SRs that reported adverse effects of individual interventions used during pregnancy, postpartum, or breastfeeding, regardless of their indication (i.e., for any disease/condition, not only primary headaches). We did not enforce a date restriction when screening for eligible SRs, but we required that, SRs should have fulfilled each of the following four minimum criteria:

1. Specified eligibility criteria for primary studies,

2. Conducted a comprehensive search (defined as searched at least two electronic databases and searched for unpublished studies through at least one source),

3. Assessed risk of bias in included studies using any instrument, and

4. Used appropriate methods for meta-analysis, if conducted.

- Supplemental Evidence

o Case reports or series of individually-reported case reports

\section{Inclusion and Exclusion Criteria for KQ 2 (Treatment of Primary Headache)}

\section{Population(s)}

- Women who are pregnant (or attempting to become pregnant/in the preconception phase), postpartum (defined as up to 12 months postdelivery), or breastfeeding (for any length of time) with acute attacks of primary headache

o Migraine, tension headache, cluster headache, or other trigeminal autonomic cephalgia (TACs)

o Women attempting to become pregnant include those actively planning pregnancy, by any method, who may wish to use only treatments found to be safe and effective during pregnancy.

- Exclude: Women with attacks of secondary headache of any origin

\section{Interventions}

- Pharmacologic interventions

o Analgesics/antipyretics (e.g., acetaminophen)

o Nonsteroidal antiinflammatory drugs (NSAIDs) (e.g., ibuprofen, naproxen, aspirin, celecoxib, ketorolac, indomethacin, ketoprofen, diclofenac, mefenamic acid)

o Other over-the-counter analgesics (e.g., combination aspirin, acetaminophen, and caffeine; combination acetaminophen, isometheptene, and dichloralphenazone)

o Antiemetics: dopamine receptor antagonists (e.g., metoclopramide, promethazine, prochlorperazine, droperidol, chlorpromazine)

o Antiemetics: 5HT3 antagonists (e.g., ondansetron)

o Antihistamines (e.g., meclizine, diphenhydramine, dimenhydrinate, promethazine, pizotifen) 
o Central nervous system stimulants (e.g., caffeine)

o Muscle relaxants (e.g., baclofen, tizanidine, metaxalone, carisoprodol)

o Corticosteroids (e.g., prednisolone, prednisolone, methylprednisolone, dexamethasone, betamethasone)

o Triptans/Serotonin receptor agonists (e.g., sumatriptan, frovatriptan, naratriptan, rizatriptan, almotriptan, eletriptan, zolmitriptan, combination sumatriptan and naproxen)

o Opioid containing analgesics (e.g., codeine, hydrocodone, oxycodone, morphine, meperidine, tramadol, butorphanol, nalbuphine)

o Butalbital-containing analgesics (e.g., butalbital; combination butalbital and acetaminophen; combination butalbital, aspirin, and caffeine)

o Ergot products (e.g., dihydroergotamine, ergotamine, combination ergotamine and caffeine)

o Sympathomimetic amines (e.g., isometheptene)

o Topical anesthetics (e.g., lidocaine)

o Antipsychotics (e.g., chlorpromazine, olanzapine)

o Somatostatin analogs (e.g., octreotide)

o Intravenous magnesium

o Other pharmacologic interventions used to treat acute attacks of primary headache (whether or not available or approved in the United States)

- Nonpharmacologic interventions

o Hydration

o Physical therapy

o Procedures (e.g., occipital nerve blocks, sphenopalatine ganglion blocks, trigger point injections)

o Noninvasive neuromodulation devices (e.g., transcutaneous electrical nerve stimulation, transcranial magnetic stimulation, transcutaneous vagal stimulation, remote electrical neurostimulation)

o Behavioral therapy (e.g., cognitive behavioral therapy, diet therapy, sleep therapy, exercise therapy, support group therapy)

o Supplements (e.g., cannabidiol)

o Complementary therapies (e.g., biofeedback, acupuncture, mindfulness-based stress reduction)

o Other nonpharmacologic interventions used to treat acute attacks of primary headache

\section{Comparators}

- Pharmacologic interventions

o Other class

o Other drug within class

o Same drug(s), different route, treatment duration, initiation time, or other aspect

o As comparator to nonpharmacologic intervention

- Nonpharmacologic interventions

o Other nonpharmacologic intervention class

o Other nonpharmacologic intervention, within class

o As comparator to pharmacologic intervention

- No pharmacologic or nonpharmacologic interventions

o Placebo 
o No intervention

\section{Outcomes}

(* denotes important outcomes that were considered when developing Strength of Evidence tables):

- Acute headache attack*

o Severity of acute headache attack

o Duration of acute headache attack

o Resolution of acute headache attack

o Recurrence of headache attacks

- Headache-related symptoms (e.g., nausea/vomiting, photosensitivity)*

o Severity of headache-related symptoms

o Duration of headache-related symptoms

o Resolution of headache-related symptoms

o Recurrence of headache-related symptoms

o Most bothersome symptom

- Emergency department visits, clinic visits, or hospitalizations*

- Quality of life*

- Functional outcomes

o Impact on family life

o Employment/school attendance

o Time spent managing disease

- Resource use

- Acceptability of intervention by patients

- Patient satisfaction with intervention

- Medication use

- Adverse effects

o Maternal

- Serious maternal adverse effects*

o "Serious" adverse effects (including those that are composite outcomes), as defined by study authors

o Cardiovascular outcomes, such as stroke, myocardial infarction

- Nonserious maternal adverse effects

o Nonobstetrical (e.g., maternal weight gain, tachycardia, hypertension, gastrointestinal)

o Preterm labor, cesarean section

o Reduced breast milk production

o Symptoms related to withdrawal of medication

- Discontinuation of intervention (or of study participation) due to maternal adverse effects*

o Fetal/child

- Serious fetal/ child adverse effects*

o "Serious" adverse effects (including those that are composite outcomes), as defined by study authors

o Spontaneous abortion or elective or induced abortion ( $<20$ weeks)

o Stillbirth or fetal death ( $\geq 20$ weeks) 
o Neonatal or infant death

o Preterm birth

o Low birth weight for gestational age

o Congenital anomalies

o Perinatal complications, e.g., low APGAR score, respiratory distress, admission to NICU

o Neurodevelopmental, behavioral, or social - gross motor development, fine motor development, social, emotional, or cognitive delay or disability

- Nonserious fetal/child adverse effects

o Breastfeeding - delayed initiation, cessation, reduced frequency, reduced volume of breast milk

o Poor infant attachment/bonding

o Symptoms related to withdrawal of medication

- Discontinuation of intervention (or of study participation) due to fetal/child adverse effects*

\section{Potential Modifiers}

- Phase

o Preconception

o First trimester

o Second trimester

o Third trimester

o Postpartum

o Breastfeeding

- Type of primary headache

o Migraine

o Tension headache

o Cluster headache

o Other TACs

\section{Timing}

- Any

\section{Setting}

- Any

\section{Design}

- Direct Evidence:

o RCTs

o NRCSs

o Single-group studies

o N-of-1 trials

o Case-control studies

o Cross-sectional studies/surveys

o Prospective or retrospective (all applicable study types)

- Indirect Evidence: 
o For adverse effects, we searched for existing SRs that reported adverse effects of individual interventions used during pregnancy, postpartum, or breastfeeding, regardless of their indication (i.e., for any disease/condition, not only primary headaches). We did not enforce a date restriction when screening for eligible SRs, but we required that, at a minimum, SRs should have fulfilled each of the following four criteria:

5. Specified eligibility criteria for primary studies,

6. Conducted a comprehensive search (defined as searched at least two electronic databases and searched for unpublished studies through at least one source),

7. Assessed risk of bias in included studies using any instrument, and

8. Used appropriate methods for meta-analysis, if conducted.

- Supplemental Evidence:

o Case reports or series of individually-reported case reports

\section{Screening Process (Details)}

We screened abstracts in the Abstrackr online software platform (http://abstrackr.cebm.brown.edu/). We created two projects in Abstrackr, one each for primary studies and SRs. For each project, we conducted two rounds of pilot screening. During each pilot round, the entire team screened the same 100 abstracts and discussed conflicts, with the goal of training the team in the nuances of the eligibility criteria and refining them to maximize clarity and efficiency of the screening process. After the pilot rounds, we screened all remaining abstracts in duplicate. The Abstrackr software has machine-learning capabilities that predict the likelihood of relevance of each unscreened abstract. Daily, Abstrackr sorts the unscreened abstracts by likely relevance so that the most relevant abstracts are presented to screeners first. This made the process of screening more efficient and enabled us to capture the large majority of relevant articles relatively early in the abstract screening process.

Potentially-relevant citations were retrieved in full text. Each of these full-text articles were rescreened by one team member with verification by another.

\section{Data Extraction (Details)}

We extracted data from eligible primary studies into the Systematic Review Data Repository (https://srdr.ahrq.gov) and data from eligible SRs into Google Sheets (https://docs.google.com/spreadsheets). For each article, one researcher extracted and entered data, which were confirmed by a second, independent researcher. Each individual primary study/SR that was reported in multiple articles was extracted as a single record. In the instance where two studies were reported within a single article, each study was extracted separately.

For each primary study, we extracted article-identifying information, study design features, funding source, population characteristics and sample sizes, intervention and comparator names and descriptions, and relevant benefit and harms outcomes and their definitions.

For each SR, we extracted article-identifying information; information pertaining to our four minimum criteria (i.e., specification of study eligibility criteria, comprehensiveness of search, assessment of risk of bias in included studies, and methods used for meta-analysis, if conducted); other features of the SR related to its quality (see following section); year of last search; number of included studies; number of included studies of women in preconception, pregnant, postpartum, or breastfeeding phases; population characteristics; intervention names and descriptions; and relevant harms outcomes and their definitions. 
For both primary studies and SRs, we extracted, as available, data on phase (i.e., preconception, First trimester of pregnancy, second trimester of pregnancy, third trimester of pregnancy, postpartum, breastfeeding) and type of primary headache (i.e., migraine, tension headache, cluster headache, other TACs).

\section{Risk of Bias Assessment (Details)}

\section{Risk of Bias Assessment for Primary Studies}

We evaluated each study for risk of bias and methodological quality. Because we included a variety of study designs, we incorporated items from three different existing commonly-used tools and tailored the set of items for each study design. The three tools were the Cochrane Risk of Bias Tool, ${ }^{1}$ the Risk of Bias in Nonrandomized Studies (ROBINS-I) Tool, ${ }^{2}$ and the National Heart, Lung, and Blood Institute (NHLBI) Quality Assessment Tool. ${ }^{3}$

For RCTs, we used all the items from the Cochrane Risk of Bias Tool, ${ }^{1}$ focusing on issues related to randomization and allocation concealment methodology; blinding of patients, study personnel/care providers, objective outcome assessors, and subjective outcome assessors; incomplete outcome data; selective outcome reporting; and other issues that could be related to bias. We also used items from the NHLBI Tool focusing on the adequacy of descriptions of study eligibility criteria, interventions, and outcomes. ${ }^{3}$

For NRCSs, we used specific sections of the ROBINS-I Tool ${ }^{2}$ that pertain to confounding and selection bias. ROBINS-I requires the identification of specific confounders of interest for the SR. For the purpose of assessing for the presence of potential confounding in studies, we considered age, severity of headache (or history of headache), and frequency of headache (or history of headache). Because NRCSs, like RCTs, can be impacted by the lack of blinding and by participant loss to followup, we also used the items from the Cochrane Risk of Bias Tool ${ }^{1}$ that focus on issues related to blinding of patients, study personnel/care providers, objective outcome assessors, and subjective outcome assessors; incomplete outcome data; selective outcome reporting; and other issues that could be related to bias. We also used items from the NHLBI Tool that pertain to the adequacy of descriptions of study eligibility criteria, interventions, and outcomes. ${ }^{3}$

For single-group studies, we used the items from the Cochrane Risk of Bias Tool ${ }^{1}$ that pertain to issues of participant loss to followup, specifically, incomplete outcome data, selective outcome reporting, and other issues that could be related to bias. We also used items from the NHLBI Tool focusing on the adequacy of descriptions of study eligibility criteria, interventions, and outcomes. ${ }^{3}$

We did not conduct a risk of bias assessment for case reports because we did not use them to inform conclusions.

\section{Quality Assessment for SRs}

We assessed the quality of the SRs using specific items from the A Measurement Tool to Assess Systematic Reviews, version 2 Tool (AMSTAR 2). ${ }^{4}$ For each SR, we assessed whether the SR authors: described the eligibility criteria for included studies (AMSTAR 2 item 1); conducted a comprehensive literature search (item 4); conducted duplicate screening of studies (item 5); conducted duplicate data extraction (independently or with verification) (item 6); adequately described the details of included studies (item 8); used a satisfactory technique for assessing risk of bias in included studies (item 9); assessed the potential impact of risk of bias 
(item 12); used appropriate meta-analysis methods (if conducted) (item 11); explained or discussed any heterogeneity (item 14); and reported SR conflict of interest (item 16).

Because we only included SRs that fulfilled each of our minimum criteria, the AMSTAR 2 items pertaining to these criteria (items 1, 2, 9, and 11) were always assessed as "Yes."

\section{Data Synthesis and Analysis (Details)}

We summarized the evidence qualitatively. We described each study included in the de novo SR narratively and using summary and evidence tables describing the study design features, participant characteristics, descriptions of interventions, outcome results, and risk of bias/methodological quality.

We described each existing SR (for adverse effects of interventions) narratively and using summary tables describing the SR's eligibility criteria, included studies, interventions, adverse effects, and reported effect sizes.

For the identified RCTs and NRCSs addressing Key Questions 1 and 2, we extracted information about the effects of interventions (pharmacologic and nonpharmacologic interventions) versus their comparators, primarily with odds ratios (ORs) or relative risks (RRs) for dichotomous outcomes (e.g., resolution of headache), "net mean differences" (NMDs, i.e., between-intervention comparison of within-intervention changes) for continuous outcomes with both pre- and post-intervention data (e.g., severity of headache), and mean differences for continuous outcomes with only post-intervention data (e.g., duration of hospitalization).

Where effect sizes were not reported for RCTs, we calculated unadjusted between-arm effect sizes based on reported arm-specific data (if feasible). When necessary for NMDs, standard errors (SEs) of the differences were estimated from reported standard deviations (or SEs) of baseline and final values. We assumed a correlation of 0.5 between baseline and final values in patients receiving a given intervention. Thus, we used the following equation to estimate the SE:

$$
\mathrm{SE}_{\text {difference }}^{2}\left(\mathrm{SE}_{\mathrm{A}}\right)^{2}+\left(\mathrm{SE}_{\mathrm{B}}\right)^{2}-2 \cdot r \cdot\left(\mathrm{SE}_{\mathrm{A}}\right) \cdot\left(\mathrm{SE}_{\mathrm{B}}\right)
$$

where $r=0.5$ (the assumed correlation) and A and B index the correlated measurements (baseline and final time points).

Where effect sizes were not reported for NRCSs, we only did this if the arms were sufficiently similar at baseline on important prognostic factors for the unadjusted effect sizes to be meaningful.

For single-group studies, between-arm effect sizes are not relevant. However, we extracted (and, where possible, calculated) within-arm changes in outcomes in these studies.

No effect sizes are relevant for case reports; we have described these studies narratively (and in summary tables). We have not used the case reports to inform conclusions.

If we identified sufficient studies reporting sufficiently similar results, we would have conducted a Bayesian network meta-analysis comparing the different interventions to each other and to placebo (or no intervention).

\section{Grading the Strength of the Body of Evidence (Details)}

We evaluated the Strength of Evidence (SoE) addressing each major comparison for each KQ. These evaluations included the relative benefits and harms (both maternal and fetal/child) for all pharmacologic and nonpharmacologic interventions for which we found studies. We graded the SoE as per the Agency for Healthcare Research and Quality (AHRQ) Methods Guide. ${ }^{5,6}$ We assessed SoE for each outcome category that we, with input from the TEP, determined a priori to be important. These categories included acute headache attacks; 
headache-related symptoms; emergency department visits, clinic visits, or hospitalizations; quality of life; serious maternal adverse effects or discontinuation of intervention (or of study participation) due to maternal adverse effects; and serious fetal/child adverse effects or discontinuation of intervention (or of study participation) due to fetal/child adverse effects.

For each SoE assessment, we considered the number of studies, their study designs, the study limitations (i.e., risk of bias and overall methodological quality), the directness of the evidence to the KQs, the consistency of study results, the precision of any estimates of effect, the likelihood of reporting bias, other limitations, and the overall findings across studies. When only one study was identified, we rated the consistency as 'not applicable (N/A).' When a single-group study was the only study identified, we rated the directness as 'indirect.' Based on these assessments, we assigned a SoE rating as being either high, moderate, low, or insufficient to estimate an effect.

We conducted SoE assessments of the evidence reported in the SRs in as similar fashion to our SoE assessment of the primary studies. When assessing RoB in the SRs, our assessments focused on the reported RoB among the studies in the SRs. By default, we rated the evidence in the SRs as indirect because they were not restricted to studies of patients with primary headache. The only exception to this was the one SR on triptans, which was focused on patients with migraine.

Outcomes with highly imprecise estimates, highly inconsistent findings across studies, or with data from only one study were deemed to have insufficient evidence to allow a conclusion (with the exception that particularly large and generalizable single studies could provide at least low SoE). This approach is consistent with the concept that for imprecise evidence "any estimate of effect is very uncertain,” the definition of Very Low quality evidence per GRADE. ${ }^{7}$

\section{Peer Review and Public Commentary}

Experts in neurology, obstetrics and gynecology, maternal and fetal medicine, and primary care, and individuals representing stakeholder and user communities were invited to provide external peer review of this SR. AHRQ and an Associate Editor from a fellow Evidence-based Practice Center also provided comments. The draft report was posted on the AHRQ Website to elicit public comment for 4 weeks (from June 2 to June 30, 2020. We addressed all reviewer comments, revising the text as appropriate. A disposition of comments table of peer and public comments is posted on the EHC Website.

\section{Glossary of Terms and Abbreviations}

\section{Terms}

Acute headache attack Breastfeeding

Postpartum

Preconception

Primary headaches

Secondary headache
An occurrence of headache with moderate to severe pain intensity The phase during which, according to the included studies, women were breastfeeding their infant(s)

The phase between delivery and up to 12 months post-delivery

The phase during which women are attempting to become pregnant Conditions where the headache itself is the disorder

Headaches that are caused by an underlying disorder, such as stroke, venous thromboembolism, and pituitary tumors 


\section{Abbreviations}

AAP

ACOG

AHRQ

AHS

AMSTAR 2

ASQ

BCBS

CBCL

CINAHL

COI

EAST

EPC

EHC

FDA

HR

KI

KQ

MD

$\mathrm{MeSH}$

NMD

NHLBI

NICU

NLM

NICHD

NRCS

NSAID

OB/GYN

OR

RCT

ROBINS-I

RR

SD

SE

SoE

SR

SUNCT

TAC

TEP

TOO

VAS

WMD
American Academy of Pediatrics

American College of Obstetricians and Gynecologists

Agency for Healthcare Research and Quality

American Headache Society

A Measurement Tool to Assess Systematic Reviews 2

Ages and Stages Questionnaire

Blue Cross Blue Shield

Child Behavior Check List

Cumulative Index to Nursing and Allied Health Literature

conflicts of interest

Emotionality, Activity, and Shyness Temperament

Evidence-based Practice Center

Effective Health Care Program

Food and Drug Administration

hazard ratio

key informant

key question

mean difference

medical subject heading

net mean difference

National Heart, Lung, and Blood Institute

neonatal intensive care unit

National Library of Medicine

National Institute of Child Health and Human Development

nonrandomized comparative study

nonsteroidal anti-inflammatory drug

obstetrician and gynecologist

odds ratio

randomized controlled trial

Risk of Bias in Nonrandomized Studies of Interventions

relative risk

standard deviation

standard error

strength of evidence

systematic review

short-lasting, unilateral, neuralgiform headache with conjunctival injection and tearing

trigeminal autonomic cephalgia

Technical Expert Panel

Task Order Officer

Visual Analog Scale

weighted mean difference 


\section{Appendix B. Results}

\section{Results of Literature Searches}

\section{Primary Search}

As illustrated by Figure B-1, our primary electronic search retrieved a combined 8,154 unique citations. An additional 395 citations were retrieved from handsearching 19 relevant SRs that were identified during this search. All told, 8,549 unique abstracts were retrieved and screened. Of these, 400 were deemed potentially relevant and retrieved in full text. After full-text screening, we identified 16 primary studies that were reported in 26 articles (direct evidence) ${ }^{8-33}$ and 19 case reports that were reported in 19 articles (supplemental evidence). ${ }^{34-52}$

Figure B-1. Flow diagram for primary studies

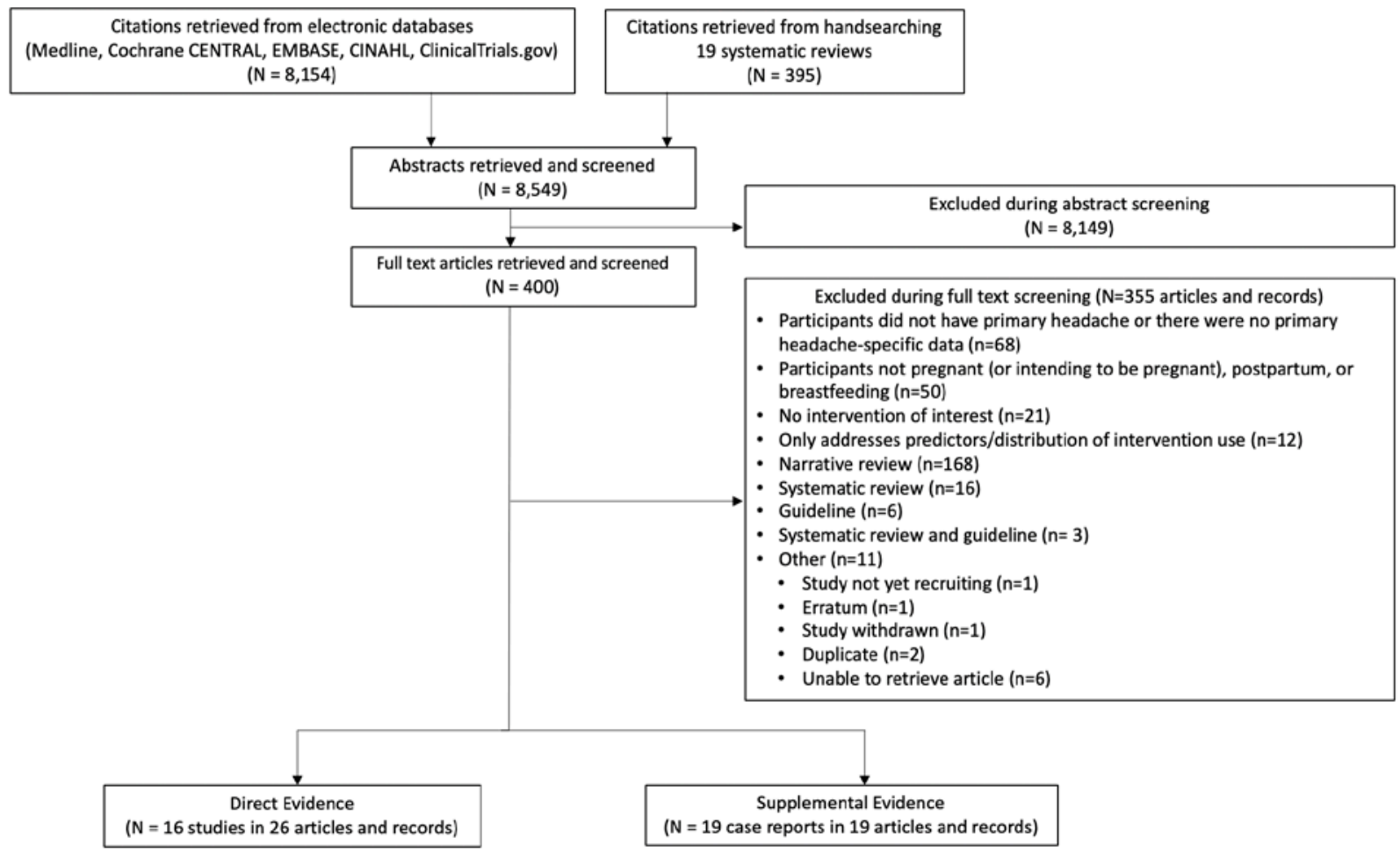

\section{SRs}

Our separate search for SRs is illustrated by the flow diagram in Figure B-2. Our electronic searches retrieved 2,788 unique citations, of which 376 were deemed potentially relevant and retrieved in full text. After full-text screening, we included 26 SRs that were reported in 29 articles (indirect evidence). ${ }^{53-81}$ 


\section{Figure B-2. Flow diagram for SRs}

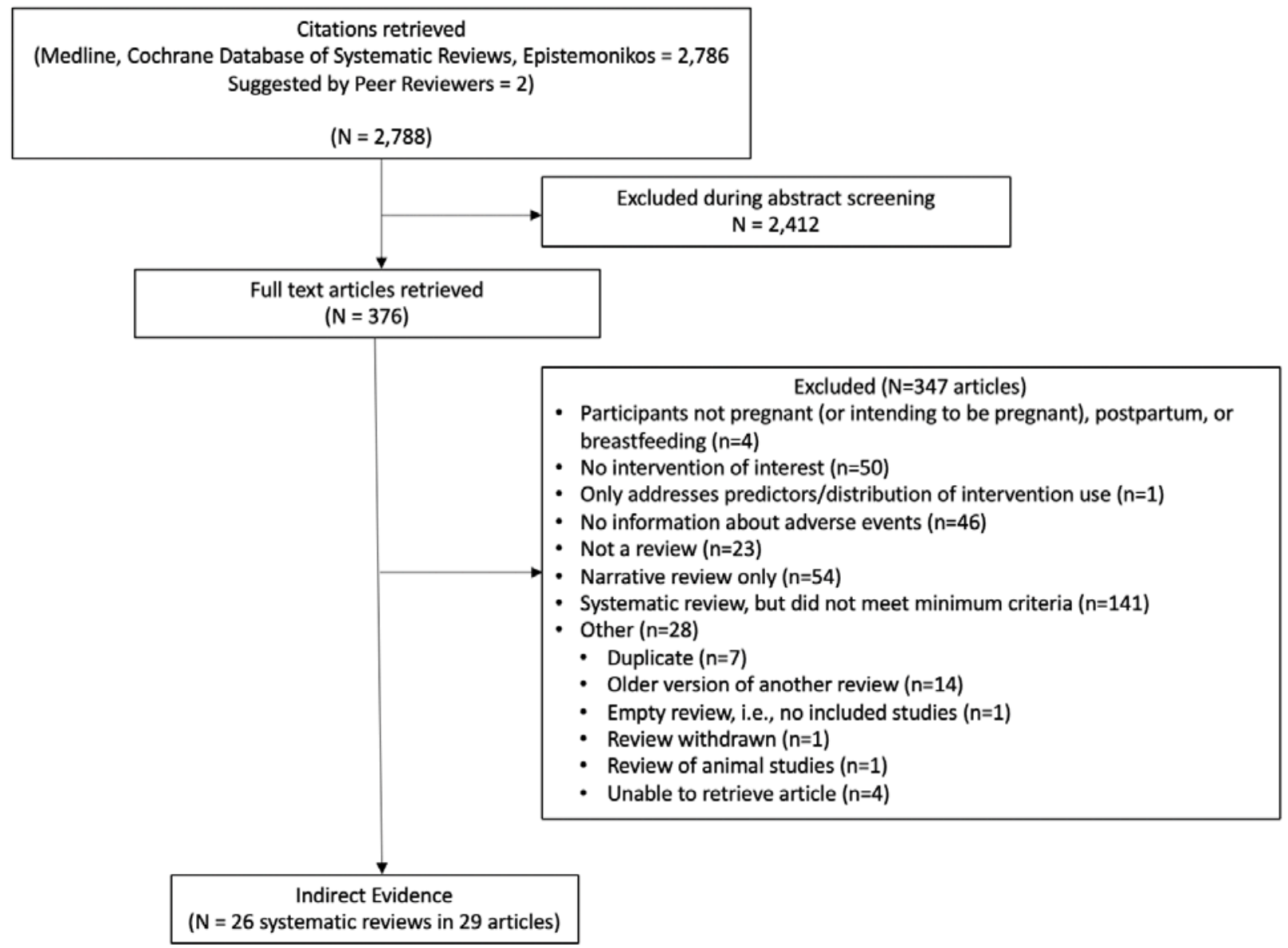




\section{Description of Included Studies}

\section{Primary Studies}

The 16 included primary studies, published between 1990 and 2018, comprised three RCTs (reported in five articles ${ }^{10,19,20,28,30}$ ), eight NRCSs (reported in 16 articles $^{11-13,15,17,18,21-26,29,31-}$ ${ }^{33}$ ), and five single-group studies (reported in six articles ${ }^{8,9,14,16,19,27}$ ). Of note, one article reported both an RCT and a single-group study (Marcus 1995). ${ }^{19}$

The 16 primary studies included a total of 14,185 patients. These included three RCTs with 138 patients (ranging from 25 to 70 patients each), eight NRCSs with 13,907 patients (ranging from 123 to 5,900 patients each), and five single-group studies with 121 patients (ranging from 5 to 240 patients each).

All three RCTs enrolled patients with tension headache and evaluated treatments (KQ 2). Two of the RCTs also included patients with migraine. ${ }^{10,19,20,28}$ All eight NRCSs enrolled patients with migraine and evaluated treatments (KQ 2). Among the five single-group studies, one examined prevention of acute migraine in patients with a history of migraine (KQ 1), ${ }^{9}$ while the other four examined treatment of either acute migraine (three studies ${ }^{8,14,16}$ ) or acute migraine and tension headache (one study ${ }^{19,}{ }^{27}$ ) (KQ 2).

Average patient ages, when reported in the studies, ranged from 23 to 34 years. Only one of the 16 studies, an RCT, reported on the racial distribution of the patients, 76 percent of whom were black. ${ }^{10,20,28}$ Most studies did not report data on the mean gravidity or parity of patients. Among the four studies that reported this information, mean gravidity and parity were usually 3 and 1 , respectively. ${ }^{10,14,16,20,28,30}$

In terms of natal phase considered, all the 16 included studies considered treatments during pregnancy. Trimesters and gestational ages varied across studies, with some studies considering patients in various trimesters as eligible. Four NRCSs, ${ }^{15,22-26,32,33}$ three of which were registry studies, ${ }^{15,}, 22-24,26,32,33$ examined the issue of timing of treatments by comparing the use of specific pharmacologic interventions (mostly triptans) during pregnancy with their use before pregnancy.

Only one of the 16 included studies addressed interventions to prevent attacks of primary headache in patients with a history of primary headaches (KQ 1). This study, a single-group study, addressed pharmacologic interventions (antiepileptics). ${ }^{9}$ None of the included studies addressed nonpharmacologic interventions for KQ 1.

Fifteen of the 16 included studies addressed interventions to treat patients experiencing attacks of primary headache. These included nine studies that addressed pharmacologic interventions (one RCT that addressed antiemetics, antihistamines, and opioid-containing analgesics ${ }^{10,20,28}$ and eight NRCSs that addressed triptans, ergot products, and NSAIDs ${ }^{11-13,15,17}$, 18, 21-26, 29, 31-33) and six studies that addressed nonpharmacologic interventions (two RCTs ${ }^{19,} 30$ and two single-group studies ${ }^{16,19,27}$ that addressed complementary, behavioral, and physical therapies, one single-group study that addressed nerve blocks, ${ }^{14}$ and one single-group study that addressed noninvasive neuromodulation devices ${ }^{8}$ ).

Among the 11 comparative studies (three RCTs and eight NRCSs), seven studies included active comparators only, ${ }^{10,13,17-20,23,25,26,28}$ three studies included inactive (i.e., routine care) comparators only, ${ }^{12,29-31}$ and one study included both active and inactive comparators. ${ }^{15,}$,22, 24, 32, 33 
All three RCTs ${ }^{10,19,20,28,30}$ and four ${ }^{8,14,16,19,27}$ of the five single-group studies reported adequate information about the dose, frequency, and intensity of the interventions. However, none of the eight NRCSs, ${ }^{11-13,15,17,18,21-26,29,31-33}$ most of which were registry-based studies, reported this information.

Among all 16 studies, six were exclusively conducted in the U.S., ${ }^{10,14,16,19,20,25,27,28}$ two exclusively in Norway, ${ }^{15,}$,2-24, 32, 33 one each exclusively in Germany, ${ }^{12,}{ }^{31}$ Denmark, ${ }^{26}$ Sweden,,${ }^{17}$, ${ }^{18}$, Brazil, ${ }^{30}$ and the U.K. ${ }^{8}$ The other three studies were international (one in the U.S. and Canada; ${ }^{29}$ one in the U.S., Canada, U.K., and 36 other countries; ${ }^{11,13,21}$ and one in the U.S., U.K., Sweden, Germany, and 14 other countries). ${ }^{9}$

Among the six registry-based NRCSs specifically (a total of 13,547 patients), two were exclusively in Norway $\left(2,560\right.$ patients $^{23}$ and 5,900 patients $\left.^{15,22,24,32,33}\right)$, one was exclusively in Sweden (3,368 patients), ${ }^{17,18}$ one was exclusively in Denmark (123 patients), one was exclusively in Germany (907 patients), ${ }^{12,31}$ and one was international (U.S., U.K., Sweden, Germany, and 14 other countries; 689 patients). ${ }^{11,13,21}$

Among all 16 included studies, four were funded by industry sources, ${ }^{8,11,13,21,25}$ five by

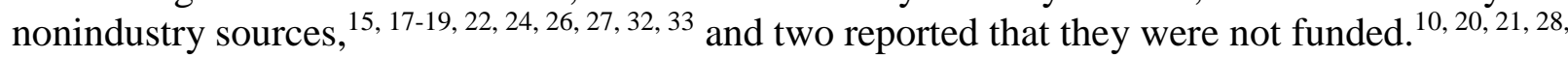
${ }^{31}$ The remaining five studies did not report their funding sources. ${ }^{9}, 14,23,29,30$ 
Table B-1. Included primary studies - Summary of design and arm details

\begin{tabular}{|c|c|c|c|c|c|c|c|c|c|c|c|c|c|}
\hline $\begin{array}{l}\text { Study, } \\
\text { Year, } \\
\text { PMID, } \\
\text { Country, } \\
\text { Funding } \\
\end{array}$ & Design & Funding & $\begin{array}{l}\text { Population } \\
\text { description }\end{array}$ & Arm & Arm Details & $\begin{array}{c}\text { Sample } \\
\text { Size }\end{array}$ & $\begin{array}{c}\text { Age } \\
\text { (years) }\end{array}$ & Race & Trimester & $\begin{array}{c}\text { Gestational } \\
\text { Age }\end{array}$ & Gravidity & Parity & $\begin{array}{c}\text { Type of } \\
\text { Primary } \\
\text { Headache }\end{array}$ \\
\hline \multirow[t]{2}{*}{$\begin{array}{l}\text { Childress, } \\
2018, \\
\text { 29723901, } \\
\text { U.S. }\end{array}$} & \multirow[t]{2}{*}{$\begin{array}{l}\text { Randomized } \\
\text { controlled trial }\end{array}$} & \multirow[t]{2}{*}{ None } & \multirow[t]{2}{*}{$\begin{array}{l}\text { Second or } \\
\text { third } \\
\text { trimester, } \\
\text { normotensiv } \\
\text { e, migraine } \\
\text { or tension } \\
\text { headache } \\
\text { not relieved } \\
\text { by } \\
\text { acetaminoph } \\
\text { en }\end{array}$} & $\begin{array}{l}\text { Combination } \\
\text { of antiemetic } \\
\text { and } \\
\text { antihistamin } \\
\text { e }\end{array}$ & $\begin{array}{l}\text { Metoclopram } \\
\text { ide } 10 \text { mg } \\
\text { intravenous } \\
\text { and } \\
\text { Diphenhydra } \\
\text { mine } 25 \text { mg } \\
\text { intravenous, } \\
\text { as a single } \\
\text { dose; } \\
\text { Second dose } \\
\text { only if } \\
\text { needed }\end{array}$ & 35 & $\begin{array}{l}\text { Median } \\
23(\mathrm{IQR} \\
21,25)\end{array}$ & $\begin{array}{l}\text { Whit } \\
\text { e: } \\
20 \% \text {, } \\
\text { Black } \\
: \\
80 \%\end{array}$ & $\begin{array}{l}\text { Second: NR } \\
\text { Third: NR }\end{array}$ & $\begin{array}{l}\text { Median } 31.9 \\
\text { (IQR 25.7, } \\
34.6)\end{array}$ & $\begin{array}{l}\text { Median } 3 \\
\text { (IQR 1, 4) }\end{array}$ & $\begin{array}{l}\text { Median } \\
1(\mathrm{IQR} \\
0,2)\end{array}$ & $\begin{array}{l}\text { Migraine: } \\
\text { NR } \\
\text { Tension } \\
\text { headache: } \\
\text { NR }\end{array}$ \\
\hline & & & & $\begin{array}{l}\text { Opioid- } \\
\text { containing } \\
\text { analgesic }\end{array}$ & $\begin{array}{l}\text { Codeine } 30 \\
\text { mg oral as a } \\
\text { single dose; } \\
\text { Second dose } \\
\text { only if } \\
\text { needed }\end{array}$ & 35 & $\begin{array}{l}\text { Median } \\
23.5 \\
(I Q R \\
21,27)\end{array}$ & $\begin{array}{l}\text { Whit } \\
\text { e: } \\
28.6 \\
\%, \\
\text { Black } \\
: \\
71.4 \\
\%\end{array}$ & $\begin{array}{l}\text { Second: NR } \\
\text { Third: NR }\end{array}$ & $\begin{array}{l}\text { Median } 28.4 \\
\text { (IQR 19.1, } \\
32.9 \text { ) }\end{array}$ & $\begin{array}{l}\text { Median 3 } \\
\text { (IQR 2, 4) }\end{array}$ & $\begin{array}{l}\text { Median } \\
1(\mathrm{IQR} \\
1,2)\end{array}$ & $\begin{array}{l}\text { Migraine: } \\
\text { NR } \\
\text { Tension } \\
\text { headache: } \\
\text { NR }\end{array}$ \\
\hline \multirow[t]{2}{*}{$\begin{array}{l}\text { Silva, 2012, } \\
\text { no PMID, } \\
\text { Brazil }\end{array}$} & $\begin{array}{l}\text { Randomized } \\
\text { controlled trial }\end{array}$ & NR & $\begin{array}{l}\text { 15- } 30 \text { w } \\
\text { gestation } \\
\text { with tension } \\
\text { headache } \\
(>=4 \text { on a } \\
\text { scale of } 0- \\
10)\end{array}$ & $\begin{array}{l}\text { Complement } \\
\text { ary therapy }\end{array}$ & $\begin{array}{l}\text { Acupuncture } \\
15 \text { needles } \\
\text { of } 40 \mathrm{~mm} \\
\text { (length) and } \\
0.2 \mathrm{~mm} \\
\text { (diameter) } \\
\text { diameter for } \\
25 \text { min, once } \\
\text { a week for } 8 \\
\text { weeks }\end{array}$ & 20 & $\begin{array}{l}27.3 \\
(4.3)\end{array}$ & NR & $\begin{array}{l}\text { Second: } \\
100 \%\end{array}$ & $19.8(4.0)$ & $2.0(2.7)$ & $\begin{array}{l}1.0 \\
(2.0)\end{array}$ & $\begin{array}{l}\text { Tension } \\
\text { headache: } \\
100 \%\end{array}$ \\
\hline & & & & $\begin{array}{l}\text { Conventional } \\
\text { treatment }\end{array}$ & Routine care & 23 & $\begin{array}{l}25.3 \\
(6.1)\end{array}$ & NR & $\begin{array}{l}\text { Second: } \\
100 \%\end{array}$ & $19.4(4.1)$ & $2.0(2.0)$ & $\begin{array}{l}1.0 \\
(2.0)\end{array}$ & $\begin{array}{l}\text { Tension } \\
\text { headache: } \\
100 \%\end{array}$ \\
\hline
\end{tabular}




\begin{tabular}{|c|c|c|c|c|c|c|c|c|c|c|c|c|c|}
\hline $\begin{array}{l}\text { Study, } \\
\text { Year, } \\
\text { PMID, } \\
\text { Country, } \\
\text { Funding } \\
\end{array}$ & Design & Funding & $\begin{array}{l}\text { Population } \\
\text { description }\end{array}$ & Arm & Arm Details & $\begin{array}{c}\text { Sample } \\
\text { Size }\end{array}$ & $\begin{array}{c}\text { Age } \\
\text { (years) }\end{array}$ & Race & Trimester & $\begin{array}{c}\text { Gestational } \\
\text { Age }\end{array}$ & Gravidity & Parity & $\begin{array}{c}\text { Type of } \\
\text { Primary } \\
\text { Headache }\end{array}$ \\
\hline \multirow[t]{2}{*}{$\begin{array}{l}\text { Marcus } \\
\text { (Study 2), } \\
1995, \\
8600478, \\
\text { U.S. }\end{array}$} & \multirow[t]{2}{*}{$\begin{array}{l}\text { Randomized } \\
\text { controlled trial }\end{array}$} & \multirow[t]{2}{*}{$\begin{array}{l}\text { Nonindust } \\
\text { ry } \\
\text { (National } \\
\text { Headache } \\
\text { Foundatio } \\
\text { n) }\end{array}$} & \multirow[t]{2}{*}{$\begin{array}{l}\text { First or } \\
\text { Second } \\
\text { trimester; } \\
\text { migraine } \\
\text { headache, } \\
\text { tension } \\
\text { headache, or } \\
\text { coexisting } \\
\text { migraine and } \\
\text { tension } \\
\text { headache; } \\
>=1 \\
\text { headache } \\
\text { per week or } \\
>=5 \\
\text { headaches } \\
\text { per month }\end{array}$} & $\begin{array}{l}\text { Combination } \\
\text { of } \\
\text { complement } \\
\text { ary therapy, } \\
\text { behavioral } \\
\text { therapy, } \\
\text { and. physical } \\
\text { therapy }\end{array}$ & $\begin{array}{l}\text { Combination } \\
\text { of thermal } \\
\text { biofeedback, } \\
\text { relaxation } \\
\text { therapy, and } \\
\text { physical } \\
\text { therapy; } \\
\text { sessions } \\
\text { lasted for } 1 \\
\text { hour } 4 \text { times } \\
\text { over } 2 \\
\text { months }\end{array}$ & 11 & $\begin{array}{l}28.6 \\
(6.3)\end{array}$ & NR & $\begin{array}{l}\text { First: NR } \\
\text { Second: NR }\end{array}$ & $17.6(4.9)$ & NR & NR & $\begin{array}{l}\text { Migraine: } \\
27.3 \% \text {, } \\
\text { Tension } \\
\text { headache: } \\
36.4 \% \text {, } \\
\text { Migraine } \\
\text { and } \\
\text { tension } \\
\text { headache } \\
\text { coexisting: } \\
36.4 \%\end{array}$ \\
\hline & & & & $\begin{array}{l}\text { Complement } \\
\text { ary therapy }\end{array}$ & $\begin{array}{l}\text { Thermal } \\
\text { biofeedback } \\
\text { for } 1 \text { hour } 4 \\
\text { times over } 2 \\
\text { months }\end{array}$ & 14 & $\begin{array}{l}29.2 \\
(4.8)\end{array}$ & NR & $\begin{array}{l}\text { First: NR } \\
\text { Second: NR }\end{array}$ & $19.8(4.4)$ & NR & NR & $\begin{array}{l}\text { Migraine: } \\
42.9 \% \text {, } \\
\text { Tension } \\
\text { headache: } \\
21.4 \% \text {, } \\
\text { Migraine } \\
\text { and } \\
\text { tension } \\
\text { headache } \\
\text { coexisting: } \\
35.7 \%\end{array}$ \\
\hline $\begin{array}{l}\text { Ephross, } \\
2014, \\
24805878, \\
18 \text { countries }\end{array}$ & $\begin{array}{l}\text { Nonrandomized } \\
\text { comparative } \\
\text { study } \\
\text { (Prospective) }\end{array}$ & $\begin{array}{l}\text { Industry } \\
\text { (Glaxo- } \\
\text { Smith- } \\
\text { Kline) }\end{array}$ & $\begin{array}{l}\text { Pregnant } \\
\text { women with } \\
\text { migraine in } \\
\text { the } \\
\text { Sumatriptan, } \\
\text { Naratriptan, } \\
\text { and Treximet } \\
\text { Pregnancy } \\
\text { Registry }\end{array}$ & $\begin{array}{l}\text { Triptans: } \\
\text { Sumatriptan }\end{array}$ & $\begin{array}{l}\text { Subcutaneou } \\
\mathrm{s}\end{array}$ & 626 & NR & NR & NR & NR & NR & NR & $\begin{array}{l}\text { Migraine: } \\
100 \%\end{array}$ \\
\hline
\end{tabular}




\begin{tabular}{|c|c|c|c|c|c|c|c|c|c|c|c|c|c|}
\hline $\begin{array}{l}\text { Study, } \\
\text { Year, } \\
\text { PMID, } \\
\text { Country, } \\
\text { Funding }\end{array}$ & Design & Funding & $\begin{array}{l}\text { Population } \\
\text { description }\end{array}$ & Arm & Arm Details & $\begin{array}{l}\text { Sample } \\
\text { Size }\end{array}$ & $\begin{array}{c}\text { Age } \\
\text { (years) }\end{array}$ & Race & Trimester & $\begin{array}{c}\text { Gestational } \\
\text { Age }\end{array}$ & Gravidity & Parity & $\begin{array}{c}\text { Type of } \\
\text { Primary } \\
\text { Headache }\end{array}$ \\
\hline & & & & $\begin{array}{l}\text { Combination } \\
\text { of Triptans } \\
\text { (Sumatriptan } \\
\text { ) and } \\
\text { NSAI Ds } \\
\text { (Naproxen) }\end{array}$ & $\begin{array}{l}\text { Subcutaneou } \\
\mathrm{s}\end{array}$ & 6 & NR & NR & NR & NR & NR & NR & $\begin{array}{l}\text { Migraine: } \\
100 \%\end{array}$ \\
\hline \multirow[t]{2}{*}{$\begin{array}{l}\text { O'Quinn, } \\
1999, \\
10728620, \\
\text { U.S. }\end{array}$} & \multirow[t]{2}{*}{$\begin{array}{l}\text { Nonrandomized } \\
\text { comparative } \\
\text { study } \\
\text { (Prospective) }\end{array}$} & \multirow[t]{2}{*}{$\begin{array}{l}\text { Industry } \\
\text { (Glaxo- } \\
\text { Wellcome } \\
\text { Research } \\
\text { Unit) }\end{array}$} & \multirow[t]{2}{*}{$\begin{array}{l}\text { Pregnant } \\
\text { women with } \\
\text { migraine }\end{array}$} & $\begin{array}{l}\text { Triptans: } \\
\text { Sumatriptan }\end{array}$ & $\begin{array}{l}\text { During first } \\
\text { trimester, } \\
\text { subcutaneou } \\
\text { s }\end{array}$ & 76 & NR & NR & NR & NR & NR & NR & $\begin{array}{l}\text { Migraine: } \\
100 \%\end{array}$ \\
\hline & & & & $\begin{array}{l}\text { Triptans: } \\
\text { Sumatriptan } \\
\text { (before } \\
\text { pregnancy } \\
\text { only) }\end{array}$ & $\begin{array}{l}\text { Before } \\
\text { pregnancy } \\
\text { only, } \\
\text { subcutaneou } \\
\text { s }\end{array}$ & 92 & NR & NR & NR & NR & NR & NR & $\begin{array}{l}\text { Migraine: } \\
100 \%\end{array}$ \\
\hline $\begin{array}{l}\text { Shuhaiber, } \\
1998, \\
9710039, \\
\text { U.S. and } \\
\text { Canada }\end{array}$ & $\begin{array}{l}\text { Nonrandomized } \\
\text { comparative } \\
\text { study } \\
\text { (Prospective) }\end{array}$ & NR & $\begin{array}{l}\text { Pregnant } \\
\text { women with } \\
\text { migraine } \\
\text { who } \\
\text { contacted a } \\
\text { Teratogen } \\
\text { Information } \\
\text { Service }\end{array}$ & No Triptans & $\begin{array}{l}\text { Did not use } \\
\text { before or } \\
\text { during } \\
\text { pregnancy }\end{array}$ & 96 & $\begin{array}{l}\text { Mean } \\
31.7 \\
\text { SD 4.5 }\end{array}$ & NR & First: $100 \%$ & NR & NR & NR & $\begin{array}{l}\text { Migraine: } \\
100 \%\end{array}$ \\
\hline \multirow[t]{2}{*}{$\begin{array}{l}\text { Nezvalova- } \\
\text { Henriksen, } \\
2013, \\
23884894, \\
\text { Norway }\end{array}$} & \multirow[t]{2}{*}{$\begin{array}{l}\text { Nonrandomized } \\
\text { comparative } \\
\text { study } \\
\text { (Retrospective) }\end{array}$} & \multirow[t]{2}{*}{ NR } & \multirow[t]{2}{*}{$\begin{array}{l}\text { Pregnant } \\
\text { women with } \\
\text { migraine in } \\
\text { the } \\
\text { Norwegian } \\
\text { Prescription } \\
\text { Database }\end{array}$} & $\begin{array}{l}\text { Triptans: } \\
\text { Any }\end{array}$ & $\begin{array}{l}\text { Sumatriptan, } \\
\text { rizatriptan, } \\
\text { eletriptan, or } \\
\text { zolmitriptan } \\
\text { during } \\
\text { pregnancy }\end{array}$ & 1465 & NR & NR & NR & $N R$ & NR & NR & $\begin{array}{l}\text { Migraine: } \\
100 \%\end{array}$ \\
\hline & & & & $\begin{array}{l}\text { Triptans: } \\
\text { Any (Before } \\
\text { pregnancy } \\
\text { only) }\end{array}$ & $\begin{array}{l}\text { Sumatriptan, } \\
\text { rizatriptan, } \\
\text { eletriptan, or } \\
\text { zolmitriptan } \\
\text { before } \\
\text { pregnancy } \\
\text { only }\end{array}$ & 1095 & NR & NR & NR & NR & NR & NR & $\begin{array}{l}\text { Migraine: } \\
100 \%\end{array}$ \\
\hline
\end{tabular}




\begin{tabular}{|c|c|c|c|c|c|c|c|c|c|c|c|c|c|}
\hline $\begin{array}{c}\text { Study, } \\
\text { Year, } \\
\text { PMID, } \\
\text { Country, } \\
\text { Funding } \\
\end{array}$ & Design & Funding & $\begin{array}{l}\text { Population } \\
\text { description }\end{array}$ & Arm & Arm Details & $\begin{array}{c}\text { Sample } \\
\text { Size }\end{array}$ & $\begin{array}{c}\text { Age } \\
\text { (years) }\end{array}$ & Race & Trimester & $\begin{array}{c}\text { Gestational } \\
\text { Age }\end{array}$ & Gravidity & Parity & $\begin{array}{c}\text { Type of } \\
\text { Primary } \\
\text { Headache }\end{array}$ \\
\hline \multirow[t]{3}{*}{$\begin{array}{l}\text { Nezvalova- } \\
\text { Henriksen } \\
2010, \\
20132339 \\
\text { Norway }\end{array}$} & \multirow[t]{3}{*}{$\begin{array}{l}\text { Nonrandomized } \\
\text { comparative } \\
\text { study } \\
\text { (Retrospective) }\end{array}$} & \multirow[t]{3}{*}{$\begin{array}{l}\text { Nonindust } \\
\text { ry } \\
\text { (Norwegia } \\
\text { n Ministry } \\
\text { of Health, } \\
\mathrm{NIH} \text {, } \\
\text { Norwegian } \\
\text { Research } \\
\text { Council) }\end{array}$} & \multirow[t]{3}{*}{$\begin{array}{l}\text { Pregnant } \\
\text { women with } \\
\text { migraine in } \\
\text { the } \\
\text { Norwegian } \\
\text { Mother and } \\
\text { Child Cohort } \\
\text { Study }\end{array}$} & $\begin{array}{l}\text { Triptans: } \\
\text { Any }\end{array}$ & $\begin{array}{l}\text { During } \\
\text { pregnancy }\end{array}$ & 1045 & NR & NR & NR & NR & NR & NR & $\begin{array}{l}\text { Migraine: } \\
100 \%\end{array}$ \\
\hline & & & & $\begin{array}{l}\text { Triptans: } \\
\text { Any (before } \\
\text { pregnancy } \\
\text { only) }\end{array}$ & $\begin{array}{l}\text { Before } \\
\text { pregnancy } \\
\text { only }\end{array}$ & 805 & NR & NR & NR & NR & NR & NR & $\begin{array}{l}\text { Migraine: } \\
100 \%\end{array}$ \\
\hline & & & & No Triptans & $\begin{array}{l}\text { Did not use } \\
\text { before or } \\
\text { during } \\
\text { pregnancy }\end{array}$ & 4050 & NR & NR & NR & NR & NR & NR & $\begin{array}{l}\text { Migraine: } \\
100 \%\end{array}$ \\
\hline \multirow[t]{3}{*}{$\begin{array}{l}\text { Kallen, 2011, } \\
\text { 21751829, } \\
\text { Sweden }\end{array}$} & \multirow[t]{3}{*}{$\begin{array}{l}\text { Nonrandomized } \\
\text { comparative } \\
\text { study } \\
\text { (Retrospective) }\end{array}$} & \multirow[t]{3}{*}{$\begin{array}{l}\text { Nonindust } \\
\text { ry (Evy } \\
\text { and } \\
\text { Gunnar } \\
\text { Sandberg } \\
\text { Foundatio } \\
\text { n) }\end{array}$} & \multirow[t]{3}{*}{$\begin{array}{l}\text { Pregnant } \\
\text { women with } \\
\text { migraine in } \\
\text { the Swedish } \\
\text { Medical Birth } \\
\text { Register }\end{array}$} & $\begin{array}{l}\text { Triptans: } \\
\text { Any }\end{array}$ & $\begin{array}{l}\text { Sumatriptan, } \\
\text { naratriptan, } \\
\text { zolmitriptan, } \\
\text { rizatriptan, } \\
\text { almotriptan, } \\
\text { or eletriptan }\end{array}$ & 2777 & NR & NR & NR & NR & NR & NR & $\begin{array}{l}\text { Migraine: } \\
100 \%\end{array}$ \\
\hline & & & & $\begin{array}{l}\text { Ergot } \\
\text { Products: } \\
\text { Any }\end{array}$ & $\begin{array}{l}\text { Dihydroergot } \\
\text { amine or } \\
\text { ergotamine } \\
\text { combinations }\end{array}$ & 527 & NR & NR & NR & NR & NR & NR & $\begin{array}{l}\text { Migraine: } \\
100 \%\end{array}$ \\
\hline & & & & $\begin{array}{l}\text { Antihistamin } \\
\text { es: Pizotifen }\end{array}$ & Pizotifen & 64 & NR & NR & NR & NR & NR & NR & $\begin{array}{l}\text { Migraine: } \\
100 \%\end{array}$ \\
\hline
\end{tabular}




\begin{tabular}{|c|c|c|c|c|c|c|c|c|c|c|c|c|c|}
\hline $\begin{array}{l}\text { Study, } \\
\text { Year, } \\
\text { PMID, } \\
\text { Country, } \\
\text { Funding }\end{array}$ & Design & Funding & $\begin{array}{l}\text { Population } \\
\text { description }\end{array}$ & Arm & Arm Details & $\begin{array}{c}\text { Sample } \\
\text { Size }\end{array}$ & $\begin{array}{c}\text { Age } \\
\text { (years) }\end{array}$ & Race & Trimester & $\begin{array}{c}\text { Gestational } \\
\text { Age }\end{array}$ & Gravidity & Parity & $\begin{array}{c}\text { Type of } \\
\text { Primary } \\
\text { Headache }\end{array}$ \\
\hline \multirow[t]{2}{*}{$\begin{array}{l}\text { Olesen } 2000 \\
\text { 10759898, } \\
\text { Denmark }\end{array}$} & \multirow[t]{2}{*}{$\begin{array}{l}\text { Nonrandomized } \\
\text { comparative } \\
\text { study } \\
\text { (Retrospective) }\end{array}$} & \multirow[t]{2}{*}{$\begin{array}{l}\text { Nonindust } \\
\text { ry } \\
\text { (Helsefon } \\
\text { den, } \\
\text { Pharmacy } \\
\text { Foundatio } \\
\text { n; EU } \\
\text { BIOMED } \\
\text { Programm } \\
\text { e, Danish } \\
\text { Medical } \\
\text { Research } \\
\text { Council, } \\
\text { North } \\
\text { Jutland } \\
\text { Research } \\
\text { Council) }\end{array}$} & \multirow[t]{2}{*}{$\begin{array}{l}\text { Pregnant } \\
\text { women with } \\
\text { migraine in } \\
\text { the } \\
\text { Pharmaco- } \\
\text { Epidemiologi } \\
\text { cal } \\
\text { Prescription } \\
\text { Database of } \\
\text { North } \\
\text { Jutland } \\
\text { County, } \\
\text { Denmark }\end{array}$} & $\begin{array}{l}\text { Triptans: } \\
\text { Sumatriptan }\end{array}$ & $\begin{array}{l}\text { During } \\
\text { pregnancy }\end{array}$ & 34 & $\begin{array}{l}\text { Mean } \\
29.6\end{array}$ & NR & NR & NR & NR & NR & $\begin{array}{l}\text { Migraine: } \\
100 \%\end{array}$ \\
\hline & & & & $\begin{array}{l}\text { Triptans: } \\
\text { Sumatriptan } \\
\text { or Ergot } \\
\text { Products: } \\
\text { Ergotamine } \\
\text { (before } \\
\text { pregnancy } \\
\text { only) }\end{array}$ & $\begin{array}{l}\text { Before } \\
\text { pregnancy } \\
\text { only }\end{array}$ & 89 & $\begin{array}{l}\text { Mean } \\
28.4\end{array}$ & NR & NR & NR & NR & NR & $\begin{array}{l}\text { Migraine: } \\
100 \%\end{array}$ \\
\hline \multirow[t]{2}{*}{$\begin{array}{l}\text { Spielmann, } \\
\text { 2018, } \\
\text { 28758416, } \\
\text { Germany }\end{array}$} & \multirow[t]{2}{*}{$\begin{array}{l}\text { Nonrandomized } \\
\text { comparative } \\
\text { study } \\
\text { (Retrospective) }\end{array}$} & \multirow[t]{2}{*}{ None } & \multirow[t]{2}{*}{$\begin{array}{l}\text { Pregnant } \\
\text { women with } \\
\text { migraine in } \\
\text { the German } \\
\text { Embryotox } \\
\text { system }\end{array}$} & $\begin{array}{l}\text { Triptans: } \\
\text { Any }\end{array}$ & $\begin{array}{l}\text { Sumatriptan, } \\
\text { zolmitriptan, } \\
\text { rizatriptan, } \\
\text { naratriptan, } \\
\text { frovatriptan, } \\
\text { eletriptan, or } \\
\text { almotriptan }\end{array}$ & 432 & $\begin{array}{l}\text { Median } \\
33(\mathrm{IQR} \\
30,37)\end{array}$ & NR & NR & NR & NR & NR & $\begin{array}{l}\text { Migraine: } \\
100 \%\end{array}$ \\
\hline & & & & No Triptans & $\begin{array}{l}\text { Any other } \\
\text { drug for } \\
\text { migraine }\end{array}$ & 475 & $\begin{array}{l}\text { Median } \\
32(\text { IQR } \\
29,36)\end{array}$ & NR & NR & NR & NR & NR & $\begin{array}{l}\text { Migraine: } \\
100 \%\end{array}$ \\
\hline
\end{tabular}




\begin{tabular}{|c|c|c|c|c|c|c|c|c|c|c|c|c|c|}
\hline $\begin{array}{l}\text { Study, } \\
\text { Year, } \\
\text { PMID, } \\
\text { Country, } \\
\text { Funding }\end{array}$ & Design & Funding & $\begin{array}{l}\text { Population } \\
\text { description }\end{array}$ & Arm & Arm Details & $\begin{array}{l}\text { Sample } \\
\text { Size }\end{array}$ & $\begin{array}{c}\text { Age } \\
\text { (years) }\end{array}$ & Race & Trimester & $\begin{array}{c}\text { Gestational } \\
\text { Age }\end{array}$ & Gravidity & Parity & $\begin{array}{c}\text { Type of } \\
\text { Primary } \\
\text { Headache }\end{array}$ \\
\hline $\begin{array}{l}\text { Castilla- } \\
\text { Puentes, } \\
2014, \\
24598456, \\
\text { U.S., U.K., } \\
\text { Canada, } \\
\text { Australia, } \\
\text { and } 36 \text { other } \\
\text { countries }\end{array}$ & $\begin{array}{l}\text { Single-group } \\
\text { (Retrospective) }\end{array}$ & $\begin{array}{l}\text { Industry } \\
\text { (J anssen; } \\
\text { previously } \\
\text { J ohnson \& } \\
\text { J ohnson) }\end{array}$ & $\begin{array}{l}\text { Pregnant } \\
\text { women with } \\
\text { a history of } \\
\text { migraine }\end{array}$ & $\begin{array}{l}\text { Antiepileptics } \\
\text { : Topiramate }\end{array}$ & $\begin{array}{l}\text { Topiramate } \\
\text { monotherapy } \\
\text { (dose, } \\
\text { duration, } \\
\text { route, } \\
\text { frequency } \\
\text { not } \\
\text { reported) }\end{array}$ & 81 & NR & NR & NR & NR & NR & NR & $\begin{array}{l}\text { History of } \\
\text { migraine: } \\
100 \%\end{array}$ \\
\hline $\begin{array}{l}\text { Govindappag } \\
\text { ari, 2014, 1, } \\
\text { U.S. }\end{array}$ & $\begin{array}{l}\text { Single-group } \\
\text { (Retrospective) }\end{array}$ & NR & $\begin{array}{l}\text { Pregnant } \\
\text { women with } \\
\text { migraine in } \\
\text { whom other } \\
\text { forms of } \\
\text { treatment } \\
\text { previously } \\
\text { had failed }\end{array}$ & $\begin{array}{l}\text { Nerve } \\
\text { blocks: } \\
\text { Peripheral }\end{array}$ & $\begin{array}{l}\text { Greater } \\
\text { occipital, } \\
\text { auriculotemp } \\
\text { oral, } \\
\text { supraorbital, } \\
\text { and } \\
\text { supratrochle } \\
\text { ar nerve } \\
\text { injections } \\
\text { with local } \\
\text { anesthetics } \\
\text { (1-2\% } \\
\text { lidocaine or } \\
0.5 \% \\
\text { bupivacaine) }\end{array}$ & 13 & $\begin{array}{l}\text { Mean } \\
28, \\
\text { Range } \\
18,36\end{array}$ & NR & NR & $\begin{array}{l}\text { Mean }=23.5 \\
\text { Range }=7,37\end{array}$ & NR & $\begin{array}{l}\text { Nullipar } \\
\text { ous: } \\
61.5 \% \\
\text { Multipar } \\
\text { ous: } \\
38.4 \%\end{array}$ & $\begin{array}{l}\text { Migraine: } \\
100 \%\end{array}$ \\
\hline $\begin{array}{l}\text { Marcus } \\
\text { (Study 1), } \\
1995, \\
8600478, \\
\text { U.S. }\end{array}$ & $\begin{array}{l}\text { Single-group } \\
\text { (Prospective) }\end{array}$ & $\begin{array}{l}\text { Nonindust } \\
\text { ry } \\
\text { (National } \\
\text { Headache } \\
\text { Foundatio } \\
\text { n) }\end{array}$ & $\begin{array}{l}\text { First or } \\
\text { second } \\
\text { trimester; } \\
\text { Migraine, } \\
\text { tension } \\
\text { headache, or } \\
\text { coexisting } \\
\text { migraine and } \\
\text { tension } \\
\text { headache; } \\
>=1 \\
\text { headache } \\
\text { per week or } \\
5 \text { headaches } \\
\text { per month }\end{array}$ & $\begin{array}{l}\text { Combination } \\
\text { of } \\
\text { complement } \\
\text { ary therapy, } \\
\text { behavioral } \\
\text { therapy, } \\
\text { and. physical } \\
\text { therapy }\end{array}$ & $\begin{array}{l}\text { Combination } \\
\text { of thermal } \\
\text { biofeedback, } \\
\text { relaxation } \\
\text { therapy, and } \\
\text { physical } \\
\text { therapy; } \\
\text { sessions } \\
\text { lasted for } 1 \\
\text { hour } 4 \text { times } \\
\text { over } 2 \\
\text { months }\end{array}$ & 19 & $\begin{array}{l}\text { Mean } \\
31.7 \\
\text { SD 5.4 }\end{array}$ & NR & $\begin{array}{l}\text { First: NR } \\
\text { Second: NR }\end{array}$ & $17.7(4.2)$ & NR & NR & $\begin{array}{l}\text { Migraine: } \\
78.9 \%, \\
\text { Tension } \\
\text { headache: } \\
15.8 \% \text {, } \\
\text { Migraine } \\
\text { and } \\
\text { tension } \\
\text { headache } \\
\text { combined: } \\
5.2 \%\end{array}$ \\
\hline
\end{tabular}




\begin{tabular}{|c|c|c|c|c|c|c|c|c|c|c|c|c|c|}
\hline $\begin{array}{l}\text { Study, } \\
\text { Year, } \\
\text { PMID, } \\
\text { Country, } \\
\text { Funding }\end{array}$ & Design & Funding & $\begin{array}{l}\text { Population } \\
\text { description }\end{array}$ & Arm & Arm Details & $\begin{array}{c}\text { Sample } \\
\text { Size }\end{array}$ & $\begin{array}{c}\text { Age } \\
\text { (years) }\end{array}$ & Race & Trimester & $\begin{array}{c}\text { Gestational } \\
\text { Age }\end{array}$ & Gravidity & Parity & $\begin{array}{c}\text { Type of } \\
\text { Primary } \\
\text { Headache }\end{array}$ \\
\hline $\begin{array}{l}\text { Hickling, } \\
\text { 1990, } \\
\text { 2401622, } \\
\text { U.S. }\end{array}$ & $\begin{array}{l}\text { Single-group } \\
\text { (Prospective) }\end{array}$ & NR & $\begin{array}{l}\text { First or } \\
\text { second } \\
\text { trimester; } \\
\text { Migraine }\end{array}$ & $\begin{array}{l}\text { Combination } \\
\text { of } \\
\text { complement } \\
\text { ary therapy } \\
\text { and } \\
\text { behavioral } \\
\text { therapy }\end{array}$ & $\begin{array}{l}\text { Combination } \\
\text { of thermal } \\
\text { biofeedback } \\
\text { and } \\
\text { progressive } \\
\text { muscle } \\
\text { relaxation, } \\
4-12 \\
\text { sessions }\end{array}$ & 5 & $\begin{array}{l}\text { Mean } \\
34, \text { SD } \\
4.9\end{array}$ & NR & $\begin{array}{l}\text { First: } 20 \% \\
\text { Second: } \\
80 \%\end{array}$ & NR & NR & $\begin{array}{l}\text { Mean } \\
1.0(\mathrm{SD} \\
1.4)\end{array}$ & $\begin{array}{l}\text { Migraine: } \\
100 \%\end{array}$ \\
\hline $\begin{array}{l}\text { Bhola, 2015, } \\
26055242, \\
\text { U.K. }\end{array}$ & $\begin{array}{l}\text { Single-group } \\
\text { (Prospective) }\end{array}$ & $\begin{array}{l}\text { Industry } \\
\text { (eNeura, } \\
\text { Inc.) }\end{array}$ & $\begin{array}{l}\text { Second } \\
\text { trimester; } \\
\text { Migraine }\end{array}$ & $\begin{array}{l}\text { Transcranial } \\
\text { magnetic } \\
\text { stimulation }\end{array}$ & $\begin{array}{l}\text { Magnetic } \\
\text { field pulse of } \\
0.9 \mathrm{~T} \\
\text { transcranially } \\
\text { over the } \\
\text { back of the } \\
\text { head, up to } \\
2 \text { pulses } \\
\text { separated by } \\
\text { at least } 15 \\
\text { mins, up to } \\
16 \text { single } \\
\text { pulses or } 8 \\
\text { double } \\
\text { pulses per } \\
\text { day, on as } \\
\text { many } \\
\text { migraine } \\
\text { days as } \\
\text { needed }\end{array}$ & 3 & $\begin{array}{l}\text { Mean } \\
30.3 \\
\text { SD 1.5 }\end{array}$ & $\mathrm{NR}$ & $\begin{array}{l}\text { Second: } \\
100 \%\end{array}$ & $\mathrm{NR}$ & NR & NR & $\begin{array}{l}\text { Migraine: } \\
100 \%\end{array}$ \\
\hline
\end{tabular}

Abbreviations: IQR = interquartile range, $\min =$ minutes, $\mathrm{NR}=$ not reported, $\mathrm{PMID}=$ PubMed identifier, $\mathrm{SD}=$ standard deviation. 
Table B-2. Risk of bias assessment for primary studies - Randomized controlled trials (RCTs)

\begin{tabular}{|c|c|c|c|c|c|c|c|c|c|c|c|c|c|c|}
\hline $\begin{array}{l}\text { KQ, Int } \\
\text { Type }\end{array}$ & $\begin{array}{c}\text { Study, } \\
\text { Year, PMID }\end{array}$ & $\begin{array}{c}\text { Random } \\
\text { Sequence } \\
\text { Generation }\end{array}$ & $\begin{array}{c}\text { Allocation } \\
\text { Concealment }\end{array}$ & $\begin{array}{l}\text { Blinding of } \\
\text { Participants }\end{array}$ & $\begin{array}{l}\text { Blinding of } \\
\text { Personnell } \\
\text { Care } \\
\text { Providers }\end{array}$ & $\begin{array}{l}\text { Blinding of } \\
\text { Outcome } \\
\text { Assessors } \\
\text { (Objective } \\
\text { Outcomes) }\end{array}$ & $\begin{array}{l}\text { Blinding of } \\
\text { Outcome } \\
\text { Assessors } \\
\text { (Subjective } \\
\text { Outcomes) }\end{array}$ & $\begin{array}{l}\text { Incomplete } \\
\text { Outcome } \\
\text { Data }\end{array}$ & $\begin{array}{l}\text { Selective } \\
\text { Outcome } \\
\text { Reporting }\end{array}$ & $\begin{array}{l}\text { Other } \\
\text { Bias }\end{array}$ & $\begin{array}{l}\text { Eligibility } \\
\text { Criteria } \\
\text { Prespecifi } \\
\text { ed and } \\
\text { Clearly } \\
\text { Described }\end{array}$ & $\begin{array}{l}\text { Intervention } \\
\text { Clearly } \\
\text { Described } \\
\text { and } \\
\text { Consistently } \\
\text { Delivered }\end{array}$ & $\begin{array}{l}\text { Outcomes } \\
\text { Prespecified, } \\
\text { Clearly } \\
\text { Defined, } \\
\text { Valid, } \\
\text { Reliable, and } \\
\text { Consistently } \\
\text { Assessed }\end{array}$ & $\begin{array}{c}\text { OVERALL } \\
\text { RISK OF } \\
\text { BIAS }\end{array}$ \\
\hline $\begin{array}{l}\text { KQ 2, } \\
\text { Pharm }\end{array}$ & $\begin{array}{l}\text { Childress, } \\
2018, \\
29723901\end{array}$ & Low & Low & High & High & High & High & Low & High & Low & Yes & Yes & Yes & HIGH \\
\hline \multirow[t]{2}{*}{$\begin{array}{l}\text { KQ 2, } \\
\text { Nonph } \\
\text { arm }\end{array}$} & $\begin{array}{l}\text { Silva, } \\
\text { 2012, no } \\
\text { PMID }\end{array}$ & Unclear & Low & High & High & High & High & Low & Low & Low & Yes & Yes & Yes & HIGH \\
\hline & $\begin{array}{l}\text { Marcus } \\
\text { (Study 2), } \\
1995, \\
8600478 \\
\end{array}$ & Unclear & Unclear & High & High & Unclear & High & High & Low & Low & Yes & Yes & Yes & HIGH \\
\hline
\end{tabular}

Abbreviations: Int = intervention KQ = Key Question, Nonpharm = nonpharmacologic, Pharm = pharmacologic, PMID = PubMed identifier, RCT = randomized controlled trial.

Ratings are color coded for emphasis only.

From the Cochrane Risk of Bias Tool (each item rated as Low, High, Unclear, or N/A [none in Table])

- Random sequence generation (selection bias): Selection bias (biased allocation to interventions) due to inadequate generation of a randomized sequence;

- Allocation concealment (selection bias): Selection bias (biased allocation to interventions) due to inadequate concealment of allocations prior to assignment;

- Blinding of participants (performance bias): Performance bias due to knowledge of the allocated interventions by participants during the study;

- Blinding of personnel/care providers (performance bias): Performance bias due to knowledge of the allocated interventions by personnel/care providers during the study;

- Blinding of outcome assessor (detection bias): Detection bias due to knowledge of the allocated interventions by outcome assessors during the study;

- Incomplete outcome data (attrition bias): Attrition bias due to amount, nature, or handling of incomplete outcome data;

- Selective outcome reporting (outcome reporting bias): Bias arising from outcomes being selectively reported based on the direction and/or strength of the results;

- Other Bias: Bias due to problems not covered elsewhere in the table.

From the National Heart, Lung, and Blood Institute (NHLBI) Quality Assessment Tool (each item rated as Yes, No [none in Table], or Unclear [none in Table])

- Eligibility criteria prespecified and clearly described: Potentially related to selection bias;

- Intervention clearly described and delivered consistently: Potentially related to performance bias;

- Outcomes prespecified, clearly defined, valid, reliable, and assessed consistently: Potentially related to detection bias.

Overall risk of bias assessed as HIGH, MODERATE (none in Table), or LOW (none in Table). 
Table B-3. Risk of bias assessment for primary studies - Nonrandomized comparative studies (NRCSs), assessment of confounding and section bias

\begin{tabular}{|c|c|c|c|c|c|c|c|c|c|c|c|c|c|c|}
\hline $\begin{array}{l}\text { KQ, Int } \\
\text { Type }\end{array}$ & Study, Year, PMID &  & 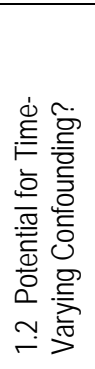 & 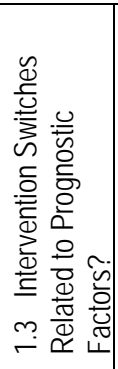 &  & 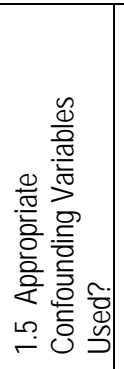 & 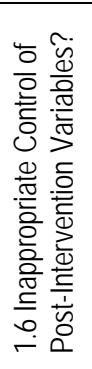 & 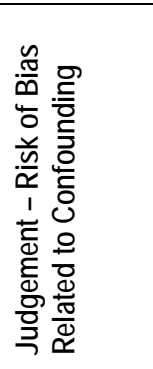 &  & 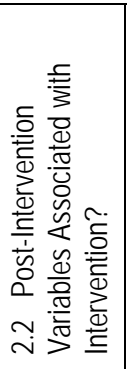 & 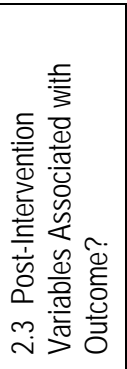 &  &  & 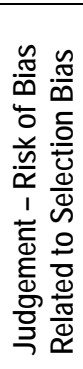 \\
\hline \multirow[t]{8}{*}{$\begin{array}{l}\text { KQ 2, } \\
\text { Pharm }\end{array}$} & $\begin{array}{l}\text { Ephross, 2014, } \\
24805878\end{array}$ & Yes & No & $\mathrm{N} / \mathrm{A}$ & No & No & No & Serious & No & N/A & N/A & Yes & $\mathrm{N} / \mathrm{A}$ & Low \\
\hline & $\begin{array}{l}\text { O'Quinn, 1999, } \\
10728620\end{array}$ & Yes & No & $\mathrm{N} / \mathrm{A}$ & No & No & No & Serious & No & $\mathrm{N} / \mathrm{A}$ & $\mathrm{N} / \mathrm{A}$ & Yes & $\mathrm{N} / \mathrm{A}$ & Low \\
\hline & $\begin{array}{l}\text { Shuhaiber, 1998, } \\
9710039\end{array}$ & Yes & No & $\mathrm{N} / \mathrm{A}$ & No & No & No & Serious & No & $\mathrm{N} / \mathrm{A}$ & $\mathrm{N} / \mathrm{A}$ & Yes & $\mathrm{N} / \mathrm{A}$ & Low \\
\hline & $\begin{array}{l}\text { Nezvalova- } \\
\text { Henriksen, 2013, } \\
23884894\end{array}$ & Yes & No & $\mathrm{N} / \mathrm{A}$ & Yes & Yes & No & Moderate & No & $\mathrm{N} / \mathrm{A}$ & $\mathrm{N} / \mathrm{A}$ & Yes & N/A & Low \\
\hline & $\begin{array}{l}\text { Nezvalova- } \\
\text { Henriksen 2010, } \\
20132339\end{array}$ & Yes & No & $\mathrm{N} / \mathrm{A}$ & Yes & Yes & No & Moderate & No & $\mathrm{N} / \mathrm{A}$ & $\mathrm{N} / \mathrm{A}$ & Yes & $\mathrm{N} / \mathrm{A}$ & Low \\
\hline & $\begin{array}{l}\text { Kallen, } 2011, \\
21751829\end{array}$ & Yes & No & $\mathrm{N} / \mathrm{A}$ & No & No & No & Serious & No & $\mathrm{N} / \mathrm{A}$ & $\mathrm{N} / \mathrm{A}$ & Yes & N/A & Low \\
\hline & $\begin{array}{l}\text { Olesen 2000, } \\
1075989\end{array}$ & Yes & No & $\mathrm{N} / \mathrm{A}$ & Yes & Yes & No & Low & No & $\mathrm{N} / \mathrm{A}$ & $\mathrm{N} / \mathrm{A}$ & Yes & $\mathrm{N} / \mathrm{A}$ & Low \\
\hline & $\begin{array}{l}\text { Spielmann, 2018, } \\
28758416\end{array}$ & Yes & No & $\mathrm{N} / \mathrm{A}$ & Yes & Yes & No & Low & No & $\mathrm{N} / \mathrm{A}$ & $\mathrm{N} / \mathrm{A}$ & Yes & $\mathrm{N} / \mathrm{A}$ & Low \\
\hline
\end{tabular}

Abbreviations: Int = intervention, KQ = Key Question, N/A = Not applicable, NI = no information, NRCS = nonrandomized comparative study, Pharm = pharmacologic, PMID = PubMed identifier, $\mathrm{PN}=$ probably no, $\mathrm{PY}=$ probably yes.

Judgements are color coded for emphasis only. Signaling questions are not color coded for simplicity and because they are only used to inform the judgements.

Responses to Risk of Bias in Nonrandomized Studies of Interventions (ROBINS-I) signaling questions 1.1 to 1.6 and 2.1 to 2.5 are in regular font. (each item rated as Yes, PY, NI, PN, No, or N/A)

Judgements about confounding and selection bias are in bold font. Each judgement is rated as Low, Moderate, Serious, Critical (none in Table), or NI (none in Table). 
Table B-4. Risk of bias assessment for primary studies - Nonrandomized comparative studies (NRCSs), assessment of remaining biases and quality

\begin{tabular}{|c|c|c|c|c|c|c|c|c|c|c|c|c|}
\hline $\begin{array}{l}\text { KQ, Type of } \\
\text { Intervention }\end{array}$ & Study, Year, PMID & $\begin{array}{l}\text { Blinding of } \\
\text { Participants }\end{array}$ & $\begin{array}{l}\text { Blinding of } \\
\text { Personnell } \\
\text { Care } \\
\text { Providers }\end{array}$ & $\begin{array}{c}\text { Blinding of } \\
\text { Outcome } \\
\text { Assessors } \\
\text { (Objective } \\
\text { Outcomes) }\end{array}$ & $\begin{array}{c}\text { Blinding of } \\
\text { Outcome } \\
\text { Assessors } \\
\text { (Subjective } \\
\text { Outcomes) }\end{array}$ & $\begin{array}{l}\text { Incomplete } \\
\text { Outcome } \\
\text { Data }\end{array}$ & $\begin{array}{l}\text { Selective } \\
\text { Outcome } \\
\text { Reporting }\end{array}$ & $\begin{array}{l}\text { Other } \\
\text { Bias }\end{array}$ & $\begin{array}{l}\text { Eligibility } \\
\text { Criteria } \\
\text { Prespecified } \\
\text { and Clearly } \\
\text { Described }\end{array}$ & $\begin{array}{l}\text { Intervention } \\
\text { Clearly } \\
\text { Described } \\
\text { and } \\
\text { Consistently } \\
\text { Delivered }\end{array}$ & $\begin{array}{l}\text { Outcomes } \\
\text { Prespecified, } \\
\text { Clearly } \\
\text { Defined, } \\
\text { Valid, } \\
\text { Reliable, and } \\
\text { Consistently } \\
\text { Assessed }\end{array}$ & $\begin{array}{c}\text { OVERALL } \\
\text { RISK OF BIAS }\end{array}$ \\
\hline \multirow[t]{8}{*}{$\begin{array}{l}\text { KQ 2, } \\
\text { Pharm }\end{array}$} & $\begin{array}{l}\text { Ephross, 2014, } \\
24805878\end{array}$ & High & High & High & N/A & Low & Low & Low & Yes & No & Yes & HIGH \\
\hline & $\begin{array}{l}\text { O'Quinn, 1999, } \\
10728620\end{array}$ & High & High & Unclear & $\mathrm{N} / \mathrm{A}$ & Low & Unclear & Low & No & No & No & HIGH \\
\hline & $\begin{array}{l}\text { Shuhaiber, } \\
1998,9710039\end{array}$ & High & High & High & High & Low & Low & Low & Yes & No & Yes & HIGH \\
\hline & $\begin{array}{l}\text { Nezvalova- } \\
\text { Henriksen, } \\
2013,23884894\end{array}$ & High & High & High & High & Low & Low & Low & Yes & No & Yes & HIGH \\
\hline & $\begin{array}{l}\text { Nezvalova- } \\
\text { Henriksen, } \\
\text { 2010, 20132339 }\end{array}$ & High & High & High & High & High & Low & Low & Yes & No & Yes & HIGH \\
\hline & $\begin{array}{l}\text { Kallen, 2011, } \\
21751829\end{array}$ & High & High & High & $\mathrm{N} / \mathrm{A}$ & Low & Low & Low & Yes & No & Yes & HIGH \\
\hline & $\begin{array}{l}\text { Olesen, } 2000 \\
1075989\end{array}$ & High & High & High & N/A & Low & Low & Low & Yes & No & Yes & MODERATE \\
\hline & $\begin{array}{l}\text { Spielmann, } \\
2018,28758416\end{array}$ & High & High & High & High & High & Low & Low & Yes & No & Yes & HIGH \\
\hline
\end{tabular}

Abbreviations: KQ = Key Question, N/A = not applicable, NRCS = nonrandomized comparative study, Pharm = pharmacologic, PMID = PubMed identifier.

Ratings are color coded for emphasis only.

From the Cochrane Risk of Bias Tool (each item rated as Low, High, Unclear, or N/A)

- Blinding of participants (performance bias): Performance bias due to knowledge of the allocated interventions by participants during the study;

- Blinding of personnel/care providers (performance bias): Performance bias due to knowledge of the allocated interventions by personnel/care providers during the study;

- Blinding of outcome assessor (detection bias): Detection bias due to knowledge of the allocated interventions by outcome assessors during the study;

- Incomplete outcome data (attrition bias): Attrition bias due to amount, nature or handling of incomplete outcome data;

- Selective outcome reporting (outcome reporting bias): Bias arising from outcomes being selectively reported based on the direction and/or strength of the results;

- $\quad$ Other Bias: Bias due to problems not covered elsewhere in the table.

From the National Heart, Lung, and Blood Institute (NHLBI) Quality Assessment Tool (each item rated as Yes, No, Unclear [none in Table], or No Data [none in Table])

- $\quad$ Eligibility criteria prespecified and clearly described: potentially related to selection bias;

- Intervention clearly described and delivered consistently: potentially related to performance bias;

- $\quad$ Outcomes prespecified, clearly defined, valid, reliable, and assessed consistently: potentially related to detection bias.

Overall risk of bias assessed as HIGH, MODERATE, or LOW (none in Table). 
Table B-5. Risk of bias assessment for primary studies - Single-group studies

\begin{tabular}{|c|l|l|l|l|l|l|l|l|}
\hline $\begin{array}{c}\text { KQ, Type of } \\
\text { Intervention }\end{array}$ & Study, Year, PMID & $\begin{array}{c}\text { Incomplete } \\
\text { Outcome } \\
\text { Data }\end{array}$ & $\begin{array}{c}\text { Selective } \\
\text { Outcome } \\
\text { Reporting }\end{array}$ & $\begin{array}{c}\text { Other } \\
\text { Bias }\end{array}$ & $\begin{array}{c}\text { Eligibility } \\
\text { Criteria } \\
\text { Prespecified } \\
\text { and Clearly } \\
\text { Described }\end{array}$ & $\begin{array}{c}\text { Intervention } \\
\text { Clearly } \\
\text { Described and } \\
\text { Consistently } \\
\text { Delivered }\end{array}$ & $\begin{array}{c}\text { Outcomes } \\
\text { Prespecified, } \\
\text { Clearly Defined, } \\
\text { Valid, Reliable, } \\
\text { and Consistently } \\
\text { Assessed }\end{array}$ & $\begin{array}{c}\text { OVERALL } \\
\text { RISK OF BIAS }\end{array}$ \\
\hline KQ 1, Pharm & $\begin{array}{l}\text { Castilla-Puentes, } \\
2014,24598456\end{array}$ & Low & Low & Low & Yes & No Data & Yes & LOW \\
\hline KQ 2, Nonpharm & $\begin{array}{l}\text { Govindappagari, } \\
2014,25415168\end{array}$ & Low & Low & Low & No & Yes & Yes & LOW \\
\cline { 2 - 9 } & $\begin{array}{l}\text { Marcus (Study 1), } \\
1995,8600478\end{array}$ & Low & Low & Low & Yes & Yes & Yes & LOW \\
\cline { 2 - 9 } & $\begin{array}{l}\text { Hickling, 1990, } \\
2401622\end{array}$ & Low & Low & Low & No Data & No Data & Yes & LOW \\
\cline { 2 - 9 } & $\begin{array}{l}\text { Bhola, 2015, } \\
26055242, \text { U.K. }\end{array}$ & Low & Low & Low & Yes & Yes & No & MODERATE \\
\hline
\end{tabular}

Abbreviations: Nonpharm = nonpharmacologic, Pharm = pharmacologic, PMID = PubMed identifier.

Ratings are color coded for emphasis only.

From the Cochrane Risk of Bias Tool (each item rated as Low, High [none in Table], Unclear [none in Table], or N/A [none in Table])

- Incomplete outcome data (attrition bias): Attrition bias due to amount, nature or handling of incomplete outcome data;

- $\quad$ Selective outcome reporting (outcome reporting bias): Bias arising from outcomes being selectively reported based on the direction and/or strength of the results;

- $\quad$ Other Bias: Bias due to problems not covered elsewhere in the table.

From the National Heart, Lung, and Blood Institute (NHLBI) Quality Assessment Tool (each item rated as Yes, No, Unclear [none in Table], or No Data)

- $\quad$ Eligibility criteria prespecified and clearly described: potentially related to selection bias;

- Intervention clearly described and delivered consistently: potentially related to performance bias;

- Outcomes prespecified, clearly defined, valid, reliable, and assessed consistently: potentially related to detection bias.

Overall risk of bias assessed as HIGH (none in Table), MODERATE, or LOW. 
Table B-6. Key Question 1: Pharmacologic interventions: Antiepileptics - Adverse effects, categorical

\begin{tabular}{|c|c|c|c|c|c|c|c|c|c|}
\hline $\begin{array}{l}\text { Study, Year, } \\
\text { Design } \\
\text { PMID }\end{array}$ & $\begin{array}{l}\text { Maternal or } \\
\text { Fetal/Child }\end{array}$ & Adverse Effect & $\begin{array}{c}\text { Category of } \\
\text { Congenital } \\
\text { Anomaly }\end{array}$ & Time & Arm & Subgroup & $\mathrm{n} / \mathrm{N}(\%)$ & $\begin{array}{c}\text { Effect } \\
\text { Size } \\
(95 \% \text { CI })\end{array}$ & $\begin{array}{c}\mathbf{P} \\
\text { Value }\end{array}$ \\
\hline $\begin{array}{l}\text { Castilla-Puentes, } \\
\text { 2014, Single-group } \\
\text { study, 24598456 }\end{array}$ & Fetal/Child & Spontaneous abortion & - & NR & $\begin{array}{l}\text { Antiepileptics: } \\
\text { Topiramate }\end{array}$ & All participants & $23 / 81(28.4)$ & $\mathrm{N} / \mathrm{A}$ & $\mathrm{N} / \mathrm{A}$ \\
\hline $\begin{array}{l}\text { Castilla-Puentes, } \\
\text { 2014, Single-group } \\
\text { study, 24598456 }\end{array}$ & Fetal/Child & $\begin{array}{l}\text { Elective or induced } \\
\text { abortion }\end{array}$ & - & NR & $\begin{array}{l}\text { Antiepileptics: } \\
\text { Topiramate }\end{array}$ & All participants & $10 / 81(12.3)$ & $\mathrm{N} / \mathrm{A}$ & $\mathrm{N} / \mathrm{A}$ \\
\hline $\begin{array}{l}\text { Castilla-Puentes, } \\
\text { 2014, Single-group } \\
\text { study, } 24598456\end{array}$ & Fetal/Child & $\begin{array}{l}\text { Congenital anomalies, } \\
\text { Any }\end{array}$ & - & At birth & $\begin{array}{l}\text { Antiepileptics: } \\
\text { Topiramate }\end{array}$ & All participants & $10 / 81(12.3)$ & $\mathrm{N} / \mathrm{A}$ & $\mathrm{N} / \mathrm{A}$ \\
\hline $\begin{array}{l}\text { Castilla-Puentes, } \\
\text { 2014, Single-group } \\
\text { study, } 24598456\end{array}$ & Fetal/Child & $\begin{array}{l}\text { Congenital anomalies, } \\
\text { Hydrocephalus }\end{array}$ & Neurological & At birth & $\begin{array}{l}\text { Antiepileptics: } \\
\text { Topiramate }\end{array}$ & All participants & $1 / 81(1.2)$ & $\mathrm{N} / \mathrm{A}$ & $\mathrm{N} / \mathrm{A}$ \\
\hline $\begin{array}{l}\text { Castilla-Puentes, } \\
\text { 2014, Single-group } \\
\text { study, 24598456 }\end{array}$ & Fetal/Child & $\begin{array}{l}\text { Congenital anomalies, } \\
\text { Meningomyelocele }\end{array}$ & Neurological & At birth & $\begin{array}{l}\text { Antiepileptics: } \\
\text { Topiramate }\end{array}$ & All participants & $1 / 81(1.2)$ & $\mathrm{N} / \mathrm{A}$ & N/A \\
\hline $\begin{array}{l}\text { Castilla-Puentes, } \\
\text { 2014, Single-group } \\
\text { study, 24598456 }\end{array}$ & Fetal/Child & $\begin{array}{l}\text { Congenital anomalies, } \\
\text { Spina bifida }\end{array}$ & Neurological & At birth & $\begin{array}{l}\text { Antiepileptics: } \\
\text { Topiramate }\end{array}$ & All participants & $1 / 81(1.2)$ & $\mathrm{N} / \mathrm{A}$ & N/A \\
\hline $\begin{array}{l}\text { Castilla-Puentes, } \\
\text { 2014, Single-group } \\
\text { study, } 24598456\end{array}$ & Fetal/Child & $\begin{array}{l}\text { Congenital anomalies, } \\
\text { Cardiovascular }\end{array}$ & Cardiovascular & At birth & $\begin{array}{l}\text { Antiepileptics: } \\
\text { Topiramate }\end{array}$ & All participants & $1 / 81(1.2)$ & $\mathrm{N} / \mathrm{A}$ & $\mathrm{N} / \mathrm{A}$ \\
\hline $\begin{array}{l}\text { Castilla-Puentes, } \\
\text { 2014, Single-group } \\
\text { study, } 24598456\end{array}$ & Fetal/Child & $\begin{array}{l}\text { Congenital anomalies, } \\
\text { Syndactyly }\end{array}$ & Malformation & At birth & $\begin{array}{l}\text { Antiepileptics: } \\
\text { Topiramate }\end{array}$ & All participants & $1 / 81(1.2)$ & $\mathrm{N} / \mathrm{A}$ & N/A \\
\hline $\begin{array}{l}\text { Castilla-Puentes, } \\
\text { 2014, Single-group } \\
\text { study, 24598456 }\end{array}$ & Fetal/Child & $\begin{array}{l}\text { Congenital anomalies, } \\
\text { Polydactyly }\end{array}$ & Malformation & At birth & $\begin{array}{l}\text { Antiepileptics: } \\
\text { Topiramate }\end{array}$ & All participants & $1 / 81(1.2)$ & $\mathrm{N} / \mathrm{A}$ & $\mathrm{N} / \mathrm{A}$ \\
\hline $\begin{array}{l}\text { Castilla-Puentes, } \\
\text { 2014, Single-group } \\
\text { study, } 24598456\end{array}$ & Fetal/Child & $\begin{array}{l}\text { Congenital anomalies, } \\
\text { Cleft palate }\end{array}$ & Malformation & At birth & $\begin{array}{l}\text { Antiepileptics: } \\
\text { Topiramate }\end{array}$ & All participants & $2 / 81(2.5)$ & $\mathrm{N} / \mathrm{A}$ & $\mathrm{N} / \mathrm{A}$ \\
\hline $\begin{array}{l}\text { Castilla-Puentes, } \\
\text { 2014, Single-group } \\
\text { study, 24598456 }\end{array}$ & Fetal/Child & $\begin{array}{l}\text { Congenital anomalies, } \\
\text { Gastrointestinal } \\
\text { obstruction }\end{array}$ & Gastrointestinal & At birth & $\begin{array}{l}\text { Antiepileptics: } \\
\text { Topiramate }\end{array}$ & All participants & $1 / 81(1.2)$ & $\mathrm{N} / \mathrm{A}$ & $\mathrm{N} / \mathrm{A}$ \\
\hline $\begin{array}{l}\text { Castilla-Puentes, } \\
\text { 2014, Single-group } \\
\text { study, 24598456 }\end{array}$ & Fetal/Child & $\begin{array}{l}\text { Congenital anomalies, } \\
\text { Pyloric stenosis }\end{array}$ & Gastrointestinal & At birth & $\begin{array}{l}\text { Antiepileptics: } \\
\text { Topiramate }\end{array}$ & All participants & $1 / 81(1.2)$ & $\mathrm{N} / \mathrm{A}$ & $\mathrm{N} / \mathrm{A}$ \\
\hline
\end{tabular}

Abbreviations: $\mathrm{CI}=$ confidence interval, N/A = not applicable, PMID = PubMed identifier. 
Table B-7. Key Question 2: Pharmacologic interventions: Antiemetics, antihistamines, opioid analgesics - Categorical outcomes

\begin{tabular}{|c|c|c|c|c|c|c|c|c|}
\hline $\begin{array}{l}\text { Study, Year, } \\
\text { Design, } \\
\text { PMID }\end{array}$ & Outcome & Outcome Definition & Time & Arm & Subgroup & $\mathrm{n} / \mathbf{N}(\%)$ & $\begin{array}{l}\text { Effect Size } \\
\text { (95\% CI) }\end{array}$ & P value \\
\hline \multirow[t]{2}{*}{$\begin{array}{l}\text { Childress, } \\
\text { 2018, RCT, } \\
\text { 29723901 }\end{array}$} & \multirow[t]{2}{*}{$\begin{array}{l}\text { Severity of } \\
\text { acute } \\
\text { headache }\end{array}$} & \multirow[t]{2}{*}{$\begin{array}{l}\text { Reduction in pain score by } \\
>=2 \text { points on a VAS (0- } \\
10 \text { ) }\end{array}$} & \multirow[t]{2}{*}{$24 \mathrm{~h}$} & $\begin{array}{l}\text { Combination of metoclopramide } \\
\text { and diphenhydramine }\end{array}$ & All participants & $34 / 34$ (100) & \multirow[t]{2}{*}{ No nonevents } & \\
\hline & & & & Codeine & All participants & $32 / 32(100)$ & & \\
\hline \multirow[t]{2}{*}{$\begin{array}{l}\text { Childress, } \\
\text { 2018, RCT, } \\
29723901\end{array}$} & \multirow[t]{2}{*}{$\begin{array}{l}\text { Resolution } \\
\text { of acute } \\
\text { headache }\end{array}$} & \multirow[t]{2}{*}{$\begin{array}{l}\text { Relief from headache with } \\
\text { one dose }\end{array}$} & \multirow[t]{2}{*}{ NR } & $\begin{array}{l}\text { Combination of metoclopramide } \\
\text { and diphenhydramine }\end{array}$ & All participants & 32/34 (94.1) & \multirow[t]{2}{*}{$\begin{array}{l}\text { OR } 1.37(1.07, \\
1.75)^{\mathrm{i}}\end{array}$} & \multirow[t]{2}{*}{$0.016^{\mathrm{i}}$} \\
\hline & & & & Codeine & All participants & $22 / 32(68.8)$ & & \\
\hline \multirow[t]{2}{*}{$\begin{array}{l}\text { Childress, } \\
\text { 2018, RCT, } \\
\text { 29723901 }\end{array}$} & \multirow[t]{2}{*}{$\begin{array}{l}\text { Resolution } \\
\text { of acute } \\
\text { headache }\end{array}$} & \multirow[t]{2}{*}{$\begin{array}{l}\text { Relief from headache with } \\
\text { two doses }\end{array}$} & \multirow[t]{2}{*}{ NR } & $\begin{array}{l}\text { Combination of metoclopramide } \\
\text { and diphenhydramine }\end{array}$ & All participants & $2 / 34(5.9)$ & \multirow[t]{2}{*}{$\begin{array}{l}\text { OR 0.44 }(0.07, \\
2.57)^{\mathrm{i}}\end{array}$} & \multirow[t]{2}{*}{$0.360^{\mathrm{i}}$} \\
\hline & & & & Codeine & All participants & $4 / 32(12.5)$ & & \\
\hline \multirow[t]{2}{*}{$\begin{array}{l}\text { Childress, } \\
\text { 2018, RCT, } \\
29723901\end{array}$} & \multirow[t]{2}{*}{$\begin{array}{l}\text { Resolution } \\
\text { of acute } \\
\text { headache }\end{array}$} & \multirow[t]{2}{*}{$\begin{array}{l}\text { Complete resolution of } \\
\text { headache }\end{array}$} & \multirow[t]{2}{*}{$24 \mathrm{~h}$} & $\begin{array}{l}\text { Combination of metoclopramide } \\
\text { and diphenhydramine }\end{array}$ & All participants & 26/34 (76.5) & \multirow[t]{2}{*}{$\begin{array}{l}\text { OR 5.42 (1.86, } \\
15.76)^{\mathrm{i}}\end{array}$} & \multirow[t]{2}{*}{$0.002^{i}$} \\
\hline & & & & Codeine & All participants & $12 / 32(37.5)$ & & \\
\hline \multirow[t]{2}{*}{$\begin{array}{l}\text { Childress, } \\
\text { 2018, RCT, } \\
\text { 29723901 }\end{array}$} & \multirow[t]{2}{*}{$\begin{array}{l}\text { Recurrence } \\
\text { of acute } \\
\text { headache }\end{array}$} & \multirow[t]{2}{*}{ Recurrence of headache } & \multirow[t]{2}{*}{$24 \mathrm{~h}$} & $\begin{array}{l}\text { Combination of metoclopramide } \\
\text { and diphenhydramine }\end{array}$ & All participants & $13 / 34(38.2)$ & \multirow[t]{2}{*}{$\begin{array}{l}\text { OR 0.42 (0.16, } \\
1.14)^{\mathrm{i}}\end{array}$} & \multirow[t]{2}{*}{$0.088^{i}$} \\
\hline & & & & Codeine & All participants & 19/32 (59.4) & & \\
\hline \multirow[t]{2}{*}{$\begin{array}{l}\text { Childress, } \\
\text { 2018, RCT, } \\
29723901\end{array}$} & \multirow[t]{2}{*}{$\begin{array}{l}\text { Medication } \\
\text { use }\end{array}$} & \multirow[t]{2}{*}{$\begin{array}{l}\text { Use of nonstudy headache } \\
\text { medication }\end{array}$} & \multirow[t]{2}{*}{$24 \mathrm{~h}$} & $\begin{array}{l}\text { Combination of metoclopramide } \\
\text { and diphenhydramine }\end{array}$ & All participants & $7 / 34(20.6)$ & \multirow[t]{2}{*}{$\begin{array}{l}\text { OR } 0.43(0.14 \\
1.29)^{i}\end{array}$} & \multirow[t]{2}{*}{$0.134^{\mathrm{i}}$} \\
\hline & & & & Codeine & All participants & $12 / 32(37.5)$ & & \\
\hline
\end{tabular}

Abbreviations: $\mathrm{CI}$ = confidence interval, $\mathrm{h}=$ hours, IQR = interquartile range, $\mathrm{OR}=$ odds ratio, $\mathrm{PMID}=$ PubMed identifier, $\mathrm{RCT}$ = randomized controlled trial, $\mathrm{VAS}=$ visual analog scale.

${ }^{i}$ Calculated by us based on reported arm-specific data. This was done only for studies with arms with baseline characteristics considered by us to be similar. 
Table B-8. Key Question 2: Pharmacologic interventions: Antiemetics, antihistamines, opioid analgesics - Continuous outcomes

\begin{tabular}{|c|c|c|c|c|c|c|c|c|c|}
\hline $\begin{array}{c}\text { Study, Year, } \\
\text { Design, } \\
\text { PMID }\end{array}$ & Outcome & $\begin{array}{l}\text { Outcome } \\
\text { Definition }\end{array}$ & Time & Arm & Subgroup & $\mathbf{N}$ & $\begin{array}{c}\text { Result, } \\
\text { Mean (SD) }\end{array}$ & Effect Size (95\% CI) & $P$ value \\
\hline \multirow[t]{12}{*}{$\begin{array}{l}\text { Childress, } \\
\text { 2018, RCT, } \\
\text { 29723901 }\end{array}$} & \multirow[t]{12}{*}{$\begin{array}{l}\text { Severity of } \\
\text { acute } \\
\text { headache }\end{array}$} & \multirow[t]{12}{*}{$\begin{array}{l}\text { Pain score on a } \\
\text { VAS }(0-10)\end{array}$} & \multirow[t]{2}{*}{ Baseline } & $\begin{array}{l}\text { Combination of metoclopramide } \\
\text { and diphenhydramine }\end{array}$ & $\begin{array}{l}\text { All } \\
\text { participants }\end{array}$ & 35 & 7.6 (NR) & \multirow[t]{2}{*}{-} & \multirow[t]{2}{*}{ - } \\
\hline & & & & Codeine & $\begin{array}{l}\text { All } \\
\text { participants }\end{array}$ & 35 & 7.4 (NR) & & \\
\hline & & & \multirow[t]{2}{*}{$30 \mathrm{~min}$} & $\begin{array}{l}\text { Combination of metoclopramide } \\
\text { and diphenhydramine }\end{array}$ & $\begin{array}{l}\text { All } \\
\text { participants }\end{array}$ & 35 & $3.0(2.8)$ & \multirow[t]{2}{*}{ NMD -3.0 (-4.2, - 1.8) } & \multirow[t]{2}{*}{$<0.001^{i}$} \\
\hline & & & & Codeine & $\begin{array}{l}\text { All } \\
\text { participants }\end{array}$ & 35 & $5.8(2.3)$ & & \\
\hline & & & \multirow[t]{2}{*}{$1 \mathrm{~h}$} & $\begin{array}{l}\text { Combination of metoclopramide } \\
\text { and diphenhydramine }\end{array}$ & $\begin{array}{l}\text { All } \\
\text { participants }\end{array}$ & 35 & $2.2(2.3)$ & \multirow[t]{2}{*}{ NMD -2.1 $(-3.3,-0.9)^{i}$} & \multirow[t]{2}{*}{0.001} \\
\hline & & & & Codeine & $\begin{array}{l}\text { All } \\
\text { participants }\end{array}$ & 35 & $4.1(3.0)$ & & \\
\hline & & & \multirow[t]{2}{*}{$6 \mathrm{~h}$} & $\begin{array}{l}\text { Combination of metoclopramide } \\
\text { and diphenhydramine }\end{array}$ & $\begin{array}{l}\text { All } \\
\text { participants }\end{array}$ & 33 & 1.8 (NR) & \multirow[t]{2}{*}{ NMD -0.9 $(-2.2,0.4)^{i}$} & \multirow[t]{2}{*}{$0.165^{i}$} \\
\hline & & & & Codeine & $\begin{array}{l}\text { All } \\
\text { participants }\end{array}$ & 32 & 2.5 (NR) & & \\
\hline & & & \multirow[t]{2}{*}{$12 \mathrm{~h}$} & $\begin{array}{l}\text { Combination of metoclopramide } \\
\text { and diphenhydramine }\end{array}$ & $\begin{array}{l}\text { All } \\
\text { participants }\end{array}$ & 33 & $1.3(2.5)$ & \multirow[t]{2}{*}{ NMD - $1.6(-2.9,-0.3)^{i}$} & \multirow[t]{2}{*}{0.016} \\
\hline & & & & Codeine & $\begin{array}{l}\text { All } \\
\text { participants }\end{array}$ & 31 & $2.7(3.0)$ & & \\
\hline & & & \multirow[t]{2}{*}{$24 \mathrm{~h}$} & $\begin{array}{l}\text { Combination of metoclopramide } \\
\text { and diphenhydramine }\end{array}$ & $\begin{array}{l}\text { All } \\
\text { participants }\end{array}$ & 34 & 2.1 (NR) & \multirow[t]{2}{*}{ NMD - $1.0(-2.3,0.3)^{i}$} & \multirow[t]{2}{*}{$0.128^{i}$} \\
\hline & & & & Codeine & $\begin{array}{l}\text { All } \\
\text { participants }\end{array}$ & 32 & 2.9 (NR) & & \\
\hline \multirow[t]{2}{*}{$\begin{array}{l}\text { Childress, } \\
\text { 2018, RCT, } \\
\text { 29723901 }\end{array}$} & \multirow[t]{2}{*}{$\begin{array}{l}\text { Resolution } \\
\text { of acute } \\
\text { headache }\end{array}$} & \multirow[t]{2}{*}{$\begin{array}{l}\text { Time to headache } \\
\text { relief in min }\end{array}$} & \multirow[t]{2}{*}{$24 \mathrm{~h}$} & $\begin{array}{l}\text { Combination of metoclopramide } \\
\text { and diphenhydramine }\end{array}$ & $\begin{array}{l}\text { All } \\
\text { participants }\end{array}$ & 35 & $\begin{array}{l}20.2 \min \\
(13.4)\end{array}$ & \multirow[t]{2}{*}{$\begin{array}{l}\text { MD }-42.2 \min (-63.7 \\
-20.7)^{i}\end{array}$} & \multirow[t]{2}{*}{$<0.001^{i}$} \\
\hline & & & & Codeine & $\begin{array}{l}\text { All } \\
\text { participants }\end{array}$ & 35 & $\begin{array}{l}62.4 \min \\
(62.2)\end{array}$ & & \\
\hline
\end{tabular}

Abbreviations: $\mathrm{CI}$ = confidence interval, $\mathrm{h}=$ hours, MD = mean difference, min = minutes, NMD = net mean difference, NR = not reported, PMID = PubMed identifier, RCT = randomized controlled trial, $\mathrm{SD}=$ standard deviation, $\mathrm{VAS}=$ visual analog scale.

${ }^{\mathrm{i}}$ Calculated by us based on reported arm-specific data. This was done only for studies with arms with baseline characteristics considered by us to be similar. 
Table B-9. Key Question 2: Pharmacologic interventions: Antiemetics, antihistamines, opioid analgesics - adverse effects, categorical

\begin{tabular}{|c|c|c|c|c|c|c|c|c|}
\hline $\begin{array}{l}\text { Study, Year, } \\
\text { Design, } \\
\text { PMID }\end{array}$ & $\begin{array}{c}\text { Maternal } \\
\text { or Infant/ } \\
\text { Child? }\end{array}$ & Outcome & Time & Arm & Subgroup & $\begin{array}{l}\mathrm{n} / \mathrm{N} \\
(\%)\end{array}$ & $\begin{array}{l}\text { Effect Size } \\
(95 \% \text { CI })\end{array}$ & $P$ value \\
\hline \multirow[t]{2}{*}{$\begin{array}{l}\text { Childress, 2018, } \\
\text { RCT, } 29723901\end{array}$} & \multirow[t]{2}{*}{ Maternal } & \multirow[t]{2}{*}{$\begin{array}{l}\text { Serious adverse } \\
\text { effects }\end{array}$} & \multirow[t]{2}{*}{$24 \mathrm{~h}$} & $\begin{array}{l}\text { Combination of } \\
\text { metoclopramide and } \\
\text { diphenhydramine }\end{array}$ & $\begin{array}{l}\text { All } \\
\text { participants }\end{array}$ & $\begin{array}{l}0 / 34 \\
(0.0)\end{array}$ & \multirow[t]{2}{*}{ No events } & \multirow[t]{2}{*}{-} \\
\hline & & & & Codeine & $\begin{array}{l}\text { All } \\
\text { participants }\end{array}$ & $\begin{array}{l}0 / 34 \\
(0.0)\end{array}$ & & \\
\hline \multirow[t]{2}{*}{$\begin{array}{l}\text { Childress, 2018, } \\
\text { RCT, } 29723901\end{array}$} & \multirow[t]{2}{*}{ Maternal } & \multirow[t]{2}{*}{$\begin{array}{l}\text { Nonserious adverse } \\
\text { effects (fatigue, } \\
\text { dizziness, agitation, } \\
\text { nausea, or } \\
\text { intravenous site } \\
\text { pain) }\end{array}$} & $24 \mathrm{~h}$ & $\begin{array}{l}\text { Combination of } \\
\text { metoclopramide and } \\
\text { diphenhydramine }\end{array}$ & $\begin{array}{l}\text { All } \\
\text { participants }\end{array}$ & $\begin{array}{l}15 / 34 \\
(44.1)\end{array}$ & \multirow[t]{2}{*}{$\begin{array}{l}\text { OR 1.74 } \\
(0.63,4.76)^{i}\end{array}$} & \multirow[t]{2}{*}{$0.283^{i}$} \\
\hline & & & & Codeine & $\begin{array}{l}\text { All } \\
\text { participants }\end{array}$ & $\begin{array}{l}10 / 32 \\
(31.3)\end{array}$ & & \\
\hline
\end{tabular}

Abbreviations: $\mathrm{CI}$ = confidence interval, $\mathrm{h}$ = hours, $\mathrm{OR}=$ odds ratio, $\mathrm{PMID}=$ PubMed identifier.

${ }^{i}$ Calculated by us based on reported arm-specific data. This was done only for studies with arms with baseline characteristics considered by us to be similar. 
Table B-10. Key Question 2: Pharmacologic interventions: Triptans, ergot products, and NSAIDs - Maternal adverse effects, categorical

\begin{tabular}{|c|c|c|c|c|c|c|c|}
\hline $\begin{array}{l}\text { Study, Year, } \\
\text { Design, } \\
\text { PMID }\end{array}$ & Outcome & Time & Arm & Subgroup & $\mathrm{n} / \mathrm{N}(\%)$ & $\begin{array}{c}\text { Adj Effect } \\
\text { Size (95\% } \\
\text { CI) }\end{array}$ & $\begin{array}{l}\text { Adj P } \\
\text { value }\end{array}$ \\
\hline \multirow{2}{*}{$\begin{array}{l}\text { O'Quinn, 1999, } \\
\text { NRCS, } 10728620\end{array}$} & \multirow{2}{*}{$\begin{array}{l}\text { Abnormal } \\
\text { pregnancy } \\
\text { outcome }\end{array}$} & \multirow[t]{2}{*}{ NR } & Triptans: Sumatriptan & All participants & 9/76 (12) & \multirow[t]{2}{*}{ NR } & \multirow[t]{2}{*}{ NR } \\
\hline & & & $\begin{array}{l}\text { Triptans: Sumatriptan (before pregnancy } \\
\text { only) }\end{array}$ & All participants & $19 / 92(21)$ & & \\
\hline \multirow{21}{*}{$\begin{array}{l}\text { Nezvalova- } \\
\text { Henriksen, 2013, } \\
\text { NRCS, } \\
23884894\end{array}$} & \multirow[t]{21}{*}{$\begin{array}{l}\text { Postpartum } \\
\text { hemorrhage } \\
>500 \mathrm{ml}\end{array}$} & \multirow[t]{21}{*}{ Delivery } & \multirow[t]{20}{*}{ Triptans: Any } & $\begin{array}{l}\text { All participants (Any triptan, } \\
\text { Any trimester) }\end{array}$ & $248 / 1465(16.9)$ & NR & NR \\
\hline & & & & Any Triptan, First trimester & $204 / 1210(16.9)$ & & \\
\hline & & & & Any Triptan, Second trimester & $65 / 304(21.4)$ & & \\
\hline & & & & Any Triptan, Third trimester & $24 / 185(13.0)$ & & \\
\hline & & & & Sumatriptan, Any trimester & $100 / 575(17.4)$ & & \\
\hline & & & & Sumatriptan, First trimester & $71 / 415$ (17.1) & & \\
\hline & & & & $\begin{array}{l}\text { Sumatriptan, Second } \\
\text { trimester }\end{array}$ & $40 / 173(23.1)$ & & \\
\hline & & & & Sumatriptan, Third trimester & $11 / 104(10.6)$ & & \\
\hline & & & & Rizatriptan, Any trimester & 49/334 (14.7) & & \\
\hline & & & & Rizatriptan, First trimester & $45 / 310(14.5)$ & & \\
\hline & & & & Rizatriptan, Second trimester & 9/43 (20.9) & & \\
\hline & & & & Rizatriptan, Third trimester & $5 / 26(19.2)$ & & \\
\hline & & & & Eletriptan, Any trimester & $30 / 207$ (14.5) & & \\
\hline & & & & Eletriptan, First trimester & $29 / 189(15.3)$ & & \\
\hline & & & & Eletriptan, Second trimester & $4 / 33(12.1)$ & & \\
\hline & & & & Eletriptan, Third trimester & $2 / 21(9.5)$ & & \\
\hline & & & & Zolmitriptan, Any trimester & $34 / 156(21.8)$ & & \\
\hline & & & & Zolmitriptan, First trimester & $33 / 144(22.9)$ & & \\
\hline & & & & $\begin{array}{l}\text { Zolmitriptan, Second } \\
\text { trimester }\end{array}$ & $6 / 26(23.1)$ & & \\
\hline & & & & Zolmitriptan, Third trimester & $2 / 17(11.8)$ & & \\
\hline & & & Triptans: Any (Before pregnancy only) & All participants & $195 / 1095$ (17.8) & & \\
\hline \multirow{5}{*}{$\begin{array}{l}\text { Nezvalova- } \\
\text { Henriksen 2010, } \\
\text { NRCS, } \\
20132339\end{array}$} & \multirow[t]{5}{*}{$\begin{array}{l}\text { Postpartum } \\
\text { hemorrhage } \\
>500 \mathrm{ml}\end{array}$} & \multirow[t]{5}{*}{ Delivery } & \multirow[t]{3}{*}{ Triptans: Any } & All participants & $255 / 1045(24.4)$ & NR & NR \\
\hline & & & & First trimester & $228 / 455(50.1)$ & $\mathrm{NR}$ & NR \\
\hline & & & & $\begin{array}{l}\text { Second and/or Third } \\
\text { trimester }\end{array}$ & $41 / 229(17.9)$ & NR & NR \\
\hline & & & Triptans: Any (before pregnancy only) & All participants & $63 / 805(7.8)$ & NR & $\mathrm{NR}$ \\
\hline & & & No Triptans & All participants & $\mathrm{NR}$ & NR & NR \\
\hline
\end{tabular}

Abbreviations: Adj = adjusted, CI = confidence interval, NR = not reported, NRCS = nonrandomized comparative study, PMID = PubMed identifier. 
Table B-11. Key Question 2: Pharmacologic interventions: Triptans, ergot products, and NSAIDs - Fetal/child adverse effects (fetal death, spontaneous abortion, elective or induced abortion, stillbirth, and infant death), categorical

\begin{tabular}{|c|c|c|c|c|c|c|c|}
\hline $\begin{array}{c}\text { Study, Year, } \\
\text { Design, } \\
\text { PMID }\end{array}$ & Outcome & Time & Arm & Subgroup & $\mathbf{n} / \mathbf{N}(\%)$ & $\begin{array}{c}\text { Adj Effect } \\
\text { Size (95\% } \\
\text { CI) } \\
\end{array}$ & $\begin{array}{l}\text { Adj P } \\
\text { value }\end{array}$ \\
\hline \multirow{15}{*}{$\begin{array}{l}\text { Ephross, 2014, } \\
\text { NRCS, } 24805878\end{array}$} & \multirow{15}{*}{$\begin{array}{l}\text { Spontaneous } \\
\text { abortion }\end{array}$} & \multirow[t]{15}{*}{ NR } & \multirow[t]{5}{*}{ Triptans: Sumatriptan } & All participants & $34 / 626(5.4)$ & NR & NR \\
\hline & & & & First trimester & $34 / 528(6.4)$ & & \\
\hline & & & & Second trimester & $0 / 78(0.0)$ & & \\
\hline & & & & Third trimester & $0 / 16(0.0)$ & & \\
\hline & & & & Unknown trimester & $0 / 4(0.0)$ & & \\
\hline & & & \multirow[t]{5}{*}{ Triptans: Naratriptan } & All participants & $5 / 57(8.8)$ & NR & NR \\
\hline & & & & First trimester & $5 / 52(9.6)$ & & \\
\hline & & & & Second trimester & $0 / 5(0.0)$ & & \\
\hline & & & & Third trimester & $0 / 0(0.0)$ & & \\
\hline & & & & Unknown trimester & $0 / 0(0.0)$ & & \\
\hline & & & \multirow[t]{5}{*}{$\begin{array}{l}\text { Combination of Triptans (Sumatriptan) and } \\
\text { NSAIDs (Naproxen) }\end{array}$} & All participants & $1 / 6(16.7)$ & NR & NR \\
\hline & & & & First trimester & $1 / 5(20.0)$ & & \\
\hline & & & & Second trimester & $0 / 1(0.0)$ & & \\
\hline & & & & Third trimester & $0 / 0(0.0)$ & & \\
\hline & & & & Unknown trimester & $0 / 0(0.0)$ & & \\
\hline \multirow{15}{*}{$\begin{array}{l}\text { Ephross, 2014, } \\
\text { NRCS, } 24805878\end{array}$} & \multirow{15}{*}{$\begin{array}{l}\text { Elective or } \\
\text { induced abortion }\end{array}$} & \multirow[t]{15}{*}{ NR } & \multirow[t]{5}{*}{ Triptans: Sumatriptan } & All participants & 16/626 (2.6) & NR & NR \\
\hline & & & & First trimester & $15 / 528(2.8)$ & & \\
\hline & & & & Second trimester & $0 / 78(0.0)$ & & \\
\hline & & & & Third trimester & $0 / 16(0.0)$ & & \\
\hline & & & & Unknown trimester & $1 / 4(25.0)$ & & \\
\hline & & & \multirow[t]{5}{*}{ Triptans: Naratriptan } & All participants & $1 / 57(1.8)$ & NR & NR \\
\hline & & & & First trimester & $1 / 52(1.9)$ & & \\
\hline & & & & Second trimester & $0 / 5(0.0)$ & & \\
\hline & & & & Third trimester & $0 / 0(0.0)$ & & \\
\hline & & & & Unknown trimester & $0 / 0(0.0)$ & & \\
\hline & & & \multirow[t]{5}{*}{$\begin{array}{l}\text { Combination of Triptans (Sumatriptan) and } \\
\text { NSAI Ds (Naproxen) }\end{array}$} & All participants & $0 / 6(0.0)$ & NR & NR \\
\hline & & & & First trimester & $0 / 5(0.0)$ & & \\
\hline & & & & Second trimester & $0 / 1(0.0)$ & & \\
\hline & & & & Third trimester & $0 / 0(0.0)$ & & \\
\hline & & & & Unknown trimester & $0 / 0(0.0)$ & & \\
\hline \multirow{5}{*}{$\begin{array}{l}\text { Ephross, 2014, } \\
\text { NRCS, } 24805878\end{array}$} & \multirow{5}{*}{$\begin{array}{l}\text { Stillbirth or fetal } \\
\text { death }\end{array}$} & \multirow[t]{5}{*}{ NR } & \multirow[t]{5}{*}{ Triptans: Sumatriptan } & All participants & $5 / 626(0.8)$ & NR & NR \\
\hline & & & & First trimester & $5 / 528(1.0)$ & & \\
\hline & & & & Second trimester & $0 / 78(0.0)$ & & \\
\hline & & & & Third trimester & $0 / 16(0.0)$ & & \\
\hline & & & & Unknown trimester & $0 / 4(0.0)$ & & \\
\hline
\end{tabular}




\begin{tabular}{|c|c|c|c|c|c|c|c|}
\hline $\begin{array}{l}\text { Study, Year, } \\
\text { Design, } \\
\text { PMID } \\
\end{array}$ & Outcome & Time & Arm & Subgroup & $\mathbf{n} / \mathbf{N}(\%)$ & $\begin{array}{l}\text { Adj Effect } \\
\text { Size (95\% } \\
\text { CI) }\end{array}$ & $\begin{array}{l}\text { Adj P } \\
\text { value }\end{array}$ \\
\hline & & & \multirow{5}{*}{ Triptans: Naratriptan } & All participants & $0 / 57(0.0)$ & NR & NR \\
\hline & & & & First trimester & $0 / 52(0.0)$ & & \\
\hline & & & & Second trimester & $0 / 5(0.0)$ & & \\
\hline & & & & Third trimester & $0 / 0(0.0)$ & & \\
\hline & & & & Unknown trimester & $0 / 0(0.0)$ & & \\
\hline & & & \multirow[t]{5}{*}{$\begin{array}{l}\text { Combination of Triptans (Sumatriptan) and } \\
\text { NSAI Ds (Naproxen) }\end{array}$} & All participants & $0 / 6(0.0)$ & NR & NR \\
\hline & & & & First trimester & $0 / 5(0.0)$ & & \\
\hline & & & & Second trimester & $0 / 1(0.0)$ & & \\
\hline & & & & Third trimester & $0 / 0(0.0)$ & & \\
\hline & & & & Unknown trimester & $0 / 0(0.0)$ & & \\
\hline \multirow{2}{*}{$\begin{array}{l}\text { O'Quinn, 1999, } \\
\text { NRCS, 10728620 }\end{array}$} & \multirow{2}{*}{$\begin{array}{l}\text { Spontaneous } \\
\text { abortion }\end{array}$} & \multirow[t]{2}{*}{ NR } & Triptans: Sumatriptan & All participants & $8 / 76(10.5)$ & \multirow[t]{2}{*}{ NR } & \multirow[t]{2}{*}{ NR } \\
\hline & & & Triptans: Sumatriptan (before pregnancy only) & All participants & $11 / 92(12)$ & & \\
\hline \multirow{2}{*}{$\begin{array}{l}\text { Shuhaiber, 1998, } \\
\text { NRCS, } 9710039\end{array}$} & \multirow{2}{*}{$\begin{array}{l}\text { Spontaneous } \\
\text { abortion }\end{array}$} & \multirow[t]{2}{*}{ NR } & Triptans: Sumatriptan & All participants & $11 / 96(11.5)$ & \multirow[t]{2}{*}{ NR } & \multirow[t]{2}{*}{ NR } \\
\hline & & & No Triptans & All participants & $6 / 96(6.3)$ & & \\
\hline \multirow{2}{*}{$\begin{array}{l}\text { Shuhaiber, 1998, } \\
\text { NRCS, } 9710039\end{array}$} & \multirow{2}{*}{$\begin{array}{l}\text { Elective or } \\
\text { induced abortion }\end{array}$} & \multirow[t]{2}{*}{ NR } & Triptans: Sumatriptan & All participants & $4 / 96(4.2)$ & \multirow[t]{2}{*}{ NR } & \multirow[t]{2}{*}{ NR } \\
\hline & & & No Triptans & All participants & $2 / 96(2.1)$ & & \\
\hline \multirow{5}{*}{$\begin{array}{l}\text { Nezvalova-Henriksen } \\
\text { 2010, NRCS, } \\
\text { 20132339 }\end{array}$} & \multirow[t]{5}{*}{ Stillbirth } & \multirow[t]{5}{*}{$\begin{array}{l}\text { At } \\
\text { birth }\end{array}$} & \multirow[t]{3}{*}{ Triptans: Any } & All participants & $0 / 1045(0.0)$ & NR & NR \\
\hline & & & & First trimester & $0 / 455(0.0)$ & & \\
\hline & & & & $\begin{array}{l}\text { Second and/or } \\
\text { third trimester }\end{array}$ & $0 / 229(0.0)$ & & \\
\hline & & & Triptans: Any (before pregnancy only) & All participants & $2 / 805(0.2)$ & & \\
\hline & & & No Triptans & All participants & NR & & \\
\hline \multirow{5}{*}{$\begin{array}{l}\text { Nezvalova-Henriksen } \\
\text { 2010, NRCS, } \\
20132339\end{array}$} & \multirow[t]{5}{*}{ Perinatal death } & \multirow[t]{5}{*}{$\begin{array}{l}\text { At } \\
\text { birth }\end{array}$} & \multirow[t]{3}{*}{ Triptans: Any } & All participants & $6 / 1045(0.6)$ & NR & NR \\
\hline & & & & First trimester & $6 / 455(1.3)$ & & \\
\hline & & & & $\begin{array}{l}\text { Second and/or } \\
\text { third trimester }\end{array}$ & $3 / 229(1.3)$ & & \\
\hline & & & Triptans: Any (before pregnancy only) & All participants & $3 / 805(0.4)$ & & \\
\hline & & & No Triptans & All participants & NR & & \\
\hline \multirow{4}{*}{$\begin{array}{l}\text { Nezvalova-Henriksen } \\
\text { 2010, NRCS, } \\
\text { 20132339 }\end{array}$} & \multirow[t]{4}{*}{ Infant death } & \multirow[t]{4}{*}{$\begin{array}{l}1 \text { y of } \\
\text { age }\end{array}$} & \multirow[t]{3}{*}{ Triptans: Any } & All participants & $5 / 1045(0.5)$ & NR & NR \\
\hline & & & & First trimester & $5 / 455(1.1)$ & & \\
\hline & & & & $\begin{array}{l}\text { Second and/or } \\
\text { third trimester }\end{array}$ & $2 / 229(0.9)$ & & \\
\hline & & & Triptans: Any (before pregnancy only) & All participants & $0 / 805(0.0)$ & & \\
\hline
\end{tabular}




\begin{tabular}{|c|c|c|c|c|c|c|c|}
\hline $\begin{array}{c}\text { Study, Year, } \\
\text { Design, } \\
\text { PMID }\end{array}$ & Outcome & Time & Arm & Subgroup & $\mathrm{n} / \mathbf{N}(\%)$ & $\begin{array}{c}\text { Adj Effect } \\
\text { Size (95\% } \\
\text { CI) } \\
\end{array}$ & $\begin{array}{l}\text { Adj P } \\
\text { value }\end{array}$ \\
\hline & & & No Triptans & All participants & NR & & \\
\hline \multirow{11}{*}{$\begin{array}{l}\text { Kallen, } 2011, \text { NRCS, } \\
21751829\end{array}$} & \multirow[t]{11}{*}{ Perinatal death } & \multirow{11}{*}{$\begin{array}{l}\text { At } \\
\text { birth }\end{array}$} & \multirow[t]{7}{*}{ Triptans: Any } & All participants & NR & $\mathrm{NR}$ & NR \\
\hline & & & & Sumatriptan & $5 / 658(0.75)$ & & \\
\hline & & & & Naratriptan & NR & & \\
\hline & & & & Zolmitriptan & NR & & \\
\hline & & & & Rizatriptan & NR & & \\
\hline & & & & Almotriptan & NR & & \\
\hline & & & & Eletriptan & NR & & \\
\hline & & & \multirow[t]{3}{*}{ Ergot Products: Any } & All participants & NR & & \\
\hline & & & & Dihydroergotamine & NR & & \\
\hline & & & & $\begin{array}{l}\text { Ergotamine } \\
\text { combinations }\end{array}$ & NR & & \\
\hline & & & Antihistamines: Pizotifen & All participants & $3 / 64(4.69)$ & & \\
\hline \multirow[t]{3}{*}{$\begin{array}{l}\text { Spielmann, 2018, } \\
\text { NRCS, } 28758416\end{array}$} & \multirow[t]{3}{*}{$\begin{array}{l}\text { Spontaneous } \\
\text { abortion }\end{array}$} & \multirow[t]{3}{*}{ NR } & \multirow[t]{2}{*}{ Triptans: Any } & All participants & $\begin{array}{l}50 / 432 \\
(11.6)\end{array}$ & \multirow[t]{2}{*}{$\begin{array}{l}\text { Adj HR } 1.41 \\
(0.9,2.2)\end{array}$} & \\
\hline & & & & First trimester & $\begin{array}{l}49 / 387 \\
(12.7)\end{array}$ & & \\
\hline & & & No Triptans & All participants & $37 / 475(7.8)$ & & \\
\hline \multirow[t]{3}{*}{$\begin{array}{l}\text { Spielmann, 2018, } \\
\text { NRCS, 28758416 }\end{array}$} & \multirow[t]{3}{*}{$\begin{array}{l}\text { Elective or } \\
\text { induced abortion }\end{array}$} & \multirow[t]{3}{*}{ NR } & \multirow[t]{2}{*}{ Triptans: Any } & All participants & $23 / 432(5.3)$ & $\begin{array}{l}\text { Adj HR } 1.58 \\
(0.8,3.0)\end{array}$ & NR \\
\hline & & & & First trimester & $23 / 387(5.9)$ & & \\
\hline & & & No Triptans & All participants & $17 / 475(3.6)$ & & \\
\hline \multirow{3}{*}{$\begin{array}{l}\text { Spielmann, 2018, } \\
\text { NRCS, 28758416 }\end{array}$} & \multirow[t]{3}{*}{ Stillbirth } & \multirow{3}{*}{$\begin{array}{l}\text { At } \\
\text { birth }\end{array}$} & \multirow[t]{2}{*}{ Triptans: Any } & All participants & $1 / 432(0.2)$ & NR & NR \\
\hline & & & & First trimester & $1 / 387(0.3)$ & & \\
\hline & & & No Triptans & All participants & $1 / 475(0.2)$ & & \\
\hline
\end{tabular}

Abbreviations: Adj = adjusted, $\mathrm{CI}=$ confidence interval, $\mathrm{h}=$ hours, HR = hazard ratio, $\mathrm{m}=$ months, NR = not reported, NRCS = nonrandomized comparative study, OR = odds ratio, $\mathrm{PMID}=$ PubMed identifier, $\mathrm{y}=$ years. 
Table B-12. Key Question 2: Pharmacologic interventions: Triptans, ergot products, and NSAIDs - Fetal/child adverse effects (perinatal complications and signs of infant distress), categorical

\begin{tabular}{|c|c|c|c|c|c|c|c|c|}
\hline $\begin{array}{l}\text { Study, Year, Design, } \\
\text { PMID }\end{array}$ & $\begin{array}{c}\text { Outcom } \\
\text { e }\end{array}$ & $\begin{array}{c}\text { Outcome } \\
\text { Definition }\end{array}$ & Time & Arm & Subgroup & $\mathrm{n} / \mathrm{N}(\%)$ & $\begin{array}{c}\text { Adj Effect } \\
\text { Size (95\% } \\
\text { CI) }\end{array}$ & $\begin{array}{c}\text { Adj } \\
\mathbf{P} \\
\text { value }\end{array}$ \\
\hline \multirow{21}{*}{$\begin{array}{l}\text { Nezvalova-Henriksen, } \\
\text { 2013, NRCS, } \\
\text { 23884894 }\end{array}$} & \multirow[t]{21}{*}{$\begin{array}{l}\text { Preterm } \\
\text { birth }\end{array}$} & \multirow[t]{21}{*}{$<37 w$} & \multirow[t]{21}{*}{ At birth } & \multirow[t]{20}{*}{ Triptans: Any } & $\begin{array}{l}\text { All participants (Any triptan, } \\
\text { Any trimester) }\end{array}$ & $92 / 1465(6.3)$ & NR & NR \\
\hline & & & & & Any Triptan, First trimester & $76 / 1210(6.3)$ & & \\
\hline & & & & & Any Triptan, Second trimester & $27 / 304(8.9)$ & & \\
\hline & & & & & Any Triptan, Third trimester & $12 / 185(6.5)$ & & \\
\hline & & & & & Sumatriptan, Any trimester & $41 / 575(7.1)$ & & \\
\hline & & & & & Sumatriptan, First trimester & $32 / 415(7.7)$ & & \\
\hline & & & & & Sumatriptan, Second trimester & $11 / 173(6.4)$ & & \\
\hline & & & & & Sumatriptan, Third trimester & $7 / 104(6.7)$ & & \\
\hline & & & & & Rizatriptan, Any trimester & $18 / 334(5.4)$ & & \\
\hline & & & & & Rizatriptan, First trimester & $17 / 310(5.5)$ & & \\
\hline & & & & & Rizatriptan, Second trimester & $6 / 43(14.0)$ & & \\
\hline & & & & & Rizatriptan, Third trimester & $2 / 26(7.7)$ & & \\
\hline & & & & & Eletriptan, Any trimester & $9 / 207(4.3)$ & & \\
\hline & & & & & Eletriptan, First trimester & $7 / 189(3.7)$ & & \\
\hline & & & & & Eletriptan, Second trimester & $3 / 33(9.1)$ & & \\
\hline & & & & & Eletriptan, Third trimester & $1 / 21(4.8)$ & & \\
\hline & & & & & Zolmitriptan, Any trimester & $14 / 156(9.0)$ & & \\
\hline & & & & & Zolmitriptan, First trimester & $13 / 144(9.0)$ & & \\
\hline & & & & & Zolmitriptan, Second trimester & $5 / 26(19.2)$ & & \\
\hline & & & & & Zolmitriptan, Third trimester & $0 / 17(0.0)$ & & \\
\hline & & & & $\begin{array}{l}\text { Triptans: Any } \\
\text { (Before pregnancy } \\
\text { only) }\end{array}$ & All participants & $108 / 1095$ (9.9) & & \\
\hline \multirow{13}{*}{$\begin{array}{l}\text { Nezvalova-Henriksen, } \\
\text { 2013, NRCS, } \\
\text { 23884894 }\end{array}$} & \multirow[t]{13}{*}{$\begin{array}{l}\text { Low birth } \\
\text { weight }\end{array}$} & \multirow[t]{13}{*}{$<2500 \mathrm{~g}$} & \multirow[t]{13}{*}{ At birth } & \multirow[t]{13}{*}{ Triptans: Any } & $\begin{array}{l}\text { All participants (Any triptan, } \\
\text { Any trimester) }\end{array}$ & $75 / 1465$ (5.1) & NR & NR \\
\hline & & & & & Any Triptan, First trimester & $61 / 1210(5.0)$ & & \\
\hline & & & & & Any Triptan, Second trimester & $22 / 304(7.2)$ & & \\
\hline & & & & & Any Triptan, Third trimester & $8 / 185(4.3)$ & & \\
\hline & & & & & Sumatriptan, Any trimester & $31 / 575(5.4)$ & & \\
\hline & & & & & Sumatriptan, First trimester & $23 / 415(5.5)$ & & \\
\hline & & & & & Sumatriptan, Second trimester & $11 / 173(6.4)$ & & \\
\hline & & & & & Sumatriptan, Third trimester & $3 / 104(2.9)$ & & \\
\hline & & & & & Rizatriptan, Any trimester & $16 / 334(4.8)$ & & \\
\hline & & & & & Rizatriptan, First trimester & $15 / 310(4.8)$ & & \\
\hline & & & & & Rizatriptan, Second trimester & $1 / 43(2.3)$ & & \\
\hline & & & & & Rizatriptan, Third trimester & $3 / 26(11.5)$ & & \\
\hline & & & & & Eletriptan, Any trimester & $7 / 207(3.4)$ & & \\
\hline
\end{tabular}




\begin{tabular}{|c|c|c|c|c|c|c|c|c|}
\hline $\begin{array}{l}\text { Study, Year, Design, } \\
\text { PMID }\end{array}$ & $\begin{array}{c}\text { Outcom } \\
\text { e }\end{array}$ & $\begin{array}{c}\text { Outcome } \\
\text { Definition }\end{array}$ & Time & Arm & Subgroup & $\mathrm{n} / \mathrm{N}(\%)$ & $\begin{array}{c}\text { Adj Effect } \\
\text { Size }(95 \% \\
\text { CI }) \\
\end{array}$ & $\begin{array}{c}\text { Adj } \\
\mathbf{P} \\
\text { value } \\
\end{array}$ \\
\hline & & & & & Eletriptan, First trimester & $6 / 189(3.2)$ & & \\
\hline & & & & & Eletriptan, Second trimester & $3 / 33(9.1)$ & & \\
\hline & & & & & Eletriptan, Third trimester & $0 / 21(0.0)$ & & \\
\hline & & & & & Zolmitriptan, Any trimester & $11 / 156(7.1)$ & & \\
\hline & & & & & Zolmitriptan, First trimester & $9 / 144(6.2)$ & & \\
\hline & & & & & Zolmitriptan, Second trimester & $4 / 26(15.4)$ & & \\
\hline & & & & & Zolmitriptan, Third trimester & $1 / 17(5.9)$ & & \\
\hline & & & & $\begin{array}{l}\text { Triptans: Any } \\
\text { (Before pregnancy } \\
\text { only) }\end{array}$ & All participants & $66 / 1095(6.0)$ & & \\
\hline \multirow[t]{21}{*}{$\begin{array}{l}\text { Nezvalova-Henriksen, } \\
\text { 2013, NRCS, } \\
\text { 23884894 }\end{array}$} & \multirow[t]{21}{*}{$\begin{array}{l}\text { Low birth } \\
\text { weight } \\
\text { for } \\
\text { gestation } \\
\text { al age }\end{array}$} & \multirow[t]{21}{*}{$\begin{array}{l}\text { <tenth } \\
\text { percentile } \\
\text { for } \\
\text { gestational } \\
\text { age }\end{array}$} & \multirow[t]{21}{*}{ At birth } & \multirow[t]{20}{*}{ Triptans: Any } & $\begin{array}{l}\text { All participants (Any triptan, } \\
\text { Any trimester) }\end{array}$ & $132 / 1465(9.0)$ & NR & NR \\
\hline & & & & & Any Triptan, First trimester & $110 / 1210(9.1)$ & & \\
\hline & & & & & Any Triptan, Second trimester & $27 / 304(8.9)$ & & \\
\hline & & & & & Any Triptan, Third trimester & 20/185 (10.8) & & \\
\hline & & & & & Sumatriptan, Any trimester & $48 / 575(8.3)$ & & \\
\hline & & & & & Sumatriptan, First trimester & $33 / 415(8.0)$ & & \\
\hline & & & & & Sumatriptan, Second trimester & $16 / 173(9.2)$ & & \\
\hline & & & & & Sumatriptan, Third trimester & $11 / 104(10.6)$ & & \\
\hline & & & & & Rizatriptan, Any trimester & $36 / 334(10.8)$ & & \\
\hline & & & & & Rizatriptan, First trimester & $36 / 310(11.6)$ & & \\
\hline & & & & & Rizatriptan, Second trimester & $2 / 43(4.7)$ & & \\
\hline & & & & & Rizatriptan, Third trimester & $4 / 26(15.4)$ & & \\
\hline & & & & & Eletriptan, Any trimester & $21 / 207(10.1)$ & & \\
\hline & & & & & Eletriptan, First trimester & 20/189 (10.6) & & \\
\hline & & & & & Eletriptan, Second trimester & $4 / 33(12.1)$ & & \\
\hline & & & & & Eletriptan, Third trimester & $1 / 21(4.8)$ & & \\
\hline & & & & & Zolmitriptan, Any trimester & $13 / 156(8.3)$ & & \\
\hline & & & & & Zolmitriptan, First trimester & $13 / 144(9.0)$ & & \\
\hline & & & & & Zolmitriptan, Second trimester & $2 / 26(7.7)$ & & \\
\hline & & & & & Zolmitriptan, Third trimester & $1 / 17(5.9)$ & & \\
\hline & & & & $\begin{array}{l}\text { Triptans: Any } \\
\text { (Before pregnancy } \\
\text { only) }\end{array}$ & All participants & $91 / 1095$ (8.3) & & \\
\hline \multirow[t]{4}{*}{$\begin{array}{l}\text { Nezvalova-Henriksen, } \\
\text { 2013, NRCS, } \\
\text { 23884894 }\end{array}$} & \multirow[t]{4}{*}{$\begin{array}{l}\text { NICU } \\
\text { admissio } \\
n\end{array}$} & \multirow[t]{4}{*}{-} & \multirow[t]{4}{*}{ At birth } & \multirow[t]{4}{*}{ Triptans: Any } & $\begin{array}{l}\text { All participants (Any triptan, } \\
\text { Any trimester) }\end{array}$ & NR & NR & NR \\
\hline & & & & & Any Triptan, First trimester & $100 / 1210(8.3)$ & & \\
\hline & & & & & Any Triptan, Second trimester & $31 / 304(10.2)$ & & \\
\hline & & & & & Any Triptan, Third trimester & 16/185 (8.6) & & \\
\hline
\end{tabular}




\begin{tabular}{|c|c|c|c|c|c|c|c|c|}
\hline $\begin{array}{c}\text { Study, Year, Design, } \\
\text { PMID }\end{array}$ & $\begin{array}{c}\text { Outcom } \\
\text { e }\end{array}$ & $\begin{array}{c}\text { Outcome } \\
\text { Definition }\end{array}$ & Time & Arm & Subgroup & $\mathrm{n} / \mathrm{N}(\%)$ & $\begin{array}{l}\text { Adj Effect } \\
\text { Size }(95 \% \\
\quad \text { CI) } \\
\end{array}$ & $\begin{array}{c}\text { Adj } \\
\mathbf{P} \\
\text { value }\end{array}$ \\
\hline & & & & & Sumatriptan, Any trimester & NR & & \\
\hline & & & & & Sumatriptan, First trimester & $41 / 415(9.9)$ & & \\
\hline & & & & & Sumatriptan, Second trimester & $14 / 173(8.1)$ & & \\
\hline & & & & & Sumatriptan, Third trimester & $5 / 104(4.8)$ & & \\
\hline & & & & & Rizatriptan, Any trimester & NR & & \\
\hline & & & & & Rizatriptan, First trimester & $23 / 310(7.4)$ & & \\
\hline & & & & & Rizatriptan, Second trimester & $5 / 43(11.6)$ & & \\
\hline & & & & & Rizatriptan, Third trimester & $4 / 26(15.4)$ & & \\
\hline & & & & & Eletriptan, Any trimester & NR & & \\
\hline & & & & & Eletriptan, First trimester & $15 / 189(7.9)$ & & \\
\hline & & & & & Eletriptan, Second trimester & $4 / 33(12.1)$ & & \\
\hline & & & & & Eletriptan, Third trimester & $1 / 21(4.8)$ & & \\
\hline & & & & & Zolmitriptan, Any trimester & $\mathrm{NR}$ & & \\
\hline & & & & & Zolmitriptan, First trimester & $12 / 144(8.3)$ & & \\
\hline & & & & & Zolmitriptan, Second trimester & $4 / 26(15.4)$ & & \\
\hline & & & & & Zolmitriptan, Third trimester & $4 / 17(23.5)$ & & \\
\hline & & & & $\begin{array}{l}\text { Triptans: Any } \\
\text { (Before pregnancy } \\
\text { only) }\end{array}$ & All participants & 120/1095 (11.0) & & \\
\hline \multirow{5}{*}{$\begin{array}{l}\text { Nezvalova-Henriksen } \\
\text { 2010, NRCS, } \\
20132339\end{array}$} & \multirow[t]{5}{*}{$\begin{array}{l}\text { Preterm } \\
\text { birth }\end{array}$} & \multirow[t]{5}{*}{$<37 \mathrm{w}$} & \multirow[t]{5}{*}{ At birth } & \multirow[t]{3}{*}{ Triptans: Any } & All participants & $86 / 1045(8.2)$ & NR & NR \\
\hline & & & & & First trimester & $82 / 455(18.0)$ & & \\
\hline & & & & & Second and/or Third trimester & $55 / 229(24.0)$ & & \\
\hline & & & & $\begin{array}{l}\text { Triptans: Any } \\
\text { (before pregnancy } \\
\text { only) }\end{array}$ & All participants & $30 / 805(3.7)$ & & \\
\hline & & & & No Triptans & All participants & NR & & \\
\hline \multirow{5}{*}{$\begin{array}{l}\text { Nezvalova-Henriksen } \\
\text { 2010, NRCS, } \\
20132339\end{array}$} & \multirow[t]{5}{*}{$\begin{array}{l}\text { Low birth } \\
\text { weight }\end{array}$} & \multirow[t]{5}{*}{$<2500 \mathrm{~g}$} & \multirow[t]{5}{*}{ At birth } & \multirow[t]{3}{*}{ Triptans: Any } & All participants & $65 / 1045(6.2)$ & NR & NR \\
\hline & & & & & First trimester & $63 / 455$ (13.9) & & \\
\hline & & & & & Second and/or Third trimester & $40 / 229(17.5)$ & & \\
\hline & & & & $\begin{array}{l}\text { Triptans: Any } \\
\text { (before pregnancy } \\
\text { only) }\end{array}$ & All participants & $19 / 805(2.3)$ & & \\
\hline & & & & No Triptans & All participants & NR & & \\
\hline \multirow[t]{3}{*}{$\begin{array}{l}\text { Nezvalova-Henriksen } \\
\text { 2010, NRCS, } \\
\text { 20132339 }\end{array}$} & \multirow[t]{3}{*}{$\begin{array}{l}\text { Apgar } \\
\text { score }<7\end{array}$} & \multirow[t]{3}{*}{-} & \multirow[t]{3}{*}{$\begin{array}{l}1 \text { min } \\
\text { after } \\
\text { birth }\end{array}$} & \multirow[t]{3}{*}{ Triptans: Any } & All participants & $88 / 1045(8.4)$ & NR & NR \\
\hline & & & & & First trimester & $81 / 455$ (17.8) & & \\
\hline & & & & & Second and/or Third trimester & $55 / 229(24.0)$ & & \\
\hline
\end{tabular}




\begin{tabular}{|c|c|c|c|c|c|c|c|c|}
\hline $\begin{array}{l}\text { Study, Year, Design, } \\
\text { PMID }\end{array}$ & $\begin{array}{c}\text { Outcom } \\
\text { e }\end{array}$ & $\begin{array}{c}\text { Outcome } \\
\text { Definition }\end{array}$ & Time & Arm & Subgroup & $\mathrm{n} / \mathrm{N}(\%)$ & $\begin{array}{c}\text { Adj Effect } \\
\text { Size (95\% } \\
\text { CI) } \\
\end{array}$ & $\begin{array}{c}\text { Adj } \\
\mathbf{P} \\
\text { value }\end{array}$ \\
\hline & & & & $\begin{array}{l}\text { Triptans: Any } \\
\text { (before pregnancy } \\
\text { only) }\end{array}$ & All participants & $18 / 805(2.2)$ & & \\
\hline & & & & No Triptans & All participants & NR & & \\
\hline & & & $\begin{array}{l}5 \text { min } \\
\text { after } \\
\text { birth }\end{array}$ & Triptans: Any & All participants & $22 / 1045(2.1)$ & NR & NR \\
\hline & & & & & First trimester & $20 / 455(4.4)$ & & \\
\hline & & & & & Second and/or Third trimester & $11 / 229(4.8)$ & & \\
\hline & & & & $\begin{array}{l}\text { Triptans: Any } \\
\text { (before pregnancy } \\
\text { only) }\end{array}$ & All participants & $4 / 805(0.5)$ & & \\
\hline & & & & No Triptans & All participants & NR & & \\
\hline \multirow{11}{*}{$\begin{array}{l}\text { Kallen, } 2011 \text {, NRCS, } \\
21751829\end{array}$} & \multirow{11}{*}{$\begin{array}{l}\text { Preterm } \\
\text { birth }\end{array}$} & \multirow[t]{11}{*}{$<37 w$} & \multirow[t]{11}{*}{ At birth } & \multirow[t]{7}{*}{ Triptans: Any } & All participants & NR & NR & NR \\
\hline & & & & & Sumatriptan & $34 / 658(5.1)$ & & \\
\hline & & & & & Naratriptan & NR & & \\
\hline & & & & & Zolmitriptan & NR & & \\
\hline & & & & & Rizatriptan & NR & & \\
\hline & & & & & Almotriptan & NR & & \\
\hline & & & & & Eletriptan & NR & & \\
\hline & & & & \multirow[t]{3}{*}{$\begin{array}{l}\text { Ergot Products: } \\
\text { Any }\end{array}$} & All participants & NR & & \\
\hline & & & & & Dihydroergotamine & NR & & \\
\hline & & & & & Ergotamine combinations & NR & & \\
\hline & & & & $\begin{array}{l}\text { Antihistamines: } \\
\text { Pizotifen }\end{array}$ & All participants & NR & & \\
\hline \multirow[t]{11}{*}{$\begin{array}{l}\text { Kallen, 2011, NRCS, } \\
21751829\end{array}$} & \multirow[t]{11}{*}{$\begin{array}{l}\text { Low birth } \\
\text { weight }\end{array}$} & \multirow[t]{11}{*}{$<2500 \mathrm{~g}$} & \multirow[t]{11}{*}{ At birth } & \multirow[t]{7}{*}{ Triptans: Any } & All participants & NR & NR & NR \\
\hline & & & & & Sumatriptan & $34 / 658(5.1)$ & & \\
\hline & & & & & Naratriptan & NR & & \\
\hline & & & & & Zolmitriptan & NR & & \\
\hline & & & & & Rizatriptan & NR & & \\
\hline & & & & & Almotriptan & NR & & \\
\hline & & & & & Eletriptan & NR & & \\
\hline & & & & \multirow[t]{3}{*}{$\begin{array}{l}\text { Ergot Products: } \\
\text { Any }\end{array}$} & All participants & NR & & \\
\hline & & & & & Dihydroergotamine & NR & & \\
\hline & & & & & Ergotamine combinations & NR & & \\
\hline & & & & $\begin{array}{l}\text { Antihistamines: } \\
\text { Pizotifen }\end{array}$ & All participants & NR & & \\
\hline $\begin{array}{l}\text { Olesen, 2000, NRCS, } \\
10759898\end{array}$ & $\begin{array}{l}\text { Preterm } \\
\text { birth }\end{array}$ & $<37 w$ & At birth & $\begin{array}{l}\text { Triptans: } \\
\text { Sumatriptan }\end{array}$ & All participants & $5 / 34(14.7)$ & $\begin{array}{l}\text { Adj OR } 6.3 \\
(1.2,32.0)\end{array}$ & NR \\
\hline
\end{tabular}




\begin{tabular}{|c|c|c|c|c|c|c|c|c|}
\hline $\begin{array}{l}\text { Study, Year, Design, } \\
\text { PMID }\end{array}$ & $\begin{array}{c}\text { Outcom } \\
\text { e }\end{array}$ & $\begin{array}{c}\text { Outcome } \\
\text { Definition }\end{array}$ & Time & Arm & Subgroup & $\mathrm{n} / \mathrm{N}(\%)$ & $\begin{array}{c}\text { Adj Effect } \\
\text { Size (95\% } \\
\text { CI) }\end{array}$ & $\begin{array}{c}\text { Adj } \\
\text { P } \\
\text { value }\end{array}$ \\
\hline & & & & $\begin{array}{l}\text { Triptans: } \\
\text { Sumatriptan or } \\
\text { Ergot Products: } \\
\text { Ergotamine } \\
\text { (before pregnancy } \\
\text { only) }\end{array}$ & All participants & $3 / 89$ (3.4) & & \\
\hline \multirow[t]{2}{*}{$\begin{array}{l}\text { Olesen, 2000, NRCS, } \\
10759898\end{array}$} & \multirow[t]{2}{*}{$\begin{array}{l}\text { Low birth } \\
\text { weight }\end{array}$} & \multirow[t]{2}{*}{$<2500 \mathrm{~g}$} & \multirow[t]{2}{*}{ At birth } & $\begin{array}{l}\text { Triptans: } \\
\text { Sumatriptan }\end{array}$ & All participants & $1 / 34(3.4)$ & \multirow[t]{2}{*}{$\begin{array}{l}\text { Adj OR } 0.9 \\
(0.1,11.8)\end{array}$} & \multirow[t]{2}{*}{ NR } \\
\hline & & & & $\begin{array}{l}\text { Triptans: } \\
\text { Sumatriptan or } \\
\text { Ergot Products: } \\
\text { Ergotamine } \\
\text { (before pregnancy } \\
\text { only) }\end{array}$ & All participants & $5 / 89(5.8)$ & & \\
\hline
\end{tabular}

Abbreviations: Adj = adjusted, CI = confidence interval, $\mathrm{m}=$ months, $\mathrm{NICU}=$ neonatal intensive care unit, $\mathrm{NR}=$ not reported, $\mathrm{NRCS}=$ nonrandomized comparative study, OR = odds ratio, $\mathrm{PMID}=$ PubMed identifier, $\mathrm{RR}=$ relative risk, $\mathrm{w}=$ weeks, $\mathrm{y}=$ years. 
Table B-13. Key Question 2: Pharmacologic interventions: Triptans, ergot products, and NSAIDs - Fetal/child adverse effects (congenital anomalies), categorical

\begin{tabular}{|c|c|c|c|c|c|c|c|}
\hline $\begin{array}{l}\text { Study, Year, } \\
\text { Design, PMID }\end{array}$ & Outcome & Time & Arm & Subgroup & $\mathbf{n} / \mathbf{N}(\%)$ & $\begin{array}{l}\text { Adj Effect } \\
\text { Size (95\% } \\
\text { CI) }\end{array}$ & $\begin{array}{l}\text { Adj } P \\
\text { value }\end{array}$ \\
\hline \multirow{15}{*}{$\begin{array}{l}\text { Ephross, 2014, } \\
\text { NRCS, 24805878 }\end{array}$} & \multirow[t]{15}{*}{ Major anomalies } & \multirow[t]{15}{*}{ At birth } & \multirow[t]{5}{*}{ Triptans: Sumatriptan } & All participants & 19/626 (3.0) & NR & NR \\
\hline & & & & First trimester & $16 / 528(3.0)$ & & \\
\hline & & & & $2^{\text {nd }}$ trimester & $3 / 78(3.8)$ & & \\
\hline & & & & $3^{\text {rd }}$ trimester & $0 / 16(0.0)$ & & \\
\hline & & & & Unknown trimester & $0 / 4(0.0)$ & & \\
\hline & & & \multirow[t]{5}{*}{ Triptans: Naratriptan } & All participants & $1 / 57(1.8)$ & & \\
\hline & & & & First trimester & $1 / 52(1.9)$ & & \\
\hline & & & & $2^{\text {nd }}$ trimester & $0 / 5(0.0)$ & & \\
\hline & & & & $3^{\text {rd }}$ trimester & $0 / 0(0.0)$ & & \\
\hline & & & & Unknown trimester & $0 / 0(0.0)$ & & \\
\hline & & & \multirow[t]{5}{*}{$\begin{array}{l}\text { Combination of Triptans } \\
\text { (Sumatriptan) and } \\
\text { NSAIDs (Naproxen) }\end{array}$} & All participants & $0 / 6(0.0)$ & & \\
\hline & & & & First trimester & $0 / 5(0.0)$ & & \\
\hline & & & & $2^{\text {nd }}$ trimester & $0 / 1(0.0)$ & & \\
\hline & & & & $3^{\text {rd }}$ trimester & $0 / 0(0.0)$ & & \\
\hline & & & & Unknown trimester & $0 / 0(0.0)$ & & \\
\hline \multirow{2}{*}{$\begin{array}{l}\text { Shuhaiber, 1998, } \\
\text { NRCS, } 9710039\end{array}$} & \multirow[t]{2}{*}{ Major anomalies } & \multirow[t]{2}{*}{ At birth } & Triptans: Sumatriptan & All participants & $1 / 82(1.2)$ & \multirow[t]{2}{*}{ NR } & \multirow[t]{2}{*}{$>=0.05$} \\
\hline & & & No Triptans & All participants & $4 / 90(4.4)$ & & \\
\hline \multirow{2}{*}{$\begin{array}{l}\text { Shuhaiber, 1998, } \\
\text { NRCS, } 9710039\end{array}$} & \multirow{2}{*}{$\begin{array}{l}\text { Minor anomalies - } \\
\text { Brown marks }\end{array}$} & \multirow[t]{2}{*}{ At birth } & Triptans: Sumatriptan & All participants & $2 / 82(2.4)$ & \multirow[t]{2}{*}{ NR } & \multirow[t]{2}{*}{$>=0.05$} \\
\hline & & & No Triptans & All participants & $4 / 90(4.4)$ & & \\
\hline \multirow{2}{*}{$\begin{array}{l}\text { Shuhaiber, 1998, } \\
\text { NRCS, } 9710039\end{array}$} & \multirow{2}{*}{$\begin{array}{l}\text { Minor anomalies - Red } \\
\text { marks }\end{array}$} & \multirow[t]{2}{*}{ At birth } & Triptans: Sumatriptan & All participants & $6 / 82(7.3)$ & \multirow[t]{2}{*}{ NR } & \multirow[t]{2}{*}{$>=0.05$} \\
\hline & & & No Triptans & All participants & $1 / 82(1.2)$ & & \\
\hline \multirow{11}{*}{$\begin{array}{l}\text { Nezvalova- } \\
\text { Henriksen, 2013, } \\
\text { NRCS, 23884894 }\end{array}$} & \multirow[t]{11}{*}{ Any anomaly } & \multirow[t]{11}{*}{ At birth } & \multirow[t]{10}{*}{ Triptans: Any } & $\begin{array}{l}\text { All participants (Any } \\
\text { triptan, Any trimester) }\end{array}$ & $85 / 1465(5.7)$ & NR & NR \\
\hline & & & & Any Triptan, First trimester & $72 / 1210(6.0)$ & & \\
\hline & & & & Sumatriptan, Any trimester & $35 / 575(6.1)$ & & \\
\hline & & & & Sumatriptan, First trimester & $28 / 415(6.7)$ & & \\
\hline & & & & Rizatriptan, Any trimester & $15 / 334(4.5)$ & & \\
\hline & & & & Rizatriptan, First trimester & $14 / 310(4.5)$ & & \\
\hline & & & & Eletriptan, Any trimester & $8 / 207(3.9)$ & & \\
\hline & & & & Eletriptan, First trimester & $8 / 189(4.2)$ & & \\
\hline & & & & Zolmitriptan, Any trimester & $12 / 156(7.7)$ & & \\
\hline & & & & Zolmitriptan, First trimester & $11 / 144(7.6)$ & & \\
\hline & & & $\begin{array}{l}\text { Triptans: Any (Before } \\
\text { pregnancy only) }\end{array}$ & All participants & $67 / 1095(6.1)$ & & \\
\hline
\end{tabular}




\begin{tabular}{|c|c|c|c|c|c|c|c|}
\hline $\begin{array}{l}\text { Study, Year, } \\
\text { Design, PMID }\end{array}$ & Outcome & Time & Arm & Subgroup & $\mathbf{n} / \mathbf{N}(\%)$ & $\begin{array}{l}\text { Adj Effect } \\
\text { Size (95\% } \\
\text { CI) } \\
\end{array}$ & $\begin{array}{l}\text { Adj P } \\
\text { value }\end{array}$ \\
\hline \multirow{11}{*}{$\begin{array}{l}\text { Nezvalova- } \\
\text { Henriksen, 2013, } \\
\text { NRCS, 23884894 }\end{array}$} & \multirow[t]{11}{*}{ Major anomalies } & \multirow[t]{11}{*}{ At birth } & \multirow[t]{10}{*}{ Triptans: Any } & $\begin{array}{l}\text { All participants (Any } \\
\text { triptan, Any trimester) }\end{array}$ & $51 / 1465$ (3.5) & NR & NR \\
\hline & & & & Any Triptan, First trimester & $43 / 1210$ (3.6) & & \\
\hline & & & & Sumatriptan, Any trimester & $19 / 575(3.3)$ & & \\
\hline & & & & Sumatriptan, First trimester & $15 / 415(3.6)$ & & \\
\hline & & & & Rizatriptan, Any trimester & $11 / 334(3.3)$ & & \\
\hline & & & & Rizatriptan, First trimester & $10 / 310(3.2)$ & & \\
\hline & & & & Eletriptan, Any trimester & $4 / 207(1.9)$ & & \\
\hline & & & & Eletriptan, First trimester & $4 / 189(2.1)$ & & \\
\hline & & & & Zolmitriptan, Any trimester & $8 / 156(5.1)$ & & \\
\hline & & & & Zolmitriptan, First trimester & $7 / 144(4.9)$ & & \\
\hline & & & $\begin{array}{l}\text { Triptans: Any (Before } \\
\text { pregnancy only) }\end{array}$ & All participants & $50 / 1095$ (4.6) & & \\
\hline \multirow{5}{*}{$\begin{array}{l}\text { Nezvalova- } \\
\text { Henriksen 2010, } \\
\text { NRCS, } 20132339\end{array}$} & \multirow[t]{5}{*}{ Any anomaly } & \multirow[t]{5}{*}{ At birth } & \multirow[t]{3}{*}{ Triptans: Any } & All participants & $75 / 1045(7.2)$ & NR & $\mathrm{NR}$ \\
\hline & & & & First trimester & $69 / 455(15.2)$ & & \\
\hline & & & & 2nd and/or 3rd trimester & $49 / 229(21.4)$ & & \\
\hline & & & $\begin{array}{l}\text { Triptans: Any (before } \\
\text { pregnancy only) }\end{array}$ & All participants & $22 / 805(2.7)$ & & \\
\hline & & & No Triptans & All participants & NR & & \\
\hline \multirow{5}{*}{$\begin{array}{l}\text { Nezvalova- } \\
\text { Henriksen 2010, } \\
\text { NRCS, 20132339 }\end{array}$} & \multirow[t]{5}{*}{ Major anomalies } & \multirow[t]{5}{*}{ At birth } & \multirow[t]{3}{*}{ Triptans: Any } & All participants & $75 / 1045$ (4.4) & NR & NR \\
\hline & & & & First trimester & $43 / 455(9.5)$ & & \\
\hline & & & & 2nd and/or 3rd trimester & $30 / 229(13.1)$ & & \\
\hline & & & $\begin{array}{l}\text { Triptans: Any (before } \\
\text { pregnancy only) }\end{array}$ & All participants & $11 / 805(1.4)$ & & \\
\hline & & & No Triptans & All participants & NR & & \\
\hline \multirow{11}{*}{$\begin{array}{l}\text { Kallen, 2011, } \\
\text { NRCS, } 21751829\end{array}$} & \multirow[t]{11}{*}{ Any anomaly } & \multirow[t]{11}{*}{ At birth } & \multirow[t]{7}{*}{ Triptans: Any } & All participants & $127 / 2777(4.57)$ & NR & NR \\
\hline & & & & Sumatriptan & $107 / 2257(4.74)$ & & \\
\hline & & & & Naratriptan & $1 / 22(4.55)$ & & \\
\hline & & & & Zolmitriptan & $12 / 362(3.31)$ & & \\
\hline & & & & Rizatriptan & $7 / 157(4.46)$ & & \\
\hline & & & & Almotriptan & $1 / 6(16.67)$ & & \\
\hline & & & & Eletriptan & $3 / 14(21.43)$ & & \\
\hline & & & \multirow[t]{3}{*}{ Ergot Products: Any } & All participants & $21 / 527(3.98)$ & & \\
\hline & & & & Dihydroergotamine & $5 / 135(3.70)$ & & \\
\hline & & & & Ergotamine combinations & $16 / 388(4.12)$ & & \\
\hline & & & Antihistamines: Pizotifen & All participants & $3 / 64(4.69)$ & & \\
\hline
\end{tabular}




\begin{tabular}{|c|c|c|c|c|c|c|c|}
\hline $\begin{array}{l}\text { Study, Year, } \\
\text { Design, PMID }\end{array}$ & Outcome & Time & Arm & Subgroup & $\mathbf{n} / \mathbf{N}(\%)$ & $\begin{array}{l}\text { Adj Effect } \\
\text { Size }(95 \% \\
\text { CI) } \\
\end{array}$ & $\begin{array}{l}\text { Adj P } \\
\text { value }\end{array}$ \\
\hline \multirow{3}{*}{$\begin{array}{l}\text { Kallen, 2011, } \\
\text { NRCS, 21751829 }\end{array}$} & \multirow[t]{3}{*}{ Major anomalies } & \multirow[t]{3}{*}{ At birth } & Triptans: Any & All participants & $92 / 2777(3.31)$ & $\mathrm{NR}$ & NR \\
\hline & & & Ergot Products: Any & All participants & $17 / 527(3.23)$ & & \\
\hline & & & Antihistamines: Pizotifen & All participants & NR & & \\
\hline \multirow{3}{*}{$\begin{array}{l}\text { Kallen, 2011, } \\
\text { NRCS, } 21751829\end{array}$} & \multirow{3}{*}{$\begin{array}{l}\text { Any cardiovascular } \\
\text { anomalies }\end{array}$} & \multirow[t]{3}{*}{ At birth } & Triptans: Any & & 29/2777 (1.04) & NR & NR \\
\hline & & & Ergot Products: Any & All participants & $7 / 527(1.33)$ & & \\
\hline & & & Antihistamines: Pizotifen & All participants & NR & & \\
\hline \multirow[t]{3}{*}{$\begin{array}{l}\text { Kallen, 2011, } \\
\text { NRCS, 21751829 }\end{array}$} & \multirow[t]{3}{*}{$\begin{array}{l}\text { Ventricular septum } \\
\text { defect and/or atrial } \\
\text { septum defect }\end{array}$} & \multirow[t]{3}{*}{ At birth } & Triptans: Any & & $17 / 2777(0.61)$ & NR & NR \\
\hline & & & Ergot Products: Any & All participants & $6 / 527(1.14)$ & & \\
\hline & & & Antihistamines: Pizotifen & All participants & NR & & \\
\hline \multirow[t]{3}{*}{$\begin{array}{l}\text { Spielmann, 2018, } \\
\text { NRCS, } 28758416\end{array}$} & \multirow[t]{3}{*}{ Any anomaly } & \multirow[t]{3}{*}{ At birth } & \multirow[t]{2}{*}{ Triptans: Any } & All participants & $25 / 372(6.7)$ & $\begin{array}{l}\text { Adj OR } 1.00 \\
(0.51,2.1)\end{array}$ & NR \\
\hline & & & & First trimester & $24 / 438(7.3)$ & & \\
\hline & & & No Triptans & All participants & $28 / 431(6.5)$ & & \\
\hline \multirow[t]{3}{*}{$\begin{array}{l}\text { Spielmann, 2018, } \\
\text { NRCS, } 28758416\end{array}$} & \multirow[t]{3}{*}{ Major anomalies } & \multirow[t]{3}{*}{ At birth } & \multirow[t]{2}{*}{ Triptans: Any } & All participants & 9/367 (2.5) & $\begin{array}{l}\text { Adj OR } 1.01 \\
(0.3,3.3)\end{array}$ & NR \\
\hline & & & & First trimester & $8 / 323(2.5)$ & & \\
\hline & & & No Triptans & All participants & $12 / 429(2.8)$ & & \\
\hline \multirow[t]{3}{*}{$\begin{array}{l}\text { Spielmann, 2018, } \\
\text { NRCS, } 28758416\end{array}$} & \multirow[t]{3}{*}{ Minor anomalies } & \multirow[t]{3}{*}{ At birth } & \multirow[t]{2}{*}{ Triptans: Any } & All participants & $11 / 364(3.0)$ & $\begin{array}{l}\text { Adj OR } 1.48 \\
(0.5,4.4)\end{array}$ & NR \\
\hline & & & & First trimester & $11 / 320(3.4)$ & & \\
\hline & & & No Triptans & All participants & $12 / 427(2.8)$ & & \\
\hline \multirow[t]{3}{*}{$\begin{array}{l}\text { Spielmann, 2018, } \\
\text { NRCS, 28758416 }\end{array}$} & \multirow[t]{3}{*}{ Genetic birth defect } & \multirow[t]{3}{*}{ At birth } & \multirow[t]{2}{*}{ Triptans: Any } & All participants & $5 / 369(1.4)$ & $\begin{array}{l}\text { Adj OR } 1.10 \\
(0.2,6.6)\end{array}$ & NR \\
\hline & & & & First trimester & $5 / 325(1.5)$ & & \\
\hline & & & No Triptans & All participants & $4 / 429(0.9)$ & & \\
\hline \multirow[t]{3}{*}{$\begin{array}{l}\text { Spielmann, 2018, } \\
\text { NRCS, 28758416 }\end{array}$} & \multirow[t]{3}{*}{$\begin{array}{l}\text { Ventricular septum } \\
\text { defect }\end{array}$} & \multirow[t]{3}{*}{ At birth } & \multirow[t]{2}{*}{ Triptans: Any } & All participants & $1 / 367(0.3)$ & NR & NR \\
\hline & & & & First trimester & NR & & \\
\hline & & & No Triptans & All participants & NR & & \\
\hline Spielmann, 2018, & Atrial septum defect & At birth & Triptans: Any & All participants & $1 / 367(0.3)$ & NR & $\mathrm{NR}$ \\
\hline & & & & First trimester & NR & & \\
\hline & & & No Triptans & All participants & NR & & \\
\hline $\begin{array}{l}\text { Spielmann, 2018, } \\
\text { NRCS, } 28758416\end{array}$ & $\begin{array}{l}\text { Pulmonary artery } \\
\text { stenosis }\end{array}$ & At birth & Triptans: Any & All participants & $1 / 367(0.3)$ & NR & NR \\
\hline & & & & First trimester & NR & & \\
\hline & & & No Triptans & All participants & NR & & \\
\hline $\begin{array}{l}\text { Spielmann, 2018, } \\
\text { NRCS, } 28758416\end{array}$ & Cataract & At birth & Triptans: Any & All participants & $1 / 367(0.3)$ & NR & NR \\
\hline
\end{tabular}




\begin{tabular}{|c|c|c|c|c|c|c|c|}
\hline $\begin{array}{l}\text { Study, Year, } \\
\text { Design, PMID }\end{array}$ & Outcome & Time & Arm & Subgroup & n/N (\%) & $\begin{array}{l}\text { Adj Effect } \\
\text { Size (95\% } \\
\text { CI) }\end{array}$ & $\begin{array}{l}\text { Adj P } \\
\text { value }\end{array}$ \\
\hline & & & & First trimester & NR & & \\
\hline & & & No Triptans & All participants & NR & & \\
\hline \multirow{3}{*}{$\begin{array}{l}\text { Spielmann, 2018, } \\
\text { NRCS, } 28758416\end{array}$} & \multirow[t]{3}{*}{ Microphthalmy } & \multirow[t]{3}{*}{ At birth } & \multirow[t]{2}{*}{ Triptans: Any } & All participants & $1 / 367(0.3)$ & NR & NR \\
\hline & & & & First trimester & NR & & \\
\hline & & & No Triptans & All participants & NR & & \\
\hline \multirow{3}{*}{$\begin{array}{l}\text { Spielmann, 2018, } \\
\text { NRCS, } 28758416\end{array}$} & \multirow[t]{3}{*}{ Cleft lip and palate } & \multirow[t]{3}{*}{ At birth } & \multirow[t]{2}{*}{ Triptans: Any } & All participants & $1 / 367(0.3)$ & NR & NR \\
\hline & & & & First trimester & NR & & \\
\hline & & & No Triptans & All participants & NR & & \\
\hline \multirow{3}{*}{$\begin{array}{l}\text { Spielmann, 2018, } \\
\text { NRCS, } 28758416\end{array}$} & \multirow[t]{3}{*}{ Club foot } & \multirow[t]{3}{*}{ At birth } & Triptans: Any & All participants & $1 / 367(0.3)$ & NR & NR \\
\hline & & & & First trimester & NR & & \\
\hline & & & No Triptans & All participants & NR & & \\
\hline \multirow[t]{3}{*}{$\begin{array}{l}\text { Spielmann, 2018, } \\
\text { NRCS, 28758416 }\end{array}$} & \multirow[t]{3}{*}{$\begin{array}{l}\text { Congenital finger } \\
\text { hypoplasia }\end{array}$} & \multirow[t]{3}{*}{ At birth } & \multirow[t]{2}{*}{ Triptans: Any } & All participants & $1 / 367(0.3)$ & NR & NR \\
\hline & & & & First trimester & NR & & \\
\hline & & & No Triptans & All participants & NR & & \\
\hline \multirow{3}{*}{$\begin{array}{l}\text { Spielmann, 2018, } \\
\text { NRCS, } 28758416\end{array}$} & \multirow[t]{3}{*}{ Patent foramen ovale } & \multirow[t]{3}{*}{ At birth } & \multirow[t]{2}{*}{ Triptans: Any } & All participants & $1 / 367(0.3)$ & NR & NR \\
\hline & & & & First trimester & NR & & \\
\hline & & & No Triptans & All participants & NR & & \\
\hline \multirow{3}{*}{$\begin{array}{l}\text { Spielmann, 2018, } \\
\text { NRCS, } 28758416\end{array}$} & \multirow[t]{3}{*}{ Poland syndrome } & \multirow[t]{3}{*}{ At birth } & \multirow[t]{2}{*}{ Triptans: Any } & All participants & $1 / 367(0.3)$ & NR & NR \\
\hline & & & & First trimester & NR & & \\
\hline & & & No Triptans & All participants & NR & & \\
\hline \multirow{3}{*}{$\begin{array}{l}\text { Spielmann, 2018, } \\
\text { NRCS, 28758416 }\end{array}$} & \multirow[t]{3}{*}{ Polydactyly of toes } & \multirow[t]{3}{*}{ At birth } & \multirow[t]{2}{*}{ Triptans: Any } & All participants & $1 / 367(0.3)$ & NR & NR \\
\hline & & & & First trimester & NR & & \\
\hline & & & No Triptans & All participants & NR & & \\
\hline \multirow{3}{*}{$\begin{array}{l}\text { Spielmann, 2018, } \\
\text { NRCS, } 28758416\end{array}$} & \multirow[t]{3}{*}{ Renal agenesis } & \multirow[t]{3}{*}{ At birth } & Triptans: Any & All participants & $1 / 367(0.3)$ & NR & $\mathrm{NR}$ \\
\hline & & & & First trimester & NR & & \\
\hline & & & No Triptans & All participants & NR & & \\
\hline Spielmann, 2018, & Syndactyly & At birth & Triptans: Any & All participants & $1 / 367(0.3)$ & NR & NR \\
\hline & & & & First trimester & NR & & \\
\hline & & & No Triptans & All participants & NR & & \\
\hline
\end{tabular}

Abbreviations: Adj = adjusted, CI = confidence interval, $\mathrm{m}=$ months, $\mathrm{NR}=$ not reported PMID = PubMed identifier, NRCS = nonrandomized comparative study, OR = odds ratio, $\mathrm{RR}=$ relative risk, $\mathrm{y}=$ years. 
Table B-14. Key Question 2: Pharmacologic interventions: Triptans, ergot products, and NSAIDs - Fetal/child adverse effects (neurodevelopmental outcomes), categorical

\begin{tabular}{|c|c|c|c|c|c|c|c|c|}
\hline $\begin{array}{l}\text { Study, Year, } \\
\text { Design, } \\
\text { PMID }\end{array}$ & Outcome & $\begin{array}{c}\text { Outcome } \\
\text { Definition }\end{array}$ & Time & Arm & Subgroup & $\mathbf{n} / \mathbf{N}(\%)$ & $\begin{array}{l}\text { Adj Effect Size } \\
\quad(95 \% \mathrm{CI})\end{array}$ & $\begin{array}{l}\text { Adj P } \\
\text { value }\end{array}$ \\
\hline \multirow{6}{*}{$\begin{array}{l}\text { Nezvalova- } \\
\text { Henriksen, 2010, } \\
\text { NRCS, } \\
20132339\end{array}$} & \multirow[t]{6}{*}{$\begin{array}{l}\text { Gross motor } \\
\text { development }\end{array}$} & \multirow[t]{6}{*}{$\begin{array}{l}\text { Z-score } \\
>=1.5 \text { on } \\
\text { the ASQ }\end{array}$} & \multirow[t]{3}{*}{$1.5 \mathrm{y}$} & Triptans: Any & All participants & $8 / 495$ (1.6) & NR & NR \\
\hline & & & & Triptans: Any (before pregnancy only) & All participants & $33 / 1002(3.3)$ & & \\
\hline & & & & No Triptans & All participants & $93 / 4050(2.3)$ & & \\
\hline & & & \multirow[t]{3}{*}{$3 y$} & Triptans: Any & All participants & $6 / 495(1.2)$ & $\begin{array}{l}\text { Vs Triptans before } \\
\text { pregnancy only } \\
\text { Adj RR } 0.86(0.23, \\
\text { 3.19) } \\
\text { Vs No Triptans } \\
\text { Adj RR } 0.58(0.17, \\
\text { 2.03) }\end{array}$ & NR \\
\hline & & & & Triptans: Any (before pregnancy only) & All participants & $30 / 1002(3.0)$ & & \\
\hline & & & & No Triptans & All participants & $122 / 4050(3.0)$ & & \\
\hline \multirow[t]{6}{*}{$\begin{array}{l}\text { Nezvalova- } \\
\text { Henriksen, 2010, } \\
\text { NRCS, 20132339 }\end{array}$} & \multirow[t]{6}{*}{$\begin{array}{l}\text { Fine motor } \\
\text { development }\end{array}$} & \multirow[t]{6}{*}{$\begin{array}{l}\text { Z-score } \\
>=1.5 \text { on } \\
\text { the ASQ }\end{array}$} & \multirow[t]{3}{*}{$1.5 \mathrm{y}$} & Triptans: Any & All participants & 69/495 (13.9) & NR & NR \\
\hline & & & & \multirow{2}{*}{$\begin{array}{l}\text { Triptans: Any (before pregnancy only) } \\
\text { No Triptans }\end{array}$} & All participants & $116 / 1002(11.6)$ & & \\
\hline & & & & & All participants & $466 / 4050(11.5)$ & & \\
\hline & & & \multirow[t]{3}{*}{$3 y$} & Triptans: Any & All participants & $47 / 495(9.5)$ & $\begin{array}{l}\text { Vs Triptans before } \\
\text { pregnancy only } \\
\text { Adj RR } 0.85(0.52, \\
1.37) \\
\text { Vs No Triptans } \\
\text { Adj RR } 0.85(0.56, \\
1.29)\end{array}$ & NR \\
\hline & & & & Triptans: Any (before pregnancy only) & All participants & 94/1002 (9.4) & & \\
\hline & & & & No Triptans & All participants & $373 / 4050(9.2)$ & & \\
\hline
\end{tabular}

Abbreviations: Adj = adjusted, ASQ = Ages and Stages Questionnaire, CI = confidence interval, $\mathrm{m}$ = months, NRCS = nonrandomized comparative study, PMID = PubMed identifier, $\mathrm{RR}=$ relative risk, $\mathrm{y}=$ years. 
Table B-15. Key Question 2: Pharmacologic interventions: Triptans, ergot products, and NSAIDs - Fetal/child adverse effects (behavioral and social outcomes), categorical

\begin{tabular}{|c|c|c|c|c|c|c|c|c|}
\hline $\begin{array}{c}\text { Study, Year, } \\
\text { Design, } \\
\text { PMID } \\
\end{array}$ & Outcome & $\begin{array}{c}\text { Outcome } \\
\text { Definition }\end{array}$ & Time & Arm & Subgroup & n/N (\%) & $\begin{array}{l}\text { Adj Effect Size } \\
(95 \% \mathrm{CI})\end{array}$ & $\begin{array}{l}\text { Adj P } \\
\text { value }\end{array}$ \\
\hline \multirow[t]{10}{*}{$\begin{array}{l}\text { Nezvalova- } \\
\text { Henriksen 2010, } \\
\text { NRCS, 20132339 }\end{array}$} & \multirow[t]{10}{*}{$\begin{array}{l}\text { Externalizing } \\
\text { behavior } \\
\text { problems }\end{array}$} & \multirow[t]{10}{*}{$\begin{array}{l}\text { Clinically significant } \\
\text { on the } C B C L\end{array}$} & \multirow[t]{5}{*}{$3 y$} & \multirow[t]{3}{*}{ Triptans: Any } & All participants & $101 / 1085(9.3)$ & $\begin{array}{l}\text { Vs No Triptans } \\
\text { Adj RR } 0.99(0.77 \text {, } \\
1.27)\end{array}$ & NR \\
\hline & & & & & First trimester & $40 / 304(13.2)$ & $\begin{array}{l}\text { Vs No Triptans } \\
\text { Adj RR } 1.75(0.98, \\
3.14)\end{array}$ & NR \\
\hline & & & & & $\begin{array}{l}\text { Second and/or third } \\
\text { trimester }\end{array}$ & $11 / 137(8.0)$ & NR & \\
\hline & & & & $\begin{array}{l}\text { Triptans: Any (before } \\
\text { pregnancy only) }\end{array}$ & All participants & 297/3354 (8.9) & & \\
\hline & & & & No Triptans & All participants & $\mathrm{NR}$ & & \\
\hline & & & \multirow[t]{5}{*}{$5 y$} & \multirow[t]{3}{*}{ Triptans: Any } & All participants & $25 / 340(7.4)$ & $\begin{array}{l}\text { Vs No Triptans } \\
\text { Adj RR } 0.68(0.44, \\
1.05)\end{array}$ & NR \\
\hline & & & & & First trimester & NR & & \\
\hline & & & & & $\begin{array}{l}\text { Second and/or third } \\
\text { trimester }\end{array}$ & NR & & \\
\hline & & & & $\begin{array}{l}\text { Triptans: Any (before } \\
\text { pregnancy only) }\end{array}$ & All participants & NR & & \\
\hline & & & & No Triptans & All participants & $15 / 1457(10.6)$ & & \\
\hline \multirow{6}{*}{$\begin{array}{l}\text { Nezvalova- } \\
\text { Henriksen 2010, } \\
\text { NRCS, } \\
20132339\end{array}$} & \multirow[t]{6}{*}{$\begin{array}{l}\text { Externalizing } \\
\text { behavior } \\
\text { problems }\end{array}$} & \multirow[t]{6}{*}{$\begin{array}{l}\text { Z-score }>=1.5 \text { on } \\
\text { the CBCL }\end{array}$} & \multirow[t]{3}{*}{$1.5 \mathrm{y}$} & Triptans: Any & All participants & $54 / 495$ (11.0) & NR & NR \\
\hline & & & & $\begin{array}{l}\text { Triptans: Any (before } \\
\text { pregnancy only) }\end{array}$ & All participants & $78 / 1002(7.8)$ & & \\
\hline & & & & No Triptans & All participants & $328 / 4050(8.1)$ & & \\
\hline & & & \multirow[t]{3}{*}{$3 y$} & Triptans: Any & All participants & 50/495 (10.0) & NR & NR \\
\hline & & & & $\begin{array}{l}\text { Triptans: Any (before } \\
\text { pregnancy only) }\end{array}$ & All participants & $65 / 1002$ (6.5) & & \\
\hline & & & & No Triptans & & $308 / 4050(7.6)$ & & \\
\hline \multirow[t]{3}{*}{$\begin{array}{l}\text { Nezvalova- } \\
\text { Henriksen 2010, } \\
\text { NRCS, 20132339 }\end{array}$} & \multirow[t]{3}{*}{$\begin{array}{l}\text { Internalizing } \\
\text { behavior } \\
\text { problems }\end{array}$} & \multirow[t]{3}{*}{$\begin{array}{l}\text { Clinically significant } \\
\text { on the CBCL }\end{array}$} & \multirow[t]{3}{*}{$3 y$} & \multirow[t]{3}{*}{ Triptans: Any } & All participants & 27/396 (6.8) & $\begin{array}{l}\text { Vs No Triptans } \\
\text { Adj RR } 1.04 \text { (0.80, } \\
1.35)\end{array}$ & NR \\
\hline & & & & & First trimester & 20/304 (6.6) & $\begin{array}{l}\text { Vs No Triptans } \\
\text { Adj RR } 1.27 \text { (0.57, } \\
2.82)\end{array}$ & NR \\
\hline & & & & & $\begin{array}{l}\text { Second and/or third } \\
\text { trimester }\end{array}$ & 7/137 (5.1) & $\begin{array}{l}\text { Vs No Triptans } \\
\text { Adj RR } 0.70(0.16 \text {, } \\
3.14)\end{array}$ & NR \\
\hline
\end{tabular}




\begin{tabular}{|c|c|c|c|c|c|c|c|c|}
\hline $\begin{array}{c}\text { Study, Year, } \\
\text { Design, } \\
\text { PMID }\end{array}$ & Outcome & $\begin{array}{c}\text { Outcome } \\
\text { Definition }\end{array}$ & Time & Arm & Subgroup & n/N (\%) & $\begin{array}{l}\text { Adj Effect Size } \\
(95 \% \text { CI })\end{array}$ & $\begin{array}{l}\text { Adj P } \\
\text { value }\end{array}$ \\
\hline & & & & $\begin{array}{l}\text { Triptans: Any (before } \\
\text { pregnancy only) }\end{array}$ & All participants & $260 / 3354(7.8)$ & & \\
\hline & & & & No Triptans & All participants & NR & & \\
\hline & & & $5 y$ & Triptans: Any & All participants & 42/343 (12.2) & $\begin{array}{l}\text { Vs No Triptans } \\
\text { Adj RR } 0.97 \text { (0.68, } \\
1.37)\end{array}$ & NR \\
\hline & & & & & First trimester & NR & & \\
\hline & & & & & $\begin{array}{l}\text { Second and/or third } \\
\text { trimester }\end{array}$ & NR & & \\
\hline & & & & $\begin{array}{l}\text { Triptans: Any (before } \\
\text { pregnancy only) }\end{array}$ & All participants & NR & & \\
\hline & & & & No Triptans & All participants & 169/1482 (11.4) & & \\
\hline \multirow{6}{*}{$\begin{array}{l}\text { Nezvalova- } \\
\text { Henriksen, 2010, } \\
\text { NRCS, } \\
20132339\end{array}$} & \multirow[t]{6}{*}{$\begin{array}{l}\text { Internalizing } \\
\text { behavior } \\
\text { problems }\end{array}$} & \multirow[t]{6}{*}{$\begin{array}{l}\text { Z-score }>=1.5 \text { on } \\
\text { the } C B C L\end{array}$} & \multirow[t]{3}{*}{$1.5 \mathrm{y}$} & Triptans: Any & All participants & $40 / 495(8.1)$ & NR & NR \\
\hline & & & & $\begin{array}{l}\text { Triptans: Any (before } \\
\text { pregnancy only) }\end{array}$ & All participants & $62 / 1002(6.2)$ & & \\
\hline & & & & No Triptans & All participants & $352 / 4050(8.7)$ & & \\
\hline & & & \multirow[t]{3}{*}{$3 y$} & Triptans: Any & All participants & $47 / 495(9.5)$ & $\begin{array}{l}\text { Vs Triptans before } \\
\text { pregnancy only } \\
\text { Adj RR } 0.69(0.41, \\
1.14) \\
\text { Vs No Triptans } \\
\text { Adj RR } 1.02(0.66, \\
1.57)\end{array}$ & NR \\
\hline & & & & $\begin{array}{l}\text { Triptans: Any (before } \\
\text { pregnancy only) }\end{array}$ & All participants & $108 / 1002(10.8)$ & & \\
\hline & & & & No Triptans & & $425 / 4050$ (10.5) & & \\
\hline \multirow{5}{*}{$\begin{array}{l}\text { Nezvalova- } \\
\text { Henriksen, 2010, } \\
\text { NRCS, 20132339 }\end{array}$} & \multirow[t]{5}{*}{ Emotionality } & \multirow[t]{5}{*}{$\begin{array}{l}\text { Z-score }>=1.5 \text { on } \\
\text { the CBCL }\end{array}$} & \multirow[t]{3}{*}{$1.5 \mathrm{y}$} & Triptans: Any & All participants & $16 / 495(3.2)$ & NR & NR \\
\hline & & & & $\begin{array}{l}\text { Triptans: Any (before } \\
\text { pregnancy only) }\end{array}$ & All participants & $53 / 1002(5.3)$ & & \\
\hline & & & & No Triptans & All participants & $207 / 4050(5.1)$ & & \\
\hline & & & \multirow[t]{2}{*}{$3 y$} & Triptans: Any & All participants & $31 / 495$ (6.3) & $\begin{array}{l}\text { Vs Triptans before } \\
\text { pregnancy only } \\
\text { Adj RR } 2.18 \text { (1.03, } \\
4.53) \\
\text { Vs No Triptans } \\
\text { Adj RR } 2.51 \text { (1.27, } \\
4.90)\end{array}$ & NR \\
\hline & & & & $\begin{array}{l}\text { Triptans: Any (before } \\
\text { pregnancy only) }\end{array}$ & All participants & $47 / 1002$ (4.7) & & \\
\hline
\end{tabular}




\begin{tabular}{|c|c|c|c|c|c|c|c|c|}
\hline $\begin{array}{l}\text { Study, Year, } \\
\text { Design, } \\
\text { PMID } \\
\end{array}$ & Outcome & $\begin{array}{c}\text { Outcome } \\
\text { Definition }\end{array}$ & Time & Arm & Subgroup & $\mathbf{n} / \mathbf{N}(\%)$ & $\begin{array}{c}\text { Adj Effect Size } \\
(95 \% \text { CI })\end{array}$ & $\begin{array}{l}\text { Adj P } \\
\text { value }\end{array}$ \\
\hline & & & & No Triptans & All participants & $158 / 4050$ (3.9) & & \\
\hline \multirow[t]{6}{*}{$\begin{array}{l}\text { Nezvalova- } \\
\text { Henriksen, 2010, } \\
\text { NRCS, 20132339 }\end{array}$} & \multirow[t]{6}{*}{ Activity } & \multirow[t]{6}{*}{$\begin{array}{l}\text { Z-score }>=1.5 \text { on } \\
\text { the EAST } \\
\text { Questionnaire }\end{array}$} & \multirow[t]{3}{*}{$1.5 \mathrm{y}$} & Triptans: Any & All participants & $46 / 495(9.2)$ & NR & NR \\
\hline & & & & $\begin{array}{l}\text { Triptans: Any (before } \\
\text { pregnancy only) }\end{array}$ & All participants & $97 / 1002(9.7)$ & & \\
\hline & & & & No Triptans & All participants & $397 / 4050(9.8)$ & & \\
\hline & & & \multirow[t]{3}{*}{$3 y$} & Triptans: Any & All participants & $41 / 495(8.3)$ & $\begin{array}{l}\text { Vs Triptans before } \\
\text { pregnancy only } \\
\text { Adj RR } 1.70 \text { (1.02, } \\
2.80) \\
\text { Vs No Triptans } \\
\text { Adj RR } 1.57 \text { (1.04, } \\
2.36)\end{array}$ & NR \\
\hline & & & & $\begin{array}{l}\text { Triptans: Any (before } \\
\text { pregnancy only) }\end{array}$ & All participants & $47 / 1002$ (4.7) & & \\
\hline & & & & No Triptans & All participants & $215 / 4050(5.3)$ & & \\
\hline \multirow[t]{6}{*}{$\begin{array}{l}\text { Nezvalova- } \\
\text { Henriksen, 2010, } \\
\text { NRCS, 20132339 }\end{array}$} & \multirow[t]{6}{*}{ Shyness } & \multirow[t]{6}{*}{$\begin{array}{l}\text { Z-score }>=1.5 \text { on } \\
\text { the EAST } \\
\text { Questionnaire }\end{array}$} & \multirow[t]{3}{*}{$1.5 \mathrm{y}$} & Triptans: Any & All participants & 24/495 (4.9) & NR & NR \\
\hline & & & & $\begin{array}{l}\text { Triptans: Any (before } \\
\text { pregnancy only) }\end{array}$ & All participants & $35 / 1002$ (3.5) & & \\
\hline & & & & No Triptans & All participants & $162 / 4050(4.0)$ & & \\
\hline & & & \multirow[t]{3}{*}{$3 y$} & Triptans: Any & All participants & $61 / 495$ (12.3) & $\begin{array}{l}\text { Vs Triptans before } \\
\text { pregnancy only } \\
\text { Adj RR } 0.92(0.52, \\
1.63) \\
\text { Vs No Triptans } \\
\text { Adj RR } 1.30(0.81 \text {, } \\
2.08)\end{array}$ & NR \\
\hline & & & & $\begin{array}{l}\text { Triptans: Any (before } \\
\text { pregnancy only) }\end{array}$ & All participants & 96/1002 (9.6) & & \\
\hline & & & & No Triptans & All participants & $312 / 4050(7.7)$ & & \\
\hline \multirow[t]{3}{*}{$\begin{array}{l}\text { Nezvalova- } \\
\text { Henriksen, 2010, } \\
\text { NRCS, } \\
20132339\end{array}$} & \multirow[t]{3}{*}{ Sociability } & \multirow[t]{3}{*}{$\begin{array}{l}\text { Z-score }>=1.5 \text { on } \\
\text { the EAST } \\
\text { Questionnaire }\end{array}$} & \multirow[t]{3}{*}{$1.5 \mathrm{y}$} & Triptans: Any & All participants & $44 / 495(8.8)$ & NR & NR \\
\hline & & & & $\begin{array}{l}\text { Triptans: Any (before } \\
\text { pregnancy only) }\end{array}$ & All participants & $68 / 1002(6.8)$ & & \\
\hline & & & & No Triptans & All participants & $377 / 4050(9.3)$ & & \\
\hline
\end{tabular}




\begin{tabular}{|c|c|c|c|c|c|c|c|c|}
\hline $\begin{array}{l}\text { Study, Year, } \\
\text { Design, } \\
\text { PMID } \\
\end{array}$ & Outcome & $\begin{array}{c}\text { Outcome } \\
\text { Definition }\end{array}$ & Time & Arm & Subgroup & n/N (\%) & $\begin{array}{c}\text { Adj Effect Size } \\
(95 \% \text { CI })\end{array}$ & $\begin{array}{l}\text { Adj P } \\
\text { value }\end{array}$ \\
\hline & & & $3 y$ & Triptans: Any & All participants & $31 / 495$ (6.3) & $\begin{array}{l}\text { Vs Triptans before } \\
\text { pregnancy only } \\
\text { Adj RR } 0.70(0.40, \\
1.38) \\
\text { Vs No Triptans } \\
\text { Adj RR } 1.13(0.70, \\
1.82)\end{array}$ & NR \\
\hline & & & & $\begin{array}{l}\text { Triptans: Any (before } \\
\text { pregnancy only) }\end{array}$ & All participants & $64 / 1002(6.4)$ & & \\
\hline & & & & No Triptans & All participants & $247 / 4050(6.1)$ & & \\
\hline \multirow{6}{*}{$\begin{array}{l}\text { Nezvalova- } \\
\text { Henriksen, 2010, } \\
\text { NRCS, 20132339 }\end{array}$} & \multirow[t]{6}{*}{$\begin{array}{l}\text { Communication } \\
\text { development }\end{array}$} & \multirow[t]{6}{*}{$\begin{array}{l}\text { Z-score }>=1.5 \text { on } \\
\text { the ASQ }\end{array}$} & \multirow[t]{3}{*}{$1.5 \mathrm{y}$} & Triptans: Any & All participants & $17 / 495$ (3.4) & NR & NR \\
\hline & & & & $\begin{array}{l}\text { Triptans: Any (before } \\
\text { pregnancy only) }\end{array}$ & All participants & $41 / 1002(4.1)$ & & \\
\hline & & & & No Triptans & All participants & $154 / 4050$ (3.8) & & \\
\hline & & & \multirow[t]{3}{*}{$3 y$} & Triptans: Any & All participants & $23 / 495$ (4.6) & $\begin{array}{l}\text { Vs Triptans before } \\
\text { pregnancy only } \\
\text { Adj RR } 1.22(0.56, \\
2.68) \\
\text { Vs No Triptans } \\
\text { Adj RR } 0.97(0.48, \\
1.95)\end{array}$ & NR \\
\hline & & & & $\begin{array}{l}\text { Triptans: Any (before } \\
\text { pregnancy only) }\end{array}$ & All participants & $45 / 1002(4.5)$ & & \\
\hline & & & & No Triptans & All participants & $211 / 4050(5.2)$ & & \\
\hline \multirow[t]{3}{*}{$\begin{array}{l}\text { Nezvalova- } \\
\text { Henriksen, 2010, } \\
\text { NRCS, } \\
20132339\end{array}$} & \multirow[t]{3}{*}{ Communication } & \multirow[t]{3}{*}{$\begin{array}{l}\text { Clinically-significant } \\
\text { communication } \\
\text { problems on the } \\
\text { ASQ }\end{array}$} & \multirow[t]{3}{*}{$5 y$} & Triptans: Any & All participants & $27 / 347(7.8)$ & $\begin{array}{l}\text { Vs No Triptans } \\
\text { Adj RR } 0.77(0.50, \\
1.18)\end{array}$ & NR \\
\hline & & & & $\begin{array}{l}\text { Triptans: Any (before } \\
\text { pregnancy only) }\end{array}$ & All participants & NR & & \\
\hline & & & & No Triptans & All participants & $135 / 1479(9.1)$ & & \\
\hline
\end{tabular}

Abbreviations: Adj = adjusted, ASQ = Ages and Stages Questionnaire, CBCL = Child Behavior Checklist, CI = confidence interval, EAST = Emotionality, Activity, and Shyness Temperament, $\mathrm{m}=$ months, NRCS = nonrandomized comparative study, PMID = PubMed identifier, RR = relative risk, $\mathrm{y}=$ years. 
Table B-16. Key Question 2: Pharmacologic interventions: Triptans, ergot products, and NSAIDs - Fetal/infant adverse effects (behavioral and social outcomes), continuous

\begin{tabular}{|c|c|c|c|c|c|c|c|c|}
\hline $\begin{array}{l}\text { Study, Year, } \\
\text { Design, } \\
\text { PMID }\end{array}$ & Outcome & Time & Arm & Subgroup & $\mathbf{N}$ & $\begin{array}{c}\text { Result, } \\
\text { Mean (SD) }\end{array}$ & $\begin{array}{c}\text { Adj Effect Size (95\% } \\
\text { CI) }\end{array}$ & $\begin{array}{l}\text { Adj P } \\
\text { value }\end{array}$ \\
\hline \multirow[t]{2}{*}{$\begin{array}{l}\text { Shuhaiber, 1998, } \\
\text { NRCS, } 9710039\end{array}$} & \multirow[t]{2}{*}{$\begin{array}{l}\text { Preterm birth - Gestational age at } \\
\text { delivery }\end{array}$} & \multirow[t]{2}{*}{$\begin{array}{l}\text { At } \\
\text { birth }\end{array}$} & $\begin{array}{l}\text { Triptans: } \\
\text { Sumatriptan }\end{array}$ & All participants & 96 & $39.2 \mathrm{w}(2.2)$ & \multirow[t]{2}{*}{ NR } & \multirow[t]{2}{*}{ NR } \\
\hline & & & No Triptans & All participants & 96 & 38.8 w (2.6) & & \\
\hline \multirow[t]{3}{*}{$\begin{array}{l}\text { Nezvalova- } \\
\text { Henriksen, 2010, } \\
\text { NRCS, 20132339 }\end{array}$} & \multirow[t]{3}{*}{$\begin{array}{l}\text { Behavioral/Social - Emotionality on } \\
\text { the EAST Questionnaire }\end{array}$} & \multirow[t]{3}{*}{$\begin{array}{l}5 y \text { of } \\
\text { age }\end{array}$} & Triptans: Any & All participants & 345 & 49.7 (9.9) & $\begin{array}{l}\text { Vs. No Triptans } \\
\text { Adj NMD }-1.02(-2.3 \text {, } \\
0.29)\end{array}$ & NR \\
\hline & & & $\begin{array}{l}\text { Triptans: Any } \\
\text { (before pregnancy } \\
\text { only) }\end{array}$ & All participants & NR & NR (NR) & & \\
\hline & & & No Triptans & All participants & 1483 & $50.5(10.0)$ & & \\
\hline \multirow[t]{3}{*}{$\begin{array}{l}\text { Nezvalova- } \\
\text { Henriksen, 2010, } \\
\text { NRCS, 20132339 }\end{array}$} & \multirow[t]{3}{*}{$\begin{array}{l}\text { Behavioral/Social - Activity on the } \\
\text { EAST Questionnaire }\end{array}$} & \multirow[t]{3}{*}{$\begin{array}{l}5 \text { y of } \\
\text { age }\end{array}$} & Triptans: Any & All participants & 351 & $49.3(10.2)$ & $\begin{array}{l}\text { Vs. No Triptans } \\
\text { Adj NMD }-0.06 \text { (-1.35, } \\
1.23)\end{array}$ & NR \\
\hline & & & $\begin{array}{l}\text { Triptans: Any } \\
\text { (before pregnancy } \\
\text { only) }\end{array}$ & All participants & NR & NR (NR) & & \\
\hline & & & No Triptans & All participants & 1493 & $50.1(10.2)$ & & \\
\hline \multirow[t]{3}{*}{$\begin{array}{l}\text { Nezvalova- } \\
\text { Henriksen, 2010, } \\
\text { NRCS, 201323339 }\end{array}$} & \multirow[t]{3}{*}{$\begin{array}{l}\text { Behavioral/Social - Shyness on the } \\
\text { EAST Questionnaire }\end{array}$} & \multirow[t]{3}{*}{$\begin{array}{l}5 y \text { of } \\
\text { age }\end{array}$} & Triptans: Any & All participants & 348 & $50.1(10.0)$ & $\begin{array}{l}\text { Vs. No Triptans } \\
\text { Adj NMD }-0.71 \text { (-2.08, } \\
0.65)\end{array}$ & NR \\
\hline & & & $\begin{array}{l}\text { Triptans: Any } \\
\text { (before pregnancy } \\
\text { only) }\end{array}$ & All participants & NR & NR (NR) & & \\
\hline & & & No Triptans & All participants & 1480 & $50.5(10.1)$ & & \\
\hline \multirow[t]{3}{*}{$\begin{array}{l}\text { Nezvalova- } \\
\text { Henriksen, 2010, } \\
\text { NRCS, 20132339 }\end{array}$} & \multirow[t]{3}{*}{$\begin{array}{l}\text { Behavioral/Social - Sociability on the } \\
\text { EAST Questionnaire }\end{array}$} & \multirow[t]{3}{*}{$\begin{array}{l}5 \text { y of } \\
\text { age }\end{array}$} & Triptans: Any & All participants & 349 & $51.0(10.4)$ & $\begin{array}{l}\text { Vs. No Triptans } \\
\text { Adj NMD } 1.66(-0.30, \\
3.02)\end{array}$ & NR \\
\hline & & & $\begin{array}{l}\text { Triptans: Any } \\
\text { (before pregnancy } \\
\text { only) }\end{array}$ & All participants & NR & NR (NR) & & \\
\hline & & & No Triptans & All participants & 1492 & $49.6(10.5)$ & & \\
\hline
\end{tabular}

Abbreviations: Adj = adjusted, CI = confidence interval, EAST = Emotionality, Activity, and Shyness Temperament, $\mathrm{h}=$ hours, IQR = interquartile range, $\mathrm{m}=$ months, ND = net mean difference, NRCS = nonrandomized comparative study, PMID = PubMed identifier, VAS = visual analog scale, $y=$ years. 
Table B-17. Key Question 2: Nonpharmacologic interventions: Complementary, behavioral, and physical therapies - Categorical

\section{outcomes}

\begin{tabular}{|c|c|c|c|c|c|c|c|c|}
\hline $\begin{array}{l}\text { Study, Year, } \\
\text { Design, } \\
\text { PMID }\end{array}$ & Outcome & Outcome Definition & Time & Arm & Subgroup & $\mathrm{n} / \mathrm{N}(\%)$ & $\begin{array}{l}\text { Effect Size } \\
(95 \% \text { CI })\end{array}$ & P value \\
\hline \multirow[t]{2}{*}{$\begin{array}{l}\text { Silva, 2012, } \\
\text { RCT, no PMID }\end{array}$} & \multirow[t]{2}{*}{$\begin{array}{l}\text { Severity of } \\
\text { acute } \\
\text { headache }\end{array}$} & \multirow[t]{2}{*}{$\begin{array}{l}\text { Reduction of average pain } \\
\text { intensity by }>=25 \% \text { on a } \\
\text { VAS }(0-10)\end{array}$} & \multirow[t]{2}{*}{$8 w$} & Acupuncture & All participants & $16 / 20(80.0)$ & \multirow[t]{2}{*}{$\begin{array}{l}\text { OR 4.36 (1.11, } \\
17.13)^{i}\end{array}$} & \multirow[t]{2}{*}{$0.035^{i}$} \\
\hline & & & & Routine care & All participants & $11 / 23(47.8)$ & & \\
\hline \multirow[t]{2}{*}{$\begin{array}{l}\text { Silva, 2012, } \\
\text { RCT, no PMID }\end{array}$} & \multirow[t]{2}{*}{$\begin{array}{l}\text { Medication } \\
\text { use }\end{array}$} & \multirow[t]{2}{*}{$\begin{array}{l}\text { Reduction of } \\
\text { acetaminophen use by } \\
>=50 \%\end{array}$} & \multirow[t]{2}{*}{$8 w$} & Acupuncture & All participants & $14 / 20(70.0)$ & \multirow[t]{2}{*}{$\begin{array}{l}\text { OR } 6.61(1.74, \\
25.1)^{i}\end{array}$} & \multirow[t]{2}{*}{$0.006^{i}$} \\
\hline & & & & Routine care & All participants & $6 / 23(26.1)$ & & \\
\hline \multirow{4}{*}{$\begin{array}{l}\text { Marcus (Study } \\
2), 1995, \mathrm{RCT}, \\
8600478\end{array}$} & \multirow[t]{4}{*}{$\begin{array}{l}\text { Medication } \\
\text { use }\end{array}$} & \multirow[t]{4}{*}{$\begin{array}{l}\text { Use of any medication for } \\
\text { headache }\end{array}$} & \multirow[t]{2}{*}{ Baseline } & $\begin{array}{l}\text { Thermal biofeedback, relaxation } \\
\text { therapy, and physical therapy }\end{array}$ & All participants & $4 / 11(36.4)$ & \multirow[t]{2}{*}{-} & \multirow[t]{2}{*}{-} \\
\hline & & & & Thermal biofeedback & All participants & $10 / 14(71.4)$ & & \\
\hline & & & \multirow[t]{2}{*}{$2 \mathrm{~m}$} & $\begin{array}{l}\text { Thermal biofeedback, relaxation } \\
\text { therapy, and physical therapy }\end{array}$ & All participants & $3 / 11(27.3)$ & \multirow[t]{2}{*}{$\begin{array}{l}\text { OR } 0.50(0.09 \\
2.73)^{i}\end{array}$} & \multirow[t]{2}{*}{$0.423^{i}$} \\
\hline & & & & Thermal biofeedback & All participants & $6 / 14(42.9)$ & & \\
\hline $\begin{array}{l}\text { Marcus (Study } \\
\text { 1), 1995, } \\
\text { Single-group } \\
\text { study, } \\
8600478\end{array}$ & $\begin{array}{l}\text { Severity of } \\
\text { acute } \\
\text { headache }\end{array}$ & $\begin{array}{l}\text { Significant improvement in } \\
\text { pain score on Headache } \\
\text { Index }(0-10)\end{array}$ & $2 \mathrm{~m}$ & $\begin{array}{l}\text { Thermal biofeedback, relaxation } \\
\text { therapy, and physical therapy }\end{array}$ & All participants & $15 / 19(79)$ & $\mathrm{N} / \mathrm{A}$ & $\mathrm{N} / \mathrm{A}$ \\
\hline
\end{tabular}

Abbreviations: $\mathrm{CI}=$ confidence interval, $\mathrm{m}=$ months, $\mathrm{N} / \mathrm{A}=$ not applicable, NRCS $=$ nonrandomized comparative study, OR = odds ratio, PMID = PubMed identifier, $\mathrm{RCT}=$ randomized controlled trial, VAS $=$ visual analog scale, $\mathrm{w}=$ weeks.

${ }^{\mathrm{i}}$ Calculated by us based on reported arm-specific data. This was done only for studies with arms with baseline characteristics considered by us to be similar. 
Table B-18. Key Question 2: Nonpharmacologic interventions: Complementary, behavioral, and physical therapies - Continuous

\begin{tabular}{|c|c|c|c|c|c|c|c|c|c|}
\hline $\begin{array}{l}\text { Study, Year, } \\
\text { Design, } \\
\text { PMID }\end{array}$ & Outcome & $\begin{array}{l}\text { Outcome } \\
\text { Definition }\end{array}$ & Time & Arm & Subgroup & $\mathbf{N}$ & $\begin{array}{l}\text { Result, Mean } \\
\text { (SD) }\end{array}$ & $\begin{array}{c}\text { Effect Size (95\% } \\
\text { CI) }\end{array}$ & $P$ value \\
\hline \multirow[t]{2}{*}{$\begin{array}{l}\text { Silva, 2012, } \\
\text { RCT, no PMID }\end{array}$} & \multirow[t]{2}{*}{$\begin{array}{l}\text { Severity of } \\
\text { acute } \\
\text { headache }\end{array}$} & \multirow[t]{2}{*}{$\begin{array}{l}\text { Reduction in pain } \\
\text { score on a VAS ( } 0 \text { - } \\
10 \text { ) }\end{array}$} & \multirow[t]{2}{*}{$8 w$} & Acupuncture & $\begin{array}{l}\text { All } \\
\text { participants }\end{array}$ & 20 & $3.9(3.4)$ & \multirow[t]{2}{*}{ MD $2.2(0.3,4.7)^{i}$} & \multirow[t]{2}{*}{$0.035^{i}$} \\
\hline & & & & Routine care & $\begin{array}{l}\text { All } \\
\text { participants }\end{array}$ & 23 & $1.7(4.4)$ & & \\
\hline \multirow[t]{2}{*}{$\begin{array}{l}\text { Silva, 2012, } \\
\text { RCT, no PMID }\end{array}$} & \multirow[t]{2}{*}{$\begin{array}{l}\text { Medication } \\
\text { use }\end{array}$} & \multirow[t]{2}{*}{$\begin{array}{l}\text { Reduction in } \\
\text { number of } 500 \mathrm{mg} \\
\text { acetaminophen } \\
\text { doses }\end{array}$} & \multirow[t]{2}{*}{$8 w$} & Acupuncture & $\begin{array}{l}\text { All } \\
\text { participants }\end{array}$ & 20 & $6.0(9.0)$ & \multirow[t]{2}{*}{ MD $5.4(1.3,9.5)^{i}$} & \multirow[t]{2}{*}{$0.011^{i}$} \\
\hline & & & & Routine care & $\begin{array}{l}\text { All } \\
\text { participants }\end{array}$ & 23 & $0.6(3.3)$ & & \\
\hline \multirow[t]{4}{*}{$\begin{array}{l}\text { Marcus (Study } \\
\text { 2), 1995, RCT, } \\
8600478\end{array}$} & \multirow[t]{4}{*}{$\begin{array}{l}\text { Severity of } \\
\text { acute } \\
\text { headache }\end{array}$} & \multirow[t]{4}{*}{$\begin{array}{l}\text { Worst pain score } \\
\text { on a VAS }(0-10) \text { in } \\
\text { past } 2 \mathrm{w}\end{array}$} & \multirow[t]{2}{*}{ Baseline } & $\begin{array}{l}\text { Combination of thermal } \\
\text { biofeedback, relaxation therapy, } \\
\text { and physical therapy }\end{array}$ & $\begin{array}{l}\text { All } \\
\text { participants }\end{array}$ & 11 & $7.8(2.1)$ & \multirow[t]{2}{*}{-} & \multirow[t]{2}{*}{-} \\
\hline & & & & Thermal biofeedback & $\begin{array}{l}\text { All } \\
\text { participants }\end{array}$ & 14 & $7.8(1.5)$ & & \\
\hline & & & \multirow[t]{2}{*}{$2 \mathrm{~m}$} & $\begin{array}{l}\text { Combination of physical } \\
\text { therapy, complementary } \\
\text { therapy, and behavioral therapy }\end{array}$ & $\begin{array}{l}\text { All } \\
\text { participants }\end{array}$ & 11 & $2.3(3.1)$ & \multirow[t]{2}{*}{$\begin{array}{l}\text { NMD - 3.4 (-5.61, - } \\
1.19)^{i}\end{array}$} & \multirow[t]{2}{*}{$0.003^{i}$} \\
\hline & & & & Thermal biofeedback & $\begin{array}{l}\text { All } \\
\text { participants }\end{array}$ & 14 & $5.7(3.3)$ & & \\
\hline \multirow[t]{4}{*}{$\begin{array}{l}\text { Marcus (Study } \\
\text { 2), 1995, RCT, } \\
8600478\end{array}$} & \multirow[t]{4}{*}{$\begin{array}{l}\text { Severity of } \\
\text { acute } \\
\text { headache }\end{array}$} & \multirow[t]{4}{*}{$\begin{array}{l}\text { Number of days in } \\
\text { past } 2 \mathrm{w} \text { with } \\
\text { headache }>1 \text { on a } \\
\text { VAS }(0-10)\end{array}$} & \multirow[t]{2}{*}{ Baseline } & $\begin{array}{l}\text { Combination of thermal } \\
\text { biofeedback, relaxation therapy, } \\
\text { and physical therapy }\end{array}$ & $\begin{array}{l}\text { All } \\
\text { participants }\end{array}$ & 11 & $11.2(3.7)$ & \multirow[t]{2}{*}{-} & \multirow[t]{2}{*}{-} \\
\hline & & & & Thermal biofeedback & $\begin{array}{l}\text { All } \\
\text { participants }\end{array}$ & 14 & $10.4(3.9)$ & & \\
\hline & & & \multirow[t]{2}{*}{$2 \mathrm{~m}$} & $\begin{array}{l}\text { Combination of thermal } \\
\text { biofeedback, relaxation therapy, } \\
\text { and physical therapy }\end{array}$ & $\begin{array}{l}\text { All } \\
\text { participants }\end{array}$ & 11 & $2.9(4.3)$ & \multirow[t]{2}{*}{$\begin{array}{l}\text { NMD -5.60 (-8.74, } \\
-2.46)^{i}\end{array}$} & \multirow[t]{2}{*}{$<0.001^{i}$} \\
\hline & & & & Thermal biofeedback & $\begin{array}{l}\text { All } \\
\text { participants }\end{array}$ & 14 & $\begin{array}{l}7.7 \text { (NR, } \\
\text { assumed same } \\
\text { as baseline) }\end{array}$ & & \\
\hline \multirow[t]{3}{*}{$\begin{array}{l}\text { Marcus (Study } \\
\text { 2), 1995, RCT, } \\
8600478\end{array}$} & \multirow[t]{3}{*}{$\begin{array}{l}\text { Severity of } \\
\text { acute } \\
\text { headache }\end{array}$} & \multirow[t]{3}{*}{$\begin{array}{l}\text { Headache score } \\
\text { average over } 2 \text { w } \\
\text { on Headache Index }\end{array}$} & \multirow[t]{2}{*}{ Baseline } & $\begin{array}{l}\text { Combination of thermal } \\
\text { biofeedback, relaxation therapy, } \\
\text { and physical therapy }\end{array}$ & $\begin{array}{l}\text { All } \\
\text { participants }\end{array}$ & 11 & $2.0(0.77)$ & & \\
\hline & & & & Thermal biofeedback & $\begin{array}{l}\text { All } \\
\text { participants }\end{array}$ & 14 & $2.5(1.80)$ & & \\
\hline & & & $2 \mathrm{~m}$ & $\begin{array}{l}\text { Combination of thermal } \\
\text { biofeedback, relaxation therapy, } \\
\text { and physical therapy }\end{array}$ & $\begin{array}{l}\text { All } \\
\text { participants }\end{array}$ & 11 & $0.44(0.70)$ & $\begin{array}{l}\text { NMD -0.86 (-1.95, } \\
0.23)^{i}\end{array}$ & $0.122^{i}$ \\
\hline
\end{tabular}




\begin{tabular}{|c|c|c|c|c|c|c|c|c|c|}
\hline $\begin{array}{l}\text { Study, Year, } \\
\text { Design, } \\
\text { PMID }\end{array}$ & Outcome & $\begin{array}{l}\text { Outcome } \\
\text { Definition }\end{array}$ & Time & Arm & Subgroup & $\mathbf{N}$ & $\begin{array}{l}\text { Result, Mean } \\
\text { (SD) }\end{array}$ & $\begin{array}{l}\text { Effect Size (95\% } \\
\text { CI) }\end{array}$ & $P$ value \\
\hline & & & & Thermal biofeedback & $\begin{array}{l}\text { All } \\
\text { participants }\end{array}$ & 14 & $1.8(2.0)$ & & \\
\hline \multirow[t]{2}{*}{$\begin{array}{l}\text { Marcus (Study } \\
1), 1995, \mathrm{RCT} \\
8600478\end{array}$} & \multirow[t]{2}{*}{$\begin{array}{l}\text { Severity of } \\
\text { acute } \\
\text { headache }\end{array}$} & \multirow[t]{2}{*}{$\begin{array}{l}\text { Worst headache } \\
\text { score on a VAS ( } 0 \text { - } \\
10 \text { ) in past } 2 \mathrm{w}\end{array}$} & Baseline & $\begin{array}{l}\text { Combination of thermal } \\
\text { biofeedback, relaxation therapy, } \\
\text { and physical therapy }\end{array}$ & $\begin{array}{l}\text { All } \\
\text { participants }\end{array}$ & 19 & $7.7(2.0)$ & - & - \\
\hline & & & $2 \mathrm{~m}$ & $\begin{array}{l}\text { Combination of thermal } \\
\text { biofeedback, relaxation therapy, } \\
\text { and physical therapy }\end{array}$ & $\begin{array}{l}\text { All } \\
\text { participants }\end{array}$ & 19 & $4.2(3.8)$ & - & - \\
\hline \multirow[t]{2}{*}{$\begin{array}{l}\text { Marcus (Study } \\
1 \text { ), 1995, RCT, } \\
8600478\end{array}$} & \multirow[t]{2}{*}{$\begin{array}{l}\text { Severity of } \\
\text { acute } \\
\text { headache }\end{array}$} & \multirow[t]{2}{*}{$\begin{array}{l}\text { Number of days in } \\
\text { past } 2 \text { weeks with } \\
\text { headache }>1 \text { on a } \\
\text { VAS }(0-10)\end{array}$} & Baseline & $\begin{array}{l}\text { Combination of thermal } \\
\text { biofeedback, relaxation therapy, } \\
\text { and physical therapy }\end{array}$ & $\begin{array}{l}\text { All } \\
\text { participants }\end{array}$ & 19 & $8.0(3.5)$ & - & - \\
\hline & & & $2 \mathrm{~m}$ & $\begin{array}{l}\text { Combination of thermal } \\
\text { biofeedback, relaxation therapy, } \\
\text { and physical therapy }\end{array}$ & $\begin{array}{l}\text { All } \\
\text { participants }\end{array}$ & 19 & $2.9(4.0)$ & - & - \\
\hline \multirow[t]{2}{*}{$\begin{array}{l}\text { Marcus (Study } \\
1 \text { ), 1995, RCT, } \\
8600478\end{array}$} & \multirow[t]{2}{*}{$\begin{array}{l}\text { Severity of } \\
\text { acute } \\
\text { headache }\end{array}$} & \multirow[t]{2}{*}{$\begin{array}{l}\text { Pain score average } \\
\text { over } 2 \text { weeks on } \\
\text { Headache Index (0- } \\
\text { 10) }\end{array}$} & Baseline & $\begin{array}{l}\text { Combination of thermal } \\
\text { biofeedback, relaxation therapy, } \\
\text { and physical therapy }\end{array}$ & $\begin{array}{l}\text { All } \\
\text { participants }\end{array}$ & 19 & $1.7(1.3)$ & - & - \\
\hline & & & $2 \mathrm{~m}$ & $\begin{array}{l}\text { Combination of thermal } \\
\text { biofeedback, relaxation therapy, } \\
\text { and physical therapy }\end{array}$ & $\begin{array}{l}\text { All } \\
\text { participants }\end{array}$ & 19 & $0.45(0.77)$ & - & - \\
\hline \multirow{3}{*}{$\begin{array}{l}\text { Hickling, } \\
\text { 1990, Single- } \\
\text { group study, } \\
2401622\end{array}$} & \multirow[t]{3}{*}{$\begin{array}{l}\text { Severity of } \\
\text { acute } \\
\text { headache }\end{array}$} & \multirow[t]{3}{*}{$\begin{array}{l}\text { Average of worst } \\
\text { headache on a VAS } \\
(0-5)\end{array}$} & Baseline & $\begin{array}{l}\text { Combination of thermal } \\
\text { biofeedback and progressive } \\
\text { muscle relaxation }\end{array}$ & $\begin{array}{l}\text { All } \\
\text { participants }\end{array}$ & 5 & $2.9(0.6)$ & - & - \\
\hline & & & $\begin{array}{l}\text { After } \\
\text { intervention }\end{array}$ & $\begin{array}{l}\text { Combination of thermal } \\
\text { biofeedback and progressive } \\
\text { muscle relaxation }\end{array}$ & $\begin{array}{l}\text { All } \\
\text { participants }\end{array}$ & 5 & $0.5(1.1)$ & - & - \\
\hline & & & $\begin{array}{l}\text { After } \\
\text { delivery }\end{array}$ & $\begin{array}{l}\text { Combination of thermal } \\
\text { biofeedback and progressive } \\
\text { muscle relaxation }\end{array}$ & $\begin{array}{l}\text { All } \\
\text { participants }\end{array}$ & 5 & $0.3(0.7)$ & - & - \\
\hline \multirow{3}{*}{$\begin{array}{l}\text { Hickling, } \\
\text { 1990, Single- } \\
\text { group study, } \\
2401622\end{array}$} & \multirow[t]{3}{*}{$\begin{array}{l}\text { Severity of } \\
\text { acute } \\
\text { headache }\end{array}$} & \multirow[t]{3}{*}{$\begin{array}{l}\text { Worst headache on } \\
\text { a VAS (0-5) }\end{array}$} & Baseline & $\begin{array}{l}\text { Combination of thermal } \\
\text { biofeedback and progressive } \\
\text { muscle relaxation }\end{array}$ & $\begin{array}{l}\text { All } \\
\text { participants }\end{array}$ & 5 & $3.9(1.0)$ & - & - \\
\hline & & & $\begin{array}{l}\text { After } \\
\text { intervention }\end{array}$ & $\begin{array}{l}\text { Combination of thermal } \\
\text { biofeedback and progressive } \\
\text { muscle relaxation }\end{array}$ & $\begin{array}{l}\text { All } \\
\text { participants }\end{array}$ & 5 & $0.6(1.3)$ & - & - \\
\hline & & & $\begin{array}{l}\text { After } \\
\text { delivery }\end{array}$ & $\begin{array}{l}\text { Combination of thermal } \\
\text { biofeedback and progressive } \\
\text { muscle relaxation }\end{array}$ & $\begin{array}{l}\text { All } \\
\text { participants }\end{array}$ & 5 & $0.9(1.3)$ & - & - \\
\hline
\end{tabular}




\begin{tabular}{|c|c|c|c|c|c|c|c|c|c|}
\hline $\begin{array}{c}\text { Study, Year, } \\
\text { Design, } \\
\text { PMID }\end{array}$ & Outcome & $\begin{array}{c}\text { Outcome } \\
\text { Definition }\end{array}$ & Time & Arm & Subgroup & $\mathbf{N}$ & $\begin{array}{l}\text { Result, Mean } \\
\text { (SD) }\end{array}$ & $\begin{array}{c}\text { Effect Size (95\% } \\
\text { CI) }\end{array}$ & P value \\
\hline \multirow{3}{*}{$\begin{array}{l}\text { Hickling, } \\
\text { 1990, Single- } \\
\text { group study, } \\
2401622\end{array}$} & \multirow[t]{3}{*}{$\begin{array}{l}\text { Acute } \\
\text { headache } \\
\text { duration }\end{array}$} & \multirow[t]{3}{*}{ Duration in hours } & Baseline & $\begin{array}{l}\text { Combination of thermal } \\
\text { biofeedback and progressive } \\
\text { muscle relaxation }\end{array}$ & $\begin{array}{l}\text { All } \\
\text { participants }\end{array}$ & 5 & 20.6 h (16.0) & - & - \\
\hline & & & $\begin{array}{l}\text { After } \\
\text { intervention }\end{array}$ & $\begin{array}{l}\text { Combination of thermal } \\
\text { biofeedback and progressive } \\
\text { muscle relaxation }\end{array}$ & $\begin{array}{l}\text { All } \\
\text { participants }\end{array}$ & 5 & $1.2 \mathrm{~h} \mathrm{(2.7)}$ & - & - \\
\hline & & & $\begin{array}{l}\text { After } \\
\text { delivery }\end{array}$ & $\begin{array}{l}\text { Combination of thermal } \\
\text { biofeedback and progressive } \\
\text { muscle relaxation }\end{array}$ & $\begin{array}{l}\text { All } \\
\text { participants }\end{array}$ & 5 & $4.8 \mathrm{~h} \mathrm{(10.7)}$ & - & - \\
\hline \multirow{3}{*}{$\begin{array}{l}\text { Hickling, } \\
\text { 1990, Single- } \\
\text { group study, } \\
2401622\end{array}$} & \multirow[t]{3}{*}{$\begin{array}{l}\text { Resolution } \\
\text { of acute } \\
\text { headache }\end{array}$} & \multirow[t]{3}{*}{$\begin{array}{l}\text { Number of } \\
\text { headache-free days } \\
\text { per week }\end{array}$} & Baseline & $\begin{array}{l}\text { Combination of thermal } \\
\text { biofeedback and progressive } \\
\text { muscle relaxation }\end{array}$ & $\begin{array}{l}\text { All } \\
\text { participants }\end{array}$ & 5 & $2.8 \mathrm{~d} / \mathrm{w}(2.6)$ & - & - \\
\hline & & & $\begin{array}{l}\text { After } \\
\text { intervention }\end{array}$ & $\begin{array}{l}\text { Combination of thermal } \\
\text { biofeedback and progressive } \\
\text { muscle relaxation }\end{array}$ & $\begin{array}{l}\text { All } \\
\text { participants }\end{array}$ & 5 & $7 \mathrm{~d} / \mathrm{w}(0)$ & - & - \\
\hline & & & $\begin{array}{l}\text { After } \\
\text { delivery }\end{array}$ & $\begin{array}{l}\text { Combination of thermal } \\
\text { biofeedback and progressive } \\
\text { muscle relaxation }\end{array}$ & $\begin{array}{l}\text { All } \\
\text { participants }\end{array}$ & 5 & $7 \mathrm{~d} / \mathrm{w}(0)$ & - & - \\
\hline
\end{tabular}

Abbreviations: $\mathrm{CI}=$ confidence interval, $\mathrm{d}=$ days $\mathrm{h}=$ hours, IQR = interquartile range, $\mathrm{m}=$ months, $\mathrm{MD}=$ mean difference, $\mathrm{NMD}=$ net mean difference, $\mathrm{PMID}=\mathrm{PubMed}$ identifier, RCT = randomized controlled trial, VAS = visual analog scale, $\mathrm{w}=$ weeks.

${ }^{i}$ Calculated by us based on reported arm-specific data. This was done only for studies with arms with baseline characteristics considered by us to be similar

Table B-19. Key Question 2: Nonpharmacologic interventions: Complementary, behavioral, and physical therapies - Adverse effects, continuous

\begin{tabular}{|c|c|c|c|c|c|c|c|c|c|}
\hline $\begin{array}{l}\text { Study, Year, Design, } \\
\text { PMID }\end{array}$ & $\begin{array}{c}\text { Maternal } \\
\text { or Fetal/ } \\
\text { Child }\end{array}$ & Outcome & Time & Arm & Subgroup & $\mathbf{N}$ & $\begin{array}{c}\text { Result, } \\
\text { Mean (SD) }\end{array}$ & Effect Size (95\% CI) & $P$ value \\
\hline \multirow{2}{*}{$\begin{array}{l}\text { Silva, 2012, RCT, no } \\
\text { PMID }\end{array}$} & \multirow[t]{2}{*}{ Fetal/Child } & \multirow[t]{2}{*}{ Birth weight } & \multirow[t]{2}{*}{ At birth } & Acupuncture & All participants & 20 & 3244 g (336) & \multirow[t]{2}{*}{ MD $98(-141,336)^{i}$} & \multirow[t]{2}{*}{$0.411^{i}$} \\
\hline & & & & Routine care & All participants & 23 & $3146 \mathrm{~g}(424)$ & & \\
\hline \multirow{4}{*}{$\begin{array}{l}\text { Silva, 2012, RCT, no } \\
\text { PMID }\end{array}$} & \multirow[t]{4}{*}{ Fetal/Child } & \multirow[t]{4}{*}{ Apgar score } & \multirow[t]{2}{*}{1 min after birth } & Acupuncture & All participants & 20 & $9(0)$ & \multirow[t]{2}{*}{ MD $0(-0.5,0.5)^{i}$} & \multirow[t]{2}{*}{$1^{i}$} \\
\hline & & & & Routine care & All participants & 23 & $9(1)$ & & \\
\hline & & & \multirow[t]{2}{*}{5 min after birth } & Acupuncture & All participants & 20 & $10(0)$ & \multirow[t]{2}{*}{ MD $0(-0.1,0.1)^{i}$} & \multirow[t]{2}{*}{$1^{i}$} \\
\hline & & & & Routine care & All participants & 23 & $10(0)$ & & \\
\hline
\end{tabular}

Abbreviations: $\mathrm{CI}=$ confidence interval, $\mathrm{h}=$ hours, $\mathrm{IQR}=$ interquartile range, $\mathrm{m}=$ months, $\mathrm{MD}=$ mean difference, min $=$ minutes, $\mathrm{PMID}=\mathrm{PubMed}$ identifier, RCT = randomized controlled trial, $\mathrm{w}=$ weeks.

${ }^{i}$ Calculated by us based on reported arm-specific data. This was done only for studies with arms with baseline characteristics considered by us to be similar. 
Table B-20. Key Question 2: Nonpharmacologic interventions: Nerve blocks - Continuous outcomes

\begin{tabular}{|c|c|c|c|c|c|c|c|c|}
\hline $\begin{array}{c}\text { Study, Year, } \\
\text { Design, } \\
\text { PMID } \\
\end{array}$ & Outcome & Time & Arm & Subgroup & $\mathbf{N}$ & Mean (SD) & $\begin{array}{c}\text { Mean (SD) } \\
\text { Change from } \\
\text { Baseline } \\
\end{array}$ & P value \\
\hline \multirow{3}{*}{$\begin{array}{l}\text { Govindappagari, } \\
\text { Single-group } \\
\text { study, 2014, } \\
25415168\end{array}$} & \multirow[t]{3}{*}{$\begin{array}{l}\text { Acute headache - } \\
\text { Severity (VAS, 0-9) }\end{array}$} & $\begin{array}{l}\text { Pre- } \\
\text { procedure }\end{array}$ & $\begin{array}{l}\text { Nerve blocks: } \\
\text { Peripheral }\end{array}$ & $\begin{array}{l}\text { All } \\
\text { participants }\end{array}$ & 13 & $8.4(1.8)$ & $\mathrm{N} / \mathrm{A}$ & - \\
\hline & & $\begin{array}{l}\text { Post- } \\
\text { procedure }\end{array}$ & $\begin{array}{l}\text { Nerve blocks: } \\
\text { Peripheral }\end{array}$ & $\begin{array}{l}\text { All } \\
\text { participants }\end{array}$ & 13 & $4.5(3.8)$ & $-4.0(2.6)$ & $<0.001$ \\
\hline & & $24 \mathrm{~h}$ & $\begin{array}{l}\text { Nerve blocks: } \\
\text { Peripheral }\end{array}$ & $\begin{array}{l}\text { All } \\
\text { participants }\end{array}$ & 13 & $4.5(4.5)$ & $-4.0(4.4)$ & 0.007 \\
\hline
\end{tabular}

Abbreviations: $\mathrm{CI}=$ confidence interval, $\mathrm{h}=$ hours, N/A = not applicable, PMID = PubMed identifier, SD = standard deviation, VAS = visual analog scale.

Table B-21. Key Question 2: Nonpharmacologic interventions: Nerve blocks - Maternal adverse effects, categorical

\begin{tabular}{|l|l|l|l|l|l|}
\hline \multicolumn{1}{|c|}{$\begin{array}{c}\text { Study, Year, Design, } \\
\text { PMID }\end{array}$} & \multicolumn{1}{|c|}{ Outcome } & Time & Arm & Subgroup & n/N (\%) \\
\hline $\begin{array}{l}\text { Govindappagari, 2014, } \\
\text { Single-group study, } \\
25415168\end{array}$ & Serious adverse effects & Post-procedure & Nerve blocks: Peripheral & All participants & $0 / 13$ (0.0) \\
\hline $\begin{array}{l}\text { Govindappagari, 2014, } \\
\text { Single-group study, } \\
25415168\end{array}$ & $\begin{array}{l}\text { Vasovagal near syncopal episode } \\
\text { with nausea }\end{array}$ & Post-procedure & Nerve blocks: Peripheral & All participants & $1 / 13$ (7.7) \\
\hline
\end{tabular}

25415168

Abbreviations: PMID = PubMed identifier.

Table B-22. Key Question 2: Nonpharmacologic interventions: Nerve blocks - Fetal/child adverse effects, categorical

\begin{tabular}{|l|l|l|l|l|l|}
\hline \multicolumn{1}{|c|}{\begin{tabular}{c}
\multicolumn{1}{c|}{ Otudy, Year, Design, } \\
PMID
\end{tabular}} & \multicolumn{1}{|c|}{ Time } & Arm & Subgroup & n/N (\%) \\
\hline $\begin{array}{l}\text { Govindappagari, 2014, } \\
\text { Single-group study, } \\
25415168\end{array}$ & Preterm birth & $29 \mathrm{w}$ & Nerve blocks: Peripheral & All participants & $2 / 13(15.3)$ \\
\hline
\end{tabular}

Abbreviations: PMID = PubMed identifier, $\mathrm{w}$ = weeks. 
Table B-23. Key Question 2: Nonpharmacologic interventions: Noninvasive neuromodulation devices - Categorical outcomes

\begin{tabular}{|l|l|l|l|c|c|}
\hline $\begin{array}{c}\text { Study, Year, Design, } \\
\text { PMID }\end{array}$ & \multicolumn{1}{|c|}{ Outcome } & \multicolumn{1}{|c|}{ Time } & \multicolumn{1}{c|}{ Arm } & Subgroup & n/N (\%) \\
\hline $\begin{array}{l}\text { Bhola, 2015, Single- } \\
\text { group study, 26055242 }\end{array}$ & Resolution of acute headache & NR & $\begin{array}{l}\text { Transcranial magnetic } \\
\text { stimulation }\end{array}$ & All participants & $3 / 3$ (100) \\
\hline $\begin{array}{l}\text { Bhola, 2015, Single- } \\
\text { group study, 26055242 }\end{array}$ & $\begin{array}{l}\text { Resolution of headache-related } \\
\text { symptoms }\end{array}$ & NR & $\begin{array}{l}\text { Transcranial magnetic } \\
\text { stimulation }\end{array}$ & All participants & $3 / 3(100)$ \\
\hline
\end{tabular}

Abbreviations: PMID = PubMed identifier, NR = not reported.

Table B-24. Key Question 2: Nonpharmacologic interventions: Noninvasive neuromodulation devices - Maternal adverse effects, categorical

\begin{tabular}{|l|l|l|l|c|c|}
\hline $\begin{array}{c}\text { Study, Year, Design, } \\
\text { PMID }\end{array}$ & \multicolumn{1}{|c|}{ Outcome } & Time & Arm & Subgroup & n/N (\%) \\
\hline $\begin{array}{l}\text { Bhola, 2015, Single- } \\
\text { group study, 26055242 }\end{array}$ & Maternal adverse events, Any & NR & $\begin{array}{l}\text { Transcranial magnetic } \\
\text { stimulation }\end{array}$ & All participants & $0 / 3(0)$ \\
\hline
\end{tabular}

Abbreviations: PMID = PubMed identifier, NR = not reported. 


\section{SRs (Indirect Evidence)}

The 26 included SRs were published between 2000 and 2020 in 29 articles (Table B-27). ${ }^{53-81}$ The SRs included a total of 740 studies (not accounting for overlap of studies between some SRs), with a median of 14.5 studies per SR (IQR 10 to 37).

In terms of natal phase considered, only three of the 26 SRs focused on the effects of interventions received during a particular phase (two SRs ${ }^{57,81}$ focused on the first trimester and one $\mathrm{SR}^{55}$ focused on the postpartum period).

All 26 SRs addressed pharmacologic interventions. These included eight SRs that assessed NSAIDs, ${ }^{55,57,58,61,64-66,72}$ two that assessed antiepileptics, ${ }^{78-80}$ two that assessed beta blockers, ${ }^{53}$, 81 two that assessed calcium channel blockers, ${ }^{53,56}$ two that assessed antiemetics (5HT3 antagonists), ${ }^{67,76}$ two that assessed antipsychotics, ${ }^{59,77}$ two that assessed antihistamines, ${ }^{63,68}$ and one each that assessed serotonin and norepinephrine reuptake inhibitors (SNRIs), ${ }^{73}, 74$ tricyclic antidepressants, ${ }^{73,74}$ benzodiazepines, ${ }^{60,62}$ corticosteroids, ${ }^{75}$ oral magnesium, ${ }^{69}$ triptans, ${ }^{70}$ analgesics/antipyretics, ${ }^{71}$ and intravenous magnesium. ${ }^{54}$ Of note, one SR addressed both tricyclic antidepressants and SNRIs, ${ }^{73,74}$ and one SR addressed both beta blockers and calcium channel blockers. ${ }^{53}$

Among all 26 SRs, 12 SRs reported maternal adverse effects, while 23 reported fetal/child adverse effects.

Table B-26 provides the results of our quality assessment of all 26 SRs (using AMSTAR 2).

Table B-27 provides all maternal adverse effects and Table B-28 provides all fetal/child adverse effects reported in the 26 SRs. 
Table B-25. Included SRs - Summary of design and arm details

\begin{tabular}{|c|c|c|c|c|c|c|c|}
\hline $\begin{array}{l}\text { Review, Year Published, } \\
\text { PMI D }\end{array}$ & $\begin{array}{c}\text { Number } \\
\text { of } \\
\text { Databases } \\
\text { Searched }\end{array}$ & $\begin{array}{c}\text { Year of } \\
\text { Last } \\
\text { Search }\end{array}$ & $\begin{array}{l}\text { Number } \\
\text { of } \\
\text { Included } \\
\text { Studies }\end{array}$ & I ntervention Class (Subclass) & Intervention Name & $\begin{array}{l}\text { Maternal } \\
\text { Adverse } \\
\text { Effects } \\
\text { Reported }\end{array}$ & $\begin{array}{c}\text { Fetal/ } \\
\text { Child } \\
\text { Adverse } \\
\text { Effects } \\
\text { Reported }\end{array}$ \\
\hline \multirow{2}{*}{ McDonagh, 2014, 25004304} & \multirow[t]{2}{*}{6} & \multirow[t]{2}{*}{2013} & \multirow[t]{2}{*}{15} & SNRIS & Venlafaxine & No & Yes \\
\hline & & & & Tricyclic antidepressants & Any & No & Yes \\
\hline Yakoob, 2013, 23753416 & 5 & 2011 & 13 & Beta blockers & Any & No & Yes \\
\hline \multirow[t]{2}{*}{ Abalos, 2018, 30277556} & \multirow[t]{2}{*}{6} & \multirow[t]{2}{*}{2017} & \multirow[t]{2}{*}{63} & Beta blockers & Any & Yes & Yes \\
\hline & & & & Calcium channel blockers & Any & Yes & Yes \\
\hline Bellos, 2020a, 32199925 & 5 & 2019 & 22 & Calcium channel blockers & Nifedipine & Yes & Yes \\
\hline \multirow[t]{5}{*}{ Veroniki, 2017, 28472982} & \multirow[t]{5}{*}{3} & \multirow[t]{5}{*}{2017} & \multirow[t]{5}{*}{96} & \multirow[t]{2}{*}{ Antiepileptics (Multiple mechanisms of action) } & Valproate & No & Yes \\
\hline & & & & & Topiramate & No & Yes \\
\hline & & & & Antiepileptics (Calcium channel modulators) & Gabapentin & No & Yes \\
\hline & & & & \multirow[t]{2}{*}{ Antiepileptics (Sodium channel modulators) } & Carbamazepine & No & Yes \\
\hline & & & & & Lamotrigine & No & Yes \\
\hline \multirow[t]{5}{*}{ Weston, 2016, 27819746} & \multirow[t]{5}{*}{6} & \multirow[t]{5}{*}{2015} & \multirow[t]{5}{*}{50} & \multirow[t]{2}{*}{ Antiepileptics (Multiple mechanisms) } & Valproate & No & Yes \\
\hline & & & & & Topiramate & No & Yes \\
\hline & & & & Antiepileptics (Calcium channel modulators) & Gabapentin & No & Yes \\
\hline & & & & \multirow[t]{2}{*}{ Antiepileptic (Sodium channel modulators) } & Carbamazepine & No & Yes \\
\hline & & & & & Lamotrigine & No & Yes \\
\hline Enato, 2011, 21272436 & 3 & 2011 & 26 & Benzodiazepines & Any & No & Yes \\
\hline Masarwa, 2018, 29688261 & 3 & 2017 & 7 & Analgesics/Antipyretics & Acetaminophen & No & Yes \\
\hline Bellos, 2020b, 32068930 & 4 & 2019 & 10 & NSAIDs & Any & Yes & No \\
\hline Hammers, 2015, 25448524 & 2 & 2014 & 27 & NSAIDS & Indomethacin & No & Yes \\
\hline $\begin{array}{l}\text { Chaemsaithong, 2019, } \\
31494125\end{array}$ & 5 & 2018 & 8 & NSAIDs & Aspirin (Low dose) & No & Yes \\
\hline Henderson, 2014, 24711050 & 6 & 2014 & 23 & NSAIDS & Aspirin (Low dose) & Yes & Yes \\
\hline Coomarasamy, 2003, 12798543 & 6 & 2001 & 14 & NSAIDs & Aspirin (Low dose) & Yes & Yes \\
\hline Duley, 2007, 17443552 & 3 & 2010 & 59 & NSAIDs & Aspirin (Low dose) & Yes & Yes \\
\hline Hamulyak, 2020, 32358837 & 4 & 2019 & 11 & NSAIDs & Aspirin (Low dose) & Yes & Yes \\
\hline Maze, 2019, 31584685 & 3 & 2018 & 22 & NSAIDS & Aspirin (Low dose) & Yes & No \\
\hline Kaplan, 2019, 30849498 & 3 & 2016 & 8 & Antiemetics (5HT3 antagonists) & Ondansetron & No & Yes \\
\hline Picot, 2020, 32420702 & 2 & 2019 & 12 & Antiemetics (5HT3 antagonists) & Ondansetron & No & Yes \\
\hline Etwel, 2017, 27878468 & 2 & 2015 & 37 & Antihistamines & Any & No & Yes \\
\hline Li, 2019, 31909512 & 4 & 2019 & 26 & Antihistamines & Any & No & Yes \\
\hline Park-Wyllie, 2000, 11091360 & 3 & 1999 & 10 & Corticosteroids & Prednisolone & No & Yes \\
\hline Marchenko, 2015, 25644494 & 17 & 2013 & 6 & Triptans & Any & No & Yes \\
\hline Coughlin, 2015, 25932852 & 3 & 2013 & 10 & Antipsychotics & Any & No & Yes \\
\hline Terrana, 2015, 26274044 & 2 & 2014 & 12 & Antipsychotics & Any & No & Yes \\
\hline Bain, 2013, 24139447 & 10 & 2012 & 143 & Intravenous magnesium & $\begin{array}{l}\text { Intravenous } \\
\text { magnesium sulphate }\end{array}$ & Yes & No \\
\hline
\end{tabular}




\begin{tabular}{|c|c|c|c|c|c|c|c|}
\hline $\begin{array}{c}\text { Review, Year Published, } \\
\text { PMI D }\end{array}$ & $\begin{array}{c}\text { Number } \\
\text { of } \\
\text { Databases } \\
\text { Searched }\end{array}$ & $\begin{array}{l}\text { Year of } \\
\text { Last } \\
\text { Search }\end{array}$ & $\begin{array}{l}\text { Number } \\
\text { of } \\
\text { Included } \\
\text { Studies }\end{array}$ & Intervention Class (Subclass) & Intervention Name & $\begin{array}{l}\text { Maternal } \\
\text { Adverse } \\
\text { Effects } \\
\text { Reported }\end{array}$ & $\begin{array}{c}\text { Fetal/ } \\
\text { Child } \\
\text { Adverse } \\
\text { Effects } \\
\text { Reported }\end{array}$ \\
\hline Makredes, 2014, 24696187 & 3 & 2013 & 10 & Oral magnesium & $\begin{array}{l}\text { Oral magnesium } \\
\text { sulphate }\end{array}$ & Yes & Yes \\
\hline
\end{tabular}

Abbreviations: Nonpharm = nonpharmacologic, NR = not reported, NSAID = nonsteroidal anti-inflammatory drug, Pharm = pharmacologic, PMID = PubMed identifier, SNRIs 
Table B-26. Included systematic reviews - Quality assessment using AMSTAR 2 criteria

\begin{tabular}{|c|c|c|c|c|c|c|c|c|c|c|c|c|}
\hline Int Type & Review, Year, PMID & $\begin{array}{l}\text { Eligibility } \\
\text { Criteria }^{\mathrm{a}}\end{array}$ & $\begin{array}{c}\text { Lit } \\
\text { Search }^{b}\end{array}$ & $\begin{array}{l}\text { Duplicate } \\
\text { Screening }\end{array}$ & $\begin{array}{c}\text { Duplicate } \\
\text { Data } \\
\text { Extraction }^{\mathrm{d}}\end{array}$ & $\begin{array}{c}\text { Study } \\
\text { Details } \\
\text { Described }^{\text {e }}\end{array}$ & $\begin{array}{c}\text { Assesse } \\
\text { d } \\
\text { Risk of } \\
\text { Bias }^{\mathrm{f}} \\
\end{array}$ & $\begin{array}{c}\text { Assessed } \\
\text { Impact of } \\
\text { Risk of } \\
\text { Bias }^{g}\end{array}$ & $\begin{array}{c}\text { Appropriate } \\
\text { Meta- } \\
\text { Analysis } \\
\text { Methods }^{\mathrm{h}}\end{array}$ & $\begin{array}{c}\text { Explained/ } \\
\text { Discussed } \\
\text { Heterogeneity }\end{array}$ & $\mathrm{COI}^{\mathrm{j}}$ & $\begin{array}{l}\text { OVERALL } \\
\text { QUALITY }\end{array}$ \\
\hline \multirow[t]{26}{*}{ Pharm } & McDonagh, 2014, 25004304 & Yes & Yes & Yes & Yes & Yes & Yes & Yes & Yes & Yes & Yes & HIGH \\
\hline & Yakoob, 2013, 23753416 & Yes & Yes & Yes & Yes & Yes & Yes & Yes & Yes & Yes & No & HIGH \\
\hline & Abalos, 2018, 30277556 & Yes & Yes & Yes & Yes & Yes & Yes & Yes & Yes & Yes & Yes & HIGH \\
\hline & Bellos, 2020a, 32199925 & Yes & Yes & Yes & Unclear & Yes & Yes & Yes & Yes & Yes & Yes & HIGH \\
\hline & Veroniki, 2017, 28472982 & Yes & Yes & Yes & Yes & Yes & Yes & Yes & Yes & No & Yes & HIGH \\
\hline & Weston, 2016, 27819746 & Yes & Yes & Yes & Yes & Yes & Yes & Yes & Yes & Yes & Yes & HIGH \\
\hline & Enato, 2011,21272436 & Yes & Yes & Yes & Unclear & Yes & Yes & Yes & Yes & Yes & Yes & HIGH \\
\hline & Masarwa, 2018, 29688261 & Yes & Yes & Yes & Unclear & Unclear & Yes & No & Yes & Yes & Yes & MODERATE \\
\hline & Bellos, 2020b, 32068930 & Yes & Yes & Unclear & Unclear & Yes & Yes & No & Yes & Yes & Yes & MODERATE \\
\hline & Hammers, 2015, 25448524 & Yes & Yes & Yes & Yes & Yes & Yes & Yes & Yes & Yes & Yes & HIGH \\
\hline & Chaemsaithong, 2019, 31494125 & Yes & Yes & Yes & Yes & Yes & Yes & Unclear & Yes & Yes & Yes & HIGH \\
\hline & Henderson, 2014, 24711050 & Yes & Yes & Yes & Yes & Yes & Yes & Yes & Yes & No & Yes & HIGH \\
\hline & Coomarasamy, 2003, 12798543 & Yes & Yes & Yes & Unclear & Yes & Yes & Unclear & Yes & Yes & Yes & MODERATE \\
\hline & Duley, 2007, 17443552 & Yes & Yes & Yes & Yes & Yes & Yes & Yes & Yes & Yes & Yes & HIGH \\
\hline & Hamulyak, 2020, 32358837 & Yes & Yes & Yes & Yes & Yes & Yes & Yes & Yes & Yes & Yes & HIGH \\
\hline & Maze, 2019, 31584685 & Yes & Yes & Yes & Yes & Yes & Yes & Yes & Yes & Yes & Yes & HIGH \\
\hline & Kaplan, 2019, 30849498 & Yes & Yes & Yes & Yes & Yes & Yes & No & Yes & Yes & Yes & HIGH \\
\hline & Picot, 2020, 32420702 & Yes & Yes & Yes & Yes & Yes & Yes & No & Yes & Yes & Yes & HIGH \\
\hline & Etwel, 2017, 27878468 & Yes & Yes & Yes & Yes & Yes & Yes & No & Yes & Yes & Yes & HIGH \\
\hline & Li, 2019, 31909512 & Yes & Yes & Unclear & Unclear & Yes & Yes & Yes & Yes & Yes & Yes & HIGH \\
\hline & Park-Wyllie, 2000, 11091360 & Yes & Yes & Yes & Yes & Yes & Yes & Yes & Yes & Yes & Unclear & HIGH \\
\hline & Marchenko, 2015, 25644494 & Yes & Yes & Yes & Yes & Yes & Yes & No & Yes & Yes & Yes & HIGH \\
\hline & Coughlin, 2015, 25932852 & Yes & Yes & Yes & Yes & Yes & Yes & No & Yes & Yes & Yes & HIGH \\
\hline & Terrana, 2015, 26274044 & Yes & Yes & Unclear & Unclear & Unclear & Yes & Yes & Yes & Yes & Yes & MODERATE \\
\hline & Bain, 2013, 24139447 & Yes & Yes & No & No & Yes & Yes & No & Yes & Yes & Yes & HIGH \\
\hline & Makredes, 2014, 24696187 & Yes & Yes & Yes & Yes & Yes & Yes & Yes & Yes & Yes & Yes & HIGH \\
\hline
\end{tabular}

Abbreviations: AMSTAR 2 = A Measurement Tool to Assess Systematic Reviews, version 2 Tool, COI $=$ conflicts of interest, Int $=$ intervention, Lit $=$ literature, Nonpharm $=$

Nonpharmacologic, Pharm $=$ Pharmacologic, PMID = PubMed identifier .

Ratings based on AMSTAR 2. Ratings of individual items: Yes = item explicitly done (or of good quality), $\mathrm{No}=$ item not done (or of poor quality), Unclear = not reported, N/A = not applicable. Ratings of overall quality: HIGH, MODERATE, and LOW (none in Table).

Ratings are color coded for emphasis only. Other abbreviations are defined in the footnotes.

a Did the authors specify research questions and inclusion criteria for the SR? (AMSTAR 2 item 1)

b Did the SR authors use a comprehensive literature search strategy? (AMSTAR 2 item 4)

c Did the SR authors perform study selection in duplicate? (AMSTAR 2 item 5)

d Did the SR authors perform data extraction in duplicate, either independently or through verification? (AMSTAR 2 item 6)

e Did the SR authors describe the included studies in adequate detail? (AMSTAR 2 item 8) 
Did the SR authors use a satisfactory technique for assessing the risk of bias in individual studies that were included in the SR? (AMSTAR 2 item 9)

g Did the SR authors assess the potential impact of risk of bias in individual studies on the summary results, interpretation, discussion? (AMSTAR 2 item 12)

h If meta-analysis (MA) was performed did the SR authors use appropriate methods for statistical combination of results? (AMSTAR 2 item 11) See subsequent footnotes.

i Did the SR authors provide a satisfactory explanation for, and discussion of, any heterogeneity observed in the results of the SR? (AMSTAR 2 item 14)

j Did the SR authors report the lack of significant potential of conflict of interest (COI) regarding conducting the SR? (AMSTAR 2 item 16) 
Table B-27. SRs addressing pharmacologic interventions - All reported maternal adverse effects

\begin{tabular}{|c|c|c|c|c|c|c|c|}
\hline $\begin{array}{c}\text { Review, Year } \\
\text { Published, } \\
\text { PMI D }\end{array}$ & Drug Class & Drug Name(s) & $\begin{array}{c}\text { Timing of } \\
\text { Occurrence } \\
\text { of Adverse } \\
\text { Effect }\end{array}$ & Adverse Effect & $\begin{array}{c}\mathbf{N} \\
\text { studies }\end{array}$ & Effect Size (95\% CI) & Conclusion \\
\hline \multirow{11}{*}{$\begin{array}{l}\text { Abalos, 2018, } \\
30277556\end{array}$} & \multirow[t]{7}{*}{ Beta blockers } & \multirow[t]{7}{*}{ Any } & \multirow[t]{2}{*}{ NR } & Adverse effects, Any & 7 & RR $3.14(0.66,15.02)$ & NS \\
\hline & & & & Discontinuation due to adverse effects & 9 & RR $1.85(0.61,5.57)$ & NS \\
\hline & & & \multirow{2}{*}{ Antepartum } & Hospitalization during pregnancy & 1 & RR $0.84(0.57,1.24)$ & NS \\
\hline & & & & Placental abruption & 3 & RR $5.11(0.25,104.96)$ & NS \\
\hline & & & \multirow[t]{3}{*}{ Delivery } & Induction of labor or cesarean section & 2 & $\operatorname{RR~} 0.97(0.84,1.12)$ & NS \\
\hline & & & & Induction of labor & 3 & $\operatorname{RR} 0.98(0.83,1.17)$ & NS \\
\hline & & & & Cesarean section & 8 & RR $1.06(0.86,1.31)$ & NS \\
\hline & \multirow{4}{*}{$\begin{array}{l}\text { Calcium } \\
\text { channel } \\
\text { blockers }\end{array}$} & \multirow[t]{4}{*}{ Any } & \multirow[t]{2}{*}{ NR } & Adverse effects, Any & 1 & RR $0.96(0.60,1.52)$ & NS \\
\hline & & & & Discontinuation due to adverse effects & 2 & RR 4.02 (0.45,35.97) & NS \\
\hline & & & Antepartum & Placental abruption & 1 & RR $1.52(0.26,8.87)$ & NS \\
\hline & & & Delivery & Cesarean section & 3 & $\operatorname{RR} 0.94(0.79,1.11)$ & NS \\
\hline \multirow{3}{*}{$\begin{array}{l}\text { Bellos, 2020a, } \\
32199925\end{array}$} & \multirow{3}{*}{$\begin{array}{l}\text { Calcium } \\
\text { channel } \\
\text { blockers }\end{array}$} & \multirow[t]{3}{*}{ Nifedipine } & Antepartum & Placental abruption & 2 & OR $0.29(0.15,0.58)$ & Intervention better \\
\hline & & & & & & & \\
\hline & & & Delivery & Cesarean section & 2 & OR $0.85(0.56,1.29)$ & NS \\
\hline \multirow{4}{*}{$\begin{array}{l}\text { Bellos, 2020b, } \\
32068930\end{array}$} & \multirow[t]{4}{*}{ NSAIDs } & \multirow[t]{4}{*}{ Any } & \multirow[t]{4}{*}{ Postpartum } & Postpartum hypertension & 4 & OR $1.52(0.77,3.01)$ & NS \\
\hline & & & & Postpartum systolic blood pressure & 4 & $\begin{array}{l}\mathrm{MD}-3.03 \mathrm{~mm} \mathrm{Hg}(-6.21 \\
0.15)\end{array}$ & NS \\
\hline & & & & Postpartum diastolic blood pressure & 4 & $\begin{array}{l}\mathrm{MD}-2.28 \mathrm{~mm} \mathrm{Hg}(-4.44,- \\
0.13)\end{array}$ & Intervention better \\
\hline & & & & Postpartum mean arterial pressure & 4 & $\begin{array}{l}\mathrm{MD}-0.38 \mathrm{~mm} \mathrm{Hg}(-1.88 \text {, } \\
1.11)\end{array}$ & NS \\
\hline \multirow{2}{*}{$\begin{array}{l}\text { Henderson, } \\
2014,24711050\end{array}$} & \multirow[t]{2}{*}{ NSAIDs } & \multirow{2}{*}{$\begin{array}{l}\text { Aspirin (Low } \\
\text { dose) }\end{array}$} & Antepartum & Placental abruption & 11 & RR $1.17(0.93,1.48)$ & NS \\
\hline & & & Postpartum & Postpartum hemorrhage & NR & NR & NS \\
\hline $\begin{array}{l}\text { Coomarasamy, } \\
2003,12798543\end{array}$ & NSAIDS & $\begin{array}{l}\text { Aspirin (Low } \\
\text { dose) }\end{array}$ & Antepartum & $\begin{array}{l}\text { Placental abruption or other } \\
\text { antepartum bleeding }\end{array}$ & 7 & OR $0.98(0.37,1.30)$ & NS \\
\hline \multirow{4}{*}{$\begin{array}{l}\text { Duley, } 2007, \\
17443552\end{array}$} & \multirow[t]{4}{*}{ NSAIDs } & \multirow{4}{*}{$\begin{array}{l}\text { Aspirin (Low } \\
\text { dose) }\end{array}$} & \multirow[t]{2}{*}{ Antepartum } & Placental abruption & 16 & RR $1.10(0.89,1.37)$ & NS \\
\hline & & & & Hospitalization during pregnancy & 3 & RR $1.03(0.97,1.10)$ & NS \\
\hline & & & \multirow[t]{2}{*}{ Delivery } & Cesarean section & 24 & RR $1.02(0.98,1.06)$ & NS \\
\hline & & & & Induction of labor & 5 & RR $1.03(0.98,1.08)$ & NS \\
\hline $\begin{array}{l}\text { Hamulyak, 2020, } \\
32358837\end{array}$ & NSAIDS & $\begin{array}{l}\text { Aspirin (Low } \\
\text { dose) }\end{array}$ & Antepartum & Adverse effect, Any & 1 & RR $1.29(0.60,2.77)$ & NS \\
\hline $\begin{array}{l}\text { Maze, 2019, } \\
31584685\end{array}$ & NSAIDs & $\begin{array}{l}\text { Aspirin (Low } \\
\text { dose) }\end{array}$ & Antepartum & Thrombosis & 4 & OR $0.8(0.1,4.3)$ & NS \\
\hline
\end{tabular}




\begin{tabular}{|c|c|c|c|c|c|c|c|}
\hline $\begin{array}{c}\text { Review, Year } \\
\text { Published, } \\
\text { PMI D }\end{array}$ & Drug Class & Drug Name(s) & $\begin{array}{c}\text { Timing of } \\
\text { Occurrence } \\
\text { of Adverse } \\
\text { Effect }\end{array}$ & Adverse Effect & $\begin{array}{c}\mathbf{N} \\
\text { studies }\end{array}$ & Effect Size (95\% CI) & Conclusion \\
\hline \multirow[t]{23}{*}{$\begin{array}{l}\text { Bain, 2013, } \\
24139447\end{array}$} & \multirow[t]{23}{*}{$\begin{array}{l}\text { Intravenous } \\
\text { magnesium }\end{array}$} & \multirow[t]{23}{*}{$\begin{array}{l}\text { Intravenous } \\
\text { magnesium } \\
\text { sulphate }\end{array}$} & \multirow[t]{21}{*}{ NR } & Adverse effect, Any & 4 & RR 4.62 $(2.42,8.83)$ & Intervention worse \\
\hline & & & & Death & 5 & RR $0.53(0.26,1.09)$ & NS \\
\hline & & & & Absent or reduced tendon reflexes & 3 & RR $1.01(0.71,1.44)$ & NS \\
\hline & & & & Slurred speech & 1 & RR $3.04(0.13,73.42)$ & NS \\
\hline & & & & Pulmonary edema & 4 & RR $1.12(0.72,1.74)$ & NS \\
\hline & & & & $\begin{array}{l}\text { Discontinuation due to adverse } \\
\text { effects }\end{array}$ & 5 & $\operatorname{RR} 2.77(2.32,3.30)$ & Intervention worse \\
\hline & & & & Respiratory arrest & 4 & RR $2.50(0.49,12.9)$ & NS \\
\hline & & & & $\begin{array}{l}\text { Respiratory depression/ other } \\
\text { respiratory problems }\end{array}$ & 5 & RR $1.41(1.07,1.86)$ & Intervention worse \\
\hline & & & & Cardiac arrest & 4 & RR $0.80(0.21,2.98)$ & NS \\
\hline & & & & Hypotension & 3 & RR $1.52(1.10,2.11)$ & Intervention worse \\
\hline & & & & Tachycardia & 1 & RR $1.53(1.03,2.29)$ & Intervention worse \\
\hline & & & & Flushing and/ or warmth & 5 & RR $6.94(4.19,11.49)$ & Intervention worse \\
\hline & & & & Nausea and/ or vomiting & 4 & $\operatorname{RR} 5.50(2.29,13.22)$ & Intervention worse \\
\hline & & & & Muscle weakness & 3 & $\operatorname{RR} 15.81(7.36,33.96)$ & Intervention worse \\
\hline & & & & Drowsiness or confusion & 3 & $\operatorname{RR} 2.46(1.83,3.29)$ & Intervention worse \\
\hline & & & & Headache & 2 & $\operatorname{RR} 2.21(1.27,3.86)$ & Intervention worse \\
\hline & & & & Thirst or mouth dryness & 2 & RR $2.38(1.59,3.56)$ & Intervention worse \\
\hline & & & & Dizziness & 2 & $\operatorname{RR} 2.62(1.63,4.21)$ & Intervention worse \\
\hline & & & & Sweating & 2 & $\operatorname{RR} 6.37(1.96,20.65)$ & Intervention worse \\
\hline & & & & Itching and/ or tingling & 1 & $\operatorname{RR} 14.5(2.0,113.4)$ & Intervention worse \\
\hline & & & & Blurred vision & 1 & RR 2.34 (1.32, 4.14) & Intervention worse \\
\hline & & & Delivery & Cesarean section & 10 & RR $1.04(1.00,1.08)$ & NS \\
\hline & & & Postpartum & Postpartum hemorrhage & 4 & $\operatorname{RR} 0.94(0.87,1.04)$ & NS \\
\hline \multirow[t]{8}{*}{$\begin{array}{l}\text { Makredes, 2014, } \\
24696187\end{array}$} & \multirow[t]{8}{*}{$\begin{array}{l}\text { Oral } \\
\text { magnesium }\end{array}$} & \multirow[t]{8}{*}{$\begin{array}{l}\text { Oral magnesium } \\
\text { sulphate }\end{array}$} & \multirow[t]{4}{*}{ NR } & Gastrointestinal symptoms & 4 & RR $0.88(0.69,1.12)$ & NS \\
\hline & & & & Systolic blood pressure & 3 & 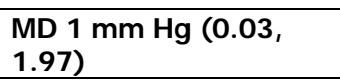 & Intervention worse \\
\hline & & & & Diastolic blood pressure & 3 & $\begin{array}{l}\text { MD } 0.23 \text { mm Hg (-0.67, } \\
1.13)\end{array}$ & NS \\
\hline & & & & Hospitalizations & 3 & RR $0.65(0.48,1.86)$ & NS \\
\hline & & & \multirow[t]{3}{*}{ Antepartum } & Pregnancy-induced hypertension & 3 & RR $0.39(0.11,1.41)$ & NS \\
\hline & & & & Eclampsia & 1 & RR $0.14(0.01,2.70)$ & NS \\
\hline & & & & Antepartum hemorrhage & 2 & RR $0.53(0.09,3.15)$ & NS \\
\hline & & & Delivery & Length of labor & 2 & MD $0.00 \mathrm{~h}(-0.50,0.50)$ & NS \\
\hline
\end{tabular}

Abbreviations: $\mathrm{CI}=$ confidence interval, $\mathrm{m}=$ months, $\mathrm{MD}=$ mean difference, $\mathrm{NR}=$ not reported, NS = no statistically significant difference in adverse effects between intervention and control, NSAID = nonsteroidal anti-inflammatory drug, PMID = PubMed identifier, OR = odds ratio, RR = relative risk. 
Adverse effects, effect sizes, and conclusions in bold font have effect sizes that are statistically significantly higher (at the $5 \%$ level) in the drug arm, suggestive of harm.

Table B-28. SRs addressing pharmacologic interventions - All reported fetal/child adverse effects

\begin{tabular}{|c|c|c|c|c|c|c|c|}
\hline $\begin{array}{l}\text { Review, Year } \\
\text { Published, } \\
\text { PMI D }\end{array}$ & Drug Class & $\begin{array}{c}\text { Drug } \\
\text { Name } \\
\text { (s) }\end{array}$ & $\begin{array}{c}\text { Timing of } \\
\text { Occurrence } \\
\text { of Adverse } \\
\text { Effect }\end{array}$ & Adverse Effect & $\begin{array}{c}\mathbf{N} \\
\text { Studies }\end{array}$ & Effect Size (95\% CI) & Conclusion \\
\hline \multirow{10}{*}{$\begin{array}{l}\text { McDonagh, 2014, } \\
25004304\end{array}$} & \multirow[t]{8}{*}{ Tricyclic Antidepressants } & \multirow[t]{8}{*}{ Any } & Perinatal & Small for gestational age & 2 & OR $0.97(0.64,1.46)$ & NS \\
\hline & & & \multirow[t]{4}{*}{ Neonatal } & Neonatal convulsions & 2 & OR $7.82(2.81,21.8)$ & Intervention worse \\
\hline & & & & Neonatal respiratory distress & 2 & OR $2.11(1.57,2.83)$ & Intervention worse \\
\hline & & & & Congenital anomalies, All or major & 2 & OR $1.31(1.04,1.65)$ & Intervention worse \\
\hline & & & & Congenital anomalies, Cardiovascular & 2 & OR $1.58(1.10,2.29)$ & Intervention worse \\
\hline & & & \multirow[t]{3}{*}{ Child } & Inability to sit without support at 6 months & 1 & OR $2.9(0.89,9.51)$ & NS \\
\hline & & & & Motor or speech delays & 1 & OR $1.0(0.14,7.17)$ & NS \\
\hline & & & & Autism spectrum disorder & 1 & OR $1.6(0.5,4.5)$ & NS \\
\hline & \multirow[t]{2}{*}{$\begin{array}{l}\text { Serotonin and } \\
\text { norepinephrine reuptake } \\
\text { inhibitors (SNRIs) }\end{array}$} & \multirow[t]{2}{*}{$\begin{array}{l}\text { Venlaf } \\
\text { axine } \\
\text { (late } \\
\text { pregna } \\
\text { ncy) }\end{array}$} & Perinatal & Preterm birth & 2 & OR $1.79(1.46,2.19)$ & Intervention worse \\
\hline & & & Neonatal & Neonatal withdrawal symptoms & 1 & OR $3.1(1.3,7.1)$ & Intervention worse \\
\hline \multirow{5}{*}{$\begin{array}{l}\text { Yakoob, 2013, } \\
23753416\end{array}$} & \multirow[t]{5}{*}{ Beta blockers } & \multirow[t]{5}{*}{ Any } & \multirow[t]{5}{*}{ Neonatal } & Congenital anomalies, All or major & 5 & OR $1.00(0.91,1.10)$ & NS \\
\hline & & & & Congenital anomalies, Severe hypospadias & 1 & OR $2.27(0.69,7.46)$ & NS \\
\hline & & & & Cardiovascular anomalies, Any & 4 & OR $2.01(1.18,3.42)$ & Intervention worse \\
\hline & & & & Congenital anomalies, Cleft lip or palate & 4 & OR $3.11(1.79,5.43)$ & Intervention worse \\
\hline & & & & Congenital anomalies, Neural tube defects & 3 & OR $3.56(1.19,10.7)$ & Intervention worse \\
\hline \multirow[t]{14}{*}{$\begin{array}{l}\text { Abalos, 2018, } \\
30277556\end{array}$} & \multirow[t]{9}{*}{ Beta blockers } & \multirow[t]{9}{*}{ Any } & $\begin{array}{l}\text { In utero, } \\
\text { Neonatal }\end{array}$ & $\begin{array}{l}\text { Fetal or neonatal death, including spontaneous } \\
\text { abortion }\end{array}$ & 29 & RR $0.72(0.50,1.04)$ & NS \\
\hline & & & \multirow[t]{2}{*}{ Perinatal } & Preterm birth ( <37 weeks) & 4 & RR $0.90(0.61,1.32)$ & NS \\
\hline & & & & Small for gestational age & 9 & RR $1.30(0.86,1.97)$ & NS \\
\hline & & & \multirow[t]{6}{*}{ Neonatal } & NICU admission & 3 & RR $1.07(0.82,1.41)$ & NS \\
\hline & & & & Neonatal hypoglycemia & 2 & RR $0.71(0.13,3.83)$ & NS \\
\hline & & & & Neonatal bradycardia & 2 & $\operatorname{RR} 2.20(0.68,7.16)$ & NS \\
\hline & & & & Neonatal jaundice & 1 & $\operatorname{RR} 0.53(0.19,1.47)$ & NS \\
\hline & & & & Neonatal pulmonary edema & 1 & RR $5.23(0.25,107.4)$ & NS \\
\hline & & & & Neonatal respiratory distress syndrome & 6 & RR $0.32(0.13,0.83)$ & Intervention better \\
\hline & \multirow[t]{5}{*}{ Calcium channel blockers } & \multirow[t]{5}{*}{ Any } & $\begin{array}{l}\text { In utero, } \\
\text { Neonatal }\end{array}$ & $\begin{array}{l}\text { Fetal or neonatal death, including spontaneous } \\
\text { abortion }\end{array}$ & 5 & RR $0.77(0.28,2.10)$ & NS \\
\hline & & & \multirow[t]{2}{*}{ Perinatal } & Preterm birth ( $<37$ weeks) & 4 & RR $1.01(0.86,1.18)$ & NS \\
\hline & & & & Small for gestational age & 3 & $\operatorname{RR~} 0.83(0.60,1.16)$ & NS \\
\hline & & & \multirow[t]{2}{*}{ Neonatal } & NICU admission & 3 & RR $1.18(0.87,1.62)$ & NS \\
\hline & & & & Neonatal hypoglycemia & 1 & RR $0.69(0.39,1.21)$ & NS \\
\hline
\end{tabular}




\begin{tabular}{|c|c|c|c|c|c|c|c|}
\hline $\begin{array}{c}\text { Review, Year } \\
\text { Published, } \\
\text { PMI D }\end{array}$ & Drug Class & $\begin{array}{c}\text { Drug } \\
\text { Name } \\
\text { (s) }\end{array}$ & $\begin{array}{c}\text { Timing of } \\
\text { Occurrence } \\
\text { of Adverse } \\
\text { Effect }\end{array}$ & Adverse Effect & $\begin{array}{c}\mathbf{N} \\
\text { Studies }\end{array}$ & Effect Size (95\% Cl) & Conclusion \\
\hline & & & & Neonatal jaundice & 1 & RR $0.62(0.35,1.10)$ & NS \\
\hline & & & & Neonatal respiratory distress syndrome & 1 & RR $0.20(0.01,4.06)$ & NS \\
\hline \multirow[t]{4}{*}{$\begin{array}{l}\text { Bellos, 2020a, } \\
32199925\end{array}$} & \multirow[t]{4}{*}{ Calcium channel blockers } & \multirow[t]{4}{*}{$\begin{array}{l}\text { Nifedip } \\
\text { ine }\end{array}$} & \multirow[t]{4}{*}{ Perinatal } & Gestational age at delivery & 2 & SMD -0.64 (-1.96, 0.68) & NS \\
\hline & & & & Preterm birth & 2 & OR $1.06(0.50,2.27)$ & NS \\
\hline & & & & Small for gestational age & 2 & OR $1.28(0.79,2.09)$ & NS \\
\hline & & & & Perinatal death & 2 & OR $0.71(0.34,1.49)$ & NS \\
\hline \multirow[t]{30}{*}{$\begin{array}{l}\text { Veroniki, 2017, } \\
28472982\end{array}$} & \multirow[t]{16}{*}{$\begin{array}{l}\text { Antiepileptics: Multiple } \\
\text { mechanisms }\end{array}$} & \multirow[t]{16}{*}{$\begin{array}{l}\text { Valpro } \\
\text { ate }\end{array}$} & \multirow[t]{2}{*}{ In utero } & Fetal death or spontaneous abortion & 96 & OR $1.83(1.04,3.45)$ & Intervention worse \\
\hline & & & & Fetal growth restriction & 96 & OR $1.28(0.86,1.95)$ & NS \\
\hline & & & Perinatal & Preterm birth & 96 & OR $0.96(0.65,1.37)$ & NS \\
\hline & & & \multirow[t]{8}{*}{ Neonatal } & Congenital anomalies, Major & 96 & OR $3.04(1.23,7.07)$ & Intervention worse \\
\hline & & & & Congenital anomalies, Cardiovascular & 96 & OR $1.54(0.98,2.37)$ & NS \\
\hline & & & & Congenital anomalies, Hypospadias & 96 & OR $2.58(1.24,5.76)$ & Intervention worse \\
\hline & & & & Congenital anomalies, Cleft lip/ palate & 96 & OR $3.26(1.38,7.57)$ & Intervention worse \\
\hline & & & & Congenital anomalies, Club foot & 96 & OR $3.26(1.43,8.25)$ & Intervention worse \\
\hline & & & & Congenital anomalies, Minor & 96 & OR $17.8(1.6,633.3)$ & Intervention worse \\
\hline & & & & Inguinal hernia & 96 & OR $1.64(0.39,10.02)$ & NS \\
\hline & & & & Undescended testes & 96 & OR $1.10(0.33,3.78)$ & NS \\
\hline & & & \multirow[t]{5}{*}{ Child } & Cognitive developmental delay & 96 & OR $7.40(3.00,18.46)$ & Intervention worse \\
\hline & & & & Autism/ dyspraxia & 96 & $\begin{array}{l}\text { OR 17.29 (2.40, } \\
217.6)\end{array}$ & Intervention worse \\
\hline & & & & Psychomotor developmental delay & 96 & OR $4.16(2.04,8.75)$ & Intervention worse \\
\hline & & & & Language delay & 96 & OR $7.95(1.50,49.13)$ & Intervention worse \\
\hline & & & & Attention deficit hyperactivity disorder & 96 & OR $2.84(0.82,9.99)$ & NS \\
\hline & \multirow[t]{12}{*}{$\begin{array}{l}\text { Antiepileptics: Multiple } \\
\text { mechanisms }\end{array}$} & \multirow[t]{12}{*}{$\begin{array}{l}\text { Topira } \\
\text { mate }\end{array}$} & \multirow[t]{2}{*}{ In utero } & Fetal death or spontaneous abortion & 96 & OR $23.6(1.2,549.6)$ & Intervention worse \\
\hline & & & & Fetal growth restriction & 96 & OR $2.64(1.41,4.63)$ & Intervention worse \\
\hline & & & Perinatal & Preterm birth & 96 & OR $1.38(0.73,2.35)$ & NS \\
\hline & & & \multirow[t]{7}{*}{ Neonatal } & Congenital anomalies, Major & 96 & OR $1.90(1.17,2.97)$ & Intervention worse \\
\hline & & & & Congenital anomalies, Cardiovascular & 96 & OR 0.66 (0.16. 2.11) & NS \\
\hline & & & & Congenital anomalies, Hypospadias & 96 & OR $3.52(0.77,15.72)$ & NS \\
\hline & & & & Congenital anomalies, Cleft lip/ palate & 96 & OR $6.12(1.89,19.1)$ & Intervention worse \\
\hline & & & & Congenital anomalies, Club foot & 96 & OR $1.77(0.16,11.44)$ & NS \\
\hline & & & & Inguinal hernia & 96 & OR $1.52(0.13,14.90)$ & NS \\
\hline & & & & Undescended testes & 96 & OR $0.14(0.00,2.72)$ & NS \\
\hline & & & \multirow[t]{2}{*}{ Child } & Cognitive developmental delay & 96 & OR $3.14(0.45,16.53)$ & NS \\
\hline & & & & Psychomotor developmental delay & 96 & OR $3.89(0.41,24.27)$ & NS \\
\hline & \multirow[t]{2}{*}{$\begin{array}{l}\text { Antiepileptics: Calcium } \\
\text { channel modulators }\end{array}$} & \multirow{2}{*}{$\begin{array}{l}\text { Gabap } \\
\text { entin }\end{array}$} & In utero & Fetal growth restriction & 96 & OR $1.37(0.44,3.61)$ & NS \\
\hline & & & Perinatal & Preterm birth & 96 & OR $1.93(0.88,4.05)$ & NS \\
\hline
\end{tabular}




\begin{tabular}{|c|c|c|c|c|c|c|c|}
\hline $\begin{array}{l}\text { Review, Year } \\
\text { Published, } \\
\text { PMI D }\end{array}$ & Drug Class & $\begin{array}{c}\text { Drug } \\
\text { Name } \\
\text { (s) }\end{array}$ & $\begin{array}{c}\text { Timing of } \\
\text { Occurrence } \\
\text { of Adverse } \\
\text { Effect }\end{array}$ & Adverse Effect & $\begin{array}{c}\mathbf{N} \\
\text { Studies }\end{array}$ & Effect Size (95\% Cl) & Conclusion \\
\hline & & & \multirow[t]{6}{*}{ Neonatal } & Congenital anomalies, Major & 96 & OR $1.00(0.47,1.89)$ & NS \\
\hline & & & & Congenital anomalies, Cardiovascular & 96 & OR $5.98(1.34,19.73)$ & Intervention worse \\
\hline & & & & Congenital anomalies, Hypospadias & 96 & OR $16.5(2.5,121.7)$ & Intervention worse \\
\hline & & & & Congenital anomalies, Cleft lip/palate & 96 & OR $5.14(0.16,38.06)$ & NS \\
\hline & & & & Congenital anomalies, Club foot & 96 & OR $5.55(0.01,165.50)$ & NS \\
\hline & & & & Inguinal hernia & 96 & OR $10.86(0.02,282.60)$ & NS \\
\hline & & & \multirow[t]{2}{*}{ Child } & Cognitive developmental delay & 96 & OR $1.46(0.04,13.48)$ & NS \\
\hline & & & & Psychomotor developmental delay & 96 & OR $9.03(1.00,62.78)$ & Intervention worse \\
\hline & \multirow[t]{16}{*}{$\begin{array}{l}\text { Antiepileptic: Sodium } \\
\text { channel modulators }\end{array}$} & \multirow[t]{16}{*}{$\begin{array}{l}\text { Carba } \\
\text { mazep } \\
\text { ine }\end{array}$} & \multirow[t]{2}{*}{ In utero } & Fetal death or spontaneous abortion & 96 & OR $1.25(0.73,2.36)$ & NS \\
\hline & & & & Fetal growth restriction & 96 & OR $1.15(0.77,1.67)$ & NS \\
\hline & & & Perinatal & Preterm birth & 96 & OR $1.10(0.77,1.56)$ & NS \\
\hline & & & \multirow[t]{8}{*}{ Neonatal } & Congenital anomalies, Major & 96 & OR $1.37(1.10,1.71)$ & Intervention worse \\
\hline & & & & Congenital anomalies, Cardiovascular & 96 & OR $0.93(0.62,1.43)$ & NS \\
\hline & & & & Congenital anomalies, Hypospadias & 96 & OR $1.09(0.53,2.61)$ & NS \\
\hline & & & & Congenital anomalies, Cleft lip/palate & 96 & OR $1.39(0.56,3.15)$ & NS \\
\hline & & & & Congenital anomalies, Club foot & 96 & OR $1.64(0.68,3.42)$ & NS \\
\hline & & & & Congenital anomalies, Minor & 96 & OR $10.8(1.4,373.9)$ & Intervention worse \\
\hline & & & & Inguinal hernia & 96 & OR $1.54(0.40,8.78)$ & NS \\
\hline & & & & Undescended testes & 96 & OR $0.53(0.14,1.96)$ & NS \\
\hline & & & \multirow[t]{5}{*}{ Child } & Cognitive developmental delay & 96 & OR $2.07(0.82,5.48)$ & NS \\
\hline & & & & Autism/dyspraxia & 96 & OR $5.76(0.76,73.43)$ & NS \\
\hline & & & & Psychomotor developmental delay & 96 & OR $1.68(0.85,3.41)$ & NS \\
\hline & & & & Language delay & 96 & OR $4.32(0.81,26.93)$ & NS \\
\hline & & & & Attention deficit hyperactivity disorder & 96 & OR $2.32(0.70,7.86)$ & NS \\
\hline & \multirow[t]{15}{*}{$\begin{array}{l}\text { Antiepileptic: Sodium } \\
\text { channel modulators }\end{array}$} & \multirow[t]{15}{*}{$\begin{array}{l}\text { Lamotr } \\
\text { igine }\end{array}$} & \multirow[t]{2}{*}{ In utero } & Fetal death or spontaneous abortion & 96 & OR $1.38(0.70,2.88)$ & NS \\
\hline & & & & Fetal growth restriction & 96 & OR $0.90(0.56,1.42)$ & NS \\
\hline & & & Perinatal & Preterm birth & 96 & OR $1.05(0.70,1.48)$ & NS \\
\hline & & & \multirow[t]{7}{*}{ Neonatal } & Congenital anomalies, Major & 96 & OR $0.96(0.72,1.25)$ & NS \\
\hline & & & & Congenital anomalies, Cardiovascular & 96 & OR $0.55(0.32,0.95)$ & Intervention better \\
\hline & & & & Congenital anomalies, Hypospadias & 96 & OR $0.66(0.23,2.26)$ & NS \\
\hline & & & & Congenital anomalies, Cleft lip/palate & 96 & OR $1.21(0.45,3.20)$ & NS \\
\hline & & & & Congenital anomalies, Club foot & 96 & OR $0.70(0.12,2.89)$ & NS \\
\hline & & & & Inguinal hernia & 96 & OR $0.86(0.17,5.92)$ & NS \\
\hline & & & & Undescended testes & 96 & OR $0.31(0.05,1.66)$ & NS \\
\hline & & & \multirow[t]{5}{*}{ Child } & Cognitive developmental delay & 96 & OR $0.93(0.09,5.10)$ & NS \\
\hline & & & & Autism/ dyspraxia & 96 & OR $8.88(1.28,112.0)$ & Intervention worse \\
\hline & & & & Psychomotor developmental delay & 96 & OR $1.86(0.72,4.76)$ & NS \\
\hline & & & & Language delay & 96 & OR $4.36(0.68,25.41)$ & NS \\
\hline & & & & Attention deficit hyperactivity disorder & 96 & OR $1.63(0.41,6.06)$ & NS \\
\hline
\end{tabular}




\begin{tabular}{|c|c|c|c|c|c|c|c|}
\hline $\begin{array}{l}\text { Review, Year } \\
\text { Published, } \\
\text { PMI D }\end{array}$ & Drug Class & $\begin{array}{l}\text { Drug } \\
\text { Name } \\
\text { (s) }\end{array}$ & $\begin{array}{c}\text { Timing of } \\
\text { Occurrence } \\
\text { of Adverse } \\
\text { Effect }\end{array}$ & Adverse Effect & $\begin{array}{c}\mathbf{N} \\
\text { Studies }\end{array}$ & Effect Size $(95 \% \mathrm{Cl})$ & Conclusion \\
\hline \multirow[t]{17}{*}{$\begin{array}{l}\text { Weston, 2016, } \\
27819746\end{array}$} & \multirow[t]{10}{*}{$\begin{array}{l}\text { Antiepileptics: Multiple } \\
\text { mechanisms }\end{array}$} & \multirow[t]{5}{*}{$\begin{array}{l}\text { Valpro } \\
\text { ate }\end{array}$} & \multirow[t]{5}{*}{ Neonatal } & Congenital anomalies, Skeletal or limb defects & 6 & RR $2.57(0.82,8.04)$ & NS \\
\hline & & & & Congenital anomalies, Major & $\mathrm{N} / \mathrm{A}$ & $\begin{array}{l}\text { Not extracted because } \\
\text { Veroniki } 2017 \text { reported } \\
\text { data for this harm. }\end{array}$ & $\mathrm{N} / \mathrm{A}$ \\
\hline & & & & Congenital anomalies, Neural tube defects & 6 & RR $5.30(1.05,26.7)$ & Intervention worse \\
\hline & & & & Congenital anomalies, Cardiovascular & $\mathrm{N} / \mathrm{A}$ & $\begin{array}{l}\text { Not extracted because } \\
\text { Veroniki } 2017 \text { reported } \\
\text { data for this harm. }\end{array}$ & $\mathrm{N} / \mathrm{A}$ \\
\hline & & & & Congenital anomalies, Orofacial clefts & 6 & RD $0.03(0.01,0.05)$ & Intervention worse \\
\hline & & \multirow[t]{5}{*}{$\begin{array}{l}\text { Topira } \\
\text { mate }\end{array}$} & \multirow[t]{5}{*}{ Neonatal } & Congenital anomalies, Major & $\mathrm{N} / \mathrm{A}$ & $\begin{array}{l}\text { Not extracted because } \\
\text { Veroniki } 2017 \text { reported } \\
\text { data for this harm. }\end{array}$ & N/A \\
\hline & & & & Congenital anomalies, Neural tube defects & $\mathrm{N} / \mathrm{A}$ & $\begin{array}{l}\text { Not extracted because } \\
\text { Veroniki } 2017 \text { reported } \\
\text { data for this harm. }\end{array}$ & $\mathrm{N} / \mathrm{A}$ \\
\hline & & & & Congenital anomalies, Cardiovascular & $\mathrm{N} / \mathrm{A}$ & $\begin{array}{l}\text { Not extracted because } \\
\text { Veroniki } 2017 \text { reported } \\
\text { data for this harm. }\end{array}$ & $\mathrm{N} / \mathrm{A}$ \\
\hline & & & & Congenital anomalies, Orofacial clefts & $\mathrm{N} / \mathrm{A}$ & $\begin{array}{l}\text { Not extracted because } \\
\text { Veroniki } 2017 \text { reported } \\
\text { data for this harm. }\end{array}$ & $\mathrm{N} / \mathrm{A}$ \\
\hline & & & & Congenital anomalies, Skeletal or limb defects & 1 & RR $1.10(0.05,26.45)$ & NS \\
\hline & $\begin{array}{l}\text { Antiepileptics: Calcium } \\
\text { channel modulators }\end{array}$ & $\begin{array}{l}\text { Gabap } \\
\text { entin }\end{array}$ & Neonatal & Congenital anomalies, Major & N/A & $\begin{array}{l}\text { Not extracted because } \\
\text { Veroniki } 2017 \text { reported } \\
\text { data for this harm. }\end{array}$ & N/A \\
\hline & \multirow[t]{6}{*}{$\begin{array}{l}\text { Antiepileptic: Sodium } \\
\text { channel modulators }\end{array}$} & \multirow[t]{5}{*}{$\begin{array}{l}\text { Carba } \\
\text { mazep } \\
\text { ine }\end{array}$} & \multirow[t]{5}{*}{ Neonatal } & Congenital anomalies, Neural tube defects & 7 & RR $0.91(0.15,5.61)$ & NS \\
\hline & & & & Congenital anomalies, Cardiovascular & $\mathrm{N} / \mathrm{A}$ & $\begin{array}{l}\text { Not extracted because } \\
\text { Veroniki } 2017 \text { reported } \\
\text { data for this harm. }\end{array}$ & $\mathrm{N} / \mathrm{A}$ \\
\hline & & & & Congenital anomalies, Orofacial clefts & $\mathrm{N} / \mathrm{A}$ & $\begin{array}{l}\text { Not extracted because } \\
\text { Veroniki } 2017 \text { reported } \\
\text { data for this harm. }\end{array}$ & $\mathrm{N} / \mathrm{A}$ \\
\hline & & & & Congenital anomalies, Skeletal or limb defects & 7 & RR $0.73(0.18,3.01)$ & NS \\
\hline & & & & Congenital anomalies, Major & $\mathrm{N} / \mathrm{A}$ & $\begin{array}{l}\text { Not extracted because } \\
\text { Veroniki } 2017 \text { reported } \\
\text { data for this harm. }\end{array}$ & $\mathrm{N} / \mathrm{A}$ \\
\hline & & $\begin{array}{l}\text { Lamotr } \\
\text { igine }\end{array}$ & Neonatal & Congenital anomalies, Major & $\mathrm{N} / \mathrm{A}$ & $\begin{array}{l}\text { Not extracted because } \\
\text { Veroniki } 2017 \text { reported } \\
\text { data for this harm. }\end{array}$ & $\mathrm{N} / \mathrm{A}$ \\
\hline
\end{tabular}




\begin{tabular}{|c|c|c|c|c|c|c|c|}
\hline $\begin{array}{l}\text { Review, Year } \\
\text { Published, } \\
\text { PMI D }\end{array}$ & Drug Class & $\begin{array}{l}\text { Drug } \\
\text { Name } \\
\text { (s) }\end{array}$ & $\begin{array}{c}\text { Timing of } \\
\text { Occurrence } \\
\text { of Adverse } \\
\text { Effect }\end{array}$ & Adverse Effect & $\begin{array}{c}\mathbf{N} \\
\text { Studies }\end{array}$ & Effect Size (95\% Cl) & Conclusion \\
\hline & & & & Congenital anomalies, Neural tube defects & 2 & No events & $\mathrm{N} / \mathrm{A}$ \\
\hline & & & & Congenital anomalies, Cardiovascular & $\mathrm{N} / \mathrm{A}$ & $\begin{array}{l}\text { Not extracted because } \\
\text { Veroniki } 2017 \text { reported } \\
\text { data for this harm. }\end{array}$ & $\mathrm{N} / \mathrm{A}$ \\
\hline & & & & Congenital anomalies, Orofacial clefts & $\mathrm{N} / \mathrm{A}$ & $\begin{array}{l}\text { Not extracted because } \\
\text { Veroniki } 2017 \text { reported } \\
\text { data for this harm. }\end{array}$ & $\mathrm{N} / \mathrm{A}$ \\
\hline & & & & Congenital anomalies, Skeletal or limb defects & 2 & $\operatorname{RR} 0.72(0.12,4.12)$ & NS \\
\hline \multirow[t]{3}{*}{$\begin{array}{l}\text { Enato, } 2011, \\
21272436\end{array}$} & \multirow[t]{3}{*}{ Benzodiazepines } & \multirow[t]{3}{*}{$\begin{array}{l}\text { Any } \\
\text { (First } \\
\text { trimest } \\
\text { er) }\end{array}$} & \multirow[t]{3}{*}{ Neonatal } & Congenital anomalies, Major & 9 & $\begin{array}{l}\text { Cohort studies: OR } 1.06 \\
\text { (0.91, 1.25) } \\
\text { CC studies: OR } \mathbf{3 . 0 1} \\
(\mathbf{1 . 3 2 , 6 . 8 4 )}\end{array}$ & $\begin{array}{l}\text { Cohort studies: NS } \\
\text { cC studies: } \\
\text { Intervention worse }\end{array}$ \\
\hline & & & & Congenital anomalies, Cardiovascular & 9 & $\begin{array}{l}\text { CC studies: OR } 1.27 \\
(0.69,2.32)\end{array}$ & NS \\
\hline & & & & Congenital anomalies, Oral cleft & 6 & $\begin{array}{l}\text { Cohort studies: OR } 1.19 \\
\text { (0.34, 4.15) } \\
\text { CC studies: OR } \mathbf{1 . 7 9} \\
(\mathbf{1 . 1 3}, \mathbf{2 . 8 2})\end{array}$ & $\begin{array}{l}\text { Cohort studies: NS } \\
\text { CC studies: } \\
\text { Intervention worse }\end{array}$ \\
\hline \multirow[t]{4}{*}{$\begin{array}{l}\text { Masarwa, 2018, } \\
29688261\end{array}$} & \multirow[t]{4}{*}{ Analgesic/ Antipyretic } & \multirow[t]{4}{*}{$\begin{array}{l}\text { Aceta } \\
\text { minop } \\
\text { hen }\end{array}$} & \multirow[t]{4}{*}{ Child } & Attention deficit hyperactivity disorder & 6 & RR 1.34 (1.21, 1.47) & Intervention worse \\
\hline & & & & Hyperactivity symptoms & 4 & RR $1.24(1.04,1.43)$ & Intervention worse \\
\hline & & & & Autism spectrum disorder & 5 & RR $1.19(1.14,1.25)$ & Intervention worse \\
\hline & & & & Conduct disorder & 4 & RR 1.23 (1.04, 1.42) & Intervention worse \\
\hline \multirow[t]{9}{*}{$\begin{array}{l}\text { Hammers, 2015, } \\
25448524\end{array}$} & \multirow[t]{9}{*}{ NSAIDS } & \multirow[t]{9}{*}{$\begin{array}{l}\text { Indom } \\
\text { ethaci } \\
\mathrm{n}\end{array}$} & \multirow[t]{9}{*}{ Neonatal } & Neonatal mortality & 15 & RR $1.04(0.77,1.41)$ & NS \\
\hline & & & & Sepsis & 12 & RR $1.12(0.94,1.34)$ & NS \\
\hline & & & & Patent ductus arteriosus & 17 & RR $1.14(0.97,1.35)$ & NS \\
\hline & & & & Bronchopulmonary dysplasia & 7 & RR $1.12(0.79,1.59)$ & NS \\
\hline & & & & Respiratory distress syndrome & 12 & RR $0.92(0.77,1.08)$ & NS \\
\hline & & & & Periventricular leukomalacia & 9 & RR $1.59(1.17,2.17)$ & Intervention worse \\
\hline & & & & Intraventricular hemorrhage: All Grades & 11 & RR $1.17(0.89,1.56)$ & NS \\
\hline & & & & Intraventricular hemorrhage: Grade III-IV & 16 & RR $1.29(1.06,1.56)$ & Intervention worse \\
\hline & & & & Necrotizing enterocolitis & 18 & RR $1.36(1.08,1.71)$ & Intervention worse \\
\hline \multirow[t]{2}{*}{$\begin{array}{l}\text { Chaemsaithong, } \\
2019,31494125\end{array}$} & \multirow[t]{2}{*}{ NSAIDS } & \multirow[t]{2}{*}{$\begin{array}{l}\text { Aspirin } \\
\text { (Low } \\
\text { dose, } \\
\text { First } \\
\text { trimest } \\
\text { er) }\end{array}$} & In utero & Fetal growth restriction & 8 & RR $1.06(0.58,1.95)$ & NS \\
\hline & & & Perinatal & Preterm birth $(<37 \mathrm{w})$ & 8 & RR $0.53(0.36,0.79)$ & Intervention better \\
\hline
\end{tabular}




\begin{tabular}{|c|c|c|c|c|c|c|c|}
\hline $\begin{array}{l}\text { Review, Year } \\
\text { Published, } \\
\text { PMI D }\end{array}$ & Drug Class & $\begin{array}{l}\text { Drug } \\
\text { Name } \\
(s)\end{array}$ & $\begin{array}{c}\text { Timing of } \\
\text { Occurrence } \\
\text { of Adverse } \\
\text { Effect }\end{array}$ & Adverse Effect & $\begin{array}{c}\mathbf{N} \\
\text { Studies }\end{array}$ & Effect Size (95\% CI) & Conclusion \\
\hline \multirow{4}{*}{$\begin{array}{l}\text { Henderson, 2014, } \\
24711050\end{array}$} & \multirow[t]{4}{*}{ NSAIDs } & \multirow{4}{*}{$\begin{array}{l}\text { Aspirin } \\
\text { (Low } \\
\text { dose) }\end{array}$} & In utero & Fetal intracranial hemorrhage & 10 & RR $0.84(0.61,1.16)$ & NS \\
\hline & & & Perinatal & Perinatal mortality & 18 & RR $0.92(0.76,1.11)$ & NS \\
\hline & & & Neonatal & Hospitalization & NR & NR & NS \\
\hline & & & Child & Developmental outcomes & NR & NR & NS \\
\hline \multirow[t]{2}{*}{$\begin{array}{l}\text { Coomarasamy, } \\
2003,12798543\end{array}$} & \multirow[t]{2}{*}{ NSAIDS } & \multirow[t]{2}{*}{$\begin{array}{l}\text { Aspirin } \\
\text { (Low } \\
\text { dose) }\end{array}$} & \multirow[t]{2}{*}{ Perinatal } & Preterm birth $(<37 \mathrm{w})$ & $\mathrm{N} / \mathrm{A}$ & $\begin{array}{l}\text { Not extracted because } \\
\text { Chaemsaithong } 2019 \\
\text { reported data for this } \\
\text { harm. }\end{array}$ & $\mathrm{N} / \mathrm{A}$ \\
\hline & & & & Birth weight & 8 & WMD $215 \mathrm{~g}(90,341)$ & Intervention better \\
\hline \multirow[t]{21}{*}{$\begin{array}{l}\text { Duley, 2007, } \\
17443552\end{array}$} & \multirow[t]{21}{*}{ NSAIDS } & \multirow[t]{21}{*}{$\begin{array}{l}\text { Aspirin } \\
\text { (Low } \\
\text { dose) }\end{array}$} & $\begin{array}{l}\text { In utero, } \\
\text { Perinatal }\end{array}$ & Spontaneous abortion or stillbirth & 28 & RR $0.96(0.78,1.18)$ & NS \\
\hline & & & \multirow[t]{3}{*}{ Perinatal } & Low birth weight $(<2500 \mathrm{~g}$ ) & 6 & $\operatorname{RR~} 0.93(0.83,1.05)$ & NS \\
\hline & & & & Preterm birth $(<37 \mathrm{w})$ & $\mathrm{N} / \mathrm{A}$ & $\begin{array}{l}\text { Not extracted because } \\
\text { Chaemsaithong } 2019 \\
\text { reported data for this } \\
\text { harm. }\end{array}$ & $\mathrm{N} / \mathrm{A}$ \\
\hline & & & & Small for gestational age & 36 & RR $0.90(0.83,0.98)$ & Intervention better \\
\hline & & & \multirow[t]{3}{*}{ Neonatal } & $\mathrm{NICU}$ admission & 15 & RR $0.95(0.90,1.01)$ & NS \\
\hline & & & & Intraventricular hemorrhage & 10 & RR $0.88(0.63,1.22)$ & NS \\
\hline & & & & Other neonatal bleed & 8 & RR $1.13(0.83,1.52)$ & NS \\
\hline & & & \multirow[t]{14}{*}{ Child } & Infant death (after discharge) & 3 & RR $0.53(0.21,1.34)$ & NS \\
\hline & & & & Child hospitalization (at 12 months) & 1 & RR $0.94(0.83,1.08)$ & NS \\
\hline & & & & Child hospitalization (at 18 months) & 1 & RR $0.99(0.89,1.11)$ & NS \\
\hline & & & & Poor gross motor function & 1 & $\operatorname{RR} 0.82(0.57,1.17)$ & NS \\
\hline & & & & Poor fine motor function & 1 & RR $0.98(0.84,1.14)$ & NS \\
\hline & & & & Poor language expression & 1 & RR $0.94(0.74,1.19)$ & NS \\
\hline & & & & Poor language comprehension & 1 & RR $0.95(0.80,1.13)$ & NS \\
\hline & & & & Language problems, Undefined & 1 & RR $0.99(0.69,1.42)$ & NS \\
\hline & & & & Hearing problems & 1 & RR $2.54(0.10,62.10)$ & NS \\
\hline & & & & Sight problems & 1 & RR $0.85(0.25,2.90)$ & NS \\
\hline & & & & Respiratory problems & 1 & RR $1.48(0.98,2.23)$ & NS \\
\hline & & & & Behavior problems (at 18 months) & 1 & RR $0.87(0.75,1.01)$ & NS \\
\hline & & & & Malformations (at 18 months) & 1 & RR $0.74(0.27,2.02)$ & NS \\
\hline & & & & Poor growth (at 18 months) & 2 & RR $0.94(0.84,1.07)$ & NS \\
\hline \multirow{2}{*}{$\begin{array}{l}\text { Hamulyak, 2020, } \\
32358837\end{array}$} & \multirow[t]{2}{*}{ NSAIDs } & \multirow{2}{*}{$\begin{array}{l}\text { Aspirin } \\
\text { (Low } \\
\text { dose) }\end{array}$} & \multirow[t]{2}{*}{ In utero } & Intrauterine growth restriction & 1 & RR $0.27(0.03,2.13)$ & NS \\
\hline & & & & Spontaneous abortion & 1 & RR $1.33(0.34,5.21)$ & NS \\
\hline
\end{tabular}




\begin{tabular}{|c|c|c|c|c|c|c|c|}
\hline $\begin{array}{l}\text { Review, Year } \\
\text { Published, } \\
\text { PMI D }\end{array}$ & Drug Class & $\begin{array}{l}\text { Drug } \\
\text { Name } \\
\text { (s) }\end{array}$ & $\begin{array}{c}\text { Timing of } \\
\text { Occurrence } \\
\text { of Adverse } \\
\text { Effect }\end{array}$ & Adverse Effect & $\begin{array}{c}\mathbf{N} \\
\text { Studies }\end{array}$ & Effect Size (95\% CI) & Conclusion \\
\hline & & & Perinatal & Preterm birth & 1 & OR $5.29(0.27,102.5)$ & NS \\
\hline & & & Neonatal & Adverse effects, Any & 1 & OR $1.06(0.07,15.60)$ & NS \\
\hline \multirow{5}{*}{$\begin{array}{l}\text { Kaplan, 2019, } \\
30849498\end{array}$} & \multirow{5}{*}{$\begin{array}{l}\text { Antiemetics: } 5 \mathrm{HT} 3 \\
\text { Antagonists }\end{array}$} & \multirow{5}{*}{$\begin{array}{l}\text { Ondan } \\
\text { setron }\end{array}$} & \multirow[t]{5}{*}{ Neonatal } & Congenital anomalies, Major & 2 & OR $1.21(0.56,2.58)$ & NS \\
\hline & & & & Congenital anomalies, Cardiovascular & 2 & OR $1.66(0.30,9.09)$ & NS \\
\hline & & & & Congenital anomalies, Hypospadias & 4 & OR $1.61(0.69,3.75)$ & NS \\
\hline & & & & Congenital anomalies, Genitourinary & 4 & OR $1.55(0.89,2.69)$ & NS \\
\hline & & & & Congenital anomalies, Orofacial clefts & 3 & OR $0.89(0.32,2.50)$ & NS \\
\hline \multirow{10}{*}{$\begin{array}{l}\text { Picot, 2020, } \\
32420702\end{array}$} & \multirow{10}{*}{$\begin{array}{l}\text { Antiemetics: } 5 \mathrm{HT} 3 \\
\text { Antagonists }\end{array}$} & \multirow{10}{*}{$\begin{array}{l}\text { Ondan } \\
\text { setron }\end{array}$} & \multirow[t]{10}{*}{ Neonatal } & Congenital anomalies, Major & 7 & OR $1.02(0.98,1.05)$ & NS \\
\hline & & & & Congenital anomalies, Cardiovascular (any) & 6 & OR $1.16(0.97,1.39)$ & NS \\
\hline & & & & $\begin{array}{l}\text { Congenital anomalies, Ventricular septum } \\
\text { defect }\end{array}$ & 6 & OR $1.11(1.00,1.23)$ & Intervention worse \\
\hline & & & & Congenital anomalies, Atrial septum defect & 5 & OR $1.08(0.83,1.41)$ & NS \\
\hline & & & & $\begin{array}{l}\text { Congenital anomalies, Hypoplastic left } \\
\text { heart }\end{array}$ & 3 & OR $1.49(1.03,2.17)$ & Intervention worse \\
\hline & & & & $\begin{array}{l}\text { Congenital anomalies, Orofacial clefts } \\
\text { (any) }\end{array}$ & 4 & OR $1.22(1.00,1.49)$ & Intervention worse \\
\hline & & & & Congenital anomalies, Cleft lip & 7 & OR $1.00(0.83,1.20)$ & NS \\
\hline & & & & Congenital anomalies, Cleft palate & 6 & OR $1.27(0.86,1.88)$ & NS \\
\hline & & & & $\begin{array}{l}\text { Congenital anomalies, Diaphragmatic } \\
\text { hernia }\end{array}$ & 3 & OR $1.71(1.18,2.49)$ & Intervention worse \\
\hline & & & & $\begin{array}{l}\text { Congenital anomalies, Respiratory system } \\
\text { anomalies }\end{array}$ & 2 & OR $1.13(1.01,1.27)$ & Intervention worse \\
\hline \multirow{5}{*}{$\begin{array}{l}\text { Etwel, 2017, } \\
27878468\end{array}$} & \multirow[t]{5}{*}{ Antihistamines } & \multirow[t]{5}{*}{ Any } & In utero & Spontaneous abortion & 13 & OR $1.00(0.83,1.20)$ & NS \\
\hline & & & \multirow[t]{3}{*}{ Perinatal } & Stillbirth & 8 & OR $1.23(0.48,3.18)$ & NS \\
\hline & & & & Preterm birth & 9 & OR $0.96(0.76,1.20)$ & NS \\
\hline & & & & Low birth weight & 3 & OR $1.20(0.63,2.29)$ & NS \\
\hline & & & Neonatal & Congenital anomalies, Major & 32 & OR $1.07(0.98,1.16)$ & NS \\
\hline \multirow{2}{*}{$\begin{array}{l}\text { Li, 2019, } \\
31909512\end{array}$} & \multirow[t]{2}{*}{ Antihistamines } & \multirow[t]{2}{*}{ Any } & \multirow[t]{2}{*}{ Neonatal } & Congenital anomalies, Any & 11 & OR $1.05(0.83,1.34)$ & NS \\
\hline & & & & Congenital anomalies, Hypospadias & 2 & OR $1.09(0.60,1.96)$ & NS \\
\hline \multirow[t]{2}{*}{$\begin{array}{l}\text { Park-Wyllie, 2000, } \\
11091360\end{array}$} & \multirow[t]{2}{*}{ Corticosteroids } & \multirow[t]{2}{*}{$\begin{array}{l}\text { Predni } \\
\text { solone }\end{array}$} & \multirow[t]{2}{*}{ Neonatal } & Congenital anomalies, Major & 6 & OR $1.45(0.80,2.60)$ & NS \\
\hline & & & & Congenital anomalies, Oral clefts & 4 & OR $3.35(1.97,5.69)$ & Intervention worse \\
\hline \multirow{3}{*}{$\begin{array}{l}\text { Marchenko, 2015, } \\
25644494\end{array}$} & \multirow[t]{3}{*}{ Triptans } & \multirow[t]{3}{*}{ Any } & In utero & Spontaneous abortion & 2 & OR $1.27(0.58,2.79)$ & NS \\
\hline & & & Perinatal & Preterm birth & 3 & OR $0.90(0.35,2.30)$ & NS \\
\hline & & & Neonatal & Congenital anomalies, Major & 3 & OR $0.84(0.61,1.16)$ & NS \\
\hline $\begin{array}{l}\text { Coughlin, 2015, } \\
25932852\end{array}$ & Antipsychotics & Any & In utero & Spontaneous abortion & 4 & OR $1.05(0.61,1.81)$ & NS \\
\hline
\end{tabular}




\begin{tabular}{|c|c|c|c|c|c|c|c|}
\hline $\begin{array}{l}\text { Review, Year } \\
\text { Published, } \\
\text { PMI D }\end{array}$ & Drug Class & $\begin{array}{c}\text { Drug } \\
\text { Name } \\
\text { (s) }\end{array}$ & $\begin{array}{c}\text { Timing of } \\
\text { Occurrence } \\
\text { of Adverse } \\
\text { Effect }\end{array}$ & Adverse Effect & $\begin{array}{c}\mathbf{N} \\
\text { Studies }\end{array}$ & Effect Size (95\% CI) & Conclusion \\
\hline & & & \multirow[t]{6}{*}{ Perinatal } & Stillbirth & 5 & OR $1.18(0.88,1.57)$ & NS \\
\hline & & & & Gestational age at birth & 3 & MD -0.21 w (-0.44, 0.01) & NS \\
\hline & & & & Preterm birth ( $<37$ weeks) & 7 & OR $1.86(1.45,2.39)$ & Intervention worse \\
\hline & & & & Birth weight & 3 & MD -58 g $(-103,-12)$ & Intervention worse \\
\hline & & & & Small for gestational age & 4 & OR $2.44(1.22,4.86)$ & Intervention worse \\
\hline & & & & Large for gestational age & 4 & OR $2.50(0.77,8.16)$ & NS \\
\hline & & & \multirow[t]{2}{*}{ Neonatal } & Congenital anomalies, Major & 7 & OR $2.12(1.25,3.57)$ & Intervention worse \\
\hline & & & & Congenital anomalies, Cardiovascular & 4 & OR $2.09(1.50,2.91)$ & Intervention worse \\
\hline \multirow{6}{*}{$\begin{array}{l}\text { Terrana, 2015, } \\
26274044\end{array}$} & \multirow[t]{6}{*}{ Antipsychotics } & \multirow[t]{6}{*}{ Any } & In utero & Spontaneous abortion & NR & OR $1.10(0.74,1.64)$ & NS \\
\hline & & & \multirow[t]{4}{*}{ Perinatal } & Stillbirth & NR & OR $0.79(0.22,2.83)$ & NS \\
\hline & & & & Preterm birth & $\mathrm{N} / \mathrm{A}$ & $\begin{array}{l}\text { Not extracted because } \\
\text { Coughlin } 2015 \text { reported } \\
\text { data for this harm. }\end{array}$ & $\mathrm{N} / \mathrm{A}$ \\
\hline & & & & Small for gestational age & NR & OR $1.58(0.91,2.74)$ & NS \\
\hline & & & & Large for gestational age & NR & OR $2.68(0.56,12.85)$ & NS \\
\hline & & & Neonatal & Congenital anomalies, Major & $\mathrm{N} / \mathrm{A}$ & $\begin{array}{l}\text { Not extracted because } \\
\text { Coughlin } 2015 \text { reported } \\
\text { data for this harm. }\end{array}$ & $\mathrm{N} / \mathrm{A}$ \\
\hline \multirow{5}{*}{$\begin{array}{l}\text { Makredes, 2014, } \\
24696187\end{array}$} & \multirow[t]{5}{*}{ Supplements } & \multirow{5}{*}{$\begin{array}{l}\text { Oral } \\
\text { magne } \\
\text { sium } \\
\text { sulpha } \\
\text { te }\end{array}$} & In utero & Spontaneous abortion & 6 & RR $0.85(0.49,1.49)$ & NS \\
\hline & & & \multirow[t]{2}{*}{ Perinatal } & Stillbirth & 4 & RR $0.73(0.43,1.25)$ & NS \\
\hline & & & & Low birth weight & 5 & $\operatorname{RR} 0.95(0.83,1.09)$ & NS \\
\hline & & & \multirow[t]{2}{*}{ Neonatal } & NICU admission & 3 & $\operatorname{RR} 0.74(0.50,1.11)$ & NS \\
\hline & & & & Neonatal death & 4 & RR $2.21(1.02,4.75)$ & Intervention worse \\
\hline
\end{tabular}

Abbreviations: $\mathrm{CI}=$ confidence interval, $\mathrm{CC}=$ case-control, $\mathrm{MD}=$ mean difference, $\mathrm{m}=$ months, NICU = neonatal intensive care unit, N/A = not applicable, $\mathrm{NICU}=$ neonatal intensive care unit, NR = not reported, NS = no statistically significant difference in adverse effects between intervention and control, NSAIDs = nonsteroidal antiinflammatory drugs, OR = odds ratio, PMID = PubMed identifier, RR = relative risk, SMD = standardized mean difference, $\mathrm{w}=$ weeks, WMD = weighted mean difference.

Adverse effects, effect sizes, and conclusions in bold font have effect sizes that are statistically significantly higher (at the 5\% level) in the drug arm, suggestive of harm. 


\section{Supplemental Evidence (Case Reports - Details)}

We identified 19 case reports, ${ }^{34-52}$ of which five reported on KQ 1 only, seven reported on KQ 2 only, and seven reported on both KQs. Thirteen case reports discussed intervention effects (Table B-29) and six reported on adverse effects (Table B-30).

We identified 19 case reports, ${ }^{34-52}$ of which five reported on interventions relevant to KQ 1 only, seven reported on interventions relevant to KQ 2 only, and seven reported on interventions relevant to both KQs. Thirteen case reports reported on benefit outcomes intervention effects and six on adverse effects. In the following subsections we describe the case reports and highlight (using italicized text) the interventions that were the focus of the case reports. As a reminder, we have not based our conclusions on case reports. We simply report what occurred to individual patients in terms of headache progression and adverse effects (neither of which can be ascribed to individual interventions in case reports).

\section{Case Reports Specific to Key Question 1 (Prevention of Primary Headache)}

\section{Case Reports Specific to Key Question 1: Benefits}

Four case reports described benefits of interventions intended to prevent primary headaches in pregnant patients. ${ }^{34,35,49,52}$ Two reports were of patients with migraine, ${ }^{34,47}$ one with cluster headache, ${ }^{35}$ and one with another TAC. ${ }^{52}$ Table B-29 summarizes the details of the case reports.

\section{Cases With History of Migraine}

Alcantra 2009 reported on a 24 year-old patient in her 3second week of pregnancy, who had a history of migraine headaches that had worsened since she became pregnant. ${ }^{34}$ She had been treating her headaches unsuccessfully with NSAIDs plus codeine (1,000 mg/day) and caffeine. She had also tried osteopathy and physical therapy with no improvement. The investigators described in detail starting a regimen of chiropractic care and massage therapy three times a week for 6 weeks, along with advice to drink water, avoid triggering foods, and sleep with an orthopedic pillow. The patient reported a reduction in pain on a VAS from 8 or 9 (of 10) to 2, and a reduction in headache attacks form one a day to one every 3 days, which subsequently reduced to one every 5 days. She also reported reduced use of the maximum dose of analgesics.

Robinson 2014 reported on a 26 year-old patient with a history of migraines that were not responsive to treatment, including promethazine, metoclopramide, isometheptene mucate (65 $\mathrm{mg}$ ), dichloralphenazone (100 mg) plus acetaminophen (325 mg), and a compound of butalbital, acetaminophen, and caffeine. ${ }^{49}$ She had been successfully treated with onabotulinumtoxinA before her pregnancy to prevent migraines, but this treatment was stopped when she became pregnant due to concerns about unknown risks. In her $18^{\text {th }}$ week of pregnancy, she resumed treatment because she had been having five or six headaches a week. She received a total dose of $71 \mathrm{U}$ and reported near resolution of her headaches until delivery. The investigators reported that there were no birth and early childhood short- or long-term adverse effects.

\section{Cases With History of Cluster Headache}

Asioli 2019 reported on a 25 year-old patient in her third trimester, with cluster headache, who had been using sumatriptan before pregnancy. ${ }^{35}$ The investigators describe treatment with methylprednisolone (60 mg) injected into the suboccipital area on the first, second, and fifth day 
of treatment. The patient's headache attacks reduced in frequency from four a day before treatment to two a day on the first day, one a day on the fourth day, and one a day during labor a month later.

\section{Cases With History of Other TACs}

Yalin 2018 reported on a 29 year-old patient with a history of seasonal headaches that were short-lasting, unilateral, and neuralgiform with conjunctival injection and tearing (SUNCT). ${ }^{52}$ When 30 weeks pregnant, she had a headache attack that lasted a week. She was treated with supra- and infra-orbital nerve blocks with lidocaine (10 mg), bupivacaine (5 mg), and methylprednisolone (40 mg). She gave birth to a healthy baby, was able to breastfeed successfully, and reported attacks completely diminished after the injection and did not recur through 1 year.

\section{Case Reports Specific to Key Question 1: Harms}

One case report described the harms associated with interventions for prevention of primary headache. ${ }^{51}$

Ten Berg reported on a 35 year-old patient whose fetus was detected with a cardiac defect at the 18-week ultrasound, which lead to induced abortion due to poor prognosis. The woman was taking 1,200 mg/day of valproate for her migraine; she had taken lower doses (900 mg/day) with her previous two pregnancies, which were uncomplicated.

\section{Case Reports Specific to Key Question 2 (Treatment of Primary Headache)}

\section{Case Reports Specific to Key Question 2: Benefits}

Five case reports described benefits of interventions intended to treat primary headaches in pregnant patients. ${ }^{39-41,48,50}$ Four reported on treatment in patients with migraine headaches and one in a patient with an unspecified primary headache.

Evans 2003 reported on a 38 year-old patient with migraine with aura, including three attacks in a prior pregnancy. ${ }^{40}$ She experienced nine attacks over 2 months during her second trimester of the current pregnancy. She was treated with a butalbital, acetaminophen, and caffeine compound. This resolved her migraine headache within a few hours.

Evans 2000 reported on a 25 year-old patient, 10 weeks pregnant, with migraine headaches about once a week. ${ }^{39}$ The patient had a 10-year history of migraine. The patient was treated with sumatriptan (50 mg), which gave her full headache relief.

Evans 2001 reported on a 32 year-old patient with a postpartum migraine. She had a history of bitemporal throbbing headaches, which were relieved by acetaminophen before her pregnancy. ${ }^{41}$ She reported having no headaches during her pregnancy. She was able to relieve postpartum migraine headaches with ibuprofen.

Rozen 2003 reported on a 27 year-old patient in her second trimester of pregnancy with migraine with aura. ${ }^{50}$ She was prescribed intravenous prochlorperazine and magnesium sulfate, which reduced her symptoms of aura and resolved her headache completely.

Richardson 2017 reported on a 22 year-old patient with unspecified primary postpartum headaches. ${ }^{48}$ She had been experiencing daily headaches for 2.5 weeks, since the infant was 3 days old. The headaches were not resolved with acetaminophen, ibuprofen, or caffeine. The patient was breastfeeding. Treatment with a liter of intravenous saline and $500 \mathrm{mg}$ of caffeine 
sodium benzoate over 1 hour was also not effective. She was subsequently treated with saline and ketorolac (30 mg), which reduced her pain from 6 to 7 (of 10) to 3 on a VAS.

\section{Case Reports Specific to Key Question 2: Harms}

Two case reports described the harms of interventions intended to treat primary headaches in pregnant patients. ${ }^{37,46}$

Demeriel 2012 reported on a patient (age not reported) whose an infant was born at 32 weeks' gestation and died 13 hours after birth from cardiopulmonary arrest. ${ }^{37}$ In her first trimester, the woman had experienced migraine attacks that were treated with a combination of acetaminophen, ergotamine tartrate, caffeine, and mecloxamine citrate.

Nair 2012 reported 30 year-old patient with migraine headaches that were treated with six tablets a day of a combination of acetaminophen and codeine during the second trimester of her pregnancy. ${ }^{46}$ Her infant was born with neonatal abstinence syndrome, which resolved without requiring pharmacologic therapy.

\section{Case Reports Addressing Both Key Question 1 (Prevention of Primary Headache) and Key Question 2 (Treatment of Primary Headache)}

\section{Case Reports Addressing Both Key Question 1 and Key Question 2: Benefits}

Four case reports described the effect of interventions intended to prevent and treat primary headaches in pregnant patients. ${ }^{36,38,45,47}$ Three reports were of patients with migraine headaches and one with cluster headache.

Levin 2018 reported on a 32 year-old woman with new-onset migraine in late pregnancy that initially responded to a combination of butalbital, acetaminophen, and caffeine every 4 hours; aspirin; and/or methylprednisolone once a day. ${ }^{45}$ However, this regimen was not effective for the 5 days before admission. She was treated with a sphenopalatine ganglion block. Treatment consisted of a $4 \%$ lidocaine solution administered through each nostril, repeated three times every 15 minutes. The patient did not experience immediate improvement in pain, but 4 hours later, pain (measured through a VAS) decreased from 10 (of 10) to 2. The next morning, however, the pain was 8 . The procedure was repeated. Fifteen minutes later, the pain decreased to 5.5, and 4 hours later, to 2. She was followed for 6 months and experienced no further migraine symptoms. The only adverse effect she experienced was mild discomfort from the lidocaine applicators.

Papadopoulos 2017 reported on a 28 year-old patient in her $18^{\text {th }}$ week of pregnancy with a history of migraine. ${ }^{47}$ Her headaches began 2 months earlier. The mild ones had responded to acetaminophen, water, and acupuncture, but the major ones had not. The patient was given an oral magnesium phosphate supplement for prevention and treatment (dose and frequency not reported). The patient reported no significant headaches in the first week and one debilitating migraine attack in the second week, which did not respond to extra doses of magnesium (two tablets every 2 hours up to a maximum of twelve tablets per day). For the 2 days following the debilitating attack in her second week, the patient experienced mild headaches that responded to the higher dose of magnesium. The patient reported one headache in the second through sixth weeks, the severity of which was ameliorated by taking extra doses of magnesium.

Dey 2002 reported on a 32 year-old patient with a history of migraine since puberty and progressively worsening migraines over the past 6 weeks. ${ }^{38}$ Before pregnancy, she had used acetaminophen, ibuprofen, codeine, combination analgesics, sumatriptan, verapamil, and 
propranolol with varying levels of effectiveness, but she stopped all medications upon becoming pregnant. To address the pain, she was prescribed biofeedback, relaxation, and avoidance of headache triggers, along with acetaminophen and oxycodone (subsequently hydromorphone) on an as-needed basis. She was also prescribed labetalol in increasing doses until she reported improvement in headache frequency and intensity. Before treatment, she reported headaches 5 days per week with pain between 6 and 10 (of 10) on a VAS. After a week on labetalol, she reported headaches 3 days per week with pain at 5 on the VAS. Her requirement for hydromorphone was also reduced from 8 to $10 \mathrm{mg}$ to 2 to $4 \mathrm{mg}$ per migraine attack. She delivered a healthy baby.

De Coo 2016 reported on a 32 year-old woman with cluster headache, who had been using sumatriptan to control her headaches from preconception through 4 weeks after delivery. ${ }^{36}$ The investigators implanted an occipital nerve stimulation device 18 months the woman became pregnant. After device implantation, the attack frequency decreased from nine per week to one per week. During pregnancy, the frequency of her attacks further reduced to one every 2 weeks. She eliminated sumatriptan use in the first trimester and used it only once in her second trimester. The device battery was not recharged at 35 weeks, and the patient's attack frequency increased to one per day, which did not decline until birth. The patient resumed sumatriptan use for acute attacks after birth and did not breastfeed. She became attack free again at 4 weeks after birth. Acute attacks were treated with oxygen and, when that was not successful, sumatriptan.

\section{Case Reports Addressing Both Key Question 1 and Key Question 2: Harms}

Three case reports described the harms of interventions intended to prevent and treat primary headaches in pregnant patients. ${ }^{42-44}$

Haaland 2010 reported on a 35 year-old woman with migraine who previously had a missed abortion and subsequently a baby with renal tubular dysgenesis, hypoplasia of the skull and the lungs, and hyaline membranes of the lungs. The patient was receiving candesartan (1 mg/day), pramipexole (0.18 mg/3x), and amitriptyline (25 mg/day) as migraine prevention, and zolmitriptan (dose not reported) and metoclopramide (dose not reported) as treatment during attacks. $^{42}$

In the other two case reports (Hughes $1988^{43}$ and Kajantie $2004^{44}$ ), pharmaceutical treatments for migraine prevention or treatment were associated with fetal deformations. Hughes 1988 reported on a patient (age not reported) with severe migraine headaches that were treated with acetaminophen, codeine, propranolol, ergotamine, and caffeine during pregnancy. ${ }^{43}$ The fetus had severe malformations, including arrested cerebral maturation, and the baby girl had paraplegia. Kajantie 2004 reported on a 24 year-old patient who suffered from recurrent migraines that were treated with bisoprolol, naproxen, and sumatriptan through the first weeks of pregnancy and acetaminophen thereafter until birth. ${ }^{44}$ Her infant had birth defects, including bilateral cleft lip and palate, marked hypertelorism, a broad nose, and a bilateral, asymmetric hypoplasia of the toes. 
Table B-29. Case reports addressing treatment effects

\begin{tabular}{|c|c|c|c|c|c|c|c|c|c|c|}
\hline KQ & $\begin{array}{l}\text { Study, } \\
\text { Year, } \\
\text { PMID, } \\
\text { Country }\end{array}$ & $\begin{array}{c}\text { Age } \\
\text { (years) }\end{array}$ & $\begin{array}{l}\text { Phase at } \\
\text { Beginning } \\
\text { of } \\
\text { Intervention }\end{array}$ & $\begin{array}{l}\text { Type of } \\
\text { Headache }\end{array}$ & $\begin{array}{l}\text { Intervention } \\
\text { Type }\end{array}$ & $\begin{array}{l}\text { Intervention } \\
\text { Class }\end{array}$ & Intervention & $\begin{array}{l}\text { Follow- } \\
\text { up Time }\end{array}$ & $\begin{array}{l}\text { Headache } \\
\text { Results }\end{array}$ & Birth Results \\
\hline 1 & $\begin{array}{l}\text { Alcantara, } \\
2009, \\
19880080, \\
\text { Canada }\end{array}$ & 24 & $\begin{array}{l}\text { Third } \\
\text { trimester }\end{array}$ & $\begin{array}{r}\text { Migraine } \\
\text { headache }\end{array}$ & Nonpharm & $\begin{array}{l}\text { - Chiropractic } \\
\text { therapy } \\
\text { - Hydration } \\
\text { therapy } \\
\text { - Complement } \\
\text { ary therapies }\end{array}$ & $\begin{array}{l}\text { - Chiropractic } \\
\text { care (spinal } \\
\text { manipulative } \\
\text { therapy, } 3 \\
\text { times/week for } \\
6 \text { weeks) } \\
\text { - Water } \\
\text { - Massage and } \\
\text { trigger point } \\
\text { therapy, Sleep } \\
\text { posture, } \\
\text { Orthopedic } \\
\text { pillow } \\
\text { - Avoidance of } \\
\text { triggering } \\
\text { foods }\end{array}$ & Delivery & $\begin{array}{l}\text { - Decrease in } \\
\text { headache } \\
\text { frequency from } \\
1 \text { attack/day to } \\
1 \text { attack/3 days } \\
\text { - Pain VAS : } \\
\text { reduced from } \\
\text { 8-9/10 to } 2 / 10\end{array}$ & \\
\hline 1 & $\begin{array}{l}\text { Robinson, } \\
2014, \\
24902141, \\
\text { U.S. }\end{array}$ & 26 & $\begin{array}{l}\text { Second } \\
\text { trimester }\end{array}$ & $\begin{array}{r}\text { Migraine } \\
\text { headache }\end{array}$ & Nonpharm & $\begin{array}{l}\text { - Chemodener } \\
\text { vation }\end{array}$ & $\begin{array}{l}\text { - Onabotulinumt } \\
\text { oxinA }(71 \mathrm{U})\end{array}$ & Delivery & $\begin{array}{l}\text { Near } \\
\text { resolution }\end{array}$ & $\begin{array}{l}\text { Normal fetal } \\
\text { movements throughout } \\
\text { the pregnancy; no } \\
\text { notable intrauterine } \\
\text { growth restriction; } 1 / 5 \\
\text { minute Apgar score of } \\
1 / 9, \text { respectively, had } \\
\text { vigorous muscular } \\
\text { movements with good } \\
\text { tone, required no } \\
\text { special care, and was } \\
\text { discharged home the } \\
\text { same day. A review of } \\
\text { the child's medical } \\
\text { charts from } 07 / 2007 \\
\text { through 09/2013 was } \\
\text { notable for normal } \\
\text { neuromuscular } \\
\text { development with all } \\
\text { developmental }\end{array}$ \\
\hline
\end{tabular}




\begin{tabular}{|c|c|c|c|c|c|c|c|c|c|c|}
\hline KQ & $\begin{array}{l}\text { Study, } \\
\text { Year, } \\
\text { PMID, } \\
\text { Country }\end{array}$ & $\begin{array}{c}\text { Age } \\
\text { (years) }\end{array}$ & $\begin{array}{c}\text { Phase at } \\
\text { Beginning } \\
\text { of } \\
\text { Intervention }\end{array}$ & $\begin{array}{c}\text { Type of } \\
\text { Headache }\end{array}$ & $\begin{array}{c}\text { Intervention } \\
\text { Type }\end{array}$ & $\begin{array}{c}\text { Intervention } \\
\text { Class }\end{array}$ & Intervention & $\begin{array}{l}\text { Follow- } \\
\text { up Time }\end{array}$ & $\begin{array}{l}\text { Headache } \\
\text { Results }\end{array}$ & Birth Results \\
\hline & & & & & & & & & & $\begin{array}{l}\text { milestones being met } \\
\text { as expected with no } \\
\text { evidence or concern }\end{array}$ \\
\hline 1 & $\begin{array}{l}\text { Asioli, } \\
2019, \\
3116401, \\
\text { Italy }\end{array}$ & 25 & $\begin{array}{l}\text { Third } \\
\text { trimester }\end{array}$ & $\begin{array}{c}\text { Cluster } \\
\text { headache }\end{array}$ & Pharm & $\begin{array}{l}\text { - Corticosteroi } \\
\text { ds (Medium } \\
\text { anti- } \\
\text { inflammatory } \\
\text { potency) }\end{array}$ & $\begin{array}{l}\text { - Methylpredniso } \\
\text { lone (60 mg, } \\
\text { slow-release in } \\
3 \text { injections: } \\
\text { first, third, and } \\
\text { fifth day) }\end{array}$ & $\begin{array}{l}\text { Infant } 6 \\
\text { months } \\
\text { old }\end{array}$ & $\begin{array}{l}\text { - } 2 \text { attacks } 1 \\
\text { day after first } \\
\text { treatment; } 1 \\
\text { attack } 4 \text { days } \\
\text { after first } \\
\text { treatment; } 1 \\
\text { attack during } \\
\text { labor; Clinical } \\
\text { control } 10 \\
\text { months after } \\
\text { the birth } \\
\text { proved no } \\
\text { recurrence of } \\
\text { attacks }\end{array}$ & $\begin{array}{l}\text { Newborn was healthy } \\
\text { and no birth defects } \\
\text { were reported }\end{array}$ \\
\hline 1 & $\begin{array}{l}\text { Yalin, } \\
2018, \\
29450873, \\
\text { Turkey }\end{array}$ & 29 & $\begin{array}{l}\text { Third } \\
\text { trimester }\end{array}$ & $\begin{array}{l}\text { Other } \\
\text { TACs }\end{array}$ & Nonpharm & - Nerve blocks & $\begin{array}{l}\text { - Supra- and } \\
\text { infraorbital } \\
\text { nerve block }\end{array}$ & Weaning & $\begin{array}{l}\text { - Attacks } \\
\text { diminished } \\
\text { after the first } \\
\text { injection, and } \\
\text { recurrence } \\
\text { was not } \\
\text { observed for } \\
1 \text { year }\end{array}$ & $\begin{array}{l}\text { Delivered a healthy } \\
\text { baby girl, and the } \\
\text { delivery was } \\
\text { uneventful }\end{array}$ \\
\hline $\begin{array}{l}1 \& \& \\
2\end{array}$ & $\begin{array}{l}\text { Levin, } \\
\text { 2018, } \\
\text { 29634560, } \\
\text { U.S. }\end{array}$ & 32 & $\begin{array}{l}\text { Third } \\
\text { trimester }\end{array}$ & $\begin{array}{r}\text { Migraine } \\
\text { headache }\end{array}$ & Nonpharm & - Nerve blocks & $\begin{array}{l}\text { - Sphenopalatin } \\
\text { e ganglion } \\
\text { block }(0.5 \mathrm{~mL} \text { of } \\
4 \% \text { lidocaine } \\
\text { solution; } 3 \\
\text { times } / 15 \\
\text { minutes) }\end{array}$ & $\begin{array}{l}\text { Infant } 5 \\
\text { months } \\
\text { old }\end{array}$ & $\begin{array}{l}\text { - } 4 \text { hours after } \\
\text { first dose VAS } \\
\text { decreased to } \\
2 \text { of } 10 ; \text { next } \\
\text { morning VAS } \\
\text { was } 8 \text { of } 10 \\
\text { - } 15 \text { minutes } \\
\text { after second } \\
\text { treatment } \\
\text { later, the pain } \\
\text { (VAS) } \\
\text { decreased to } \\
5.5 \text { of } 10, \text { and }\end{array}$ & \\
\hline
\end{tabular}




\begin{tabular}{|c|c|c|c|c|c|c|c|c|c|c|}
\hline KQ & $\begin{array}{l}\text { Study, } \\
\text { Year, } \\
\text { PMID, } \\
\text { Country }\end{array}$ & $\begin{array}{c}\text { Age } \\
\text { (years) }\end{array}$ & $\begin{array}{c}\text { Phase at } \\
\text { Beginning } \\
\text { of } \\
\text { Intervention }\end{array}$ & $\begin{array}{c}\text { Type of } \\
\text { Headache }\end{array}$ & $\begin{array}{c}\text { Intervention } \\
\text { Type }\end{array}$ & $\begin{array}{l}\text { Intervention } \\
\text { Class }\end{array}$ & Intervention & $\begin{array}{l}\text { Follow- } \\
\text { up Time }\end{array}$ & $\begin{array}{l}\text { Headache } \\
\text { Results }\end{array}$ & Birth Results \\
\hline & & & & & & & & & $\begin{array}{l}4 \text { hours later } \\
\text { to } 2 \text { of } 10 \\
\text { - At } 6 \text { months } \\
\text { no return of } \\
\text { migraine } \\
\text { symptoms. }\end{array}$ & \\
\hline $\begin{array}{l}1 \& \\
2 \&\end{array}$ & $\begin{array}{l}\text { Papadopo } \\
\text { ulos, } \\
2017 \text {, No } \\
\text { PMID, } \\
\text { Australia }\end{array}$ & 28 & $\begin{array}{l}\text { Second } \\
\text { trimester }\end{array}$ & $\begin{array}{r}\text { Migraine } \\
\text { headache }\end{array}$ & Nonpharm & $\begin{array}{l}\text { - Oral } \\
\text { magnesium }\end{array}$ & $\begin{array}{l}\text { - Magnesium } \\
\text { sulfate (low } \\
\text { elemental } \\
\text { dose) }\end{array}$ & $\begin{array}{l}17 \text { weeks } \\
\text { pregnanc } \\
y\end{array}$ & $\begin{array}{l}\text { - No significant } \\
\text { headaches in } \\
\text { first week; } \\
\text { one } \\
\text { debilitating } \\
\text { migraine in } \\
\text { second week, } \\
\text { did not } \\
\text { respond to } \\
\text { extra doses of } \\
\text { the } \\
\text { magnesium } \\
\text { supplement } \\
\text { (two tablets } \\
\text { every two } \\
\text { hours up to a } \\
\text { maximum of } \\
\text { twelve tablets } \\
\text { per day). For } \\
\text { the following } \\
\text { two days she } \\
\text { experienced } \\
\text { mild } \\
\text { headaches } \\
\text { which did } \\
\text { respond to a } \\
\text { higher dose of } \\
\text { magnesium; } \\
\text { one headache } \\
\text { in third to } \\
\text { sixth weeks, } \\
\text { the severity of } \\
\text { which was }\end{array}$ & \\
\hline
\end{tabular}




\begin{tabular}{|c|c|c|c|c|c|c|c|c|c|c|}
\hline KQ & $\begin{array}{l}\text { Study, } \\
\text { Year, } \\
\text { PMID, } \\
\text { Country }\end{array}$ & $\begin{array}{c}\text { Age } \\
\text { (years) }\end{array}$ & $\begin{array}{c}\text { Phase at } \\
\text { Beginning } \\
\text { of } \\
\text { Intervention }\end{array}$ & $\begin{array}{l}\text { Type of } \\
\text { Headache }\end{array}$ & $\begin{array}{c}\text { Intervention } \\
\text { Type }\end{array}$ & $\begin{array}{c}\text { Intervention } \\
\text { Class }\end{array}$ & Intervention & $\begin{array}{l}\text { Follow- } \\
\text { up Time }\end{array}$ & $\begin{array}{l}\text { Headache } \\
\text { Results }\end{array}$ & Birth Results \\
\hline & & & & & & & & & $\begin{array}{l}\text { ameliorated } \\
\text { by taking } \\
\text { extra doses of } \\
\text { magnesium }\end{array}$ & \\
\hline $\begin{array}{l}1 \& \\
2\end{array}$ & $\begin{array}{l}\text { Dey, } \\
2002, \\
1242217, \\
\text { U.S. }\end{array}$ & 32 & $\begin{array}{l}\text { Second } \\
\text { trimester }\end{array}$ & $\begin{array}{l}\text { Migraine } \\
\text { headache }\end{array}$ & Pharm & $\begin{array}{l}\text { - Opioid- } \\
\text { containing } \\
\text { analgesics } \\
\text { - Beta } \\
\text { blockers }\end{array}$ & $\begin{array}{l}\text { - Hydromorphon } \\
\text { e (8-10 mg, as } \\
\text { needed for } 6 \\
\text { weeks) } \\
\text { - Labetalol (150 } \\
\text { mg 2/day for } 6 \\
\text { weeks) }\end{array}$ & Delivery & $\begin{array}{l}\text { Pain VAS: } 6-10 \\
\text { of } 10 \text { at } 24 \\
\text { weeks } \\
5 \text { of } 10 \text { at } 25 \\
\text { weeks }\end{array}$ & $\begin{array}{l}\text { LFTs, fetal and } \\
\text { obstetrical parameters } \\
\text { within normal limits. } \\
\text { Healthy baby at } 38 \\
\text { weeks. }\end{array}$ \\
\hline $2^{1 \&}$ & $\begin{array}{l}\text { De Coo, } \\
2016, \\
25834272, \\
\text { Netherlan } \\
\text { ds }\end{array}$ & 32 & $\begin{array}{l}\text { Preconcepti } \\
\text { on }\end{array}$ & $\begin{array}{l}\text { Cluster } \\
\text { headache }\end{array}$ & Nonpharm & - Nerve Blocks & $\begin{array}{l}\text { - Occipital nerve } \\
\text { stimulation }\end{array}$ & $\begin{array}{l}\text { Infant } 4 \\
\text { weeks } \\
\text { old }\end{array}$ & $\begin{array}{l}\text { Second } \\
\text { trimester } 1 \\
\text { attack/2weeks; } \\
\text { third trimester } 1 \\
\text { attack/6 weeks; } \\
\text { postpartum } 1 \\
\text { day frequent } \\
\text { severe attacks; } \\
\text { attack-free after } \\
4 \text { weeks }\end{array}$ & $\begin{array}{l}\text { parturition was } \\
\text { uncomplicated except } \\
\text { for a surgical removal } \\
\text { of the placenta; baby } \\
\text { made a good start and } \\
\text { did not have any birth } \\
\text { defects }\end{array}$ \\
\hline $2^{1 \&}$ & $\begin{array}{l}\text { De Coo, } \\
2016, \\
25834272, \\
\text { Netherlan } \\
\text { ds }\end{array}$ & 32 & $\begin{array}{l}\text { Preconcepti } \\
\text { on }\end{array}$ & $\begin{array}{l}\text { Cluster } \\
\text { headache }\end{array}$ & Pharm & $\begin{array}{l}\text { - Triptans/Serot } \\
\text { onin receptor } \\
\text { agonists }\end{array}$ & - Sumatriptan & $\begin{array}{l}\text { Infant } 4 \\
\text { weeks } \\
\text { old }\end{array}$ & $\begin{array}{l}\text { Successful } \\
\text { acute } \\
\text { treatment; once } \\
\text { during } \\
\text { pregnancy and } \\
\text { once } \\
\text { postpartum } \\
\text { (breastfeeding } \\
\text { suspended) }\end{array}$ & \\
\hline $2^{1 \&}$ & $\begin{array}{l}\text { De Coo, } \\
2016, \\
25834272, \\
\text { Netherlan } \\
\text { ds }\end{array}$ & 32 & $\begin{array}{l}\text { Preconcepti } \\
\text { on }\end{array}$ & $\begin{array}{l}\text { Cluster } \\
\text { headache }\end{array}$ & Nonpharm & $\begin{array}{r}\text { - Oxygen } \\
\text { therapy }\end{array}$ & $\begin{array}{c}\text { - Oxygen (9 } \\
\text { L/min) }\end{array}$ & $\begin{array}{l}\text { Infant } 4 \\
\text { weeks } \\
\text { old }\end{array}$ & $\begin{array}{l}\text { Successful } \\
\text { acute } \\
\text { treatment; until } \\
\text { the day after } \\
\text { birth }\end{array}$ & \\
\hline 2 & $\begin{array}{l}\text { Evans, } \\
2003, \\
12864766, \\
\text { U.S. }\end{array}$ & 38 & $\begin{array}{l}\text { Second } \\
\text { trimester }\end{array}$ & $\begin{array}{r}\text { Migraine } \\
\text { headache }\end{array}$ & $\begin{array}{c}\text { Pharm + } \\
\text { nonpharm }\end{array}$ & $\begin{array}{l}\text { - Butalbital- } \\
\text { containing } \\
\text { analgesics } \\
\text { - Sleep therapy }\end{array}$ & $\begin{array}{l}\text { - Butalbital, } \\
\text { acetaminophen } \\
\text {, caffeine } \\
\text { compound }\end{array}$ & $\begin{array}{l}28 \\
\text { weeks } \\
\text { pregnan } \\
\text { cy }\end{array}$ & $\begin{array}{l}\text { Resolution after } \\
\text { a few hours }\end{array}$ & \\
\hline
\end{tabular}




\begin{tabular}{|c|c|c|c|c|c|c|c|c|c|c|}
\hline KQ & $\begin{array}{l}\text { Study, } \\
\text { Year, } \\
\text { PMID, } \\
\text { Country }\end{array}$ & $\begin{array}{c}\text { Age } \\
\text { (years) }\end{array}$ & $\begin{array}{c}\text { Phase at } \\
\text { Beginning } \\
\text { of } \\
\text { Intervention }\end{array}$ & $\begin{array}{c}\text { Type of } \\
\text { Headache }\end{array}$ & $\begin{array}{c}\text { Intervention } \\
\text { Type }\end{array}$ & $\begin{array}{c}\text { Intervention } \\
\text { Class }\end{array}$ & Intervention & $\begin{array}{l}\text { Follow- } \\
\text { up Time }\end{array}$ & $\begin{array}{l}\text { Headache } \\
\text { Results }\end{array}$ & Birth Results \\
\hline & & & & & & & - Sleep therapy & & & \\
\hline 2 & $\begin{array}{l}\text { Evans, } \\
2000, \\
11135034, \\
\text { U.S. }\end{array}$ & 25 & $\begin{array}{l}\text { Preconcepti } \\
\text { on }\end{array}$ & $\begin{array}{c}\text { Migraine } \\
\text { headache }\end{array}$ & Pharm & $\begin{array}{l}\text { Triptans/Serot } \\
\text { onin receptor } \\
\text { agonists }\end{array}$ & $\begin{array}{l}\text { - Sumatriptan } \\
\text { (50 mg) }\end{array}$ & NR & Complete relief & \\
\hline 2 & $\begin{array}{l}\text { Evans, } \\
2001, \\
11554965, \\
\text { U.S. }\end{array}$ & 35 & Postpartum & $\begin{array}{c}\text { Migraine } \\
\text { headache }\end{array}$ & Pharm & - NSAIDS & - Ibuprofen & NR & $\begin{array}{l}\text { Decreased but } \\
\text { did not resolve } \\
\text { headache }\end{array}$ & \\
\hline 2 & $\begin{array}{l}\text { Rozen, } \\
2003, \\
12940813, \\
\text { U.S. }\end{array}$ & 27 & $\begin{array}{l}\text { Second } \\
\text { trimester }\end{array}$ & $\begin{array}{c}\text { Migraine } \\
\text { headache }\end{array}$ & $\begin{array}{c}\text { Pharm + } \\
\text { nonpharm }\end{array}$ & $\begin{array}{l}\text { - Antiemetics: } \\
\text { Dopamine } \\
\text { receptor } \\
\text { antagonists } \\
\text { - Oral } \\
\text { magnesium }\end{array}$ & $\begin{array}{l}\text { - Prochlorperazi } \\
\text { ne } \\
\text { - Magnesium } \\
\text { sulfate }\end{array}$ & NR & $\begin{array}{l}\text { Complete } \\
\text { resolution }\end{array}$ & \\
\hline 2 & $\begin{array}{l}\text { Richardso } \\
\text { n, 2017, } \\
29095177, \\
\text { U.S. }\end{array}$ & 22 & Postpartum & NR & $\begin{array}{c}\text { Pharm + } \\
\text { nonpharm }\end{array}$ & $\begin{array}{l}\text { - NSAIDS } \\
\text { - Hydration } \\
\text { therapy }\end{array}$ & $\begin{array}{l}\text { - Ketorolac (30 } \\
\text { mg, IV) } \\
\text { - } \mathrm{NaCl} \mathrm{0.9 \%} \\
(125 \mathrm{ml} / \mathrm{hr}, \mathrm{IV})\end{array}$ & NR & $\begin{array}{l}\text { Pain VAS } \\
\text { decreased to } \\
3 / 10\end{array}$ & \\
\hline
\end{tabular}

Abbreviations: CNS = central nervous system; hr = hour, IV = intravenous, LFT = liver function test, Nonpharm = nonpharmacologic NR = not reported, NSAID = nonsteroidal anti-inflammatory drug, Pharm = pharmacologic, PMID = PubMed identifier, TAC = trigeminal autonomic cephalgia, VAS $=$ visual analog scale 
Table B-30. Case reports addressing adverse effects

\begin{tabular}{|c|c|c|c|c|c|c|c|c|c|}
\hline KQ & $\begin{array}{l}\text { Study, Year, } \\
\text { PMID, Country }\end{array}$ & $\begin{array}{c}\text { Age } \\
\text { (years) }\end{array}$ & $\begin{array}{l}\text { Phase at } \\
\text { Beginning of } \\
\text { Intervention }\end{array}$ & $\begin{array}{l}\text { Type of } \\
\text { Headache }\end{array}$ & $\begin{array}{l}\text { Interventi } \\
\text { on Type }\end{array}$ & $\begin{array}{c}\text { Drug/Intervention } \\
\text { Class }\end{array}$ & Interventions & $\begin{array}{l}\text { Follow-up } \\
\text { Time }\end{array}$ & Adverse Effect \\
\hline 1 & $\begin{array}{l}\text { Ten Berg, 2005, } \\
\text { 15712340, } \\
\text { Netherlands }\end{array}$ & 35 & Preconception & $\begin{array}{l}\text { Migraine } \\
\text { headache }\end{array}$ & Pharm & - Antiepileptic drugs & $\begin{array}{l}\text { Valproate (1200 } \\
\text { mg/day in two } \\
\text { equal dosages) }\end{array}$ & Termination & $\begin{array}{l}\text { A fetal cardiac defect with a } \\
\text { hypoplastic right ventricle and } \\
\text { anomaly of the ascending } \\
\text { aorta. Due to poor prognosis } \\
\text { pregnancy was terminated at } \\
203 / 7 \text { weeks. }\end{array}$ \\
\hline $1 \& 2$ & $\begin{array}{l}\text { Haaland, 2010, } \\
20063032, \\
\text { Norway }\end{array}$ & 35 & Preconception & $\begin{array}{l}\text { Migraine } \\
\text { headache }\end{array}$ & Pharm & $\begin{array}{l}\text { - Renin- } \\
\text { angiotensin- } \\
\text { aldosterone } \\
\text { system inhibitors } \\
\text { - Tricyclic } \\
\text { antidepressants } \\
\end{array}$ & $\begin{array}{l}\text { - Candesartan (16 } \\
\text { mg/day) } \\
\text { - pramipexole } \\
\text { (0.18mg/3x) } \\
\text { - Amitriptyline (25 } \\
\text { mg/day) }\end{array}$ & Termination & Miscarriage \\
\hline $1 \& 2$ & $\begin{array}{l}\text { Haaland, 2010, } \\
20063032, \\
\text { Norway }\end{array}$ & 35 & Preconception & $\begin{array}{l}\text { Migraine } \\
\text { headache }\end{array}$ & Pharm & $\begin{array}{l}\text { - Triptans/Serotoni } \\
\mathrm{n} \text { receptor } \\
\text { agonists } \\
\text { - Dopamine } \\
\text { receptor } \\
\text { antagonists } \\
\end{array}$ & $\begin{array}{l}\text { Zolmitriptan } \\
\text { - Metoclopramide } \\
\text { (during attacks) }\end{array}$ & Termination & Miscarriage \\
\hline $1 \& 2$ & $\begin{array}{l}\text { Hughes, 1988, } \\
\text { 3398007, } \\
\text { Canada }\end{array}$ & NR & Preconception & $\begin{array}{l}\text { Migraine } \\
\text { headache }\end{array}$ & Pharm & $\begin{array}{l}\text { - Analgesics/Antipy } \\
\text { retics } \\
\text { - Opioid-containing } \\
\text { analgesics } \\
\text { - Beta blockers } \\
\text { - Ergotamine } \\
\text { - CNS stimulants }\end{array}$ & $\begin{array}{l}\text { - Acetaminophen } \\
\text { (325 mg; 6- } \\
\text { 20/day) } \\
\text { - Codeine (8 mg; } \\
\text { 6-20/day) } \\
\text { - Propranolol } \\
\text { (40mg 2/day) } \\
\text { - Ergotamine } \\
\text { (2mg 1-4/week) } \\
\text { - Caffeine (100mg } \\
\text { 1-4/week) }\end{array}$ & $\begin{array}{l}20 \text { weeks } \\
\text { pregnancy }\end{array}$ & $\begin{array}{l}\text { Infant was clinically } \\
\text { microcephalic with a head } \\
\text { circumference of } 31 \mathrm{~cm} \text { and } \\
\text { the anterior fontanelle was } \\
\text { almost closed. Infant was } \\
\text { paraplegic with } \\
\text { underdeveloped and } \\
\text { hypotonic lower limbs. The } \\
\text { anal, knee, and ankle reflexes } \\
\text { were absent. Sensation was } \\
\text { absent up to the level of the } \\
\text { knees and it was variably } \\
\text { absent on the thighs. The } \\
\text { findings suggested a spinal } \\
\text { cord abnormality and it was } \\
\text { estimated to be in the upper } \\
\text { lumbar region. Both hips were } \\
\text { dislocated and there was a } \\
\text { marked equinovarus } \\
\text { deformity bilaterally. }\end{array}$ \\
\hline
\end{tabular}




\begin{tabular}{|c|c|c|c|c|c|c|c|c|c|}
\hline KQ & $\begin{array}{c}\text { Study, Year, } \\
\text { PMID, Country }\end{array}$ & $\begin{array}{c}\text { Age } \\
\text { (years) }\end{array}$ & $\begin{array}{l}\text { Phase at } \\
\text { Beginning of } \\
\text { Intervention }\end{array}$ & $\begin{array}{l}\text { Type of } \\
\text { Headache }\end{array}$ & $\begin{array}{l}\text { Interventi } \\
\text { on Type }\end{array}$ & $\begin{array}{c}\text { Drug/Intervention } \\
\text { Class }\end{array}$ & Interventions & $\begin{array}{l}\text { Follow-up } \\
\text { Time }\end{array}$ & Adverse Effect \\
\hline $1 \& 2$ & $\begin{array}{l}\text { Kajantie, 2004, } \\
\text { 15194960, } \\
\text { Finland }\end{array}$ & 24 & NR & $\begin{array}{l}\text { Migraine } \\
\text { headache }\end{array}$ & Pharm & $\begin{array}{l}\text { - } \text { Beta blockers } \\
\text { - NSAIDs } \\
\text { - Triptans/Serotonin } \\
\text { receptor agonists }\end{array}$ & $\begin{array}{l}\text { - } \text { Bisoprolol } \\
\text { - Naproxen } \\
\text { - Sumatriptan }\end{array}$ & $\begin{array}{l}\text { Through fifth } \\
\text { premenstrua } \\
\text { I week }\end{array}$ & $\begin{array}{l}\text { Wide bilateral cleft lip and } \\
\text { palate, marked hypertelorism } \\
\text { and a broad nose; bilateral, } \\
\text { asymmetric toe abnormalities }\end{array}$ \\
\hline $1 \& 2$ & $\begin{array}{l}\text { Kajantie, 2004, } \\
\text { 15194960, } \\
\text { Finland }\end{array}$ & 24 & NR & $\begin{array}{l}\text { Migraine } \\
\text { headache }\end{array}$ & Pharm & $\begin{array}{l}\text { - Over-the-counter } \\
\text { analgesics }\end{array}$ & - Acetaminophen & Until delivery & $\begin{array}{l}\text { Wide bilateral cleft lip and } \\
\text { palate, marked hypertelorism } \\
\text { and a broad nose; bilateral, } \\
\text { asymmetric toe abnormalities }\end{array}$ \\
\hline 2 & $\begin{array}{l}\text { Demirel, 2012, } \\
\text { 22417229, } \\
\text { Turkey }\end{array}$ & NR & First trimester & $\begin{array}{l}\text { Migraine } \\
\text { headache }\end{array}$ & Pharm & $\begin{array}{l}\text { - Over-the-counter } \\
\text { analgesics }\end{array}$ & $\begin{array}{l}\text { - Acetaminophen } \\
325 \mathrm{mg}, \\
\text { ergotamine } \\
\text { tartrate } 0.75 \mathrm{mg} \text {, } \\
\text { caffeine } 80 \mathrm{mg} \text {, } \\
\text { and } \\
\text { mecloxamine } \\
\text { citrate } 20 \mathrm{mg} \\
\text { combination }\end{array}$ & $\begin{array}{l}\text { weeks } \\
\text { pregnancy }\end{array}$ & $\begin{array}{l}\text { Infant death: } 13 \text { hours after } \\
\text { birth from cardiopulmonary } \\
\text { arrest }\end{array}$ \\
\hline 2 & $\begin{array}{l}\text { Nair, 2012, } \\
\text { 23633904, } \\
\text { Canada }\end{array}$ & 30 & Third trimester & $\begin{array}{l}\text { Migraine } \\
\text { headache }\end{array}$ & Pharm & $\begin{array}{l}\text { - Analgesics/Antipy } \\
\text { retics } \\
\text { - Opioid-containing } \\
\text { analgesics }\end{array}$ & $\begin{array}{l}\text { - Acetaminophen, } \\
\text { codeine } \\
\text { combination (up } \\
\text { to 6/day) }\end{array}$ & Until delivery & $\begin{array}{l}\text { Neonatal abstinence } \\
\text { syndrome. Infant recovered } \\
\text { without requiring } \\
\text { pharmacologic therapy }\end{array}$ \\
\hline
\end{tabular}

Abbreviations: Nonpharm = nonpharmacologic, Pharm = pharmacologic, PMID = PubMed identifier, NR = not reported.

\section{Details on Strength of Evidence}

\section{Primary Studies}

Table B-31. Key Question 1: Pharmacologic interventions: Antiepileptics - Full evidence profile

\begin{tabular}{|c|c|c|c|c|c|c|c|c|c|}
\hline Topic & Comparison & Outcome & $\begin{array}{l}\text { N Studies } \\
\text { (Subjects) }\end{array}$ & RoB & Consistency & Precision & Directness & SoE & Conclusions \\
\hline \multirow[t]{7}{*}{ Benefits } & \multirow{7}{*}{$\begin{array}{l}\text { Topiramate } \\
\text { (No } \\
\text { comparison) }\end{array}$} & Acute headache attacks - Occurrence & 0 & - & - & - & - & - & - \\
\hline & & Acute headache attacks - Frequency & 0 & - & - & - & - & - & - \\
\hline & & Acute headache attacks - Severity & 0 & - & - & - & - & - & - \\
\hline & & Acute headache attacks - Duration & 0 & - & - & - & - & - & - \\
\hline & & Headache-related symptoms - Occurrence & 0 & - & - & - & - & - & - \\
\hline & & Headache-related symptoms - Frequency & 0 & - & - & - & - & - & - \\
\hline & & Headache-related symptoms - Severity & 0 & - & - & - & - & - & - \\
\hline
\end{tabular}




\begin{tabular}{|c|c|c|c|c|c|c|c|c|c|}
\hline Topic & Comparison & Outcome & $\begin{array}{l}\text { N Studies } \\
\text { (Subjects) }\end{array}$ & RoB & Consistency & Precision & Directness & SoE & Conclusions \\
\hline & & Headache-related symptoms - Duration & 0 & - & - & - & - & - & - \\
\hline & & Emergency department or clinic visits & 0 & - & - & - & - & - & - \\
\hline & & Hospitalizations & 0 & - & - & - & - & - & - \\
\hline & & Quality of life & 0 & - & - & - & - & - & - \\
\hline \multirow[t]{14}{*}{ Harms } & \multirow{14}{*}{$\begin{array}{l}\text { Topiramate } \\
\text { (No } \\
\text { comparison) }\end{array}$} & AEs - Maternal - Serious, Any & 0 & - & - & - & - & - & - \\
\hline & & AEs - Maternal - Serious, Cardiovascular & 0 & - & - & - & - & - & - \\
\hline & & $\begin{array}{l}\text { AEs - Maternal - Discontinuation due to } \\
\text { AEs }\end{array}$ & 0 & - & - & - & - & - & - \\
\hline & & AEs - Maternal - Serious, Cardiovascular & 0 & - & - & - & - & - & - \\
\hline & & AEs - Fetal/Child - Serious, Any & 0 & - & - & - & - & - & - \\
\hline & & $\begin{array}{l}\text { AEs - Fetal/Child - Serious, Spontaneous } \\
\text { abortion or elective or induced abortion }\end{array}$ & $1(81)$ & Moderate & Not applicable & Imprecise & Indirect & Insufficient & No conclusion made \\
\hline & & $\begin{array}{l}\text { AEs - Fetal/Child - Serious, Stillbirth or } \\
\text { fetal death }\end{array}$ & 0 & - & - & - & - & - & - \\
\hline & & $\begin{array}{l}\text { AEs - Fetal/Child - Serious, Neonatal or } \\
\text { infant death }\end{array}$ & 0 & - & - & - & - & - & - \\
\hline & & AEs - Fetal/Child - Serious, Preterm birth & 0 & - & - & - & - & - & - \\
\hline & & $\begin{array}{l}\text { AEs - Fetal/Child - Serious, Low birth } \\
\text { weight }\end{array}$ & 0 & - & - & - & - & - & - \\
\hline & & $\begin{array}{l}\text { AEs - Fetal/Child - Serious, Congenital } \\
\text { anomalies }\end{array}$ & $1(81)$ & Moderate & Not applicable & Imprecise & Indirect & Insufficient & No conclusion made \\
\hline & & $\begin{array}{l}\text { AEs - Fetal/Child - Serious, Perinatal } \\
\text { complications }\end{array}$ & 0 & - & - & - & - & - & - \\
\hline & & $\begin{array}{l}\text { AEs - Fetal/Child - Serious, } \\
\text { Neurodevelopmental/Behavioral/Social }\end{array}$ & 0 & - & - & - & - & - & - \\
\hline & & $\begin{array}{l}\text { AEs - Fetal/Child - Discontinuation due to } \\
\text { AEs }\end{array}$ & 0 & - & - & - & - & - & - \\
\hline
\end{tabular}

Abbreviations: $\mathrm{AE}=$ adverse effect, $\mathrm{RoB}=$ risk of bias, $\mathrm{SoE}=$ strength of evidence.

Table B-32. Key Question 2: Pharmacologic interventions: Triptans, ergot products, and NSAIDs, full evidence profile

\begin{tabular}{|c|c|c|c|c|c|c|c|c|c|}
\hline Topic & Comparison & Outcome & $\begin{array}{l}\text { N Studies } \\
\text { (Subjects) }\end{array}$ & RoB & Consistency & Precision & Directness & SoE & Conclusions \\
\hline \multirow[t]{8}{*}{ Benefits } & \multirow[t]{8}{*}{$\begin{array}{l}\text { Sumatriptan vs. } \\
\text { Naratriptan (During } \\
\text { Pregnancy) }\end{array}$} & Acute headache attacks - Severity & 0 & - & - & - & - & - & - \\
\hline & & Acute headache attacks - Duration & 0 & - & - & - & - & - & - \\
\hline & & Acute headache attacks - Resolution & 0 & - & - & - & - & - & - \\
\hline & & Acute headache attacks - Recurrence & 0 & - & - & - & - & - & - \\
\hline & & Headache-related symptoms - Severity & 0 & - & - & - & - & - & - \\
\hline & & Headache-related symptoms - Duration & 0 & - & - & - & - & - & - \\
\hline & & Headache-related symptoms - Resolution & 0 & - & - & - & - & - & - \\
\hline & & Headache-related symptoms - Recurrence & 0 & - & - & - & - & - & - \\
\hline
\end{tabular}




\begin{tabular}{|c|c|c|c|c|c|c|c|c|c|}
\hline Topic & Comparison & Outcome & $\begin{array}{l}\text { N Studies } \\
\text { (Subjects) }\end{array}$ & RoB & Consistency & Precision & Directness & SoE & Conclusions \\
\hline & & Emergency department or clinic visits & 0 & - & - & - & - & - & - \\
\hline & & Hospitalizations & 0 & - & - & - & - & - & - \\
\hline & & Quality of life & 0 & - & - & - & - & - & - \\
\hline \multirow[t]{11}{*}{ Benefits } & \multirow[t]{11}{*}{$\begin{array}{l}\text { 2: Sumatriptan vs. } \\
\text { Sumatriptan and } \\
\text { Naproxen } \\
\text { Combination } \\
\text { (During Pregnancy) }\end{array}$} & Acute headache attacks - Severity & 0 & - & - & - & - & - & - \\
\hline & & Acute headache attacks - Duration & 0 & - & - & - & - & - & - \\
\hline & & Acute headache attacks - Resolution & 0 & - & - & - & - & - & - \\
\hline & & Acute headache attacks - Recurrence & 0 & - & - & - & - & - & - \\
\hline & & Headache-related symptoms - Severity & 0 & - & - & - & - & - & - \\
\hline & & Headache-related symptoms - Duration & 0 & - & - & - & - & - & - \\
\hline & & Headache-related symptoms - Resolution & 0 & - & - & - & - & - & - \\
\hline & & Headache-related symptoms - Recurrence & 0 & - & - & - & - & - & - \\
\hline & & Emergency department or clinic visits & 0 & - & - & - & - & - & - \\
\hline & & Hospitalizations & 0 & - & - & - & - & - & - \\
\hline & & Quality of life & 0 & - & - & - & - & - & - \\
\hline \multirow[t]{11}{*}{ Benefits } & \multirow[t]{11}{*}{$\begin{array}{l}\text { Naratriptan vs. } \\
\text { Sumatriptan and } \\
\text { Naproxen } \\
\text { Combination } \\
\text { (During Pregnancy) }\end{array}$} & Acute headache attacks - Severity & 0 & - & - & - & - & - & - \\
\hline & & Acute headache attacks - Duration & 0 & - & - & - & - & - & - \\
\hline & & Acute headache attacks - Resolution & 0 & - & - & - & - & - & - \\
\hline & & Acute headache attacks - Recurrence & 0 & - & - & - & - & - & - \\
\hline & & Headache-related symptoms - Severity & 0 & - & - & - & - & - & - \\
\hline & & Headache-related symptoms - Duration & 0 & - & - & - & - & - & - \\
\hline & & Headache-related symptoms - Resolution & 0 & - & - & - & - & - & - \\
\hline & & Headache-related symptoms - Recurrence & 0 & - & - & - & - & - & - \\
\hline & & Emergency department or clinic visits & 0 & - & - & - & - & - & - \\
\hline & & Hospitalizations & 0 & - & - & - & - & - & - \\
\hline & & Quality of life & 0 & - & - & - & - & - & - \\
\hline \multirow[t]{9}{*}{ Benefits } & \multirow[t]{9}{*}{$\begin{array}{l}\text { Any Triptan vs. Any } \\
\text { Ergot Product } \\
\text { (During Pregnancy) }\end{array}$} & Acute headache attacks - Severity & 0 & - & - & - & - & - & - \\
\hline & & Acute headache attacks - Duration & 0 & - & - & - & - & - & - \\
\hline & & Acute headache attacks - Resolution & 0 & - & - & - & - & - & - \\
\hline & & Acute headache attacks - Recurrence & 0 & - & - & - & - & - & - \\
\hline & & Headache-related symptoms - Severity & 0 & - & - & - & - & - & - \\
\hline & & Headache-related symptoms - Duration & 0 & - & - & - & - & - & - \\
\hline & & Headache-related symptoms - Resolution & 0 & - & - & - & - & - & - \\
\hline & & Headache-related symptoms - Recurrence & 0 & - & - & - & - & - & - \\
\hline & & Emergency department or clinic visits & 0 & - & - & - & - & - & - \\
\hline
\end{tabular}




\begin{tabular}{|c|c|c|c|c|c|c|c|c|c|}
\hline Topic & Comparison & Outcome & $\begin{array}{l}\text { N Studies } \\
\text { (Subjects) }\end{array}$ & RoB & Consistency & Precision & Directness & SoE & Conclusions \\
\hline & & Hospitalizations & 0 & - & - & - & - & - & - \\
\hline & & Quality of life & 0 & - & - & - & - & - & - \\
\hline \multirow[t]{11}{*}{ Benefits } & \multirow[t]{11}{*}{$\begin{array}{l}\text { Any Triptan vs. } \\
\text { Pizotifen (During } \\
\text { Pregnancy) }\end{array}$} & Acute headache attacks - Severity & 0 & - & - & - & - & - & - \\
\hline & & Acute headache attacks - Duration & 0 & - & - & - & - & - & - \\
\hline & & Acute headache attacks - Resolution & 0 & - & - & - & - & - & - \\
\hline & & Acute headache attacks - Recurrence & 0 & - & - & - & - & - & - \\
\hline & & Headache-related symptoms - Severity & 0 & - & - & - & - & - & - \\
\hline & & Headache-related symptoms - Duration & 0 & - & - & - & - & - & - \\
\hline & & Headache-related symptoms - Resolution & 0 & - & - & - & - & - & - \\
\hline & & Headache-related symptoms - Recurrence & 0 & - & - & - & - & - & - \\
\hline & & Emergency department or clinic visits & 0 & - & - & - & - & - & - \\
\hline & & Hospitalizations & 0 & - & - & - & - & - & - \\
\hline & & Quality of life & 0 & - & - & - & - & - & - \\
\hline \multirow[t]{11}{*}{ Benefits } & \multirow[t]{11}{*}{$\begin{array}{l}\text { Any Ergot Product } \\
\text { vs. Pizotifen } \\
\text { (During Pregnancy) }\end{array}$} & Acute headache attacks - Severity & 0 & - & - & - & - & - & - \\
\hline & & Acute headache attacks - Duration & 0 & - & - & - & - & - & - \\
\hline & & Acute headache attacks - Resolution & 0 & - & - & - & - & - & - \\
\hline & & Acute headache attacks - Recurrence & 0 & - & - & - & - & - & - \\
\hline & & Headache-related symptoms - Severity & 0 & - & - & - & - & - & - \\
\hline & & Headache-related symptoms - Duration & 0 & - & - & - & - & - & - \\
\hline & & Headache-related symptoms - Resolution & 0 & - & - & - & - & - & - \\
\hline & & Headache-related symptoms - Recurrence & 0 & - & - & - & - & - & - \\
\hline & & Emergency department or clinic visits & 0 & - & - & - & - & - & - \\
\hline & & Hospitalizations & 0 & - & - & - & - & - & - \\
\hline & & Quality of life & 0 & - & - & - & - & - & - \\
\hline \multirow[t]{11}{*}{ Benefits } & \multirow[t]{11}{*}{$\begin{array}{l}\text { Any Triptan (During } \\
\text { Pregnancy) vs. Any } \\
\text { Triptan (Before } \\
\text { Pregnancy) }\end{array}$} & Acute headache attacks - Severity & 0 & - & - & - & - & - & - \\
\hline & & Acute headache attacks - Duration & 0 & - & - & - & - & - & - \\
\hline & & Acute headache attacks - Resolution & 0 & - & - & - & - & - & - \\
\hline & & Acute headache attacks - Recurrence & 0 & - & - & - & - & - & - \\
\hline & & Headache-related symptoms - Severity & 0 & - & - & - & - & - & - \\
\hline & & Headache-related symptoms - Duration & 0 & - & - & - & - & - & - \\
\hline & & Headache-related symptoms - Resolution & 0 & - & - & - & - & - & - \\
\hline & & Headache-related symptoms - Recurrence & 0 & - & - & - & - & - & - \\
\hline & & Emergency department or clinic visits & 0 & - & - & - & - & - & - \\
\hline & & Hospitalizations & 0 & - & - & - & - & - & - \\
\hline & & Quality of life & 0 & - & - & - & - & - & - \\
\hline
\end{tabular}




\begin{tabular}{|c|c|c|c|c|c|c|c|c|c|}
\hline Topic & Comparison & Outcome & $\begin{array}{l}\text { N Studies } \\
\text { (Subjects) }\end{array}$ & RoB & Consistency & Precision & Directness & SoE & Conclusions \\
\hline \multirow[t]{11}{*}{$\begin{array}{l}\text { Effective } \\
\text { ness }\end{array}$} & \multirow[t]{11}{*}{$\begin{array}{l}\text { Sumatriptan } \\
\text { (During Pregnancy) } \\
\text { vs. Sumatriptan } \\
\text { (Before Pregnancy) }\end{array}$} & Acute headache attacks - Severity & 0 & - & - & - & - & - & - \\
\hline & & Acute headache attacks - Duration & 0 & - & - & - & - & - & - \\
\hline & & Acute headache attacks - Resolution & 0 & - & - & - & - & - & - \\
\hline & & Acute headache attacks - Recurrence & 0 & - & - & - & - & - & - \\
\hline & & Headache-related symptoms - Severity & 0 & - & - & - & - & - & - \\
\hline & & Headache-related symptoms - Duration & 0 & - & - & - & - & - & - \\
\hline & & Headache-related symptoms - Resolution & 0 & - & - & - & - & - & - \\
\hline & & Headache-related symptoms - Recurrence & 0 & - & - & - & - & - & - \\
\hline & & Emergency department or clinic visits & 0 & - & - & - & - & - & - \\
\hline & & Hospitalizations & 0 & - & - & - & - & - & - \\
\hline & & Quality of life & 0 & - & - & - & - & - & - \\
\hline \multirow[t]{11}{*}{$\begin{array}{l}\text { Effective } \\
\text { ness }\end{array}$} & \multirow[t]{11}{*}{$\begin{array}{l}\text { Any Triptan (During } \\
\text { Pregnancy) vs. No } \\
\text { Triptans (During or } \\
\text { Before Pregnancy) }\end{array}$} & Acute headache attacks - Severity & 0 & - & - & - & - & - & - \\
\hline & & Acute headache attacks - Duration & 0 & - & - & - & - & - & - \\
\hline & & Acute headache attacks - Resolution & 0 & - & - & - & - & - & - \\
\hline & & Acute headache attacks - Recurrence & 0 & - & - & - & - & - & - \\
\hline & & Headache-related symptoms - Severity & 0 & - & - & - & - & - & - \\
\hline & & Headache-related symptoms - Duration & 0 & - & - & - & - & - & - \\
\hline & & Headache-related symptoms - Resolution & 0 & - & - & - & - & - & - \\
\hline & & Headache-related symptoms - Recurrence & 0 & - & - & - & - & - & - \\
\hline & & Emergency department or clinic visits & 0 & - & - & - & - & - & - \\
\hline & & Hospitalizations & 0 & - & - & - & - & - & - \\
\hline & & Quality of life & 0 & - & - & - & - & - & - \\
\hline \multirow[t]{11}{*}{ Harms } & \multirow[t]{11}{*}{$\begin{array}{l}\text { Sumatriptan vs. } \\
\text { Naratriptan (During } \\
\text { Pregnancy) }\end{array}$} & AEs - Maternal - Serious, Any & 0 & - & - & - & - & - & - \\
\hline & & AEs - Maternal - Serious, Cardiovascular & 0 & - & - & - & - & - & - \\
\hline & & AEs - Maternal - Discontinuation due to AEs & 0 & - & - & - & - & - & - \\
\hline & & AEs - Fetal/Child - Serious, Any & 0 & & & & & & \\
\hline & & $\begin{array}{l}\text { AEs - Fetal/Child - Serious, Spontaneous abortion or } \\
\text { elective or induced abortion }\end{array}$ & $1(689)$ & High & $\begin{array}{l}\text { Not } \\
\text { applicable }\end{array}$ & $\begin{array}{l}\text { Not } \\
\text { applicable }\end{array}$ & Direct & $\begin{array}{l}\text { Insufficien } \\
\mathrm{t}\end{array}$ & No conclusion made \\
\hline & & AEs - Fetal/Child - Serious, Stillbirth or fetal death & $1(689)$ & High & $\begin{array}{l}\text { Not } \\
\text { applicable }\end{array}$ & $\begin{array}{l}\text { Not } \\
\text { applicable }\end{array}$ & Direct & $\begin{array}{l}\text { Insufficien } \\
\mathrm{t}\end{array}$ & No conclusion made \\
\hline & & AEs - Fetal/Child - Serious, Neonatal or infant death & 0 & - & - & - & - & - & - \\
\hline & & AEs - Fetal/Child - Serious, Preterm birth & 0 & - & - & - & - & - & - \\
\hline & & AEs - Fetal/Child - Serious, Low birth weight & 0 & - & - & - & - & - & - \\
\hline & & AEs - Fetal/Child - Serious, Congenital anomalies & $1(689)$ & High & $\begin{array}{l}\text { Not } \\
\text { applicable }\end{array}$ & $\begin{array}{l}\text { Not } \\
\text { applicable }\end{array}$ & Direct & $\begin{array}{l}\text { Insufficien } \\
\mathrm{t}\end{array}$ & No conclusion made \\
\hline & & AEs - Fetal/Child - Serious, Perinatal complications & 0 & - & - & - & - & - & - \\
\hline
\end{tabular}




\begin{tabular}{|c|c|c|c|c|c|c|c|c|c|}
\hline Topic & Comparison & Outcome & $\begin{array}{l}\text { N Studies } \\
\text { (Subjects) }\end{array}$ & RoB & Consistency & Precision & Directness & SoE & Conclusions \\
\hline & & $\begin{array}{l}\text { AEs - Fetal/Child - Serious, } \\
\text { Neurodevelopmental/Behavioral/Social }\end{array}$ & 0 & - & - & - & - & - & - \\
\hline & & AEs - Fetal/Child - Discontinuation due to AEs & 0 & - & - & - & - & - & - \\
\hline \multirow[t]{13}{*}{ Harms } & \multirow[t]{13}{*}{$\begin{array}{l}\text { Sumatriptan vs. } \\
\text { Sumatriptan and } \\
\text { Naproxen } \\
\text { Combination } \\
\text { (During Pregnancy) }\end{array}$} & AEs - Maternal - Serious, Any & 0 & - & - & - & - & - & - \\
\hline & & AEs - Maternal - Serious, Cardiovascular & 0 & - & - & - & - & - & - \\
\hline & & AEs - Maternal - Discontinuation due to AEs & 0 & - & - & - & - & - & - \\
\hline & & AEs - Fetal/Child - Serious, Any & 0 & & & & & & \\
\hline & & $\begin{array}{l}\text { AEs - Fetal/Child - Serious, Spontaneous abortion or } \\
\text { elective or induced abortion }\end{array}$ & 1 (689) & High & $\begin{array}{l}\text { Not } \\
\text { applicable }\end{array}$ & $\begin{array}{l}\text { Not } \\
\text { applicable }\end{array}$ & Direct & $\begin{array}{l}\text { Insufficien } \\
\mathrm{t}\end{array}$ & No conclusion made \\
\hline & & AEs - Fetal/Child - Serious, Stillbirth or fetal death & $1(689)$ & High & $\begin{array}{l}\text { Not } \\
\text { applicable }\end{array}$ & $\begin{array}{l}\text { Not } \\
\text { applicable }\end{array}$ & Direct & $\begin{array}{l}\text { Insufficien } \\
\mathrm{t}\end{array}$ & No conclusion made \\
\hline & & AEs - Fetal/Child - Serious, Neonatal or infant death & 0 & - & - & - & - & - & - \\
\hline & & AEs - Fetal/Child - Serious, Preterm birth & 0 & - & - & - & - & - & - \\
\hline & & AEs - Fetal/Child - Serious, Low birth weight & 0 & - & - & - & - & - & - \\
\hline & & AEs - Fetal/Child - Serious, Congenital anomalies & 1 (689) & High & $\begin{array}{l}\text { Not } \\
\text { applicable }\end{array}$ & $\begin{array}{l}\text { Not } \\
\text { applicable }\end{array}$ & Direct & $\begin{array}{l}\text { Insufficien } \\
\mathrm{t}\end{array}$ & No conclusion made \\
\hline & & AEs - Fetal/Child - Serious, Perinatal complications & 0 & - & - & - & - & - & - \\
\hline & & $\begin{array}{l}\text { AEs - Fetal/Child - Serious, } \\
\text { Neurodevelopmental/Behavioral/Social }\end{array}$ & 0 & - & - & - & - & - & - \\
\hline & & AEs - Fetal/Child - Discontinuation due to AEs & 0 & - & - & - & - & - & - \\
\hline \multirow[t]{13}{*}{ Harms } & \multirow[t]{13}{*}{$\begin{array}{l}\text { Naratriptan vs. } \\
\text { Sumatriptan and } \\
\text { Naproxen } \\
\text { Combination } \\
\text { (During Pregnancy) }\end{array}$} & AEs - Maternal - Serious, Any & 0 & - & - & - & - & - & - \\
\hline & & AEs - Maternal - Serious, Cardiovascular & 0 & - & - & - & - & - & - \\
\hline & & AEs - Maternal - Discontinuation due to AEs & 0 & - & - & - & - & - & - \\
\hline & & AEs - Fetal/Child - Serious, Any & 0 & & & & & & \\
\hline & & $\begin{array}{l}\text { AEs - Fetal/Child - Serious, Spontaneous abortion or } \\
\text { elective or induced abortion }\end{array}$ & $1(689)$ & High & $\begin{array}{l}\text { Not } \\
\text { applicable }\end{array}$ & $\begin{array}{l}\text { Not } \\
\text { applicable }\end{array}$ & Direct & $\begin{array}{l}\text { Insufficien } \\
\mathrm{t}\end{array}$ & No conclusion made \\
\hline & & AEs - Fetal/Child - Serious, Stillbirth or fetal death & $1(689)$ & High & $\begin{array}{l}\text { Not } \\
\text { applicable }\end{array}$ & $\begin{array}{l}\text { Not } \\
\text { applicable }\end{array}$ & Direct & $\begin{array}{l}\text { Insufficien } \\
\mathrm{t}\end{array}$ & No conclusion made \\
\hline & & AEs - Fetal/Child - Serious, Neonatal or infant death & 0 & - & - & - & - & - & - \\
\hline & & AEs - Fetal/Child - Serious, Preterm birth & 0 & - & - & - & - & - & - \\
\hline & & AEs - Fetal/Child - Serious, Low birth weight & 0 & - & - & - & - & - & - \\
\hline & & AEs - Fetal/Child - Serious, Congenital anomalies & 1 (689) & High & $\begin{array}{l}\text { Not } \\
\text { applicable }\end{array}$ & $\begin{array}{l}\text { Not } \\
\text { applicable }\end{array}$ & Direct & $\begin{array}{l}\text { Insufficien } \\
\mathrm{t}\end{array}$ & No conclusion made \\
\hline & & AEs - Fetal/Child - Serious, Perinatal complications & 0 & - & - & - & - & - & - \\
\hline & & $\begin{array}{l}\text { AEs - Fetal/Child - Serious, } \\
\text { Neurodevelopmental/Behavioral/Social }\end{array}$ & 0 & - & - & - & - & - & - \\
\hline & & AEs - Fetal/Child - Discontinuation due to AEs & 0 & - & - & - & - & - & - \\
\hline
\end{tabular}




\begin{tabular}{|c|c|c|c|c|c|c|c|c|c|}
\hline Topic & Comparison & Outcome & $\begin{array}{l}\text { N Studies } \\
\text { (Subjects) }\end{array}$ & RoB & Consistency & Precision & Directness & SoE & Conclusions \\
\hline \multirow[t]{13}{*}{ Harms } & \multirow[t]{13}{*}{$\begin{array}{l}\text { Any Triptan vs. Any } \\
\text { Ergot Product } \\
\text { (During Pregnancy) }\end{array}$} & AEs - Maternal - Serious, Any & 0 & - & - & - & - & - & - \\
\hline & & AEs - Maternal - Serious, Cardiovascular & 0 & - & - & - & - & - & - \\
\hline & & AEs - Maternal - Discontinuation due to AEs & 0 & - & - & - & - & - & - \\
\hline & & AEs - Fetal/Child - Serious, Any & 0 & - & - & - & - & - & - \\
\hline & & $\begin{array}{l}\text { AEs - Fetal/Child - Serious, Spontaneous abortion or } \\
\text { elective or induced abortion }\end{array}$ & 0 & - & - & - & - & - & - \\
\hline & & AEs - Fetal/Child - Serious, Stillbirth or fetal death & 1 (3368) & High & $\begin{array}{l}\text { Not } \\
\text { applicable }\end{array}$ & $\begin{array}{l}\text { Not } \\
\text { applicable }\end{array}$ & Direct & $\begin{array}{l}\text { Insufficien } \\
\mathrm{t}\end{array}$ & No conclusion made \\
\hline & & AEs - Fetal/Child - Serious, Neonatal or infant death & 0 & - & - & - & - & - & - \\
\hline & & AEs - Fetal/Child - Serious, Preterm birth & 1 (3368) & High & $\begin{array}{l}\text { Not } \\
\text { applicable }\end{array}$ & $\begin{array}{l}\text { Not } \\
\text { applicable }\end{array}$ & Direct & $\begin{array}{l}\text { Insufficien } \\
\mathrm{t}\end{array}$ & No conclusion made \\
\hline & & AEs - Fetal/Child - Serious, Low birth weight & $1(3368)$ & High & $\begin{array}{l}\text { Not } \\
\text { applicable }\end{array}$ & $\begin{array}{l}\text { Not } \\
\text { applicable }\end{array}$ & Direct & $\begin{array}{l}\text { Insufficien } \\
\mathrm{t}\end{array}$ & No conclusion made \\
\hline & & AEs - Fetal/Child - Serious, Congenital anomalies & $1(3368)$ & High & $\begin{array}{l}\text { Not } \\
\text { applicable }\end{array}$ & $\begin{array}{l}\text { Not } \\
\text { applicable }\end{array}$ & Direct & $\begin{array}{l}\text { Insufficien } \\
\mathrm{t}\end{array}$ & No conclusion made \\
\hline & & AEs - Fetal/Child - Serious, Perinatal complications & 0 & - & - & - & - & - & - \\
\hline & & $\begin{array}{l}\text { AEs - Fetal/Child - Serious, } \\
\text { Neurodevelopmental/Behavioral/Social }\end{array}$ & 0 & - & - & - & - & - & - \\
\hline & & AEs - Fetal/Child - Discontinuation due to AEs & 0 & - & - & - & - & - & - \\
\hline \multirow[t]{13}{*}{ Harms } & \multirow[t]{13}{*}{$\begin{array}{l}\text { Any Triptan vs. } \\
\text { Pizotifen (During } \\
\text { Pregnancy) }\end{array}$} & AEs - Maternal - Serious, Any & 0 & - & - & - & - & - & - \\
\hline & & AEs - Maternal - Serious, Cardiovascular & 0 & - & - & - & - & - & - \\
\hline & & AEs - Maternal - Discontinuation due to AEs & 0 & - & - & - & - & - & - \\
\hline & & AEs - Fetal/Child - Serious, Any & 0 & - & - & - & - & - & - \\
\hline & & $\begin{array}{l}\text { AEs - Fetal/Child - Serious, Spontaneous abortion or } \\
\text { elective or induced abortion }\end{array}$ & 0 & - & - & - & - & - & - \\
\hline & & AEs - Fetal/Child - Serious, Stillbirth or fetal death & $1(3368)$ & High & $\begin{array}{l}\text { Not } \\
\text { applicable }\end{array}$ & $\begin{array}{l}\text { Not } \\
\text { applicable }\end{array}$ & Direct & $\begin{array}{l}\text { Insufficien } \\
\mathrm{t}\end{array}$ & No conclusion made \\
\hline & & AEs - Fetal/Child - Serious, Neonatal or infant death & 0 & - & - & - & - & - & - \\
\hline & & AEs - Fetal/Child - Serious, Preterm birth & 1 (3368) & High & $\begin{array}{l}\text { Not } \\
\text { applicable }\end{array}$ & $\begin{array}{l}\text { Not } \\
\text { applicable }\end{array}$ & Direct & $\begin{array}{l}\text { Insufficien } \\
\mathrm{t}\end{array}$ & No conclusion made \\
\hline & & AEs - Fetal/Child - Serious, Low birth weight & $1(3368)$ & High & $\begin{array}{l}\text { Not } \\
\text { applicable }\end{array}$ & $\begin{array}{l}\text { Not } \\
\text { applicable }\end{array}$ & Direct & $\begin{array}{l}\text { Insufficien } \\
\mathrm{t}\end{array}$ & No conclusion made \\
\hline & & AEs - Fetal/Child - Serious, Congenital anomalies & 1 (3368) & High & $\begin{array}{l}\text { Not } \\
\text { applicable }\end{array}$ & $\begin{array}{l}\text { Not } \\
\text { applicable }\end{array}$ & Direct & $\begin{array}{l}\text { Insufficien } \\
\mathrm{t}\end{array}$ & No conclusion made \\
\hline & & AEs - Fetal/Child - Serious, Perinatal complications & 0 & - & - & - & - & - & - \\
\hline & & $\begin{array}{l}\text { AEs - Fetal/Child - Serious, } \\
\text { Neurodevelopmental/Behavioral/Social }\end{array}$ & 0 & - & - & - & - & - & - \\
\hline & & AEs - Fetal/Child - Discontinuation due to AEs & 0 & - & - & - & - & - & - \\
\hline Harms & $\begin{array}{l}\text { Any Ergot Product } \\
\text { vs. Pizotifen } \\
\text { (During Pregnancy) }\end{array}$ & AEs - Maternal - Serious, Any & 0 & - & - & - & - & - & - \\
\hline
\end{tabular}




\begin{tabular}{|c|c|c|c|c|c|c|c|c|c|}
\hline Topic & Comparison & Outcome & $\begin{array}{l}\text { N Studies } \\
\text { (Subjects) }\end{array}$ & RoB & Consistency & Precision & Directness & SoE & Conclusions \\
\hline & & AEs - Maternal - Serious, Cardiovascular & 0 & - & - & - & - & - & - \\
\hline & & AEs - Maternal - Discontinuation due to AEs & 0 & - & - & - & - & - & - \\
\hline & & AEs - Fetal/Child - Serious, Any & 0 & - & - & - & - & - & - \\
\hline & & $\begin{array}{l}\text { AEs - Fetal/Child - Serious, Spontaneous abortion or } \\
\text { elective or induced abortion }\end{array}$ & 0 & - & - & - & - & - & - \\
\hline & & AEs - Fetal/Child - Serious, Stillbirth or fetal death & 0 & - & - & - & - & - & - \\
\hline & & AEs - Fetal/Child - Serious, Neonatal or infant death & 0 & - & - & - & - & - & - \\
\hline & & AEs - Fetal/Child - Serious, Preterm birth & 0 & - & - & - & - & - & - \\
\hline & & AEs - Fetal/Child - Serious, Low birth weight & 0 & - & - & - & - & - & - \\
\hline & & AEs - Fetal/Child - Serious, Congenital anomalies & $1(5900)$ & High & $\begin{array}{l}\text { Not } \\
\text { applicable }\end{array}$ & $\begin{array}{l}\text { Not } \\
\text { applicable }\end{array}$ & Direct & $\begin{array}{l}\text { Insufficien } \\
\mathrm{t}\end{array}$ & No conclusion made \\
\hline & & AEs - Fetal/Child - Serious, Perinatal complications & 0 & - & - & - & - & - & - \\
\hline & & $\begin{array}{l}\text { AEs - Fetal/Child - Serious, } \\
\text { Neurodevelopmental/Behavioral/Social }\end{array}$ & 0 & - & - & - & - & - & - \\
\hline & & AEs - Fetal/Child - Discontinuation due to AEs & 0 & - & - & - & - & - & - \\
\hline \multirow[t]{13}{*}{ Harms } & \multirow[t]{13}{*}{$\begin{array}{l}\text { Any Triptan (During } \\
\text { Pregnancy) vs. Any } \\
\text { Triptan (Before } \\
\text { Pregnancy) }\end{array}$} & AEs - Maternal - Serious, Any & $2(8460)$ & High & $\begin{array}{l}\text { Not } \\
\text { applicable }\end{array}$ & $\begin{array}{l}\text { Not } \\
\text { applicable }\end{array}$ & Direct & $\begin{array}{l}\text { Insufficien } \\
t\end{array}$ & No conclusion made \\
\hline & & AEs - Maternal - Serious, Cardiovascular & 0 & - & - & - & - & - & - \\
\hline & & AEs - Maternal - Discontinuation due to AEs & 0 & - & - & - & - & - & - \\
\hline & & AEs - Fetal/Child - Serious, Any & 0 & - & - & - & - & - & - \\
\hline & & $\begin{array}{l}\text { AEs - Fetal/Child - Serious, Spontaneous abortion or } \\
\text { elective or induced abortion }\end{array}$ & 0 & - & - & - & - & - & - \\
\hline & & AEs - Fetal/Child - Serious, Stillbirth or fetal death & $1(5900)$ & High & $\begin{array}{l}\text { Not } \\
\text { applicable }\end{array}$ & $\begin{array}{l}\text { Not } \\
\text { applicable }\end{array}$ & Direct & $\begin{array}{l}\text { Insufficien } \\
\mathrm{t}\end{array}$ & No conclusion made \\
\hline & & AEs - Fetal/Child - Serious, Neonatal or infant death & $1(5900)$ & High & $\begin{array}{l}\text { Not } \\
\text { applicable }\end{array}$ & $\begin{array}{l}\text { Not } \\
\text { applicable }\end{array}$ & Direct & $\begin{array}{l}\text { Insufficien } \\
\mathrm{t}\end{array}$ & No conclusion made \\
\hline & & AEs - Fetal/Child - Serious, Preterm birth & $2(8460)$ & High & $\begin{array}{l}\text { Not } \\
\text { applicable }\end{array}$ & $\begin{array}{l}\text { Not } \\
\text { applicable }\end{array}$ & Direct & $\begin{array}{l}\text { Insufficien } \\
\mathrm{t}\end{array}$ & No conclusion made \\
\hline & & AEs - Fetal/Child - Serious, Low birth weight & $2(8460)$ & High & $\begin{array}{l}\text { Not } \\
\text { applicable }\end{array}$ & $\begin{array}{l}\text { Not } \\
\text { applicable }\end{array}$ & Direct & $\begin{array}{l}\text { Insufficien } \\
\mathrm{t}\end{array}$ & No conclusion made \\
\hline & & AEs - Fetal/Child - Serious, Congenital anomalies & $2(8460)$ & High & $\begin{array}{l}\text { Not } \\
\text { applicable }\end{array}$ & $\begin{array}{l}\text { Not } \\
\text { applicable }\end{array}$ & Direct & $\begin{array}{l}\text { Insufficien } \\
\mathrm{t}\end{array}$ & No conclusion made \\
\hline & & AEs - Fetal/Child - Serious, Perinatal complications & $2(8460)$ & High & $\begin{array}{l}\text { Not } \\
\text { applicable }\end{array}$ & $\begin{array}{l}\text { Not } \\
\text { applicable }\end{array}$ & Direct & $\begin{array}{l}\text { Insufficien } \\
\mathrm{t}\end{array}$ & No conclusion made \\
\hline & & $\begin{array}{l}\text { AEs - Fetal/Child - Serious, } \\
\text { Neurodevelopmental/Behavioral/Social }\end{array}$ & $1(5900)$ & High & $\begin{array}{l}\text { Not } \\
\text { applicable }\end{array}$ & Imprecise & Direct & Low & $\begin{array}{l}\text { Similar gross motor } \\
\text { and fine motor } \\
\text { development, but } \\
\text { worse emotionality and } \\
\text { activity outcomes for at } \\
3 \text { years for use during } \\
\text { pregnancy versus } \\
\text { before pregnancy. }\end{array}$ \\
\hline & & AEs - Fetal/Child - Discontinuation due to AEs & 0 & - & - & - & - & - & - \\
\hline
\end{tabular}




\begin{tabular}{|c|c|c|c|c|c|c|c|c|c|}
\hline Topic & Comparison & Outcome & $\begin{array}{l}\text { N Studies } \\
\text { (Subjects) }\end{array}$ & RoB & Consistency & Precision & Directness & SoE & Conclusions \\
\hline \multirow[t]{13}{*}{ Harms } & \multirow[t]{13}{*}{$\begin{array}{l}\text { Sumatriptan } \\
\text { (During Pregnancy) } \\
\text { vs. Sumatriptan } \\
\text { (Before Pregnancy) }\end{array}$} & AEs - Maternal - Serious, Any & $1(168)$ & High & $\begin{array}{l}\text { Not } \\
\text { applicable }\end{array}$ & $\begin{array}{l}\text { Not } \\
\text { applicable }\end{array}$ & Direct & $\begin{array}{l}\text { Insufficien } \\
\mathrm{t}\end{array}$ & No conclusion made \\
\hline & & AEs - Maternal - Serious, Cardiovascular & 0 & - & - & - & - & - & - \\
\hline & & AEs - Maternal - Discontinuation due to AEs & 0 & - & - & - & - & - & - \\
\hline & & AEs - Fetal/Child - Serious, Any & 0 & - & - & - & - & - & - \\
\hline & & $\begin{array}{l}\text { AEs - Fetal/Child - Serious, Spontaneous abortion or } \\
\text { elective or induced abortion }\end{array}$ & $1(168)$ & High & $\begin{array}{l}\text { Not } \\
\text { applicable }\end{array}$ & $\begin{array}{l}\text { Not } \\
\text { applicable }\end{array}$ & Direct & $\begin{array}{l}\text { Insufficien } \\
\mathrm{t}\end{array}$ & No conclusion made \\
\hline & & AEs - Fetal/Child - Serious, Stillbirth or fetal death & 0 & - & - & - & - & - & - \\
\hline & & AEs - Fetal/Child - Serious, Neonatal or infant death & 0 & - & - & - & - & - & - \\
\hline & & AEs - Fetal/Child - Serious, Preterm birth & $1(123)$ & $\begin{array}{l}\text { Mod } \\
\text { erat } \\
\text { e }\end{array}$ & $\begin{array}{l}\text { Not } \\
\text { applicable }\end{array}$ & Imprecise & Direct & $\begin{array}{l}\text { Insufficien } \\
\mathrm{t}\end{array}$ & No conclusion made \\
\hline & & AEs - Fetal/Child - Serious, Low birth weight & $1(123)$ & $\begin{array}{l}\text { Mod } \\
\text { erat } \\
\text { e }\end{array}$ & $\begin{array}{l}\text { Not } \\
\text { applicable }\end{array}$ & Imprecise & Direct & $\begin{array}{l}\text { Insufficien } \\
\mathrm{t}\end{array}$ & No conclusion made \\
\hline & & AEs - Fetal/Child - Serious, Congenital anomalies & 0 & - & - & - & - & - & - \\
\hline & & AEs - Fetal/Child - Serious, Perinatal complications & 0 & - & - & - & - & - & - \\
\hline & & $\begin{array}{l}\text { AEs - Fetal/Child - Serious, } \\
\text { Neurodevelopmental/Behavioral/Social }\end{array}$ & 0 & - & - & - & - & - & - \\
\hline & & AEs - Fetal/Child - Discontinuation due to AEs & 0 & - & - & - & - & - & - \\
\hline \multirow[t]{10}{*}{ Harms } & \multirow[t]{10}{*}{$\begin{array}{l}\text { Any Triptan (During } \\
\text { Pregnancy) vs. No } \\
\text { Triptans (During or } \\
\text { Before Pregnancy) }\end{array}$} & AEs - Maternal - Serious, Any & $1(5900)$ & High & $\begin{array}{l}\text { Not } \\
\text { applicable }\end{array}$ & $\begin{array}{l}\text { Not } \\
\text { applicable }\end{array}$ & Indirect & $\begin{array}{l}\text { Insufficien } \\
\mathrm{t}\end{array}$ & No conclusion made \\
\hline & & AEs - Maternal - Serious, Cardiovascular & 0 & - & - & - & - & - & - \\
\hline & & AEs - Maternal - Discontinuation due to AEs & 0 & - & - & - & - & - & - \\
\hline & & AEs - Fetal/Child - Serious, Any & 0 & - & - & - & - & - & - \\
\hline & & $\begin{array}{l}\text { AEs - Fetal/Child - Serious, Spontaneous abortion or } \\
\text { elective or induced abortion }\end{array}$ & $2(1099)$ & High & $\mathrm{N} / \mathrm{A}$ & N/A & Direct & Low & $\begin{array}{l}\text { No difference for } \\
\text { spontaneous or elective } \\
\text { abortion }\end{array}$ \\
\hline & & AEs - Fetal/Child - Serious, Stillbirth or fetal death & 2 (6807) & High & $\mathrm{N} / \mathrm{A}$ & $\mathrm{N} / \mathrm{A}$ & Direct & Low & $\begin{array}{l}\text { No adjusted between- } \\
\text { arm estimates }\end{array}$ \\
\hline & & AEs - Fetal/Child - Serious, Neonatal or infant death & $1(5900)$ & High & N/A & N/A & Direct & Low & $\begin{array}{l}\text { No adjusted between- } \\
\text { arm estimates available }\end{array}$ \\
\hline & & AEs - Fetal/Child - Serious, Preterm birth & $1(5900)$ & High & $\begin{array}{l}\text { Not } \\
\text { applicable }\end{array}$ & $\begin{array}{l}\text { Not } \\
\text { applicable }\end{array}$ & Indirect & $\begin{array}{l}\text { Insufficien } \\
\mathrm{t}\end{array}$ & No conclusion made \\
\hline & & AEs - Fetal/Child - Serious, Low birth weight & $1(5900)$ & High & $\begin{array}{l}\text { Not } \\
\text { applicable }\end{array}$ & $\begin{array}{l}\text { Not } \\
\text { applicable }\end{array}$ & Indirect & $\begin{array}{l}\text { Insufficien } \\
\mathrm{t}\end{array}$ & No conclusion made \\
\hline & & AEs - Fetal/Child - Serious, Congenital anomalies & $3(6999)$ & High & $\begin{array}{l}\text { Not } \\
\text { applicable }\end{array}$ & Imprecise & Direct & Low & $\begin{array}{l}\text { No difference for any, } \\
\text { major, minor, and } \\
\text { genetic birth defects. } \\
\text { spontaneous or elective } \\
\text { abortion. }\end{array}$ \\
\hline
\end{tabular}




\begin{tabular}{|c|c|c|c|c|c|c|c|c|c|}
\hline Topic & Comparison & Outcome & $\begin{array}{l}\text { N Studies } \\
\text { (Subjects) }\end{array}$ & RoB & Consistency & Precision & Directness & SoE & Conclusions \\
\hline & & AEs - Fetal/Child - Serious, Perinatal complications & $1(5900)$ & High & $\begin{array}{l}\text { Not } \\
\text { applicable }\end{array}$ & $\begin{array}{l}\text { Not } \\
\text { applicable }\end{array}$ & Indirect & $\begin{array}{l}\text { Insufficien } \\
\mathrm{t}\end{array}$ & No conclusion made \\
\hline & & $\begin{array}{l}\text { AEs - Fetal/Child - Serious, } \\
\text { Neurodevelopmental/Behavioral/Social }\end{array}$ & $1(5900)$ & High & $\begin{array}{l}\text { Not } \\
\text { applicable }\end{array}$ & Imprecise & Direct & Low & $\begin{array}{l}\text { Similar gross motor } \\
\text { and fine motor } \\
\text { development, but } \\
\text { worse emotionality and } \\
\text { activity for use during } \\
\text { pregnancy versus } \\
\text { nonuse (during or } \\
\text { before pregnancy). }\end{array}$ \\
\hline & & AEs - Fetal/Child - Discontinuation due to AEs & 0 & - & - & - & - & - & - \\
\hline
\end{tabular}

Abbreviations: $\mathrm{AE}=$ adverse effect, NS = not statistically significant, RoB = risk of bias, SoE = strength of evidence.

Consistency was deemed "N/A" when it could not be assessed because only one study was one found. Consistency was also deemed "N/A" when in some instances where more than one study was

found because at least one of the studies did not report adjusted between-arm effect sizes, precluding an assessment of consistency.

Precision was deemed "N/A" when it could not be assessed because adjusted between-arm effect sizes were not reported.

Table B-33. Key Question 2: Pharmacologic interventions: Antiemetics, antihistamines, opioid analgesics - Full evidence profile

\begin{tabular}{|c|c|c|c|c|c|c|c|c|c|}
\hline Topic & Comparison & Outcome & $\begin{array}{l}\text { N Studies } \\
\text { (Subjects) }\end{array}$ & RoB & Consistency & Precision & Directness & SoE & Conclusions \\
\hline \multirow[t]{11}{*}{ Benefits } & \multirow[t]{11}{*}{$\begin{array}{l}\text { Combination of } \\
\text { metoclopramide } \\
\text { and } \\
\text { diphenhydramine } \\
\text { vs. codeine }\end{array}$} & Acute headache attacks - Severity & $1(70)$ & High & $\begin{array}{l}\text { Not } \\
\text { applicable }\end{array}$ & Imprecise & Direct & Low & $\begin{array}{l}\text { Severity reduced more } \\
\text { in combination arm }\end{array}$ \\
\hline & & Acute headache attacks - Duration & 0 & - & - & - & - & - & - \\
\hline & & Acute headache attacks - Resolution & $1(70)$ & High & $\begin{array}{l}\text { Not } \\
\text { applicable }\end{array}$ & Imprecise & Direct & Low & $\begin{array}{l}\text { Resolution more likely } \\
\text { and sooner in } \\
\text { combination arm }\end{array}$ \\
\hline & & Acute headache attacks - Recurrence & $1(70)$ & High & $\begin{array}{l}\text { Not } \\
\text { applicable }\end{array}$ & Imprecise & Direct & Low & $\begin{array}{l}\text { Recurrence lower in } \\
\text { combination arm, but NS }\end{array}$ \\
\hline & & Headache-related symptoms - Severity & 0 & - & - & - & - & - & - \\
\hline & & Headache-related symptoms - Duration & 0 & - & - & - & - & - & - \\
\hline & & Headache-related symptoms - Resolution & 0 & - & - & - & - & - & - \\
\hline & & Headache-related symptoms - Recurrence & 0 & - & - & - & - & - & - \\
\hline & & Emergency department or clinic visits & 0 & - & - & - & - & - & - \\
\hline & & Hospitalizations & 0 & - & - & - & - & - & - \\
\hline & & Quality of life & 0 & - & - & - & - & - & - \\
\hline \multirow[t]{3}{*}{ Harms } & \multirow[t]{3}{*}{$\begin{array}{l}\text { Combination of } \\
\text { metoclopramide } \\
\text { and } \\
\text { diphenhydramine } \\
\text { vs. codeine }\end{array}$} & AEs - Maternal - Serious, Any & $1(70)$ & High & $\begin{array}{l}\text { Not } \\
\text { applicable }\end{array}$ & Imprecise & Direct & Low & No events in either arm \\
\hline & & AEs - Maternal - Serious, Cardiovascular & 0 & - & - & - & - & - & - \\
\hline & & $\begin{array}{l}\text { AEs - Maternal - Discontinuation due to } \\
\text { AEs }\end{array}$ & 0 & - & - & - & - & - & - \\
\hline
\end{tabular}




\begin{tabular}{|c|c|c|c|c|c|c|c|c|c|}
\hline Topic & Comparison & Outcome & $\begin{array}{l}\text { N Studies } \\
\text { (Subjects) }\end{array}$ & RoB & Consistency & Precision & Directness & SoE & Conclusions \\
\hline & & AEs - Fetal/Child - Serious, Any & 0 & - & - & - & - & - & - \\
\hline & & $\begin{array}{l}\text { AEs - Fetal/Child - Serious, Spontaneous } \\
\text { abortion or elective or induced abortion }\end{array}$ & 0 & - & - & - & - & - & - \\
\hline & & $\begin{array}{l}\text { AEs - Fetal/Child - Serious, Stillbirth or } \\
\text { fetal death }\end{array}$ & 0 & - & - & - & - & - & - \\
\hline & & $\begin{array}{l}\text { AEs - Fetal/Child - Serious, Neonatal or } \\
\text { infant death }\end{array}$ & 0 & - & - & - & - & - & - \\
\hline & & AEs - Fetal/Child - Serious, Preterm birth & 0 & - & - & - & - & - & - \\
\hline & & $\begin{array}{l}\text { AEs - Fetal/Child - Serious, Low birth } \\
\text { weight }\end{array}$ & 0 & - & - & - & - & - & - \\
\hline & & $\begin{array}{l}\text { AEs - Fetal/Child - Serious, Congenital } \\
\text { anomalies }\end{array}$ & 0 & - & - & - & - & - & - \\
\hline & & $\begin{array}{l}\text { AEs - Fetal/Child - Serious, Perinatal } \\
\text { complications }\end{array}$ & 0 & - & - & - & - & - & - \\
\hline & & $\begin{array}{l}\text { AEs - Fetal/Child - Serious, } \\
\text { Neurodevelopmental/Behavioral/Social }\end{array}$ & 0 & - & - & - & - & - & - \\
\hline & & $\begin{array}{l}\text { AEs - Fetal/Child - Discontinuation due to } \\
\text { AEs }\end{array}$ & 0 & - & - & - & - & - & - \\
\hline
\end{tabular}

Abbreviations: $\mathrm{AE}=$ adverse effect, NS = not statistically significant, RoB = risk of bias, SoE = strength of evidence. 
Table B-34. Key Question 2: Nonpharmacologic interventions: Complementary, behavioral, and physical therapies - Full evidence profile

\begin{tabular}{|c|c|c|c|c|c|c|c|c|c|}
\hline Topic & Comparison & Outcome & $\begin{array}{l}\text { N Studies } \\
\text { (Subjects) }\end{array}$ & RoB & Consistency & Precision & $\begin{array}{c}\text { Directne } \\
\text { ss }\end{array}$ & SoE & Conclusions \\
\hline \multirow[t]{11}{*}{ Benefits } & \multirow[t]{11}{*}{$\begin{array}{l}\text { 1. Acupuncture vs. } \\
\text { Routine Care }\end{array}$} & Acute headache attacks - Severity & $1(43)$ & High & $\begin{array}{l}\text { Not } \\
\text { applicable }\end{array}$ & Imprecise & Direct & Insufficient & No conclusion made \\
\hline & & Acute headache attacks - Duration & 0 & - & - & - & - & - & - \\
\hline & & Acute headache attacks - Resolution & 0 & - & - & - & - & - & - \\
\hline & & Acute headache attacks - Recurrence & 0 & - & - & - & - & - & - \\
\hline & & Headache-related symptoms - Severity & 0 & - & - & - & - & - & - \\
\hline & & Headache-related symptoms - Duration & 0 & - & - & - & - & - & - \\
\hline & & Headache-related symptoms - Resolution & 0 & - & - & - & - & - & - \\
\hline & & Headache-related symptoms - Recurrence & 0 & - & - & - & - & - & - \\
\hline & & Emergency department or clinic visits & 0 & - & - & - & - & - & - \\
\hline & & Hospitalizations & 0 & - & - & - & - & - & - \\
\hline & & Quality of life & 0 & - & - & - & - & - & - \\
\hline \multirow[t]{11}{*}{ Benefits } & \multirow[t]{11}{*}{$\begin{array}{l}\text { 2. Combination of } \\
\text { thermal biofeedback, } \\
\text { relaxation therapy, } \\
\text { and physical therapy }\end{array}$} & Acute headache attacks - Severity & $2(44)$ & High & $\begin{array}{l}\text { Not } \\
\text { applicable }\end{array}$ & Imprecise & Direct & Insufficient & No conclusion made \\
\hline & & Acute headache attacks - Duration & 0 & - & - & - & - & - & - \\
\hline & & Acute headache attacks - Resolution & 0 & - & - & - & - & - & - \\
\hline & & Acute headache attacks - Recurrence & 0 & - & - & - & - & - & - \\
\hline & & Headache-related symptoms - Severity & 0 & - & - & - & - & - & - \\
\hline & & Headache-related symptoms - Duration & 0 & - & - & - & - & - & - \\
\hline & & Headache-related symptoms - Resolution & 0 & - & - & - & - & - & - \\
\hline & & Headache-related symptoms - Recurrence & 0 & - & - & - & - & - & - \\
\hline & & Emergency department or clinic visits & 0 & - & - & - & - & - & - \\
\hline & & Hospitalizations & 0 & - & - & - & - & - & - \\
\hline & & Quality of life & 0 & - & - & - & - & - & - \\
\hline \multirow[t]{11}{*}{ Benefits } & \multirow[t]{11}{*}{$\begin{array}{l}\text { 3. Combination of } \\
\text { thermal biofeedback } \\
\text { and relaxation } \\
\text { therapy }\end{array}$} & Acute headache attacks - Severity & $1(5)$ & Low & $\begin{array}{l}\text { Not } \\
\text { applicable }\end{array}$ & Imprecise & Indirect & Insufficient & No conclusion made \\
\hline & & Acute headache attacks - Duration & $1(5)$ & Low & $\begin{array}{l}\text { Not } \\
\text { applicable }\end{array}$ & Imprecise & Indirect & Insufficient & No conclusion made \\
\hline & & Acute headache attacks - Resolution & $1(5)$ & Low & $\begin{array}{l}\text { Not } \\
\text { applicable }\end{array}$ & Imprecise & Indirect & Insufficient & No conclusion made \\
\hline & & Acute headache attacks - Recurrence & 0 & - & - & - & - & - & - \\
\hline & & Headache-related symptoms - Severity & 0 & - & - & - & - & - & - \\
\hline & & Headache-related symptoms - Duration & 0 & - & - & - & - & - & - \\
\hline & & Headache-related symptoms - Resolution & 0 & - & - & - & - & - & - \\
\hline & & Headache-related symptoms - Recurrence & 0 & - & - & - & - & - & - \\
\hline & & Emergency department or clinic visits & 0 & - & - & - & - & - & - \\
\hline & & Hospitalizations & 0 & - & - & - & - & - & - \\
\hline & & Quality of life & 0 & - & - & - & - & - & - \\
\hline
\end{tabular}




\begin{tabular}{|c|c|c|c|c|c|c|c|c|c|}
\hline Topic & Comparison & Outcome & $\begin{array}{l}\text { N Studies } \\
\text { (Subjects) }\end{array}$ & RoB & Consistency & Precision & $\begin{array}{l}\text { Directne } \\
\text { ss }\end{array}$ & SoE & Conclusions \\
\hline \multirow[t]{13}{*}{ Harms } & \multirow{13}{*}{$\begin{array}{l}\text { 1. Acupuncture vs. } \\
\text { Routine Care }\end{array}$} & AEs - Maternal - Serious, Any & 0 & - & - & - & - & - & - \\
\hline & & AEs - Maternal - Serious, Cardiovascular & 0 & - & - & - & - & - & - \\
\hline & & AEs - Maternal - Discontinuation due to AEs & 0 & - & - & - & - & - & - \\
\hline & & AEs - Fetal/Child - Serious, Any & 0 & - & - & - & - & - & - \\
\hline & & $\begin{array}{l}\text { AEs - Fetal/Child - Serious, Spontaneous abortion } \\
\text { or elective or induced abortion }\end{array}$ & 0 & - & - & - & - & - & - \\
\hline & & $\begin{array}{l}\text { AEs - Fetal/Child - Serious, Stillbirth or fetal } \\
\text { death }\end{array}$ & 0 & - & - & - & - & - & - \\
\hline & & AEs - Fetal/Child - Neonatal or infant death & 0 & - & - & - & - & - & - \\
\hline & & AEs - Fetal/Child - Serious, Preterm birth & 0 & - & - & - & - & - & - \\
\hline & & AEs - Fetal/Child - Serious, Low birth weight & $1(43)$ & High & $\begin{array}{l}\text { Not } \\
\text { applicable }\end{array}$ & Imprecise & Direct & Insufficient & No conclusion made \\
\hline & & AEs - Fetal/Child - Serious, Congenital anomalies & 0 & - & - & - & - & - & - \\
\hline & & $\begin{array}{l}\text { AEs - Fetal/Child - Serious, Perinatal } \\
\text { complications }\end{array}$ & $1(43)$ & High & $\begin{array}{l}\text { Not } \\
\text { applicable }\end{array}$ & Imprecise & Direct & Insufficient & No conclusion made \\
\hline & & AEs - Fetal/Child - Serious, Neurodevelopmental & 0 & - & - & - & - & - & - \\
\hline & & AEs - Fetal/Child - Discontinuation due to AEs & 0 & - & - & - & - & - & - \\
\hline \multirow[t]{13}{*}{ Harms } & \multirow[t]{13}{*}{$\begin{array}{l}\text { 2. Combination of } \\
\text { thermal biofeedback, } \\
\text { relaxation therapy, } \\
\text { and physical therapy }\end{array}$} & AEs - Maternal - Serious, Any & 0 & - & - & - & - & - & - \\
\hline & & AEs - Maternal - Serious, Cardiovascular & 0 & - & - & - & - & - & - \\
\hline & & AEs - Maternal - Discontinuation due to AEs & 0 & - & - & - & - & - & - \\
\hline & & AEs - Fetal/Child - Serious, Any & 0 & - & - & - & - & - & - \\
\hline & & $\begin{array}{l}\text { AEs - Fetal/Child - Serious, Spontaneous abortion } \\
\text { or elective or induced abortion }\end{array}$ & 0 & - & - & - & - & - & - \\
\hline & & $\begin{array}{l}\text { AEs - Fetal/Child - Serious, Stillbirth or fetal } \\
\text { death }\end{array}$ & 0 & - & - & - & - & - & - \\
\hline & & AEs - Fetal/Child - Neonatal or infant death & 0 & - & - & - & - & - & - \\
\hline & & AEs - Fetal/Child - Serious, Preterm birth & 0 & - & - & - & - & - & - \\
\hline & & AEs - Fetal/Child - Serious, Low birth weight & 0 & - & - & - & - & - & - \\
\hline & & AEs - Fetal/Child - Serious, Congenital anomalies & 0 & - & - & - & - & - & - \\
\hline & & $\begin{array}{l}\text { AEs - Fetal/Child - Serious, Perinatal } \\
\text { complications }\end{array}$ & 0 & - & - & - & - & - & - \\
\hline & & AEs - Fetal/Child - Serious, Neurodevelopmental & 0 & - & - & - & - & - & - \\
\hline & & AEs - Fetal/Child - Discontinuation due to AEs & 0 & - & - & - & - & - & - \\
\hline \multirow[t]{4}{*}{ Harms } & \multirow[t]{4}{*}{$\begin{array}{l}\text { 3. Combination of } \\
\text { thermal biofeedback } \\
\text { and relaxation } \\
\text { therapy }\end{array}$} & AEs - Maternal - Serious, Any & 0 & - & - & - & - & - & - \\
\hline & & AEs - Maternal - Serious, Cardiovascular & 0 & - & - & - & - & - & - \\
\hline & & AEs - Maternal - Discontinuation due to AEs & 0 & - & - & - & - & - & - \\
\hline & & AEs - Fetal/Child - Serious, Any & 0 & - & - & - & - & - & - \\
\hline
\end{tabular}




\begin{tabular}{|c|c|c|c|c|c|c|c|c|c|}
\hline Topic & Comparison & Outcome & $\begin{array}{l}\text { N Studies } \\
\text { (Subjects) }\end{array}$ & RoB & Consistency & Precision & $\begin{array}{c}\text { Directne } \\
\text { ss }\end{array}$ & SoE & Conclusions \\
\hline & & $\begin{array}{l}\text { AEs - Fetal/Child - Serious, Spontaneous abortion } \\
\text { or elective or induced abortion }\end{array}$ & 0 & - & - & - & - & - & - \\
\hline & & $\begin{array}{l}\text { AEs - Fetal/Child - Serious, Stillbirth or fetal } \\
\text { death }\end{array}$ & 0 & - & - & - & - & - & - \\
\hline & & AEs - Fetal/Child - Neonatal or infant death & 0 & - & - & - & - & - & - \\
\hline & & AEs - Fetal/Child - Serious, Preterm birth & 0 & - & - & - & - & - & - \\
\hline & & AEs - Fetal/Child - Serious, Low birth weight & 0 & - & - & - & - & - & - \\
\hline & & AEs - Fetal/Child - Serious, Congenital anomalies & 0 & - & - & - & - & - & - \\
\hline & & $\begin{array}{l}\text { AEs - Fetal/Child - Serious, Perinatal } \\
\text { complications }\end{array}$ & 0 & - & - & - & - & - & - \\
\hline & & $\begin{array}{l}\text { AEs - Fetal/Child - Serious, } \\
\text { Neurodevelopmental/Behavioral/Social }\end{array}$ & 0 & - & - & - & - & - & - \\
\hline & & AEs - Fetal/Child - Discontinuation due to AEs & 0 & - & - & - & - & - & - \\
\hline
\end{tabular}

Abbreviations: $\mathrm{AE}=$ adverse effect, $\mathrm{min}=$ minutes, $\mathrm{RoB}=$ risk of bias, $\mathrm{SoE}=$ strength of evidence.

Table B-35. Key Question 2: Nonpharmacologic interventions: Procedures, full evidence profile

\begin{tabular}{|c|c|c|c|c|c|c|c|c|c|}
\hline Topic & Comparison & Outcome & $\begin{array}{r}\text { N Studies } \\
\text { (Subjects) }\end{array}$ & RoB & Consistency & Precision & Directness & SoE & Conclusions \\
\hline \multirow[t]{11}{*}{ Benefits } & \multirow[t]{11}{*}{$\begin{array}{l}\text { Nerve blocks (No } \\
\text { comparison) }\end{array}$} & Acute headache attacks - Severity & $1(13)$ & Low & $\begin{array}{l}\text { Not } \\
\text { applicable }\end{array}$ & $\begin{array}{l}\text { Not } \\
\text { applicable }\end{array}$ & Indirect & Insufficient & $\begin{array}{l}\text { No conclusion } \\
\text { made }\end{array}$ \\
\hline & & Acute headache attacks - Duration & 0 & - & - & - & - & - & - \\
\hline & & Acute headache attacks - Resolution & 0 & - & - & - & - & - & - \\
\hline & & Acute headache attacks - Recurrence & 0 & - & - & - & - & - & - \\
\hline & & Headache-related symptoms - Severity & 0 & - & - & - & - & - & - \\
\hline & & Headache-related symptoms - Duration & 0 & - & - & - & - & - & - \\
\hline & & Headache-related symptoms - Resolution & 0 & - & - & - & - & - & - \\
\hline & & $\begin{array}{l}\text { Headache-related symptoms - } \\
\text { Recurrence }\end{array}$ & 0 & - & - & - & - & - & - \\
\hline & & Emergency department or clinic visits & 0 & - & - & - & - & - & - \\
\hline & & Hospitalizations & 0 & - & - & - & - & - & - \\
\hline & & Quality of life & 0 & - & - & - & - & - & - \\
\hline \multirow[t]{6}{*}{ Harms } & \multirow[t]{6}{*}{$\begin{array}{l}\text { Nerve blocks (No } \\
\text { comparison) }\end{array}$} & AEs - Maternal - Serious, Any & $1(13)$ & Low & $\begin{array}{l}\text { Not } \\
\text { applicable }\end{array}$ & $\begin{array}{l}\text { Not } \\
\text { applicable }\end{array}$ & Indirect & Insufficient & $\begin{array}{l}\text { No conclusion } \\
\text { made }\end{array}$ \\
\hline & & AEs - Maternal - Serious, Cardiovascular & 0 & - & - & - & - & - & - \\
\hline & & $\begin{array}{l}\text { AEs - Maternal - Discontinuation due to } \\
\text { AEs }\end{array}$ & 0 & - & - & - & - & - & - \\
\hline & & AEs - Fetal/Child - Serious, Any & 0 & - & - & - & - & - & - \\
\hline & & $\begin{array}{l}\text { AEs - Fetal/Child - Serious, Spontaneous } \\
\text { abortion or elective or induced abortion }\end{array}$ & 0 & - & - & - & - & - & - \\
\hline & & $\begin{array}{l}\text { AEs - Fetal/Child - Serious, Stillbirth or } \\
\text { fetal death }\end{array}$ & 0 & - & - & - & - & - & - \\
\hline
\end{tabular}




\begin{tabular}{|c|c|c|c|c|c|c|c|c|c|}
\hline Topic & Comparison & Outcome & $\begin{array}{l}\text { N Studies } \\
\text { (Subjects) }\end{array}$ & RoB & Consistency & Precision & Directness & SoE & Conclusions \\
\hline & & $\begin{array}{l}\text { AEs - Fetal/Child - Neonatal or infant } \\
\text { death }\end{array}$ & 0 & - & - & - & - & - & - \\
\hline & & AEs - Fetal/Child - Serious, Preterm birth & 1 (13) & Low & $\begin{array}{l}\text { Not } \\
\text { applicable }\end{array}$ & $\begin{array}{l}\text { Not } \\
\text { applicable }\end{array}$ & Indirect & Insufficient & $\begin{array}{l}\text { No conclusion } \\
\text { made }\end{array}$ \\
\hline & & $\begin{array}{l}\text { AEs - Fetal/Child - Serious, Low birth } \\
\text { weight }\end{array}$ & 0 & - & - & - & - & - & - \\
\hline & & $\begin{array}{l}\text { AEs - Fetal/Child - Serious, Congenital } \\
\text { anomalies }\end{array}$ & 0 & - & - & - & - & - & - \\
\hline & & $\begin{array}{l}\text { AEs - Fetal/Child - Serious, Perinatal } \\
\text { complications }\end{array}$ & 0 & - & - & - & - & - & - \\
\hline & & $\begin{array}{l}\text { AEs - Fetal/Child - Serious, } \\
\text { Neurodevelopmental/Behavioral/Social }\end{array}$ & 0 & - & - & - & - & - & - \\
\hline & & $\begin{array}{l}\text { AEs - Fetal/Child - Discontinuation due } \\
\text { to AEs }\end{array}$ & 0 & - & - & - & - & - & - \\
\hline
\end{tabular}

Abbreviations: $\mathrm{AE}$ = adverse effect, NS = not statistically significant, RoB = risk of bias, SoE = strength of evidence. 
Table B-36. Key Question 2: Nonpharmacologic interventions: Noninvasive neuromodulation devices, full evidence profile

\begin{tabular}{|c|c|c|c|c|c|c|c|c|c|}
\hline Topic & Comparison & Outcome & $\begin{array}{r}\text { N Studies } \\
\text { (Subjects } \\
\text { ) }\end{array}$ & RoB & Consistency & Precision & Directness & SoE & Conclusions \\
\hline \multirow[t]{11}{*}{$\begin{array}{l}\text { Benef } \\
\text { its }\end{array}$} & \multirow[t]{11}{*}{$\begin{array}{l}\text { Transcranial magnetic } \\
\text { stimulation (No } \\
\text { comparison) }\end{array}$} & Acute headache attacks - Severity & 0 & - & - & - & - & - & - \\
\hline & & Acute headache attacks - Duration & 0 & - & - & - & - & - & - \\
\hline & & Acute headache attacks - Resolution & $1(3)$ & Moderate & $\begin{array}{l}\text { Not } \\
\text { applicable }\end{array}$ & $\begin{array}{l}\text { Not } \\
\text { applicable }\end{array}$ & Indirect & Insufficient & $\begin{array}{l}\text { No conclusion } \\
\text { made }\end{array}$ \\
\hline & & Acute headache attacks - Recurrence & 0 & - & - & - & - & - & - \\
\hline & & Headache-related symptoms - Severity & & & & & & & \\
\hline & & Headache-related symptoms - Duration & 0 & - & - & - & - & - & - \\
\hline & & Headache-related symptoms - Resolution & $1(3)$ & Moderate & $\begin{array}{l}\text { Not } \\
\text { applicable }\end{array}$ & $\begin{array}{l}\text { Not } \\
\text { applicable }\end{array}$ & Indirect & Insufficient & $\begin{array}{l}\text { No conclusion } \\
\text { made }\end{array}$ \\
\hline & & Headache-related symptoms - Recurrence & 0 & - & - & - & - & - & - \\
\hline & & Emergency department or clinic visits & 0 & - & - & - & - & - & - \\
\hline & & Hospitalizations & 0 & - & - & - & - & - & - \\
\hline & & Quality of life & 0 & - & - & - & - & - & - \\
\hline \multirow[t]{13}{*}{$\begin{array}{l}\text { Harm } \\
\text { s }\end{array}$} & \multirow[t]{13}{*}{$\begin{array}{l}\text { Transcranial magnetic } \\
\text { stimulation (No } \\
\text { comparison) }\end{array}$} & AEs - Maternal - Serious, Any & $1(3)$ & Moderate & $\begin{array}{l}\text { Not } \\
\text { applicable }\end{array}$ & $\begin{array}{l}\text { Not } \\
\text { applicable }\end{array}$ & Indirect & Insufficient & $\begin{array}{l}\text { No conclusion } \\
\text { made }\end{array}$ \\
\hline & & AEs - Maternal - Serious, Cardiovascular & 0 & - & - & - & - & - & - \\
\hline & & $\begin{array}{l}\text { AEs - Maternal - Discontinuation due to } \\
\text { AEs }\end{array}$ & 0 & - & - & - & - & - & - \\
\hline & & AEs - Fetal/Child - Serious, Any & 0 & - & - & - & - & - & - \\
\hline & & $\begin{array}{l}\text { AEs - Fetal/Child - Serious, Spontaneous } \\
\text { abortion or elective or induced abortion }\end{array}$ & 0 & - & - & - & - & - & - \\
\hline & & $\begin{array}{l}\text { AEs - Fetal/Child - Serious, Stillbirth or } \\
\text { fetal death }\end{array}$ & 0 & - & - & - & - & - & - \\
\hline & & AEs - Fetal/Child - Neonatal or infant death & 0 & - & - & - & - & - & - \\
\hline & & AEs - Fetal/Child - Serious, Preterm birth & 0 & - & - & - & - & - & - \\
\hline & & $\begin{array}{l}\text { AEs - Fetal/Child - Serious, Low birth } \\
\text { weight }\end{array}$ & 0 & - & - & - & - & - & - \\
\hline & & $\begin{array}{l}\text { AEs - Fetal/Child - Serious, Congenital } \\
\text { anomalies }\end{array}$ & 0 & - & - & - & - & - & - \\
\hline & & $\begin{array}{l}\text { AEs - Fetal/Child - Serious, Perinatal } \\
\text { complications }\end{array}$ & 0 & - & - & - & - & - & - \\
\hline & & $\begin{array}{l}\text { AEs - Fetal/Child - Serious, } \\
\text { Neurodevelopmental/Behavioral/Social }\end{array}$ & 0 & - & - & - & - & - & - \\
\hline & & $\begin{array}{l}\text { AEs - Fetal/Child - Discontinuation due to } \\
\text { AEs }\end{array}$ & 0 & - & - & - & - & - & - \\
\hline
\end{tabular}

Abbreviations: $\mathrm{AE}=$ adverse effect, $\mathrm{NS}=$ not statistically significant, $\mathrm{RoB}=$ risk of bias, $\mathrm{SoE}=$ strength of evidence. 


\section{Systematic Reviews}

Table B-37. Systematic reviews of harms of pharmacologic interventions (regardless of indication) - Full evidence profile

\begin{tabular}{|c|c|c|c|c|c|c|c|c|c|}
\hline Class & Drug & Outcome & $\begin{array}{r}\text { N SRs (N } \\
\text { Studies) }\end{array}$ & RoB & Consistency & Precision & Directness & SoE & Conclusions \\
\hline \multirow{13}{*}{$\begin{array}{l}\text { Tricyclic } \\
\text { antidepressants }\end{array}$} & \multirow[t]{13}{*}{ Any } & AEs - Maternal - Serious, Any & 0 & & & & & None & None \\
\hline & & AEs - Maternal - Serious, Cardiovascular & 0 & & & & & None & None \\
\hline & & AEs - Maternal - Discontinuation due to AEs & 0 & & & & & None & None \\
\hline & & AEs - Fetal/Child - Serious, Any & 0 & & & & & None & None \\
\hline & & $\begin{array}{l}\text { AEs - Fetal/Child - Serious, Spontaneous abortion } \\
\text { or elective or induced abortion }\end{array}$ & 0 & & & & & None & None \\
\hline & & AEs - Fetal/Child - Serious, Stillbirth or fetal death & 0 & & & & & None & None \\
\hline & & $\begin{array}{l}\text { AEs - Fetal/Child - Serious, Neonatal or infant } \\
\text { death }\end{array}$ & 0 & & & & & None & None \\
\hline & & AEs - Fetal/Child - Serious, Preterm birth & 0 & & & & & None & None \\
\hline & & AEs - Fetal/Child - Serious, Low birth weight & $1(2)$ & Moderate & Consistent & Precise & Indirect & Moderate & $\begin{array}{l}\text { No increased risk of small for } \\
\text { gestational age }\end{array}$ \\
\hline & & AEs - Fetal/Child - Serious, Congenital anomalies & $1(2)$ & Moderate & Consistent & Precise & Indirect & Moderate & $\begin{array}{l}\text { Increased major and } \\
\text { cardiovascular anomalies }\end{array}$ \\
\hline & & AEs - Fetal/Child - Serious, Perinatal complications & $1(2)$ & Moderate & Consistent & Precise & Indirect & Moderate & $\begin{array}{l}\text { Increased neonatal convulsions } \\
\text { and respiratory distress }\end{array}$ \\
\hline & & $\begin{array}{l}\text { AEs - Fetal/Child - Serious, } \\
\text { Neurodevelopmental/Behavioral/Social }\end{array}$ & $1(1)$ & Moderate & $\mathrm{N} / \mathrm{A}$ & Imprecise & Indirect & Insufficient & None \\
\hline & & AEs - Fetal/Child - Discontinuation due to AEs & 0 & & & & & None & None \\
\hline \multirow{11}{*}{$\begin{array}{l}\text { Serotonin and } \\
\text { norepinephrine } \\
\text { reuptake } \\
\text { inhibitors } \\
\text { (SNRIs) }\end{array}$} & \multirow[t]{11}{*}{$\begin{array}{l}\text { Venlafa } \\
\text { xine }\end{array}$} & AEs - Maternal - Serious, Any & 0 & & & & & None & None \\
\hline & & AEs - Maternal - Serious, Cardiovascular & 0 & & & & & None & None \\
\hline & & AEs - Maternal - Discontinuation due to AEs & 0 & & & & & None & None \\
\hline & & AEs - Fetal/Child - Serious, Any & 0 & & & & & None & None \\
\hline & & $\begin{array}{l}\text { AEs - Fetal/Child - Serious, Spontaneous abortion } \\
\text { or elective or induced abortion }\end{array}$ & 0 & & & & & None & None \\
\hline & & AEs - Fetal/Child - Serious, Stillbirth or fetal death & 0 & & & & & None & None \\
\hline & & $\begin{array}{l}\text { AEs - Fetal/Child - Serious, Neonatal or infant } \\
\text { death }\end{array}$ & 0 & & & & & None & None \\
\hline & & AEs - Fetal/Child - Serious, Preterm birth & $1(2)$ & Moderate & Consistent & Precise & Indirect & Moderate & Increased preterm birth \\
\hline & & AEs - Fetal/Child - Serious, Low birth weight & 0 & & & & & None & None \\
\hline & & AEs - Fetal/Child - Serious, Congenital anomalies & 0 & & & & & None & None \\
\hline & & AEs - Fetal/Child - Serious, Perinatal complications & 0 & & & & & None & None \\
\hline
\end{tabular}




\begin{tabular}{|c|c|c|c|c|c|c|c|c|c|}
\hline Class & Drug & Outcome & $\begin{array}{r}\text { N SRs (N } \\
\text { Studies) } \\
\end{array}$ & RoB & Consistency & Precision & Directness & SoE & Conclusions \\
\hline & & $\begin{array}{l}\text { AEs - Fetal/Child - Serious, } \\
\text { Neurodevelopmental/Behavioral/Social }\end{array}$ & 0 & & & & & None & None \\
\hline & & AEs - Fetal/Child - Discontinuation due to AEs & 0 & & & & & None & None \\
\hline \multirow[t]{13}{*}{ Beta blockers } & \multirow[t]{13}{*}{ Any } & AEs - Maternal - Serious, Any & 0 & & & & & None & None \\
\hline & & AEs - Maternal - Serious, Cardiovascular & 0 & & & & & None & None \\
\hline & & AEs - Maternal - Discontinuation due to AEs & $1(9)$ & Moderate & Consistent & Precise & Indirect & Low & No increased risk \\
\hline & & AEs - Fetal/Child - Serious, Any & 0 & & & & & None & None \\
\hline & & $\begin{array}{l}\text { AEs - Fetal/Child - Serious, Spontaneous abortion } \\
\text { or elective or induced abortion }\end{array}$ & 0 & & & & & None & None \\
\hline & & AEs - Fetal/Child - Serious, Stillbirth or fetal death & 0 & & & & & None & None \\
\hline & & $\begin{array}{l}\text { AEs - Fetal/Child - Serious, Neonatal or infant } \\
\text { death }\end{array}$ & 0 & & & & & None & None \\
\hline & & AEs - Fetal/Child - Serious, Preterm birth & $1(4)$ & Moderate & Consistent & Precise & Indirect & Moderate & No increased risk \\
\hline & & AEs - Fetal/Child - Serious, Low birth weight & 0 & & & & & None & None \\
\hline & & AEs - Fetal/Child - Serious, Congenital anomalies & $1\left(1-5^{*}\right)$ & $\begin{array}{l}\text { Low to } \\
\text { moderate }\end{array}$ & Consistent & Precise & Indirect & Moderate & $\begin{array}{l}\text { Increased cardiovascular } \\
\text { anomalies, cleft lip/palate, and } \\
\text { neural tube defects }\end{array}$ \\
\hline & & AEs - Fetal/Child - Serious, Perinatal complications & $1(1)$ & Moderate & $\mathrm{N} / \mathrm{A}$ & Precise & Indirect & Insufficient & None \\
\hline & & $\begin{array}{l}\text { AEs - Fetal/Child - Serious, } \\
\text { Neurodevelopmental/Behavioral/Social }\end{array}$ & 0 & & & & & None & None \\
\hline & & AEs - Fetal/Child - Discontinuation due to AEs & 0 & & & & & None & None \\
\hline \multirow{13}{*}{$\begin{array}{l}\text { Calcium } \\
\text { channel } \\
\text { blockers }\end{array}$} & \multirow[t]{13}{*}{ Any } & AEs - Maternal - Serious, Any & 0 & & & & & None & None \\
\hline & & AEs - Maternal - Serious, Cardiovascular & 0 & & & & & None & None \\
\hline & & AEs - Maternal - Discontinuation due to AEs & $1(2)$ & Moderate & Consistent & Imprecise & Indirect & Low & No increased risk \\
\hline & & AEs - Fetal/Child - Serious, Any & 0 & & & & & None & None \\
\hline & & $\begin{array}{l}\text { AEs - Fetal/Child - Serious, Spontaneous abortion } \\
\text { or elective or induced abortion }\end{array}$ & $1(5)$ & Moderate & Consistent & Imprecise & Indirect & Low & No increased risk \\
\hline & & AEs - Fetal/Child - Serious, Stillbirth or fetal death & $1(5)$ & Moderate & Consistent & Imprecise & Indirect & Low & No increased risk \\
\hline & & $\begin{array}{l}\text { AEs - Fetal/Child - Serious, Neonatal or infant } \\
\text { death }\end{array}$ & $1(5)$ & Moderate & Consistent & Imprecise & Indirect & Low & No increased risk \\
\hline & & AEs - Fetal/Child - Serious, Preterm birth & $1(4)$ & Moderate & Consistent & Precise & Indirect & Low & No increased risk \\
\hline & & AEs - Fetal/Child - Serious, Low birth weight & 0 & & & & & None & None \\
\hline & & AEs - Fetal/Child - Serious, Congenital anomalies & 0 & & & & & None & None \\
\hline & & AEs - Fetal/Child - Serious, Perinatal complications & $1\left(1-3^{*}\right)$ & $\begin{array}{l}\text { Low to } \\
\text { moderate }\end{array}$ & Consistent & Precise & Indirect & Moderate & $\begin{array}{l}\text { No increased risk of NICU } \\
\text { admission, neonatal respiratory } \\
\text { distress syndrome }\end{array}$ \\
\hline & & $\begin{array}{l}\text { AEs - Fetal/Child - Serious, } \\
\text { Neurodevelopmental/Behavioral/Social }\end{array}$ & 0 & & & & & None & None \\
\hline & & AEs - Fetal/Child - Discontinuation due to AEs & 0 & & & & & None & None \\
\hline $\begin{array}{l}\text { Calcium } \\
\text { channel } \\
\text { blockers }\end{array}$ & $\begin{array}{l}\text { Nifedipi } \\
\text { ne }\end{array}$ & AEs - Maternal - Serious, Any & 0 & & & & & None & None \\
\hline
\end{tabular}




\begin{tabular}{|c|c|c|c|c|c|c|c|c|c|}
\hline Class & Drug & Outcome & $\begin{array}{r}\text { N SRs (N } \\
\text { Studies) } \\
\end{array}$ & RoB & Consistency & Precision & Directness & SoE & Conclusions \\
\hline & & AEs - Maternal - Serious, Cardiovascular & 0 & & & & & None & None \\
\hline & & AEs - Maternal - Discontinuation due to AEs & 0 & & & & & None & None \\
\hline & & AEs - Fetal/Child - Serious, Any & 0 & & & & & None & None \\
\hline & & $\begin{array}{l}\text { AEs - Fetal/Child - Serious, Spontaneous abortion } \\
\text { or elective or induced abortion }\end{array}$ & 0 & & & & & None & None \\
\hline & & AEs - Fetal/Child - Serious, Stillbirth or fetal death & 0 & & & & & None & None \\
\hline & & $\begin{array}{l}\text { AEs - Fetal/Child - Serious, Neonatal or infant } \\
\text { death }\end{array}$ & $1(2)$ & Moderate & Consistent & Precise & Indirect & Moderate & No increased risk \\
\hline & & AEs - Fetal/Child - Serious, Preterm birth & $1(2)$ & Moderate & Consistent & Imprecise & Indirect & Low & No increased risk \\
\hline & & AEs - Fetal/Child - Serious, Low birth weight & 0 & & & & & None & None \\
\hline & & AEs - Fetal/Child - Serious, Congenital anomalies & 0 & & & & & None & None \\
\hline & & AEs - Fetal/Child - Serious, Perinatal complications & 0 & & & & & None & None \\
\hline & & $\begin{array}{l}\text { AEs - Fetal/Child - Serious, } \\
\text { Neurodevelopmental/Behavioral/Social }\end{array}$ & 0 & & & & & None & None \\
\hline & & AEs - Fetal/Child - Discontinuation due to AEs & 0 & & & & & None & None \\
\hline \multirow[t]{13}{*}{ Anti-epileptics } & \multirow{13}{*}{$\begin{array}{l}\text { Valproat } \\
\text { e }\end{array}$} & AEs - Maternal - Serious, Any & 0 & & & & & None & None \\
\hline & & AEs - Maternal - Serious, Cardiovascular & 0 & & & & & None & None \\
\hline & & AEs - Maternal - Discontinuation due to AEs & 0 & & & & & None & None \\
\hline & & AEs - Fetal/Child - Serious, Any & 0 & & & & & None & None \\
\hline & & $\begin{array}{l}\text { AEs - Fetal/Child - Serious, Spontaneous abortion } \\
\text { or elective or induced abortion }\end{array}$ & 1 (96) & $\begin{array}{l}\text { Low to } \\
\text { moderate }\end{array}$ & Consistent & Precise & Indirect & Moderate & Increased spontaneous abortion \\
\hline & & AEs - Fetal/Child - Serious, Stillbirth or fetal death & $1(96)$ & $\begin{array}{l}\text { Low to } \\
\text { moderate }\end{array}$ & Consistent & Precise & Indirect & Moderate & Increased fetal death \\
\hline & & $\begin{array}{l}\text { AEs - Fetal/Child - Serious, Neonatal or infant } \\
\text { death }\end{array}$ & 0 & & & & & None & None \\
\hline & & AEs - Fetal/Child - Serious, Preterm birth & $1(96)$ & $\begin{array}{l}\text { Low to } \\
\text { moderate }\end{array}$ & Consistent & Precise & Indirect & Moderate & No increased risk \\
\hline & & AEs - Fetal/Child - Serious, Low birth weight & 0 & & & & & None & None \\
\hline & & AEs - Fetal/Child - Serious, Congenital anomalies & $2(96)$ & $\begin{array}{l}\text { Low to } \\
\text { moderate }\end{array}$ & Consistent & Precise & Indirect & Moderate & $\begin{array}{l}\text { Increased major anomalies, } \\
\text { hypospadias, cleft lip/palate, } \\
\text { club foot, neural tube defects }\end{array}$ \\
\hline & & AEs - Fetal/Child - Serious, Perinatal complications & 0 & & & & & None & None \\
\hline & & $\begin{array}{l}\text { AEs - Fetal/Child - Serious, } \\
\text { Neurodevelopmental/Behavioral/Social }\end{array}$ & $1(96)$ & $\begin{array}{l}\text { Low to } \\
\text { moderate }\end{array}$ & Consistent & Precise & Indirect & Moderate & $\begin{array}{l}\text { Increased cognitive delay, } \\
\text { autism/dyspraxia, psychomotor } \\
\text { developmental delay, language } \\
\text { delay }\end{array}$ \\
\hline & & AEs - Fetal/Child - Discontinuation due to AEs & 0 & & & & & None & None \\
\hline Anti-epileptics & $\begin{array}{l}\text { Topiram } \\
\text { ate }\end{array}$ & AEs - Maternal - Serious, Any & 0 & & & & & None & None \\
\hline
\end{tabular}




\begin{tabular}{|c|c|c|c|c|c|c|c|c|c|}
\hline Class & Drug & Outcome & $\begin{array}{r}\text { N SRs (N } \\
\text { Studies) }\end{array}$ & RoB & Consistency & Precision & Directness & SoE & Conclusions \\
\hline & & AEs - Maternal - Serious, Cardiovascular & 0 & & & & & None & None \\
\hline & & AEs - Maternal - Discontinuation due to AEs & 0 & & & & & None & None \\
\hline & & AEs - Fetal/Child - Serious, Any & $1(96)$ & $\begin{array}{l}\text { Low to } \\
\text { moderate }\end{array}$ & Consistent & Precise & Indirect & Moderate & $\begin{array}{l}\text { Increased fetal growth } \\
\text { restriction }\end{array}$ \\
\hline & & $\begin{array}{l}\text { AEs - Fetal/Child - Serious, Spontaneous abortion } \\
\text { or elective or induced abortion }\end{array}$ & 1 (96) & $\begin{array}{l}\text { Low to } \\
\text { moderate }\end{array}$ & Consistent & Precise & Indirect & Moderate & Increased spontaneous abortion \\
\hline & & AEs - Fetal/Child - Serious, Stillbirth or fetal death & $1(96)$ & $\begin{array}{l}\text { Low to } \\
\text { moderate }\end{array}$ & Consistent & Precise & Indirect & Moderate & Increased fetal death \\
\hline & & $\begin{array}{l}\text { AEs - Fetal/Child - Serious, Neonatal or infant } \\
\text { death }\end{array}$ & 0 & & & & & None & None \\
\hline & & AEs - Fetal/Child - Serious, Preterm birth & $1(96)$ & $\begin{array}{l}\text { Low to } \\
\text { moderate }\end{array}$ & Consistent & Precise & Indirect & Moderate & No increased risk \\
\hline & & AEs - Fetal/Child - Serious, Low birth weight & 0 & & & & & None & None \\
\hline & & AEs - Fetal/Child - Serious, Congenital anomalies & $1(96)$ & $\begin{array}{l}\text { Low to } \\
\text { moderate }\end{array}$ & Consistent & Precise & Indirect & Moderate & $\begin{array}{l}\text { Increased major anomalies and } \\
\text { cleft lip/palate }\end{array}$ \\
\hline & & AEs - Fetal/Child - Serious, Perinatal complications & 0 & & & & & None & None \\
\hline & & $\begin{array}{l}\text { AEs - Fetal/Child - Serious, } \\
\text { Neurodevelopmental/Behavioral/Social }\end{array}$ & $1(96)$ & $\begin{array}{l}\text { Low to } \\
\text { moderate }\end{array}$ & Consistent & Imprecise & Indirect & Low & $\begin{array}{l}\text { No increased risk of cognitive or } \\
\text { developmental delays }\end{array}$ \\
\hline & & AEs - Fetal/Child - Discontinuation due to AEs & 0 & & & & & None & None \\
\hline \multirow[t]{13}{*}{ Anti-epileptics } & \multirow{13}{*}{$\begin{array}{l}\text { Gabape } \\
\text { ntin }\end{array}$} & AEs - Maternal - Serious, Any & 0 & & & & & None & None \\
\hline & & AEs - Maternal - Serious, Cardiovascular & 0 & & & & & None & None \\
\hline & & AEs - Maternal - Discontinuation due to AEs & 0 & & & & & None & None \\
\hline & & AEs - Fetal/Child - Serious, Any & $1(96)$ & $\begin{array}{l}\text { Low to } \\
\text { moderate }\end{array}$ & Consistent & Imprecise & Indirect & Low & $\begin{array}{l}\text { No increased risk of fetal growth } \\
\text { restriction }\end{array}$ \\
\hline & & $\begin{array}{l}\text { AEs - Fetal/Child - Serious, Spontaneous abortion } \\
\text { or elective or induced abortion }\end{array}$ & 0 & & & & & None & None \\
\hline & & AEs - Fetal/Child - Serious, Stillbirth or fetal death & 0 & & & & & None & None \\
\hline & & $\begin{array}{l}\text { AEs - Fetal/Child - Serious, Neonatal or infant } \\
\text { death }\end{array}$ & 0 & & & & & & \\
\hline & & AEs - Fetal/Child - Serious, Preterm birth & $1(96)$ & $\begin{array}{l}\text { Low to } \\
\text { moderate }\end{array}$ & Consistent & Precise & Indirect & Low & No increased risk \\
\hline & & AEs - Fetal/Child - Serious, Low birth weight & 0 & & & & & None & None \\
\hline & & AEs - Fetal/Child - Serious, Congenital anomalies & $1(96)$ & $\begin{array}{l}\text { Low to } \\
\text { moderate }\end{array}$ & Inconsistent & Imprecise & Indirect & Low & $\begin{array}{l}\text { Increased cardiovascular } \\
\text { anomalies and hypospadias, but } \\
\text { not cleft lip/palate or club foot }\end{array}$ \\
\hline & & AEs - Fetal/Child - Serious, Perinatal complications & 0 & & & & & None & None \\
\hline & & $\begin{array}{l}\text { AEs - Fetal/Child - Serious, } \\
\text { Neurodevelopmental/Behavioral/Social }\end{array}$ & $1(96)$ & $\begin{array}{l}\text { Low to } \\
\text { moderate }\end{array}$ & Inconsistent & Precise & Indirect & Low & $\begin{array}{l}\text { Increased psychomotor } \\
\text { developmental delay, but not } \\
\text { cognitive developmental delays }\end{array}$ \\
\hline & & AEs - Fetal/Child - Discontinuation due to AEs & 0 & & & & & None & None \\
\hline
\end{tabular}




\begin{tabular}{|c|c|c|c|c|c|c|c|c|c|}
\hline Class & Drug & Outcome & $\begin{array}{r}\text { N SRs (N } \\
\text { Studies) } \\
\end{array}$ & RoB & Consistency & Precision & Directness & SoE & Conclusions \\
\hline \multirow[t]{13}{*}{ Anti-epileptics } & \multirow{13}{*}{$\begin{array}{l}\text { Carbam } \\
\text { azepine }\end{array}$} & AEs - Maternal - Serious, Any & 0 & & & & & None & None \\
\hline & & AEs - Maternal - Serious, Cardiovascular & 0 & & & & & None & None \\
\hline & & AEs - Maternal - Discontinuation due to AEs & 0 & & & & & None & None \\
\hline & & AEs - Fetal/Child - Serious, Any & 0 & & & & & None & None \\
\hline & & $\begin{array}{l}\text { AEs - Fetal/Child - Serious, Spontaneous abortion } \\
\text { or elective or induced abortion }\end{array}$ & 1 (96) & $\begin{array}{l}\text { Low to } \\
\text { moderate }\end{array}$ & Consistent & Precise & Indirect & Low & No increased risk \\
\hline & & AEs - Fetal/Child - Serious, Stillbirth or fetal death & $1(96)$ & $\begin{array}{l}\text { Low to } \\
\text { moderate }\end{array}$ & Consistent & Precise & Indirect & Low & No increased risk \\
\hline & & $\begin{array}{l}\text { AEs - Fetal/Child - Serious, Neonatal or infant } \\
\text { death }\end{array}$ & 0 & & & & & None & None \\
\hline & & AEs - Fetal/Child - Serious, Preterm birth & 1 (96) & $\begin{array}{l}\text { Low to } \\
\text { moderate }\end{array}$ & Consistent & Precise & Indirect & Low & No increased risk \\
\hline & & AEs - Fetal/Child - Serious, Low birth weight & 0 & & & & & None & None \\
\hline & & AEs - Fetal/Child - Serious, Congenital anomalies & $1(96)$ & $\begin{array}{l}\text { Low to } \\
\text { moderate }\end{array}$ & Consistent & Precise & Indirect & Moderate & $\begin{array}{l}\text { Increased major and minor } \\
\text { anomalies }\end{array}$ \\
\hline & & AEs - Fetal/Child - Serious, Perinatal complications & 0 & & & & & None & None \\
\hline & & $\begin{array}{l}\text { AEs - Fetal/Child - Serious, } \\
\text { Neurodevelopmental/Behavioral/Social }\end{array}$ & 1 (96) & $\begin{array}{l}\text { Low to } \\
\text { moderate }\end{array}$ & Consistent & Precise & Indirect & Moderate & No increased risk \\
\hline & & AEs - Fetal/Child - Discontinuation due to AEs & 0 & & & & & None & None \\
\hline \multirow[t]{11}{*}{ Anti-epileptics } & \multirow{11}{*}{$\begin{array}{l}\text { Lamotri } \\
\text { gine }\end{array}$} & AEs - Maternal - Serious, Any & 0 & & & & & None & None \\
\hline & & AEs - Maternal - Serious, Cardiovascular & 0 & & & & & None & None \\
\hline & & AEs - Maternal - Discontinuation due to AEs & 0 & & & & & None & None \\
\hline & & AEs - Fetal/Child - Serious, Any & 1 (96) & $\begin{array}{l}\text { Low to } \\
\text { moderate }\end{array}$ & Consistent & Precise & Indirect & Moderate & No increased risk \\
\hline & & $\begin{array}{l}\text { AEs - Fetal/Child - Serious, Spontaneous abortion } \\
\text { or elective or induced abortion }\end{array}$ & 1 (96) & $\begin{array}{l}\text { Low to } \\
\text { moderate }\end{array}$ & Consistent & Precise & Indirect & Moderate & No increased risk \\
\hline & & AEs - Fetal/Child - Serious, Stillbirth or fetal death & $1(96)$ & $\begin{array}{l}\text { Low to } \\
\text { moderate }\end{array}$ & Consistent & Precise & Indirect & Moderate & No increased risk \\
\hline & & $\begin{array}{l}\text { AEs - Fetal/Child - Serious, Neonatal or infant } \\
\text { death }\end{array}$ & 0 & & & & & None & None \\
\hline & & AEs - Fetal/Child - Serious, Preterm birth & $1(96)$ & $\begin{array}{l}\text { Low to } \\
\text { moderate }\end{array}$ & Consistent & Precise & Indirect & Moderate & No increased risk \\
\hline & & AEs - Fetal/Child - Serious, Low birth weight & 0 & & & & & None & None \\
\hline & & AEs - Fetal/Child - Serious, Congenital anomalies & $1(96)$ & $\begin{array}{l}\text { Low to } \\
\text { moderate }\end{array}$ & Consistent & Precise & Indirect & Moderate & No increased risk \\
\hline & & AEs - Fetal/Child - Serious, Perinatal complications & 0 & & & & & None & None \\
\hline
\end{tabular}




\begin{tabular}{|c|c|c|c|c|c|c|c|c|c|}
\hline Class & Drug & Outcome & $\begin{array}{r}\text { N SRs (N } \\
\text { Studies) } \\
\end{array}$ & RoB & Consistency & Precision & Directness & SoE & Conclusions \\
\hline & & $\begin{array}{l}\text { AEs - Fetal/Child - Serious, } \\
\text { Neurodevelopmental/Behavioral/Social }\end{array}$ & $1(96)$ & $\begin{array}{l}\text { Low to } \\
\text { moderate }\end{array}$ & Consistent & Precise & Indirect & Moderate & $\begin{array}{l}\text { Increased autism/dyspraxia, but } \\
\text { no increased risk of cognitive or } \\
\text { psychomotor developmental } \\
\text { delays, language delay, for } \\
\text { attention deficit hyperactivity } \\
\text { disorder }\end{array}$ \\
\hline & & AEs - Fetal/Child - Discontinuation due to AEs & 0 & & & & & None & None \\
\hline \multirow{13}{*}{$\begin{array}{l}\text { Benzodiazepine } \\
\mathrm{s}\end{array}$} & \multirow[t]{13}{*}{ Any } & AEs - Maternal - Serious, Any & 0 & & & & & None & None \\
\hline & & AEs - Maternal - Serious, Cardiovascular & 0 & & & & & None & None \\
\hline & & AEs - Maternal - Discontinuation due to AEs & 0 & & & & & None & None \\
\hline & & AEs - Fetal/Child - Serious, Any & 0 & & & & & None & None \\
\hline & & $\begin{array}{l}\text { AEs - Fetal/Child - Serious, Spontaneous abortion } \\
\text { or elective or induced abortion }\end{array}$ & 0 & & & & & None & None \\
\hline & & AEs - Fetal/Child - Serious, Stillbirth or fetal death & 0 & & & & & None & None \\
\hline & & $\begin{array}{l}\text { AEs - Fetal/Child - Serious, Neonatal or infant } \\
\text { death }\end{array}$ & 0 & & & & & None & None \\
\hline & & AEs - Fetal/Child - Serious, Preterm birth & 0 & & & & & None & None \\
\hline & & AEs - Fetal/Child - Serious, Low birth weight & 0 & & & & & None & None \\
\hline & & AEs - Fetal/Child - Serious, Congenital anomalies & $1\left(6-9^{*}\right)$ & Moderate & Consistent & Precise & Indirect & Low & $\begin{array}{l}\text { Increased major congenital } \\
\text { anomalies and oral cleft }\end{array}$ \\
\hline & & AEs - Fetal/Child - Serious, Perinatal complications & 0 & & & & & None & None \\
\hline & & AEs - Fetal/Child - Serious, Neurodevelopmental & 0 & & & & & None & None \\
\hline & & AEs - Fetal/Child - Discontinuation due to AEs & 0 & & & & & None & None \\
\hline \multirow{13}{*}{$\begin{array}{l}\text { Analgesics/ } \\
\text { Antipyretics }\end{array}$} & \multirow{13}{*}{$\begin{array}{l}\text { Acetami } \\
\text { nophen }\end{array}$} & AEs - Maternal - Serious, Any & 0 & & & & & None & None \\
\hline & & AEs - Maternal - Serious, Cardiovascular & 0 & & & & & None & None \\
\hline & & AEs - Maternal - Discontinuation due to AEs & 0 & & & & & None & None \\
\hline & & AEs - Fetal/Child - Serious, Any & 0 & & & & & None & None \\
\hline & & $\begin{array}{l}\text { AEs - Fetal/Child - Serious, Spontaneous abortion } \\
\text { or elective or induced abortion }\end{array}$ & 0 & & & & & None & None \\
\hline & & AEs - Fetal/Child - Serious, Stillbirth or fetal death & 0 & & & & & None & None \\
\hline & & $\begin{array}{l}\text { AEs - Fetal/Child - Serious, Neonatal or infant } \\
\text { death }\end{array}$ & 0 & & & & & None & None \\
\hline & & AEs - Fetal/Child - Serious, Preterm birth & 0 & & & & & None & None \\
\hline & & AEs - Fetal/Child - Serious, Low birth weight & 0 & & & & & None & None \\
\hline & & AEs - Fetal/Child - Serious, Congenital anomalies & 0 & & & & & None & None \\
\hline & & AEs - Fetal/Child - Serious, Perinatal complications & 0 & & & & & None & None \\
\hline & & $\begin{array}{l}\text { AEs - Fetal/Child - Serious, } \\
\text { Neurodevelopmental/Behavioral/Social }\end{array}$ & $1\left(4-6^{*}\right)$ & Moderate & Inconsistent & Precise & Indirect & Low & $\begin{array}{l}\text { Increased attention deficit } \\
\text { hyperactivity disorder, } \\
\text { hyperactivity symptoms, autism } \\
\text { spectrum disorder, and conduct } \\
\text { disorder }\end{array}$ \\
\hline & & AEs - Fetal/Child - Discontinuation due to AEs & 0 & & & & & None & None \\
\hline
\end{tabular}




\begin{tabular}{|c|c|c|c|c|c|c|c|c|c|}
\hline Class & Drug & Outcome & $\begin{array}{r}\text { N SRs (N } \\
\text { Studies) }\end{array}$ & RoB & Consistency & Precision & Directness & SoE & Conclusions \\
\hline \multirow[t]{13}{*}{ NSAI Ds } & \multirow[t]{13}{*}{ Any } & AEs - Maternal - Serious, Any & 0 & & & & & None & None \\
\hline & & AEs - Maternal - Serious, Cardiovascular & $1(4)$ & Moderate & Consistent & Precise & Indirect & Moderate & $\begin{array}{l}\text { No increased risk of postpartum } \\
\text { hypertension }\end{array}$ \\
\hline & & AEs - Maternal - Discontinuation due to AEs & 0 & & & & & None & None \\
\hline & & AEs - Fetal/Child - Serious, Any & 0 & & & & & None & None \\
\hline & & $\begin{array}{l}\text { AEs - Fetal/Child - Serious, Spontaneous abortion } \\
\text { or elective or induced abortion }\end{array}$ & 0 & & & & & None & None \\
\hline & & AEs - Fetal/Child - Serious, Stillbirth or fetal death & 0 & & & & & None & None \\
\hline & & $\begin{array}{l}\text { AEs - Fetal/Child - Serious, Neonatal or infant } \\
\text { death }\end{array}$ & 0 & & & & & None & None \\
\hline & & AEs - Fetal/Child - Serious, Preterm birth & 0 & & & & & None & None \\
\hline & & AEs - Fetal/Child - Serious, Low birth weight & 0 & & & & & None & None \\
\hline & & AEs - Fetal/Child - Serious, Congenital anomalies & 0 & & & & & None & None \\
\hline & & AEs - Fetal/Child - Serious, Perinatal complications & 0 & & & & & None & None \\
\hline & & $\begin{array}{l}\text { AEs - Fetal/Child - Serious, } \\
\text { Neurodevelopmental/Behavioral/Social }\end{array}$ & 0 & & & & & None & None \\
\hline & & AEs - Fetal/Child - Discontinuation due to AEs & 0 & & & & & None & None \\
\hline \multirow[t]{13}{*}{ NSAI Ds } & \multirow{13}{*}{$\begin{array}{l}\text { Indome } \\
\text { thacin }\end{array}$} & AEs - Maternal - Serious, Any & 0 & & & & & None & None \\
\hline & & AEs - Maternal - Serious, Cardiovascular & 0 & & & & & None & None \\
\hline & & AEs - Maternal - Discontinuation due to AEs & 0 & & & & & None & None \\
\hline & & AEs - Fetal/Child - Serious, Any & 0 & & & & & None & None \\
\hline & & $\begin{array}{l}\text { AEs - Fetal/Child - Serious, Spontaneous abortion } \\
\text { or elective or induced abortion }\end{array}$ & 0 & & & & & None & None \\
\hline & & AEs - Fetal/Child - Serious, Stillbirth or fetal death & 0 & & & & & None & None \\
\hline & & $\begin{array}{l}\text { AEs - Fetal/Child - Serious, Neonatal or infant } \\
\text { death }\end{array}$ & $1(15)$ & Unclear & Consistent & Precise & Indirect & Low & $\begin{array}{l}\text { No increased risk of neonatal } \\
\text { death }\end{array}$ \\
\hline & & AEs - Fetal/Child - Serious, Preterm birth & 0 & & & & & None & None \\
\hline & & AEs - Fetal/Child - Serious, Low birth weight & 0 & & & & & None & None \\
\hline & & AEs - Fetal/Child - Serious, Congenital anomalies & $1(17)$ & Unclear & Consistent & Precise & Indirect & Low & $\begin{array}{l}\text { No increased risk of patent } \\
\text { ductus arteriosus }\end{array}$ \\
\hline & & AEs - Fetal/Child - Serious, Perinatal complications & $1(9-18)$ & Unclear & Consistent & Precise & Indirect & Low & $\begin{array}{l}\text { Increased risk of periventricular } \\
\text { leukomalacia, Grade III-IV } \\
\text { intraventrucular hemorrhage, } \\
\text { and necrotizing enterocolitis }\end{array}$ \\
\hline & & $\begin{array}{l}\text { AEs - Fetal/Child - Serious, } \\
\text { Neurodevelopmental/Behavioral/Social }\end{array}$ & 0 & & & & & None & None \\
\hline & & AEs - Fetal/Child - Discontinuation due to AEs & 0 & & & & & None & None \\
\hline NSAI Ds & $\begin{array}{l}\text { Low- } \\
\text { dose } \\
\text { aspirin }\end{array}$ & AEs - Maternal - Serious, Any & $1(3)$ & Low & Consistent & Precise & Indirect & Moderate & $\begin{array}{l}\text { No increased risk of } \\
\text { hospitalization }\end{array}$ \\
\hline
\end{tabular}




\begin{tabular}{|c|c|c|c|c|c|c|c|c|c|}
\hline Class & Drug & Outcome & $\begin{array}{r}\text { N SRs (N } \\
\text { Studies) }\end{array}$ & RoB & Consistency & Precision & Directness & SoE & Conclusions \\
\hline & & AEs - Maternal - Serious, Cardiovascular & 0 & & & & & None & None \\
\hline & & AEs - Maternal - Discontinuation due to AEs & 0 & & & & & None & None \\
\hline & & AEs - Fetal/Child - Serious, Any & 0 & & & & & None & None \\
\hline & & $\begin{array}{l}\text { AEs - Fetal/Child - Serious, Spontaneous abortion } \\
\text { or elective or induced abortion }\end{array}$ & $3(3-28)$ & $\begin{array}{l}\text { Low to } \\
\text { moderate }\end{array}$ & Consistent & Precise & Indirect & Low & $\begin{array}{l}\text { No increased risk of } \\
\text { spontaneous abortion }\end{array}$ \\
\hline & & AEs - Fetal/Child - Serious, Stillbirth or fetal death & $3(3-28)$ & $\begin{array}{l}\text { Low to } \\
\text { moderate }\end{array}$ & Consistent & Precise & Indirect & Low & $\begin{array}{l}\text { No increased risk of stillbirth, } \\
\text { perinatal mortality }\end{array}$ \\
\hline & & $\begin{array}{l}\text { AEs - Fetal/Child - Serious, Neonatal or infant } \\
\text { death }\end{array}$ & $3(3-28)$ & $\begin{array}{l}\text { Low to } \\
\text { moderate }\end{array}$ & Consistent & Precise & Indirect & Low & No increased risk of infant death \\
\hline & & AEs - Fetal/Child - Serious, Preterm birth & $4(9)$ & $\begin{array}{l}\text { Low to } \\
\text { moderate }\end{array}$ & Consistent & Precise & Indirect & Low & No increased risk \\
\hline & & AEs - Fetal/Child - Serious, Low birth weight & $2(8)$ & $\begin{array}{l}\text { Low to } \\
\text { moderate }\end{array}$ & Inconsistent & Precise & Indirect & Low & No increased risk \\
\hline & & AEs - Fetal/Child - Serious, Congenital anomalies & 0 & & & & & None & \\
\hline & & AEs - Fetal/Child - Serious, Perinatal complications & $1(8-15)$ & $\begin{array}{l}\text { Low to } \\
\text { moderate }\end{array}$ & Inconsistent & Precise & Indirect & Low & $\begin{array}{l}\text { No increased risk of NICU } \\
\text { admission, intraventricular } \\
\text { hemorrhage, other neonatal } \\
\text { bleed }\end{array}$ \\
\hline & & $\begin{array}{l}\text { AEs - Fetal/Child - Serious, } \\
\text { Neurodevelopmental/Behavioral/Social }\end{array}$ & $1(1)$ & Low & $\mathrm{N} / \mathrm{A}$ & Imprecise & Indirect & Low & $\begin{array}{l}\text { No increased risk of gross } \\
\text { motor, fine motor, language, } \\
\text { hearing, speech, etc. }\end{array}$ \\
\hline & & AEs - Fetal/Child - Discontinuation due to AEs & 0 & & & & & None & None \\
\hline \multirow{13}{*}{$\begin{array}{l}\text { Antiemetics: } \\
5 \mathrm{HT3} \\
\text { Antagonists }\end{array}$} & \multirow[t]{13}{*}{$\begin{array}{l}\text { Ondans } \\
\text { etron }\end{array}$} & AEs - Maternal - Serious, Any & 0 & & & & & None & None \\
\hline & & AEs - Maternal - Serious, Cardiovascular & 0 & & & & & None & None \\
\hline & & AEs - Maternal - Discontinuation due to AEs & 0 & & & & & None & None \\
\hline & & AEs - Fetal/Child - Serious, Any & 0 & & & & & None & None \\
\hline & & $\begin{array}{l}\text { AEs - Fetal/Child - Serious, Spontaneous abortion } \\
\text { or elective or induced abortion }\end{array}$ & 0 & & & & & None & None \\
\hline & & AEs - Fetal/Child - Serious, Stillbirth or fetal death & 0 & & & & & None & None \\
\hline & & $\begin{array}{l}\text { AEs - Fetal/Child - Serious, Neonatal or infant } \\
\text { death }\end{array}$ & 0 & & & & & None & None \\
\hline & & AEs - Fetal/Child - Serious, Preterm birth & 0 & & & & & None & None \\
\hline & & AEs - Fetal/Child - Serious, Low birth weight & 0 & & & & & None & None \\
\hline & & AEs - Fetal/Child - Serious, Congenital anomalies & $2(16)$ & Moderate & Consistent & Precise & Indirect & Moderate & $\begin{array}{l}\text { Increased risk of cardiovascular } \\
\text { anomalies, orofacial clefts, } \\
\text { diaphragmatic hernia, and } \\
\text { respiratory system anomalies }\end{array}$ \\
\hline & & AEs - Fetal/Child - Serious, Perinatal complications & 0 & & & & & None & None \\
\hline & & $\begin{array}{l}\text { AEs - Fetal/Child - Serious, } \\
\text { Neurodevelopmental/Behavioral/Social }\end{array}$ & 0 & & & & & None & None \\
\hline & & AEs - Fetal/Child - Discontinuation due to AEs & 0 & & & & & None & None \\
\hline Antihistamines & Any & AEs - Maternal - Serious, Any & 0 & & & & & None & None \\
\hline
\end{tabular}




\begin{tabular}{|c|c|c|c|c|c|c|c|c|c|}
\hline Class & Drug & Outcome & $\begin{array}{r}\text { N SRs (N } \\
\text { Studies) } \\
\end{array}$ & RoB & Consistency & Precision & Directness & SoE & Conclusions \\
\hline & & AEs - Maternal - Serious, Cardiovascular & 0 & & & & & None & None \\
\hline & & AEs - Maternal - Discontinuation due to AEs & 0 & & & & & None & None \\
\hline & & AEs - Fetal/Child - Serious, Any & 0 & & & & & None & None \\
\hline & & $\begin{array}{l}\text { AEs - Fetal/Child - Serious, Spontaneous abortion } \\
\text { or elective or induced abortion }\end{array}$ & $1(8-13)$ & Low & Consistent & Precise & Indirect & Moderate & $\begin{array}{l}\text { No increased risk of } \\
\text { spontaneous abortion }\end{array}$ \\
\hline & & AEs - Fetal/Child - Serious, Stillbirth or fetal death & $1(8-13)$ & Low & Consistent & Precise & Indirect & Moderate & No increased risk of stillbirth \\
\hline & & $\begin{array}{l}\text { AEs - Fetal/Child - Serious, Neonatal or infant } \\
\text { death }\end{array}$ & 0 & & & & & None & None \\
\hline & & AEs - Fetal/Child - Serious, Preterm birth & $1(9)$ & Low & Consistent & Precise & Indirect & Moderate & No increased risk \\
\hline & & AEs - Fetal/Child - Serious, Low birth weight & $1(3)$ & Low & Consistent & Precise & Indirect & Moderate & No increased risk \\
\hline & & AEs - Fetal/Child - Serious, Congenital anomalies & $2(43)$ & Low & Consistent & Precise & Indirect & Moderate & $\begin{array}{l}\text { No increased risk of major } \\
\text { congenital anomalies }\end{array}$ \\
\hline & & AEs - Fetal/Child - Serious, Perinatal complications & 0 & & & & & None & None \\
\hline & & $\begin{array}{l}\text { AEs - Fetal/Child - Serious, } \\
\text { Neurodevelopmental/Behavioral/Social }\end{array}$ & 0 & & & & & None & None \\
\hline \multirow[t]{12}{*}{ Corticosteroids } & \multirow{12}{*}{$\begin{array}{l}\text { Prednis } \\
\text { olone }\end{array}$} & AEs - Maternal - Serious, Any & 0 & & & & & None & None \\
\hline & & AEs - Maternal - Serious, Cardiovascular & 0 & & & & & None & None \\
\hline & & AEs - Maternal - Discontinuation due to AEs & 0 & & & & & None & None \\
\hline & & AEs - Fetal/Child - Serious, Any & 0 & & & & & None & None \\
\hline & & $\begin{array}{l}\text { AEs - Fetal/Child - Serious, Spontaneous abortion } \\
\text { or elective or induced abortion }\end{array}$ & 0 & & & & & None & None \\
\hline & & AEs - Fetal/Child - Serious, Stillbirth or fetal death & 0 & & & & & None & None \\
\hline & & $\begin{array}{l}\text { AEs - Fetal/Child - Serious, Neonatal or infant } \\
\text { death }\end{array}$ & 0 & & & & & None & None \\
\hline & & AEs - Fetal/Child - Serious, Preterm birth & 0 & & & & & None & None \\
\hline & & AEs - Fetal/Child - Serious, Low birth weight & 0 & & & & & None & None \\
\hline & & AEs - Fetal/Child - Serious, Congenital anomalies & $1(4-6)$ & Unclear & Inconsistent & Precise & Indirect & Low & $\begin{array}{l}\text { Increased oral clefts, but no } \\
\text { increased risk of major } \\
\text { anomalies }\end{array}$ \\
\hline & & AEs - Fetal/Child - Serious, Perinatal complications & 0 & & & & & None & None \\
\hline & & $\begin{array}{l}\text { AEs - Fetal/Child - Serious, } \\
\text { Neurodevelopmental/Behavioral/Social }\end{array}$ & 0 & & & & & None & None \\
\hline \multirow[t]{9}{*}{ Triptans } & \multirow[t]{9}{*}{ Any } & AEs - Maternal - Serious, Any & 0 & & & & & None & None \\
\hline & & AEs - Maternal - Serious, Cardiovascular & 0 & & & & & None & None \\
\hline & & AEs - Maternal - Discontinuation due to AEs & 0 & & & & & None & None \\
\hline & & AEs - Fetal/Child - Serious, Any & 0 & & & & & None & None \\
\hline & & $\begin{array}{l}\text { AEs - Fetal/Child - Serious, Spontaneous abortion } \\
\text { or elective or induced abortion }\end{array}$ & $1(2)$ & Unclear & Consistent & Precise & Direct & Moderate & $\begin{array}{l}\text { No increased risk of } \\
\text { spontaneous abortion }\end{array}$ \\
\hline & & AEs - Fetal/Child - Serious, Stillbirth or fetal death & 0 & & & & & None & None \\
\hline & & $\begin{array}{l}\text { AEs - Fetal/Child - Serious, Neonatal or infant } \\
\text { death }\end{array}$ & 0 & & & & & None & None \\
\hline & & AEs - Fetal/Child - Serious, Preterm birth & $1(3)$ & Unclear & Inconsistent & Imprecise & Direct & Low & No increased risk \\
\hline & & AEs - Fetal/Child - Serious, Low birth weight & 0 & & & & & None & None \\
\hline
\end{tabular}




\begin{tabular}{|c|c|c|c|c|c|c|c|c|c|}
\hline Class & Drug & Outcome & $\begin{array}{r}\text { N SRs (N } \\
\text { Studies) } \\
\end{array}$ & RoB & Consistency & Precision & Directness & SoE & Conclusions \\
\hline & & AEs - Fetal/Child - Serious, Congenital anomalies & $1(3)$ & Unclear & Consistent & Precise & Direct & Moderate & $\begin{array}{l}\text { No increased risk of major } \\
\text { anomalies }\end{array}$ \\
\hline & & AEs - Fetal/Child - Serious, Perinatal complications & 0 & & & & & None & None \\
\hline & & $\begin{array}{l}\text { AEs - Fetal/Child - Serious, } \\
\text { Neurodevelopmental/Behavioral/Social }\end{array}$ & 0 & & & & & None & None \\
\hline \multirow[t]{12}{*}{ Antipsychotics } & \multirow[t]{12}{*}{ Any } & AEs - Maternal - Serious, Any & 0 & & & & & None & None \\
\hline & & AEs - Maternal - Serious, Cardiovascular & 0 & & & & & None & None \\
\hline & & AEs - Maternal - Discontinuation due to AEs & 0 & & & & & None & None \\
\hline & & AEs - Fetal/Child - Serious, Any & 0 & & & & & None & None \\
\hline & & $\begin{array}{l}\text { AEs - Fetal/Child - Serious, Spontaneous abortion } \\
\text { or elective or induced abortion }\end{array}$ & $2(7)$ & Moderate & Inconsistent & Precise & Indirect & Low & $\begin{array}{l}\text { No increased risk of } \\
\text { spontaneous abortion }\end{array}$ \\
\hline & & AEs - Fetal/Child - Serious, Stillbirth or fetal death & $2(7)$ & Moderate & Inconsistent & Precise & Indirect & Low & No increased risk of stillbirth \\
\hline & & $\begin{array}{l}\text { AEs - Fetal/Child - Serious, Neonatal or infant } \\
\text { death }\end{array}$ & 0 & & & & & None & None \\
\hline & & AEs - Fetal/Child - Serious, Preterm birth & $2(7)$ & Moderate & Consistent & Precise & Indirect & Moderate & Increased preterm birth \\
\hline & & AEs - Fetal/Child - Serious, Low birth weight & $2(3)$ & Moderate & Consistent & Precise & Indirect & Moderate & $\begin{array}{l}\text { Increased risk of birth weight, } \\
\text { small for gestational age }\end{array}$ \\
\hline & & AEs - Fetal/Child - Serious, Congenital anomalies & $2(4-7)$ & Moderate & Inconsistent & Precise & Indirect & Low & $\begin{array}{l}\text { Increased major and } \\
\text { cardiovascular anomalies }\end{array}$ \\
\hline & & AEs - Fetal/Child - Serious, Perinatal complications & 0 & & & & & None & None \\
\hline & & $\begin{array}{l}\text { AEs - Fetal/Child - Serious, } \\
\text { Neurodevelopmental/Behavioral/Social }\end{array}$ & 0 & & & & & None & None \\
\hline \multirow[t]{12}{*}{$\begin{array}{l}\text { Intravenous } \\
\text { magnesium }\end{array}$} & \multirow[t]{12}{*}{$\begin{array}{l}\text { Magnesi } \\
\text { us }\end{array}$} & AEs - Maternal - Serious, Any & $1(4-5)$ & Unclear & Unclear & Precise & Indirect & Low & $\begin{array}{l}\text { Increased respiratory } \\
\text { depression/other respiratory } \\
\text { problems, but no increased risk } \\
\text { of respiratory arrest or death }\end{array}$ \\
\hline & & AEs - Maternal - Serious, Cardiovascular & $1(4-5)$ & Unclear & Unclear & Imprecise & Indirect & Low & $\begin{array}{l}\text { Increased hypotension, } \\
\text { tachycardia, but no increased } \\
\text { risk of increased cardiac arrest } \\
\text { or death }\end{array}$ \\
\hline & & AEs - Maternal - Discontinuation due to AEs & $1(5)$ & Unclear & Unclear & Precise & Indirect & Low & $\begin{array}{l}\text { Increased discontinuation due } \\
\text { to AEs }\end{array}$ \\
\hline & & AEs - Fetal/Child - Serious, Any & 0 & & & & & None & None \\
\hline & & $\begin{array}{l}\text { AEs - Fetal/Child - Serious, Spontaneous abortion } \\
\text { or elective or induced abortion }\end{array}$ & 0 & & & & & None & None \\
\hline & & AEs - Fetal/Child - Serious, Stillbirth or fetal death & 0 & & & & & None & None \\
\hline & & $\begin{array}{l}\text { AEs - Fetal/Child - Serious, Neonatal or infant } \\
\text { death }\end{array}$ & 0 & & & & & None & None \\
\hline & & AEs - Fetal/Child - Serious, Preterm birth & 0 & & & & & None & None \\
\hline & & AEs - Fetal/Child - Serious, Low birth weight & 0 & & & & & None & None \\
\hline & & AEs - Fetal/Child - Serious, Congenital anomalies & 0 & & & & & None & None \\
\hline & & AEs - Fetal/Child - Serious, Perinatal complications & 0 & & & & & None & None \\
\hline & & $\begin{array}{l}\text { AEs - Fetal/Child - Serious, } \\
\text { Neurodevelopmental/Behavioral/Social }\end{array}$ & 0 & & & & & None & None \\
\hline
\end{tabular}




\begin{tabular}{|c|c|c|c|c|c|c|c|c|c|}
\hline Class & Drug & Outcome & $\begin{array}{r}\text { N SRs (N } \\
\text { Studies) }\end{array}$ & RoB & Consistency & Precision & Directness & SoE & Conclusions \\
\hline \multirow[t]{12}{*}{$\begin{array}{l}\text { Oral } \\
\text { magnesium }\end{array}$} & \multirow[t]{12}{*}{$\begin{array}{l}\text { Magnesi } \\
\text { us }\end{array}$} & AEs - Maternal - Serious, Any & $1(1-5)$ & $\begin{array}{l}\text { Low to } \\
\text { moderate }\end{array}$ & Inconsistent & Precise & Indirect & Low & $\begin{array}{l}\text { No increased risk of } \\
\text { hospitalization or eclampsia }\end{array}$ \\
\hline & & AEs - Maternal - Serious, Cardiovascular & 0 & & & & & None & None \\
\hline & & AEs - Maternal - Discontinuation due to AEs & 0 & & & & & None & None \\
\hline & & AEs - Fetal/Child - Serious, Any & 0 & & & & & None & None \\
\hline & & $\begin{array}{l}\text { AEs - Fetal/Child - Serious, Spontaneous abortion } \\
\text { or elective or induced abortion }\end{array}$ & $1(6)$ & $\begin{array}{l}\text { Low to } \\
\text { moderate }\end{array}$ & Consistent & Precise & Indirect & Low & $\begin{array}{l}\text { No increased risk of } \\
\text { spontaneous abortion }\end{array}$ \\
\hline & & AEs - Fetal/Child - Serious, Stillbirth or fetal death & $1(4)$ & $\begin{array}{l}\text { Low to } \\
\text { moderate }\end{array}$ & Consistent & Precise & Indirect & Low & No increased risk of stillbirth \\
\hline & & $\begin{array}{l}\text { AEs - Fetal/Child - Serious, Neonatal or infant } \\
\text { death }\end{array}$ & $1(4)$ & $\begin{array}{l}\text { Low to } \\
\text { moderate }\end{array}$ & Consistent & Precise & Indirect & Low & Increased neonatal death \\
\hline & & AEs - Fetal/Child - Serious, Preterm birth & 0 & & & & & None & None \\
\hline & & AEs - Fetal/Child - Serious, Low birth weight & $1(5)$ & $\begin{array}{l}\text { Low to } \\
\text { moderate }\end{array}$ & Consistent & Precise & Indirect & Low & $\begin{array}{l}\text { No increased risk of NICU } \\
\text { admission }\end{array}$ \\
\hline & & AEs - Fetal/Child - Serious, Congenital anomalies & 0 & & & & & None & None \\
\hline & & AEs - Fetal/Child - Serious, Perinatal complications & $1(3)$ & $\begin{array}{l}\text { Low to } \\
\text { moderate }\end{array}$ & Consistent & Precise & Indirect & Low & $\begin{array}{l}\text { No increased risk of NICU } \\
\text { admission }\end{array}$ \\
\hline & & $\begin{array}{l}\text { AEs - Fetal/Child - Serious, } \\
\text { Neurodevelopmental/Behavioral/Social }\end{array}$ & 0 & & & & & None & None \\
\hline
\end{tabular}

Abbreviations: $\mathrm{AE}$ = adverse effect, NICU = neonatal intensive care unit, NSAID = nonsteroidal antiinflammatory drug 


\section{Excluded Studies}

\section{Primary Studies}

The 355 excluded articles, along with reasons for exclusion, are summarized in Table B-38. The most common reasons for exclusion were that the articles were not primary studies, were not focused on primary headache, or participants were not pregnant (or attempting to be pregnant), postpartum, or breastfeeding.

Table B-38. Excluded primary studies with reasons for exclusion

\begin{tabular}{|c|c|c|c|c|c|}
\hline No. & $\begin{array}{l}\text { PMI D or Other } \\
\text { I dentifier }\end{array}$ & $\begin{array}{l}\text { First Author } \\
\text { Last Name }\end{array}$ &  & J ournal & Reason for Exclusion \\
\hline 1 & 30574176 & Afridi & $\begin{array}{l}\text { Current concepts in } \\
\text { migraine and their relevance } \\
\text { to pregnancy }\end{array}$ & Obstet Med & Narrative review \\
\hline 2 & 20464586 & Airola & $\begin{array}{l}\text { Non-pharmacological } \\
\text { management of migraine } \\
\text { during pregnancy }\end{array}$ & Neurol Sci & Narrative review \\
\hline 3 & $\begin{array}{l}108093518 \\
\text { (CINAHL) }\end{array}$ & Albrecht & $\begin{array}{l}\text { Is triptan therapy as safe } \\
\text { option for acute migraine in } \\
\text { pregnancy }\end{array}$ & $\begin{array}{l}\text { Evidence- } \\
\text { Based Practice }\end{array}$ & Narrative review \\
\hline 4 & 15108609 & Allais & $\begin{array}{l}\text { [Migraine during pregnancy } \\
\text { and lactation: treatment of } \\
\text { the acute attack and non- } \\
\text { pharmacological } \\
\text { prophylactic strategies] }\end{array}$ & Minerva Med & Narrative review \\
\hline 5 & 30835003 & Allais & $\begin{array}{l}\text { Acupuncture treatment of } \\
\text { migraine, nausea, and } \\
\text { vomiting in pregnancy }\end{array}$ & Neurol Sci & Narrative review \\
\hline 6 & 15549555 & Allais & $\begin{array}{l}\text { Picotamide in migraine aura } \\
\text { prevention: a pilot study }\end{array}$ & Neurol Sci & $\begin{array}{l}\text { Participants not pregnant (or } \\
\text { attempting to be pregnant), } \\
\text { postpartum, or breastfeeding }\end{array}$ \\
\hline 7 & 28759918 & Alrasheed & $\begin{array}{l}\text { Special Considerations for } \\
\text { Primary and Secondary } \\
\text { Stroke Prevention in Women }\end{array}$ & Semin Neurol & $\begin{array}{l}\text { Participants did not have primary } \\
\text { headache or there were no } \\
\text { primary headache-specific data }\end{array}$ \\
\hline 8 & 25797654 & Alsaad & $\begin{array}{l}\text { First trimester exposure to } \\
\text { topiramate and the risk of } \\
\text { oral clefts in the offspring: A } \\
\text { systematic review and meta- } \\
\text { analysis }\end{array}$ & $\begin{array}{l}\text { Reprod } \\
\text { Toxicol }\end{array}$ & 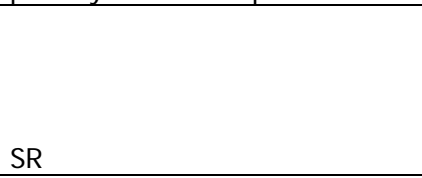 \\
\hline 9 & 30020646 & Altabakhi & $\begin{array}{l}\text { Acetaminophen/Aspirin/Caff } \\
\text { eine }\end{array}$ & StatPearls & Narrative review \\
\hline 10 & 212950 & Aminoff & $\begin{array}{l}\text { Neurological disorders and } \\
\text { pregnancy }\end{array}$ & $\begin{array}{l}\text { AmJ Obstet } \\
\text { Gynecol }\end{array}$ & Narrative review \\
\hline 11 & 25776823 & Amundsen & $\begin{array}{l}\text { Pharmacological treatment } \\
\text { of migraine during } \\
\text { pregnancy and } \\
\text { breastfeeding }\end{array}$ & $\begin{array}{l}\text { Nat Rev } \\
\text { Neurol }\end{array}$ & Narrative review \\
\hline 12 & 27624901 & Amundsen & $\begin{array}{l}\text { Use of antimigraine } \\
\text { medications and information } \\
\text { needs during pregnancy and } \\
\text { breastfeeding: a cross- } \\
\text { sectional study among } 401 \\
\text { Norwegian women } \\
\end{array}$ & $\begin{array}{l}\text { Eur J Clin } \\
\text { Pharmacol }\end{array}$ & $\begin{array}{l}\text { Only addresses } \\
\text { predictors/distribution of } \\
\text { intervention use }\end{array}$ \\
\hline 13 & 30819714 & Amundsen & $\begin{array}{l}\text { Risk perception, beliefs } \\
\text { about medicines and } \\
\text { medical adherence among } \\
\text { pregnant and breastfeeding } \\
\text { women with migraine: } \\
\text { findings from a cross- } \\
\text { sectional study in Norway }\end{array}$ & BMJ Open & $\begin{array}{l}\text { Only addresses } \\
\text { predictors/distribution of } \\
\text { intervention use }\end{array}$ \\
\hline
\end{tabular}




\begin{tabular}{|c|c|c|c|c|c|}
\hline No. & $\begin{array}{l}\text { PMI D or Other } \\
\text { I dentifier }\end{array}$ & $\begin{array}{l}\text { First Author } \\
\text { Last Name }\end{array}$ & Title & Journal & Reason for Exclusion \\
\hline 14 & 29873961 & Andrade & $\begin{array}{l}\text { Valproate in Pregnancy: } \\
\text { Recent Research and } \\
\text { Regulatory Responses }\end{array}$ & $\begin{array}{l}\text { J Clin } \\
\text { Psychiatry }\end{array}$ & $\begin{array}{l}\text { Participants did not have primary } \\
\text { headache or there were no } \\
\text { primary headache-specific data }\end{array}$ \\
\hline 15 & 16478288 & Ashkenazi & $\begin{array}{l}\text { Hormone-related headache: } \\
\text { pathophysiology and } \\
\text { treatment }\end{array}$ & CNS Drugs & Narrative review \\
\hline 16 & 10487510 & Aube & Migraine in pregnancy & Neurology & Narrative review \\
\hline 17 & 30091332 & Ayer & $\begin{array}{l}\text { [Headaches in pregnancy : } \\
\text { management in the } \\
\text { emergency department] }\end{array}$ & $\begin{array}{l}\text { Rev Med } \\
\text { Suisse }\end{array}$ & Narrative review \\
\hline 18 & 27137420 & Balon & $\begin{array}{l}\text { Should women of } \\
\text { childbearing potential be } \\
\text { prescribed valproate? a call } \\
\text { to action }\end{array}$ & $\begin{array}{l}\text { J Clin } \\
\text { Psychiatry }\end{array}$ & Narrative review \\
\hline 19 & 17097212 & Banhidy & $\begin{array}{l}\text { Pregnancy complications } \\
\text { and delivery outcomes in } \\
\text { pregnant women with } \\
\text { severe migraine }\end{array}$ & $\begin{array}{l}\text { Eur J Obstet } \\
\text { Gynecol } \\
\text { Reprod Biol }\end{array}$ & No intervention of interest \\
\hline 20 & 12073705 & Barnett & Migraine in women & Practitioner & Narrative review \\
\hline 21 & 26996986 & Bateman & $\begin{array}{l}\text { Persistent opioid use } \\
\text { following cesarean delivery: } \\
\text { patterns and predictors } \\
\text { among opioid-naive women }\end{array}$ & $\begin{array}{l}\text { AmJ Obstet } \\
\text { Gynecol }\end{array}$ & No intervention of interest \\
\hline 22 & 25877672 & Becker & $\begin{array}{l}\text { Acute Migraine Treatment in } \\
\text { Adults }\end{array}$ & Headache & Narrative review \\
\hline 23 & 26252584 & Becker & Acute Migraine Treatment & $\begin{array}{l}\text { Continuum } \\
\text { (Minneap } \\
\text { Minn) }\end{array}$ & SR \\
\hline 24 & 22270537 & Bendtsen & $\begin{array}{l}\text { Reference programme: } \\
\text { diagnosis and treatment of } \\
\text { headache disorders and } \\
\text { facial pain. Danish } \\
\text { Headache Society, 2nd } \\
\text { Edition, } 2012\end{array}$ & $\begin{array}{l}\text { J Headache } \\
\text { Pain }\end{array}$ & Guideline \\
\hline 25 & 22612391 & Berard & $\begin{array}{l}\text { Dihydroergotamine (DHE) } \\
\text { use during gestation and the } \\
\text { risk of adverse pregnancy } \\
\text { outcomes }\end{array}$ & Headache & $\begin{array}{l}\text { Participants did not have primary } \\
\text { headache or there were no } \\
\text { primary headache-specific data }\end{array}$ \\
\hline 26 & 21243447 & Bigal & Migraine chronification & $\begin{array}{l}\text { Curr Neurol } \\
\text { Neurosci Rep }\end{array}$ & No intervention of interest \\
\hline 27 & 31242344 & Black & $\begin{array}{l}\text { Medication Use and Pain } \\
\text { Management in Pregnancy: } \\
\text { A Critical Review }\end{array}$ & Pain Pract & 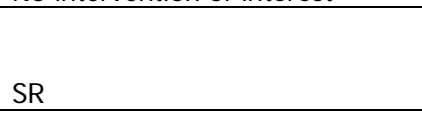 \\
\hline 28 & 10637811 & Block & $\begin{array}{l}\text { [Neurologic diseases and } \\
\text { pregnancy] }\end{array}$ & Nervenarzt & $\begin{array}{l}\text { Participants did not have primary } \\
\text { headache or there were no } \\
\text { primary headache-specific data }\end{array}$ \\
\hline 29 & 23406160 & Blumenfeld & $\begin{array}{l}\text { Expert consensus } \\
\text { recommendations for the } \\
\text { performance of peripheral } \\
\text { nerve blocks for headaches- } \\
\text {-a narrative review }\end{array}$ & Headache & $\begin{array}{l}\text { Participants not pregnant (or } \\
\text { attempting to be pregnant), } \\
\text { postpartum, or breastfeeding }\end{array}$ \\
\hline 30 & $\begin{array}{l}104249214 \\
\text { (CINAHL) }\end{array}$ & Blumenfeld & $\begin{array}{l}\text { Expert Consensus } \\
\text { Recommendations for the } \\
\text { Performance of Peripheral } \\
\text { Nerve Blocks for Headaches } \\
\text { - A Narrative Review }\end{array}$ & $\begin{array}{l}\text { Headache: } \\
\text { The Journal of } \\
\text { Head \& Face } \\
\text { Pain }\end{array}$ & $\begin{array}{l}\text { Participants not pregnant (or } \\
\text { attempting to be pregnant), } \\
\text { postpartum, or breastfeeding }\end{array}$ \\
\hline 31 & 28974300 & Bolz & $\begin{array}{l}\text { The Treatment of Illnesses } \\
\text { Arising in Pregnancy }\end{array}$ & $\begin{array}{l}\text { Dtsch Arztebl } \\
\text { Int }\end{array}$ & Narrative review \\
\hline 32 & 27050859 & Bordini & $\begin{array}{l}\text { Recommendations for the } \\
\text { treatment of migraine } \\
\text { attacks - a Brazilian } \\
\text { consensus }\end{array}$ & $\begin{array}{l}\text { Arq } \\
\text { Neuropsiquiatr }\end{array}$ & $\begin{array}{l}\text { Participants not pregnant (or } \\
\text { attempting to be pregnant), } \\
\text { postpartum, or breastfeeding }\end{array}$ \\
\hline
\end{tabular}




\begin{tabular}{|c|c|c|c|c|c|}
\hline No. & $\begin{array}{l}\text { PMI D or Other } \\
\text { I dentifier }\end{array}$ & $\begin{array}{l}\text { First Author } \\
\text { Last Name }\end{array}$ & Title & J ournal & Reason for Exclusion \\
\hline 33 & 18325295 & Brandes & $\begin{array}{l}\text { Headache related to } \\
\text { pregnancy: management of } \\
\text { migraine and migraine } \\
\text { headache in pregnancy }\end{array}$ & $\begin{array}{l}\text { Curr Treat } \\
\text { Options } \\
\text { Neurol }\end{array}$ & Narrative review \\
\hline 34 & 22868545 & Brandes & Migraine in women & $\begin{array}{l}\text { Continuum } \\
\text { (Minneap } \\
\text { Minn) }\end{array}$ & $\begin{array}{l}\text { Participants not pregnant (or } \\
\text { attempting to be pregnant), } \\
\text { postpartum, or breastfeeding }\end{array}$ \\
\hline 35 & 26635276 & Brin & $\begin{array}{l}\text { Pregnancy outcomes } \\
\text { following exposure to } \\
\text { onabotulinumtoxinA. }\end{array}$ & $\begin{array}{l}\text { Pharmacoepid } \\
\text { emiology and } \\
\text { drug safety }\end{array}$ & $\begin{array}{l}\text { Participants did not have primary } \\
\text { headache or there were no } \\
\text { primary headache-specific data }\end{array}$ \\
\hline 36 & 29270933 & Broner & Migraine in Women & Semin Neurol & Narrative review \\
\hline 37 & $\begin{array}{l}\text { CN-00440883 } \\
\text { (Cochrane) }\end{array}$ & Brown Jr & $\begin{array}{l}\text { A comparative study of } \\
\text { butoconazole vs. miconazole }\end{array}$ & $\begin{array}{l}\text { Journal of } \\
\text { reproductive } \\
\text { medicine for } \\
\text { the } \\
\text { obstetrician } \\
\text { and } \\
\text { gynecologist }\end{array}$ & $\begin{array}{l}\text { Participants did not have primary } \\
\text { headache or there were no } \\
\text { primary headache-specific data }\end{array}$ \\
\hline 38 & 24001268 & Browne & $\begin{array}{l}\text { Maternal butalbital use and } \\
\text { selected defects in the } \\
\text { national birth defects } \\
\text { prevention study }\end{array}$ & Headache & $\begin{array}{l}\text { Participants did not have primary } \\
\text { headache or there were no } \\
\text { primary headache-specific data }\end{array}$ \\
\hline 39 & 30470274 & Burch & $\begin{array}{l}\text { Headache in Pregnancy and } \\
\text { the Puerperium }\end{array}$ & Neurol Clin & Narrative review \\
\hline 40 & 22814005 & Burdan & $\begin{array}{l}\text { Prenatal tolerability of } \\
\text { acetaminophen and other } \\
\text { over-the-counter non- } \\
\text { selective cyclooxygenase } \\
\text { inhibitors }\end{array}$ & $\begin{array}{l}\text { Pharmacol } \\
\text { Rep }\end{array}$ & $\begin{array}{l}\text { Participants did not have primary } \\
\text { headache or there were no } \\
\text { primary headache-specific data }\end{array}$ \\
\hline 41 & 29595872 & Bushman & $\begin{array}{l}\text { Headaches Through a } \\
\text { Woman's Life }\end{array}$ & $\begin{array}{l}\text { Obstet } \\
\text { Gynecol Surv }\end{array}$ & SR \\
\hline 42 & 28980122 & Calhoun & $\begin{array}{l}\text { Migraine Treatment in } \\
\text { Pregnancy and Lactation }\end{array}$ & $\begin{array}{l}\text { Curr Pain } \\
\text { Headache Rep }\end{array}$ & Narrative review \\
\hline 43 & 20425207 & Calhoun & $\begin{array}{l}\text { Treatment of cluster } \\
\text { headache in pregnancy and } \\
\text { lactation }\end{array}$ & $\begin{array}{l}\text { Curr Pain } \\
\text { Headache Rep }\end{array}$ & Narrative review \\
\hline 44 & 16999965 & Campos & $\begin{array}{l}\text { Intracerebral hemorrhage in } \\
\text { postpartum cerebral } \\
\text { angiopathy associated with } \\
\text { the use of isometheptene }\end{array}$ & $\begin{array}{l}\text { Int J Gynaecol } \\
\text { Obstet }\end{array}$ & $\begin{array}{l}\text { Participants did not have primary } \\
\text { headache or there were no } \\
\text { primary headache-specific data }\end{array}$ \\
\hline 45 & 22113510 & Cardona & $\begin{array}{l}\text { Early postpartum headache: } \\
\text { case discussions }\end{array}$ & Semin Neurol & Narrative review \\
\hline 46 & 22993393 & Canville & $\begin{array}{l}\text { Diagnosis and management } \\
\text { of headaches in young } \\
\text { people and adults: summary } \\
\text { of NICE guidance }\end{array}$ & $B m j$ & $\begin{array}{l}\text { Participants not pregnant (or } \\
\text { attempting to be pregnant), } \\
\text { postpartum, or breastfeeding }\end{array}$ \\
\hline 47 & 20662551 & Cassina & $\begin{array}{l}\text { Migraine therapy during } \\
\text { pregnancy and lactation }\end{array}$ & $\begin{array}{l}\text { Expert Opin } \\
\text { Drug Saf }\end{array}$ & SR \\
\hline 48 & 3632373 & Chen & $\begin{array}{l}\text { Migraine and other diseases } \\
\text { in women of reproductive } \\
\text { age. The influence of } \\
\text { smoking on observed } \\
\text { associations }\end{array}$ & Arch Neurol & $\begin{array}{l}\text { Only addresses } \\
\text { predictors/distribution of } \\
\text { intervention use }\end{array}$ \\
\hline 49 & $\begin{array}{l}\text { NCT03951649 } \\
\text { (ClinicalTrials.gov) }\end{array}$ & ClinicalTrials.gov & $\begin{array}{l}\text { Acute Headache Treatment } \\
\text { in Pregnancy: Occipital } \\
\text { Nerve Block vs PO } \\
\text { Acetaminophen With } \\
\text { Caffeine }\end{array}$ & - & Study not yet recruiting \\
\hline 50 & $\begin{array}{l}\text { NCT00632606 } \\
\text { (ClinicalTrials.gov) }\end{array}$ & ClinicalTrials.gov & $\begin{array}{l}\text { MgSO4 vs Metoclopramide } \\
\text { for Headache in Pregnant } \\
\text { Women }\end{array}$ & - & Study withdrawn \\
\hline
\end{tabular}




\begin{tabular}{|c|c|c|c|c|c|}
\hline No. & $\begin{array}{l}\text { PMI D or Other } \\
\text { I dentifier }\end{array}$ & $\begin{array}{l}\text { First Author } \\
\text { Last Name }\end{array}$ & Title & Journal & Reason for Exclusion \\
\hline 51 & $\begin{array}{l}\text { NCT01821807 } \\
\text { (ClinicalTrials.gov) }\end{array}$ & ClinicalTrials.gov & $\begin{array}{l}\text { Comparison of Two Spinal } \\
\text { Needles Regarding Postdural } \\
\text { Puncture Headache }\end{array}$ & - & $\begin{array}{l}\text { Participants did not have primary } \\
\text { headache or there were no } \\
\text { primary headache-specific data }\end{array}$ \\
\hline 52 & $\begin{array}{l}\text { NCT02219269 } \\
\text { (ClinicalTrials.gov) }\end{array}$ & ClinicalTrials.gov & $\begin{array}{l}\text { A Complex Contraception } \\
\text { Registry }\end{array}$ & - & $\begin{array}{l}\text { Participants not pregnant (or } \\
\text { attempting to be pregnant), } \\
\text { postpartum, or breastfeeding }\end{array}$ \\
\hline 53 & $\begin{array}{l}\text { NCT02962427 } \\
\text { (ClinicalTrials.gov) }\end{array}$ & ClinicalTrials.gov & $\begin{array}{l}\text { Treatment of Post-dural } \\
\text { Puncture Headache in } \\
\text { Postpartum Patients: } \\
\text { Sphenopalatine Ganglion } \\
\text { Block to Epidural Blood } \\
\text { Patch. }\end{array}$ & - & $\begin{array}{l}\text { Participants did not have primary } \\
\text { headache or there were no } \\
\text { primary headache-specific data }\end{array}$ \\
\hline 54 & $\begin{array}{l}\text { NCT03185130 } \\
\text { (ClinicalTrials.gov) }\end{array}$ & ClinicalTrials.gov & $\begin{array}{l}\text { Intravenous Fluids in Benign } \\
\text { Headaches Trail }\end{array}$ & - & $\begin{array}{l}\text { Participants not pregnant (or } \\
\text { attempting to be pregnant), } \\
\text { postpartum, or breastfeeding }\end{array}$ \\
\hline 55 & $\begin{array}{l}\text { NCT02549300 } \\
\text { (ClinicalTrials.gov) }\end{array}$ & ClinicalTrials.gov & $\begin{array}{l}\text { The Effects of Connective } \\
\text { Tissue Massage and } \\
\text { Lifestyle Modifications in } \\
\text { Adolescents Tension Type } \\
\text { Headache }\end{array}$ & - & $\begin{array}{l}\text { Participants not pregnant (or } \\
\text { attempting to be pregnant), } \\
\text { postpartum, or breastfeeding }\end{array}$ \\
\hline 56 & $\begin{array}{l}\text { NCT04148846 } \\
\text { (ClinicalTrials.gov) }\end{array}$ & ClinicalTrials.gov & $\begin{array}{l}\text { Sphenopalatine Blockade } \\
\text { Versus Clinical Treatment }\end{array}$ & - & $\begin{array}{l}\text { Participants did not have primary } \\
\text { headache or there were no } \\
\text { primary headache-specific data }\end{array}$ \\
\hline 57 & $\begin{array}{l}\text { NCT02017444 } \\
\text { (ClinicalTrials.gov) }\end{array}$ & ClinicalTrials.gov & $\begin{array}{l}\text { Safety and Effectiveness of } \\
\text { 11b-Hydroxysteroid } \\
\text { Dehydrogenase Type } 1 \\
\text { Inhibitor (AZD4017) to Treat } \\
\text { Idiopathic Intracranial } \\
\text { Hypertension. }\end{array}$ & - & $\begin{array}{l}\text { Participants not pregnant (or } \\
\text { attempting to be pregnant), } \\
\text { postpartum, or breastfeeding }\end{array}$ \\
\hline 58 & $\begin{array}{l}\text { NCT03389945 } \\
\text { (ClinicalTrials.gov) }\end{array}$ & ClinicalTrials.gov & $\begin{array}{l}\text { Different Spinal Needles } \\
\text { Sizes and Dural Puncture } \\
\text { Epidural For Labor Analgesia }\end{array}$ & - & $\begin{array}{l}\text { Participants did not have primary } \\
\text { headache or there were no } \\
\text { primary headache-specific data }\end{array}$ \\
\hline 59 & $\begin{array}{l}\text { NCT03831659 } \\
\text { (ClinicalTrials.gov) }\end{array}$ & ClinicalTrials.gov & Migraine and Infertility & - & $\begin{array}{l}\text { Participants not pregnant (or } \\
\text { attempting to be pregnant), } \\
\text { postpartum, or breastfeeding }\end{array}$ \\
\hline 60 & $\begin{array}{l}\text { NCT01803984 } \\
\text { (ClinicalTrials.gov) }\end{array}$ & ClinicalTrials.gov & $\begin{array}{l}\text { MIBRAIN - Migraine and the } \\
\text { Brain: Consequences, } \\
\text { Causes, and Vascular } \\
\text { Interaction }\end{array}$ & - & $\begin{array}{l}\text { Participants not pregnant (or } \\
\text { attempting to be pregnant), } \\
\text { postpartum, or breastfeeding }\end{array}$ \\
\hline 61 & $\begin{array}{l}\text { NCT03606707 } \\
\text { (ClinicalTrials.gov) }\end{array}$ & ClinicalTrials.gov & $\begin{array}{l}\text { Efficacy of Fluoroscopic } \\
\text { Guided Atlantoaxial Joint } \\
\text { Injection on Head and Neck } \\
\text { Pain and Sleep Quality in RA } \\
\text { Patients }\end{array}$ & - & $\begin{array}{l}\text { Participants did not have primary } \\
\text { headache or there were no } \\
\text { primary headache-specific data }\end{array}$ \\
\hline 62 & $\begin{array}{l}\text { NCT03767803 } \\
\text { (ClinicalTrials.gov) }\end{array}$ & ClinicalTrials.gov & $\begin{array}{l}\text { Collection of Whole Blood } \\
\text { Samples for the Evaluation } \\
\text { of Preeclampsia (Pre-E) } \\
\text { Biomarkers From Pregnant } \\
\text { Women }\end{array}$ & - & $\begin{array}{l}\text { Participants did not have primary } \\
\text { headache or there were no } \\
\text { primary headache-specific data }\end{array}$ \\
\hline 63 & $\begin{array}{l}\text { NCT02122419 } \\
\text { (ClinicalTrials.gov) }\end{array}$ & ClinicalTrials.gov & $\begin{array}{l}\text { The Effect of Patient } \\
\text { Position on Postdural } \\
\text { Puncture Headache }\end{array}$ & - & $\begin{array}{l}\text { Participants did not have primary } \\
\text { headache or there were no } \\
\text { primary headache-specific data }\end{array}$ \\
\hline 64 & $\begin{array}{l}\text { NCT02999919 } \\
\text { (ClinicalTrials.gov) }\end{array}$ & ClinicalTrials.gov & $\begin{array}{l}\text { Body Mass Index and Post- } \\
\text { dural Puncture Headache }\end{array}$ & - & $\begin{array}{l}\text { Participants did not have primary } \\
\text { headache or there were no } \\
\text { primary headache-specific data }\end{array}$ \\
\hline 65 & NCT01194661 & ClinicalTrials.gov & $\begin{array}{l}\text { Neural Dynamics and } \\
\text { Connectivity in Response } \\
\text { Inhibition and Traumatic } \\
\text { Brain Injury } \\
\end{array}$ & - & $\begin{array}{l}\text { Participants did not have primary } \\
\text { headache or there were no } \\
\text { primary headache-specific data }\end{array}$ \\
\hline 66 & 30290741 & Coad & $\begin{array}{l}\text { Acute medical problems in } \\
\text { pregnancy }\end{array}$ & $\begin{array}{l}\text { Br/ Hosp Med } \\
\text { (Lond) }\end{array}$ & No intervention of interest \\
\hline
\end{tabular}




\begin{tabular}{|c|c|c|c|c|c|}
\hline No. & $\begin{array}{l}\text { PMI D or Other } \\
\text { I dentifier }\end{array}$ & $\begin{array}{l}\text { First Author } \\
\text { Last Name }\end{array}$ & Title & Journal & Reason for Exclusion \\
\hline 67 & 11412202 & Cohen & $\begin{array}{l}\text { A new interest in an old } \\
\text { remedy for headache and } \\
\text { backache for our obstetric } \\
\text { patients: a sphenopalatine } \\
\text { ganglion block }\end{array}$ & Anaesthesia & $\begin{array}{l}\text { Participants did not have primary } \\
\text { headache or there were no } \\
\text { primary headache-specific data }\end{array}$ \\
\hline 68 & 1540370 & Cohen & $\begin{array}{l}\text { Grand mal seizure in a } \\
\text { postpartum patient following } \\
\text { intravenous infusion of } \\
\text { caffeine sodium benzoate to } \\
\text { treat persistent headache }\end{array}$ & J Clin Anesth & $\begin{array}{l}\text { Participants did not have primary } \\
\text { headache or there were no } \\
\text { primary headache-specific data }\end{array}$ \\
\hline 69 & 0 & Collin-Lavesque & $\begin{array}{l}\text { Infant Exposure to } \\
\text { Methylphenidate and } \\
\text { Duloxetine during Lactation }\end{array}$ & $\begin{array}{l}\text { Breastfeeding } \\
\text { Medicine }\end{array}$ & $\begin{array}{l}\text { Participants did not have primary } \\
\text { headache or there were no } \\
\text { primary headache-specific data }\end{array}$ \\
\hline 70 & 23857445 & Coluzzi & $\begin{array}{l}\text { Chronic pain management in } \\
\text { pregnancy and lactation }\end{array}$ & $\begin{array}{l}\text { Minerva } \\
\text { Anestesiol }\end{array}$ & Narrative review \\
\hline 71 & 16266607 & Conner & $\begin{array}{l}\text { Clinical Inquiries. What are } \\
\text { the best therapies for acute } \\
\text { migraine in pregnancy? }\end{array}$ & J Fam Pract & Narrative review \\
\hline 72 & 16670039 & Conner & $\begin{array}{l}\text { Clinical inquiries. How can } \\
\text { you prevent migraines } \\
\text { during pregnancy? }\end{array}$ & J Fam Pract & Narrative review \\
\hline 73 & 20930632 & Contag & $\begin{array}{l}\text { Contemporary management } \\
\text { of migrainous disorders in } \\
\text { pregnancy }\end{array}$ & $\begin{array}{l}\text { Curr Opin } \\
\text { Obstet } \\
\text { Gynecol }\end{array}$ & Narrative review \\
\hline 74 & 19597515 & Contag & $\begin{array}{l}\text { Migraine during pregnancy: } \\
\text { is it more than a headache? }\end{array}$ & $\begin{array}{l}\text { Nat Rev } \\
\text { Neurol }\end{array}$ & Narrative review \\
\hline 75 & 2871927 & Dalessio & $\begin{array}{l}\text { Classification and treatment } \\
\text { of headache during } \\
\text { pregnancy }\end{array}$ & $\begin{array}{l}\text { Clin } \\
\text { Neuropharmac } \\
\text { ol }\end{array}$ & Narrative review \\
\hline 76 & No PubMed ID & Damase-Michel & $\begin{array}{l}\text { What do pregnant women } \\
\text { know about non-steroidal } \\
\text { anti-inflammatory drugs? }\end{array}$ & $\begin{array}{l}\text { Pharmacoepid } \\
\text { emiology and } \\
\text { Drug Safety }\end{array}$ & $\begin{array}{l}\text { Participants did not have primary } \\
\text { headache or there were no } \\
\text { primary headache-specific data }\end{array}$ \\
\hline 77 & 6440873 & Damasio & $\begin{array}{l}\text { Drug management of adult } \\
\text { vascular headaches } \\
\text { (migraine and cluster } \\
\text { headache): Part II-- } \\
\text { Prevention and attacks }\end{array}$ & Iowa Med & $\begin{array}{l}\text { Participants not pregnant (or } \\
\text { attempting to be pregnant), } \\
\text { postpartum, or breastfeeding }\end{array}$ \\
\hline 78 & 25217187 & Davanzo & $\begin{array}{l}\text { Breastfeeding and migraine } \\
\text { drugs }\end{array}$ & $\begin{array}{l}\text { Eur J Clin } \\
\text { Pharmacol }\end{array}$ & SR \\
\hline 79 & 2134841 & Day & $\begin{array}{l}\text { Migraine and other vascular } \\
\text { headaches. An overview of } \\
\text { diagnosis and management }\end{array}$ & $\begin{array}{l}\text { Aust Fam } \\
\text { Physician }\end{array}$ & Narrative review \\
\hline 80 & 23446156 & de Wit & $\begin{array}{l}\text { [Neonatal abstinence } \\
\text { syndrome after maternal } \\
\text { use of tramadol] }\end{array}$ & $\begin{array}{l}\text { Ned Tijdschr } \\
\text { Geneeskd }\end{array}$ & $\begin{array}{l}\text { Participants did not have primary } \\
\text { headache or there were no } \\
\text { primary headache-specific data }\end{array}$ \\
\hline 81 & No PubMed ID & Deck & $\begin{array}{l}\text { Congenital malformations in } \\
\text { infants exposed to } \\
\text { antiepileptic medications in } \\
\text { utero at Boston Medical } \\
\text { Center from } 2003 \text { to } 2010\end{array}$ & $\begin{array}{l}\text { Epilepsy and } \\
\text { Behavior }\end{array}$ & $\begin{array}{l}\text { Participants did not have primary } \\
\text { headache or there were no } \\
\text { primary headache-specific data }\end{array}$ \\
\hline 82 & 11251702 & Demirkaya & $\begin{array}{l}\text { Efficacy of intravenous } \\
\text { magnesium sulfate in the } \\
\text { treatment of acute migraine } \\
\text { attacks }\end{array}$ & Headache & $\begin{array}{l}\text { Participants did not have primary } \\
\text { headache or there were no } \\
\text { primary headache-specific data }\end{array}$ \\
\hline 83 & 28561915 & Deneris & $\begin{array}{l}\text { Migraines in Women: } \\
\text { Current Evidence for } \\
\text { Management of Episodic } \\
\text { and Chronic Migraines }\end{array}$ & $\begin{array}{l}\text { J Midwifery } \\
\text { Womens } \\
\text { Health }\end{array}$ & Narrative review \\
\hline 84 & 22419343 & Derry & $\begin{array}{l}\text { Caffeine as an analgesic } \\
\text { adjuvant for acute pain in } \\
\text { adults }\end{array}$ & $\begin{array}{l}\text { Cochrane } \\
\text { Database Syst } \\
\text { Rev }\end{array}$ & $\begin{array}{l}\text { Participants not pregnant (or } \\
\text { attempting to be pregnant), } \\
\text { postpartum, or breastfeeding }\end{array}$ \\
\hline 85 & 25502052 & Derry & $\begin{array}{l}\text { Caffeine as an analgesic } \\
\text { adjuvant for acute pain in } \\
\text { adults }\end{array}$ & $\begin{array}{l}\text { Cochrane } \\
\text { Database Syst } \\
\text { Rev }\end{array}$ & $\begin{array}{l}\text { Participants not pregnant (or } \\
\text { attempting to be pregnant), } \\
\text { postpartum, or breastfeeding }\end{array}$ \\
\hline
\end{tabular}




\begin{tabular}{|c|c|c|c|c|c|}
\hline No. & $\begin{array}{l}\text { PMI D or Other } \\
\text { I dentifier }\end{array}$ & $\begin{array}{l}\text { First Author } \\
\text { Last Name }\end{array}$ & Title & J ournal & Reason for Exclusion \\
\hline 86 & 21530095 & Dhillon & $\begin{array}{l}\text { A new horizon into the } \\
\text { pathobiology, etiology and } \\
\text { treatment of migraine }\end{array}$ & $\begin{array}{l}\text { Med } \\
\text { Hypotheses }\end{array}$ & Narrative review \\
\hline 87 & 4821163 & Diamond & $\begin{array}{l}\text { The diagnosis and treatment } \\
\text { of headache }\end{array}$ & $\begin{array}{l}\text { Med Trial } \\
\text { Tech } Q\end{array}$ & Narrative review \\
\hline 88 & 0 & Diamond & $\begin{array}{l}\text { Headache treatment during } \\
\text { lactation }\end{array}$ & Consultant & $\begin{array}{l}\text { Participants not pregnant (or } \\
\text { attempting to be pregnant), } \\
\text { postpartum, or breastfeeding }\end{array}$ \\
\hline 89 & 18336060 & Diav-Citrin & $\begin{array}{l}\text { Pregnancy outcome after in } \\
\text { utero exposure to valproate } \\
: \text { evidence of dose } \\
\text { relationship in teratogenic } \\
\text { effect }\end{array}$ & CNS Drugs & $\begin{array}{l}\text { Participants did not have primary } \\
\text { headache or there were no } \\
\text { primary headache-specific data }\end{array}$ \\
\hline 90 & 11772289 & Diener & $\begin{array}{l}\text { Advances in pharmacological } \\
\text { treatment of migraine }\end{array}$ & $\begin{array}{l}\text { Expert Opin } \\
\text { Investig Drugs }\end{array}$ & Narrative review \\
\hline 91 & 23563877 & Digre & $\begin{array}{l}\text { Headaches during } \\
\text { pregnancy }\end{array}$ & $\begin{array}{l}\text { Clin Obstet } \\
\text { Gynecol }\end{array}$ & Narrative review \\
\hline 92 & 22518165 & Dixit & $\begin{array}{l}\text { Headache in pregnancy: a } \\
\text { nuisance or a new sense? }\end{array}$ & $\begin{array}{l}\text { Obstet } \\
\text { Gynecol Int }\end{array}$ & Narrative review \\
\hline 93 & 20553334 & Dodick & $\begin{array}{l}\text { Transcranial magnetic } \\
\text { stimulation for migraine: a } \\
\text { safety review }\end{array}$ & Headache & SR \\
\hline 94 & 19022842 & Duncan & $\begin{array}{l}\text { Diagnosis and management } \\
\text { of headache in adults: } \\
\text { summary of SI GN guideline }\end{array}$ & $B m j$ & $\begin{array}{l}\text { Participants not pregnant (or } \\
\text { attempting to be pregnant), } \\
\text { postpartum, or breastfeeding }\end{array}$ \\
\hline 95 & 20547518 & Duong & $\begin{array}{l}\text { Safety of triptans for } \\
\text { migraine headaches during } \\
\text { pregnancy and } \\
\text { breastfeeding }\end{array}$ & $\begin{array}{l}\text { Can Fam } \\
\text { Physician }\end{array}$ & Narrative review \\
\hline 96 & 30074315 & Ehi & $\begin{array}{l}\text { Migraine management in } \\
\text { pregnancy }\end{array}$ & $\begin{array}{l}\text { Clin Exp } \\
\text { Obstet } \\
\text { Gynecol }\end{array}$ & Narrative review \\
\hline 97 & 27030834 & Ekusheva & $\begin{array}{l}\text { [Current approaches to } \\
\text { treatment of migraine } \\
\text { during pregnancy] }\end{array}$ & $\begin{array}{l}\text { Zh Nevrol } \\
\text { Psikhiatr ImS } \\
\text { S Korsakova }\end{array}$ & Narrative review \\
\hline 98 & 23643373 & Elder & $\begin{array}{l}\text { Acupuncture and migraine } \\
\text { prophylaxis, probiotics and } \\
\text { C. Difficile-associated } \\
\text { diarrhea, preventive group } \\
\text { counseling and postpartum } \\
\text { depression, black cohosh } \\
\text { and menopausal symptoms, } \\
\text { deep needling } \\
\text { electroacupuncture and } \\
\text { trigeminal neuralgia }\end{array}$ & Explore (NY) & Narrative review \\
\hline 99 & 10838359 & Eldridge & $\begin{array}{l}\text { Monitoring birth outcomes in } \\
\text { the Sumatriptan Pregnancy } \\
\text { Registry }\end{array}$ & $\begin{array}{l}\text { Prim Care } \\
\text { Update } O b \\
\text { Gyns }\end{array}$ & $\begin{array}{l}\text { Participants did not have primary } \\
\text { headache or there were no } \\
\text { primary headache-specific data }\end{array}$ \\
\hline 100 & CN-01803902 & Euctr & $\begin{array}{l}\text { A Multicenter Study } \\
\text { Evaluating the Efficacy and } \\
\text { Safety of BOTOX } \neg / \mathbb{E} \\
\text { (Botulinum Toxin Type A) } \\
\text { Purified Neurotoxin Complex } \\
\text { as Headache Prophylaxis in } \\
\text { Migraine Patients with } 15 \text { or } \\
\text { More Headache Days per 4- } \\
\text { Week Period in a 24-Week, } \\
\text { Double-Blind, Randomized, } \\
\text { Placebo-Controlled, Parallel- } \\
\text { Group Phase Followed by a } \\
\text { 32-Week Open-Label } \\
\text { Extension Phase }\end{array}$ & $\begin{array}{l}\text { Http://www.w } \\
\text { ho.int/trialsear } \\
\text { ch/trial2.aspx? } \\
\text { Trialid=euctr2 } \\
\text { o05-004637- } \\
\text { 17-de }\end{array}$ & $\begin{array}{l}\text { Participants not pregnant (or } \\
\text { attempting to be pregnant), } \\
\text { postpartum, or breastfeeding }\end{array}$ \\
\hline 101 & 18349309 & Evans & $\begin{array}{l}\text { Use of 5-HT1 agonists in } \\
\text { pregnancy }\end{array}$ & $\begin{array}{l}\text { Ann } \\
\text { Pharmacother }\end{array}$ & SR \\
\hline
\end{tabular}




\begin{tabular}{|c|c|c|c|c|c|}
\hline No. & $\begin{array}{l}\text { PMI D or Other } \\
\text { I dentifier }\end{array}$ & $\begin{array}{l}\text { First Author } \\
\text { Last Name }\end{array}$ & Title & J ournal & Reason for Exclusion \\
\hline 102 & 18806984 & Evers & $\begin{array}{l}\text { [Alternatives to beta } \\
\text { blockers in preventive } \\
\text { migraine treatment] }\end{array}$ & Nervenarzt & Narrative review \\
\hline 103 & 29728203 & Faubion & $\begin{array}{l}\text { Migraine Throughout the } \\
\text { Female Reproductive Life } \\
\text { Cycle }\end{array}$ & Mayo Clin Proc & Narrative review \\
\hline 104 & 6629764 & Featherstone & $\begin{array}{l}\text { Fetal demise in a migraine } \\
\text { patient on propranolol }\end{array}$ & Headache & $\begin{array}{l}\text { Participants did not have primary } \\
\text { headache or there were no } \\
\text { primary headache-specific data }\end{array}$ \\
\hline 105 & 23350149 & Fedorets & $\begin{array}{l}\text { [Headache in pregnant } \\
\text { women] }\end{array}$ & Lik Sprava & Narrative review \\
\hline 106 & 8336286 & Feller & $\begin{array}{l}\text { Headaches during } \\
\text { pregnancy: diagnosis and } \\
\text { management }\end{array}$ & $\begin{array}{l}\text { J Perinat } \\
\text { Neonatal Nurs }\end{array}$ & Narrative review \\
\hline 107 & 7551126 & Ferrari & $\begin{array}{l}\text { Acute treatment of migraine } \\
\text { attacks }\end{array}$ & $\begin{array}{l}\text { Curr Opin } \\
\text { Neurol }\end{array}$ & Narrative review \\
\hline 108 & 25822385 & Flake & $\begin{array}{l}\text { Practical selection of } \\
\text { antiemetics in the } \\
\text { ambulatory setting }\end{array}$ & $\begin{array}{l}\text { Am Fam } \\
\text { Physician }\end{array}$ & No intervention of interest \\
\hline 109 & 26614723 & Forde & $\begin{array}{l}\text { Managing Chronic Headache } \\
\text { Disorders }\end{array}$ & $\begin{array}{l}\text { Med Clin } \\
\text { North Am }\end{array}$ & $\begin{array}{l}\text { Participants not pregnant (or } \\
\text { attempting to be pregnant), } \\
\text { postpartum, or breastfeeding }\end{array}$ \\
\hline 110 & 24934057 & Forderreuther & $\begin{array}{l}\text { [Treatment of migraine in } \\
\text { pregnancy, in patients with } \\
\text { comorbidities and in elderly } \\
\text { people] }\end{array}$ & $\begin{array}{l}\text { MMW Fortschr } \\
\text { Med }\end{array}$ & Narrative review \\
\hline 111 & 15330843 & Fox & $\begin{array}{l}\text { Revised estimates for } \\
\text { probability of successful } \\
\text { outcome of pregnancy after } \\
\text { sumatriptan exposure }\end{array}$ & Headache & Narrative review \\
\hline 112 & 12005279 & Fox & $\begin{array}{l}\text { Evidence-based assessment } \\
\text { of pregnancy outcome after } \\
\text { sumatriptan exposure }\end{array}$ & Headache & Narrative review \\
\hline 113 & 15962998 & Fox & $\begin{array}{l}\text { Migraine during pregnancy: } \\
\text { options for therapy }\end{array}$ & CNS Drugs & Narrative review \\
\hline 114 & $\begin{array}{l}106081110 \\
\text { (CINAHL) }\end{array}$ & Fox & $\begin{array}{l}\text { Revised estimates for } \\
\text { probability of successful } \\
\text { outcome of pregnancy after } \\
\text { sumatriptan } \\
\text { exposure...Headache. } 2001 \\
\text { Apr; } 41(4): 351-6\end{array}$ & $\begin{array}{l}\text { Headache: } \\
\text { The Journal of } \\
\text { Head \& Face } \\
\text { Pain }\end{array}$ & $\begin{array}{l}\text { Participants did not have primary } \\
\text { headache or there were no } \\
\text { primary headache-specific data }\end{array}$ \\
\hline 115 & 11135036 & Fox & $\begin{array}{l}\text { Sumatriptan and pregnancy } \\
\text { outcome }\end{array}$ & Headache & $\begin{array}{l}\text { Participants did not have primary } \\
\text { headache or there were no } \\
\text { primary headache-specific data }\end{array}$ \\
\hline 116 & 15330822 & Friedman & $\begin{array}{l}\text { Local inflammation as a } \\
\text { mediator of migraine and } \\
\text { tension-type headache }\end{array}$ & Headache & $\begin{array}{l}\text { Participants not pregnant (or } \\
\text { attempting to be pregnant), } \\
\text { postpartum, or breastfeeding }\end{array}$ \\
\hline 117 & 1319244 & Fullerton & $\begin{array}{l}\text { Sumatriptan: a selective } 5- \\
\text { hydroxytryptamine receptor } \\
\text { agonist for the acute } \\
\text { treatment of migraine }\end{array}$ & $\begin{array}{l}\text { Ann } \\
\text { Pharmacother }\end{array}$ & $\begin{array}{l}\text { Participants not pregnant (or } \\
\text { attempting to be pregnant), } \\
\text { postpartum, or breastfeeding }\end{array}$ \\
\hline 118 & 24475654 & Gaul & $\begin{array}{l}\text { [Aspirin for migraine in } \\
\text { pregnancy. This } \\
\text { recommendation seems } \\
\text { questionable] }\end{array}$ & $\begin{array}{l}\text { MMW Fortschr } \\
\text { Med }\end{array}$ & Narrative review \\
\hline 119 & 15316764 & Gendolla & $\begin{array}{l}\text { [Difficult decisions: } \\
\text { headache treatment in } \\
\text { pregnancy and childhood] }\end{array}$ & Schmerz & Narrative review \\
\hline 120 & 24571806 & Gentile & $\begin{array}{l}\text { Risks of neurobehavioral } \\
\text { teratogenicity associated } \\
\text { with prenatal exposure to } \\
\text { valproate monotherapy: a } \\
\text { systematic review with } \\
\text { regulatory repercussions }\end{array}$ & CNS Spectr & $\begin{array}{l}\text { Participants did not have primary } \\
\text { headache or there were no } \\
\text { primary headache-specific data }\end{array}$ \\
\hline
\end{tabular}




\begin{tabular}{|c|c|c|c|c|c|}
\hline No. & $\begin{array}{l}\text { PMI D or Other } \\
\text { I dentifier }\end{array}$ & $\begin{array}{l}\text { First Author } \\
\text { Last Name }\end{array}$ & Title & Journal & Reason for Exclusion \\
\hline 121 & 21302868 & Gilmore & $\begin{array}{l}\text { Treatment of acute migraine } \\
\text { headache }\end{array}$ & $\begin{array}{l}\text { Am Fam } \\
\text { Physician }\end{array}$ & Narrative review \\
\hline 122 & 9421548 & Gilmore & $\begin{array}{l}\text { Medication use during } \\
\text { pregnancy for neurologic } \\
\text { conditions }\end{array}$ & Neurol Clin & $\begin{array}{l}\text { Participants did not have primary } \\
\text { headache or there were no } \\
\text { primary headache-specific data }\end{array}$ \\
\hline 123 & 19125883 & Giraud & $\begin{array}{l}\text { Cluster headache during } \\
\text { pregnancy: case report and } \\
\text { literature review }\end{array}$ & Headache & No intervention of interest \\
\hline 124 & 15095535 & Gladstone & $\begin{array}{l}\text { Migraine in special } \\
\text { populations. Treatment } \\
\text { strategies for children and } \\
\text { adolescents, pregnant } \\
\text { women, and the elderly }\end{array}$ & Postgrad Med & $\begin{array}{l}\text { Participants not pregnant (or } \\
\text { attempting to be pregnant), } \\
\text { postpartum, or breastfeeding }\end{array}$ \\
\hline 125 & 18583683 & Goadsby & Migraine in pregnancy & $B m j$ & Narrative review \\
\hline 126 & 20104718 & Gobel & $\begin{array}{l}\text { [Migraine therapy in general } \\
\text { practice 2006] }\end{array}$ & $\begin{array}{l}\text { MMW Fortschr } \\
\text { Med }\end{array}$ & $\begin{array}{l}\text { Participants not pregnant (or } \\
\text { attempting to be pregnant), } \\
\text { postpartum, or breastfeeding }\end{array}$ \\
\hline 127 & 14579489 & Gobel & $\begin{array}{l}\text { [Treatment of migraine: } \\
\text { analgetic plus antiemetic or } \\
\text { tryptan] }\end{array}$ & $\begin{array}{l}\text { MMW Fortschr } \\
\text { Med }\end{array}$ & $\begin{array}{l}\text { Participants not pregnant (or } \\
\text { attempting to be pregnant), } \\
\text { postpartum, or breastfeeding }\end{array}$ \\
\hline 128 & 6133267 & Golightly & $\begin{array}{l}\text { Pindolol: a review of its } \\
\text { pharmacology, } \\
\text { pharmacokinetics, clinical } \\
\text { uses, and adverse effects }\end{array}$ & $\begin{array}{l}\text { Pharmacother } \\
\text { apy }\end{array}$ & Narrative review \\
\hline 129 & 31047730 & Gonzalez-Garcia & $\begin{array}{l}\text { Headache: pregnancy and } \\
\text { breastfeeding } \\
\text { Recommendations of the } \\
\text { Spanish Society of } \\
\text { Neurology's Headache Study } \\
\text { Group }\end{array}$ & Neurologia & Guideline \\
\hline 130 & $\begin{array}{l}109666935 \\
\text { (CINAHL) }\end{array}$ & Govindappagari & $\begin{array}{l}\text { Peripheral nerve blocks in } \\
\text { pregnant patients with } \\
\text { headache }\end{array}$ & $\begin{array}{l}\text { Obstetrics \& } \\
\text { Gynecology }\end{array}$ & No intervention of interest \\
\hline 131 & 24986563 & Grant & $\begin{array}{l}\text { Transnasal topical } \\
\text { sphenopalatine ganglion } \\
\text { block to treat tension } \\
\text { headache in a pregnant } \\
\text { patient }\end{array}$ & $\begin{array}{l}\text { Int J Obstet } \\
\text { Anesth }\end{array}$ & $\begin{array}{l}\text { Participants did not have primary } \\
\text { headache or there were no } \\
\text { primary headache-specific data }\end{array}$ \\
\hline 132 & 16647669 & Graves & $\begin{array}{l}\text { Management of migraine } \\
\text { headaches }\end{array}$ & $\begin{array}{l}\text { J Midwifery } \\
\text { Womens } \\
\text { Health }\end{array}$ & Narrative review \\
\hline 133 & 22724387 & Green & $\begin{array}{l}\text { Utilization of topiramate } \\
\text { during pregnancy and risk of } \\
\text { birth defects }\end{array}$ & Headache & No intervention of interest \\
\hline 134 & 28101987 & Grossman & $\begin{array}{l}\text { Delivery Outcomes of } \\
\text { Patients with Acute Migraine } \\
\text { in Pregnancy: A } \\
\text { Retrospective Study }\end{array}$ & Headache & No intervention of interest \\
\hline 135 & $\begin{array}{l}\text { CN-00979620 } \\
\text { (Cochrane) }\end{array}$ & Guerreiro da Silva & $\begin{array}{l}\text { Corrigendum to Acupuncture } \\
\text { for tension-type headache in } \\
\text { pregnancy: a prospective, } \\
\text { randomized, controlled } \\
\text { study }\end{array}$ & $\begin{array}{l}\text { European } \\
\text { journal of } \\
\text { integrative } \\
\text { medicine }\end{array}$ & Erratum \\
\hline 136 & 11387882 & $\begin{array}{l}\text { Gutierrez } \\
\text { Moctezuma }\end{array}$ & [Migraine in pregnancy] & $\begin{array}{l}\text { Ginecol Obstet } \\
\text { Mex }\end{array}$ & Narrative review \\
\hline 137 & 909023 & Habib & $\begin{array}{l}\text { Effects on the neonate of } \\
\text { propranolol administered } \\
\text { during pregnancy. }\end{array}$ & $\begin{array}{l}\text { The Journal of } \\
\text { pediatrics }\end{array}$ & $\begin{array}{l}\text { Participants did not have primary } \\
\text { headache or there were no } \\
\text { primary headache-specific data }\end{array}$ \\
\hline 138 & 17160116 & Hagen & $\begin{array}{l}\text { [Treatment of migraine } \\
\text { during pregnancy and } \\
\text { breast feeding] }\end{array}$ & $\begin{array}{l}\text { Tidsskr Nor } \\
\text { Laegeforen }\end{array}$ & Narrative review \\
\hline
\end{tabular}




\begin{tabular}{|c|c|c|c|c|c|}
\hline No. & $\begin{array}{l}\text { PMI D or Other } \\
\text { I dentifier }\end{array}$ & $\begin{array}{l}\text { First Author } \\
\text { Last Name }\end{array}$ & Title & Journal & Reason for Exclusion \\
\hline 139 & 20407056 & Haghshenas & $\begin{array}{l}\text { High-flow oxygen for cluster } \\
\text { headache }\end{array}$ & Jama & $\begin{array}{l}\text { Participants not pregnant (or } \\
\text { attempting to be pregnant), } \\
\text { postpartum, or breastfeeding }\end{array}$ \\
\hline 140 & 12068456 & Hainline & $\begin{array}{l}\text { Migraine and other } \\
\text { headache conditions }\end{array}$ & Adv Neurol & Narrative review \\
\hline 141 & 7990784 & Hainline & Headache & Neurol Clin & Narrative review \\
\hline 142 & 30403400 & Hamilton & $\begin{array}{l}\text { Migraine Treatment in } \\
\text { Pregnant Women Presenting } \\
\text { to Acute Care: A } \\
\text { Retrospective Observational } \\
\text { Study }\end{array}$ & Headache & $\begin{array}{l}\text { Only addresses } \\
\text { predictors/distribution of } \\
\text { intervention use }\end{array}$ \\
\hline 143 & 29292614 & Hammerman & $\begin{array}{l}\text { [PSYCHO-MEDICAL } \\
\text { ASPECTS OF PRIMARY } \\
\text { HEADACHES] }\end{array}$ & Harefuah & Narrative review \\
\hline 144 & 19910 & Hardebo & $\begin{array}{l}\text { Reduced sensitivity to alpha- } \\
\text { and beta-adrenergic } \\
\text { receptor agonists of intra- } \\
\text { and extracranial vessels } \\
\text { during pregnancy. } \\
\text { Relevance to migraine }\end{array}$ & $\begin{array}{l}\text { Acta Neurol } \\
\text { Scand Suppl }\end{array}$ & Narrative review \\
\hline 145 & 28705177 & Harris & $\begin{array}{l}\text { Patterns and predictors of } \\
\text { analgesic use in pregnancy: } \\
\text { a longitudinal drug } \\
\text { utilization study with special } \\
\text { focus on women with } \\
\text { migraine }\end{array}$ & $\begin{array}{l}\text { BMC } \\
\text { Pregnancy } \\
\text { Childbirth }\end{array}$ & $\begin{array}{l}\text { Only addresses } \\
\text { predictors/distribution of } \\
\text { intervention use }\end{array}$ \\
\hline 146 & 24708567 & Hashmi & $\begin{array}{l}\text { Low-pressure headache } \\
\text { presenting in early } \\
\text { pregnancy with dramatic } \\
\text { response to glucocorticoids: } \\
\text { a case report. }\end{array}$ & $\begin{array}{l}\text { Journal of } \\
\text { medical case } \\
\text { reports }\end{array}$ & $\begin{array}{l}\text { Participants did not have primary } \\
\text { headache or there were no } \\
\text { primary headache-specific data }\end{array}$ \\
\hline 147 & No PubMed ID & Hernandez-Diaz & $\begin{array}{l}\text { Comparative safety of } \\
\text { antiepileptic drugs during } \\
\text { pregnancy }\end{array}$ & Neurology & $\begin{array}{l}\text { Participants did not have primary } \\
\text { headache or there were no } \\
\text { primary headache-specific data }\end{array}$ \\
\hline 148 & 15316107 & Hilaire & $\begin{array}{l}\text { Treatment of migraine } \\
\text { headaches with sumatriptan } \\
\text { in pregnancy }\end{array}$ & $\begin{array}{l}\text { Ann } \\
\text { Pharmacother }\end{array}$ & 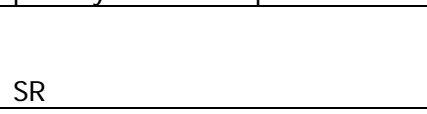 \\
\hline 149 & 20518610 & Hill & $\begin{array}{l}\text { Teratogenic effects of } \\
\text { antiepileptic drugs }\end{array}$ & $\begin{array}{l}\text { Expert Rev } \\
\text { Neurother }\end{array}$ & Narrative review \\
\hline 150 & 202428 & Hopkins & Neurological disorders & $\begin{array}{l}\text { Clin Obstet } \\
\text { Gynaecol }\end{array}$ & Narrative review \\
\hline 151 & 9679377 & Horne & $\begin{array}{l}\text { Treating headaches. A } \\
\text { conceptual framework }\end{array}$ & $\begin{array}{l}\text { Aust Fam } \\
\text { Physician }\end{array}$ & $\begin{array}{l}\text { Participants not pregnant (or } \\
\text { attempting to be pregnant), } \\
\text { postpartum, or breastfeeding }\end{array}$ \\
\hline 152 & 23154716 & Hoshiyama & $\begin{array}{l}\text { Postpartum migraines: a } \\
\text { long-term prospective study }\end{array}$ & Intern Med & $\begin{array}{l}\text { Only addresses } \\
\text { predictors/distribution of } \\
\text { intervention use }\end{array}$ \\
\hline 153 & 23983844 & Hosley & $\begin{array}{l}\text { Acute neurological issues in } \\
\text { pregnancy and the } \\
\text { peripartum }\end{array}$ & $\begin{array}{l}\text { Neurohospitali } \\
\text { st }\end{array}$ & Narrative review \\
\hline 154 & 29250761 & $\mathrm{Hsu}$ & $\begin{array}{l}\text { Medical Treatment } \\
\text { Guidelines for Acute } \\
\text { Migraine Attacks }\end{array}$ & $\begin{array}{l}\text { Acta Neurol } \\
\text { Taiwan }\end{array}$ & $\begin{array}{l}\text { Participants not pregnant (or } \\
\text { attempting to be pregnant), } \\
\text { postpartum, or breastfeeding }\end{array}$ \\
\hline 155 & 28752512 & Huang & $\begin{array}{l}\text { Medical Treatment } \\
\text { Guidelines for Preventive } \\
\text { Treatment of Migraine }\end{array}$ & $\begin{array}{l}\text { Acta Neurol } \\
\text { Taiwan }\end{array}$ & $\begin{array}{l}\text { Participants not pregnant (or } \\
\text { attempting to be pregnant), } \\
\text { postpartum, or breastfeeding }\end{array}$ \\
\hline 156 & 3574535 & Huisjes & [Drugs in migraine] & $\begin{array}{l}\text { Ned Tijdschr } \\
\text { Geneeskd }\end{array}$ & No intervention of interest \\
\hline 157 & 27807736 & Hultzsch & $\begin{array}{l}\text { [Analgesic drugs during } \\
\text { pregnancy] }\end{array}$ & Schmerz & Narrative review \\
\hline
\end{tabular}




\begin{tabular}{|c|c|c|c|c|c|}
\hline No. & $\begin{array}{l}\text { PMI D or Other } \\
\text { I dentifier }\end{array}$ & $\begin{array}{l}\text { First Author } \\
\text { Last Name }\end{array}$ & Title & Journal & Reason for Exclusion \\
\hline 158 & 18645165 & Hunt & $\begin{array}{l}\text { Topiramate in pregnancy: } \\
\text { preliminary experience from } \\
\text { the UK Epilepsy and } \\
\text { Pregnancy Register }\end{array}$ & Neurology & $\begin{array}{l}\text { Participants did not have primary } \\
\text { headache or there were no } \\
\text { primary headache-specific data }\end{array}$ \\
\hline 159 & 16111449 & Hunt & $\begin{array}{l}\text { Safety of antiepileptic drugs } \\
\text { during pregnancy }\end{array}$ & $\begin{array}{l}\text { Expert Opin } \\
\text { Drug Saf }\end{array}$ & $\begin{array}{l}\text { Participants did not have primary } \\
\text { headache or there were no } \\
\text { primary headache-specific data }\end{array}$ \\
\hline 160 & 23465038 & Hutchinson & $\begin{array}{l}\text { Use of common migraine } \\
\text { treatments in breast-feeding } \\
\text { women: a summary of } \\
\text { recommendations }\end{array}$ & Headache &  \\
\hline 161 & $\begin{array}{l}\text { CN-01754801 } \\
\text { (Cochrane) }\end{array}$ & Jahanfar & $\begin{array}{l}\text { Modifications of maternal } \\
\text { caffeine intake for improving } \\
\text { pregnancy outcome }\end{array}$ & $\begin{array}{l}\text { Cochrane } \\
\text { database of } \\
\text { systematic } \\
\text { reviews } \\
\text { (Online) }\end{array}$ & $\begin{array}{l}\text { Participants did not have primary } \\
\text { headache or there were no } \\
\text { primary headache-specific data }\end{array}$ \\
\hline 162 & 20025128 & Janszky & $\begin{array}{l}\text { [Role of zonisamid in } \\
\text { treating epilepsy, Parkinson } \\
\text { disorders and other } \\
\text { neurological diseases] }\end{array}$ & Ideggyogy Sz & Narrative review \\
\hline 163 & 29371217 & Janvis & $\begin{array}{l}\text { Managing migraine in } \\
\text { pregnancy }\end{array}$ & $B m j$ & Narrative review \\
\hline 164 & 15172516 & Johnson & Headache in women & Prim Care & Narrative review \\
\hline 165 & 19170693 & Jurgens & $\begin{array}{l}\text { Treatment of cluster } \\
\text { headache in pregnancy and } \\
\text { lactation }\end{array}$ & Cephalalgia & Narrative review \\
\hline 166 & 27154242 & Kallen & $\begin{array}{l}\text { Ongoing Pharmacological } \\
\text { Management of Chronic Pain } \\
\text { in Pregnancy }\end{array}$ & Drugs & Narrative review \\
\hline 167 & 19810997 & Kanner & $\begin{array}{l}\text { Valproate: a practical review } \\
\text { of its uses in neurological } \\
\text { and psychiatric disorders }\end{array}$ & $\begin{array}{l}\text { Expert Rev } \\
\text { Neurother }\end{array}$ & Narrative review \\
\hline 168 & 15557546 & Kaplan & $\begin{array}{l}\text { Reproductive health effects } \\
\text { and teratogenicity of } \\
\text { antiepileptic drugs }\end{array}$ & Neurology & Narrative review \\
\hline 169 & 31089104 & Karpova & $\begin{array}{l}\text { [Migraine in women: clinical } \\
\text { and therapeutical aspects] }\end{array}$ & $\begin{array}{l}\text { Zh Nevrol } \\
\text { Psikhiatr Im S } \\
\text { S Korsakova }\end{array}$ & Narrative review \\
\hline 170 & 23972191 & Kennis & $\begin{array}{l}\text { Diagnosis and management } \\
\text { of headaches in young } \\
\text { people and adults: NICE } \\
\text { guideline }\end{array}$ & Br」 Gen Pract & $\begin{array}{l}\text { Participants not pregnant (or } \\
\text { attempting to be pregnant), } \\
\text { postpartum, or breastfeeding }\end{array}$ \\
\hline 171 & 23516693 & Kevat & $\begin{array}{l}\text { Neurological diseases in } \\
\text { pregnancy }\end{array}$ & $\begin{array}{l}\text { J Coll } \\
\text { Physicians } \\
\text { Edinb } \\
\end{array}$ & Narrative review \\
\hline 172 & 3804145 & Kromer & $\begin{array}{l}\text { [Drug treatment of pain. 4: } \\
\text { Headache and migraine, } \\
\text { drug interactions, contra- } \\
\text { indications, use of } \\
\text { analgesics in pregnancy and } \\
\text { lactation] }\end{array}$ & Fortschr Med & Narrative review \\
\hline 173 & 20415949 & Kuczkowski & $\begin{array}{l}\text { The potential dangers of } \\
\text { caffeine in pregnancy }\end{array}$ & $\begin{array}{l}\text { Acta } \\
\text { Anaesthesiol } \\
\text { Scand }\end{array}$ & No intervention of interest \\
\hline 174 & 20456148 & Kurth & $\begin{array}{l}\text { Commentary: Triptan use } \\
\text { during pregnancy: a safe } \\
\text { choice? }\end{array}$ & Headache & Narrative review \\
\hline 175 & 21442333 & Kvisvik & $\begin{array}{l}\text { Headache and migraine } \\
\text { during pregnancy and } \\
\text { puerperium: the MIGRA- } \\
\text { study }\end{array}$ & $\begin{array}{l}\text { J Headache } \\
\text { Pain }\end{array}$ & No intervention of interest \\
\hline 176 & 2867457 & Lance & $\begin{array}{l}\text { The pharmacotherapy of } \\
\text { migraine }\end{array}$ & Med J Aust & Narrative review \\
\hline
\end{tabular}




\begin{tabular}{|c|c|c|c|c|c|}
\hline No. & $\begin{array}{l}\text { PMI D or Other } \\
\text { I dentifier }\end{array}$ & $\begin{array}{l}\text { First Author } \\
\text { Last Name }\end{array}$ & Title & J ournal & Reason for Exclusion \\
\hline 177 & 5912494 & Lance & $\begin{array}{l}\text { Some clinical aspects of } \\
\text { migraine. A prospective } \\
\text { survey of } 500 \text { patients }\end{array}$ & Arch Neurol & $\begin{array}{l}\text { Participants did not have primary } \\
\text { headache or there were no } \\
\text { primary headache-specific data }\end{array}$ \\
\hline 178 & 15172517 & Landy & $\begin{array}{l}\text { Challenging or difficult } \\
\text { headache patients }\end{array}$ & Prim Care & Narrative review \\
\hline 179 & 10194980 & Landy & $\begin{array}{l}\text { Divalproex sodium--review } \\
\text { of prophylactic migraine } \\
\text { efficacy, safety and dosage, } \\
\text { with recommendations }\end{array}$ & Tenn Med & Narrative review \\
\hline 180 & $\begin{array}{l}104982660 \\
\text { (CINAHL) }\end{array}$ & Landy & $\begin{array}{l}\text { [Commentary on] Chen HM, } \\
\text { Chen SF, Chen YH, Lin HC. } \\
\text { Increased risk of adverse } \\
\text { pregnancy outcomes for } \\
\text { women with migraines: A } \\
\text { nationwide population-based } \\
\text { study. Cephalalgia. 2010; } \\
\text { 30:433-438 }\end{array}$ & $\begin{array}{l}\text { Headache: } \\
\text { The Journal of } \\
\text { Head \& Face } \\
\text { Pain }\end{array}$ & No intervention of interest \\
\hline 181 & 23246266 & Lanteri-Minet & $\begin{array}{l}\text { [Guidelines for the diagnosis } \\
\text { and management of } \\
\text { migraine in adults and } \\
\text { children] }\end{array}$ & $\begin{array}{l}\text { Rev Neurol } \\
\text { (Paris) }\end{array}$ & Guideline \\
\hline 182 & 6366275 & Laska & $\begin{array}{l}\text { Caffeine as an analgesic } \\
\text { adjuvant }\end{array}$ & Jama & Narrative review \\
\hline 183 & 16628532 & Lay & $\begin{array}{l}\text { Special considerations in the } \\
\text { treatment of migraine in } \\
\text { women }\end{array}$ & Semin Neurol & $\begin{array}{l}\text { Participants not pregnant (or } \\
\text { attempting to be pregnant), } \\
\text { postpartum, or breastfeeding }\end{array}$ \\
\hline 184 & 9075493 & Lewis & $\begin{array}{l}\text { Tramadol: a new centrally } \\
\text { acting analgesic }\end{array}$ & $\begin{array}{l}\text { AmJ Health } \\
\text { Syst Pharm }\end{array}$ & Narrative review \\
\hline 185 & 2872511 & Lindhout & $\begin{array}{l}\text { In-utero exposure to } \\
\text { valproate and neural tube } \\
\text { defects. }\end{array}$ & $\begin{array}{l}\text { Lancet } \\
\text { (London, } \\
\text { England) }\end{array}$ & $\begin{array}{l}\text { Participants did not have primary } \\
\text { headache or there were no } \\
\text { primary headache-specific data }\end{array}$ \\
\hline 186 & $\begin{array}{l}108080885 \\
\text { (CINAHL) }\end{array}$ & Lloyd & $\begin{array}{l}\text { Acupuncture during } \\
\text { pregnancy for daily frontal } \\
\text { headaches }\end{array}$ & $\begin{array}{l}\text { Journal of the } \\
\text { Acupuncture } \\
\text { Association of } \\
\text { Chartered } \\
\text { Physiotherapis } \\
\text { ts }\end{array}$ & Unable to retrieve article \\
\hline 187 & $\begin{array}{l}108113640 \\
\text { (CINAHL) }\end{array}$ & Lock & $\begin{array}{l}\text { Acupuncture and } \\
\text { physiotherapy for chronic } \\
\text { tension-type headache in a } \\
\text { pregnant patient }\end{array}$ & $\begin{array}{l}\text { Journal of the } \\
\text { Acupuncture } \\
\text { Association of } \\
\text { Chartered } \\
\text { Physiotherapis } \\
\text { ts }\end{array}$ & Unable to retrieve article \\
\hline 188 & 17940921 & Loder & Migraine in pregnancy & Semin Neurol & Narrative review \\
\hline 189 & 12467489 & Loder & $\begin{array}{l}\text { Safety of sumatriptan in } \\
\text { pregnancy: a review of the } \\
\text { data so far }\end{array}$ & CNS Drugs & SR \\
\hline 190 & 16792985 & Lopez & $\begin{array}{l}\text { [Safety of antimigraine } \\
\text { drugs during pregnancy] }\end{array}$ & $\begin{array}{l}\text { Med Clin } \\
\text { (Barc) }\end{array}$ & Narrative review \\
\hline 191 & 11800529 & Lowe & $\begin{array}{l}\text { Drugs in pregnancy. } \\
\text { Anticonvulsants and drugs } \\
\text { for neurological disease }\end{array}$ & $\begin{array}{l}\text { Best Pract Res } \\
\text { Clin Obstet } \\
\text { Gynaecol }\end{array}$ & Narrative review \\
\hline 192 & 26865183 & Lucas & $\begin{array}{l}\text { The Pharmacology of } \\
\text { Indomethacin }\end{array}$ & Headache & Narrative review \\
\hline 193 & 19728967 & Lucas & $\begin{array}{l}\text { Medication use in the } \\
\text { treatment of migraine } \\
\text { during pregnancy and } \\
\text { lactation }\end{array}$ & $\begin{array}{l}\text { Curr Pain } \\
\text { Headache Rep }\end{array}$ & Narrative review \\
\hline
\end{tabular}




\begin{tabular}{|c|c|c|c|c|c|}
\hline No. & $\begin{array}{l}\text { PMI D or Other } \\
\text { I dentifier }\end{array}$ & $\begin{array}{l}\text { First Author } \\
\text { Last Name }\end{array}$ & Title & Journal & Reason for Exclusion \\
\hline 194 & 31241597 & Lucas & $\begin{array}{l}\text { Migraine and Other } \\
\text { Headache Disorders: ACOG } \\
\text { Clinical Updates In Women's } \\
\text { Health Care Primary and } \\
\text { Preventive Care Review } \\
\text { Summary Volume XVIII, } \\
\text { Number } 4\end{array}$ & $\begin{array}{l}\text { Obstet } \\
\text { Gynecol }\end{array}$ & Guideline \\
\hline 195 & 24867839 & MacGregor & $\begin{array}{l}\text { Migraine in pregnancy and } \\
\text { lactation }\end{array}$ & Neurol Sci & Narrative review \\
\hline 196 & 24492815 & Macgregor & Headache in pregnancy & $\begin{array}{l}\text { Continuum } \\
\text { (Minneap } \\
\text { Minn) } \\
\end{array}$ & Narrative review \\
\hline 197 & 22840792 & MacGregor & Headache in pregnancy & Neurol Clin & Narrative review \\
\hline 198 & 17407673 & MacGregor & $\begin{array}{l}\text { Migraine in pregnancy and } \\
\text { lactation: a clinical review }\end{array}$ & $\begin{array}{l}\text { J Fam Plann } \\
\text { Reprod Health } \\
\text { Care }\end{array}$ & SR \\
\hline 199 & No PubMed ID & Magee & $\begin{array}{l}\text { The safety of calcium } \\
\text { channel blockers in human } \\
\text { pregnancy: A prospective, } \\
\text { multicenter cohort study }\end{array}$ & $\begin{array}{l}\text { American } \\
\text { Journal of } \\
\text { Obstetrics and } \\
\text { Gynecology }\end{array}$ & $\begin{array}{l}\text { Participants did not have primary } \\
\text { headache or there were no } \\
\text { primary headache-specific data }\end{array}$ \\
\hline 200 & 27300484 & Maggioni & $\begin{array}{l}\text { Triptans or Not? This Is the } \\
\text { Question. Management of } \\
\text { Migraine Attacks During } \\
\text { Pregnancy }\end{array}$ & Headache & Narrative review \\
\hline 201 & 9399007 & Maggioni & Headache during pregnancy & Cephalalgia & No intervention of interest \\
\hline 202 & 12061464 & Mannix & $\begin{array}{l}\text { Women and headache: a } \\
\text { treatment approach based } \\
\text { on life stages }\end{array}$ & $\begin{array}{l}\text { Cleve Clin J } \\
\text { Med }\end{array}$ & Narrative review \\
\hline 203 & 25644494 & Marchenko & $\begin{array}{l}\text { Pregnancy outcome } \\
\text { following prenatal exposure } \\
\text { to triptan medications: a } \\
\text { meta-analysis }\end{array}$ & Headache & SR \\
\hline 204 & 11934341 & Marcus & $\begin{array}{l}\text { Pregnancy and chronic } \\
\text { headache }\end{array}$ & $\begin{array}{l}\text { Expert Opin } \\
\text { Pharmacother }\end{array}$ & Narrative review \\
\hline 205 & 10358852 & Marcus & $\begin{array}{l}\text { Focus on primary care } \\
\text { diagnosis and management } \\
\text { of headache in women }\end{array}$ & $\begin{array}{l}\text { Obstet } \\
\text { Gynecol Sunv }\end{array}$ & Narrative review \\
\hline 206 & 17288886 & Marcus & Headache in pregnancy & $\begin{array}{l}\text { Curr Treat } \\
\text { Options } \\
\text { Neurol }\end{array}$ & Narrative review \\
\hline 207 & 12828878 & Marcus & Headache in pregnancy & $\begin{array}{l}\text { Curr Pain } \\
\text { Headache Rep }\end{array}$ & Narrative review \\
\hline 208 & 18345969 & Marcus & $\begin{array}{l}\text { Managing headache during } \\
\text { pregnancy and lactation }\end{array}$ & $\begin{array}{l}\text { Expert Rev } \\
\text { Neurother }\end{array}$ & Narrative review \\
\hline 209 & 11252843 & Marcus & $\begin{array}{l}\text { Management of headache in } \\
\text { women }\end{array}$ & $\begin{array}{l}\text { J Gend Specif } \\
\text { Med }\end{array}$ & $\begin{array}{l}\text { Participants not pregnant (or } \\
\text { attempting to be pregnant), } \\
\text { postpartum, or breastfeeding }\end{array}$ \\
\hline 210 & No PubMed ID & Margulis & $\begin{array}{l}\text { Use of topiramate in } \\
\text { pregnancy and risk of oral } \\
\text { clefts }\end{array}$ & $\begin{array}{l}\text { American } \\
\text { Journal of } \\
\text { Obstetrics and } \\
\text { Gynecology }\end{array}$ & $\begin{array}{l}\text { Participants did not have primary } \\
\text { headache or there were no } \\
\text { primary headache-specific data }\end{array}$ \\
\hline 211 & 25096056 & Marmura & $\begin{array}{l}\text { Safety of topiramate for } \\
\text { treating migraines }\end{array}$ & $\begin{array}{l}\text { Expert Opin } \\
\text { Drug Saf }\end{array}$ & Narrative review \\
\hline 212 & 22012659 & Marmura & $\begin{array}{l}\text { Use of dopamine } \\
\text { antagonists in treatment of } \\
\text { migraine }\end{array}$ & $\begin{array}{l}\text { Curr Treat } \\
\text { Options } \\
\text { Neurol }\end{array}$ & Narrative review \\
\hline 213 & 15725852 & Martin & $\begin{array}{l}\text { Approach to the pregnant } \\
\text { patient with headache }\end{array}$ & $\begin{array}{l}\text { Clin Obstet } \\
\text { Gynecol }\end{array}$ & Narrative review \\
\hline 214 & 927751 & Massey & Migraine during pregnancy & $\begin{array}{l}\text { Obstet } \\
\text { Gynecol Surv }\end{array}$ & Narrative review \\
\hline 215 & 11961994 & Matharu & $\begin{array}{l}\text { Understanding migraine in } \\
\text { women }\end{array}$ & Practitioner & Narrative review \\
\hline
\end{tabular}




\begin{tabular}{|c|c|c|c|c|c|}
\hline No. & $\begin{array}{l}\text { PMI D or Other } \\
\text { I dentifier }\end{array}$ & $\begin{array}{l}\text { First Author } \\
\text { Last Name }\end{array}$ & Title & Journal & Reason for Exclusion \\
\hline 216 & 25649095 & Mehta & $\begin{array}{l}\text { Headaches in the pregnant } \\
\text { patient }\end{array}$ & $\begin{array}{l}\text { R I Med J } \\
\text { (2013) }\end{array}$ & Narrative review \\
\hline 217 & 18332840 & Menon & Headache and pregnancy & Neurologist & Narrative review \\
\hline 218 & 15423706 & Merritt & $\begin{array}{l}\text { The diagnosis and } \\
\text { management of patients } \\
\text { with chronic recurrent } \\
\text { headache }\end{array}$ & $\begin{array}{l}\text { New Orleans } \\
\text { Med SurgJ }\end{array}$ & $\begin{array}{l}\text { Participants did not have primary } \\
\text { headache or there were no } \\
\text { primary headache-specific data }\end{array}$ \\
\hline 219 & 26305473 & Migliore & $\begin{array}{l}\text { Prenatal Paracetamol } \\
\text { Exposure and Wheezing in } \\
\text { Childhood: Causation or } \\
\text { Confounding? }\end{array}$ & Plos One & $\begin{array}{l}\text { Participants did not have primary } \\
\text { headache or there were no } \\
\text { primary headache-specific data }\end{array}$ \\
\hline 220 & 8525351 & Miles & $\begin{array}{l}\text { Treatment of migraine } \\
\text { during pregnancy and } \\
\text { lactation }\end{array}$ & SDJ Med & $\begin{array}{l}\text { Participants did not have primary } \\
\text { headache or there were no } \\
\text { primary headache-specific data }\end{array}$ \\
\hline 221 & 4914209 & Miller & $\begin{array}{l}\text { Propoxyphene } \\
\text { hydrochloride. A critical } \\
\text { review }\end{array}$ & Jama & Narrative review \\
\hline 222 & 42893 & Milton-Thompson & Anti-nauseant drugs & Practitioner & Narrative review \\
\hline 223 & 24692316 & Mines & $\begin{array}{l}\text { Topiramate use in } \\
\text { pregnancy and the birth } \\
\text { prevalence of oral clefts }\end{array}$ & $\begin{array}{l}\text { Pharmacoepid } \\
\text { emiol Drug } \\
\text { Saf }\end{array}$ & $\begin{array}{l}\text { Participants did not have primary } \\
\text { headache or there were no } \\
\text { primary headache-specific data }\end{array}$ \\
\hline 224 & 21535375 & Moloney & $\begin{array}{l}\text { Migraine headaches: } \\
\text { diagnosis and management }\end{array}$ & $\begin{array}{l}\text { J Midwifery } \\
\text { Womens } \\
\text { Health }\end{array}$ & Narrative review \\
\hline 225 & 10703023 & Moloney & $\begin{array}{l}\text { Caring for the woman with } \\
\text { migraine headaches }\end{array}$ & Nurse Pract & Narrative review \\
\hline 226 & 16361610 & Morgan & $\begin{array}{l}\text { Botulinum toxin A during } \\
\text { pregnancy: a survey of } \\
\text { treating physicians. }\end{array}$ & $\begin{array}{l}\text { Journal of } \\
\text { neurology, } \\
\text { neurosurgery, } \\
\text { and psychiatry }\end{array}$ & $\begin{array}{l}\text { Participants did not have primary } \\
\text { headache or there were no } \\
\text { primary headache-specific data }\end{array}$ \\
\hline 227 & 12534326 & Nappi & $\begin{array}{l}\text { Tolerability of the triptans: } \\
\text { clinical implications }\end{array}$ & Drug Saf & Narrative review \\
\hline 228 & 21465113 & Nappi & $\begin{array}{l}\text { Headaches during } \\
\text { pregnancy }\end{array}$ & $\begin{array}{l}\text { Curr Pain } \\
\text { Headache Rep }\end{array}$ & No intervention of interest \\
\hline 229 & 29563831 & Negro & $\begin{array}{l}\text { Serotonin receptor agonists } \\
\text { in the acute treatment of } \\
\text { migraine: a review on their } \\
\text { therapeutic potential }\end{array}$ & J Pain Res & Narrative review \\
\hline 230 & 29052046 & Negro & $\begin{array}{l}\text { Headache and pregnancy: a } \\
\text { systematic review }\end{array}$ & $\begin{array}{l}\text { J Headache } \\
\text { Pain }\end{array}$ & SR \\
\hline 231 & 20132339 & $\begin{array}{l}\text { Nezvalova- } \\
\text { Henriksen }\end{array}$ & $\begin{array}{l}\text { Triptan exposure during } \\
\text { pregnancy and the risk of } \\
\text { major congenital } \\
\text { malformations and adverse } \\
\text { pregnancy outcomes: } \\
\text { results from the Norwegian } \\
\text { Mother and Child Cohort } \\
\text { Study }\end{array}$ & Headache & Duplicate \\
\hline 232 & No PubMed ID & $\begin{array}{l}\text { Nezvalova- } \\
\text { Henriksen }\end{array}$ & $\begin{array}{l}\text { Effects of ibuprofen, } \\
\text { diclofenac, naproxen, and } \\
\text { piroxicam on the course of } \\
\text { pregnancy and pregnancy } \\
\text { outcome: A prospective } \\
\text { cohort study }\end{array}$ & $\begin{array}{l}\text { BJOG: An } \\
\text { International } \\
\text { Journal of } \\
\text { Obstetrics and } \\
\text { Gynaecology }\end{array}$ & $\begin{array}{l}\text { Participants did not have primary } \\
\text { headache or there were no } \\
\text { primary headache-specific data }\end{array}$ \\
\hline 233 & 19911464 & $\begin{array}{l}\text { Nezvalova- } \\
\text { Henriksen }\end{array}$ & $\begin{array}{l}\text { Maternal characteristics and } \\
\text { migraine pharmacotherapy } \\
\text { during pregnancy: cross- } \\
\text { sectional analysis of data } \\
\text { from a large cohort study }\end{array}$ & Cephalalgia & $\begin{array}{l}\text { Only addresses } \\
\text { predictors/distribution of } \\
\text { intervention use }\end{array}$ \\
\hline
\end{tabular}




\begin{tabular}{|c|c|c|c|c|c|}
\hline No. & $\begin{array}{l}\text { PMI D or Other } \\
\text { I dentifier }\end{array}$ & $\begin{array}{l}\text { First Author } \\
\text { Last Name }\end{array}$ & Title & J ournal & Reason for Exclusion \\
\hline 234 & 19895705 & Nino-Maldonado & $\begin{array}{l}\text { Efficacy and tolerability of } \\
\text { intravenous } \\
\text { methylergonovine in } \\
\text { migraine female patients } \\
\text { attending the emergency } \\
\text { department: a pilot open- } \\
\text { label study }\end{array}$ & $\begin{array}{l}\text { Head Face } \\
\text { Med }\end{array}$ & No intervention of interest \\
\hline 235 & 8459173 & None listed & $\begin{array}{l}\text { [Diagnosis and therapy in } \\
\text { patients with headache } \\
\text { (discussion)] }\end{array}$ & $\begin{array}{l}\text { Nihon Naika } \\
\text { Gakkai Zasshi }\end{array}$ & Narrative review \\
\hline 236 & 24662840 & None listed & $\begin{array}{l}\text { In brief: warning against } \\
\text { use of valproate for } \\
\text { migraine prevention during } \\
\text { pregnancy }\end{array}$ & $\begin{array}{l}\text { Med Lett } \\
\text { Drugs Ther }\end{array}$ & Narrative review \\
\hline 237 & 30681655 & None listed & $\begin{array}{l}\text { Fremanezumab (Ajovy) and } \\
\text { galcanezumab (Emgality) for } \\
\text { migraine prevention }\end{array}$ & $\begin{array}{l}\text { Med Lett } \\
\text { Drugs Ther }\end{array}$ & Narrative review \\
\hline 238 & 30000371 & None listed & Dichloralphenazone & $\begin{array}{l}\text { Drugs and } \\
\text { Lactation } \\
\text { Database } \\
\text { (LactMed) }\end{array}$ & Narrative review \\
\hline 239 & 21304447 & None listed & Drugs for migraine & $\begin{array}{l}\text { Treat Guidel } \\
\text { Med Lett }\end{array}$ & Narrative review \\
\hline 240 & 25964975 & None listed & Triptans during pregnancy & Prescrire Int & Narrative review \\
\hline 241 & 28170366 & None listed & Drugs for migraine & $\begin{array}{l}\text { Med Lett } \\
\text { Drugs Ther }\end{array}$ & Narrative review \\
\hline 242 & 25802922 & None listed & $\begin{array}{l}\text { Prevention of migraine } \\
\text { attacks. First-choice } \\
\text { treatments }\end{array}$ & Prescrire Int & Narrative review \\
\hline 243 & 26768660 & None listed & $\begin{array}{l}\text { Errata...Marchenko, A, Etwel } \\
\text { F, Olutunfese O,et al. } \\
\text { Pregnancy Outcome } \\
\text { Following Prenatal Exposure } \\
\text { to Triptan Medications: A } \\
\text { Meta-Analysis. Headache } \\
\text { 2015;55:490-501 }\end{array}$ & $\begin{array}{l}\text { Headache: } \\
\text { The Journal of } \\
\text { Head \& Face } \\
\text { Pain }\end{array}$ & $\mathrm{SR}$ \\
\hline 244 & 18686655 & None listed & $\begin{array}{l}\text { [Treatment guidelines for } \\
\text { preventive treatment of } \\
\text { migraine] }\end{array}$ & $\begin{array}{l}\text { Acta Neurol } \\
\text { Taiwan }\end{array}$ & Guideline \\
\hline 245 & $\begin{array}{l}107171571 \\
\text { (CINAHL) }\end{array}$ & None listed & $\begin{array}{l}\text { Early pregnancy sumatriptan } \\
\text { exposure }\end{array}$ & $\begin{array}{l}\text { Nurses' Drug } \\
\text { Alert }\end{array}$ & Unable to retrieve article \\
\hline 246 & $\begin{array}{l}108081307 \\
\text { (CINAHL) }\end{array}$ & None listed & $\begin{array}{l}\text { NICE develops its first } \\
\text { clinical guideline on } \\
\text { headaches }\end{array}$ & $\begin{array}{l}\text { Guidelines in } \\
\text { Practice }\end{array}$ & Unable to retrieve article \\
\hline 247 & 30000045 & None listed & Ibuprofen & $\begin{array}{l}\text { Drugs and } \\
\text { Lactation } \\
\text { Database } \\
\text { (LactMed) }\end{array}$ & $\begin{array}{l}\text { Participants did not have primary } \\
\text { headache or there were no } \\
\text { primary headache-specific data }\end{array}$ \\
\hline 248 & 30000253 & None listed & Acetaminophen & $\begin{array}{l}\text { Drugs and } \\
\text { Lactation } \\
\text { Database } \\
\text { (LactMed) }\end{array}$ & $\begin{array}{l}\text { Participants did not have primary } \\
\text { headache or there were no } \\
\text { primary headache-specific data }\end{array}$ \\
\hline 249 & 29913472 & None listed & $\begin{array}{l}\text { Erenumab (Aimovig) for } \\
\text { migraine prevention }\end{array}$ & $\begin{array}{l}\text { Med Lett } \\
\text { Drugs Ther }\end{array}$ & $\begin{array}{l}\text { Participants not pregnant (or } \\
\text { attempting to be pregnant), } \\
\text { postpartum, or breastfeeding }\end{array}$ \\
\hline 250 & 18220021 & None listed & $\begin{array}{l}\text { [Treatment guidelines for } \\
\text { acute migraine attacks] }\end{array}$ & $\begin{array}{l}\text { Acta Neurol } \\
\text { Taiwan }\end{array}$ & $\begin{array}{l}\text { Participants not pregnant (or } \\
\text { attempting to be pregnant), } \\
\text { postpartum, or breastfeeding }\end{array}$ \\
\hline 251 & 25964974 & None listed & $\begin{array}{l}\text { Migraine and pregnancy. } \\
\text { Choice of treatment }\end{array}$ & Prescrire Int & $\begin{array}{l}\text { Only addresses } \\
\text { predictors/distribution of } \\
\text { intervention use }\end{array}$ \\
\hline
\end{tabular}




\begin{tabular}{|c|c|c|c|c|c|}
\hline No. & $\begin{array}{l}\text { PMI D or Other } \\
\text { I dentifier }\end{array}$ & $\begin{array}{l}\text { First Author } \\
\text { Last Name }\end{array}$ & Title & Journal & Reason for Exclusion \\
\hline 252 & 15863557 & None listed & $\begin{array}{l}\text { Topiramate (topamax) for } \\
\text { prevention of migraine }\end{array}$ & $\begin{array}{l}\text { Obstet } \\
\text { Gynecol }\end{array}$ & $\begin{array}{l}\text { Participants not pregnant (or } \\
\text { attempting to be pregnant), } \\
\text { postpartum, or breastfeeding }\end{array}$ \\
\hline 253 & 25964970 & None listed & $\begin{array}{l}\text { Triptans: beware of } \\
\text { vasoconstrictive effects }\end{array}$ & Prescrire Int & $\begin{array}{l}\text { Participants did not have primary } \\
\text { headache or there were no } \\
\text { primary headache-specific data }\end{array}$ \\
\hline 254 & No PubMed ID & Nordeng & $\begin{array}{l}\text { Medication safety in } \\
\text { pregnancy „Äi Results from } \\
\text { the MoBa study }\end{array}$ & $\begin{array}{l}\text { Norsk } \\
\text { Epidemiologi }\end{array}$ & Narrative review \\
\hline 255 & 26638119 & Noruzzadeh & $\begin{array}{l}\text { Memantine for Prophylactic } \\
\text { Treatment of Migraine } \\
\text { Without Aura: A } \\
\text { Randomized Double-Blind } \\
\text { Placebo-Controlled Study }\end{array}$ & Headache & $\begin{array}{l}\text { Participants not pregnant (or } \\
\text { attempting to be pregnant), } \\
\text { postpartum, or breastfeeding }\end{array}$ \\
\hline 256 & 28473606 & O'Neal & $\begin{array}{l}\text { Headaches complicating } \\
\text { pregnancy and the } \\
\text { postpartum period }\end{array}$ & Pract Neurol & Narrative review \\
\hline 257 & 11251709 & Olesen & $\begin{array}{l}\text { Sumatriptan: what do we } \\
\text { know about fetal risks? }\end{array}$ & Headache & $\begin{array}{l}\text { Participants did not have primary } \\
\text { headache or there were no } \\
\text { primary headache-specific data }\end{array}$ \\
\hline 258 & 17598713 & Ostendorf & $\begin{array}{l}\text { [Acupuncture for pregnancy } \\
\text { support] }\end{array}$ & $\begin{array}{l}\text { Versicherungs } \\
\text { medizin }\end{array}$ & Narrative review \\
\hline 259 & 30291521 & Parikh & $\begin{array}{l}\text { Unique Populations with } \\
\text { Episodic Migraine: Pregnant } \\
\text { and Lactating Women }\end{array}$ & $\begin{array}{l}\text { Curr Pain } \\
\text { Headache Rep }\end{array}$ & Narrative review \\
\hline 260 & 20309829 & Pascual-Gomez & $\begin{array}{l}\text { [Migraine and gestation: a } \\
\text { complex relationship] }\end{array}$ & Rev Neurol & Narrative review \\
\hline 261 & 10563361 & Pastore & $\begin{array}{l}\text { Risk of stillbirth from } \\
\text { medications, illnesses and } \\
\text { medical procedures }\end{array}$ & $\begin{array}{l}\text { Paediatr } \\
\text { Perinat } \\
\text { Epidemiol }\end{array}$ & $\begin{array}{l}\text { Participants did not have primary } \\
\text { headache or there were no } \\
\text { primary headache-specific data }\end{array}$ \\
\hline 262 & 8610754 & Paulson & $\begin{array}{l}\text { Headaches in women, } \\
\text { including women who are } \\
\text { pregnant }\end{array}$ & $\begin{array}{l}\text { AmJ Obstet } \\
\text { Gynecol }\end{array}$ & Narrative review \\
\hline 263 & 22828113 & Pearce & $\begin{array}{l}\text { Headache and neurological } \\
\text { disease in pregnancy }\end{array}$ & $\begin{array}{l}\text { Clin Obstet } \\
\text { Gynecol }\end{array}$ & Narrative review \\
\hline 264 & 30477838 & Peng & $\begin{array}{l}\text { Utilization of complementary } \\
\text { and alternative medicine } \\
\text { and conventional medicine } \\
\text { for headache or migraine } \\
\text { during pregnancy: A cross- } \\
\text { sectional survey of } 1,835 \\
\text { pregnant women }\end{array}$ & $\begin{array}{l}\text { Complement } \\
\text { Ther Med }\end{array}$ & $\begin{array}{l}\text { Only addresses } \\
\text { predictors/distribution of } \\
\text { intervention use }\end{array}$ \\
\hline 265 & 10904600 & Pfaffenrath & $\begin{array}{l}\text { [Migraine therapy in } \\
\text { pregnancy. Paracetamol } \\
\text { leads in acute therapy] }\end{array}$ & $\begin{array}{l}\text { MMW Fortschr } \\
\text { Med }\end{array}$ & Narrative review \\
\hline 266 & 9825951 & Pfaffenrath & $\begin{array}{l}\text { Migraine in pregnancy: what } \\
\text { are the safest treatment } \\
\text { options? }\end{array}$ & Drug Saf & Narrative review \\
\hline 267 & 18747391 & Pfeffer & $\begin{array}{l}\text { Migraine: the pill and } \\
\text { pregnancy }\end{array}$ & West J Med & $\begin{array}{l}\text { Only addresses } \\
\text { predictors/distribution of } \\
\text { intervention use }\end{array}$ \\
\hline 268 & 9644438 & Pintz & $\begin{array}{l}\text { Prescribing medication in } \\
\text { pregnancy }\end{array}$ & $\begin{array}{l}\text { Lippincotts } \\
\text { Prim Care } \\
\text { Pract }\end{array}$ & Narrative review \\
\hline 269 & 17724970 & Pollmann & $\begin{array}{l}\text { [Acute headaches--when to } \\
\text { treat immediately, when to } \\
\text { wait] }\end{array}$ & $\begin{array}{l}\text { MMW Fortschr } \\
\text { Med }\end{array}$ & Narrative review \\
\hline 270 & 22683887 & Pringsheim & $\begin{array}{l}\text { Canadian Headache Society } \\
\text { guideline for migraine } \\
\text { prophylaxis }\end{array}$ & $\begin{array}{l}\text { CanJ Neurol } \\
\text { Sci }\end{array}$ & SR and guideline \\
\hline 271 & 6425308 & Proctor & Biofeedback pain control & $\begin{array}{l}\text { Hosp Pract } \\
\text { (Off Ed) }\end{array}$ & Narrative review \\
\hline
\end{tabular}




\begin{tabular}{|c|c|c|c|c|c|}
\hline No. & $\begin{array}{l}\text { PMI D or Other } \\
\text { I dentifier }\end{array}$ & $\begin{array}{l}\text { First Author } \\
\text { Last Name }\end{array}$ & Title & Journal & Reason for Exclusion \\
\hline 272 & 1337766 & Prusinski & $\begin{array}{l}\text { [Sumatriptan and its use in } \\
\text { treatment of migraine and } \\
\text { cluster headaches] }\end{array}$ & $\begin{array}{l}\text { Neurol } \\
\text { Neurochir Pol }\end{array}$ & Narrative review \\
\hline 273 & 29802634 & Raggi & $\begin{array}{l}\text { Behavioral Approaches for } \\
\text { Primary Headaches: Recent } \\
\text { Advances }\end{array}$ & Headache & SR \\
\hline 274 & 18368683 & Rana-Martinez & [Migraine in females] & Rev Neurol & Narrative review \\
\hline 275 & 9356103 & Rathmell & $\begin{array}{l}\text { Management of nonobstetric } \\
\text { pain during pregnancy and } \\
\text { lactation }\end{array}$ & Anesth Analg & Narrative review \\
\hline 276 & 30880363 & Rau & $\begin{array}{l}\text { Other Preventive Anti- } \\
\text { Migraine Treatments: ACE } \\
\text { Inhibitors, ARBs, Calcium } \\
\text { Channel Blockers, Serotonin } \\
\text { Antagonists, and NMDA } \\
\text { Receptor Antagonists }\end{array}$ & $\begin{array}{l}\text { Curr Treat } \\
\text { Options } \\
\text { Neurol }\end{array}$ & Narrative review \\
\hline 277 & No PubMed ID & Ravishankar & $\begin{array}{l}\text { Guidelines on the diagnosis } \\
\text { and the current } \\
\text { management of headache } \\
\text { and related disorders }\end{array}$ & $\begin{array}{l}\text { Annals of } \\
\text { Indian } \\
\text { Academy of } \\
\text { Neurology }\end{array}$ & $\begin{array}{l}\text { Participants not pregnant (or } \\
\text { attempting to be pregnant), } \\
\text { postpartum, or breastfeeding }\end{array}$ \\
\hline 278 & 3752178 & Rayburn & $\begin{array}{l}\text { Drug prescribing for chronic } \\
\text { medical disorders during } \\
\text { pregnancy: an overview }\end{array}$ & $\begin{array}{l}\text { AmJ Obstet } \\
\text { Gynecol }\end{array}$ & Narrative review \\
\hline 279 & 4147459 & Regli & $\begin{array}{l}\text { [Treatment of vascular } \\
\text { headaches] }\end{array}$ & $\begin{array}{l}\text { Dtsch Med } \\
\text { Wochenschr }\end{array}$ & Narrative review \\
\hline 280 & 10649172 & Reiff-Eldridge & $\begin{array}{l}\text { Monitoring pregnancy } \\
\text { outcomes after prenatal } \\
\text { drug exposure through } \\
\text { prospective pregnancy } \\
\text { registries: a pharmaceutical } \\
\text { company commitment }\end{array}$ & $\begin{array}{l}\text { AmJ Obstet } \\
\text { Gynecol }\end{array}$ & $\begin{array}{l}\text { Participants did not have primary } \\
\text { headache or there were no } \\
\text { primary headache-specific data }\end{array}$ \\
\hline 281 & 3143135 & Reik & Headaches in pregnancy & Semin Neurol & Narrative review \\
\hline 282 & 18045126 & Reynolds & $\begin{array}{l}\text { Valproate and } \\
\text { neuroendocrine changes in } \\
\text { relation to women treated } \\
\text { for epilepsy and bipolar } \\
\text { disorder: a review }\end{array}$ & $\begin{array}{l}\text { Curr Med } \\
\text { Chem }\end{array}$ & $\begin{array}{l}\text { Participants did not have primary } \\
\text { headache or there were no } \\
\text { primary headache-specific data }\end{array}$ \\
\hline 283 & 8039469 & Richens & Safety of lamotrigine & Epilepsia & Narrative review \\
\hline 284 & 30074551 & Robbins & Headache in Pregnancy & $\begin{array}{l}\text { Continuum } \\
\text { (Minneap } \\
\text { Minn) }\end{array}$ & Narrative review \\
\hline 285 & 23921799 & Roberto & $\begin{array}{l}\text { Triptans and serious adverse } \\
\text { vascular events: data mining } \\
\text { of the FDA Adverse Effect } \\
\text { Reporting System database }\end{array}$ & Cephalalgia & $\begin{array}{l}\text { Participants did not have primary } \\
\text { headache or there were no } \\
\text { primary headache-specific data }\end{array}$ \\
\hline 286 & 20352590 & Robertson & $\begin{array}{l}\text { Management of migraine } \\
\text { headache in the emergency } \\
\text { department }\end{array}$ & Semin Neurol & $\begin{array}{l}\text { Participants not pregnant (or } \\
\text { attempting to be pregnant), } \\
\text { postpartum, or breastfeeding }\end{array}$ \\
\hline 287 & 8003593 & Roquer & [Treatment of migraine] & Aten Primaria & Narrative review \\
\hline 288 & 18973735 & Rosen & $\begin{array}{l}\text { Psychological issues in the } \\
\text { evaluation and treatment of } \\
\text { tension-type headache }\end{array}$ & $\begin{array}{l}\text { Curr Pain } \\
\text { Headache Rep }\end{array}$ & $\begin{array}{l}\text { Participants not pregnant (or } \\
\text { attempting to be pregnant), } \\
\text { postpartum, or breastfeeding }\end{array}$ \\
\hline 289 & 23054980 & Rosen & $\begin{array}{l}\text { Psychological issues in the } \\
\text { evaluation and treatment of } \\
\text { tension-type headache }\end{array}$ & $\begin{array}{l}\text { Curr Pain } \\
\text { Headache Rep }\end{array}$ & $\begin{array}{l}\text { Participants not pregnant (or } \\
\text { attempting to be pregnant), } \\
\text { postpartum, or breastfeeding }\end{array}$ \\
\hline 290 & 7091205 & Rosene & $\begin{array}{l}\text { Cerebral ischemia associated } \\
\text { with parenteral terbutaline } \\
\text { use in pregnant migraine } \\
\text { patients }\end{array}$ & $\begin{array}{l}\text { AmJ Obstet } \\
\text { Gynecol }\end{array}$ & No intervention of interest \\
\hline
\end{tabular}




\begin{tabular}{|c|c|c|c|c|c|}
\hline No. & $\begin{array}{l}\text { PMI D or Other } \\
\text { I dentifier }\end{array}$ & $\begin{array}{l}\text { First Author } \\
\text { Last Name }\end{array}$ & Title & Journal & Reason for Exclusion \\
\hline 291 & 22482825 & Rozen & $\begin{array}{l}\text { Female cluster headache in } \\
\text { the United States of } \\
\text { America: what are the } \\
\text { gender differences? Results } \\
\text { from the United States } \\
\text { Cluster Headache Survey }\end{array}$ & J Neurol Sci & No intervention of interest \\
\hline 292 & 25890621 & Rubin & Migraines in women & Dis Mon & Narrative review \\
\hline 293 & $\begin{array}{l}105348935 \\
\text { (CINAHL) }\end{array}$ & Rubin & $\begin{array}{l}\text { Case studies. Good } \\
\text { medication choices for } \\
\text { pregnancy }\end{array}$ & $\begin{array}{l}\text { NHF Head } \\
\text { Lines }\end{array}$ & $\begin{array}{l}\text { Participants not pregnant (or } \\
\text { attempting to be pregnant), } \\
\text { postpartum, or breastfeeding }\end{array}$ \\
\hline 294 & 28132364 & Sacco & Migraine in pregnancy & $\begin{array}{l}\text { J Headache } \\
\text { Pain }\end{array}$ & Narrative review \\
\hline 295 & 20177448 & Sachdeva & $\begin{array}{l}\text { Drug use in pregnancy; a } \\
\text { point to ponder! }\end{array}$ & $\begin{array}{l}\text { Indian J } \\
\text { Pharm Sci }\end{array}$ & $\begin{array}{l}\text { Participants did not have primary } \\
\text { headache or there were no } \\
\text { primary headache-specific data }\end{array}$ \\
\hline 296 & 30522137 & Sader & $\begin{array}{l}\text { Headache in Pregnancy, the } \\
\text { Puerperium, and menopause }\end{array}$ & Semin Neurol & Narrative review \\
\hline 297 & 17545337 & Sadler & $\begin{array}{l}\text { Complementary, holistic, } \\
\text { and integrative medicine: } \\
\text { butterbur }\end{array}$ & Pediatr Rev & Narrative review \\
\hline 298 & 20649650 & Saper & $\begin{array}{l}\text { A practice guide for } \\
\text { continuous opioid therapy } \\
\text { for refractory daily } \\
\text { headache: patient selection, } \\
\text { physician requirements, and } \\
\text { treatment monitoring }\end{array}$ & Headache & $\begin{array}{l}\text { Participants not pregnant (or } \\
\text { attempting to be pregnant), } \\
\text { postpartum, or breastfeeding }\end{array}$ \\
\hline 299 & $\begin{array}{l}104567436 \\
\text { (CINAHL) }\end{array}$ & Sarchielli & $\begin{array}{l}\text { Italian guidelines for primary } \\
\text { headaches: } 2012 \text { revised } \\
\text { version }\end{array}$ & $\begin{array}{l}\text { Journal of } \\
\text { Headache \& } \\
\text { Pain }\end{array}$ & Guideline \\
\hline 300 & 25834672 & Schoen & $\begin{array}{l}\text { Headache in pregnancy: an } \\
\text { approach to emergency } \\
\text { department evaluation and } \\
\text { management }\end{array}$ & $\begin{array}{l}\text { West J Emerg } \\
\text { Med }\end{array}$ & Narrative review \\
\hline 301 & 18325296 & Schurks & $\begin{array}{l}\text { Update on the prophylaxis } \\
\text { of migraine }\end{array}$ & $\begin{array}{l}\text { Curr Treat } \\
\text { Options } \\
\text { Neurol } \\
\end{array}$ & $\begin{array}{l}\text { Participants not pregnant (or } \\
\text { attempting to be pregnant), } \\
\text { postpartum, or breastfeeding }\end{array}$ \\
\hline 302 & 4725480 & Selbach & $\begin{array}{l}\text { [Caffeine, coffee, headache } \\
\text { and migraine] }\end{array}$ & Med Klin & Narrative review \\
\hline 303 & 30880281 & Shaheen & $\begin{array}{l}\text { Prescribed analgesics in } \\
\text { pregnancy and risk of } \\
\text { childhood asthma }\end{array}$ & $\begin{array}{l}\text { The European } \\
\text { respiratory } \\
\text { journal }\end{array}$ & $\begin{array}{l}\text { Participants did not have primary } \\
\text { headache or there were no } \\
\text { primary headache-specific data }\end{array}$ \\
\hline 304 & 15017339 & Shehata & $\begin{array}{l}\text { Neurological disorders in } \\
\text { pregnancy }\end{array}$ & $\begin{array}{l}\text { Curr Opin } \\
\text { Obstet } \\
\text { Gynecol }\end{array}$ & Narrative review \\
\hline 305 & 29224452 & Silberstein & Migraine and women & Postgrad Med & Narrative review \\
\hline 306 & 7716087 & Silberstein & $\begin{array}{l}\text { Migraine and women. The } \\
\text { link between headache and } \\
\text { hormones }\end{array}$ & Postgrad Med & Narrative review \\
\hline 307 & 11371755 & Silberstein & $\begin{array}{l}\text { Headache and female } \\
\text { hormones: what you need } \\
\text { to know }\end{array}$ & $\begin{array}{l}\text { Curr Opin } \\
\text { Neurol }\end{array}$ & Narrative review \\
\hline 308 & 27902848 & Silberstein & $\begin{array}{l}\text { Topiramate in Migraine } \\
\text { Prevention: A } 2016 \\
\text { Perspective }\end{array}$ & Headache & Narrative review \\
\hline 309 & 15474764 & Silberstein & Headaches in pregnancy & Neurol Clin & Narrative review \\
\hline 310 & 9058407 & Silberstein & Migraine and pregnancy & 11903523 & Narrative review \\
\hline 311 & 12457199 & Silberstein & $\begin{array}{l}\text { MIGRAINE AND } \\
\text { PREGNANCY }\end{array}$ & J sogc & Narrative review \\
\hline 312 & 16362655 & Silberstein & Headaches in pregnancy & $\begin{array}{l}\text { J Headache } \\
\text { Pain }\end{array}$ & Narrative review \\
\hline
\end{tabular}




\begin{tabular}{|c|c|c|c|c|c|}
\hline No. & $\begin{array}{l}\text { PMI D or Other } \\
\text { I dentifier }\end{array}$ & $\begin{array}{l}\text { First Author } \\
\text { Last Name }\end{array}$ & Title & Journal & Reason for Exclusion \\
\hline 313 & 7904984 & Silberstein & $\begin{array}{l}\text { Headaches and women: } \\
\text { treatment of the pregnant } \\
\text { and lactating migraineur }\end{array}$ & Headache & Narrative review \\
\hline 314 & 9793694 & Silberstein & Methysergide & Cephalalgia & $\begin{array}{l}\text { Participants not pregnant (or } \\
\text { attempting to be pregnant), } \\
\text { postpartum, or breastfeeding }\end{array}$ \\
\hline 315 & $\begin{array}{l}\text { CN-01006941 } \\
\text { (Cochrane) }\end{array}$ & Silva & $\begin{array}{l}\text { Acupuncture for tension- } \\
\text { type headache in } \\
\text { pregnancy: a prospective, } \\
\text { randomized, controlled } \\
\text { study }\end{array}$ & $\begin{array}{l}\text { Journal of } \\
\text { alternative } \\
\text { and } \\
\text { complementar } \\
\text { y medicine } \\
\text { (new york, } \\
\text { N.Y.) }\end{array}$ & Duplicate \\
\hline 316 & 29736103 & Skarica & $\begin{array}{l}\text { Effectiveness of Manual } \\
\text { Treatment on Pregnancy } \\
\text { Symptoms: Usefulness of } \\
\text { Manual Treatment in } \\
\text { Treating Pregnancy } \\
\text { Symptoms }\end{array}$ & Med Arch & $\begin{array}{l}\text { Participants did not have primary } \\
\text { headache or there were no } \\
\text { primary headache-specific data }\end{array}$ \\
\hline 317 & 25835347 & Skeik & $\begin{array}{l}\text { Postpartum reversible } \\
\text { cerebral vasoconstriction } \\
\text { syndrome: review and } \\
\text { analysis of the current data }\end{array}$ & Vasc Med & $\begin{array}{l}\text { Participants did not have primary } \\
\text { headache or there were no } \\
\text { primary headache-specific data }\end{array}$ \\
\hline 318 & 18223456 & Soldin & Triptans in pregnancy & $\begin{array}{l}\text { Ther Drug } \\
\text { Monit }\end{array}$ & Narrative review \\
\hline 319 & 6440302 & Spector & Migraine & $\begin{array}{l}\text { Surv } \\
\text { Ophthalmol }\end{array}$ & No intervention of interest \\
\hline 320 & 25488459 & Suetterlin & $\begin{array}{l}\text { Diagnosis and management } \\
\text { of headache }\end{array}$ & $\begin{array}{l}\text { BrJ Hosp Med } \\
\text { (Lond) }\end{array}$ & $\begin{array}{l}\text { Participants not pregnant (or } \\
\text { attempting to be pregnant), } \\
\text { postpartum, or breastfeeding }\end{array}$ \\
\hline 321 & 19545260 & Taylor & $\begin{array}{l}\text { Headache prevention with } \\
\text { complementary and } \\
\text { alternative medicine }\end{array}$ & Headache & $\begin{array}{l}\text { Participants not pregnant (or } \\
\text { attempting to be pregnant), } \\
\text { postpartum, or breastfeeding }\end{array}$ \\
\hline 322 & No PubMed ID & Tennis & $\begin{array}{l}\text { Topiramate use during } \\
\text { pregnancy and major } \\
\text { congenital malformations in } \\
\text { multiple populations }\end{array}$ & $\begin{array}{l}\text { Birth Defects } \\
\text { Research Part } \\
\text { A - Clinical } \\
\text { and Molecular } \\
\text { Teratology } \\
\end{array}$ & $\begin{array}{l}\text { Participants did not have primary } \\
\text { headache or there were no } \\
\text { primary headache-specific data }\end{array}$ \\
\hline 323 & 25881682 & Tepper & $\begin{array}{l}\text { Pregnancy and lactation-- } \\
\text { migraine management }\end{array}$ & Headache & Narrative review \\
\hline 324 & No PubMed ID & Tepper & Onabotulinum A (Botox) & Headache & Narrative review \\
\hline 325 & 24400754 & Tepper & $\begin{array}{l}\text { Should butalbital ever be } \\
\text { given, much less to a } \\
\text { pregnant woman? }\end{array}$ & Headache & Narrative review \\
\hline 326 & 16097850 & Tietjen & $\begin{array}{l}\text { The risk of stroke in patients } \\
\text { with migraine and } \\
\text { implications for migraine } \\
\text { management }\end{array}$ & CNS Drugs & $\begin{array}{l}\text { Participants not pregnant (or } \\
\text { attempting to be pregnant), } \\
\text { postpartum, or breastfeeding }\end{array}$ \\
\hline 327 & 21198577 & Tobin & $\begin{array}{l}\text { Treatment of migraine with } \\
\text { occipital nerve blocks using } \\
\text { only corticosteroids }\end{array}$ & Headache & $\begin{array}{l}\text { Participants did not have primary } \\
\text { headache or there were no } \\
\text { primary headache-specific data }\end{array}$ \\
\hline 328 & 29855724 & Todd & $\begin{array}{l}\text { Women and Migraine: the } \\
\text { Role of Hormones }\end{array}$ & $\begin{array}{l}\text { Curr Neurol } \\
\text { Neurosci Rep }\end{array}$ & Narrative review \\
\hline 329 & 2202585 & Todd & $\begin{array}{l}\text { Naproxen. A reappraisal of } \\
\text { its pharmacology, and } \\
\text { therapeutic use in rheumatic } \\
\text { diseases and pain states }\end{array}$ & Drugs & $\begin{array}{l}\text { Participants did not have primary } \\
\text { headache or there were no } \\
\text { primary headache-specific data }\end{array}$ \\
\hline 330 & 22805351 & Tomson & $\begin{array}{l}\text { Teratogenic effects of } \\
\text { antiepileptic drugs }\end{array}$ & Lancet Neurol & $\begin{array}{l}\text { Participants did not have primary } \\
\text { headache or there were no } \\
\text { primary headache-specific data }\end{array}$ \\
\hline 331 & 20464584 & Torelli & $\begin{array}{l}\text { Clinical review of headache } \\
\text { in pregnancy }\end{array}$ & Neurol SCi & Narrative review \\
\hline
\end{tabular}




\begin{tabular}{|c|c|c|c|c|c|}
\hline No. & $\begin{array}{l}\text { PMI D or Other } \\
\text { I dentifier }\end{array}$ & $\begin{array}{l}\text { First Author } \\
\text { Last Name }\end{array}$ & Title & Journal & Reason for Exclusion \\
\hline 332 & 6146972 & Turner & $\begin{array}{l}\text { Beta-blocking drugs in } \\
\text { migraine }\end{array}$ & $\begin{array}{l}\text { Postgrad Med } \\
\text { J }\end{array}$ & $\begin{array}{l}\text { Participants not pregnant (or } \\
\text { attempting to be pregnant), } \\
\text { postpartum, or breastfeeding }\end{array}$ \\
\hline 333 & 1889976 & Uknis & $\begin{array}{l}\text { Review article: migraine and } \\
\text { pregnancy }\end{array}$ & Headache & No intervention of interest \\
\hline 334 & No PubMed ID & Urbaczek & $\begin{array}{l}\text { Migraines during pregnancy } \\
\text { treated with acupuncture - A } \\
\text { case report }\end{array}$ & $\begin{array}{l}\text { Revista } \\
\text { Internacional } \\
\text { de Acupuntura }\end{array}$ & Unable to retrieve article \\
\hline 335 & 23461556 & Vajda & $\begin{array}{l}\text { Associations between } \\
\text { particular types of fetal } \\
\text { malformation and } \\
\text { antiepileptic drug exposure } \\
\text { in utero }\end{array}$ & $\begin{array}{l}\text { Acta Neurol } \\
\text { Scand }\end{array}$ & $\begin{array}{l}\text { Participants did not have primary } \\
\text { headache or there were no } \\
\text { primary headache-specific data }\end{array}$ \\
\hline 336 & 26711274 & VanderPluym & $\begin{array}{l}\text { Cluster Headache: Special } \\
\text { Considerations for } \\
\text { Treatment of Female } \\
\text { Patients of Reproductive } \\
\text { Age and Pediatric Patients }\end{array}$ & $\begin{array}{l}\text { Curr Neurol } \\
\text { Neurosci Rep }\end{array}$ & Narrative review \\
\hline 337 & 30109437 & Vatzaki & $\begin{array}{l}\text { Latest clinical } \\
\text { recommendations on } \\
\text { valproate use for migraine } \\
\text { prophylaxis in women of } \\
\text { childbearing age: overview } \\
\text { from European Medicines } \\
\text { Agency and European } \\
\text { Headache Federation }\end{array}$ & $\begin{array}{l}\text { J Headache } \\
\text { Pain }\end{array}$ & SR and guideline \\
\hline 338 & 30684032 & Veronese & $\begin{array}{l}\text { Magnesium and health } \\
\text { outcomes: an umbrella } \\
\text { review of systematic reviews } \\
\text { and meta-analyses of } \\
\text { observational and } \\
\text { intervention studies }\end{array}$ & EurJ Nutr & $\begin{array}{l}\text { Only addresses } \\
\text { predictors/distribution of } \\
\text { intervention use }\end{array}$ \\
\hline 339 & 29446070 & Vgontzas & $\begin{array}{l}\text { A Hospital Based } \\
\text { Retrospective Study of } \\
\text { Acute Postpartum Headache }\end{array}$ & Headache & No intervention of interest \\
\hline 340 & 30225735 & Vikelis & $\begin{array}{l}\text { Sustained } \\
\text { onabotulinumtoxinA } \\
\text { therapeutic benefits in } \\
\text { patients with chronic } \\
\text { migraine over } 3 \text { years of } \\
\text { treatment }\end{array}$ & $\begin{array}{l}\text { J Headache } \\
\text { Pain }\end{array}$ & $\begin{array}{l}\text { Participants not pregnant (or } \\
\text { attempting to be pregnant), } \\
\text { postpartum, or breastfeeding }\end{array}$ \\
\hline 341 & 11889417 & Von Wald & Headache during pregnancy & $\begin{array}{l}\text { Obstet } \\
\text { Gynecol Surv }\end{array}$ & Narrative review \\
\hline 342 & 26049338 & Vsc & $\begin{array}{l}\text { [Migraines in pregnant } \\
\text { patients: how safe are } \\
\text { triptans?] }\end{array}$ & $\begin{array}{l}\text { MMW Fortschr } \\
\text { Med }\end{array}$ & Narrative review \\
\hline 343 & 634879 & Wainscott & $\begin{array}{l}\text { The outcome of pregnancy } \\
\text { in women suffering from } \\
\text { migraine }\end{array}$ & $\begin{array}{l}\text { Postgrad Med } \\
\text { J }\end{array}$ & $\begin{array}{l}\text { Participants not pregnant (or } \\
\text { attempting to be pregnant), } \\
\text { postpartum, or breastfeeding }\end{array}$ \\
\hline 344 & 1288557 & Wall & $\begin{array}{l}\text { Breastfeeding and migraine } \\
\text { headaches }\end{array}$ & J Hum Lact & $\begin{array}{l}\text { Only addresses } \\
\text { predictors/distribution of } \\
\text { intervention use }\end{array}$ \\
\hline 345 & 27888528 & Warnock & $\begin{array}{l}\text { Hormone-Related Migraine } \\
\text { Headaches and Mood } \\
\text { Disorders: Treatment with } \\
\text { Estrogen Stabilization }\end{array}$ & $\begin{array}{l}\text { Pharmacother } \\
\text { apy }\end{array}$ & Narrative review \\
\hline 346 & 24291939 & Watanabe & $\begin{array}{l}\text { [Management of chronic } \\
\text { migraine in Japan] }\end{array}$ & $\begin{array}{l}\text { Rinsho } \\
\text { Shinkeigaku }\end{array}$ & $\begin{array}{l}\text { Participants not pregnant (or } \\
\text { attempting to be pregnant), } \\
\text { postpartum, or breastfeeding }\end{array}$ \\
\hline 347 & 27993305 & Weinstock & Postpartum Headaches & $\begin{array}{l}\text { Ann Emerg } \\
\text { Med }\end{array}$ & Narrative review \\
\hline 348 & 8291477 & Welch & Migraine and pregnancy & Adv Neurol & Narrative review \\
\hline
\end{tabular}




\begin{tabular}{|c|c|c|c|c|c|}
\hline No. & $\begin{array}{l}\text { PMI D or Other } \\
\text { I dentifier }\end{array}$ & $\begin{array}{l}\text { First Author } \\
\text { Last Name }\end{array}$ & Title & J ournal & Reason for Exclusion \\
\hline 349 & 27002079 & Wells & $\begin{array}{l}\text { Managing Migraine During } \\
\text { Pregnancy and Lactation }\end{array}$ & $\begin{array}{l}\text { Curr Neurol } \\
\text { Neurosci Rep }\end{array}$ & Narrative review \\
\hline 350 & 22550159 & Williams & $\begin{array}{l}\text { An update in the treatment } \\
\text { of neurologic disorders } \\
\text { during pregnancy--focus on } \\
\text { migraines and seizures }\end{array}$ & J Pharm Pract & Narrative review \\
\hline 351 & 8866921 & WojnaB-Horton & $\begin{array}{l}\text { Distribution and excretion of } \\
\text { sumatriptan in human milk }\end{array}$ & $\begin{array}{l}\text { BrJ Clin } \\
\text { Pharmacol }\end{array}$ & $\begin{array}{l}\text { Participants did not have primary } \\
\text { headache or there were no } \\
\text { primary headache-specific data }\end{array}$ \\
\hline 352 & 26554750 & Wood & $\begin{array}{l}\text { Prenatal triptan exposure } \\
\text { and parent-reported early } \\
\text { childhood } \\
\text { neurodevelopmental } \\
\text { outcomes: an application of } \\
\text { propensity score calibration } \\
\text { to adjust for unmeasured } \\
\text { confounding by migraine } \\
\text { severity }\end{array}$ & $\begin{array}{l}\text { Pharmacoepid } \\
\text { emiol Drug } \\
\text { Saf }\end{array}$ & $\begin{array}{l}\text { Participants did not have primary } \\
\text { headache or there were no } \\
\text { primary headache-specific data }\end{array}$ \\
\hline 353 & 23968886 & Worthington & $\begin{array}{l}\text { Canadian Headache Society } \\
\text { Guideline: acute drug } \\
\text { therapy for migraine } \\
\text { headache }\end{array}$ & $\begin{array}{l}\text { Can J Neurol } \\
\text { Sci }\end{array}$ & SR and guideline \\
\hline 354 & 30403278 & Yilmaz & $\begin{array}{l}\text { Headache in challenging and } \\
\text { special circumstances: } \\
\text { Pregnancy and lactation }\end{array}$ & Agri & Narrative review \\
\hline 355 & No PubMed ID & Yusta Izquierdo & $\begin{array}{l}\text { A 32-year old woman with } \\
\text { recurrent hemicranial } \\
\text { headache that gets worse } \\
\text { during pregnancy }\end{array}$ & $\begin{array}{l}\text { Medicine } \\
\text { (Spain) }\end{array}$ & Unable to retrieve article \\
\hline
\end{tabular}

Abbreviations: PMID = PubMed identifier, SR = systematic review. 


\section{SRs}

The 347 excluded articles, along with reasons for exclusion, are listed in Table B-39. The most common reasons for exclusion were that the articles were SRs that did not meet our minim criteria, there were no interventions of interest, or there was no information about adverse effects.

Table B-39. Excluded systematic reviews with reasons for exclusion

\begin{tabular}{|c|c|c|c|c|c|}
\hline No. & $\begin{array}{l}\text { PMID or } \\
\text { Other } \\
\text { Identifier }\end{array}$ & $\begin{array}{c}\text { First } \\
\text { Author } \\
\text { Last Name }\end{array}$ & Title & J ournal & Reason for Exclusion \\
\hline 1 & 24504933 & Abalos & $\begin{array}{l}\text { Antihypertensive drug therapy for mild } \\
\text { to moderate hypertension during } \\
\text { pregnancy }\end{array}$ & $\begin{array}{l}\text { Cochrane Database } \\
\text { Syst Rev }\end{array}$ & $\begin{array}{l}\text { Older version of another } \\
\text { review }\end{array}$ \\
\hline 2 & 17253478 & Abalos & $\begin{array}{l}\text { Antihypertensive drug therapy for mild } \\
\text { to moderate hypertension during } \\
\text { pregnancy }\end{array}$ & $\begin{array}{l}\text { Cochrane Database } \\
\text { Syst Rev }\end{array}$ & $\begin{array}{l}\text { Older version of another } \\
\text { review }\end{array}$ \\
\hline 3 & 15266543 & Adab & $\begin{array}{l}\text { Common antiepileptic drugs in } \\
\text { pregnancy in women with epilepsy }\end{array}$ & $\begin{array}{l}\text { Cochrane Database } \\
\text { Syst Rev }\end{array}$ & Duplicate \\
\hline 4 & 26678040 & Adab & $\begin{array}{l}\text { Common antiepileptic drugs in } \\
\text { pregnancy in women with epilepsy }\end{array}$ & $\begin{array}{l}\text { Cochrane Database } \\
\text { of Systematic } \\
\text { Reviews }\end{array}$ & Review withdrawn \\
\hline 5 & 22942331 & Adams & $\begin{array}{l}\text { Safety of pain therapy during } \\
\text { pregnancy and lactation in patients with } \\
\text { inflammatory arthritis: a systematic } \\
\text { literature review }\end{array}$ & J Rheumatol Supp/ & $\begin{array}{l}\text { SR, but did not meet } \\
\text { minimum criteria }\end{array}$ \\
\hline 6 & 11717636 & Aghajafari & $\begin{array}{l}\text { Multiple courses of antenatal } \\
\text { corticosteroids: a systematic review and } \\
\text { meta-analysis }\end{array}$ & Am J Obstet Gynecol & $\begin{array}{l}\text { SR, but did not meet } \\
\text { minimum criteria }\end{array}$ \\
\hline 7 & 17266890 & Aguilera & [Low dose of aspirin during pregnancy] & Med Clin (Barc) & Narrative review only \\
\hline 8 & 25797654 & Alsaad & $\begin{array}{l}\text { First trimester exposure to topiramate } \\
\text { and the risk of oral clefts in the } \\
\text { offspring: A systematic review and } \\
\text { meta-analysis }\end{array}$ & Reprod Toxicol & $\begin{array}{l}\text { No information about } \\
\text { adverse effects }\end{array}$ \\
\hline 9 & 8615404 & Altshuler & $\begin{array}{l}\text { Pharmacologic management of } \\
\text { psychiatric illness during pregnancy: } \\
\text { dilemmas and guidelines }\end{array}$ & AmJ Psychiatry & Narrative review only \\
\hline 10 & 25881578 & Amer & $\begin{array}{l}\text { Safety of Popular Herbal Supplements } \\
\text { in Lactating Women }\end{array}$ & J Hum Lact & Narrative review only \\
\hline 11 & 17980183 & Amin & $\begin{array}{l}\text { Metaanalysis of the effect of antenatal } \\
\text { indomethacin on neonatal outcomes }\end{array}$ & AmJ Obstet Gynecol & No intervention of interest \\
\hline 12 & 25732401 & $\begin{array}{l}\text { Aminoshari } \\
\text { ae }\end{array}$ & Acetaminophen: old drug, new issues & J Endod & Narrative review only \\
\hline 13 & 31577868 & Andrade & $\begin{array}{l}\text { Gestational Exposure to } \\
\text { Benzodiazepines, 2: The Risk of } \\
\text { Congenital Malformations Examined } \\
\text { Through the Prism of Compatibility } \\
\text { Intervals }\end{array}$ & J Clin Psychiatry & Narrative review only \\
\hline 14 & 32044579 & Antza & $\begin{array}{l}\text { The flipside of hydralazine in } \\
\text { pregnancy: A systematic review and } \\
\text { meta-analysis }\end{array}$ & $\begin{array}{l}\text { Pregnancy } \\
\text { Hypertens }\end{array}$ & No intervention of interest \\
\hline 15 & 2605908 & Areia & $\begin{array}{l}\text { Low-moleculaB-weight heparin plus } \\
\text { aspirin versus aspirin alone in pregnant } \\
\text { women with hereditary thrombophilia to } \\
\text { improve live birth rate: meta-analysis of } \\
\text { randomized controlled trials }\end{array}$ & $\begin{array}{l}\text { Archives of } \\
\text { gynecology and } \\
\text { obstetrics }\end{array}$ & $\begin{array}{l}\text { No information about } \\
\text { adverse effects }\end{array}$ \\
\hline 16 & 24443652 & Arrowsmith & Drugs acting on the pregnant uterus & $\begin{array}{l}\text { Obstet Gynaecol } \\
\text { Reprod Med }\end{array}$ & Narrative review only \\
\hline 17 & 17512048 & Askie & $\begin{array}{l}\text { Antiplatelet agents for prevention of } \\
\text { pre-eclampsia: a meta-analysis of } \\
\text { individual patient data }\end{array}$ & Lancet & No intervention of interest \\
\hline 18 & 29039130 & Atallah & Aspirin for Prevention of Preeclampsia & Drugs & Narrative review only \\
\hline
\end{tabular}




\begin{tabular}{|c|c|c|c|c|c|}
\hline No. & $\begin{array}{l}\text { PMI D or } \\
\text { Other } \\
\text { I dentifier }\end{array}$ & $\begin{array}{c}\text { First } \\
\text { Author } \\
\text { Last Name }\end{array}$ & Title & J ournal & Reason for Exclusion \\
\hline 19 & 10084341 & Austin & $\begin{array}{l}\text { Use of psychotropic medications in } \\
\text { breast-feeding women: acute and } \\
\text { prophylactic treatment }\end{array}$ & Aust N ZJ Psychiatry & Narrative review only \\
\hline 20 & 9830392 & Austin & $\begin{array}{l}\text { Psychotropic medications in pregnant } \\
\text { women: treatment dilemmas }\end{array}$ & Med / Aust & $\begin{array}{l}\text { SR, but did not meet } \\
\text { minimum criteria }\end{array}$ \\
\hline 21 & 26652709 & Baber & $\begin{array}{l}\text { The pharmacogenetics of opioid } \\
\text { therapy in the management of } \\
\text { postpartum pain: a systematic review }\end{array}$ & Pharmacogenomics & $\begin{array}{l}\text { No information about } \\
\text { adverse effects }\end{array}$ \\
\hline 22 & 24708875 & Baldacchino & $\begin{array}{l}\text { Neurobehavioral consequences of } \\
\text { chronic intrauterine opioid exposure in } \\
\text { infants and preschool children: a } \\
\text { systematic review and meta-analysis }\end{array}$ & BMC Psychiatry & $\begin{array}{l}\text { SR, but did not meet } \\
\text { minimum criteria }\end{array}$ \\
\hline 23 & 20000869 & Banach & $\begin{array}{l}\text { Long-term developmental outcome of } \\
\text { children of women with epilepsy, } \\
\text { unexposed or exposed prenatally to } \\
\text { antiepileptic drugs: a meta-analysis of } \\
\text { cohort studies }\end{array}$ & Drug Saf & $\begin{array}{l}\text { SR, but did not meet } \\
\text { minimum criteria }\end{array}$ \\
\hline 24 & 29341895 & Bauer & $\begin{array}{l}\text { Prenatal paracetamol exposure and } \\
\text { child neurodevelopment: A review }\end{array}$ & Horm Behav & $\begin{array}{l}\text { SR, but did not meet } \\
\text { minimum criteria }\end{array}$ \\
\hline 25 & 12044345 & Beardmore & $\begin{array}{l}\text { Excretion of antihypertensive } \\
\text { medication into human breast milk: a } \\
\text { systematic review }\end{array}$ & $\begin{array}{l}\text { Hypertens } \\
\text { Pregnancy }\end{array}$ & $\begin{array}{l}\text { No information about } \\
\text { adverse effects }\end{array}$ \\
\hline 26 & 26252584 & Becker & Acute Migraine Treatment & $\begin{array}{l}\text { Continuum (Minneap } \\
\text { Minn) }\end{array}$ & Narrative review only \\
\hline 27 & 8205012 & Beilin & Aspirin and pre-eclampsia & $B m j$ & Narrative review only \\
\hline 28 & 17397101 & Bellantuono & $\begin{array}{l}\text { Serotonin reuptake inhibitors in } \\
\text { pregnancy and the risk of major } \\
\text { malformations: a systematic review }\end{array}$ & $\begin{array}{l}\text { Hum } \\
\text { Psychopharmacol }\end{array}$ & No intervention of interest \\
\hline 29 & 25784291 & Bellantuono & $\begin{array}{l}\text { The safety of serotonin-noradrenaline } \\
\text { reuptake inhibitors (SNRIs) in } \\
\text { pregnancy and breastfeeding: a } \\
\text { comprehensive review }\end{array}$ & $\begin{array}{l}\text { Hum } \\
\text { Psychopharmacol }\end{array}$ & $\begin{array}{l}\text { SR, but did not meet } \\
\text { minimum criteria }\end{array}$ \\
\hline 30 & $\begin{array}{l}\text { No PubMed } \\
\text { ID }\end{array}$ & Berg & $\begin{array}{l}\text { Effects of Opioid Agonist Treatment for } \\
\text { Pregnant Opioid Dependent Women }\end{array}$ & $\begin{array}{l}\text { NIPH Systematic } \\
\text { Reviews: Executive } \\
\text { Summaries }\end{array}$ & No intervention of interest \\
\hline 31 & 29320133 & Berg & $\begin{array}{l}\text { NIPH Systematic Reviews: Executive } \\
\text { Summaries }\end{array}$ & $\begin{array}{l}\text { Effects of Opioid } \\
\text { Agonist Treatment } \\
\text { for Pregnant Opioid } \\
\text { Dependent Women }\end{array}$ & Unable to retrieve article \\
\hline 32 & 26731178 & Bergeron & $\begin{array}{l}\text { Prevention of Preeclampsia with Aspirin } \\
\text { in Multiple Gestations: A Systematic } \\
\text { Review and Meta-analysis }\end{array}$ & Am J Perinatol & $\begin{array}{l}\text { SR, but did not meet } \\
\text { minimum criteria }\end{array}$ \\
\hline 33 & 25833188 & Berhan & $\begin{array}{l}\text { Should magnesium sulfate be } \\
\text { administered to women with mild pre- } \\
\text { eclampsia? A systematic review of } \\
\text { published reports on eclampsia }\end{array}$ & $\begin{array}{l}\text { J Obstet Gynaecol } \\
\text { Res }\end{array}$ & $\begin{array}{l}\text { SR, but did not meet } \\
\text { minimum criteria }\end{array}$ \\
\hline 34 & 25515299 & Bjorn & $\begin{array}{l}\text { Use of inhaled and oral corticosteroids } \\
\text { in pregnancy and the risk of } \\
\text { malformations or miscarriage }\end{array}$ & $\begin{array}{l}\text { Basic Clin Pharmacol } \\
\text { Toxicol }\end{array}$ & $\begin{array}{l}\text { SR, but did not meet } \\
\text { minimum criteria }\end{array}$ \\
\hline 35 & 31242344 & Black & $\begin{array}{l}\text { Medication Use and Pain Management } \\
\text { in Pregnancy: A Critical Review }\end{array}$ & Pain Practice & $\begin{array}{l}\text { SR, but did not meet } \\
\text { minimum criteria }\end{array}$ \\
\hline 36 & 27168518 & Boelig & $\begin{array}{l}\text { Interventions for treating hyperemesis } \\
\text { gravidarum }\end{array}$ & $\begin{array}{l}\text { Cochrane Database } \\
\text { Syst Rev }\end{array}$ & $\begin{array}{l}\text { No information about } \\
\text { adverse effects }\end{array}$ \\
\hline 37 & 28614956 & Boelig & $\begin{array}{l}\text { Interventions for treating hyperemesis } \\
\text { gravidarum: a Cochrane systematic } \\
\text { review and meta-analysis }\end{array}$ & $\begin{array}{l}\text { J Matern Fetal } \\
\text { Neonatal Med }\end{array}$ & $\begin{array}{l}\text { No information about } \\
\text { adverse effects }\end{array}$ \\
\hline 38 & 25150272 & Brogly & $\begin{array}{l}\text { Prenatal buprenorphine versus } \\
\text { methadone exposure and neonatal } \\
\text { outcomes: systematic review and meta- } \\
\text { analysis }\end{array}$ & AmJ Epidemiol & No intervention of interest \\
\hline
\end{tabular}




\begin{tabular}{|c|c|c|c|c|c|}
\hline No. & $\begin{array}{l}\text { PMI D or } \\
\text { Other } \\
\text { I dentifier }\end{array}$ & $\begin{array}{c}\text { First } \\
\text { Author } \\
\text { Last Name }\end{array}$ & Title & Journal & Reason for Exclusion \\
\hline 39 & 25354543 & Bromley & $\begin{array}{l}\text { Treatment for epilepsy in pregnancy: } \\
\text { neurodevelopmental outcomes in the } \\
\text { child }\end{array}$ & $\begin{array}{l}\text { Cochrane Database } \\
\text { Syst Rev }\end{array}$ & $\begin{array}{l}\text { No information about } \\
\text { adverse effects }\end{array}$ \\
\hline 40 & 19863482 & Broy & $\begin{array}{l}\text { Gestational exposure to antidepressants } \\
\text { and the risk of spontaneous abortion: a } \\
\text { review }\end{array}$ & Curr Drug Deliv & $\begin{array}{l}\text { SR, but did not meet } \\
\text { minimum criteria }\end{array}$ \\
\hline 41 & 25845914 & Bruning & $\begin{array}{l}\text { Antidepressants during pregnancy and } \\
\text { postpartum hemorrhage: a systematic } \\
\text { review }\end{array}$ & $\begin{array}{l}\text { EurJ Obstet Gynecol } \\
\text { Reprod Biol }\end{array}$ & $\begin{array}{l}\text { SR, but did not meet } \\
\text { minimum criteria }\end{array}$ \\
\hline 42 & 20664402 & Bujold & $\begin{array}{l}\text { Prevention of preeclampsia and } \\
\text { intrauterine growth restriction with } \\
\text { aspirin started in early pregnancy: a } \\
\text { meta-analysis }\end{array}$ & $\begin{array}{l}\text { Obstetrics and } \\
\text { gynecology }\end{array}$ & $\begin{array}{l}\text { SR, but did not meet } \\
\text { minimum criteria }\end{array}$ \\
\hline 43 & 29595872 & Bushman & Headaches Through a Woman's Life & Obstet Gynecol Sunv & Not a review \\
\hline 44 & 29187414 & Cairns & $\begin{array}{l}\text { Postpartum management of } \\
\text { hypertensive disorders of pregnancy: a } \\
\text { systematic review }\end{array}$ & BMJ Open & $\begin{array}{l}\text { No information about } \\
\text { adverse effects }\end{array}$ \\
\hline 45 & 27054939 & Carstairs & $\begin{array}{l}\text { Ondansetron Use in Pregnancy and } \\
\text { Birth Defects: A Systematic Review }\end{array}$ & Obstet Gynecol & $\begin{array}{l}\text { SR, but did not meet } \\
\text { minimum criteria }\end{array}$ \\
\hline 46 & 20662551 & Cassina & $\begin{array}{l}\text { Migraine therapy during pregnancy and } \\
\text { lactation }\end{array}$ & $\begin{array}{l}\text { Expert Opin Drug } \\
\text { Saf }\end{array}$ & $\begin{array}{l}\text { SR, but did not meet } \\
\text { minimum criteria }\end{array}$ \\
\hline 47 & 10576835 & Cates & $\begin{array}{l}\text { Benzodiazepine use in pregnancy and } \\
\text { major malformations or oral clefts. } \\
\text { Pooled results are sensitive to zero } \\
\text { transformation used }\end{array}$ & $B m j$ & Not a review \\
\hline 48 & 21130227 & Chatillon & $\begin{array}{l}\text { [Antepartum depression: prevalence, } \\
\text { diagnosis and treatment] }\end{array}$ & Encephale & $\begin{array}{l}\text { SR, but did not meet } \\
\text { minimum criteria }\end{array}$ \\
\hline 49 & 25429049 & Cheelo & $\begin{array}{l}\text { Paracetamol exposure in pregnancy and } \\
\text { early childhood and development of } \\
\text { childhood asthma: a systematic review } \\
\text { and meta-analysis }\end{array}$ & Arch Dis Child & $\begin{array}{l}\text { No information about } \\
\text { adverse effects }\end{array}$ \\
\hline 50 & 28646257 & Chen & $\begin{array}{l}\text { Effect of epilepsy in pregnancy on fetal } \\
\text { growth restriction: a systematic review } \\
\text { and meta-analysis }\end{array}$ & Arch Gynecol Obstet & $\begin{array}{l}\text { No information about } \\
\text { adverse effects }\end{array}$ \\
\hline 51 & 24323370 & Chin & $\begin{array}{l}\text { Re-analysis of safety data supporting } \\
\text { doxylamine use for nausea and } \\
\text { vomiting of pregnancy }\end{array}$ & AmJ Perinatol & No intervention of interest \\
\hline 52 & 25674710 & Cluver & $\begin{array}{l}\text { Interventions for helping to turn term } \\
\text { breech babies to head first presentation } \\
\text { when using external cephalic version }\end{array}$ & $\begin{array}{l}\text { Cochrane Database } \\
\text { Syst Rev }\end{array}$ & No intervention of interest \\
\hline 53 & 22258940 & Cluver & $\begin{array}{l}\text { Interventions for helping to turn term } \\
\text { breech babies to head first presentation } \\
\text { when using external cephalic version }\end{array}$ & $\begin{array}{l}\text { Cochrane Database } \\
\text { Syst Rev }\end{array}$ & No intervention of interest \\
\hline 54 & 25674710 & Cluver & $\begin{array}{l}\text { Interventions for helping to turn term } \\
\text { breech babies to head first presentation } \\
\text { when using external cephalic version }\end{array}$ & $\begin{array}{l}\text { Cochrane Database } \\
\text { Syst Rev }\end{array}$ & Duplicate \\
\hline 55 & 8031346 & Cohen & $\begin{array}{l}\text { A reevaluation of risk of in utero } \\
\text { exposure to lithium }\end{array}$ & Jama & Narrative review only \\
\hline 56 & 31129438 & Cole & $\begin{array}{l}\text { A systematic review of the safety and } \\
\text { effectiveness of repetitive transcranial } \\
\text { magnetic stimulation in the treatment } \\
\text { of peripartum depression }\end{array}$ & J Psychiatr Res & $\begin{array}{l}\text { SR, but did not meet } \\
\text { minimum criteria }\end{array}$ \\
\hline 57 & $\begin{array}{l}\text { No PubMed } \\
\text { ID }\end{array}$ & Costa & $\begin{array}{l}\text { Eslicarbazepine acetate exposure in } \\
\text { pregnant women with epilepsy }\end{array}$ & Seizure & No intervention of interest \\
\hline 58 & 19622997 & Costantine & $\begin{array}{l}\text { Effects of antenatal exposure to } \\
\text { magnesium sulfate on neuroprotection } \\
\text { and mortality in preterm infants: a } \\
\text { meta-analysis }\end{array}$ & Obstet Gynecol & Narrative review only \\
\hline 59 & 25639010 & Costoloni & $\begin{array}{l}\text { [Mood stabilisers and pregnancy } \\
\text { outcomes - a review] }\end{array}$ & Psychiatr Pol & Narrative review only \\
\hline
\end{tabular}




\begin{tabular}{|c|c|c|c|c|c|}
\hline No. & $\begin{array}{l}\text { PMI D or } \\
\text { Other } \\
\text { I dentifier }\end{array}$ & $\begin{array}{c}\text { First } \\
\text { Author } \\
\text { Last Name }\end{array}$ & Title & J ournal & Reason for Exclusion \\
\hline 60 & 29487964 & Crettenand & $\begin{array}{l}\text { [Use of antiepileptic drugs during } \\
\text { breastfeeding : What do we tell the } \\
\text { mother?] }\end{array}$ & Nervenarzt & $\begin{array}{l}\text { SR, but did not meet } \\
\text { minimum criteria }\end{array}$ \\
\hline 61 & 7631713 & Crowley & $\begin{array}{l}\text { Antenatal corticosteroid therapy: a } \\
\text { meta-analysis of the randomized trials, } \\
1972 \text { to } 1994\end{array}$ & AmJ Obstet Gynecol & $\begin{array}{l}\text { SR, but did not meet } \\
\text { minimum criteria }\end{array}$ \\
\hline 62 & 26142898 & Crowther & $\begin{array}{l}\text { Repeat doses of prenatal corticosteroids } \\
\text { for women at risk of preterm birth for } \\
\text { improving neonatal health outcomes }\end{array}$ & $\begin{array}{l}\text { Cochrane Database } \\
\text { Syst Rev }\end{array}$ & No intervention of interest \\
\hline 63 & 29725376 & Cui & $\begin{array}{l}\text { Low-dose aspirin at }</=16 \text { weeks of } \\
\text { gestation for preventing preeclampsia } \\
\text { and its maternal and neonatal adverse } \\
\text { outcomes: A systematic review and } \\
\text { meta-analysis }\end{array}$ & Exp Ther Med & $\begin{array}{l}\text { SR, but did not meet } \\
\text { minimum criteria }\end{array}$ \\
\hline 64 & 26520624 & Dalili & Lamotrigine effects on breastfed infants & Acta Med Iran & $\begin{array}{l}\text { SR, but did not meet } \\
\text { minimum criteria }\end{array}$ \\
\hline 65 & 31273431 & Dathe & $\begin{array}{l}\text { Risk estimation of fetal adverse effects } \\
\text { after short-term second trimester } \\
\text { exposure to non-steroidal anti- } \\
\text { inflammatory drugs: a literature review }\end{array}$ & Eur J Clin Pharmacol & Narrative review only \\
\hline 66 & 25217187 & Davanzo & Breastfeeding and migraine drugs & EurJ Clin Pharmacol & Narrative review only \\
\hline 67 & 20958101 & Davanzo & $\begin{array}{l}\text { Antidepressant drugs and } \\
\text { breastfeeding: a review of the literature }\end{array}$ & Breastfeed Med & $\begin{array}{l}\text { SR, but did not meet } \\
\text { minimum criteria }\end{array}$ \\
\hline 68 & 23985170 & Davanzo & Antiepileptic drugs and breastfeeding & $\begin{array}{l}\text { Italian J ournal of } \\
\text { Pediatrics }\end{array}$ & $\begin{array}{l}\text { SR, but did not meet } \\
\text { minimum criteria }\end{array}$ \\
\hline 69 & 8760737 & de Craen & $\begin{array}{l}\text { Analgesic efficacy and safety of } \\
\text { paracetamol-codeine combinations } \\
\text { versus paracetamol alone: a systematic } \\
\text { review }\end{array}$ & $B m j$ & $\begin{array}{l}\text { Participants not pregnant } \\
\text { (or attempting to be } \\
\text { pregnant), postpartum, or } \\
\text { breastfeeding }\end{array}$ \\
\hline 70 & 27398292 & de Jong & $\begin{array}{l}\text { The Risk of Specific Congenital } \\
\text { Anomalies in Relation to Newer } \\
\text { Antiepileptic Drugs: A Literature Review }\end{array}$ & $\begin{array}{l}\text { Drugs Real World } \\
\text { Outcomes }\end{array}$ & $\begin{array}{l}\text { SR, but did not meet } \\
\text { minimum criteria }\end{array}$ \\
\hline 71 & 28486556 & Deshmukh & $\begin{array}{l}\text { Antenatal corticosteroids for neonates } \\
\text { born before } 25 \text { Weeks-A systematic } \\
\text { review and meta-analysis }\end{array}$ & Plos One & $\begin{array}{l}\text { No information about } \\
\text { adverse effects }\end{array}$ \\
\hline 72 & 23136875 & Dideriksen & $\begin{array}{l}\text { First trimester in utero exposure to } \\
\text { methylphenidate }\end{array}$ & $\begin{array}{l}\text { Basic Clin Pharmacol } \\
\text { Toxicol }\end{array}$ & No intervention of interest \\
\hline 73 & 23884904 & Dodd & $\begin{array}{l}\text { Antithrombotic therapy for improving } \\
\text { maternal or infant health outcomes in } \\
\text { women considered at risk of placental } \\
\text { dysfunction }\end{array}$ & $\begin{array}{l}\text { Cochrane Database } \\
\text { Syst Rev }\end{array}$ & No intervention of interest \\
\hline 74 & 20553334 & Dodick & $\begin{array}{l}\text { Transcranial magnetic stimulation for } \\
\text { migraine: a safety review }\end{array}$ & Headache & Narrative review only \\
\hline 75 & 28029463 & Doret & $\begin{array}{l}\text { [Tocolysis for preterm labor without } \\
\text { premature preterm rupture of } \\
\text { membranes] }\end{array}$ & $\begin{array}{l}\text { J Gynecol Obstet Biol } \\
\text { Reprod (Paris) }\end{array}$ & No intervention of interest \\
\hline 76 & 21128087 & Doucet & $\begin{array}{l}\text { Interventions for the prevention and } \\
\text { treatment of postpartum psychosis: a } \\
\text { systematic review }\end{array}$ & $\begin{array}{l}\text { Arch Womens Ment } \\
\text { Health }\end{array}$ & $\begin{array}{l}\text { No information about } \\
\text { adverse effects }\end{array}$ \\
\hline 77 & 19461430 & Doyle & $\begin{array}{l}\text { Antenatal magnesium sulfate and } \\
\text { neurologic outcome in preterm infants: } \\
\text { a systematic review }\end{array}$ & Obstet Gynecol & $\begin{array}{l}\text { SR, but did not meet } \\
\text { minimum criteria }\end{array}$ \\
\hline 78 & 21718553 & Duckitt & Recurrent miscarriage & BMJ Clin Evid & Narrative review only \\
\hline 79 & 19450314 & Duckitt & Recurrent miscarriage & BMJ Clin Evid & $\begin{array}{l}\text { Older version of another } \\
\text { review }\end{array}$ \\
\hline 80 & 29030992 & Duffy & $\begin{array}{l}\text { Inadequate safety reporting in pre- } \\
\text { eclampsia trials: a systematic evaluation }\end{array}$ & Bjog & $\begin{array}{l}\text { SR, but did not meet } \\
\text { minimum criteria }\end{array}$ \\
\hline 81 & 21718554 & Duley & $\begin{array}{l}\text { Pre-eclampsia, eclampsia, and } \\
\text { hypertension }\end{array}$ & BMJ Clin Evid & Narrative review only \\
\hline
\end{tabular}




\begin{tabular}{|c|c|c|c|c|c|}
\hline No. & $\begin{array}{l}\text { PMI D or } \\
\text { Other } \\
\text { I dentifier }\end{array}$ & $\begin{array}{c}\text { First } \\
\text { Author } \\
\text { Last Name }\end{array}$ & Title & J ournal & Reason for Exclusion \\
\hline 82 & $\begin{array}{l}\text { CD000025 } \\
\text { (Cochrane) }\end{array}$ & Duley & $\begin{array}{l}\text { Magnesium sulphate and other } \\
\text { anticonvulsants for women with } \\
\text { pre,Äêeclampsia }\end{array}$ & $\begin{array}{l}\text { Cochrane Database } \\
\text { of Systematic } \\
\text { Reviews }\end{array}$ & No intervention of interest \\
\hline 83 & 14583911 & Duley & $\begin{array}{l}\text { Magnesium sulphate versus phenytoin } \\
\text { for eclampsia }\end{array}$ & $\begin{array}{l}\text { Cochrane Database } \\
\text { Syst Rev }\end{array}$ & No intervention of interest \\
\hline 84 & 11279786 & Duley & $\begin{array}{l}\text { Magnesium sulphate versus lytic } \\
\text { cocktail for eclampsia }\end{array}$ & $\begin{array}{l}\text { Cochrane Database } \\
\text { Syst Rev }\end{array}$ & No intervention of interest \\
\hline 85 & 20824833 & Duley & $\begin{array}{l}\text { Magnesium sulphate versus lytic } \\
\text { cocktail for eclampsia }\end{array}$ & $\begin{array}{l}\text { Cochrane Database } \\
\text { Syst Rev }\end{array}$ & No intervention of interest \\
\hline 86 & 21069663 & Duley & $\begin{array}{l}\text { Magnesium sulphate and other } \\
\text { anticonvulsants for women with pre- } \\
\text { eclampsia }\end{array}$ & $\begin{array}{l}\text { Cochrane Database } \\
\text { Syst Rev }\end{array}$ & No intervention of interest \\
\hline 87 & 23900968 & Duley & $\begin{array}{l}\text { Drugs for treatment of very high blood } \\
\text { pressure during pregnancy }\end{array}$ & $\begin{array}{l}\text { Cochrane Database } \\
\text { Syst Rev }\end{array}$ & $\begin{array}{l}\text { No information about } \\
\text { adverse effects }\end{array}$ \\
\hline 88 & $\begin{array}{l}\text { CD004659 } \\
\text { (Cochrane) }\end{array}$ & Duley & $\begin{array}{l}\text { Antiplatelet agents for preventing } \\
\text { pre,Äêeclampsia and its complications }\end{array}$ & $\begin{array}{l}\text { Cochrane Database } \\
\text { of Systematic } \\
\text { Reviews }\end{array}$ & $\begin{array}{l}\text { No information about } \\
\text { adverse effects }\end{array}$ \\
\hline 89 & 19445808 & Duley & $\begin{array}{l}\text { Pre-eclampsia, eclampsia, and } \\
\text { hypertension }\end{array}$ & BMJ Clin Evid & $\begin{array}{l}\text { Older version of another } \\
\text { review }\end{array}$ \\
\hline 90 & 12804383 & Duley & $\begin{array}{l}\text { Magnesium sulphate and other } \\
\text { anticonvulsants for women with pre- } \\
\text { eclampsia }\end{array}$ & $\begin{array}{l}\text { Cochrane Database } \\
\text { Syst Rev }\end{array}$ & $\begin{array}{l}\text { Older version of another } \\
\text { review }\end{array}$ \\
\hline 91 & 16855969 & Duley & $\begin{array}{l}\text { Drugs for treatment of very high blood } \\
\text { pressure during pregnancy }\end{array}$ & $\begin{array}{l}\text { Cochrane Database } \\
\text { Syst Rev }\end{array}$ & $\begin{array}{l}\text { Older version of another } \\
\text { review }\end{array}$ \\
\hline 92 & 14974075 & Duley & $\begin{array}{l}\text { Antiplatelet agents for preventing pre- } \\
\text { eclampsia and its complications }\end{array}$ & $\begin{array}{l}\text { Cochrane Database } \\
\text { Syst Rev }\end{array}$ & $\begin{array}{l}\text { Older version of another } \\
\text { review }\end{array}$ \\
\hline 93 & 10796090 & Duley & $\begin{array}{l}\text { Anticonvulsants for women with pre- } \\
\text { eclampsia }\end{array}$ & $\begin{array}{l}\text { Cochrane Database } \\
\text { Syst Rev }\end{array}$ & $\begin{array}{l}\text { Older version of another } \\
\text { review }\end{array}$ \\
\hline 94 & 20687086 & Duley & $\begin{array}{l}\text { Alternative magnesium sulphate } \\
\text { regimens for women with pre-eclampsia } \\
\text { and eclampsia }\end{array}$ & $\begin{array}{l}\text { Cochrane Database } \\
\text { Syst Rev }\end{array}$ & $\begin{array}{l}\text { Older version of another } \\
\text { review }\end{array}$ \\
\hline 95 & 26115649 & Durst & $\begin{array}{l}\text { Pregnancy in Women With Solid-Organ } \\
\text { Transplants: A Review }\end{array}$ & Obstet Gynecol Surv & No intervention of interest \\
\hline 96 & 16529525 & $\begin{array}{l}\text { Eberhard- } \\
\text { Gran }\end{array}$ & $\begin{array}{l}\text { Use of psychotropic medications in } \\
\text { treating mood disorders during lactation } \\
\text { : practical recommendations }\end{array}$ & CNS Drugs & $\begin{array}{l}\text { SR, but did not meet } \\
\text { minimum criteria }\end{array}$ \\
\hline 97 & 15742359 & Einarson & $\begin{array}{l}\text { Newer antidepressants in pregnancy } \\
\text { and rates of major malformations: a } \\
\text { meta-analysis of prospective } \\
\text { comparative studies }\end{array}$ & $\begin{array}{l}\text { Pharmacoepidemiol } \\
\text { Drug Saf }\end{array}$ & $\begin{array}{l}\text { SR, but did not meet } \\
\text { minimum criteria }\end{array}$ \\
\hline 98 & 24360293 & Eltonsy & $\begin{array}{l}\text { Beta2-agonists use during pregnancy } \\
\text { and perinatal outcomes: a systematic } \\
\text { review }\end{array}$ & Respir Med & $\begin{array}{l}\text { SR, but did not meet } \\
\text { minimum criteria }\end{array}$ \\
\hline 99 & 25536446 & Ennis & $\begin{array}{l}\text { Pregnancy exposure to olanzapine, } \\
\text { quetiapine, risperidone, aripiprazole and } \\
\text { risk of congenital malformations. A } \\
\text { systematic review }\end{array}$ & $\begin{array}{l}\text { Basic Clin Pharmacol } \\
\text { Toxicol }\end{array}$ & $\begin{array}{l}\text { SR, but did not meet } \\
\text { minimum criteria }\end{array}$ \\
\hline 100 & 26854889 & Etwel & $\begin{array}{l}\text { When positive studies of novel } \\
\text { therapies are subsequently nullified: } \\
\text { cumulative meta-analyses in } \\
\text { preeclampsia }\end{array}$ & Clin Invest Med & Not a review \\
\hline 101 & 24678814 & Etwel & $\begin{array}{l}\text { The fetal safety of cetirizine: an } \\
\text { observational cohort study and meta- } \\
\text { analysis }\end{array}$ & J Obstet Gynaecol & No intervention of interest \\
\hline 102 & 18349309 & Evans & Use of $5-\mathrm{HT} 1$ agonists in pregnancy & Ann Pharmacother & Narrative review only \\
\hline 103 & 21338428 & Eyers & $\begin{array}{l}\text { Paracetamol in pregnancy and the risk } \\
\text { of wheezing in offspring: a systematic } \\
\text { review and meta-analysis }\end{array}$ & Clin Exp Allergy & $\begin{array}{l}\text { SR, but did not meet } \\
\text { minimum criteria }\end{array}$ \\
\hline 104 & 28237129 & Fan & $\begin{array}{l}\text { Prenatal paracetamol use and asthma in } \\
\text { childhood: A systematic review and } \\
\text { meta-analysis }\end{array}$ & $\begin{array}{l}\text { Allergol } \\
\text { Immunopathol } \\
\text { (Madr) }\end{array}$ & $\begin{array}{l}\text { SR, but did not meet } \\
\text { minimum criteria }\end{array}$ \\
\hline
\end{tabular}




\begin{tabular}{|c|c|c|c|c|c|}
\hline No. & $\begin{array}{l}\text { PMID or } \\
\text { Other } \\
\text { I dentifier }\end{array}$ & $\begin{array}{c}\text { First } \\
\text { Author } \\
\text { Last Name }\end{array}$ & Title & J ournal & Reason for Exclusion \\
\hline 105 & 11094241 & Ferrer & $\begin{array}{l}\text { Management of mild chronic } \\
\text { hypertension during pregnancy: a } \\
\text { review }\end{array}$ & Obstet Gynecol & $\begin{array}{l}\text { No information about } \\
\text { adverse effects }\end{array}$ \\
\hline 106 & 19454064 & Festin & Nausea and vomiting in early pregnancy & BMJ Clin Evid & Not a review \\
\hline 107 & 24646807 & Festin & Nausea and vomiting in early pregnancy & BMJ Clin Evid & Narrative review only \\
\hline 108 & 21726485 & Festin & Nausea and vomiting in early pregnancy & BMJ Clin Evid & $\begin{array}{l}\text { Older version of another } \\
\text { review }\end{array}$ \\
\hline 109 & 24832366 & Firoz & $\begin{array}{l}\text { Oral antihypertensive therapy for } \\
\text { severe hypertension in pregnancy and } \\
\text { postpartum: a systematic review }\end{array}$ & Bjog & $\begin{array}{l}\text { SR, but did not meet } \\
\text { minimum criteria }\end{array}$ \\
\hline 110 & 26105410 & Firoz & $\begin{array}{l}\text { PP088. Oral antihypertensive therapy } \\
\text { for severe hypertension in pregnancy }\end{array}$ & $\begin{array}{l}\text { Pregnancy } \\
\text { Hypertens }\end{array}$ & $\begin{array}{l}\text { SR, but did not meet } \\
\text { minimum criteria }\end{array}$ \\
\hline 111 & 31648376 & Fitton & $\begin{array}{l}\text { In utero exposure to antidepressant } \\
\text { medication and neonatal and child } \\
\text { outcomes: a systematic review }\end{array}$ & Acta Psychiatr Scand & $\begin{array}{l}\text { SR, but did not meet } \\
\text { minimum criteria }\end{array}$ \\
\hline 112 & 20060203 & Fleet & $\begin{array}{l}\text { Non-axial administration of fentanyl in } \\
\text { childbirth: a review of the efficacy and } \\
\text { safety of fentanyl for mother and } \\
\text { neonate }\end{array}$ & Midwifery & No intervention of interest \\
\hline 113 & 24903678 & Flenady & $\begin{array}{l}\text { Oxytocin receptor antagonists for } \\
\text { inhibiting preterm labour }\end{array}$ & $\begin{array}{l}\text { Cochrane Database } \\
\text { Syst Rev }\end{array}$ & No intervention of interest \\
\hline 114 & 32421208 & Foong & $\begin{array}{l}\text { Oral galactagogues (natural therapies } \\
\text { or drugs) for increasing breast milk } \\
\text { production in mothers of } \\
\text { non, Äêhospitalised term infants }\end{array}$ & $\begin{array}{l}\text { Cochrane Database } \\
\text { of Systematic } \\
\text { Reviews }\end{array}$ & $\begin{array}{l}\text { No information about } \\
\text { adverse effects }\end{array}$ \\
\hline 115 & 31623458 & Fornaro & $\begin{array}{l}\text { Lithium Exposure During Pregnancy } \\
\text { and the Postpartum Period: A } \\
\text { Systematic Review and Meta-Analysis } \\
\text { of Safety and Efficacy Outcomes }\end{array}$ & AmJ Psychiatry & $\begin{array}{l}\text { SR, but did not meet } \\
\text { minimum criteria }\end{array}$ \\
\hline 116 & 19736267 & $\begin{array}{l}\text { Fortinguerr } \\
\text { a }\end{array}$ & $\begin{array}{l}\text { Psychotropic drug use during } \\
\text { breastfeeding: a review of the evidence }\end{array}$ & Pediatrics & $\begin{array}{l}\text { SR, but did not meet } \\
\text { minimum criteria }\end{array}$ \\
\hline 117 & 14756581 & Fried & $\begin{array}{l}\text { Malformation rates in children of } \\
\text { women with untreated epilepsy: a } \\
\text { meta-analysis }\end{array}$ & Drug Saf & $\begin{array}{l}\text { Participants not pregnant } \\
\text { (or attempting to be } \\
\text { pregnant), postpartum, or } \\
\text { breastfeeding }\end{array}$ \\
\hline 118 & 21034180 & Galbally & $\begin{array}{l}\text { Mood stabilizers in pregnancy: a } \\
\text { systematic review }\end{array}$ & Aust N ZJ Psychiatry & $\begin{array}{l}\text { SR, but did not meet } \\
\text { minimum criteria }\end{array}$ \\
\hline 119 & 22972143 & Garrison & Magnesium for skeletal muscle cramps & $\begin{array}{l}\text { Cochrane Database } \\
\text { Syst Rev }\end{array}$ & $\begin{array}{l}\text { No information about } \\
\text { adverse effects }\end{array}$ \\
\hline 120 & 12076417 & Gates & $\begin{array}{l}\text { Prophylaxis for venous thromboembolic } \\
\text { disease in pregnancy and the early } \\
\text { postnatal period }\end{array}$ & $\begin{array}{l}\text { Cochrane Database } \\
\text { Syst Rev }\end{array}$ & $\begin{array}{l}\text { No information about } \\
\text { adverse effects }\end{array}$ \\
\hline 121 & 24571806 & Gentile & $\begin{array}{l}\text { Risks of neurobehavioral teratogenicity } \\
\text { associated with prenatal exposure to } \\
\text { valproate monotherapy: a systematic } \\
\text { review with regulatory repercussions }\end{array}$ & CNS Spectr & Narrative review only \\
\hline 122 & 17407365 & Gentile & $\begin{array}{l}\text { Serotonin reuptake inhibitoB-induced } \\
\text { perinatal complications }\end{array}$ & Paediatr Drugs & No intervention of interest \\
\hline 123 & 25189088 & Gentile & $\begin{array}{l}\text { Pregnancy exposure to second- } \\
\text { generation antipsychotics and the risk } \\
\text { of gestational diabetes }\end{array}$ & $\begin{array}{l}\text { Expert Opin Drug } \\
\text { Saf }\end{array}$ & $\begin{array}{l}\text { SR, but did not meet } \\
\text { minimum criteria }\end{array}$ \\
\hline 124 & 20583298 & Gentile & $\begin{array}{l}\text { Neurodevelopmental effects of prenatal } \\
\text { exposure to psychotropic medications }\end{array}$ & Depress Anxiety & $\begin{array}{l}\text { SR, but did not meet } \\
\text { minimum criteria }\end{array}$ \\
\hline 125 & 20414166 & Gentile & $\begin{array}{l}\text { On categorizing gestational, birth, and } \\
\text { neonatal complications following late } \\
\text { pregnancy exposure to antidepressants: } \\
\text { the prenatal antidepressant exposure } \\
\text { syndrome }\end{array}$ & CNS Spectr & $\begin{array}{l}\text { SR, but did not meet } \\
\text { minimum criteria }\end{array}$ \\
\hline 126 & 18787227 & Gentile & $\begin{array}{l}\text { Antipsychotic therapy during early and } \\
\text { late pregnancy. A systematic review }\end{array}$ & Schizophr Bull & $\begin{array}{l}\text { SR, but did not meet } \\
\text { minimum criteria }\end{array}$ \\
\hline
\end{tabular}




\begin{tabular}{|c|c|c|c|c|c|}
\hline No. & $\begin{array}{l}\text { PMI D or } \\
\text { Other } \\
\text { I dentifier }\end{array}$ & $\begin{array}{c}\text { First } \\
\text { Author } \\
\text { Last Name }\end{array}$ & Title & Journal & Reason for Exclusion \\
\hline 127 & 18370569 & Gentile & $\begin{array}{l}\text { Infant safety with antipsychotic therapy } \\
\text { in breast-feeding: a systematic review }\end{array}$ & J Clin Psychiatry & $\begin{array}{l}\text { SR, but did not meet } \\
\text { minimum criteria }\end{array}$ \\
\hline 128 & 27866497 & Gentile & $\begin{array}{l}\text { Neurodevelopmental outcomes in } \\
\text { infants exposed in utero to } \\
\text { antipsychotics: a systematic review of } \\
\text { published data }\end{array}$ & CNS Spectr & $\begin{array}{l}\text { SR, but did not meet } \\
\text { minimum criteria }\end{array}$ \\
\hline 129 & 31026107 & Gentile & Schizophrenia and motherhood & $\begin{array}{l}\text { Psychiatry Clin } \\
\text { Neurosci }\end{array}$ & $\begin{array}{l}\text { SR, but did not meet } \\
\text { minimum criteria }\end{array}$ \\
\hline 130 & 15150376 & Gentile & $\begin{array}{l}\text { Clinical utilization of atypical } \\
\text { antipsychotics in pregnancy and } \\
\text { lactation }\end{array}$ & Ann Pharmacother & $\begin{array}{l}\text { SR, but did not meet } \\
\text { minimum criteria }\end{array}$ \\
\hline 131 & 27283340 & Gerosa & $\begin{array}{l}\text { Challenges and treatment options for } \\
\text { rheumatoid arthritis during pregnancy }\end{array}$ & $\begin{array}{l}\text { Expert Opin } \\
\text { Pharmacother }\end{array}$ & Narrative review only \\
\hline 132 & 25307228 & Gilboa & $\begin{array}{l}\text { Antihistamines and birth defects: a } \\
\text { systematic review of the literature }\end{array}$ & $\begin{array}{l}\text { Expert Opin Drug } \\
\text { Saf }\end{array}$ & Narrative review only \\
\hline 133 & 25436639 & Gillon & $\begin{array}{l}\text { Hypertensive disorders of pregnancy: a } \\
\text { systematic review of international } \\
\text { clinical practice guidelines }\end{array}$ & PLoS One & Narrative review only \\
\hline 134 & 31317955 & Gimenez & $\begin{array}{l}\text { Adverse outcomes during pregnancy } \\
\text { and major congenital malformations in } \\
\text { infants of patients with bipolar and } \\
\text { schizoaffective disorders treated with } \\
\text { antiepileptic drugs: A systematic review }\end{array}$ & Psychiatr Pol & $\begin{array}{l}\text { SR, but did not meet } \\
\text { minimum criteria }\end{array}$ \\
\hline 135 & 23946962 & Glacy & $\begin{array}{l}\text { AHRQ Comparative Effectiveness } \\
\text { Reviews }\end{array}$ & $\begin{array}{l}\text { Treatments for } \\
\text { Seasonal Allergic } \\
\text { Rhinitis }\end{array}$ & Unable to retrieve article \\
\hline 136 & 10917399 & $\begin{array}{l}\text { Goldstein } \\
\text { DJ }\end{array}$ & $\begin{array}{l}\text { Olanzapine-exposed pregnancies and } \\
\text { lactation: early experience }\end{array}$ & $\begin{array}{l}\text { J Clin } \\
\text { Psychopharmacol }\end{array}$ & Not a review \\
\hline 137 & 24518915 & Gordon & $\begin{array}{l}\text { Magnesium sulphate for the } \\
\text { management of preeclampsia and } \\
\text { eclampsia in low and middle income } \\
\text { countries: a systematic review of tested } \\
\text { dosing regimens }\end{array}$ & $\begin{array}{l}\text { J Obstet Gynaecol } \\
\text { Can }\end{array}$ & No intervention of interest \\
\hline 138 & 26105485 & Gordon & $\begin{array}{l}\text { PP164. Magnesium sulphate for } \\
\text { prevention and treatment of eclampsia } \\
\text { in low and middle income countries: } \\
\text { Systematic review of tested regimens }\end{array}$ & $\begin{array}{l}\text { Pregnancy } \\
\text { Hypertens }\end{array}$ & No intervention of interest \\
\hline 139 & 30654621 & Gou & $\begin{array}{l}\text { Association of maternal prenatal } \\
\text { acetaminophen use with the risk of } \\
\text { attention deficit/hyperactivity disorder } \\
\text { in offspring: A meta-analysis }\end{array}$ & Aust N ZJ Psychiatry & $\begin{array}{l}\text { SR, but did not meet } \\
\text { minimum criteria }\end{array}$ \\
\hline 140 & 24259987 & Gregersen & $\begin{array}{l}\text { Safety of bronchodilators and } \\
\text { corticosteroids for asthma during } \\
\text { pregnancy: what we know and what we } \\
\text { need to do better }\end{array}$ & J Asthma Allergy & Narrative review only \\
\hline 141 & 12709924 & $\begin{array}{l}\text { Griessham } \\
\text { mer }\end{array}$ & $\begin{array}{l}\text { Acquired thrombophilia in pregnancy: } \\
\text { essential thrombocythemia }\end{array}$ & $\begin{array}{l}\text { Semin Thromb } \\
\text { Hemost }\end{array}$ & Narrative review only \\
\hline 142 & 31294935 & Grigoriadis & $\begin{array}{l}\text { Benzodiazepine Use During Pregnancy } \\
\text { Alone or in Combination With an } \\
\text { Antidepressant and Congenital } \\
\text { Malformations: Systematic Review and } \\
\text { Meta-Analysis }\end{array}$ & J Clin Psychiatry & $\begin{array}{l}\text { SR, but did not meet } \\
\text { minimum criteria }\end{array}$ \\
\hline 143 & 32148076 & Grigoriadis & $\begin{array}{l}\text { Pregnancy and Delivery Outcomes } \\
\text { Following Benzodiazepine Exposure: A } \\
\text { Systematic Review and Meta-analysis }\end{array}$ & Can J Psychiatry & $\begin{array}{l}\text { SR, but did not meet } \\
\text { minimum criteria }\end{array}$ \\
\hline 144 & 23528915 & Groeneveld & $\begin{array}{l}\text { Preconceptional low-dose aspirin for the } \\
\text { prevention of hypertensive pregnancy } \\
\text { complications and preterm delivery } \\
\text { after IVF: a meta-analysis with } \\
\text { individual patient data }\end{array}$ & Hum Reprod & Not a review \\
\hline
\end{tabular}




\begin{tabular}{|c|c|c|c|c|c|}
\hline No. & $\begin{array}{l}\text { PMID or } \\
\text { Other } \\
\text { Identifier }\end{array}$ & $\begin{array}{c}\text { First } \\
\text { Author } \\
\text { Last Name }\end{array}$ & Title & Journal & Reason for Exclusion \\
\hline 145 & 29469929 & $\begin{array}{l}\text { Grzeskowia } \\
\mathrm{k}\end{array}$ & $\begin{array}{l}\text { Domperidone for increasing breast milk } \\
\text { volume in mothers expressing breast } \\
\text { milk for their preterm infants: a } \\
\text { systematic review and meta-analysis }\end{array}$ & Bjog & $\begin{array}{l}\text { No information about } \\
\text { adverse effects }\end{array}$ \\
\hline 146 & 28333256 & Gurney & $\begin{array}{l}\text { Analgesia use during pregnancy and } \\
\text { risk of cryptorchidism: a systematic } \\
\text { review and meta-analysis }\end{array}$ & Hum Reprod & $\begin{array}{l}\text { No information about } \\
\text { adverse effects }\end{array}$ \\
\hline 147 & 14669141 & $\begin{array}{l}\text { Gutierrez- } \\
\text { Alvarez }\end{array}$ & $\begin{array}{l}\text { [Use of anticonvulsive drugs during } \\
\text { pregnancy and the risk of } \\
\text { malformations in the newborn: a meta- } \\
\text { analysis] }\end{array}$ & Rev Neurol & Unable to retrieve article \\
\hline 148 & 16138282 & $\begin{array}{l}\text { Gutierrez- } \\
\text { Alvarez }\end{array}$ & $\begin{array}{l}\text { [The risk of defects in the neural tube } \\
\text { caused by valproic acid and } \\
\text { carbamazepine] }\end{array}$ & Rev Neurol & Unable to retrieve article \\
\hline 149 & 21463540 & Haas & Preterm birth & BMJ Clin Evid & $\begin{array}{l}\text { No information about } \\
\text { adverse effects }\end{array}$ \\
\hline 150 & 14980290 & Halliday & Use of steroids in the perinatal period & Paediatr Respir Rev & Narrative review only \\
\hline 151 & 19398681 & Harden & $\begin{array}{l}\text { Practice parameter update: } \\
\text { management issues for women with } \\
\text { epilepsy--focus on pregnancy (an } \\
\text { evidence-based review): teratogenesis } \\
\text { and perinatal outcomes: report of the } \\
\text { Quality Standards Subcommittee and } \\
\text { Therapeutics and Technology } \\
\text { Assessment Subcommittee of the } \\
\text { American Academy of Neurology and } \\
\text { American Epilepsy Society }\end{array}$ & Neurology & Not a review \\
\hline 152 & 19398680 & Harden & $\begin{array}{l}\text { Practice parameter update: } \\
\text { management issues for women with } \\
\text { epilepsy--focus on pregnancy (an } \\
\text { evidence-based review): vitamin K, folic } \\
\text { acid, blood levels, and breastfeeding: } \\
\text { report of the Quality Standards } \\
\text { Subcommittee and Therapeutics and } \\
\text { Technology Assessment Subcommittee } \\
\text { of the American Academy of Neurology } \\
\text { and American Epilepsy Society }\end{array}$ & Neurology & Not a review \\
\hline 153 & 28825316 & Haskey & $\begin{array}{l}\text { Mood stabilizers in pregnancy and child } \\
\text { developmental outcomes: A systematic } \\
\text { review }\end{array}$ & Aust N ZJ Psychiatry & $\begin{array}{l}\text { SR, but did not meet } \\
\text { minimum criteria }\end{array}$ \\
\hline 154 & $\begin{array}{l}\text { No PubMed } \\
\text { ID }\end{array}$ & Henderson & $\begin{array}{l}\text { Low-Dose Aspirin for the Prevention of } \\
\text { Morbidity and Mortality From } \\
\text { Preeclampsia: A Systematic Evidence } \\
\text { Review for the U.S. Preventive Services } \\
\text { Task Force }\end{array}$ & $\begin{array}{l}\text { U.S. Preventive } \\
\text { Services Task Force } \\
\text { Evidence Syntheses, } \\
\text { formerly Systematic } \\
\text { Evidence Reviews }\end{array}$ & Duplicate \\
\hline 155 & 15316107 & Hilaire & $\begin{array}{l}\text { Treatment of migraine headaches with } \\
\text { sumatriptan in pregnancy }\end{array}$ & $\begin{array}{l}\text { The Annals of } \\
\text { pharmacotherapy }\end{array}$ & $\begin{array}{l}\text { SR, but did not meet } \\
\text { minimum criteria }\end{array}$ \\
\hline 156 & $\begin{array}{l}\text { No PubMed } \\
\text { ID }\end{array}$ & Hobson & Melatonin for preventing pre-eclampsia & $\begin{array}{l}\text { Cochrane Database } \\
\text { of Systematic } \\
\text { Reviews }\end{array}$ & Not a review \\
\hline 157 & 26400006 & Hoover & $\begin{array}{l}\text { Association Between Prenatal } \\
\text { Acetaminophen Exposure and Future } \\
\text { Risk of Attention Deficit/Hyperactivity } \\
\text { Disorder in Children }\end{array}$ & Ann Pharmacother & $\begin{array}{l}\text { SR, but did not meet } \\
\text { minimum criteria }\end{array}$ \\
\hline 158 & 22771225 & Hovdenak & $\begin{array}{l}\text { Influence of mineral and vitamin } \\
\text { supplements on pregnancy outcome }\end{array}$ & $\begin{array}{l}\text { EurJ Obstet Gynecol } \\
\text { Reprod Biol }\end{array}$ & Narrative review only \\
\hline 159 & 24094568 & Huang & $\begin{array}{l}\text { A meta-analysis of the relationship } \\
\text { between antidepressant use in } \\
\text { pregnancy and the risk of preterm birth } \\
\text { and low birth weight }\end{array}$ & Gen Hosp Psychiatry & $\begin{array}{l}\text { SR, but did not meet } \\
\text { minimum criteria }\end{array}$ \\
\hline
\end{tabular}




\begin{tabular}{|c|c|c|c|c|c|}
\hline No. & $\begin{array}{l}\text { PMI D or } \\
\text { Other } \\
\text { I dentifier }\end{array}$ & $\begin{array}{c}\text { First } \\
\text { Author } \\
\text { Last Name }\end{array}$ & Title & Journal & Reason for Exclusion \\
\hline 160 & 30030084 & $\begin{array}{l}\text { HubeB- } \\
\text { Mollema }\end{array}$ & $\begin{array}{l}\text { Exposure to antiepileptic drugs in } \\
\text { pregnancy: The need for a family factor } \\
\text { framework }\end{array}$ & Epilepsy Behav & $\begin{array}{l}\text { No information about } \\
\text { adverse effects }\end{array}$ \\
\hline 161 & 9744134 & Hulse & $\begin{array}{l}\text { Assessing the relationship between } \\
\text { maternal opiate use and neonatal } \\
\text { mortality }\end{array}$ & Addiction & Narrative review only \\
\hline 162 & 23465038 & Hutchinson & $\begin{array}{l}\text { Use of common migraine treatments in } \\
\text { breast-feeding women: a summary of } \\
\text { recommendations }\end{array}$ & Headache & Narrative review only \\
\hline 163 & 31551795 & Imaz & $\begin{array}{l}\text { Clinical Lactation Studies of Lithium: A } \\
\text { Systematic Review }\end{array}$ & Front Pharmacol & $\begin{array}{l}\text { SR, but did not meet } \\
\text { minimum criteria }\end{array}$ \\
\hline 164 & 1829118 & Imperiale & $\begin{array}{l}\text { A meta-analysis of low-dose aspirin for } \\
\text { the prevention of pregnancy-induced } \\
\text { hypertensive disease }\end{array}$ & Jama & $\begin{array}{l}\text { SR, but did not meet } \\
\text { minimum criteria }\end{array}$ \\
\hline 165 & 26408639 & Jackson & $\begin{array}{l}\text { In utero exposure to valproate } \\
\text { increases the risk of isolated cleft palate }\end{array}$ & $\begin{array}{l}\text { Arch Dis Child Fetal } \\
\text { Neonatal Ed }\end{array}$ & $\begin{array}{l}\text { SR, but did not meet } \\
\text { minimum criteria }\end{array}$ \\
\hline 166 & 21127116 & Jentink & $\begin{array}{l}\text { Intrauterine exposure to carbamazepine } \\
\text { and specific congenital malformations: } \\
\text { systematic review and case-control } \\
\text { study }\end{array}$ & $B m j$ & $\begin{array}{l}\text { SR, but did not meet } \\
\text { minimum criteria }\end{array}$ \\
\hline 167 & 14583914 & Jewell & $\begin{array}{l}\text { Interventions for nausea and vomiting } \\
\text { in early pregnancy }\end{array}$ & $\begin{array}{l}\text { Cochrane Database } \\
\text { Syst Rev }\end{array}$ & $\begin{array}{l}\text { No information about } \\
\text { adverse effects }\end{array}$ \\
\hline 168 & 11869567 & Jewell & $\begin{array}{l}\text { Interventions for nausea and vomiting } \\
\text { in early pregnancy }\end{array}$ & $\begin{array}{l}\text { Cochrane Database } \\
\text { Syst Rev }\end{array}$ & Duplicate \\
\hline 169 & 10796155 & Jewell & $\begin{array}{l}\text { Interventions for nausea and vomiting } \\
\text { in early pregnancy }\end{array}$ & $\begin{array}{l}\text { Cochrane Database } \\
\text { Syst Rev }\end{array}$ & Duplicate \\
\hline 170 & 23106923 & Jones & $\begin{array}{l}\text { Buprenorphine treatment of opioid- } \\
\text { dependent pregnant women: a } \\
\text { comprehensive review }\end{array}$ & Addiction & No intervention of interest \\
\hline 171 & 22084456 & Kahan & $\begin{array}{l}\text { Canadian guideline for safe and } \\
\text { effective use of opioids for chronic } \\
\text { noncancer pain: clinical summary for } \\
\text { family physicians. Part 2: special } \\
\text { populations }\end{array}$ & Can Fam Physician & Not a review \\
\hline 172 & 11394728 & Kalis & Oxcarbazepine, an antiepileptic agent & Clin Ther & Narrative review only \\
\hline 173 & 10576836 & Khan & $\begin{array}{l}\text { Benzodiazepine use in pregnancy and } \\
\text { major malformations or oral clefts. } \\
\text { Quality of primary studies must } \\
\text { influence inferences made from meta- } \\
\text { analyses }\end{array}$ & $B m j$ & Not a review \\
\hline 174 & 9332996 & Khan & $\begin{array}{l}\text { Seizure prophylaxis in hypertensive } \\
\text { pregnancies: a framework for making } \\
\text { clinical decisions }\end{array}$ & Br J Obstet Gynaecol & Not a review \\
\hline 175 & 20180735 & Khan & $\begin{array}{l}\text { Safety concerns for the use of calcium } \\
\text { channel blockers in pregnancy for the } \\
\text { treatment of spontaneous preterm } \\
\text { labour and hypertension: a systematic } \\
\text { review and meta-regression analysis }\end{array}$ & $\begin{array}{l}\text { J Matern Fetal } \\
\text { Neonatal Med }\end{array}$ & $\begin{array}{l}\text { SR, but did not meet } \\
\text { minimum criteria }\end{array}$ \\
\hline 176 & 23724438 & Klinger & Antipsychotic drugs and breastfeeding & $\begin{array}{l}\text { Pediatr Endocrinol } \\
\text { Rev }\end{array}$ & $\begin{array}{l}\text { SR, but did not meet } \\
\text { minimum criteria }\end{array}$ \\
\hline 177 & 28657488 & Kong & $\begin{array}{l}\text { The risks associated with the use of } \\
\text { lamotrigine during pregnancy }\end{array}$ & $\begin{array}{l}\text { IntJ Psychiatry Clin } \\
\text { Pract }\end{array}$ & Narrative review only \\
\hline 178 & 16638921 & Koren & $\begin{array}{l}\text { Nonsteroidal antiinflammatory drugs } \\
\text { during third trimester and the risk of } \\
\text { premature closure of the ductus } \\
\text { arteriosus: a meta-analysis }\end{array}$ & Ann Pharmacother & $\begin{array}{l}\text { SR, but did not meet } \\
\text { minimum criteria }\end{array}$ \\
\hline 179 & 16639967 & Koren & Major malformations with valproic acid & Can Fam Physician & $\begin{array}{l}\text { SR, but did not meet } \\
\text { minimum criteria }\end{array}$ \\
\hline 180 & 12852485 & Kozer & $\begin{array}{l}\text { Effects of aspirin consumption during } \\
\text { pregnancy on pregnancy outcomes: } \\
\text { meta-analysis }\end{array}$ & $\begin{array}{l}\text { Birth Defects Res } B \\
\text { Dev Reprod Toxicol }\end{array}$ & $\begin{array}{l}\text { SR, but did not meet } \\
\text { minimum criteria }\end{array}$ \\
\hline
\end{tabular}




\begin{tabular}{|c|c|c|c|c|c|}
\hline No. & $\begin{array}{l}\text { PMI D or } \\
\text { Other } \\
\text { I dentifier }\end{array}$ & $\begin{array}{c}\text { First } \\
\text { Author } \\
\text { Last Name }\end{array}$ & Title & J ournal & Reason for Exclusion \\
\hline 181 & 12501074 & Kozer & $\begin{array}{l}\text { Aspirin consumption during the first } \\
\text { trimester of pregnancy and congenital } \\
\text { anomalies: a meta-analysis }\end{array}$ & Am J Obstet Gynecol & $\begin{array}{l}\text { SR, but did not meet } \\
\text { minimum criteria }\end{array}$ \\
\hline 182 & 8998825 & Kucera & [Is lithium a teratogen?] & Cas Lek Cesk & $\begin{array}{l}\text { SR, but did not meet } \\
\text { minimum criteria }\end{array}$ \\
\hline 183 & 19661763 & $\begin{array}{l}\text { Lanza di } \\
\text { Scalea }\end{array}$ & $\begin{array}{l}\text { Antidepressant medication use during } \\
\text { breastfeeding }\end{array}$ & Clin Obstet Gynecol & $\begin{array}{l}\text { SR, but did not meet } \\
\text { minimum criteria }\end{array}$ \\
\hline 184 & 27852343 & Larsen & $\begin{array}{l}\text { Pregnancy and bipolar disorder: the risk } \\
\text { of recurrence when discontinuing } \\
\text { treatment with mood stabilisers: a } \\
\text { systematic review }\end{array}$ & Acta Neuropsychiatr & $\begin{array}{l}\text { No information about } \\
\text { adverse effects }\end{array}$ \\
\hline 185 & 26435496 & Lassen & $\begin{array}{l}\text { First-Trimester Pregnancy Exposure to } \\
\text { Venlafaxine or Duloxetine and Risk of } \\
\text { Major Congenital Malformations: A } \\
\text { Systematic Review }\end{array}$ & $\begin{array}{l}\text { Basic Clin Pharmacol } \\
\text { Toxicol }\end{array}$ & $\begin{array}{l}\text { SR, but did not meet } \\
\text { minimum criteria }\end{array}$ \\
\hline 186 & 15507273 & Lassere & $\begin{array}{l}\text { Treatment of antiphospholipid } \\
\text { syndrome in pregnancy--a systematic } \\
\text { review of randomized therapeutic trials }\end{array}$ & Thromb Res & $\begin{array}{l}\text { SR, but did not meet } \\
\text { minimum criteria }\end{array}$ \\
\hline 187 & 29754832 & Lavecchia & $\begin{array}{l}\text { Ondansetron in Pregnancy and the Risk } \\
\text { of Congenital Malformations: A } \\
\text { Systematic Review }\end{array}$ & $\begin{array}{l}\text { J Obstet Gynaecol } \\
\text { Can }\end{array}$ & $\begin{array}{l}\text { SR, but did not meet } \\
\text { minimum criteria }\end{array}$ \\
\hline 188 & 16034877 & Lede & $\begin{array}{l}\text { Uterine muscle relaxant drugs for } \\
\text { threatened miscarriage }\end{array}$ & $\begin{array}{l}\text { Cochrane Database } \\
\text { Syst Rev }\end{array}$ & No intervention of interest \\
\hline 189 & 9141582 & Leitich & $\begin{array}{l}\text { A meta-analysis of low dose aspirin for } \\
\text { the prevention of intrauterine growth } \\
\text { retardation }\end{array}$ & BrJ Obstet Gynaecol & $\begin{array}{l}\text { SR, but did not meet } \\
\text { minimum criteria }\end{array}$ \\
\hline 190 & 9681097 & Lewis & $\begin{array}{l}\text { Drug and environmental factors } \\
\text { associated with adverse pregnancy } \\
\text { outcomes. Part I: Antiepileptic drugs, } \\
\text { contraceptives, smoking, and folate }\end{array}$ & Ann Pharmacother & Narrative review only \\
\hline 191 & 28562278 & Lind & $\begin{array}{l}\text { Maternal Use of Opioids During } \\
\text { Pregnancy and Congenital } \\
\text { Malformations: A Systematic Review }\end{array}$ & Pediatrics & $\begin{array}{l}\text { SR, but did not meet } \\
\text { minimum criteria }\end{array}$ \\
\hline 192 & 23141179 & Liu & $\begin{array}{l}\text { [Clinical efficacy and perinatal outcome } \\
\text { of nifedipine for severe preeclampsia: } \\
\text { meta-analysis] }\end{array}$ & $\begin{array}{l}\text { Zhonghua Fu Chan } \\
\text { Ke Za Zhi }\end{array}$ & Narrative review only \\
\hline 193 & 12467489 & Loder & $\begin{array}{l}\text { Safety of sumatriptan in pregnancy: a } \\
\text { review of the data so far }\end{array}$ & CNS Drugs & Narrative review only \\
\hline 194 & 22370064 & Lopez-Yarto & $\begin{array}{l}\text { Do psychiatric medications, especially } \\
\text { antidepressants, adversely impact } \\
\text { maternal metabolic outcomes? }\end{array}$ & J Affect Disord & $\begin{array}{l}\text { SR, but did not meet } \\
\text { minimum criteria }\end{array}$ \\
\hline 195 & 27575940 & $\begin{array}{l}\text { Lourido- } \\
\text { Cebreiro } \\
\end{array}$ & $\begin{array}{l}\text { The association between paracetamol } \\
\text { and asthma is still under debate }\end{array}$ & J Asthma & $\begin{array}{l}\text { SR, but did not meet } \\
\text { minimum criteria }\end{array}$ \\
\hline 196 & 17407673 & MacGregor & $\begin{array}{l}\text { Migraine in pregnancy and lactation: a } \\
\text { clinical review }\end{array}$ & $\begin{array}{l}J \text { Fam Plann Reprod } \\
\text { Health Care }\end{array}$ & $\begin{array}{l}\text { SR, but did not meet } \\
\text { minimum criteria }\end{array}$ \\
\hline 197 & 21975760 & Mackeen & $\begin{array}{l}\text { Tocolytics for preterm premature } \\
\text { rupture of membranes }\end{array}$ & $\begin{array}{l}\text { Cochrane Database } \\
\text { Syst Rev }\end{array}$ & No intervention of interest \\
\hline 198 & 24578236 & Mackeen & $\begin{array}{l}\text { Tocolytics for preterm premature } \\
\text { rupture of membranes }\end{array}$ & $\begin{array}{l}\text { Cochrane Database } \\
\text { Syst Rev }\end{array}$ & No intervention of interest \\
\hline 199 & 9326758 & Macones & $\begin{array}{l}\text { Evidence for magnesium sulfate as a } \\
\text { tocolytic agent }\end{array}$ & Obstet Gynecol Surv & No intervention of interest \\
\hline 200 & 18998750 & Madadi & $\begin{array}{l}\text { Establishing causality of CNS depression } \\
\text { in breastfed infants following maternal } \\
\text { codeine use }\end{array}$ & Paediatr Drugs & $\begin{array}{l}\text { SR, but did not meet } \\
\text { minimum criteria }\end{array}$ \\
\hline 201 & $\begin{array}{l}\text { CD004351 } \\
\text { (Cochrane) }\end{array}$ & Magee & $\begin{array}{l}\text { Prevention and treatment of } \\
\text { postpartum hypertension }\end{array}$ & $\begin{array}{l}\text { Cochrane Database } \\
\text { of Systematic } \\
\text { Reviews }\end{array}$ & $\begin{array}{l}\text { No information about } \\
\text { adverse effects }\end{array}$ \\
\hline 202 & 11034777 & Magee & $\begin{array}{l}\text { Oral beta-blockers for mild to moderate } \\
\text { hypertension during pregnancy }\end{array}$ & $\begin{array}{l}\text { Cochrane Database } \\
\text { Syst Rev }\end{array}$ & $\begin{array}{l}\text { Older version of another } \\
\text { review }\end{array}$ \\
\hline 203 & & Magee & $\begin{array}{l}\text { Oral beta,Äêblockers for mild to } \\
\text { moderate hypertension during } \\
\text { pregnancy }\end{array}$ & $\begin{array}{l}\text { Cochrane Database } \\
\text { of Systematic } \\
\text { Reviews }\end{array}$ & $\begin{array}{l}\text { Older version of another } \\
\text { review }\end{array}$ \\
\hline
\end{tabular}




\begin{tabular}{|c|c|c|c|c|c|}
\hline No. & $\begin{array}{l}\text { PMI D or } \\
\text { Other } \\
\text { Identifier }\end{array}$ & $\begin{array}{c}\text { First } \\
\text { Author } \\
\text { Last Name }\end{array}$ & Title & J ournal & Reason for Exclusion \\
\hline 204 & 14576246 & Magee & $\begin{array}{l}\text { Hydralazine for treatment of severe } \\
\text { hypertension in pregnancy: meta- } \\
\text { analysis }\end{array}$ & $B m j$ & $\begin{array}{l}\text { SR, but did not meet } \\
\text { minimum criteria }\end{array}$ \\
\hline 205 & 11687087 & Makrides & $\begin{array}{l}\text { Magnesium supplementation in } \\
\text { pregnancy }\end{array}$ & $\begin{array}{l}\text { Cochrane Database } \\
\text { Syst Rev }\end{array}$ & $\begin{array}{l}\text { Older version of another } \\
\text { review }\end{array}$ \\
\hline 206 & 10796220 & Makrides & $\begin{array}{l}\text { Magnesium supplementation in } \\
\text { pregnancy }\end{array}$ & $\begin{array}{l}\text { Cochrane Database } \\
\text { Syst Rev }\end{array}$ & $\begin{array}{l}\text { Older version of another } \\
\text { review }\end{array}$ \\
\hline 207 & 26530179 & Marcellin & $\begin{array}{l}\text { [Breast-feeding (part IV): Therapeutic } \\
\text { uses, dietetic and addictions--guidelines } \\
\text { for clinical practice] }\end{array}$ & $\begin{array}{l}\text { J Gynecol Obstet Biol } \\
\text { Reprod (Paris) }\end{array}$ & Narrative review only \\
\hline 208 & 20645675 & Marinucci & $\begin{array}{l}\text { Diazepam effects on non-syndromic } \\
\text { cleft lip with or without palate: } \\
\text { epidemiological studies, clinical findings, } \\
\text { genes and extracellular matrix }\end{array}$ & $\begin{array}{l}\text { Expert Opin Drug } \\
\text { Saf }\end{array}$ & No intervention of interest \\
\hline 209 & 21794529 & $\begin{array}{l}\text { Martinez } \\
\text { Lopez }\end{array}$ & $\begin{array}{l}\text { [Systematic review: is the use of } \\
\text { NSAI Ds safe during pregnancy in } \\
\text { women with rheumatic disease?] }\end{array}$ & Reumatol Clin & $\begin{array}{l}\text { SR, but did not meet } \\
\text { minimum criteria }\end{array}$ \\
\hline 210 & 30651174 & $\begin{array}{l}\text { Martinez- } \\
\text { Paredes }\end{array}$ & Depression in Pregnancy & $\begin{array}{l}\text { Rev Colomb } \\
\text { Psiquiatr }\end{array}$ & $\begin{array}{l}\text { Participants not pregnant } \\
\text { (or attempting to be } \\
\text { pregnant), postpartum, or } \\
\text { breastfeeding }\end{array}$ \\
\hline 211 & 30170040 & Masarwa & $\begin{array}{l}\text { Prenatal exposure to selective serotonin } \\
\text { reuptake inhibitors and serotonin } \\
\text { norepinephrine reuptake inhibitors and } \\
\text { risk for persistent pulmonary } \\
\text { hypertension of the newborn: a } \\
\text { systematic review, meta-analysis, and } \\
\text { network meta-analysis }\end{array}$ & Am J Obstet Gynecol & $\begin{array}{l}\text { SR, but did not meet } \\
\text { minimum criteria }\end{array}$ \\
\hline 212 & 11934528 & Matalon & $\begin{array}{l}\text { The teratogenic effect of } \\
\text { carbamazepine: a meta-analysis of } \\
1255 \text { exposures }\end{array}$ & Reprod Toxicol & $\begin{array}{l}\text { SR, but did not meet } \\
\text { minimum criteria }\end{array}$ \\
\hline 213 & 26348534 & Matthews & $\begin{array}{l}\text { Interventions for nausea and vomiting } \\
\text { in early pregnancy }\end{array}$ & $\begin{array}{l}\text { Cochrane Database } \\
\text { Syst Rev }\end{array}$ & No intervention of interest \\
\hline 214 & 20824863 & Matthews & $\begin{array}{l}\text { Interventions for nausea and vomiting } \\
\text { in early pregnancy }\end{array}$ & $\begin{array}{l}\text { Cochrane Database } \\
\text { Syst Rev }\end{array}$ & $\begin{array}{l}\text { No information about } \\
\text { adverse effects }\end{array}$ \\
\hline 215 & 24659261 & Matthews & $\begin{array}{l}\text { Interventions for nausea and vomiting } \\
\text { in early pregnancy }\end{array}$ & $\begin{array}{l}\text { Cochrane Database } \\
\text { Syst Rev }\end{array}$ & $\begin{array}{l}\text { No information about } \\
\text { adverse effects }\end{array}$ \\
\hline 216 & 25618222 & $\begin{array}{l}\text { Mauri } \\
\text { Llerda }\end{array}$ & $\begin{array}{l}\text { The Spanish Society of Neurology's } \\
\text { official clinical practice guidelines for } \\
\text { epilepsy. Special considerations in } \\
\text { epilepsy: comorbidities, women of } \\
\text { childbearing age, and elderly patients }\end{array}$ & $\begin{array}{l}\text { Neurologia } \\
\text { (Barcelona, Spain) }\end{array}$ & $\begin{array}{l}\text { SR, but did not meet } \\
\text { minimum criteria }\end{array}$ \\
\hline 217 & 10230583 & Mazzotta & $\begin{array}{l}\text { Treating allergic rhinitis in pregnancy. } \\
\text { Safety considerations }\end{array}$ & Drug Saf & No intervention of interest \\
\hline 218 & 20465753 & $\begin{array}{l}\text { McCauley- } \\
\text { Elsom }\end{array}$ & Antipsychotics in pregnancy & $\begin{array}{l}\text { J Psychiatr Ment } \\
\text { Health Nurs }\end{array}$ & Narrative review only \\
\hline 219 & 22703834 & McDonald & $\begin{array}{l}\text { A systematic review of maternal and } \\
\text { infant outcomes following magnesium } \\
\text { sulfate for pre-eclampsia/eclampsia in } \\
\text { real-world use }\end{array}$ & $\begin{array}{l}\text { Int J Gynaecol } \\
\text { Obstet }\end{array}$ & $\begin{array}{l}\text { SR, but did not meet } \\
\text { minimum criteria }\end{array}$ \\
\hline 220 & 17118042 & McKenna & $\begin{array}{l}\text { What over-the-counter preparations are } \\
\text { pregnant women taking? A literature } \\
\text { review }\end{array}$ & J $A d v$ Nurs & $\begin{array}{l}\text { No information about } \\
\text { adverse effects }\end{array}$ \\
\hline 221 & 21982021 & McKinlay & $\begin{array}{l}\text { Repeat antenatal glucocorticoids for } \\
\text { women at risk of preterm birth: a } \\
\text { Cochrane Systematic Review }\end{array}$ & $\begin{array}{l}\text { AmJ Obstet } \\
\text { Gynecoll Clin } \\
\text { Psychopharmacol }\end{array}$ & No intervention of interest \\
\hline 222 & 27701665 & McParlin & $\begin{array}{l}\text { Treatments for Hyperemesis } \\
\text { Gravidarum and Nausea and Vomiting } \\
\text { in Pregnancy: A Systematic Review }\end{array}$ & Jama & $\begin{array}{l}\text { No information about } \\
\text { adverse effects }\end{array}$ \\
\hline
\end{tabular}




\begin{tabular}{|c|c|c|c|c|c|}
\hline No. & $\begin{array}{l}\text { PMID or } \\
\text { Other } \\
\text { I dentifier }\end{array}$ & $\begin{array}{c}\text { First } \\
\text { Author } \\
\text { Last Name }\end{array}$ & Title & Journal & Reason for Exclusion \\
\hline 223 & 18565732 & Meador & $\begin{array}{l}\text { Pregnancy outcomes in women with } \\
\text { epilepsy: a systematic review and meta- } \\
\text { analysis of published pregnancy } \\
\text { registries and cohorts }\end{array}$ & Epilepsy Res & $\begin{array}{l}\text { SR, but did not meet } \\
\text { minimum criteria }\end{array}$ \\
\hline 224 & 27810551 & Meher & $\begin{array}{l}\text { Antiplatelet therapy before or after } 16 \\
\text { weeks' gestation for preventing } \\
\text { preeclampsia: an individual participant } \\
\text { data meta-analysis }\end{array}$ & AmJ Obstet Gynecol & $\begin{array}{l}\text { SR, but did not meet } \\
\text { minimum criteria }\end{array}$ \\
\hline 225 & 27704220 & Mehta & $\begin{array}{l}\text { A review of the safety of clozapine } \\
\text { during pregnancy and lactation }\end{array}$ & $\begin{array}{l}\text { Arch Womens Ment } \\
\text { Health }\end{array}$ & $\begin{array}{l}\text { SR, but did not meet } \\
\text { minimum criteria }\end{array}$ \\
\hline 226 & 20550539 & $\begin{array}{l}\text { Merce } \\
\text { Fernandez- } \\
\text { Balsells }\end{array}$ & $\begin{array}{l}\text { Prenatal dexamethasone use for the } \\
\text { prevention of virilization in pregnancies } \\
\text { at risk for classical congenital adrenal } \\
\text { hyperplasia because of 21-hydroxylase } \\
\text { (CYP21A2) deficiency: a systematic } \\
\text { review and meta-analyses }\end{array}$ & Clin Endocrinol (Oxf) & $\begin{array}{l}\text { SR, but did not meet } \\
\text { minimum criteria }\end{array}$ \\
\hline 227 & 24366859 & Minozzi & $\begin{array}{l}\text { Maintenance agonist treatments for } \\
\text { opiate-dependent pregnant women }\end{array}$ & $\begin{array}{l}\text { Cochrane Database } \\
\text { Syst Rev }\end{array}$ & No intervention of interest \\
\hline 228 & $\begin{array}{l}\text { CD006318 } \\
\text { (Cochrane) }\end{array}$ & Minozzi & $\begin{array}{l}\text { Maintenance agonist treatments for } \\
\text { opiate,Äêdependent pregnant women }\end{array}$ & $\begin{array}{l}\text { Cochrane Database } \\
\text { of Systematic } \\
\text { Reviews }\end{array}$ & No intervention of interest \\
\hline 229 & 18425946 & Minozzi & $\begin{array}{l}\text { Maintenance agonist treatments for } \\
\text { opiate dependent pregnant women }\end{array}$ & $\begin{array}{l}\text { Cochrane Database } \\
\text { Syst Rev }\end{array}$ & No intervention of interest \\
\hline 230 & 25211400 & Molyneaux & $\begin{array}{l}\text { Antidepressant treatment for postnatal } \\
\text { depression }\end{array}$ & $\begin{array}{l}\text { Cochrane Database } \\
\text { Syst Rev }\end{array}$ & No intervention of interest \\
\hline 231 & 15969868 & Montouris & $\begin{array}{l}\text { Safety of the newer antiepileptic drug } \\
\text { oxcarbazepine during pregnancy }\end{array}$ & Curr Med Res Opin & $\begin{array}{l}\text { SR, but did not meet } \\
\text { minimum criteria }\end{array}$ \\
\hline 232 & 15900008 & $\begin{array}{l}\text { Moses- } \\
\text { Kolko }\end{array}$ & $\begin{array}{l}\text { Neonatal signs after late in utero } \\
\text { exposure to serotonin reuptake } \\
\text { inhibitors: literature review and } \\
\text { implications for clinical applications }\end{array}$ & Jama & $\begin{array}{l}\text { SR, but did not meet } \\
\text { minimum criteria }\end{array}$ \\
\hline 233 & $\begin{array}{l}\text { No PubMed } \\
\text { ID }\end{array}$ & Munk-Olsen & $\begin{array}{l}\text { Maternal and infant outcomes } \\
\text { associated with lithium use in } \\
\text { pregnancy: an international } \\
\text { collaborative meta-analysis of six cohort } \\
\text { studies }\end{array}$ & $\begin{array}{l}\text { The lancet. } \\
\text { Psychiatry }\end{array}$ & Narrative review only \\
\hline 234 & 24422733 & Nakhai-Pour & $\begin{array}{l}\text { Major malformations after first trimester } \\
\text { exposure to aspirin and NSAIDs }\end{array}$ & $\begin{array}{l}\text { Expert Rev Clin } \\
\text { Pharmacol }\end{array}$ & $\begin{array}{l}\text { SR, but did not meet } \\
\text { minimum criteria }\end{array}$ \\
\hline 235 & 22903964 & Namazy & $\begin{array}{l}\text { Effects of asthma severity, } \\
\text { exacerbations and oral corticosteroids } \\
\text { on perinatal outcomes }\end{array}$ & Eur Respir J & $\begin{array}{l}\text { SR, but did not meet } \\
\text { minimum criteria }\end{array}$ \\
\hline 236 & 29024912 & Navaratnam & $\begin{array}{l}\text { How important is aspirin adherence } \\
\text { when evaluating effectiveness of low- } \\
\text { dose aspirin? }\end{array}$ & $\begin{array}{l}\text { Eur J Obstet Gynecol } \\
\text { Reprod Biol }\end{array}$ & $\begin{array}{l}\text { No information about } \\
\text { adverse effects }\end{array}$ \\
\hline 237 & 29052046 & Negro & $\begin{array}{l}\text { Headache and pregnancy: a systematic } \\
\text { review }\end{array}$ & J Headache Pain & $\begin{array}{l}\text { SR, but did not meet } \\
\text { minimum criteria }\end{array}$ \\
\hline 238 & 25668040 & Nensi & $\begin{array}{l}\text { Effect of magnesium sulphate on fetal } \\
\text { heart rate parameters: a systematic } \\
\text { review }\end{array}$ & $\begin{array}{l}\text { J Obstet Gynaecol } \\
\text { Can }\end{array}$ & $\begin{array}{l}\text { SR, but did not meet } \\
\text { minimum criteria }\end{array}$ \\
\hline 239 & 31180257 & Newmark & $\begin{array}{l}\text { Risk-Benefit assessment of infant } \\
\text { exposure to lithium through breast } \\
\text { milk: a systematic review of the } \\
\text { literature }\end{array}$ & Int Rev Psychiatry & $\begin{array}{l}\text { SR, but did not meet } \\
\text { minimum criteria }\end{array}$ \\
\hline 240 & 19330496 & Nguyen & $\begin{array}{l}\text { Teratogenesis associated with } \\
\text { antibipolar agents }\end{array}$ & Adv Ther & Narrative review only \\
\hline 241 & 20591204 & Nij Bijvank & $\begin{array}{l}\text { Nicardipine for the treatment of severe } \\
\text { hypertension in pregnancy: a review of } \\
\text { the literature }\end{array}$ & Obstet Gynecol Surv & $\begin{array}{l}\text { SR, but did not meet } \\
\text { minimum criteria }\end{array}$ \\
\hline 242 & 19882796 & None listed & $\begin{array}{l}\text { Renal colic in adults: NSAI Ds and } \\
\text { morphine are effective for pain relief }\end{array}$ & Prescrire Int & Narrative review only \\
\hline 243 & 19536941 & None listed & $\begin{array}{l}\text { Sleep complaints: Whenever possible, } \\
\text { avoid the use of sleeping pills }\end{array}$ & Prescrire Int & Narrative review only \\
\hline
\end{tabular}




\begin{tabular}{|c|c|c|c|c|c|}
\hline No. & $\begin{array}{l}\text { PMID or } \\
\text { Other } \\
\text { I dentifier }\end{array}$ & $\begin{array}{c}\text { First } \\
\text { Author } \\
\text { Last Name }\end{array}$ & Title & Journal & Reason for Exclusion \\
\hline 244 & 24720593 & Nooij & $\begin{array}{l}\text { The optimal treatment of severe } \\
\text { hypertension in pregnancy: update of } \\
\text { the role of nicardipine }\end{array}$ & $\begin{array}{l}\text { Curr Pharm } \\
\text { Biotechnol }\end{array}$ & Not a review \\
\hline 245 & 27199497 & $\begin{array}{l}\text { Noormoha } \\
\text { mmadi }\end{array}$ & $\begin{array}{l}\text { Buprenorphine Versus Methadone for } \\
\text { Opioid Dependence in Pregnancy }\end{array}$ & Ann Pharmacother & No intervention of interest \\
\hline 246 & 12934124 & Nordeng & $\begin{array}{l}\text { [Use of antipsychotics during pregnancy } \\
\text { and lactation] }\end{array}$ & $\begin{array}{l}\text { Tidsskr Nor } \\
\text { Laegeforen }\end{array}$ & $\begin{array}{l}\text { SR, but did not meet } \\
\text { minimum criteria }\end{array}$ \\
\hline 247 & 25527798 & Nulman & $\begin{array}{l}\text { The effects of the new antipsychotic } \\
\text { medications on mothers and babies }\end{array}$ & $\begin{array}{l}\text { J Popul Ther Clin } \\
\text { Pharmacol }\end{array}$ & Narrative review only \\
\hline 248 & 27731292 & O'Donnell & $\begin{array}{l}\text { Treatments for hyperemesis gravidarum } \\
\text { and nausea and vomiting in pregnancy: } \\
\text { a systematic review and economic } \\
\text { assessment }\end{array}$ & $\begin{array}{l}\text { Health Technol } \\
\text { Assess }\end{array}$ & $\begin{array}{l}\text { No information about } \\
\text { adverse effects }\end{array}$ \\
\hline 249 & 27891798 & Oladapo & $\begin{array}{l}\text { Authors' reply re: Clinical } \\
\text { pharmacokinetic properties of } \\
\text { magnesium sulphate in women with } \\
\text { pre-eclampsia and eclampsia: a } \\
\text { systematic review }\end{array}$ & Bjog & Not a review \\
\hline 250 & 25572308 & Orsolini & $\begin{array}{l}\text { Serotonin reuptake inhibitors and } \\
\text { breastfeeding: a systematic review }\end{array}$ & $\begin{array}{l}\text { Hum } \\
\text { Psychopharmacol }\end{array}$ & $\begin{array}{l}\text { SR, but did not meet } \\
\text { minimum criteria }\end{array}$ \\
\hline 251 & 22483705 & Oyebode & $\begin{array}{l}\text { Psychotropics in pregnancy: safety and } \\
\text { other considerations }\end{array}$ & Pharmacol Ther & $\begin{array}{l}\text { SR, but did not meet } \\
\text { minimum criteria }\end{array}$ \\
\hline 252 & 27568278 & Pacchiarotti & $\begin{array}{l}\text { Mood stabilizers and antipsychotics } \\
\text { during breastfeeding: Focus on bipolar } \\
\text { disorder }\end{array}$ & $\begin{array}{l}\text { Eur } \\
\text { Neuropsychopharma } \\
\text { col }\end{array}$ & $\begin{array}{l}\text { SR, but did not meet } \\
\text { minimum criteria }\end{array}$ \\
\hline 253 & 24071819 & Paganelli & $\begin{array}{l}\text { Retrospective analysis on the efficacy of } \\
\text { corticosteroid prophylaxis prior to } \\
\text { elective caesarean section to reduce } \\
\text { neonatal respiratory complications at } \\
\text { term of pregnancy: review of literature }\end{array}$ & Arch Gynecol Obstet & No intervention of interest \\
\hline 254 & 28434134 & Pariente & $\begin{array}{l}\text { Pregnancy Outcomes Following In Utero } \\
\text { Exposure to Lamotrigine: A Systematic } \\
\text { Review and Meta-Analysis }\end{array}$ & CNS Drugs & $\begin{array}{l}\text { SR, but did not meet } \\
\text { minimum criteria }\end{array}$ \\
\hline 255 & 10488364 & Pattinson & $\begin{array}{l}\text { A meta-analysis of the use of } \\
\text { corticosteroids in pregnancies } \\
\text { complicated by preterm premature } \\
\text { rupture of membranes }\end{array}$ & S Afr Med J & $\begin{array}{l}\text { SR, but did not meet } \\
\text { minimum criteria }\end{array}$ \\
\hline 256 & 25475074 & Paul & $\begin{array}{l}\text { Use of domperidone as a galactagogue } \\
\text { drug: a systematic review of the } \\
\text { benefit-risk ratio }\end{array}$ & J Hum Lact & No intervention of interest \\
\hline 257 & 26695642 & Pergialiotis & $\begin{array}{l}\text { Propranolol and oxytocin versus } \\
\text { oxytocin alone for induction and } \\
\text { augmentation of labor: a meta-analysis } \\
\text { of randomized trials }\end{array}$ & Arch Gynecol Obstet & $\begin{array}{l}\text { No information about } \\
\text { adverse effects }\end{array}$ \\
\hline 258 & 24211103 & Pirie & $\begin{array}{l}\text { Effects of monitoring strategies on } \\
\text { seizures in pregnant women on } \\
\text { lamotrigine: a meta-analysis }\end{array}$ & $\begin{array}{l}\text { EurJ Obstet Gynecol } \\
\text { Reprod Biol }\end{array}$ & No intervention of interest \\
\hline 259 & 29948232 & Poels & $\begin{array}{l}\text { Long-term neurodevelopmental } \\
\text { consequences of intrauterine exposure } \\
\text { to lithium and antipsychotics: a } \\
\text { systematic review and meta-analysis }\end{array}$ & $\begin{array}{l}\text { Eur Child Adolesc } \\
\text { Psychiatry }\end{array}$ & $\begin{array}{l}\text { SR, but did not meet } \\
\text { minimum criteria }\end{array}$ \\
\hline 260 & 26485229 & Pratt & $\begin{array}{l}\text { Alternative regimens of magnesium } \\
\text { sulfate for treatment of preeclampsia } \\
\text { and eclampsia: a systematic review of } \\
\text { non-randomized studies }\end{array}$ & $\begin{array}{l}\text { Acta Obstet Gynecol } \\
\text { Scand }\end{array}$ & $\begin{array}{l}\text { SR, but did not meet } \\
\text { minimum criteria }\end{array}$ \\
\hline 261 & 22683887 & Pringsheim & $\begin{array}{l}\text { Canadian Headache Society guideline } \\
\text { for migraine prophylaxis }\end{array}$ & CanJ Neurol Sci & Not a review \\
\hline 262 & 29802634 & Raggi & $\begin{array}{l}\text { Behavioral Approaches for Primary } \\
\text { Headaches: Recent Advances }\end{array}$ & Headache & $\begin{array}{l}\text { SR, but did not meet } \\
\text { minimum criteria }\end{array}$ \\
\hline 263 & 31303443 & Rajiv & $\begin{array}{l}\text { Status epilepticus in pregnancy - Can } \\
\text { we frame a uniform treatment protocol? }\end{array}$ & Epilepsy Behav & $\begin{array}{l}\text { No information about } \\
\text { adverse effects }\end{array}$ \\
\hline
\end{tabular}




\begin{tabular}{|c|c|c|c|c|c|}
\hline No. & $\begin{array}{l}\text { PMI D or } \\
\text { Other } \\
\text { I dentifier }\end{array}$ & $\begin{array}{c}\text { First } \\
\text { Author } \\
\text { Last Name }\end{array}$ & Title & Journal & Reason for Exclusion \\
\hline 264 & 29692634 & Ray-Griffith & $\begin{array}{l}\text { Chronic pain during pregnancy: a } \\
\text { review of the literature }\end{array}$ & Int J Womens Health & Not a review \\
\hline 265 & 27454720 & Reichmann & $\begin{array}{l}\text { Ondansetron Use in Pregnancy } \\
\text { andOndansetron Use in Pregnancy and } \\
\text { Birth Defects: A Systematic Review }\end{array}$ & Obstet Gynecol & Not a review \\
\hline 266 & 9361646 & Rey & $\begin{array}{l}\text { Report of the Canadian Hypertension } \\
\text { Society Consensus Conference: } 3 . \\
\text { Pharmacologic treatment of } \\
\text { hypertensive disorders in pregnancy }\end{array}$ & Cmaj & Not a review \\
\hline 267 & 26906184 & Roberge & $\begin{array}{l}\text { Low-Dose Aspirin in Early Gestation for } \\
\text { Prevention of Preeclampsia and Small- } \\
\text { foB-Gestational-Age Neonates: Meta- } \\
\text { analysis of Large Randomized Trials }\end{array}$ & Am J Perinatol & Narrative review only \\
\hline 268 & 22495898 & Roberge & $\begin{array}{l}\text { Early administration of low-dose aspirin } \\
\text { for the prevention of severe and mild } \\
\text { preeclampsia: a systematic review and } \\
\text { meta-analysis }\end{array}$ & AmJ Perinatol & $\begin{array}{l}\text { No information about } \\
\text { adverse effects }\end{array}$ \\
\hline 269 & 29138036 & Roberge & $\begin{array}{l}\text { Aspirin for the prevention of preterm } \\
\text { and term preeclampsia: systematic } \\
\text { review and metaanalysis }\end{array}$ & Am J Obstet Gynecol & $\begin{array}{l}\text { No information about } \\
\text { adverse effects }\end{array}$ \\
\hline 270 & 23362106 & Roberge & $\begin{array}{l}\text { Prevention of perinatal death and } \\
\text { adverse perinatal outcome using low- } \\
\text { dose aspirin: a meta-analysis }\end{array}$ & $\begin{array}{l}\text { Ultrasound Obstet } \\
\text { Gynecol }\end{array}$ & $\begin{array}{l}\text { SR, but did not meet } \\
\text { minimum criteria }\end{array}$ \\
\hline 271 & 29305829 & Roberge & $\begin{array}{l}\text { Meta-analysis on the effect of aspirin } \\
\text { use for prevention of preeclampsia on } \\
\text { placental abruption and antepartum } \\
\text { hemorrhage }\end{array}$ & AmJ Obstet Gynecol & $\begin{array}{l}\text { SR, but did not meet } \\
\text { minimum criteria }\end{array}$ \\
\hline 272 & 27640943 & Roberge & $\begin{array}{l}\text { The role of aspirin dose on the } \\
\text { prevention of preeclampsia and fetal } \\
\text { growth restriction: systematic review } \\
\text { and meta-analysis }\end{array}$ & AmJ Obstet Gynecol & $\begin{array}{l}\text { SR, but did not meet } \\
\text { minimum criteria }\end{array}$ \\
\hline 273 & 22441437 & Roberge & $\begin{array}{l}\text { Early administration of low-dose aspirin } \\
\text { for the prevention of preterm and term } \\
\text { preeclampsia: a systematic review and } \\
\text { meta-analysis }\end{array}$ & Fetal Diagn Ther & $\begin{array}{l}\text { SR, but did not meet } \\
\text { minimum criteria }\end{array}$ \\
\hline 274 & 23075483 & Robinson & $\begin{array}{l}\text { Treatment of schizophrenia in } \\
\text { pregnancy and postpartum }\end{array}$ & $\begin{array}{l}\text { J Popul Ther Clin } \\
\text { Pharmacol }\end{array}$ & Narrative review only \\
\hline 275 & 32412703 & Rommel & $\begin{array}{l}\text { Long-Term Effects of Intrauterine } \\
\text { Exposure to Antidepressants on } \\
\text { Physical, Neurodevelopmental, and } \\
\text { Psychiatric Outcomes: A Systematic } \\
\text { Review }\end{array}$ & J Clin Psychiatry & $\begin{array}{l}\text { SR, but did not meet } \\
\text { minimum criteria }\end{array}$ \\
\hline 276 & 21641104 & Rossi & $\begin{array}{l}\text { Prevention of pre-eclampsia with low- } \\
\text { dose aspirin or vitamins C and } E \text { in } \\
\text { women at high or low risk: a systematic } \\
\text { review with meta-analysis }\end{array}$ & $\begin{array}{l}\text { EurJ Obstet Gynecol } \\
\text { Reprod Biol }\end{array}$ & $\begin{array}{l}\text { SR, but did not meet } \\
\text { minimum criteria }\end{array}$ \\
\hline 277 & 16254678 & Ruano & $\begin{array}{l}\text { Prevention of preeclampsia with low- } \\
\text { dose aspirin -- a systematic review and } \\
\text { meta-analysis of the main randomized } \\
\text { controlled trials }\end{array}$ & Clinics (Sao Paulo) & $\begin{array}{l}\text { SR, but did not meet } \\
\text { minimum criteria }\end{array}$ \\
\hline 278 & 15591613 & Rubin & $\begin{array}{l}\text { When breastfeeding mothers need CNS- } \\
\text { acting drugs }\end{array}$ & Can J Clin Pharmacol & $\begin{array}{l}\text { SR, but did not meet } \\
\text { minimum criteria }\end{array}$ \\
\hline 279 & 28363609 & Ryan & $\begin{array}{l}\text { Maternal-Fetal Monitoring of Opioid- } \\
\text { Exposed Pregnancies: Analysis of a Pilot } \\
\text { Community-Based Protocol and Review } \\
\text { of the Literature }\end{array}$ & $\begin{array}{l}\text { J Obstet Gynaecol } \\
\text { Can }\end{array}$ & Not a review \\
\hline 280 & 26516340 & Saha & $\begin{array}{l}\text { Postpartum women's use of medicines } \\
\text { and breastfeeding practices: a } \\
\text { systematic review }\end{array}$ & $\begin{array}{l}\text { International } \\
\text { breastfeeding } \\
\text { journal }\end{array}$ & $\begin{array}{l}\text { No information about } \\
\text { adverse effects }\end{array}$ \\
\hline 281 & 21361848 & Sanu & $\begin{array}{l}\text { Hyperemesis gravidarum: pathogenesis } \\
\text { and the use of antiemetic agents }\end{array}$ & $\begin{array}{l}\text { Expert Opin } \\
\text { Pharmacother }\end{array}$ & Narrative review only \\
\hline
\end{tabular}




\begin{tabular}{|c|c|c|c|c|c|}
\hline No. & $\begin{array}{l}\text { PMID or } \\
\text { Other } \\
\text { I dentifier }\end{array}$ & $\begin{array}{c}\text { First } \\
\text { Author } \\
\text { Last Name }\end{array}$ & Title & J ournal & Reason for Exclusion \\
\hline 282 & 31425493 & $\begin{array}{l}\text { Schoretsani } \\
\text { tis }\end{array}$ & $\begin{array}{l}\text { Excretion of Antipsychotics Into the } \\
\text { Amniotic Fluid, Umbilical Cord Blood, } \\
\text { and Breast Milk: A Systematic Critical } \\
\text { Review and Combined Analysis }\end{array}$ & Ther Drug Monit & $\begin{array}{l}\text { No information about } \\
\text { adverse effects }\end{array}$ \\
\hline 283 & 29083536 & Scrandis & $\begin{array}{l}\text { Bipolar Disorder in Pregnancy: A Review } \\
\text { of Pregnancy Outcomes }\end{array}$ & $\begin{array}{l}J \text { Midwifery Womens } \\
\text { Health }\end{array}$ & $\begin{array}{l}\text { SR, but did not meet } \\
\text { minimum criteria }\end{array}$ \\
\hline 284 & 29588190 & Seidler & $\begin{array}{l}\text { Optimal aspirin dosing for preeclampsia } \\
\text { prevention }\end{array}$ & Am J Obstet Gynecol & Not a review \\
\hline 285 & 9259911 & Seto & $\begin{array}{l}\text { Pregnancy outcome following first } \\
\text { trimester exposure to antihistamines: } \\
\text { meta-analysis }\end{array}$ & AmJ Perinatol & $\begin{array}{l}\text { SR, but did not meet } \\
\text { minimum criteria }\end{array}$ \\
\hline 286 & 26448875 & Shah & $\begin{array}{l}\text { Pain Management in Pregnancy: } \\
\text { Multimodal Approaches }\end{array}$ & Pain Res Treat & Narrative review only \\
\hline 287 & 26113232 & Shekhar & $\begin{array}{l}\text { Oral nifedipine versus intravenous } \\
\text { labetalol for severe hypertension during } \\
\text { pregnancy: a systematic review and } \\
\text { meta-analysis }\end{array}$ & Bjog & $\begin{array}{l}\text { No information about } \\
\text { adverse effects }\end{array}$ \\
\hline 288 & 31809499 & Shepherd & $\begin{array}{l}\text { Antenatal magnesium sulphate and } \\
\text { adverse neonatal outcomes: A } \\
\text { systematic review and meta-analysis }\end{array}$ & PLoS Med & $\begin{array}{l}\text { SR, but did not meet } \\
\text { minimum criteria }\end{array}$ \\
\hline 289 & 27807847 & Siristatidis & Aspirin for in vitro fertilisation & $\begin{array}{l}\text { Cochrane Database } \\
\text { Syst Rev }\end{array}$ & No intervention of interest \\
\hline 290 & 26631373 & Smit & $\begin{array}{l}\text { Mirtazapine in pregnancy and lactation - } \\
\text { A systematic review }\end{array}$ & $\begin{array}{l}\text { Eur } \\
\text { Neuropsychopharma } \\
\text { col }\end{array}$ & $\begin{array}{l}\text { SR, but did not meet } \\
\text { minimum criteria }\end{array}$ \\
\hline 291 & 30173590 & Sridharan & $\begin{array}{l}\text { Interventions for treating hyperemesis } \\
\text { gravidarum: a network meta-analysis of } \\
\text { randomized clinical trials }\end{array}$ & $\begin{array}{l}\text { J Matern Fetal } \\
\text { Neonatal Med }\end{array}$ & No intervention of interest \\
\hline 292 & 30261764 & Sridharan & $\begin{array}{l}\text { Interventions for treating nausea and } \\
\text { vomiting in pregnancy: a network meta- } \\
\text { analysis and trial sequential analysis of } \\
\text { randomized clinical trials }\end{array}$ & $\begin{array}{l}\text { Expert Rev Clin } \\
\text { Pharmacol }\end{array}$ & $\begin{array}{l}\text { No information about } \\
\text { adverse effects }\end{array}$ \\
\hline 293 & 29974489 & Sridharan & $\begin{array}{l}\text { Drugs for treating severe hypertension } \\
\text { in pregnancy: a network meta-analysis } \\
\text { and trial sequential analysis of } \\
\text { randomized clinical trials }\end{array}$ & BrJ Clin Pharmacol & $\begin{array}{l}\text { SR, but did not meet } \\
\text { minimum criteria }\end{array}$ \\
\hline 294 & 23112017 & Tan & $\begin{array}{l}\text { Does low-moleculaB-weight heparin } \\
\text { improve live birth rates in pregnant } \\
\text { women with thrombophilic disorders? A } \\
\text { systematic review }\end{array}$ & Singapore Med J & No intervention of interest \\
\hline 295 & 31336231 & Tanos & $\begin{array}{l}\text { Review of migraine incidence and } \\
\text { management in obstetrics and } \\
\text { gynaecology }\end{array}$ & $\begin{array}{l}\text { EurJ Obstet Gynecol } \\
\text { Reprod Biol }\end{array}$ & $\begin{array}{l}\text { No information about } \\
\text { adverse effects }\end{array}$ \\
\hline 296 & 26044279 & Tanoshima & $\begin{array}{l}\text { Risks of congenital malformations in } \\
\text { offspring exposed to valproic acid in } \\
\text { utero: A systematic review and } \\
\text { cumulative meta-analysis }\end{array}$ & Clin Pharmacol Ther & $\begin{array}{l}\text { SR, but did not meet } \\
\text { minimum criteria }\end{array}$ \\
\hline 297 & 19837868 & Tegethoff & $\begin{array}{l}\text { Effects of intrauterine exposure to } \\
\text { synthetic glucocorticoids on fetal, } \\
\text { newborn, and infant hypothalamic- } \\
\text { pituitary-adrenal axis function in } \\
\text { humans: a systematic review }\end{array}$ & Endocr Rev & $\begin{array}{l}\text { SR, but did not meet } \\
\text { minimum criteria }\end{array}$ \\
\hline 298 & 30111493 & Tenorio & $\begin{array}{l}\text { Oral antioxidant therapy for prevention } \\
\text { and treatment of preeclampsia: Meta- } \\
\text { analysis of randomized controlled trials }\end{array}$ & $\begin{array}{l}\text { Nutr Metab } \\
\text { Cardiovasc Dis }\end{array}$ & No intervention of interest \\
\hline 299 & 19434568 & Ter Horst & $\begin{array}{l}\text { [Antidepressants during pregnancy and } \\
\text { lactation] }\end{array}$ & Tijdschr Psychiatr & $\begin{array}{l}\text { SR, but did not meet } \\
\text { minimum criteria }\end{array}$ \\
\hline 300 & 20919996 & Thajam & $\begin{array}{l}\text { Is neonatal abstinence syndrome } \\
\text { related to the amount of opiate used? }\end{array}$ & $\begin{array}{l}\text { J Obstet Gynecol } \\
\text { Neonatal Nurs }\end{array}$ & $\begin{array}{l}\text { SR, but did not meet } \\
\text { minimum criteria }\end{array}$ \\
\hline
\end{tabular}




\begin{tabular}{|c|c|c|c|c|c|}
\hline No. & $\begin{array}{l}\text { PMI D or } \\
\text { Other } \\
\text { I dentifier }\end{array}$ & $\begin{array}{c}\text { First } \\
\text { Author } \\
\text { Last Name }\end{array}$ & Title & Journal & Reason for Exclusion \\
\hline 301 & $\begin{array}{l}\text { No PubMed } \\
\text { ID }\end{array}$ & Thibaut & $\begin{array}{l}\text { WFSBP * and IAWMH } * * \text { Guidelines for } \\
\text { the treatment of alcohol use disorders } \\
\text { in pregnant women }\end{array}$ & $\begin{array}{l}\text { The world journal of } \\
\text { biological psychiatry } \\
\text { : the official journal } \\
\text { of the World } \\
\text { Federation of } \\
\text { Societies of } \\
\text { Biological Psychiatry }\end{array}$ & No intervention of interest \\
\hline 302 & 28297592 & Tosato & $\begin{array}{l}\text { A Systematized Review of Atypical } \\
\text { Antipsychotics in Pregnant Women: } \\
\text { Balancing Between Risks of Untreated } \\
\text { Illness and Risks of Drug-Related } \\
\text { Adverse Effects }\end{array}$ & J Clin Psychiatry & $\begin{array}{l}\text { SR, but did not meet } \\
\text { minimum criteria }\end{array}$ \\
\hline 303 & 21654128 & Trivedi & $\begin{array}{l}\text { A meta-analysis of low-dose aspirin for } \\
\text { prevention of preeclampsia }\end{array}$ & J Postgrad Med & $\begin{array}{l}\text { SR, but did not meet } \\
\text { minimum criteria }\end{array}$ \\
\hline 304 & 19698902 & Tuccori & $\begin{array}{l}\text { Safety concerns associated with the use } \\
\text { of serotonin reuptake inhibitors and } \\
\text { other serotonergic/noradrenergic } \\
\text { antidepressants during pregnancy: a } \\
\text { review }\end{array}$ & Clin Ther & $\begin{array}{l}\text { SR, but did not meet } \\
\text { minimum criteria }\end{array}$ \\
\hline 305 & 31479546 & Turner & $\begin{array}{l}\text { The impact of low-dose aspirin on } \\
\text { adverse perinatal outcomes: a meta- } \\
\text { analysis and meta-regression }\end{array}$ & $\begin{array}{l}\text { Ultrasound Obstet } \\
\text { Gynecol }\end{array}$ & $\begin{array}{l}\text { SR, but did not meet } \\
\text { minimum criteria }\end{array}$ \\
\hline 306 & 21034181 & Udechuku & $\begin{array}{l}\text { Antidepressants in pregnancy: a } \\
\text { systematic review }\end{array}$ & Aust N ZJ Psychiatry & $\begin{array}{l}\text { SR, but did not meet } \\
\text { minimum criteria }\end{array}$ \\
\hline 307 & 30624301 & Uguz & $\begin{array}{l}\text { Antipsychotic Use During Pregnancy } \\
\text { and the Risk of Gestational Diabetes } \\
\text { Mellitus: A Systematic Review }\end{array}$ & $\begin{array}{l}\text { J Clin } \\
\text { Psychopharmacol }\end{array}$ & Narrative review only \\
\hline 308 & 27028982 & Uguz & $\begin{array}{l}\text { Second-Generation Antipsychotics } \\
\text { During the Lactation Period: A } \\
\text { Comparative Systematic Review on } \\
\text { Infant Safety }\end{array}$ & $\begin{array}{l}\text { J Clin } \\
\text { Psychopharmacol }\end{array}$ & Narrative review only \\
\hline 309 & 27297617 & Uguz & $\begin{array}{l}\text { Mood stabilizers during breastfeeding: a } \\
\text { systematic review of the recent } \\
\text { literature }\end{array}$ & Bipolar Disord & Narrative review only \\
\hline 310 & 31425466 & Uguz & $\begin{array}{l}\text { The Use of Antidepressant Medications } \\
\text { During Pregnancy and the Risk of } \\
\text { Neonatal Seizures: A Systematic Review }\end{array}$ & $\begin{array}{l}\text { J Clin } \\
\text { Psychopharmacol }\end{array}$ & Narrative review only \\
\hline 311 & 29596147 & Uguz & $\begin{array}{l}\text { Maternal Antidepressant Use During } \\
\text { Pregnancy and the Risk of Attention- } \\
\text { Deficit/Hyperactivity Disorder in } \\
\text { Children: A Systematic Review of the } \\
\text { Current Literature }\end{array}$ & $\begin{array}{l}\text { J Clin } \\
\text { Psychopharmacol }\end{array}$ & $\begin{array}{l}\text { SR, but did not meet } \\
\text { minimum criteria }\end{array}$ \\
\hline 312 & 27941417 & Uguz & $\begin{array}{l}\text { Is There Any Association Between Use } \\
\text { of Antidepressants and Preeclampsia or } \\
\text { Gestational Hypertension?: A } \\
\text { Systematic Review of Current Studies }\end{array}$ & $\begin{array}{l}\text { J Clin } \\
\text { Psychopharmacol }\end{array}$ & $\begin{array}{l}\text { SR, but did not meet } \\
\text { minimum criteria }\end{array}$ \\
\hline 313 & 31416730 & $\begin{array}{l}\text { Valencia- } \\
\text { Mendoza }\end{array}$ & $\begin{array}{l}\text { Fatal reversible cerebral } \\
\text { vasoconstriction syndrome: A } \\
\text { systematic review of case series and } \\
\text { case reports }\end{array}$ & J Clin Neurosci & $\begin{array}{l}\text { Participants not pregnant } \\
\text { (or attempting to be } \\
\text { pregnant), postpartum, or } \\
\text { breastfeeding }\end{array}$ \\
\hline 314 & 30109437 & Vatzaki & $\begin{array}{l}\text { Latest clinical recommendations on } \\
\text { valproate use for migraine prophylaxis } \\
\text { in women of childbearing age: overview } \\
\text { from European Medicines Agency and } \\
\text { European Headache Federation }\end{array}$ & J Headache Pain & Not a review \\
\hline 315 & 25102018 & Verdurmen & $\begin{array}{l}\text { The influence of corticosteroids on fetal } \\
\text { heart rate variability: a systematic } \\
\text { review of the literature }\end{array}$ & Obstet Gynecol Sunv & No intervention of interest \\
\hline 316 & 26329145 & Verrotti & $\begin{array}{l}\text { Foetal safety of old and new } \\
\text { antiepileptic drugs }\end{array}$ & $\begin{array}{l}\text { Expert Opin Drug } \\
\text { Saf }\end{array}$ & Narrative review only \\
\hline 317 & 26318519 & Viale & $\begin{array}{l}\text { Epilepsy in pregnancy and reproductive } \\
\text { outcomes: a systematic review and } \\
\text { meta-analysis }\end{array}$ & Lancet & $\begin{array}{l}\text { SR, but did not meet } \\
\text { minimum criteria }\end{array}$ \\
\hline
\end{tabular}




\begin{tabular}{|c|c|c|c|c|c|}
\hline No. & $\begin{array}{l}\text { PMID or } \\
\text { Other } \\
\text { I dentifier }\end{array}$ & $\begin{array}{c}\text { First } \\
\text { Author } \\
\text { Last Name }\end{array}$ & Title & Journal & Reason for Exclusion \\
\hline 318 & 31293454 & $\begin{array}{l}\text { VillamoB- } \\
\text { Martinez }\end{array}$ & $\begin{array}{l}\text { Cerebellar Hemorrhage in Preterm } \\
\text { Infants: A Meta-Analysis on Risk Factors } \\
\text { and Neurodevelopmental Outcome }\end{array}$ & Front Physiol & Narrative review only \\
\hline 319 & 28005135 & Vitale & $\begin{array}{l}\text { Psychopharmacotherapy in Pregnancy } \\
\text { and Breastfeeding }\end{array}$ & Obstet Gynecol Sunv & $\begin{array}{l}\text { SR, but did not meet } \\
\text { minimum criteria }\end{array}$ \\
\hline 320 & 18034353 & Vlastarakos & $\begin{array}{l}\text { Treating common ear problems in } \\
\text { pregnancy: what is safe? }\end{array}$ & $\begin{array}{l}\text { Eur Arch } \\
\text { Otorhinolaryngol }\end{array}$ & Narrative review only \\
\hline 321 & 30421346 & Wang & $\begin{array}{l}\text { Advances in Epidemiological Methods } \\
\text { and Utilisation of Large Databases: A } \\
\text { Methodological Review of Observational } \\
\text { Studies on Central Nervous System } \\
\text { Drug Use in Pregnancy and Central } \\
\text { Nervous System Outcomes in Children }\end{array}$ & Drug Saf & $\begin{array}{l}\text { Only addresses } \\
\text { predictors/distribution of } \\
\text { intervention use }\end{array}$ \\
\hline 322 & 15369649 & Waterman & $\begin{array}{l}\text { Do commonly used oral } \\
\text { antihypertensives alter fetal or neonatal } \\
\text { heart rate characteristics? A systematic } \\
\text { review }\end{array}$ & $\begin{array}{l}\text { Hypertens } \\
\text { Pregnancy }\end{array}$ & $\begin{array}{l}\text { No information about } \\
\text { adverse effects }\end{array}$ \\
\hline 323 & $\begin{array}{l}\text { CD004411 } \\
\text { (Cochrane) }\end{array}$ & Webb & $\begin{array}{l}\text { Antipsychotic drugs for non,Äêaffective } \\
\text { psychosis during pregnancy and } \\
\text { postpartum }\end{array}$ & $\begin{array}{l}\text { Cochrane Database } \\
\text { of Systematic } \\
\text { Reviews }\end{array}$ & $\begin{array}{l}\text { No information about } \\
\text { adverse effects }\end{array}$ \\
\hline 324 & 15106251 & Webb & $\begin{array}{l}\text { Antipsychotic drugs for non-affective } \\
\text { psychosis during pregnancy and } \\
\text { postpartum }\end{array}$ & $\begin{array}{l}\text { Cochrane Database } \\
\text { Syst Rev }\end{array}$ & $\begin{array}{l}\text { Empty review, i.e., no } \\
\text { included studies }\end{array}$ \\
\hline 325 & 15169695 & Weissman & $\begin{array}{l}\text { Pooled analysis of antidepressant levels } \\
\text { in lactating mothers, breast milk, and } \\
\text { nursing infants }\end{array}$ & AmJ Psychiatry & $\begin{array}{l}\text { SR, but did not meet } \\
\text { minimum criteria }\end{array}$ \\
\hline 326 & 15507199 & Wen & $\begin{array}{l}\text { Risk of fetal exposure to tricyclic } \\
\text { antidepressants }\end{array}$ & $\begin{array}{l}\text { J Obstet Gynaecol } \\
\text { Can }\end{array}$ & Review of animal studies \\
\hline 327 & $\begin{array}{l}\text { CD010527 } \\
\text { (Cochrane) }\end{array}$ & Wilkinson & $\begin{array}{l}\text { Melatonin for women in pregnancy for } \\
\text { neuroprotection of the fetus }\end{array}$ & $\begin{array}{l}\text { Cochrane Database } \\
\text { of Systematic } \\
\text { Reviews }\end{array}$ & $\begin{array}{l}\text { No information about } \\
\text { adverse effects }\end{array}$ \\
\hline 328 & 18246981 & Wise & $\begin{array}{l}\text { Treatment of narcolepsy and other } \\
\text { hypersomnias of central origin }\end{array}$ & Sleep & $\begin{array}{l}\text { SR, but did not meet } \\
\text { minimum criteria }\end{array}$ \\
\hline 329 & 10517430 & Wisner & $\begin{array}{l}\text { Pharmacologic treatment of depression } \\
\text { during pregnancy }\end{array}$ & Jama & $\begin{array}{l}\text { SR, but did not meet } \\
\text { minimum criteria }\end{array}$ \\
\hline 330 & 21501542 & Wong & Substance use in pregnancy & $\begin{array}{l}\text { J Obstet Gynaecol } \\
\text { Can }\end{array}$ & Not a review \\
\hline 331 & 23968886 & $\begin{array}{l}\text { Worthingto } \\
\mathrm{n}\end{array}$ & $\begin{array}{l}\text { Canadian Headache Society Guideline: } \\
\text { acute drug therapy for migraine } \\
\text { headache }\end{array}$ & CanJ Neurol Sci & Not a review \\
\hline 332 & 20824872 & Woudstra & $\begin{array}{l}\text { Corticosteroids for HELLP (hemolysis, } \\
\text { elevated liver enzymes, low platelets) } \\
\text { syndrome in pregnancy }\end{array}$ & $\begin{array}{l}\text { Cochrane Database } \\
\text { of Systematic } \\
\text { Reviews }\end{array}$ & $\begin{array}{l}\text { No information about } \\
\text { adverse effects }\end{array}$ \\
\hline 333 & 16595080 & $\mathrm{Wu}$ & $\begin{array}{l}\text { Screening for thrombophilia in high-risk } \\
\text { situations: systematic review and cost- } \\
\text { effectiveness analysis. The Thrombosis: } \\
\text { Risk and Economic Assessment of } \\
\text { Thrombophilia Screening (TREATS) } \\
\text { study }\end{array}$ & $\begin{array}{l}\text { Health Technol } \\
\text { Assess }\end{array}$ & $\begin{array}{l}\text { No information about } \\
\text { adverse effects }\end{array}$ \\
\hline 334 & $\begin{array}{l}\text { No PubMed } \\
\text { ID }\end{array}$ & Wu & $\begin{array}{l}\text { The medical management of } \\
\text { antiphospholipid syndrome in } \\
\text { pregnancy: a meta-analysis }\end{array}$ & $\begin{array}{l}\text { Obstetrics and } \\
\text { gynecology }\end{array}$ & $\begin{array}{l}\text { SR, but did not meet } \\
\text { minimum criteria }\end{array}$ \\
\hline 335 & 12792553 & Wunsch & Treatment of pain in pregnancy & Clin J Pain & $\begin{array}{l}\text { SR, but did not meet } \\
\text { minimum criteria }\end{array}$ \\
\hline 336 & 28216406 & Xiao & $\begin{array}{l}\text { The relationship between maternal } \\
\text { corticosteroid use and orofacial clefts-a } \\
\text { meta-analysis }\end{array}$ & Reprod Toxicol & $\begin{array}{l}\text { SR, but did not meet } \\
\text { minimum criteria }\end{array}$ \\
\hline 337 & 25833349 & $\mathrm{Xu}$ & $\begin{array}{l}\text { Low-Dose Aspirin for Preventing } \\
\text { Preeclampsia and Its Complications: A } \\
\text { Meta-Analysis }\end{array}$ & $\begin{array}{l}\text { J Clin Hypertens } \\
\text { (Greenwich) }\end{array}$ & $\begin{array}{l}\text { SR, but did not meet } \\
\text { minimum criteria }\end{array}$ \\
\hline
\end{tabular}




\begin{tabular}{|c|c|c|c|c|c|}
\hline No. & $\begin{array}{l}\text { PMID or } \\
\text { Other } \\
\text { Identifier }\end{array}$ & $\begin{array}{c}\text { First } \\
\text { Author } \\
\text { Last Name }\end{array}$ & Title & J ournal & Reason for Exclusion \\
\hline 338 & 26111687 & Yao & $\begin{array}{l}\text { [Early intervention with aspirin for } \\
\text { preventing preeclampsia in high-risk } \\
\text { women: a meta-analysis] }\end{array}$ & $\begin{array}{l}\text { Nan Fang Yi Ke Da } \\
\text { Xue Xue Bao }\end{array}$ & $\begin{array}{l}\text { SR, but did not meet } \\
\text { minimum criteria }\end{array}$ \\
\hline 339 & 10796091 & Young & $\begin{array}{l}\text { Antihistamines versus aspirin for itching } \\
\text { in late pregnancy }\end{array}$ & $\begin{array}{l}\text { Cochrane Database } \\
\text { Syst Rev }\end{array}$ & $\begin{array}{l}\text { No information about } \\
\text { adverse effects }\end{array}$ \\
\hline 340 & 19445755 & Young & Leg cramps & BMJ Clin Evid & Duplicate \\
\hline 341 & 25970567 & Young & Leg cramps & BMJ Clin Evid & Duplicate \\
\hline 342 & 26735551 & Zeng & $\begin{array}{l}\text { Effects and Safety of Magnesium } \\
\text { Sulfate on Neuroprotection: A Meta- } \\
\text { analysis Based on PRISMA Guidelines }\end{array}$ & Medicine (Baltimore) & $\begin{array}{l}\text { SR, but did not meet } \\
\text { minimum criteria }\end{array}$ \\
\hline 343 & 26559249 & Zhang & $\begin{array}{l}\text { Antithrombotic Treatment for Recurrent } \\
\text { Miscarriage: Bayesian Network Meta- } \\
\text { Analysis and Systematic Review }\end{array}$ & Medicine (Baltimore) & $\begin{array}{l}\text { SR, but did not meet } \\
\text { minimum criteria }\end{array}$ \\
\hline 344 & 26262909 & Zhou & $\begin{array}{l}\text { Interventions for leg cramps in } \\
\text { pregnancy }\end{array}$ & $\begin{array}{l}\text { Cochrane Database } \\
\text { Syst Rev }\end{array}$ & No intervention of interest \\
\hline 345 & 23806368 & Zhou & $\begin{array}{l}\text { Chinese herbal medicine in treatment of } \\
\text { polyhydramnios: a meta-analysis and } \\
\text { systematic review }\end{array}$ & Chin Med SciJ & $\begin{array}{l}\text { SR, but did not meet } \\
\text { minimum criteria }\end{array}$ \\
\hline 346 & 21144482 & $\begin{array}{l}\text { ZrouB- } \\
\text { Hassen }\end{array}$ & $\begin{array}{l}\text { [Safety of rheumatic disease drugs at } \\
\text { childbearing age] }\end{array}$ & Therapie & Narrative review only \\
\hline 347 & 29747656 & Zwink & $\begin{array}{l}\text { Maternal drug use and the risk of } \\
\text { anorectal malformations: systematic } \\
\text { review and meta-analysis }\end{array}$ & Orphanet J Rare Dis & $\begin{array}{l}\text { SR, but did not meet } \\
\text { minimum criteria }\end{array}$ \\
\hline
\end{tabular}

Abbreviations: PMID = PubMed identifier, SR = systematic review . 


\section{References}

1. Higgins JP, Altman DG, Gotzsche PC, et al. The Cochrane Collaboration's tool for assessing risk of bias in randomised trials. BMJ (Clinical research ed). 2011 Oct 18;343:d5928. doi: 10.1136/bmj.d5928. PMID: 22008217.

2. Sterne JA, Hernan MA, Reeves BC, et al. ROBINS-I: a tool for assessing risk of bias in non-randomised studies of interventions. BMJ (Clinical research ed). 2016 Oct 12;355:i4919. doi: 10.1136/bmj.i4919. PMID: 27733354.

3. National Heart, Lung, and Blood Institute. Study Quality Assessment Tools.; 2019. https://www.nhlbi.nih.gov/healthtopics/study-quality-assessment-tools. Accessed on January 23, 2020.

4. Shea BJ, Reeves BC, Wells G, et al. AMSTAR 2: a critical appraisal tool for systematic reviews that include randomised or nonrandomised studies of healthcare interventions, or both. BMJ (Clinical research ed). 2017 Sep 21;358:j4008. doi: 10.1136/bmj.j4008. PMID: 28935701.

5. Berkman ND, Lohr KN, Ansari M, et al. AHRQ Methods for Effective Health Care. Grading the Strength of a Body of Evidence When Assessing Health Care Interventions for the Effective Health Care Program of the Agency for Healthcare Research and Quality: An Update. Methods Guide for Effectiveness and Comparative Effectiveness Reviews. Rockville (MD): Agency for Healthcare Research and Quality (US); 2008.

6. Berkman ND, Lohr KN, Ansari MT, et al. Grading the strength of a body of evidence when assessing health care interventions: an EPC update. Journal of clinical epidemiology. 2015 Nov;68(11):1312-24. doi: 10.1016/j.jclinepi.2014.11.023. PMID: 25721570.

7. Guyatt GH, Oxman AD, Kunz R, et al. Going from evidence to recommendations. BMJ (Clinical research ed). 2008 May 10;336(7652):1049-51. doi: 10.1136/bmj.39493.646875.AE. PMID: 18467413.
8. Bhola R, Kinsella E, Giffin N, et al. Single-pulse transcranial magnetic stimulation (sTMS) for the acute treatment of migraine: evaluation of outcome data for the UK post market pilot program. The journal of headache and pain. 2015;16:535. doi: 10.1186/s10194-015-0535-3. PMID: 26055242.

9. Castilla-Puentes R, Ford L, Manera L, et al. Topiramate monotherapy use in women with and without epilepsy: pregnancy and neonatal outcomes. Epilepsy Res. 2014 May;108(4):717-24. doi: 10.1016/j.eplepsyres.2014.01.021. PMID: 24598456.

10. Childress KMS, Dothager C, Gavard JA, et al. Metoclopramide and Diphenhydramine: A Randomized Controlled Trial of a Treatment for Headache in Pregnancy when Acetaminophen Alone Is Ineffective (MAD Headache Study). Am J Perinatol. 2018 Nov;35(13):1281-6. doi: 10.1055/s-00381646952. PMID: 29723901.

11. Cunnington M, Ephross S, Churchill P. The safety of sumatriptan and naratriptan in pregnancy: what have we learned? Headache. 2009 Nov-Dec;49(10):1414-22. doi: 10.1111/j.1526-4610.2009.01529.x. PMID: 19804390.

12. Drks. Fetotoxical risk analysis of maternal triptan therapy during pregnancy in the context of migraine disorder. Http://wwwwhoint/trialsearch/trial2aspx? Trialid=drks00007660. 2019. PMID: CN01550349.

13. Ephross SA, Sinclair SM. Final results from the 16-year sumatriptan, naratriptan, and treximet pregnancy registry. Headache. 2014 Jul-Aug;54(7):1158-72. doi: 10.1111/head.12375. PMID: 24805878.

14. Govindappagari S, Grossman TB, Dayal AK, et al. Peripheral nerve blocks in the treatment of migraine in pregnancy. Obstetrics and gynecology. 2014 Dec;124(6):1169-74. doi: 10.1097/aog.0000000000000555. PMID: 25415168. 
15. Harris GE, Wood M, Ystrom E, et al. Prenatal triptan exposure and neurodevelopmental outcomes in 5-year-old children: Follow-up from the Norwegian Mother and Child Cohort Study. Paediatr Perinat Epidemiol. 2018 May;32(3):247-55. doi: 10.1111/ppe.12461. PMID: 29569251.

16. Hickling EJ, Silverman DJ, Loos W. A nonpharmacological treatment of vascular headache during pregnancy. Headache. 1990 Jun;30(7):407-10. doi: 10.1111/j.15264610.1990.hed3007407.x. PMID: 2401622.

17. Kallen B, Lygner PE. Delivery outcome in women who used drugs for migraine during pregnancy with special reference to sumatriptan. Headache. 2001 Apr;41(4):351-6. doi: 10.1046/j.15264610.2001.111006351.x. PMID: 11318881.

18. Kallen B, Nilsson E, Otterblad Olausson P. Delivery outcome after maternal use of drugs for migraine: a register study in Sweden. Drug Saf. 2011 Aug 1;34(8):691703. doi: 10.2165/11590370-00000000000000. PMID: 21751829.

19. Marcus DA, Scharff L, Turk DC. Nonpharmacological management of headaches during pregnancy. Psychosom Med. 1995 Nov-Dec;57(6):527-35. doi: 10.1097/00006842-199511000-00004. PMID: 8600478.

20. Nct. A Cost Effective Treatment for Headache in Pregnancy When Acetaminophen Alone is Ineffective. https://clinicaltrialsgov/show/NCT02295280 . 2014. PMID: CN-01550349.

21. Nct. Sumatriptan and Naratriptan Pregnancy Registry. https://ClinicalTrialsgov/show/NCT0105960 4. 2014. PMID: NCT01059604.

22. Nezvalova-Henriksen K, Spigset O, Nordeng H. Triptan exposure during pregnancy and the risk of major congenital malformations and adverse pregnancy outcomes: results from the Norwegian Mother and Child Cohort Study. Headache. 2010 Apr;50(4):563-75. doi: 10.1111/j.1526-4610.2010.01619.x. PMID: 20132339.
23. Nezvalova-Henriksen K, Spigset O, Nordeng H. Triptan safety during pregnancy: a Norwegian population registry study. Eur J Epidemiol. 2013 Sep;28(9):759-69. doi: 10.1007/s10654-013-9831-x. PMID: 23884894.

24. Nezvalova-Henriksen K, Spigset O, Nordeng HM. Errata in "Triptan exposure during pregnancy and the risk of major congenital malformations and adverse pregnancy outcomes: results from the norwegian mother and child cohort study". Headache. 2012 Sep;52(8):1319-20. doi: 10.1111/j.1526-4610.2012.02207.x. PMID: 22946832.

25. O'Quinn S, Ephross SA, Williams V, et al. Pregnancy and perinatal outcomes in migraineurs using sumatriptan: a prospective study. Arch Gynecol Obstet. 1999 Nov;263(1-2):7-12. doi: 10.1007/s004040050252. PMID: 10728620.

26. Olesen C, Steffensen FH, Sorensen HT, et al. Pregnancy outcome following prescription for sumatriptan. Headache. 2000 Jan;40(1):20-4. doi: 10.1046/j.15264610.2000.00003.x. PMID: 10759898.

27. Scharff L, Marcus DA, Turk DC. Maintenance of effects in the nonmedical treatment of headaches during pregnancy. Headache. 1996 May;36(5):285-90. doi: 10.1046/j.1526-4610.1996.3605285.x. PMID: 8682668.

28. Scolari Childress KM, Lebovitz SJ, Mostello DJ. Metoclopramide and diphenhydramine costeffective therapy for headache in an obstetric triage unit. Obstetrics and gynecology. 2015;125:1S-2S. doi: 10.1097/01.AOG.0000463522.05160.e6. PMID: CN-01173373.

29. Shuhaiber S, Pastuszak A, Schick B, et al. Pregnancy outcome following first trimester exposure to sumatriptan. Neurology. 1998 Aug;51(2):581-3. doi: 10.1212/wnl.51.2.581. PMID: 9710039.

30. Silva JBGd, Nakamura MU, Cordeiro JA, et al. Acupuncture for tension-type headache in pregnancy: A prospective, randomized, controlled study. European Journal of Integrative Medicine. 2012 2012/12/01/;4(4):e366-e70. doi: https://doi.org/10.1016/j.eujim.2012.04.002. 
31. Spielmann K, Kayser A, Beck E, et al. Pregnancy outcome after anti-migraine triptan use: A prospective observational cohort study. Cephalalgia : an international journal of headache. 2018 May;38(6):1081-92. doi: 10.1177/0333102417724152. PMID: 28758416.

32. Wood ME, Frazier JA, Nordeng HM, et al. Longitudinal changes in neurodevelopmental outcomes between 18 and 36 months in children with prenatal triptan exposure: findings from the Norwegian Mother and Child Cohort Study. BMJ Open. 2016 Sep 13;6(9):e011971. doi: 10.1136/bmjopen-2016-011971. PMID: 27625061.

33. Wood ME, Lapane K, Frazier JA, et al. Prenatal Triptan Exposure and Internalising and Externalising Behaviour Problems in 3Year-Old Children: Results from the Norwegian Mother and Child Cohort Study. Paediatr Perinat Epidemiol. 2016 Mar;30(2):190-200. doi: 10.1111/ppe.12253. PMID: 26525300.

34. Alcantara J, Cossette M. Intractable migraine headaches during pregnancy under chiropractic care. Complement Ther Clin Pract. 2009 Nov;15(4):192-7. doi: 10.1016/j.ctcp.2009.03.005. PMID: 19880080.

35. Asioli GM, Merli E, Favoni V, et al. Greater Occipital Nerve Infiltration During Pregnancy in Cluster Headache: A Case Report. Headache. 2019 Jun;59(6):930-2. doi: 10.1111/head.13553. PMID: 31106401.

36. de Coo IF, Wilbrink LA, Haan J. Effective occipital nerve stimulation during pregnancy in a cluster headache patient. Cephalalgia : an international journal of headache. 2016 Jan;36(1):98-9. doi: 10.1177/0333102415580111. PMID: 25834272.

37. Demirel G, Oguz SS, Erdeve O, et al. Unilateral renal agenesis and urethral atresia associated with ergotamine intake during pregnancy. Ren Fail. 2012;34(5):643-4. doi: 10.3109/0886022x.2012.668156. PMID: 22417229.
38. Dey R, Khan S, Akhouri V, et al. Labetalol for prophylactic treatment of intractable migraine during pregnancy. Headache. 2002 Jul-Aug;42(7):642-5. doi: 10.1046/j.15264610.2002.02152.x. PMID: 12482217.

39. Evans RW, Diamond ML. Is sumatriptan use safe during pregnancy? Headache. 2000 NovDec;40(10):856-7. doi: 10.1046/j.15264610.2000.00156.x. PMID: 11135034.

40. Evans RW, Loder EW. Migraine with aura during pregnancy. Headache. 2003 Jan;43(1):80-4. doi: 10.1046/j.1526-4610.2003.03017.x. PMID: 12864766.

41. Evans RW, Wilson MC. Postpartum headaches. Headache. 2001 Jul-Aug;41(7):731-2. doi: 10.1046/j.1526-4610.2001.041007731.x. PMID: 11554965.

42. Haaland K. Angiotensin II receptor antagonists against migraine in pregnancy: fatal outcome. The journal of headache and pain. 2010 Apr;11(2):167-9. doi: 10.1007/s10194009-0182-7. PMID: 20063032.

43. Hughes HE, Goldstein DA. Birth defects following maternal exposure to ergotamine, beta blockers, and caffeine. J Med Genet. 1988 Jun;25(6):396-9. doi: 10.1136/jmg.25.6.396. PMID: 3398007.

44. Kajantie E, Somer M. Bilateral cleft lip and palate, hypertelorism and hypoplastic toes. Clin Dysmorphol. 2004 Jul;13(3):195-6. doi: 10.1097/01.mcd.0000133499.91871.52. PMID: 15194960.

45. Levin D, Cohen S, Mellender S, et al. Sphenopalatine Ganglion Block Successfully Treats Migraines in a Type 1 Arnold Chiari Malformation Pregnant Patient: A Case Report. A A Pract. 2018 Jul 15;11(2):32-4. doi: 10.1213/xaa.0000000000000722. PMID: 29634560.

46. Nair V, Soraisham AS, Akierman A. Neonatal withdrawal syndrome due to maternal codeine use. Paediatr Child Health. 2012 May;17(5):e40-1. doi: 10.1093/pch/17.5.e40. PMID: 23633904.

47. Papadopoulos G. A case of migraine headache successfully treated with low-dose magnesium phosphate in a pregnant woman. Australian Journal of Herbal Medicine. 2017;29(4):136. 
48. Richardson KJ. Postpartum Headache. Adv Emerg Nurs J. 2017 Oct/Dec;39(4):258-65. doi: 10.1097/tme.0000000000000162. PMID: 29095177.

49. Robinson AY, Grogan PM. OnabotulinumtoxinA successfully used as migraine prophylaxis during pregnancy: a case report. Mil Med. 2014 Jun;179(6):e703-4. doi: 10.7205/milmed-d-13-00477. PMID: 24902141.

50. Rozen TD. Aborting a prolonged migrainous aura with intravenous prochlorperazine and magnesium sulfate. Headache. 2003 Sep;43(8):901-3. PMID: 12940813.

51. ten Berg K, van Oppen AC, Nikkels PG, et al. Complex cardiac defect with hypoplastic right ventricle in a fetus with valproate exposure. Prenat Diagn. 2005 Feb;25(2):156-8. doi: 10.1002/pd.1098. PMID: 15712340.

52. Yalin OO, Uluduz D, Ozge A. Peripheral nerve blocks for the treatment of short-lasting unilateral neuralgiform headache with conjunctival injection and tearing (SUNCT) during pregnancy. Agri. 2018 Jan;30(1):2830. doi: 10.5505/agri.2016.25991. PMID: 29450873.

53. Abalos E, Duley L, Steyn DW, et al. Antihypertensive drug therapy for mild to moderate hypertension during pregnancy. Cochrane Database Syst Rev. 2018 Oct 1;10:Cd002252. doi: 10.1002/14651858.CD002252.pub4. PMID: 30277556.

54. Bain ES, Middleton PF, Crowther CA. Maternal adverse effects of different antenatal magnesium sulphate regimens for improving maternal and infant outcomes: a systematic review. BMC Pregnancy Childbirth. 2013 Oct 21;13:195. doi: 10.1186/1471-2393-13195. PMID: 24139447.

55. Bellos I, Pergialiotis V, Antsaklis A, et al. Safety of non-steroidal anti-inflammatory drugs in the postpartum period among women with hypertensive disorders of pregnancy: a meta-analysis. Ultrasound Obstet Gynecol. 2020 Feb 18. doi: 10.1002/uog.21997. PMID: 32068930.
56. Bellos I, Pergialiotis V, Papapanagiotou A, et al. Comparative efficacy and safety of oral antihypertensive agents in pregnant women with chronic hypertension: a network metaanalysis. American journal of obstetrics and gynecology. 2020 Mar 19. doi: 10.1016/j.ajog.2020.03.016. PMID: 32199925.

57. Chaemsaithong P, Cuenca-Gomez D, Plana MN, et al. Does low-dose aspirin initiated before 11 weeks' gestation reduce the rate of preeclampsia? American journal of obstetrics and gynecology. 2019 Sep 5. doi: 10.1016/j.ajog.2019.08.047. PMID: 31494125.

58. Coomarasamy A, Honest H, Papaioannou S, et al. Aspirin for prevention of preeclampsia in women with historical risk factors: a systematic review. Obstetrics and gynecology. 2003 Jun;101(6):1319-32. doi: 10.1016/s0029-7844(03)00169-8. PMID: 12798543.

59. Coughlin CG, Blackwell KA, Bartley C, et al. Obstetric and neonatal outcomes after antipsychotic medication exposure in pregnancy. Obstetrics and gynecology. 2015 May;125(5):1224-35. doi: 10.1097/aog.0000000000000759. PMID: 25932852.

60. Dolovich LR, Addis A, Vaillancourt JM, et al. Benzodiazepine use in pregnancy and major malformations or oral cleft: meta-analysis of cohort and case-control studies. BMJ (Clinical research ed). 1998 Sep 26;317(7162):839-43. doi: 10.1136/bmj.317.7162.839. PMID: 9748174.

61. Duley L, Henderson-Smart DJ, Meher S, et al. Antiplatelet agents for preventing preeclampsia and its complications. Cochrane Database Syst Rev. 2007 Apr 18(2):Cd004659. doi: 10.1002/14651858.CD004659.pub2. PMID: 17443552.

62. Enato E, Moretti M, Koren G. The fetal safety of benzodiazepines: an updated meta-analysis. J Obstet Gynaecol Can. 2011 Jan;33(1):468. doi: 10.1016/s1701-2163(16)34772-7. PMID: 21272436. 
63. Etwel F, Faught LH, Rieder MJ, et al. The Risk of Adverse Pregnancy Outcome After First Trimester Exposure to H1 Antihistamines: A Systematic Review and Meta-Analysis. Drug Saf. 2017 Feb;40(2):121-32. doi: 10.1007/s40264-016-0479-9. PMID: 27878468.

64. Hammers AL, Sanchez-Ramos L, Kaunitz AM. Antenatal exposure to indomethacin increases the risk of severe intraventricular hemorrhage, necrotizing enterocolitis, and periventricular leukomalacia: a systematic review with metaanalysis. American journal of obstetrics and gynecology. 2015 Apr;212(4):505.e1-13. doi: 10.1016/j.ajog.2014.10.1091. PMID: 25448524.

65. Hamulyák EN, Scheres LJ, Marijnen MC, et al. Aspirin or heparin or both for improving pregnancy outcomes in women with persistent antiphospholipid antibodies and recurrent pregnancy loss. Cochrane Database Syst Rev. 2020 May 2;5(5):Cd012852. doi: 10.1002/14651858.CD012852.pub2. PMID: 32358837.

66. Henderson JT, Whitlock EP, O'Connor E, et al. Low-dose aspirin for prevention of morbidity and mortality from preeclampsia: a systematic evidence review for the U.S. Preventive Services Task Force. Annals of internal medicine. 2014 May 20;160(10):695-703. doi: 10.7326/m132844. PMID: 24711050.

67. Kaplan YC, Richardson JL, Keskin-Arslan E, et al. Use of ondansetron during pregnancy and the risk of major congenital malformations: A systematic review and meta-analysis. Reprod Toxicol. 2019 Jun;86:1-13. doi: 10.1016/j.reprotox.2019.03.001. PMID: 30849498.

68. Li CM, Zhernakova A, Engstrand L, et al. Systematic review with meta-analysis: the risks of proton pump inhibitors during pregnancy. Aliment Pharmacol Ther. 2020 Feb;51(4):410-20. doi: 10.1111/apt.15610. PMID: 31909512.

69. Makrides M, Crosby DD, Bain E, et al. Magnesium supplementation in pregnancy. Cochrane Database Syst Rev. 2014 Apr 3(4):Cd000937. doi: 10.1002/14651858.CD000937.pub2. PMID: 24696187.
70. Marchenko A, Etwel F, Olutunfese O, et al. Pregnancy outcome following prenatal exposure to triptan medications: a metaanalysis. Headache. 2015 Apr;55(4):490501. doi: 10.1111/head.12500. PMID: 25644494.

71. Masarwa R, Levine H, Gorelik E, et al. Prenatal Exposure to Acetaminophen and Risk for Attention Deficit Hyperactivity Disorder and Autistic Spectrum Disorder: A Systematic Review, Meta-Analysis, and MetaRegression Analysis of Cohort Studies. Am J Epidemiol. 2018 Aug 1;187(8):1817-27. doi: 10.1093/aje/kwy086. PMID: 29688261.

72. Maze D, Kazi S, Gupta V, et al. Association of Treatments for Myeloproliferative Neoplasms During Pregnancy With Birth Rates and Maternal Outcomes: A Systematic Review and Meta-analysis. JAMA Netw Open. 2019 Oct 2;2(10):e1912666. doi: 10.1001/jamanetworkopen.2019.12666. PMID: 31584685.

73. McDonagh M, Matthews A, Phillipi C, et al. Antidepressant Treatment of Depression During Pregnancy and the Postpartum Period. Evid Rep Technol Assess (Full Rep). 2014 Jul(216):1-308. doi: 10.23970/ahrqepcerta216. PMID: 30313002.

74. McDonagh MS, Matthews A, Phillipi C, et al. Depression drug treatment outcomes in pregnancy and the postpartum period: a systematic review and meta-analysis. Obstetrics and gynecology. 2014 Sep;124(3):526-34. doi: 10.1097/aog.0000000000000410. PMID: 25004304.

75. Park-Wyllie L, Mazzotta P, Pastuszak A, et al. Birth defects after maternal exposure to corticosteroids: prospective cohort study and meta-analysis of epidemiological studies. Teratology. 2000 Dec;62(6):385-92. doi: 10.1002/1096-9926(200012)62:6<385::Aidtera5>3.0.Co;2-z. PMID: 11091360.

76. Picot C, Berard A, Grenet G, et al. Risk of malformation after ondansetron in pregnancy: An updated systematic review and meta-analysis. Birth Defects Res. 2020 May 18. doi: 10.1002/bdr2.1705. PMID: 32420702. 
77. Terrana N, Koren G, Pivovarov J, et al.

Pregnancy Outcomes Following In Utero Exposure to Second-Generation

Antipsychotics: A Systematic Review and Meta-Analysis. J Clin Psychopharmacol. 2015 Oct;35(5):559-65. doi: 10.1097/jcp.0000000000000391. PMID: 26274044.

78. Veroniki AA, Cogo E, Rios P, et al. Comparative safety of anti-epileptic drugs during pregnancy: a systematic review and network meta-analysis of congenital malformations and prenatal outcomes. BMC Med. 2017 May 5;15(1):95. doi: 10.1186/s12916-0170845-1. PMID: 28472982.

79. Veroniki AA, Rios P, Cogo E, et al. Comparative safety of antiepileptic drugs for neurological development in children exposed during pregnancy and breast feeding: a systematic review and network meta-analysis. BMJ Open. 2017 Jul 20;7(7):e017248. doi: 10.1136/bmjopen-2017-017248. PMID: 28729328.

80. Weston J, Bromley R, Jackson CF, et al. Monotherapy treatment of epilepsy in pregnancy: congenital malformation outcomes in the child. Cochrane Database Syst Rev. 2016 Nov 7;11:Cd010224. doi: 10.1002/14651858.CD010224.pub2. PMID: 27819746.

81. Yakoob MY, Bateman BT, Ho E, et al. The risk of congenital malformations associated with exposure to beta-blockers early in pregnancy: a meta-analysis. Hypertension. 2013 Aug;62(2):375-81. doi:

10.1161/hypertensionaha.111.00833. PMID: 23753416. 